\title{
Experimenting for change? \\ The politics of accomplishing environmental governance through smart energy pilot projects
}

\author{
Fredrik Envall
}

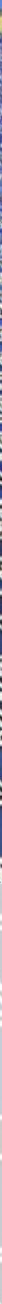





\title{
Experimenting for change?
}

\section{The politics of accomplishing environmental governance through smart energy pilot projects}

\author{
Fredrik Envall
}

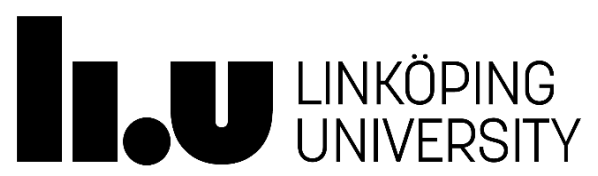

Linköping Studies in Arts and Sciences No. 800

Faculty of Arts and Sciences

Linköping 2021 
At the Faculty of Arts and Sciences at Linköping University, research and doctoral studies are carried out within broad problem areas. Research is organized in interdisciplinary research environments and doctoral studies mainly in graduate schools. Jointly, they publish the series Linköping Studies in Arts and Sciences. This thesis comes from the Department of Thematic Studies - Technology and Social Change.

Distributed by:

Department of Thematic Studies - Technology and Social Change

Linköping University

58183 Linköping

Fredrik Envall

Experimenting for change?

The politics of accomplishing environmental governance through smart energy pilot projects

Edition 1:1

ISBN 978-91-7929-727-5

ISSN 0282-9800

CFredrik Envall

Department of Thematic Studies - Technology and Social Change 2021

Printed by: LiU-Tryck, Linköping 2021

Cover image: Monocropping, by Isak Anshelm.

(c) EY-NC This work is licensed under a Creative Commons AttributionNonCommercial 4.0 International License.

https://creativecommons.org/licenses/by-nc/4.0/ 


\section{Graduate School in Energy Systems}

This thesis is based on work conducted within the interdisciplinary graduate school, entitled Graduate School in Energy Systems. The research groups that constitute the Graduate School in Energy Systems are established at universities and institutes all over Sweden. The national Graduate School in Energy Systems aims at creating competence in solving complex energy problems by combining technical and social sciences. The research analyses processes for the conversion, transmission and utilisation of energy, combined in order to fulfil specific needs. More information is found at www.foes.se.

\section{GRADUATE SCHOOL IN ENERGY SYSTEMS}


För Stig 


\section{Abstract}

This thesis investigates how smart energy experimentation arranges environmental governance in Sweden, focusing on the politics of such processes, against the background of an escalating environmental and climate crisis that necessitates urgent energy transformation. Empirically the thesis includes case studies of pilot projects in Stockholm, Malmö, Västerås, and on Gotland, and analysis of the policy landscape, mainly through text analysis and interviews. Theoretically the study takes a critical approach based on a Foucauldian understanding of governance. Concepts are derived from "governmentality studies" and science and technology studies. This approach aims to unpack experimentation as governance arrangement through asking questions about how governance is arranged beyond singular experiments, such as ideas and practices of achieving broader change beyond isolated experiments.

The thesis shows how smart energy experimentation is incorporated into an existing governmental apparatus and underpinned by a broader political rationality, a "rationale of governance" crystallized in institutional arrangements and policy instruments. This political rationality underpins governance arrangements shaped through experimentation both across governmental agencies and policy networks and on a local level. The investigation also highlights contingencies of arranging governance across cases as ambitions are materialized, as well as the significance of different local contexts and the import of infrastructures on how governance is produced.

The main contribution is a theoretical conceptualization of "experimentation" as arranging environmental governance, and empirically uncovering how governance is shaped beyond singular experiments in a contemporary Swedish context. Such analysis is currently lacking in the literature on environmental politics and energy transitions. The thesis thus elucidates how power relations are shaped through smart energy experimentation, contributing to shaping knowledge generation and interpretation of environmental issues, thus institutionalizing particular ways of handling environmental issues and improving the environmental condition.

Keywords: environmental governance, political rationality, experiment, smart energy, sociotechnical perspective, knowledge politics, power relations, infrastructure. 


\section{Acknowledgements}

Never mind that some claim every social scientist is a proto-geographer, I would never imagine calling myself a geographer. I'm certainly not qualified! Still, since this thesis leans into concepts from geography, the term "space" will have to supply the red thread to hold these acknowledgements together. (I will try to keep it concise and develop a clear argument, Harald)

Three spaces have been crucial in the life of this thesis. First, Harald's office, the space where most supervision meetings have taken place. Of course, this space was eventually exchanged for virtual space in the shape of Zoom. Here I could say something about the materiality of "virtual" spaces, but let's not go there. Harald, Dick, and Josefin - I consider myself superbly lucky to have been able to call you my supervisors.

Harald, you have been crucial for the existence of this thesis. I imagine I might not always have been the easiest PhD student to supervise, considering I might have a tendency, from time to time, to write ever so slightly too long texts, and perhaps I harbor an inclination to go on 10page sidetracks that does not necessarily help the argument along. Sometimes I also write really long sentences (see what I did there?). But you have really helped me. Above all, you have the enviable superhuman ability to be both extremely encouraging and highly critical (in a positive way). Your door has always remained open during these past five years (both the office door and the Zoom door!), and you have always stood ready to discuss any issues, encouraging me and feeding my curiosity by bringing new aspects to light, while at the same time you have always been at the ready to force me down from my abstract, theoretical clouds (sorry Harald, I'm losing the conciseness here now). Thank you.

Dick, you have been more important than you probably know. Besides all the endless reading of text I have put you through, you have really helped me feel at home at Tema, and you have aided me no matter if I needed to ventilate issues when teaching at other departments or if I got stuck when writing up my methods chapter. Thank you.

No specific space can perhaps be tied to you, Josefin - we have circulated from Linköping to Stockholm, between Refused concerts and Danish metal festivals, to conferences in Glasgow and Finland - but you have also been vital for the eventual completion of this thesis. You have provided the lengthy process of writing with both oxygen and stringency, breathing creative life and helping me find structure with your brilliant metaphors. Thank you. To the three of my supervisors - I will never be able to repay you, but know that I am grateful. 
The second space is the seminar room Faros. This is where both research seminar series I have had the pleasure to attend these past years have mainly been taking place. Sometimes the academic ocean has felt too vast and deep, or indeed like a void rather than a space. The seminar series Socio-technical Research on Infrastructures, Politics, and the Environment (STRIPE) has constituted a steadfast home island in this ocean. Thank you to all its participants, past and present. The Green Room: Nature, Culture, Politics, formerly the Environmental Humanities Forum, has provided a space for theoretical and methodological immersion as well as collegial exchange across the Tema boundaries. Crucially, it has served to spur curiosity and provide a durable link to the environmental politics scholarship. To all participants, past and present, thank you. It was also here that my $60 \%$ and $90 \%$ seminars took place. To Eva Lövbrand, Sara Brorström, Jonas Anshelm, Johannes Stripple, Lotta Björklund Larsen, Simon Haikola - thank you for critical reading and instructive input. I owe Eva and Jonas my deepest gratitude especially, for taking an interest in my work and providing critical comments at various important junctures throughout the course of my $\mathrm{PhD}$.

The third space is a space of considerable importance: the home space. Matilda and Cleo, you have literally kept me going, especially in the final stages of finishing up the thesis. I love you both immensely. I have been able to shift between firing on all cylinders and resting in the home space, often accompanied by The Ocean Collective's contemplations on geological time, the human condition, and eternal recurrence. Many ideas were hatched in this space, and this is where I have also spent time with friends outside academia who have been important for the development of ideas (until we switched to virtual space, that is). You all know who you are - thank you for putting up with me even in the weird spatio-temporal situatedness of thesis time. Martin Forsman Hedman deserves special recognition; my gratitude to you stretches far deeper than discussing the tribulations of thesis writing or theories. A thank you feels vastly insufficient, but thank you, nonetheless.

Now I will have to speak straight into the void (sorry Harald, despite my best intentions I lost the read thread).

I would like to sincerely thank all interviewees, who generously shared their insights, knowledge, and daily struggles. Thank you to the Energy Agency for the opportunity to conduct this research - and thank you for the Energy Systems Research School. To everyone in FoES - thank you! To my project colleagues in New Networks of Power, thanks a lot for the interesting and spurring exchange of ideas! Best of luck on your new adventures, Verena \& Kristina. To all the administrative staff at Tema and wider LiU - especially Eva Danielsson - thank you so much for all the practical help these past years. To the D15-team, what a time to be a PhD student! Amelia, for the dirty chai fikas, hangouts, and conference fun in Finland; Daniel, for all the theoretical discussions and insights; Nimmo, for the svorsk and for your 
infectious laughter; Jeff, for the joys of sharing an office! Thank you. To Pelle - you are one of the main reasons I am in academia, and your phrase "don't forget about power!" still echoes. Hopefully, I haven't forgotten about power. I sure haven't forgotten all you've done for me at least. Thank you.

To my family - dad, for structured analytical thinking; mom, for instilling in me the power of imagination; Frida, you have always been a role model in every sense. My deepest thanks and love.

Finally, to Jim Puckett. If I manage to channel a fragment of the fervor with which you have worked relentlessly every day for a better world, I would be content.

And finally-finally, Matilda and Cleo - I know I already said so, but I really do love you. Looking forward to a life together after all this madness. (Sorry about the lack of clarity regarding the argument, Harald. Let's hope the actual dissertation sticks closer to a red thread!) 


\section{Table of contents}

Introduction .................................................................................................. 1

From global governance of the environment to smart energy experimentation ............ 2

Transforming energy systems in a fragmented environmental governance landscape:

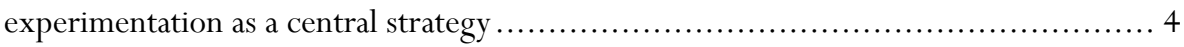

Experimenting with smart energy for green transformations $\ldots \ldots \ldots \ldots \ldots \ldots \ldots \ldots \ldots \ldots$

Smart energy experiments as political junctures: producing environmental governance in

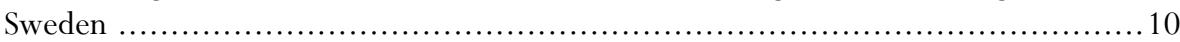

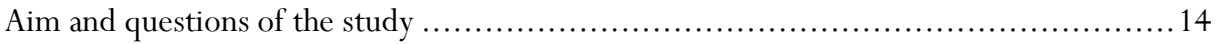

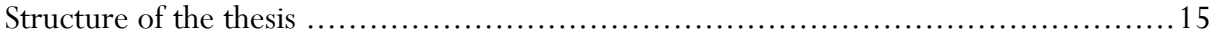

Situating experimentation: conceptualizing smart energy experimentation as governance arrangement.....................................................................17

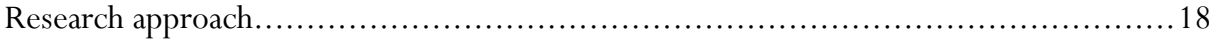

Experimentation as governance arrangement: reconfiguring society through showing,

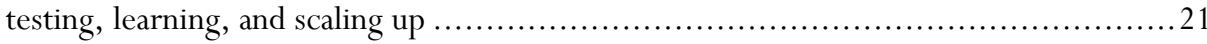

Governance, politics, and power: conceptualizing dynamics of environmental governance

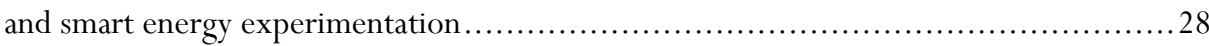

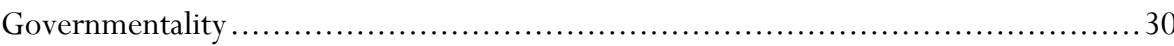

The underpinnings of governance: conceptualizing governance arrangements as political

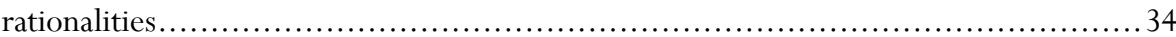

Conceptualizing contemporary environmental governance as political rationality .......36

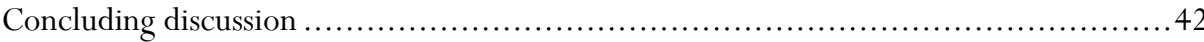

\section{Studying experimentation as governance: operationalizing theoretical} conceptualizations............................................................................45

Politics of experimentation: configuring knowledge, configuring power ............... 45

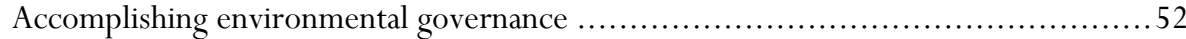

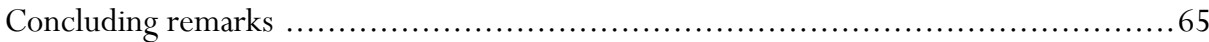

Method and material ............................................................................69

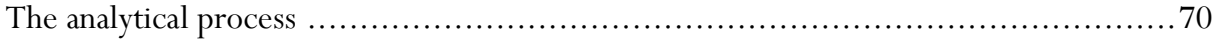

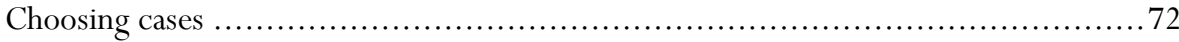

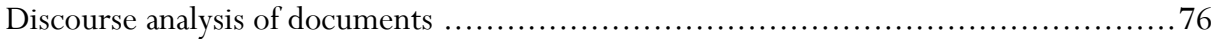

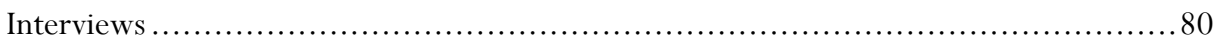




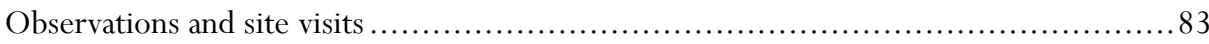

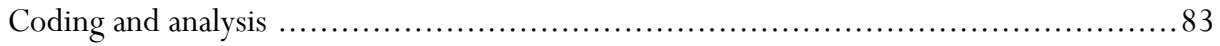

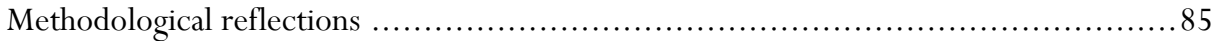

Setting the scene: Swedish energy politics, green political rationality, and experimentation .............................................................................87

Experimentation as innovation instrument in Swedish energy politics ....................8 87

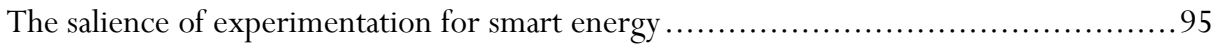

Reducing uncertainty, ensuring prosperity: the discursive constitution of smart energy experimentation in Sweden .............................................99

Swedish energy experimentation - cooperation, consensus, and exporting green energy

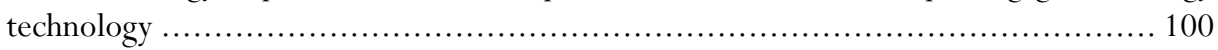

Political rationality underpinning smart energy experimentation - reaching climate policy

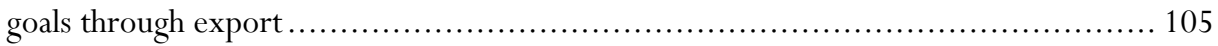

Coordination as an instrument of ordering: from the Coordination Council to the Swedish Smart Grid Forum ............................................................. 110

The governmental apparatus of experimentation: coordination, consensus, and techno-

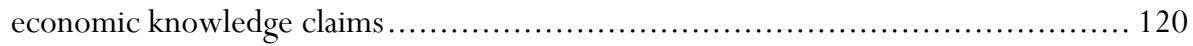

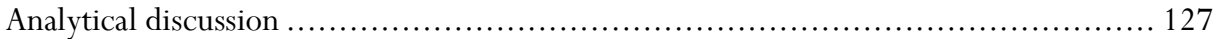

Ordering governance through smart energy experimentation: political rationality and experts' notions of experimentation .................................131

Socio-technical experimentation: setting up experiments ............................ 132

Experiments as catalysts of incremental change .................................. 132

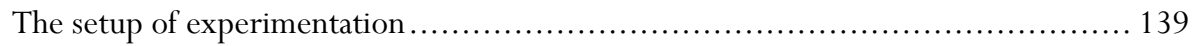

Socio-technical experimentation as tests: learning through experiments ............... 144

Socio-technical experimentation as mobilization for change .......................... 149

Experiments as creating pressure for change in the energy industry .................. 149

Experiments as arenas for mobilization ....................................... 151

Mobilization through knowledge generation and enrollment of actors ................ 155

Socio-technical experimentation as policy input .............................. 159

Socio-technical experimentation as demonstration ................................. 162

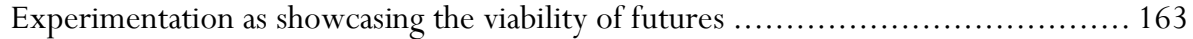

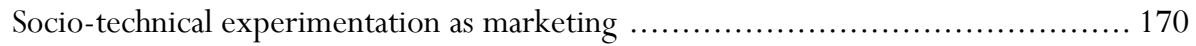


Moving beyond experiments? Achieving transformative change through experimentation 176

Analytical discussion

Shaping smart energy futures: accomplishing environmental governance through urban experiments ..............................................................187

Norra Djurgårdsstaden - Smart Energy City ................................... 188

Authorizing and assembling intervention: triggering green transformation through an

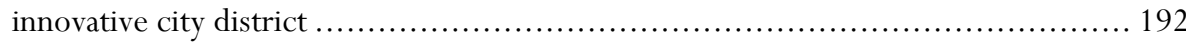

Knowledge circulation within organizations and marketing through networks ........ 221

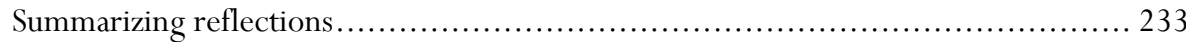

Hyllie - Smart grids for a sustainable energy system in Hyllie and beyond ............... 236

Authorizing and assembling intervention: making a post-industrial city green through coordinated experimentation ................................................ 237

Shaping urban infrastructure development and environmental governance through

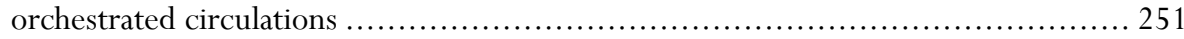

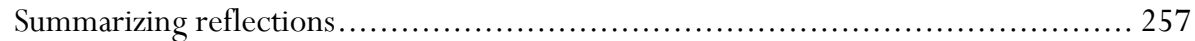

Västerås - experimentation as tinkering and expanding imagination ..................... 260

Authorizing and assembling intervention through tinkering: showing that different energy

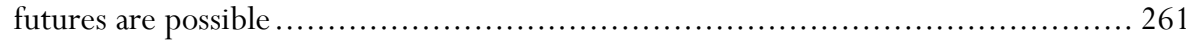

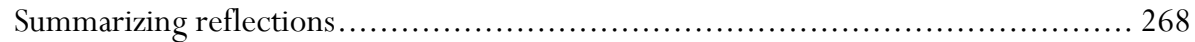

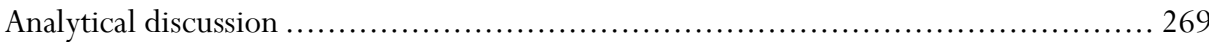

Gotland as an energy pilot region: becoming an environmental frontrunner through experimentation? ...................................................................273

Prelude to making Gotland an energy pilot region: Smart Grid Gotland ............... 274

Technology development, environmental benefits, and place-branding through smart

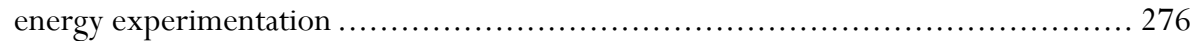

After SGG: knowledge circulations and dismantling .............................. 292

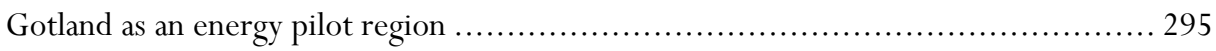

Becoming a pilot region as opportunity and concern: opening up and closing down relations through authorizing and assembling intervention ........................ 297

Circulations: scaling up through infrastructure of nodes and channels? ................ 329

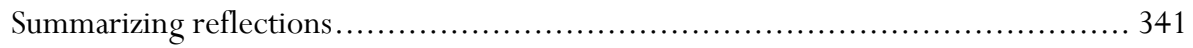

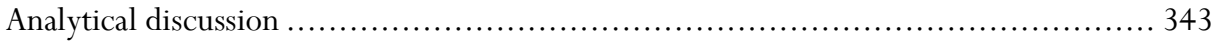


Concluding discussion: opening up and closing down fields of intervention through smart energy experimentation ...............................................347

Incorporating smart energy experimentation into green governmental apparatus? ...... 347

The micro-politics of experimentation: refracting political rationality through dynamics of

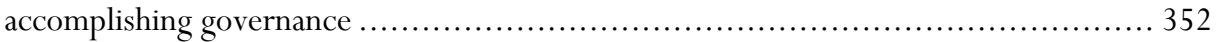

Smart energy experimentation as depoliticizing and repoliticizing environmental

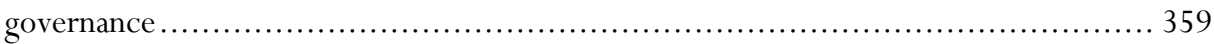

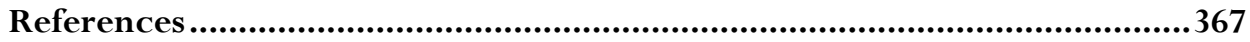

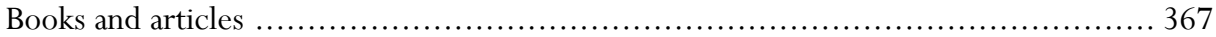

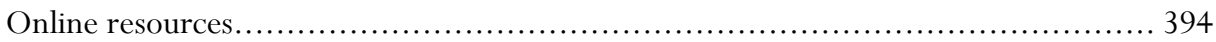

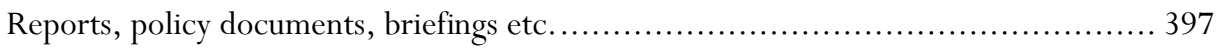

Appendix - Interview guide, example of question clusters.......................402 
An entire domain of possible and necessary interventions appears within the field thus delimited, but these interventions will not necessarily, or not as a general rule, and very often not at all take the form of rules and regulations. It will be necessary to arouse, to facilitate, and to laisser faire, in other words to manage and no longer to control through rules and regulations.

Michel Foucault

Security, Territory, Population: Lectures at the College de France 1977-1978

We are just like reptiles

Giant rulers of the world

Within the blink of an eye

Wiped off the face of the earth

The Ocean Collective - Jurassic | Cretaceous 



\section{Introduction}

In August 2019 on Iceland, a funeral was held. The funeral attracted a significant number of attendees, including Iceland's prime minister. The subject of the funeral was not a person, but the glacier Okjökull. Or, rather, former glacier. The funeral was held to commemorate the loss of the glacier to climate change. A plaque was drilled into a rock at the funeral site, as a memorial to what was now irrevocably lost. The plaque read:

A letter to the future.

Ok is the first Icelandic glacier to lose its status as a glacier. In the next 200 years all our glaciers are expected to follow the same path. This monument is to acknowledge that we know what is happening and what needs to be done. Only you know if we did it.

$$
\begin{gathered}
\text { Ágúst } 2019 \\
\text { 415PPM CO}
\end{gathered}
$$

This thesis is written against this background, and the ultimate concern is environmental politics. I am interested in how environmental issues, such as climate change, are made sense of and handled in practice at a time when glaciers are disappearing before our very eyes. Glaciologist Guðfinna Aðalgeirsdóttir referred to the climatic changes resulting in the rapid decline of Okjökull as the largest uncontrolled experiment that humans have ever done. In this thesis I will assume that there is an intimate connection between knowing and governing, following French philosopher Michel Foucault. ${ }^{1}$ There are many conceivable spaces of governance to investigate, since environmental issues are governed through processes extending from taxation, intergovernmental negotiations, emissions trading systems, and private labeling schemes. ${ }^{2}$ Experimentation has emerged as an important practice spanning different environmental issues and spaces of governance, gaining increased importance not least for changing expansive socio-technical infrastructures. Therefore I will attend to a specific area of environmental politics where experimentation has become important, and which sits at the heart of any attempt to steer clear of the grim prospect of all glaciers being lost within 200 years, namely attempts to transform the energy system, specifically through smart energy experimentation in Sweden. More precisely, I ask how contemporary smart energy

\footnotetext{
${ }^{1}$ Foucault 2007. Security, territory, population: lectures at the Collège de France, 1977-1978. Edited by Senellart \& Davidson. Houndmills, Basingstoke, Hampshire: Palgrave Macmillan.

${ }^{2}$ See Bulkeley \& Newell 2015. Governing Climate Change. Second edition. Abingdon, Oxon: Routledge. Governance will be exhaustively discussed in subsequent chapters, disentangling how it will be approached in this thesis. Suffice to say for now that governance will be approached as processes of ordering society, and as intertwined with particular cognitive and language patterns. Cf. Foucault 2007. Security, territory, population. This includes various forms of administration and government, and institutions, practices, and forms of knowledge both within and outside the realms of formal government. Such an approach puts processes in the center, focusing on the network which connects different elements together. For a similar approach see Braun 2014. A New Urban Dispositif? Governing life in an age of climate change. Environment and Planning D: Society and Space, 32(1).
} 
experimentation arranges environmental governance, and the politics of these processes, assuming a connection between knowing and governing. Such an analysis entails asking what happens beyond singular experiments, thus unpacking how experimentation contributes to particular governance arrangements which are rarely named or described as such.

I will do this by analyzing how governance is arranged through specific cases of experiments and broader governance arrangements across governmental institutions and policy networks, and by examining interlinkages between these broader governance arrangements and specific experiments. ${ }^{3}$ To further explicate the study and present why smart energy experimentation is worthy of close scrutiny when environmental politics is my ultimate concern, we will now move from Iceland to Swedish smart energy experimentation by way of calls for the transformation of energy systems, the contemporary global climate governance regime, experimentation as a governance strategy, and smart city experiments.

\section{From global governance of the environment to smart energy experimentation}

The remarkable event on Iceland exemplifies the type of mourning rituals novelist Amitav Gosh has recently called for in the wake of the so-called age of man, the Anthropocene. ${ }^{4}$ It is indeed necessary, it has been claimed, not just to attune ourselves to the havoc the human species is wreaking on planet Earth, but to establish an intimate connection to this destruction through mourning what is lost in the process. ${ }^{5}$ Or, to be more precise, it is select parts of the human population who are wreaking havoc on planet earth, while it is often distant others who are feeling the effects. ${ }^{6}$ Further, the havoc is characterized less by direct violence and more by

\footnotetext{
${ }^{3}$ In the context of this study, policy networks signify more or less coherent relations of actors engaged in policymaking outside the context of the formalized policy process within the state apparatus. Concrete examples include the Swedish Smart Grid Forum or International Smart Grid Action Network (ISGAN) - more on both of these actor/platform hybrids will follow throughout the thesis. Policy networks can also include less formal compositions, such as platforms provided by conferences or international interlinkages between civil servants across departments or governmental institutions in different countries.

${ }^{4}$ On the Anthropocene, see Crutzen \& Stoermer 2000. The "Anthropocene". IGBP Newsletter 41(17-18). For deliberations and debates on the politics of the terminology of the Anthropocene, see e.g. Malm \& Hornborg, 2014. The geology of mankind? A critique of the Anthropocene narrative. The Anthropocene Review, 1(1); Lövbrand, Beck, Chilvers et al. 2015. Who speaks for the future of Earth? How critical social science can extend the conversation on the Anthropocene. Global Environmental Change, 32; Haraway 2016. Staying with the trouble: making kin in the Chthulucene. Durham: Duke University Press; Moore 2015. Capitalism in the web of life: ecology and the accumulation of capital. New York: Verso.

${ }^{5}$ Cunsolo \& Ellis 2018. Ecological grief as a mental health response to climate change-related loss. Nature Climate Change, 8 .

${ }^{6}$ See Malm \& Hornborg 2014. The geology of mankind?; Beck 2009. World at Risk. Cambridge: Polity Press; Dauvergne 2008. The shadows of consumption: consequences for the global environment. Cambridge, Mass.: MIT Press.
} 
the "slow violence" of an ever-growing capitalist political economy devouring ever more materials and energy. ${ }^{7}$ As the effects of climate change are increasingly reverberating across the globe, embodied for example in raging wildfires, changed precipitation patterns, and an increase in droughts, biodiversity loss further is accelerating into what has been called the sixth mass extinction. Human ecologist Andreas Malm has aptly asserted that we are in a mess, since increased knowledge about these consequences has resulted mainly in the burning of ever more fossil fuels. ${ }^{8}$ We are living in times of intertwined and escalating ecological crises. ${ }^{9}$ Despite political charges and misinformation campaigns against environmental movements, and generally in defense of the status quo, this new reality has increasingly become established as a fact of life. ${ }^{10}$

The inimitable former president of the Maldives, Mohammed Nasheed, once iconically stated that there can be no plan B since there is no planet B, underlining the urgency with which action to counter these catastrophic trends need to be undertaken. Perhaps his call is finally being heeded, with the United Nations' Intergovernmental Panel on Climate Change (IPCC) calling for rapid societal transformation on a scale never witnessed before. ${ }^{11}$ Rhetoric about transforming society has gradually filtered down through contemporary institutions, as demonstrated in calls for transitions to a low-carbon economy and green industrial revolutions echoed across international organizations, as well as the massive worldwide wave of protests instigated by the Fridays for Future youth movement. ${ }^{12}$ Considering how the conversion and use of energy is intimately bound up with the ecological crisis, deliberations and interventions related to such green transformations largely revolve around changing the composition of energy infrastructure. As climate scientist Kevin Anderson reminds us, global emissions reductions could be delivered swiftly but would require immediate political action and "a Marshall-style transition to zero-carbon energy supply”, in his words. Energy systems across the globe are highly dependent upon fossil energy, as evidenced by ever increasing

${ }^{7}$ Nixon 2011. Slow violence and the environmentalism of the poor. Cambridge, Mass.: Harvard University Press; Schlosberg \& Coles 2016. The new environmentalism of everyday life: Sustainability, material flows and movements. Contemporary Political Theory, 15; Krausman Lauk, Haas, and Wiedenhofer 2018. From resource extraction to outflows of wastes and emissions: The socioeconomic metabolism of the global economy, 1900-2015. Global Environmental Change, 52; Hickel \& Kallis 2020. Is Green Growth Possible? New Political Economy, 25(4).

${ }^{8}$ Malm 2016. Fossil Capital: the rise of steam-power and the roots of global warming. London: Verso. p. 3; cf. Norgaard 2011. Living in denial: climate change, emotions, and everyday life. Cambridge, Mass.: MIT Press.

${ }^{9}$ See Rockström, Steffen, Noone et al. 2009. A safe operating space for humanity. Nature, 461.

${ }^{10}$ Eder 1996. The social construction of nature: a sociology of ecological enlightenment. London: Sage.

${ }^{11}$ IPCC 2018. Global Warming of $1.5^{\circ} \mathrm{C}$, an IPCC special report on the impacts of global warming of $1.5^{\circ} \mathrm{C}$ above pre-industrial levels and related global greenhouse gas emission pathways, in the context of strengthening the global response to the threat of climate change, sustainable development, and efforts to eradicate poverty. IPCC Special Report. https://www.ipcc.ch/sr15/ [2019-10-22].

${ }^{12}$ Cf. Scoones, Leach, and Newell (eds.) 2015. The politics of green transformations. Abingdon: Routledge. 
consumption of fossil fuels. ${ }^{13}$ However, energy use can only be adequately grasped if the sociotechnical systems through which energy is converted and used are taken into account. Culturally and materially we are drenched in oil, from the clothes we wear, through the way we transport ourselves, to the vast physical infrastructures constituting the political economy and beyond. ${ }^{14}$ Clearly, energy system change inevitably sits at the heart of efforts for green transformation.

\section{Transforming energy systems in a fragmented environmental governance landscape: experimentation as a central strategy}

Such an energy system change cannot be conceived simply in terms of substituting single technological components; a systemic change of infrastructural setup is required. The energy system is comprised of wires, substations, transmission grids, electricity markets, and institutional arrangements, among other socio-material elements, making it a socio-technical configuration. ${ }^{15}$ Transforming the energy system thus entails change encompassing and extending beyond regulations, practices, and relations between actors. ${ }^{16}$ Worryingly, the International Energy Agency (IEA) recently concluded that existing energy policies fall well short of reaching the internationally agreed goals of the Paris climate agreement. ${ }^{17}$ Changing energy infrastructure to the extent necessary, and swiftly enough to prevent disastrous carbon lock-in, presents a tremendously complex undertaking. The ubiquity of fossil energy, which is woven into socio-technical systems stretching across nations, sustains strong vested interests, with neither fossil-dependent nations nor fossil fuel-dependent companies demonstrating a clear desire to change. Further, transforming energy systems as urgently as is required inevitably means taking action within contemporary environmental governance frameworks, with the climate governance regime perhaps constituting the main example. Climate change has gone from being primarily governed by multilateral cooperation, as epitomized by the Conference of the Parties (COP) to the United Nations Framework Convention on Climate Change (UNFCCC), to become an issue that stretches across a more dispersed policy landscape. ${ }^{18}$ Contemporary climate governance is often described as a patchwork, characterized by different processes and attempts at governing climate change by different

\footnotetext{
${ }^{13}$ Pirani 2018. Burning Up: A Global History of Fossil Fuel Consumption. London: Pluto Press.

${ }^{14}$ See Szeman 2019. On Petrocultures: Globalization, culture, and energy. Morgantown: West Virginia University Press; Mitchell 2013. Carbon Democracy: Political power in the age of oil. London: Verso; Ervine 2018. Carbon. Polity Press; Malm 2016. Fossil Capital.

${ }^{15}$ See Hughes 1983. Networks of power: Electrification in Western society, 1880-1930. Baltimore: Johns Hopkins Univ. Press; Graham \& Marvin 2001. Splintering urbanism: Networked infrastructures, technological mobilities and the urban condition. London: Routledge.

${ }^{16}$ See e.g. Markard 2018. The next phase of the energy transition and its implications for research and policy. Nature Energy, 3(8).

${ }^{17}$ IEA 2019. Tracking Clean Energy Progress. https://www.iea.org/tcep/ [2019-09-17].

${ }^{18}$ Bulkeley 2016. Accomplishing Climate Governance. Cambridge: Cambridge University Press.
} 
actors, taking place across a plethora of spaces, and spanning different scales ${ }^{19}$ Climate change is governed e.g. through international negotiations, bottom-up community efforts, corporate action, and social movements. Contemporary climate governance is characterized by state-led instruments such as subsidies and intergovernmental negotiations as much as it is by decentralization and dispersed authority, thus displaying a degree of fragmentation. For instance, cities and regions have increasingly become designated as both central actors and sites of climate governance, enshrined for example in the IPCC Cities and Climate Change Initiative and Sustainable Development Goal no. 11 "Sustainable Cities and Communities". ${ }^{20}$

The widespread consensus regarding the necessity to transform energy systems, and the urgency with which this transformation needs to progress, is bound up within this contemporary landscape of environmental politics. However, the flip side of these fragmented governance structures and dispersed authority is that energy system transformation is, in principle, an open process. In the absence of hierarchical, top-down implementation, energy system change will inevitably unfold differently across different places with different local circumstances, histories, power relations, and governance structures. ${ }^{21}$ Departing from such a perspective highlights how the transformation of energy infrastructures involves different interests and values, potentially entrenching existing lines of conflict as well as creating new frictions, or offering opportunities to align different agendas in a common endeavor. Tensions arising in different settings where energy system transformation is undertaken include questions of control over the energy system; whereas incumbent actors might wish to retain their control over the system, others who harbor hopes of democratizing energy supply might sense an opportunity when transformation is to be done in practice. ${ }^{22}$ Other tensions include who carries the costs and who benefits, as well as whether energy infrastructure is best configured through large-scale, centralized grids or through decentralized energy communities. ${ }^{23}$ Consequently, transformation processes are thoroughly permeated by power. Broader political questions arise, such as what exactly it is that is to be transformed, as a sociotechnical perspective underlines, and who will actually do the transforming in practice, as well

\footnotetext{
${ }^{19}$ Bulkeley \& Newell 2015. Governing Climate Change.

${ }^{20}$ See e.g. Bulkeley \& Castán Broto 2013. Government by experiment? Global cities and the governing of climate change. Transactions of the Institute of British Geographers, 38(3); Bulkeley \& Betsill 2003. Cities and Climate Change: Urban sustainability and global environmental governance. London: Routledge; Bulkeley, Castán Broto, and Edwards 2015. An urban politics of climate change: Experimentation and the governing of sociotechnical transitions. London: Routledge.

${ }^{21}$ Cf. Boyer 2019. Energopolitics: Wind and power in the Anthropocene. Duke University Press; Howe 2019. Ecologics: Wind and power in the Anthropocene. Durham: Duke University Press.

${ }^{22}$ Petrocultures Research Group 2016. After Oil. Edmonton: University of Alberta. p. 71. Although it might be added that it is not necessarily the case that incumbents always strive for the status quo; some might actively attempt to shape socio-technical change processes in order to benefit themselves, e.g. by taking on new roles or steering transitions in specific directions.

${ }^{23}$ See e.g. Stephens, Wilson, and Peterson 2015. Smart Grid (R)evolution: Electric power struggles. New York, NY, USA: Cambridge University Press. p. 7.
} 
as whether transformation entails far-reaching and radical societal change or if incrementalism is enough. ${ }^{24}$ This illuminates the long-term and contested nature of energy system transformation. ${ }^{25}$

In this contemporary political landscape, where calls to transform energy systems are made in an environmental governance structure marked by simultaneous processes of state-led and non-state interventions, and thus of dispersed authority, experimentation has emerged as a central strategy to instigate and govern such transformation of energy systems. ${ }^{26}$ This mirrors how, in recent years, experimentation has even been used to designate a prominent characteristic of contemporary society. ${ }^{27}$ Some scholars speak of "the experimental society" or a "knowledge society disposition", while others underscore how urban governance has increasingly come to revolve around experimentation. ${ }^{28}$ Experiments, variously termed pilot and demonstration projects, test beds, and living labs, are regularly and increasingly afforded a central role as instruments for instigating and achieving socio-technical change of energy systems by a wide range of actors, including policymakers, researchers, and both corporate and civil society actors. While such endeavors have traditionally resided within industrial innovation policy, primarily as instruments to test and commercialize new products, experimentation has seeped out from the confines of corporate R\&D departments and into the realms of environmental governance. Such experimentation often entails testing new sociotechnical configurations, including but extending beyond technological innovations, also encompassing new social practices and institutional changes, in spatially and temporally limited settings. This increasingly central position of experimentation as an environmental governance strategy is further mirrored in the EU's strategies and initiatives, such as funding

\footnotetext{
${ }^{24}$ Scoones, Newell, and Leach 2015. The politics of green transformations. In Scoones, Leach, and Newell (eds.) The politics of green transformations. pp. 1-24.

${ }^{25}$ Burke \& Stephens 2016. Political power and renewable energy futures: A critical review. Energy Research \& Social Science, 35.

${ }^{26}$ I will use experimentation as an umbrella term to approach the main question animating the thesis, namely how experimentation arranges environmental governance and the politics of these processes. Consequently I will remain open to the different forms experimentation might take and the different ways through which it might be described in empirical material, including common terms such as demonstration, pilot, project, test bed, living lab, experiment, and so on and so forth. In a maximalist definition, instances of experimentation studied in this thesis include articulated attempts to change sociotechnical configuration of energy infrastructure, often by some form of spatio-temporally bound project where testing is accentuated as a central activity to improve the environmental condition.

${ }^{27}$ Ansell \& Bartenberger 2016. Varieties of experimentalism. Ecological Economics, 130.

${ }^{28}$ Engels, Wentland, and Pfotenhauer 2019. Testing future societies? Developing a framework for test beds and living labs as instruments of innovation governance. Research Policy, 48(9); Evans, Karvonen, and Raven (eds.) 2016. The Experimental City. London: Routledge.
} 
schemes and research platforms where concepts such as testing, demonstration, and upscaling are often key. ${ }^{29}$

Political scientist Maarten Hajer argues that this rise to prominence of experimentation also runs parallel to long-term processes of neoliberalization, such as the breakthrough of New Public Management (NPM) as a mode of governance for the public sector. Policy programs of neoliberalization are often exemplified by the emblematic Washington Consensus, including fiscal discipline, tax cuts, financial deregulation, trade liberalization, promotion of foreign investments, privatization, reduction of public expenditure, and deregulation of property and labor markets. ${ }^{30}$ NPM rests upon such neoliberal economic rationality, and includes a prioritization of fiscal frugality such as cutting costs across the public sector, engineering public administration in line with market logic as a guiding principle, the proliferation of evaluation and accounting techniques, and public-private partnerships, among other things. ${ }^{31}$ Public sectors across the world have seen reforms in this neoliberal vein for decades now, generally through deregulation and privatization, vindicated by rhetoric of economic efficiency, attracting capital through place-branding, and efficient problem-solving. ${ }^{32}$ Hajer states that the apparent contemporary appeal of experimentation is partly connected to macro-economic tendencies, and specifically to austerity policy. According to Hajer, this has led to shrinking budgets for public policy actors on the local level, and thus to the necessity of "doing more with less", i.e. he claims there is a link between NPM and the proliferation of experimentation as a governance strategy. ${ }^{33}$ In this context, experimentation has particular appeal, since it is perceived as a strategy which allows for the involvement of more actors and quicker learning

${ }^{29}$ See e.g. European Commission 2006. European Technology Platform Smart Grids: Vision and Strategy for Europe's Electricity Networks of the Future. Directorate-General for Research, Sustainable Energy Systems. EUR 22040; European Commission 2009. Communication from the Commission: Investing in the Development of Low Carbon Technologies (SET-Plan). Brussels, COM (2009) 519/4; European Commission 2012. Communication from the Commission: Smart Cities and Communities - European Innovation Partnership. Brussels, 10.7.2012 C (2012) 4701 final; cf. Vesnic-Alujevic, Breitegger, and Guimarães Pereira 2016. What smart grids tell about innovation narratives in the European Union: Hopes, imaginaries and policy. Energy Research \& Social Science, 12.

${ }^{30}$ See Pellizoni \& Ylönen 2012. Introduction. p. 4. In Pellizoni \& Ylönen (eds.) 2012. Neoliberalism and Technoscience: Critical Assessments. Farnham: Ashgate. pp. 1-24.

${ }^{31}$ See Hood 1995. The "New Public Management" in the 1980s: Variations on a Theme. Accounting, Organizations and Society, 20 (2-3).

32 See Harvey 1989. From Managerialism to Entrepreneurialism: The Transformation in Urban Governance in Late Capitalism. Geografiska Annaler. Series B, Human Geography, 71(1). In this study, I will approach neoliberalization as processes rather than a stable program or coherent end-state. Neoliberalization processes tend to unfold as a response to crises engendered by neoliberal reforms themselves, meaning that such processes are rather an amalgamation of geographically diverse policies, practices, and discourses. Still, there are enough common features across contexts to warrant naming such processes neoliberal. For a thorough discussion of neoliberalism and neoliberalization, see Pellizzoni 2015. Ontological Politics in Disposable World: The New Mastery of Nature. Farnham: Ashgate. pp. 57-59.

${ }^{33}$ Hajer 2016. Foreword. In Evans et al. (eds.) 2016. The experimental city. pp. xvi-xix. 
loops than traditional policy processes. For instance, through a widespread projectification of the public sector, pilots as an organizational form have increasingly become commonplace, while testing and learning have simultaneously become embedded as central activities in public administrations. ${ }^{34}$

\section{Experimenting with smart energy for green transformations}

A central subset of energy transformation endeavors where experimentation has significant appeal is within the realm of so-called smart grids and smart cities. A smart grid, or a smart energy system, is usually described as a system where energy flows in different directions as a result of extensive integration of decentralized, intermittent, and large-scale renewable energy sources, often enabled through the application of information and communications technology (ICT) in different parts of the energy system. ${ }^{35}$ The smart energy concept includes:

$[\ldots]$ a variety of interlinked technologies including advanced meters and sensors, the management of "big data", and other technological configurations that enable increased reliability, more renewable electricity, and improved efficiency, resilience, and flexibility. ${ }^{36}$

The motivations for transforming current energy infrastructure into a smart energy system differ greatly, however, extending far beyond sustainability concerns. For some it is about increased integration of intermittent renewable energy, such as solar photovoltaics (PV), through balancing electricity loads and thus reducing peak demand enabled by smart technology, e.g. sensors in the distribution grid, automation, and battery storage. Others point to the role of energy users, as smart grids often entail ideas of empowering and engaging energy users, e.g. through smart electricity metering allowing for push notices via smartphones which can be combined with dynamic tariffs, incentivizing energy users to act as rational customers in the energy market. ${ }^{37}$ Simultaneously, smart grids as a concept also bring hopes for long-ranging transformations of energy systems, such as grassroots organizing to empower individuals and communities to construct decentralized energy systems. ${ }^{38}$ Other frequently mentioned goals of smart energy relate to increasing economic growth by exporting new green technology, or avoiding capacity issues in large-scale power grids through demand-

\footnotetext{
${ }^{34}$ See Hodgson, Fred, Bailey, and Hall (eds.) 2019. The Projectification of the Public Sector. New York: Routledge.

${ }^{35}$ Stephens et al. 2015. Smart Grid (R)evolution.

${ }^{36}$ Stephens et al. 2015. Smart Grid (R)evolution. p. 4.

${ }^{37}$ See e.g. Strengers 2013. Smart energy technologies in everyday life: Smart utopia? New York: Palgrave Macmillan.

${ }^{38}$ See Stephens et al. 2015. Smart Grid (R)evolution. pp. 4-5.
} 
response enabled by digital technologies. For some actors, making energy systems smart is about enhancing grid stability and reliability, i.e. grid optimization. ${ }^{39}$

Within the context of smart cities, smart energy experimentation is often assigned an integral role. Despite contestation over its social and political dimensions, the notion of smart cities has been in circulation for more than a decade, building upon previous narratives of intelligent and creative cities. ${ }^{40}$ There is no coherent definition of a smart city, but the idea tends to revolve around optimizing and greening urban infrastructures and everyday life through digital technology and technological innovations. ${ }^{41}$ Promises of increased control of urban environments are thus central to the concept of smart cities, e.g. through the widespread application of surveillance and monitoring equipment, the optimization of energy flows via digital technologies, and computational logics instituted in dashboards and control centers to digitally enhance urban flows. ${ }^{42}$ Further, the technologies of smart cities tend to be corporately sourced through public-private partnerships. ${ }^{43}$

Some have noted the global character of the smart city notion and its circulation. ${ }^{44}$ However, this global narrative of the smart city takes on different forms when it hits the ground, becoming embedded into different socio-material urban fabrics with their specific histories and power relations. ${ }^{45}$ This also makes smart city initiatives particularly ripe for experimentation: there are smart city projects unfolding across the entire globe, such as

\footnotetext{
${ }^{39}$ Stephens et al. 2015. Smart Grid (R)evolution. pp. 19-20.

${ }^{40}$ McLaren \& Agyeman 2019. Smart for a reason: Sustainability and social inclusion in the sharing city. In Coletta, Heaphy, Evans, and Kitchin 2019. Creating Smart Cities. Abingdon, Oxon: Routledge. pp. 169181; cf. Graham \& Marvin 2001. Splintering urbanism. On the contested political and social aspects of smart cities, see e.g. Hollands 2008. Will the Real Smart City Please Stand Up? City, 12(3); Vanolo 2014. Smartmentality: The Smart City as Disciplinary Strategy. Urban Studies, 51(5); Wiig 2015. IBM's smart city as techno-utopian policy mobility. City, 19(2-3).

${ }^{41}$ Granath 2016. The smart city - how smart can "IT" be?: discourses on digitalisation in policy and planning of urban development. Diss. Linköping: Linköping University.

${ }^{42}$ See e.g. Marvin \& Luque-Ayala 2020. Urban Operating Systems: Producing the Computational City. MIT Press; Sadowski 2020. Too smart: how digital capitalism is extracting data, controlling our lives, and taking over the world. Cambridge, Massachusetts: The MIT Press.

${ }^{43}$ Hollands 2015. Critical Interventions into the Corporate Smart City. Cambridge

Journal of Regions, Economy and Society, 8; Lee, Hancock, and Hu. 2014. Towards an Effective Framework for Building Smart Cities: Lessons from Seoul and San Francisco. Technological Forecasting and Social Change, 89.

${ }^{44}$ See e.g. Joss, Sengers, Schraven, Caprotti, and Dayot 2019. The Smart City as Global Discourse: Storylines and Critical Junctures across 27 Cities. Journal of Urban Technology, 26(1); cf. McCann \& Ward (eds.) 2011. Mobile Urbanism: cities and policymaking in the global age. Minneapolis: University of Minnesota Press.

${ }^{45}$ See Karvonen, Cugurullo, and Caprotti (eds.) 2019. Inside Smart Cities: Place, Politics and Urban Innovation. Abingdon, Oxon: Routledge.
} 
climate-smart city district pilot projects and urban living labs. ${ }^{46}$ Considering the central role ascribed to cities in particular for climate governance, the promise of greening cities by making them smart constitutes an important element of contemporary environmental governance. Thus, unfolding smart city experiments are translating the hopes pinned on local and regional action for the desired green transformation in the climate governance regime into actual environmental interventions. Transforming energy systems is often an integral part of such interventions, hence the interconnection between smart cities and smart energy systems.

\section{Smart energy experiments as political junctures: producing environmental governance in Sweden}

In addition to the increasingly common deployment of experimentation as an environmental governance strategy, this interpretative flexibility of smart grids and smart cities means that the currently unfolding experiments play an important role in providing discursive and material content for the sought-after green transformations. However, experiments are rarely conceived of or described as instituting particular governance arrangements. They are more commonly conceptualized as singular, isolated interventions. Within both policy and academia, there are ongoing discussions about how to move beyond singular experiments, although what actually happens in practice beyond singular experiments is not discussed to the same extent. In this study, the analysis will focus on how experimentation arranges environmental governance in particular ways, in terms of arranging governance both through and beyond singular experiments, and across governmental institutions and policy networks. Put differently, the study revolves around how governance processes unfold in practice as experimentation arranges environmental governance - through practices at a micro level across experiments, and through notions and practices across governmental agencies and policy documents.

In practice, there are many conceivable empirical foci for such an investigation. In this thesis, Sweden will provide an entry point to how smart energy experimentation arranges environmental governance, and the politics of such processes. Utilizing Sweden as an empirical example is highly relevant considering Sweden's self-proclaimed status as an environmental frontrunner in the international arena. Further, smart energy experimentation has been highlighted as important in Swedish environmental, climate, and energy policy. Smart energy

\footnotetext{
${ }^{46}$ Karvonen et al. (eds.) 2019. Inside Smart Cities; Trindade, Hinnig, Moreira da Costa et al. 2017. Sustainable Development of Smart Cities: A Systematic Review of the Literature. Journal of Open Innovation: Technology, Market, and Complexity, 3(11); Marvin Bulkeley, Mai, McCormick, and Voytenko (eds) 2018. Urban Living Labs: Experimenting with City Futures. London: Routledge; Parks 2018. The Sustainable City Becomes Climate-Smart: how smart city ideas reshape urban environmental governance. Diss. Linköping: Linköping University.
} 
experiments therefore provide an important example of interventions where ambitions of green transformation are to be put into practice. A broader policy formation around smart energy is currently ongoing in Sweden, while many smart energy experiments are being carried out. One prominent initiative was assigned by the government to the Swedish Energy Agency in 2017, in the form of an investigation into how the island of Gotland could become a pilot model for a smart and sustainable energy system for the rest of Sweden to emulate. It concluded in the spring of 2018, but the initiative continued beyond the initial investigation as the Energy Agency was tasked by the government with developing a roadmap for Gotland, published in 2019, and facilitating the implementation of the roadmap beyond its publication. This provides a suitable avenue into how smart energy experimentation arranges environmental governance, especially considering how the island of Gotland was the scene for a previous large smart grid demonstration project called Smart Grid Gotland, concluded in 2017, and it was explicitly stated in the government's directive to the Energy Agency that the lessons learnt from other experiments are to be transferred into the larger initiative of making Gotland a pilot model. Apart from the initiatives on Gotland, many smart energy experiments in Sweden focus on urban development.

In parallel with the Smart Grid Gotland project, two other large smart grid demonstrations were conducted, both in urban settings. One was called Smart Grids for a Sustainable Hyllie, carried out in conjunction with a large urban development project in the city of Malmö in southern Sweden, where the City of Malmö aims to make the city a test bed for greening urban areas through smart urban experiments. This experiment was concluded in 2016. Activity related to smart energy is still ongoing in the district of Hyllie and in wider Malmö. The other demonstration project, Smart Energy City, was concluded in late 2018. This experiment was also connected to a large urban development project, called Norra Djurgårdsstaden, or Stockholm Royal Seaport. These two have regularly been framed as Sweden's flagship smart grid projects, together with Smart Grid Gotland. All three demonstration projects mainly involved utilizing ICT to optimize grid operations and load-shift through incentivizing households, while the Gotland pilot model initiative is significantly broader in scope. The three demonstration projects were co-financed by different consortiums of industry and public actors, as well as the Energy Agency, and were mainly run by large incumbent energy utilities. Simultaneously, a smart energy experiment was launched in Västerås, which does not include large energy companies or the Energy Agency. There, a self-described climate-activist company, backed through crowdfunding, aims to build passive houses made of wood and a local solar-powered direct current nanogrid. ${ }^{47}$ These endeavors constitute interventions with

\footnotetext{
${ }^{47}$ The nanogrid ambition had to be discarded however, but more on that in the empirical chapter on urban smart energy experiments.
} 
an explicit ambition of transforming the energy system, making it "smart" and sustainable. Experimentation across these interventions encompasses e.g. energy users' behavior, technical infrastructure, actor constellations, and regulatory input. There is thus an intention to govern people and infrastructures, and they can consequently be conceived as socio-technical experiments. There is an explicit expectation of gradual discovery through experimentation, and then scaling up the experiments and feeding the experiences gained and knowledge generated into policy.

These cases provide an entry point into the politics of arranging environmental governance through smart energy experimentation. I have already mentioned that I assume an intimate connection between knowing and governing, underlining that specific ways of knowing configure environmental governance in specific ways. What it means to become green through experimentation and who is to be the principal agent of transformation are open questions, and they are inherently political questions. These questions might be answered, subtly or overtly, through the knowledge-configuring activities within smart energy experiments. Further, energy transformation is political since it always extends beyond replacing sources of energy. A specific technology or energy source is not in itself a guarantee of a greener, better, or more democratic future, notwithstanding the many environmental benefits of renewable energy in comparison to fossil fuels. ${ }^{48}$ It matters greatly how the technology becomes woven into the social fabric, be it through the implementation of "urban operating systems" attempting to improve urban life through data-driven analytics or small-scale energy communities in rural settings, and here experimentation plays a key role in constituting particular futures above others. In the words of geographer Harriet Bulkeley and political ecologist Gareth Edwards:

Modes of practice which regard the future as not only uncertain but also indeterminate must not only calculate possible futures, but demonstrate their potential by enacting them in the present in order that alternative means of determining what constitutes practicable or ethical or economic practice can be recognised. These modes of practice are not merely neutral devices through which optimum social or technical solutions are derived, but actively political in constituting particular kinds of future above others and in configuring the nature and dynamics of power, capacity and responsibility through the assemblages they create (Braun, 2014; Dalby, 2013; Delgado and Callén, 2017). As Gibson-Graham and Roelvink (2009: 342) put it, 'Small actions and networks can be seen to have sweeping global effects, and rapid large-scale change can emerge from diffuse local transformations. ${ }^{49}$

${ }^{48}$ Cf. Mitchell 2013. Carbon Democracy. However, see Dunlap 2019. Renewing Destruction: wind energy development, conflict and resistance in a Latin American context. Lanham: Rowman \& Littlefield International. ${ }^{49}$ Edwards \& Bulkeley 2017 Heterotopia and the urban politics of climate change experimentation. Environment and Planning D: Society and Space, 36(2). p. 3; cf. Luque-Ayala, Bulkeley, and Marvin (eds.) 2018. Rethinking Urban Transitions: Politics in the low carbon city. Abingdon, Oxon: Routledge. 
Acknowledging that experimentation cannot be reduced to a neutral search for optimal technical solutions, but is intimately tied to specific political rationality, becomes increasingly important to take seriously in a context where socio-technical experimentation constitutes a prominent strategy of environmental governance, such as transforming energy infrastructure. ${ }^{50}$ Emphasizing political rationality draws attention to practical reasoning underpinning governance, thus determining "the institutionally embedded ways of specifying what is problematic" and the specific calculative methods employed to delimit how solutions to these problems are constructed. ${ }^{51}$ Knowledge can consequently be perceived as a key political aspect of governing energy infrastructure change, since it functions to highlight specific relations and construct solutions whilst "filtering out complexities deemed irrelevant or unknowable". ${ }^{52}$ From this perspective, power relations, conceptualized in productive terms, are consequently intimately connected with knowledge. ${ }^{53}$ Therefore, actors who can influence how socio-technical systems are known and perceived can subtly exercise political power. ${ }^{54}$ Since socio-technical experiments are increasingly becoming a core arrangement for instituting energy system change, it is vital to attend to how experimentation draws upon and potentially reconfigures broader political rationality nested across governmental institutions and policy networks, as well as how environmental governance is accomplished in practice through cases of smart energy experimentation. Investigating this is especially pertinent in a context where experiments are increasingly considered key instruments for achieving green transformations, as it is generally assumed that the main purpose of experiments is to have a broader impact beyond their specific bounded places. There is not much research on what happens beyond singular experiments, however. Such analysis can highlight the politics of arranging environmental governance through experimentation, e.g. through elucidating ideas and practices of achieving transformative change beyond singular experiments, how experimentation contributes to foregrounding particular knowledge claims, and how power relations are configured through experimentation.

In this thesis, I will investigate what kind of green transformation is being accomplished through smart energy experimentation, by analyzing the political rationality underpinning broader governance arrangements around smart energy experiments, e.g. becoming nested

${ }^{50}$ Cf. Cashmore, Stissing Jensen, and Späth 2019. Introduction: The knowledge politics of urban sustainability transitions. p. 9. In Stissing Jensen, Cashmore, and Späth (eds.). The Politics of Urban Sustainability Transitions: Knowledge, Power and Governance. Abingdon, Oxon: Routledge.

${ }^{51} \mathrm{Ibid}$; see also Dean 2010. Governmentality: power and rule in modern society. 2nd ed. Thousand Oaks, CA: SAGE Publications.

52 Ibid.

${ }^{53}$ Foucault 2007. Security, Territory, Population.

${ }^{54}$ Cashmore, Stissing Jensen, and Späth 2019. Introduction; cf. Dean 2010. Governmentality; Rose \& Miller 2008. Governing the present: administering economic, social and personal life. Cambridge: Polity. 
across governmental institutions, and by analyzing how governing is done in practice through specific cases of smart energy experimentation. Such a study is motivated since this order of things has yet to be empirically examined systematically. Scholarly work on experimentation as an environmental governance strategy has mainly revolved around either aggregated studies of experiments as instruments in the experimental workshop of climate governance, or ethnographic studies of singular cases of smart energy experimentation. Close scrutiny of the interrelation between broader political rationality underpinning smart energy experimentation and how governance is accomplished across cases of experimentation is yet to be undertaken. The study is motivated further since this order of things, which is currently becoming established, is in no way natural. It has emerged historically and is permeated by power relations, making "the environment" governable in specific ways at the expense of other possibilities. This thesis is therefore an inquiry into how power is produced through smart energy experimentation, through configuring ways of knowing and acting upon environmental issues.

\section{Aim and questions of the study}

The main concern of this thesis is how smart energy experimentation arranges environmental governance, and the politics of such processes. Put differently, I will investigate unfolding processes as ambitions of green transformation are put into practice. This analytical endeavor rests upon the conviction that it is vital to attend to unfolding processes and situate experimentation historically ${ }^{55}$ as governance arrangement, in order to understand how smart energy experimentation and environmental governance unfold and interact dynamically.

I will do this by analyzing both how a broader political rationality underpins smart energy experimentation, and how this political rationality becomes nested across spaces of governance, as well as analyzing how governance is accomplished in specific experiments, and the interconnection between specific experiments and broader political rationality underpinning smart energy experimentation. To the ends of this analytical endeavor, I will draw upon concepts found in governmentality studies to investigate the political rationality.

\footnotetext{
${ }^{55}$ Historically in the Foucauldian sense, not as in Whig history. Whig history refers to a tendency within historical analysis to present historical processes as the inevitable progress and betterment of humankind, i.e. as a constant progression toward a better world for all. Such an approach disregards the co-production of social and technological arrangements and fails to acknowledge the meanderings and failures of modern science, as well as the risks created through said science (e.g. nuclear waste, climate change, etc.). Instead, a Foucauldian approach to history, often termed "genealogy", entails connecting ideas, practices, and institutions to their historical framework, i.e. the problematization that allowed them to gain traction. Thus, a genealogical approach attempts to excavate meaning formations from their historical embeddedness.
} 
Further, I will draw upon concepts that make it possible to conceptualize how such a political rationality conditions specific cases of experimentation in assembling practices, for example, and whether experiments challenge or co-constitute this political rationality, as well as whether specific elements assembled in experiments are circulated and reconfigure the political rationality underpinning experimentation. By focusing on the assembling of elements and relations as well as circulations and contingent practices within and beyond specific experiments, in relation to the analysis of broader political rationality, the analytical aims can be achieved.

I will thus attend to a "policy landscape", as well as zooming in on some large, publicized experiments and contrasting these with a less publicized experiment. This study design highlights specific spaces where smart energy experimentation arranges environmental governance, both micro-politics within and across specific experiments and broader governance arrangements extending across governmental institutions and policy networks. Following how governance is produced and plays out across these different empirical domains, and how such processes interplay with a broader political rationality, can enshrine how relations are forged, sustained, or challenged, illuminating how smart energy experimentation arranges environmental governance as such processes unfold. This amounts to an analysis of how governance is arranged through experimentation in Sweden beyond singular experiments. Such an analysis is currently lacking in literature on both environmental politics and energy transition.

The specific questions guiding this thesis are:

- How does smart energy experimentation co-constitute environmental governance across spaces of governance, such as on a national level and across different experiments?

- Who is allowed to generate knowledge in experiments, and who gets access to this knowledge? Who is excluded and who is marginalized? Which knowledge claims are viewed as legitimate and robust, and which are neglected?

- Which actors are portrayed as central to performing smart energy experiments, and why?

- How is the field of intervention for environmental governance delineated through concrete cases of experimentation? Which relations are created, and which actors become central and which are excluded as a consequence?

- How do different actors imagine broader change to occur beyond singular experiments? How are attempts to "move beyond" individual experiments organized in practice?

\section{Structure of the thesis}

Following this introduction, in which the research problem is presented, I will discuss research 
where experimentation has been conceptualized as governance arrangement in the next chapter, in order to situate the study and arrive at a relevant analytical approach. Next, in the chapter titled "Studying experimentation as governance", I will highlight the specific concepts which will be put to work analytically, and will endeavor to show how these concepts will be operationalized. Together, these two chapters make up the study's theoretical framework. Methods and methodological considerations are discussed in the "Method and material" chapter. Before moving to the empirical part of the thesis, a chapter to ground the study in Swedish energy and environmental politics is also included. This chapter provides relevant background, particularly emphasizing how experimentation has figured historically in Swedish energy politics and contemporary smart energy policy, as well as highlighting how a broader political rationality underpins contemporary Swedish environmental politics.

The empirical part of the thesis is structured into four chapters, each focusing on different spaces where smart energy experimentation arranges environmental governance. The first empirical chapter is focused on broader governance arrangements, mainly on a national level, elucidating a governmental apparatus which smart energy experimentation is becoming incorporated into, and the political rationality underpinning it. The second empirical chapter shifts the analytical focus to take a closer look inside the governmental apparatus outlined in the previous chapter, investigating how experts across governmental institutions and policy networks reason in practical terms about smart energy experimentation. This can be conceived heuristically as a meso-level analysis. The third empirical chapter moves on to examine an urban experiment in Stockholm, and contrasts this with urban experiments in Malmö and Västerås, still focused on how experimentation arranges environmental governance but from a micro perspective on the ground. The analytical focus extends beyond the immediate confines of experimental sites in the chapter, to trace relations established through experiments across local public administrations, for example. The final empirical chapter revolves around a major governmental initiative, attempting to make Gotland an energy pilot region, and the interrelation with a previous smart energy experiment on Gotland. The chapter is mainly focused on how governance is arranged through the major governmental initiative, which can be conceptualized as an ecology of interventions, and how the preceding experiment comes into play in this initiative.

Finally, a concluding chapter draws the analysis of the four chapters together, to synthesize and highlight what can be learned about how smart energy experimentation arranges environmental governance in contemporary Sweden. The chapter emphasizes that the analysis unpacks how experimentation contributes to instituting particular governance arrangements, which are rarely named or explicitly described as such, across different spaces of governance, thus elucidating attempts to achieve transformative change from experiments in practice. In particular, the relation between the political rationality underpinning smart energy experimentation and specific experiments is discussed. 


\section{Situating experimentation: conceptualizing smart energy experimentation as governance arrangement}

In this chapter, I will focus on how experimentation has been conceptualized as governance arrangement in research, in the sense of organizing social relations and institutional arrangements. ${ }^{56} \mathrm{I}$ am particularly interested in disentangling how the relationship between knowledge, or knowledge claims, and governing has been conceptualized. The goal of this discussion is to arrive at a relevant analytical approach.

The starting point for the chapter, and for the broader analytical endeavor, is that analyzing unfolding governance processes necessitates situating smart energy experimentation. Based on this conviction, this chapter will excavate how experimentation has been conceptualized as governance arrangement in different research strands. This endeavor will help me arrive at an adequate conceptualization of experimentation as governance arrangement, which can be analyzed empirically. It can situate experimentation for the empirical analysis as well, adding analytical depth by uncovering affinities of experimentation with broader contemporary political rationality.

First, I will situate the study by outlining its theory of science orientation. Then, I will attend to literature concerned with how experimentation reconfigures society, and thus arranges governance, often emphasizing how such ordering tends to occur on a micro level. After that, I will move to literature explicitly concerned with governance, especially studies taking political rationality as a starting point for analyzing governance arrangements. Following this, I will discuss literature where a contemporary political rationality of environmental politics is conceptualized, particularly focusing on literature about smart energy experimentation. Such conceptualizations contribute historicity to the upcoming empirical analysis, by highlighting how experimentation is embedded within and perhaps reconfigures broader contemporary environmental governance arrangements. Finally, I will draw together what has been learnt

\footnotetext{
${ }^{56} \mathrm{~A}$ maximalist definition of institutional arrangement is provided by political scientist B. Guy Peters, which will be utilized here. He states that institutions are in some ways a structural feature of a polity, either formal (e.g. a legal framework) or informal (e.g. a network of organizations or shared norms). Thus, institutions create patterned interactions. Institutions display some degree of stability over time, and they affect individual behavior, and, finally, they create a sense of shared values and meaning among members of the institution. See Peters 2012. Institutional theory in political science: The new institutionalism. 3rd [rev.] ed. London: Continuum.
} 
through this chapter and explain how I will analytically approach how smart energy experimentation arranges environmental governance in the present.

\section{Research approach}

Poststructuralist scholars Jason Glynos and David Howarth have stated that it is necessary to reflect on ontology in analytical endeavors - although not in order to make "reality judgments", i.e. discovering how things really are in the world.$^{57}$ Rather, they claim, this is necessary in order to make visible and reflexively attend to one's own presuppositions. Ontology helps fix the gaze on the basic concepts which are mobilized in any empirical investigation. Based on this stance, Howarth argues that "poststructuralists ought to focus on the meanings and beliefs that social actors accord the objects with which they engage", but he also states that "this focus is radically insufficient" ${ }^{58} \mathrm{He}$ maintains that these meanings must be tied to their particular contexts and discourses, following post-Marxist scholars Ernesto Laclau and Chantal Mouffe. To exemplify, a rock has material properties, but it becomes a weapon, construction materials, or a component in a contemplative practice only in specific discursive configurations. ${ }^{59}$ Howarth elaborates thus:

$[\ldots]$ activities [...] are also meaningful practices that consist of interconnected assemblages of objects, subjects, and actions, which are in turn related to other practices, objects, contexts, and environments. And these assemblages can and must be identified and explained in specific ways. The relational and contextual character of meaning is thus important for making sense of practices and processes in social life. ${ }^{60}$

In other words, how phenomena are understood is tied to specific spatio-temporal settings and intimately connected to practices. ${ }^{61}$ This insight resonates with Foucault, as Howarth mentions explicitly. The resonance can be illuminated through the following quotation:

I would like to show with precise examples that in analyzing discourses themselves, one sees the loosening of the embrace, apparently so tight, of words and things, and the emergence of a group of rules proper to discursive practice. These rules define not the dumb existence of a reality, nor the canonical use of a vocabulary, but the ordering of objects. 'Words and things' is the entirely serious title of a problem; it is the ironic title of a work that modifies its own form, displaces its own data, and reveals, at the end of the day, a quite different task. A task that consists of not - of no longer -

${ }^{57}$ Glynos \& Howarth 2007. Logics of Critical Explanation in Social and Political Theory. London: Routledge. pp. 108-109.

${ }^{58}$ Howarth 2013. Poststructuralism and after: structure, subjectivity and power. New York: Palgrave Macmillan. p. 114.

${ }^{59}$ Laclau \& Mouffe 1985. Hegemony and Socialist Strategy. London: Verso.

${ }^{60}$ Howarth, 2013. Poststructuralism and after. p. 114, emphasis added.

${ }^{61}$ Cf. Mouffe 2013. Agonistics: thinking the world politically. London: Verso. 
treating discourses as groups of signs (signifying elements referring to contents or representations) but as practices that systematically form the objects of which they speak. ${ }^{62}$

Glynos and Howarth refer to Foucault and advocate a problem-driven approach to research. ${ }^{63}$ They state, along with Foucault, that analysts should focus on problematizations and the practices through which problematizations are formed ${ }^{64}$ An object of study is constructed, they argue, through drawing disparate empirical phenomena together and constituting them as a research problem. ${ }^{65}$ This study's overarching research ethos is in line with such an attitude, taking it as a point of departure to synthesize insights from poststructuralist governmentality studies and science and technology studies (STS) for analytical purposes. I will draw empirical phenomena together to constitute a research problem, in Glynos and Howarth's sense, based on concerns raised in previous research which are in line with my own research interest and normative interest in how environmental issues are made sense of and handled in practice in the so-called Anthropocene.

This resonates with environmental sociologist and STS scholar Luigi Pellizzoni, who stated that:

[...] in order to understand and effectively criticize the world in which we live, we have first and foremost to trace the conditions of possibility of the horizon of meaning that defines the present. This entails that history and not ideas comes first; that the appearance and success of new concepts and views cannot be assessed in terms of their alleged advancement in the direction of the truth about the constitution of reality - in terms of learning from, and remedying, previous errors or weaknesses - but rather needs to be considered in the light of the historically constituted problematic field that makes them possible. ${ }^{66}$

What Pellizzoni effectively tells us is to move through any analysis concerned with meaningmaking attentively. The conditions of possibility for specific meaning formations and practices to arise need to be taken into account to understand said practices. Therefore, it is necessary to consider the historically constituted problematic field, in Pellizzoni's words, in which experimentation arranges environmental governance in the Swedish context at this particular moment in time. Others have suggested the term "political rationality" for similar purposes. ${ }^{67}$ Such an approach can highlight how ideas and practices of experimentation relate to their historical framework:

${ }^{62}$ Foucault, 1972. The archaeology of knowledge. New York: Pantheon Books. p. 49.

${ }^{63}$ Glynos \& Howarth 2007. Logics of Critical Explanation in Social and Political Theory. p. 167. This should not be confused with an instrumental problem-solving approach.

${ }^{64}$ Ibid.

${ }^{65}$ Ibid.

${ }^{66}$ Pellizzioni. Ontological Politics in a Disposable World. p. 51, emphasis in original.

${ }^{67}$ Brown 2015. Undoing the Demos: Neoliberalism's stealth revolution. New York: Zone Books; Dean 2010. Governmentality. 
[...] allowing for certain things to appear as given, certain questions to arise and certain types of answers to be conceived. ${ }^{68}$

Consequently, a problem-driven, abductive research approach is my point of departure. ${ }^{69}$ It is indeed a critical study, rather than problem-solving. However, there are many different modes of being critical. ${ }^{70}$ Within critical environmental social science, there is a long-standing discussion on appropriate modes of critical research. One way of thinking about critical research has been summarized in the field of political ecology as entailing both the ambition of critiquing problematic taken-for-granted notions and planting something else in their stead, expressed through the metaphor of viewing political ecology as both hatchet and seed. ${ }^{71}$ In this study, I endeavor to follow such an overarching critical ethos. As geographer Ruth Machen neatly summarizes, critical research:

\section{[...] illuminates the philosophical contingency of knowledge, of social structures, and relations. ${ }^{72}$}

Machen further states that critical research can serve as a constant reminder that "what is" at present is only ever a partiality of what might be. According to Machen, critical research can be pursued through different modes and avenues, but the overarching ambition is to destabilize categories which are generally taken for granted, to provide space for alternatives.$^{73}$ It is in this vein of critical research that this study should be read, i.e. as a generative critique of the politics of how smart energy experimentation arranges environmental governance.

To accomplish this in practical terms, I am inspired by French philosopher Paul Ricœur's hermeneutics of suspicion and sympathy, which postulates that a well-founded analysis

\footnotetext{
${ }^{68}$ Pellizzioni 2015. Ontological Politics in a Disposable World. p. 7.

${ }^{69}$ See Glynos \& Howarth 2007. Logics of Critical Explanation in Social and Political Theory. p. 167.

${ }^{70}$ See e.g. Fassin 2017. The endurance of critique. Anthropological Theory, 17(1); Murray Li 2017. The Practice of Critique: A Comment on Fassin. Anthropological Theory, 17(2); Glynos \& Howarth 2007. Logics of Critical Explanation in Social and Political Theory. pp. 191-199; Latour 2004. Why has critique run out of steam? Critical Inquiry, 30(2); Hornborg 2017. Dithering while the planet burns: Anthropologists' approaches to the Anthropocene. Reviews in Anthropology, 46(2-3).

${ }^{71}$ Cavanagh \& Benjaminsen 2017. Political ecology, variegated green economies, and the foreclosure of alternative sustainabilities. Journal of Political Ecology, 24(1); Robbins 2012. Political ecology: A critical introduction. Chichester: Wiley. Not everyone agrees that political ecology has been successful in this endeavor, however. See e.g. Latour 2004. Politics of Nature: How to bring the sciences into democracy. Cambridge, Mass.: Harvard University Press. While critical of political ecologists for their lack of reflexivity, Latour hardly cites any political ecology scholars, making it difficult to grasp who is the target for his anti-criticism critique.

${ }^{72}$ Machen 2019. Critical research impact: On making space for alternatives. Area, 52(2). p. 331.

${ }^{73}$ Machen 2019. Critical research impact.
} 
develops through a pendulum movement between critique and sympathy. ${ }^{74}$ This means approaching empirical analysis sympathetically, such as by genuinely attempting to understand the life-worlds and logics at play for different actors, without losing critical potential by also taking a suspicious approach toward the material. The analytical process has been a constant movement between these two extremes. It should also be emphasized that I am not at all critical of individuals whom I have interviewed; judging or critiquing specific individuals is never the errand. Rather, I am interested in the phenomena which can be derived from articulations by individuals as representatives of different organizations, to critically approach these phenomena.

\section{Experimentation as governance arrangement: reconfiguring society through showing, testing, learning, and scaling up}

There is an abundance of literature describing experimentation as a natural science ideal type. There, attempts to isolate processes, removal of disturbing effects, intervention, and observation are described as some of the key characteristics of a natural science experiment, as well as the predictability of experiments. Natural science experiments are generally about testing a pre-postulated hypothesis. ${ }^{75}$ Notions of objective, scientific knowledge generation have often constituted a source of legitimacy when it comes to experiments. It was only more recently that experimentation emerged in literature concerned with, for example, environmental politics.

Studies where experiments are described in an ideal-type way do not explicitly conceptualize experiments as ordering society, however. A seminal study highlighting the co-production of knowledge generation and social order through experiments is that of STS scholars Steven Shapin and Simon Schaffer. They show how experimentation gained prominence as a method for producing knowledge claims in the 1700 s specifically by virtue of its demonstrative capacity, through showcasing in public forums. ${ }^{76}$ Shapin and Schaffer's account highlights how experiments are, to an extent, about convincing specific publics. Their account illustrates that historically, experiments have come to be significant for knowledge generation and substantiating knowledge claims, based on positivist-inspired scientific method and the demonstrative capacity of experiments. By making the knowledge generation in experiments in principle transparent, and by creating a language with which to speak about experimentation,

\footnotetext{
${ }^{74}$ See e.g. Kristensson Uggla 1994. Kommunikation på bristningsgränsen: en studie i Paul Ricoeurs projekt. Dissertation. Lund: Lund University.

${ }^{75}$ See e.g. Chalmers 2013. What is this thing called science? 4th ed. Maidenhead: Open University Press/McGraw-Hill Education. p. 26.

${ }^{76}$ Shapin \& Schaffer 1985. Leviathan and the Air-Pump: Hobbes, Boyle, and the experimental life. Princeton, N.J.: Princeton University Press.
} 
a specific social order was co-produced where authority was gradually removed from a supreme monarch to verifiable science. ${ }^{77}$ In contemporary societies, the continued influence of natural science experimentation is illustrated by the popularity of the concept of evidencebased policymaking, as this is envisioned to build upon scientific evidence that is often described in a positivist sense. ${ }^{78}$ Experimentation, in its many guises, often draws upon this legitimacy with which experiments have historically been associated through their connection to practices within the natural sciences. This is an important background for understanding how environmental governance is arranged through smart energy experimentation as well, as it can hardly be considered to be decoupled from such notions.

Convincing publics through experiments, as highlighted by Shapin and Schaffer, provides important input for conceptualizing experimentation as governance arrangement. If experiments function in a sense to convince people, they are likely set up to do so in specific ways, arranging and becoming incorporated into governance for such purposes. This is further highlighted by STS scholars who have shown how experiments often serve as "technoscientific dramas", constituting specific publics across different arenas, drawing together and discerning citizens, public administration, scientists, and managers, to convince them of particular solutions. ${ }^{79}$ Consequently, experiments cannot be considered neutral tests. The actors involved attempt to stabilize particular socio-technical configurations, including technologies, actor constellations, and values. Importantly, such studies highlight how experiments can serve both to solidify power relations, benefiting dominant actors, and to offer marginalized actors opportunities to influence collective practices and decisions. ${ }^{80}$ STS scholar Brice Laurent has expanded upon such aspects, stating that experiments can be conceptualized as technologies of democracy. ${ }^{81}$ For Laurent, experiments produce specific political orders. Working through local spaces, experiments quickly extend beyond their localities, for example forcing new elements to be included as objects of governance by the public administration through the socio-material practices of experiments. ${ }^{82}$ STS researchers Alain Nadaï and Olivier Labussière show how experiments frame political participation in particular ways, by filtering out complexities deemed irrelevant and making certain options for action

\footnotetext{
${ }^{77}$ Shapin \& Schaffer 1985. Leviathan and the Air-Pump.

${ }^{78}$ See e.g. Bohlin \& Sager (eds.) 2011. Evidensens många ansikten: Evidensbaserad praktik i praktiken. Lund: Arkiv.

${ }^{79}$ E.g. Möllers 2016. Shifting in and out of context: Technoscientific drama as technology of the self. Social Studies of Science, 46(3); Rosental 2013. Toward a Sociology of Public Demonstrations. Sociological Theory, 31(4); Nadaï \& Labussière 2018. Technological Demonstration at the Core of the Energy Transition. In Labussière \& Nadaï (eds.). Energy Transitions. A Socio-technical Inquiry. Cham: Palgrave Macmillan. pp. 191237.

${ }^{80}$ Nadaï \& Labussière 2018. Technological Demonstration at the Core of the Energy Transition.

${ }^{81}$ Laurent 2011. Technologies of Democracy: Experiments and Demonstrations. Science and Engineering Ethics, 17(4); Laurent 2016. Political experiments that matter: Ordering democracy from experimental sites. Social Studies of Science, 46(5).

${ }^{82}$ Laurent 2016. Political experiments that matter.
} 
feasible in experiments. ${ }^{83}$ This also encompasses learning processes, as certain elements will become suppressed and pushed to the background within such a framework created through experiments, while other aspects will be placed at the forefront. ${ }^{84}$

These studies illuminate how experiments constitute specific publics and attempt to convince them of certain solutions. Thus, experiments can produce legitimacy for certain policy programs or socio-technical configurations, by demonstrating publicly that public funds are used in a sensible way. These studies reveal important characteristics of experimentation as governance arrangement, beyond singular experiments. They show how governance is not only something that happens from policy proposals via implementation, but is also arranged from a micro level in more distributed, complex arrangements. As Laurent shows, experiments are, in a sense, technologies of ordering democracy. These studies show how it is important to take the contingencies and particularities of experiments seriously, as situated experiments contribute to shaping specific governance arrangements from below, extending far beyond the localities of situated experiments. Additionally, they highlight how learning is often articulated as a central rationale of experiments, as is testing socio-technical configurations on a small scale. The studies contribute to conceptualizing experiments as important political spaces through which governance is ordered, even if governance is not a preferred term within such literature. Consequently, they show how it is important to take seriously and attend to how orders are created through specific experiments, as such orders are rarely confined to an imagined closed space within which experiments take place.

There are numerous studies across research fields where experiments are further conceptualized as forming parts of governance arrangements, even if they are not expressed as such. A prominent line of thinking has evolved from innovation studies, where experiments, often conceptualized as pilot and demonstration plants, are highlighted as being important for industrial innovation and the diffusion of new technologies through commercialization. ${ }^{85}$ Such studies emphasize the importance of pilots and demonstrations for balancing the verification of technologies whilst simultaneously creating a new market, and they also emphasize how organizational, market, and institutional uncertainties can be mitigated through pilot and demonstration projects. ${ }^{86}$ Consequently, such studies highlight setting up learning processes as a central aspect of arranging governance through experiments, since such learning can come to reconfigure institutional arrangements. This is generally conceptualized through the notion

${ }^{83}$ Cf. Stissing Jensen, Späth, and Cashmore (eds.) 2019. The politics of urban sustainability transitions.

${ }^{84}$ Nadaï \& Labussière 2018. Technological Demonstration at the Core of the Energy Transition; cf. Cashmore et al. 2019. Introduction.

${ }^{85}$ E.g. Hellsmark et al. 2016. The role of pilot and demonstration plants in technology development and innovation policy. Research Policy, 45; Frishammar et al. 2014. The role of pilot and demonstration plants in technological development: synthesis and directions for future research. Technology Analysis \& Strategic Management, 27:1.

${ }^{86}$ Hellsmark et al. 2016. The role of pilot and demonstration plants in technology development and innovation policy. p. 1744. 
of upscaling, i.e. experiments function as small-scale tests which, if successful, can be replicated and scaled up. Such literature also tends to emphasize the necessity of establishing new cooperative endeavors between actors, often in the form of public-private partnerships in experiments. ${ }^{87}$

Other accounts underline the opportunities of experiments as innovation instruments, but also emphasize how small-scale experiments advance new socio-technical arrangements through their testing, potentially impacting broader patterns of governance. ${ }^{88}$ Other scholars underline how experimentation has become a prominent form of social change through adaptive learning in conditions of profound uncertainty and the decline of top-down policy implementation. ${ }^{89}$ They also highlight how a central feature of experiments is that they are assumed to constitute alternatives to the status quo. The focus in such studies is less on scaling up experiments and more on "real-world experiments", and when upscaling is conceptualized it is rather through emphasizing how scalability is conditioned by socio-political and cultural settings. Testing through experiments has long caught the attention of researchers, but has recently come under close scrutiny from a slightly different perspective. STS researchers Noortje Marres and David Stark pose the question of what is actually tested in experiments, and what testing can actually mean. They highlight that testing is generative, so rather than scrutinizing the results of tests, research should focus on what results from tests, i.e. what is actually generated through instances of testing. ${ }^{90}$ The proliferation of testing across social life is linked to an organizational, technical, and material modification of society, making the observation and analysis of life increasingly ubiquitous and influenceable by different actors. They underline how tests unfold in an ecology of testing, rather than in specific testable moments, which may redefine the relations between testing sites and their environments. Rather than testing specific sociotechnical configurations, tests directly and deliberately modify the social environment. ${ }^{91}$

From these studies one can gather how adaptive learning through experimentation has been argued to constitute a central feature of experiments, as a strategy for coping with uncertainties and institutionalizing an openness to surprises within governing bodies such as

${ }^{87}$ See e.g. Hellsmark et al. 2016. The role of pilot and demonstration plants in technology development and innovation policy.

${ }^{88}$ Engels et al. 2019. Testing future societies?; Späth \& Rohracher 2012. Local Demonstrations for Global Transitions - Dynamics across Governance Levels Fostering Socio-Technical Regime Change Towards Sustainability. European Planning Studies, 20(3).

${ }^{89}$ Gross 2016. Give Me an Experiment and I Will Raise a Laboratory. Science, Technology, \& Human Values, 41(4); Ansell \& Bartenberger 2016. Varieties of experimentalism. Ecological Economics, 130; Overdevest, Bleicher, and Gross 2010. The Experimental Turn in Environmental Sociology: Pragmatism and New Forms of Governance. In Gross \& Heinrichs (eds.) 2010. Environmental Sociology: European Perspectives and Interdisciplinary Challenges. pp. 279-294.

${ }^{90}$ Marres \& Stark 2020. Put to the test: For a new sociology of testing. The British Journal of Sociology, 71(3).

${ }^{91}$ Marres \& Stark 2020. Put to the test. 
public administrations. They add understanding of how such learning in practice is more complicated than is often imagined, highlighting for example how such experiments are designed to cope with unknowns by anchoring them in variously configured laboratory contexts, and how adaptive learning can come to reconfigure governance arrangements step by step. Additionally, they highlight how experimentation tends to be set up as cooperative endeavors, particularly in the form of public-private partnerships, and that experiments constitute alternatives to or explicit attempts at changing the status quo. Finally, they complicate notions of testing in closed-off environments, underlining how testing comes to reconfigure broader social relations. This draws attention to how testing is incorporated in practice in specific experiments, as well as how different actors operating within such an ecology of testing make sense of the tests, as this can serve to heighten analytical sensibility toward how governance is arranged through experimentation in a broader sense.

Another strand of literature, which builds on innovation studies, treats experiments as integral instruments for instigating changes to sprawling socio-technical systems, following an evolutionary logic. Such strands can be summarized as transition studies, encompassing the multi-level perspective, strategic niche management, and sustainability transitions literature. These strands of literature deal with how experimentation arranges governance on a higher level of analytical abstraction, compared to the micro-inclined studies accounted for above. Research in this vein envisions changes of socio-technical systems to take place in a sequential manner through interactions between three heuristically distinguished analytical levels, called the socio-technical landscape, the incumbent socio-technical regime, and niche innovations. ${ }^{92}$ Here, experiments play the role of initiators of change, and examples of experiments include behavior practices such as car sharing, new technologies, new business models, or combinations of these. ${ }^{93}$ Such experiments appear in what is called the emergence phase, and gather steam through various mechanisms, whereby they diffuse to create windows of opportunity for widespread transformative change as regimes become destabilized by these new configurations, leading eventually to broader system transformation. ${ }^{94}$ This literature has often taken a historical perspective on transitions occurring across specific sectors such as electricity grid infrastructure.

\footnotetext{
${ }^{92}$ Geels et al. 2018. Reducing energy demand through low carbon innovation: A sociotechnical transitions perspective and thirteen research debates. Energy Research \& Social Science, 40; Sengers, Wieczorek, and Raven 2019. Experimenting for sustainability transitions: A systematic literature review. Technological Forecasting and Social Change, 145.

${ }^{93}$ Geels et al. 2018. Reducing energy demand through low carbon innovation; Geels 2002. Technological transitions as evolutionary reconfiguration processes: a multi-level perspective and a case-study. Research Policy, 31(8-9); Schot \& Geels 2008. Strategic niche management and sustainable innovation journeys: theory, findings, research agenda, and policy. Technology Analysis \& Strategic Management, 20(5).

${ }^{94}$ Geels et al. 2018. Reducing energy demand through low carbon innovation.
} 
The approach of strategic niche management (SNM) includes perhaps the most pervasive conceptualization of experiments within the transition studies literature. ${ }^{95} \mathrm{SNM}$ researchers observe that incumbent socio-technical regimes, such as a consolidated energy system, ${ }^{96}$ are inherently resistant to anything other than incremental change, leading to the failure of many promising new technologies. ${ }^{97}$ Therefore, it is necessary to create "protected spaces" through policy measures and the strategic development of niches in specific markets to challenge the incumbent, unsustainable socio-technical regimes. ${ }^{98}$ The core idea is that such a strategic management of experiments in niches can then lead to the eventual upscaling of these experiments, ultimately resulting in the disruption and transformation of dominant sociotechnical regimes. ${ }^{99}$ Expanding on the idea of upscaling, Rolf Naber and colleagues state that this is a process that can unfold in different ways. They state that in order to scale up experiments, broad and deep social network building between actors, shared and clearly articulated visions and expectations, and broad and reflexive learning processes are necessary. ${ }^{100}$

This literature contributes conceptualizations of experimentation as part of governance arrangements on a higher level of analytical abstraction, compared to the studies previously accounted for. Further, it highlights how experiments are always underpinned by specific theories of change, such as the evolutionary account of change provided by the multi-level perspective (MLP) and SNM, where small-scale experiments can gather momentum and eventually transform broader socio-technical regimes. Such theories of change contribute to specific orderings of society by setting up experiments in particular ways, and are visible in the notion of protected spaces or conceptualizations of pilot and demonstration plants as innovation instruments, for example. The literature also highlights how experimentation is envisioned to necessitate testing socio-technical configurations on a smaller scale, with the normative intent to scale up such configurations. Upscaling seems to be highly compatible with the emphasis in the literature on public-private partnerships and cooperation, which is visible when upscaling is claimed to necessitate social network building and the articulation of common visions. These accounts pose questions about how experiments contribute to

\footnotetext{
${ }^{95}$ Hoogma, Kemp, Schot, and Truffer 2002. Experimenting for Sustainable Transport: The Approach of Strategic Niche Management. London: Spon.

${ }^{96}$ Cf. Hughes 1983. Networks of power; Hommels 2005. Unbuilding Cities: Obduracy in Urban Sociotechnical Change. Cambridge, Mass.: MIT.

${ }^{97}$ Sengers, Berkhout, Wieczorek, and Raven 2016. Experimenting in the city: unpacking notions of experimentation for sustainability. p. 17. In Evans et al. (eds.) The Experimental City. pp. 15-31.

${ }^{98}$ See e.g. Schot \& Geels 2008. Strategic niche management and sustainable innovation journeys; Smith \& Raven 2012. What is protective space? Reconsidering niches in transitions to sustainability. Research Policy, 41(6).

${ }^{99}$ Sengers et al. 2016. Experimenting in the city. p. 18; Geels et al. 2018. Reducing energy demand through low carbon innovation.

${ }^{100}$ Naber, Raven, Kouw, and Dassen 2017. Scaling up sustainable energy innovations. Research Policy, 110. It should be noted that this does not depart to any great extent from the general description in the SNM literature; see e.g. Geels et al. 2018. Reducing energy demand through low carbon innovation.
} 
reconfiguring social relations, illuminating how experiments can gradually gain momentum and change infrastructure regimes. They further highlight how there is rarely any grand plan, rather emphasizing adaptive learning through experiments.

The literature discussed in this section illuminates how experimentation can be conceptualized as contributing to specific governance arrangements, both from a micro level and through becoming embedded in broader governance structures, as well as through reconfiguring entire socio-material settings. The literature destabilizes experimentation by showing how smallscale experiments can reconfigure vast socio-technical structures, often in unpredictable and unintended ways. Thus, the studies discussed point to how governance becomes arranged through experiments. Experimentation tends to be described as small-scale tests of sociotechnical configurations breaking with business as usual, often in public-private partnerships, where adaptive and iterative learning can unfold, which can eventually lead to transformative change of infrastructures, for example. ${ }^{101}$ This body of literature show how experiments can contribute to reconfiguring society in a more wide-ranging way than is often imagined, by changing social relations and socio-technical systems. It highlights how different ways of conceptualizing how experimentation as governance arrangement is underpinned by theories of change, evident in examples such as the evolutionary logic permeating MLP and the emphasis on ecologies of testing within sociology of testing.

These studies offer relevant points of departure for analyzing experimentation as governance arrangement, underlining how governance becomes arranged through processes unfolding both on a micro level from experimental sites and through broader governance settings, or ecologies of testing. However, I also intend to analytically approach experimentation as governance arrangements from a historicizing perspective, to dig deep into how experimentation arranges governance within a particular historically constituted problematic field. ${ }^{102}$ Following Pellizzoni, this is necessary to analyze experimentation in a situated way, to examine the conditions of possibility for experimentation to arise and unfold in particular ways in particular spatio-temporal settings, i.e. to relate ideas and practices of experimentation as governance arrangement to their historical framework. This includes analyzing how experimentation as a phenomenon arranges governance in particular ways, extending beyond singular experiments, sensitizing the analysis to historically sedimented power relations. Further, in the literature that approaches governance more explicitly, such as SNM, conceptualizations of governance are rather limited from a historicizing perspective. Consequently, I will now discuss literature that approaches governance arrangements in such an explicit way, to enable an analysis of how the historical phenomenon of smart energy

\footnotetext{
${ }^{101}$ It seems so taken for granted that experiments are supposed to test configurations which diverge from the status quo that it is rarely discussed in the literature, highlighting how this is ascribed as a central characteristic of experiments.

${ }^{102}$ Historicizing in the "history of the present" sense, which I will do through the concept of political rationality. More on this below.
} 
experimentation and contemporary environmental governance dynamically unfold and interact.

\section{Governance, politics, and power: conceptualizing dynamics of environmental governance and smart energy experimentation}

This section will approach literature explicitly concerned with governance, focusing particularly on how governance arrangements can be conceptualized to analyze the conditions of possibility for particular orchestrations to unfold. The focus will be on the concept of political rationality, to show it is apt for such a task, and to disentangle how smart energy experimentation can fruitfully be analyzed through engaging with political rationality. Finally, research on political rationality of contemporary environmental politics will be highlighted, emphasizing literature that focuses specifically on smart energy experiments, to deepen the conceptualization of how smart energy experimentation and environmental governance are co-constituted.

Governance is an ambiguous term which is deployed differently across the social sciences and humanities. Therefore, I will briefly discuss governance in a broad sense, to disentangle how I will conceptualize governance in this study, before expanding on the concept of political rationality.

As a starting point, governance is often contrasted with government, where government signifies the formal system of rule of a sovereign government over a specified territory. ${ }^{103} \mathrm{By}$ contrast, governance is described as something more amorphous, extending beyond direct steering or top-down decision-making through the official channels of a sovereign nation state. In the words of the Commission on Global Governance:

Governance is the sum of the many ways individuals and institutions, public and private, manage their common affairs. ${ }^{104}$

Governance, then, involves more actors than the formal government of a nation state, and more activities than decision-making procedures in such states. According to political scientists Stephen Buzdugan and Anthony Payne, governance gained currency as a term for analyzing global politics after the Cold War. They claim that politics experienced remarkable shifts during these years, especially in terms of the actors involved in shaping politics, which grew to extend far beyond sovereign nation states. ${ }^{105}$ One very broad definition of governance from

\footnotetext{
${ }^{103}$ See e.g. Rosenau \& Czempiel 1992. Governance without Government: Order and change in World Politics. Cambridge: Cambridge Univ. Press; Sinclair 2012. Global Governance. Cambridge: Polity. p. 28.

${ }^{104}$ The Commission on Global Governance 1995. Our global neighbourhood: the report of the Commission on Global Governance. Oxford: Oxford University Press. p. 4.

${ }^{105}$ Buzdugan \& Payne 2016. The Long Battle for Global Governance. Abingdon, Oxon: Routledge.
} 
political scientist James Rosenau, which sprang from these debates, became widely used. In this definition, governance is described as:

$[\ldots]$ spheres of authority $[\ldots]$ at all levels of human activity $[\ldots]$ that amount to systems of rule in which goals are pursued through the exercise of control. ${ }^{106}$

In other words, governance is about "getting things done", according to Rosenau. Thus, in literature on governance, a shift from government to governance has regularly been emphasized. ${ }^{107}$ Critical scholars have noted that this shift has coincided with neoliberal governance strategies such as deregulation and privatization, and argue that this has led to a democratic gap since political issues which were previously debated and dealt with in the public sector have increasingly been moved to the private sector to be dealt with by experts. ${ }^{108}$ For some scholars, this signifies a post-political condition, where the political, in the sense of genuine contestations over values and political choices, has been replaced by technocratic governance. ${ }^{109}$ Some argue that this is especially the case in environmental politics. ${ }^{110}$ Whatever position one takes in this discussion, it appears clear that this shift from government to governance has coincided with the project politics within which smart energy experiments are embroiled, signified by a blurring of boundaries between public and private through the use of pilots as an organizational form, often in public-private partnerships, and by moving matters of concern which were previously dealt with by public institutions to private actors. ${ }^{11}$

Political scientists often talk about multi-level governance, as a means to capture how different levels of political systems, such as municipalities, regions, and national institutions, have become more intertwined with each other over time, and especially how these different levels affect each other. ${ }^{112}$ The EU is often used as an example, since decrees such as directives have to be transposed into national law by its member states, while nation states (through their

${ }^{106}$ Rosenau 1997. Along the domestic-foreign frontier: exploring governance in a turbulent world. Cambridge: Cambridge Univ. Press. p. 145.

107 Rhodes 1997. Understanding Governance: Policy Networks, Governance, Reflexivity and Accountability. London: Open University Press.

${ }^{108}$ Fawcett, Flinders, Hay, and Wood (eds.) 2017. Anti-politics, depoliticization, and governance. Oxford: Oxford University Press; Brown 2015. Undoing the Demos.

${ }^{109}$ See e.g. Mouffe 2005. On the Political. London: Routledge; Mouffe 2000. The Democratic Paradox. London: Verso; Ranciére 2006. Hatred of Democracy. London: Verso.

${ }^{110}$ Swyngedouw 2010. Apocalypse Forever? Post-Political Populism and the Spectre of Climate Change. Theory Culture \& Society, 27; Swyngedouw 2013. The Non-political Politics of Climate Change. ACME: An International Journal for Critical Geographies, 12(1); Blühdorn \& Welsh (eds.) 2014. The politics of unsustainability: eco-politics in the post-ecologist era. London: Routledge.

${ }^{111}$ Hodgson et al. (eds.) 2019. The Projectification of the Public Sector; cf. Brown 2015. Undoing the Demos.

${ }^{112}$ See e.g. Bulkeley \& Newell 2015. Governing Climate Change; Vogler 2003. Taking Institutions Seriously: How Regimes Can Be Relevant to Multilevel Environmental Governance. Global Environmental Politics, 3(2). 
membership) and interest groups (through lobbying) can influence the institutions of the EU. ${ }^{113}$ In this literature, however, governance still resides in the realms of the formal political system, even though the scope of analysis has been significantly broadened to include more actors, institutions, and arenas which are understood to also influence processes of governing.

\section{Governmentality}

However, governance is not necessarily intimately tied to formal political institutions such as governments, at least not in a direct sense. Scholarly accounts that depart from such an understanding of governance could be argued as more in line with Rosenau's definition of governance, although they depart from different theoretical terrains and are situated within different empirical settings. According to Bulkeley and Newell, the landscape of governing complex issues such as climate change encompasses scales from the local to the global, and a wide array of actors across state, non-state, public, private, and public-private hybrid organizations. ${ }^{114}$ They claim that it is no longer possible to view climate governance as mainly carried out by states and international institutions, since the issue has become mainstreamed and now includes initiatives such as private codes and standard setting, public-private initiatives, grassroots movements such as Transition Towns, and international NGOs, presenting huge policy coordination and coherence problems. Socio-technical experimentation has emerged as a prominent strategy of environmental governance, particularly in urban domains, as have transnational networks such as coalitions of municipalities. ${ }^{115}$ Bulkeley and Newell also emphasize how there has been a growing trend toward governance arrangements where the main responsibility resides with private actors, and policymakers have been increasingly inclined to prefer market instruments. ${ }^{116}$

This expanded view of governance often resides within broadly Foucauldian research approaches. Here, governance is understood as wider sets of regulatory mechanisms which shape specific forms of behavior and organization. ${ }^{117}$ Thus, it becomes possible to speak of more encompassing governance arrangements, or governmentalities. Consider for instance

\footnotetext{
${ }^{113}$ See e.g. Magone 2011. Contemporary European Politics. London: Routledge; Hix \& Høyland 2011. The Political System of the European Union. 3rd ed. Basingstoke: Palgrave Macmillan.

${ }^{114}$ Bulkeley \& Newell 2015. Governing Climate Change.

${ }^{115}$ Bulkeley \& Castán Broto 2013. Government by experiment?; Bulkeley et al. 2015. An Urban Politics of Climate Change; Verbong \& Geels 2010. Exploring sustainability transitions in the electricity sector with socio-technical pathways. Technological Forecasting and Social Change, 77(8); Späth \& Rohracher 2010. 'Energy regions': The transformative power of regional discourses on socio-technical futures. Research Policy, 39(4).

${ }^{116}$ Bulkeley \& Newell 2015. Governing Climate Change; cf. Hajer 1995. The Politics of Environmental Discourse: Ecological Modernization and the Policy Process. Oxford: Oxford University Press; Dryzek 2013. The Politics of the Earth: Environmental discourses. 3. ed. Oxford: Oxford University Press.

${ }^{117}$ See Foucault 2007. Security, Territory, Population.
} 
the argument of David Harvey, who argued in 1989 that the governance of cities had undergone a seismic shift from what he called managerialist to entrepreneurial governance. ${ }^{118}$ As urban geographer Mark Davidson puts it:

Since the advent of entrepreneurialism in the late 1970s, the transformation of urban governance has therefore not simply occurred in city hall. It has also occurred in public understandings of what the city does, who runs it and what it operates for. ${ }^{119}$

In line with such an expanded conceptualization of governance, and building on Foucault's insights, there is a research orientation called governmentality studies. Its scholars are concerned with the practices that render issues such as climate change governable. ${ }^{120}$ Generally speaking, the governmentality literature builds upon two lecture series given by Foucault in 1978 and 1979. ${ }^{121}$ In these lectures, Foucault was concerned with the genealogy of the modern state and what he called "the art of government". He highlighted how government is concerned with the wellbeing of populations, achieved through a right way of disposing things so as to lead them to an end suitable for each of the things to be governed. ${ }^{122}$ He defined government as the conduct of conduct, as in the attempt to shape conduct through calculated means. Thus, governance entails setting out conditions rather than coercion, and it is an inherently expansive activity. The purpose of government, according to Foucault, is to:

$[\ldots]$ improve the condition of the population, to increase its wealth, its longevity, and its health. ${ }^{123}$ sThus, the notion of the population was central to this art of government, whose historical origins Foucault traced, as was the knowledge developed in scientific disciplines and technologies of calculation, such as those developed within statistics, which made the population an object of governing:

$[\ldots]$ the constitution of political economy was made possible when population emerged as a new subject from the different elements of wealth. Well, a new science called "political economy" and, at the same time, a characteristic form of governmental intervention, that is, intervention in the field of the economy and population, will be brought into being by reference to this continuous and multiple network of relationships between the population, the territory, and wealth. ${ }^{124}$

${ }^{118}$ Harvey 1989. From Managerialism to Entrepreneurialism.

${ }^{119}$ Davidson 2017. Governance. p. 151. In Jayne \& Ward (eds). Urban Theory: New Critical Perspectives. London: Routledge. pp. 146-157.

${ }^{120}$ Oels 2005. Rendering climate change governable: from biopower to advanced liberal government. Journal of Environmental Policy and Planning, 7(3).

${ }^{121}$ Foucault 2007. Security, Territory, Population.

${ }^{122}$ Ibid. p. 99.

${ }^{123}$ Ibid. p. 105.

${ }^{124}$ Ibid. p. 106. 
To characterize this genealogy of the art of government, Foucault coined the term governmentality. He defined governmentality as follows:

First, by "governmentality" I understand the ensemble formed by institutions, procedures, analyses and reflections, calculations, and tactics that allow the exercise of this very specific, albeit very

complex, power that has the population as its target, political economy as its major form of knowledge, and apparatuses of security as its essential technical instrument. ${ }^{125}$

He also included in governmentality the long-term tendency of government, as understood in this vein, to rise to preeminence over other forms of power, such as discipline, leading to the development of a series of governmental apparatuses and specific forms of knowledge. ${ }^{126}$ Governmental apparatus, or dispositif, is a keyword to understand Foucault's approach to governance. As the quotes above elucidate, a governmental apparatus for Foucault is the system of relations that is established as heterogeneous elements are interlinked, regulating social life in an encompassing way - extending for example across discourses, institutions, administrative procedures, and scientific knowledge production. For Foucault, every historical epoch can be productively gauged through investigating what is said and what remains unsaid across such domains. Any governmental apparatus is permeated by a rationale of governing - a political rationality - which underpins it and is generative of it. This underlines how, for Foucault, governance is a dynamic process which is always intertwined with the knowledge-making and specific technologies that make up and delineate problems to be solved through acts of governing. To govern is not to chase one dogmatic goal, according to Foucault, but rather a whole series of specific finalities. This is important as it conveys the complexities and contingencies of governance; finalities may be multiple and incompatible, thus governance must be constantly reconfigured. The line of thinking taken up by Foucault in this lecture series has been summarized as follows by sociologist Thomas Lemke:

The semantic linking of governing ('gouverner') and modes of thought ('mentalite') indicates that it is not possible to study the technologies of power without an analysis of the political rationality underpinning them. In other words, there are two sides of governmentality [...]. On the one hand, the term pin-points a specific form of representation; government defines a discursive field in which exercising power is 'rationalized'. This occurs, among other things, by the delineation of concepts, the specification of objects and borders, the provision of arguments and justifications, etc. In this manner, government enables a problem to be addressed and offers certain strategies for solving/handling the problem. On the other hand, it also structures specific forms of intervention. For a political rationality is not pure, neutral knowledge which simply 're-presents' the governing reality; instead, it itself constitutes the intellectual processing of the reality which political

${ }^{125}$ Ibid. p. 108.

${ }^{126}$ Ibid. p. 108. He also adds a historical understanding of governmentality, stretching back to the Middle Ages, to describe how former modes of power gradually morphed into governmentality. Such an understanding is of less relevance in this study, which is rather a history of the present, to use another Foucauldian term. 
technologies can then tackle. This is understood to include agencies, procedures, institutions, legal forms, etc., that are intended to enable us to govern the objects and subjects of a political rationality. ${ }^{127}$

This shifts the analytical attention from reified notions of nation states, legitimacy, incentives, grand political schemes, and stable interests of actors toward processes of governing, focusing for example on the mundane techniques and mechanisms which make carbon into a governable object. ${ }^{128}$ As political scientists Eva Lövbrand and Johannes Stripple state:

The cycling of carbon has to be 'stabilized', i.e. located in spaces (e.g. national territories) and in objects (e.g. carbon credits) that make sense within a political discourse. ${ }^{129}$

Thus, the analytical emphasis is shifted from predefined notions of geographical territories toward political spaces formed through circulations of devices and artefacts. ${ }^{130}$ Studying governance in this vein entails focusing on governmental apparatuses underpinned by distinct political rationality, forming the right manner of disposing things. This drastically widens the spectrum of governance, away from a narrow focus on formal political institutions toward myriad actors, activities, knowledge orders, and arenas. In this study, I will subscribe to such a broadened understanding of governance in order to follow how experimentation arranges governance across different spaces, from interactions within and across individual experiments into the corridors of government agencies. ${ }^{131}$ Evidently, governmentality studies draws on poststructuralist insights. I view poststructuralism as a research orientation, and governmentality as a specific approach to governance broadly residing within this poststructuralist research orientation.

To paraphrase anthropologist Tania Murray Li, governance seen through a governmentality lens is about conducting conduct, optimizing processes, and devising interventions which secure the welfare of the population and the improvement of its condition. ${ }^{132}$ Murray Li adds that besides problematization, identified by Foucault as a central process of governance, rendering technical is essential for governing. By this she refers to acts of making up intelligible

${ }^{127}$ Lemke 2011. 'The birth of bio-politics': Michel Foucault's lecture at the Collège de France on neoliberal governmentality. Economy and Society, 30(2). p. 191.

${ }^{128}$ Cf. Lövbrand \& Stripple 2011. Making climate change governable: accounting for carbon as sinks, credits and personal budgets. Critical Policy Studies, 5(2).

${ }^{129}$ Lövbrand \& Stripple 2011. Making climate change governable. p. 188.

${ }^{130}$ See e.g. Barry 2001. Political machines: Governing a technological society. London \& New York: Athlone Press; cf. Johannisson, 1988. Det mätbara samhället: statistik och samhällsdröm i 1700-talets Europa. Stockholm: Norstedts.

${ }^{131}$ Thus, I follow Lemke's emphasis on governance as "processes of rule”. See Lemke 2007. An Indigestible Meal?: Foucault, Governmentality and State Theory. Distinktion: Scandinavian Journal of Social Theory, 8(2). ${ }^{132}$ Murray Li 2019. Problematising the Project System: Rural Development in Indonesia. In Hodgson et al. (eds). The Projectification of the Public Sector. pp. 56-74. 
fields of intervention, which is intimately linked to the solution experts can provide in particular settings. Such a field of intervention, devising problems and solutions, is coproduced within assemblages of diagnoses, prescriptions, and techniques available to properly trained experts. ${ }^{133}$ Scholarship concerned with governmentality, then, emphasizes how governing shapes the conduct of conduct, encompassing both how authority is exercised and governance practiced from a distance, and how individuals govern themselves, through specific techniques and forms of knowledge. ${ }^{134}$ To analyze governance through the lens of governmentality entails focusing on how governing is done within different regimes, and the conditions of possibility for such a regime to emerge in the first place as well as its transformation. ${ }^{135}$

\section{The underpinnings of governance: conceptualizing governance arrangements as political rationalities}

Political rationality is a concept that has flickered by in the section above. In the following, I will highlight how it has been used by scholars to analyze governance arrangements, providing input for my conceptualization of how smart energy experimentation arranges environmental governance.

Political rationality figures in Foucault's work, as we have seen. However, disentangling Foucault's use of it is no easy task, considering the intricacy of Foucault's thought and his inclination to move quickly between analytical endeavors. ${ }^{136}$ The concept was taken up in English-speaking academia and developed by scholars in what came to be known as governmentality studies, especially by sociologists such as Mitchell Dean, Thomas Lemke, Peter Miller, and Nikolas Rose. According to Dean, governmentality entails analyzing ways of seeing and perceiving, specific ways of thinking and questioning reliant upon specific vocabularies and procedures for truth production, ways of acting and intervening which are constructed around particular rationalities such as forms of expertise and related techniques and technologies, and ways of forming subjects. ${ }^{137}$ For Dean, political rationality signals the form of reasoning underpinning particular forms of governmental intervention. ${ }^{138}$

\footnotetext{
${ }^{133}$ Murray Li 2007. The Will to Improve: Governmentality, development, and the practice of politics. Durham, N.C.: Duke University Press. p. 7.

${ }^{134}$ Dean 2010. Governmentality. pp. 18-19.

${ }^{135}$ Ibid. p. 33.

${ }^{136}$ As Foucault himself wrote in the introduction to The Archaeology of Knowledge: "Do not ask who I am and do not ask me to remain the same: leave it to our bureaucrats and our police to see that our papers are in order". For a thorough examination of the term "political rationality" in relation to other uses, see Cornelissen 2018. What is political rationality? Parrhesia, 29.

${ }^{137}$ Dean 2010. Governmentality. p. 33.

${ }^{138}$ Ibid.
} 
Critical scholar Wendy Brown has extensively analyzed neoliberalism as a particular political rationality, to highlight how it comes to underpin social life in a ubiquitous way - from individuals' behavior to statecraft and education. ${ }^{139}$ For Brown, political rationality can be summarized as the conditions, legitimacy, and dissemination of particular regimes of powerknowledge which organizes social life in particular ways. ${ }^{140}$ Political rationality is not timeless; it is always constituted in particular forms, circulates specific norms, and posits particular relations. ${ }^{141}$ Thus, she analyzes how governance arrangements are always underpinned by particular political rationality, ordering relations in specific ways, and becoming reconstituted through such orderings. In Brown's analysis, political rationality is not an instrument of governmental practice; rather, it constitutes the condition of possibility of particular governance instruments, and the field of reason from which governance is shaped. ${ }^{142}$ Her analysis, then, moves on a more aggregate level in comparison to, for example, the more micro-inclined studies of experimentation accounted for previously. Political rationality, understood in this way, is more encompassing than its companion concept discourse. Whereas discourses constitute particular fields through normalization, political rationality highlights how broader orders of reason come to legitimately govern, ordering life in a ubiquitous way. ${ }^{143}$ Discourses can crisscross and compete within a political rationality, whereas political rationalities are always historically contingent orders that are generative of entire social systems, constituting conditions of possibility for particular relations to enter into force in the first place, until challenged by another political rationality. ${ }^{144}$ For Brown, neoliberal political rationality is marked out by governance practices such as best practice benchmarking, responsibilization, and devolution, i.e. moving large-scale issues such as climate change down the multi-level governance system it generates to smaller units that are less capable of handling such issues. ${ }^{145}$

According to sociologists Peter Miller and Nikolas Rose, government is a problematizing activity in the sense that "it poses the obligations of rulers in terms of the problems they seek to address". ${ }^{146}$ Miller and Rose state that governance is inextricably intertwined with specific

\footnotetext{
${ }^{139}$ Brown 2015. Undoing the Demos.

${ }^{140}$ Ibid. p. 116.

${ }^{141}$ Ibid. p. 115.

${ }^{142}$ Ibid. p. 116.

${ }^{143}$ Ibid. p. 117.

${ }^{144}$ Ibid. p. 121.

${ }^{145}$ Ibid. pp. 131-150. It should also be noted that Brown is critical of the use of "governance" as a term, preferring to use "governing", as governance is conceptualized as an integral part of the neoliberal political rationality she seeks to unearth and criticize.

${ }^{146}$ Miller \& Rose 2008. Governing the Present. p. 61.
} 
formulations of problems to be solved, around which distinct programs of government become enacted and technologies assembled. ${ }^{147}$ According to them:

It is through technologies that political rationalities and the programmes of government that articulate them become capable of deployment. But this is not a matter of the 'implementation' of ideal schemes in the real, or of the extension of control from the seat of power into the minutiae of existence. Rather, it is a question of the complex assemblage of diverse forces - legal, architectural, professional, administrative, financial, judgmental - such that aspects of the decisions and actions of individuals, groups, organizations and populations come to be understood and regulated in relation to authoritative criteria. ${ }^{148}$

This quotation highlights how political rationality generates and is crystallized in particular practices, such as policy programs, which constitute political fields such as environmental politics. This can be summarized in the term governmental apparatus, briefly discussed above.

From this literature, governance through interventions such as smart energy experimentation can be conceptualized as being arranged on an aggregate level, insisting how a political rationality underpins practices and shapes governance arrangements across spheres of society - from individuals' behavior to formal institutions and implicit notions used to make sense of everyday life, instituting particular power-knowledge assemblages. Political rationality, then, can contribute by unearthing the conditions of possibility for particular governance arrangements to be generated across different fields, such as environmental politics. An analysis of this sort moves at a high level of abstraction, which contributes an analytical point of departure for analyzing smart energy experimentation as governance arrangement in an encompassing way. I will now move on to examine literature approaching environmental governance and smart energy experimentation from such a conceptualization of governance.

\section{Conceptualizing contemporary environmental governance as political rationality}

Environmental governance is often described as multi-level, networked, transnational, polycentric, and fragmented. ${ }^{149}$ Non-state actors are afforded increasing importance in climate governance, whilst cities have become central sites and actors of decarbonization. ${ }^{150}$ Consequently, environmental governance can at least partly be characterized as an experimental workshop, where a plethora of governance initiatives across different levels are

\footnotetext{
${ }^{147}$ Ibid.

${ }^{148}$ Ibid. p. 63.

${ }^{149}$ See e.g. Bulkeley \& Newell 2015. Governing climate change; Hale 2020. Transnational Actors and Transnational Governance in Global Environmental Politics. Annual Review of Political Science, 23(1).

${ }^{150}$ Green 2014. Rethinking Private Authority: Agents and Entrepreneurs in Global Environmental Governance. Princeton University Press; Nasiritousi 2016. Shapers, brokers and doers: the dynamic roles of non-state actors in global climate change governance. Diss. Linköping: Linköping University; Bulkeley \& Betsill 2003. Cities and Climate Change.
} 
unfolding, including public-private partnerships, the institutionalization of carbon markets, voluntary corporate labeling schemes, and transnational municipal networks. ${ }^{151}$ Experiments have been articulated as central within this contemporary setting. ${ }^{152}$ Particularly after the Paris climate agreement of 2015, which is reliant upon legally non-binding nationally determined contributions (NDCs), experimentation has gained importance through an explicit encouragement of climate action by a plethora of non-state and subnational actors such as local governments, civil society, firms, and investors. ${ }^{153}$

Scholars have described how environmental politics across different contexts tend to have similar characteristics, suggesting that a "green" political rationality underpins environmental politics as a field. ${ }^{154}$ This highlights how a Foucault-inspired analysis of power-knowledge assemblages has become increasingly common in analyses of environmental politics. Such research shows how and through which technologies and knowledge practices the environment is made into a governable object, and thus how specific governance arrangements become legitimized and consolidated. Thus, such research illuminates how the environment is constructed as a field of intervention and acted upon. ${ }^{155}$ These studies extend the analysis of e.g. Wendy Brown and Mitchell Dean into the domain of environmental governance, underlining how regimes of knowledge intertwine with technologies for governing the environment across different fields, conducting conduct and constituting particular environmental policy domains into fields of intervention in specific ways. ${ }^{156}$

Summarizing this literature, Luigi Pellizzoni draws on a range of scholars to substantiate how the problematic field of the environment is constituted, including:

${ }^{151}$ Bulkeley 2016. Accomplishing Climate Governance.

${ }^{152}$ Hoffman 2011. Climate Governance at the crossroads: experimenting with a global response after Kyoto. Oxford: Oxford University Press; Bulkeley et al. 2015. An Urban Politics of Climate Change.

${ }^{153}$ van Asselt, Huitema, and Jordan. 2018. Global Climate Governance after Paris: Setting the Stage for Experimentation? In Turnheim, Kivimaa, and Berkhout (eds.). Innovating Climate Governance: Moving Beyond Experiments. Moving Beyond Experiments. Cambridge: Cambridge University Press. pp. 27-46; Bernstein \& Hoffman 2018. The politics of decarbonization and the catalytic impact of subnational climate experiments. Policy Sciences, 51; Hale 2016. All hands on deck: The Paris Agreement and non-state climate action. Global Environmental Politics, 16(2).

${ }^{154}$ Agrawal 2005. Environmentality: Technologies of government and the making of subjects. Durham: Duke University Press; Uggla \& Soneryd 2017. Green Governmentality, Responsibilization and Resistance: International ENGOs' issue framings of future energy supply and climate change mitigation. Socijalna Ekologija, Zagreb, 26(3); Rutherford 2007. Green governmentality: insights and opportunities in the study of nature's rule. Progress in Human Geography, 31(3).

${ }^{155}$ Cf. Dean 2010. Governmentality. p. 33.

${ }^{156}$ Malette 2009. Foucault for the next century: eco-governmentality. In Binkley \& Capetillo Ponce (eds.). A Foucault for the 21st Century: Governmentality, Biopolitics and Discipline in the New Millennium. Newcastle: Cambridge Scholars Publishing. pp. 221-239; Death 2013. The Limits of Climate Governmentality. In Stripple \& Bulkeley (eds.). Governing the climate: new approaches to rationality, power and politics. New York: Cambridge University Press. pp. 77-92. 
[...] ecological thinking, the perceived need of an environmental governance, the idea of ecological crisis, the differently involved problems, knowledges, actors, and forms of intervention [...]. ${ }^{157}$

Pellizzoni thus underlines how the environment has actively been constituted as an object of knowledge, and thereby as an area of intervention in order to manage it. ${ }^{158}$ Scholars concerned with analyzing environmental governance as underpinned by a green political rationality highlight how particular arrangements bearing similar characteristics are instituted across specific environmental policy fields, often displaying striking kinship with neoliberal policy programs. Common arrangements include e.g. basing governance on market logic, publicprivate partnership constellations, policies to stimulate technological development by private firms, frameworks to support the commercialization of new technological products and services, consumer choice, and benchmarking best practices through private labelling schemes and standards, all in the pursuit of aligning environmental policy goals with sustained "greened" economic growth. ${ }^{159}$ Such arrangements are often intertwined with and co-constitutive of scientific expertise, and increasingly technoscience in particular. ${ }^{160}$ Environmental sociologists and STS researchers Luigi Pellizzoni and Marja Ylönen contend that neoliberalism as a political rationality and technoscience develop in close connection with profound reciprocal effects. ${ }^{161}$ They state that a marked neoliberalization of science can be observed, as well as a scientization of neoliberal governance. ${ }^{162}$ Further, they emphasize that:

[...] for the neoliberal mentality of government, the 'healthy' game of competition, and its legitimation as a 'natural' fact, cannot work if resources and rewards cannot be constantly changed or expanded, and vice versa. This brings advancements in science and technology to the forefront. ${ }^{163}$ Smart energy experimentation can certainly be viewed in such a light, through the strong emphasis on developing and exporting new green energy technologies to expand energy use and thus the energy system. Such a sentiment underscores why political rationality is a relevant concept through which to analyze smart energy experimentation, as it can highlight the particular actors, forms of knowledge, and techniques instigated through experimentation

${ }^{157}$ Pellizzoni 2015. Ontological Politics in a Disposable World. p. 57.

${ }^{158}$ Warde, Robin, and Sörlin 2018. The environment: a history of the idea. Baltimore, Maryland: Johns Hopkins University Press.

${ }^{159}$ Dryzek 2013. The Politics of the Earth. pp. 170-173; Darier 1996. Environmental Governmentality: The Case of Canada's Green Plan. Environmental Politics 5(4); Darier (ed.) 1999. Discourses of the environment. Malden, Mass.: Blackwell; Oels 2005. Rendering climate change governable; Lövbrand \& Stripple 2011. Making climate change governable; Kronsell \& Mukhtar-Landgren 2018. Experimental governance: the role of municipalities in urban living labs. European Planning Studies, 26(5).

${ }^{160}$ Wynne 1992. Misunderstood misunderstanding: Social identities and public uptake of science. Public Understanding of Science, 1(3); Pellizzoni \& Ylönen 2012. Neoliberalism and Technoscience: Critical Assessments. Farnham: Ashgate.

${ }^{161}$ Cf. Birch 2017. Techno-economic Assumptions. Science as Culture, 26(4).

${ }^{162}$ Pellizzoni \& Ylönen 2012. Introduction. In Pellizzoni \& Ylönen 2012. Neoliberalism and Technoscience. p. 9.

${ }^{163}$ Ibid. p. 6. 
which constitute the field of intervention for environmental governance in particular ways. It turns the analytical spotlight toward the condition of possibility for certain orderings to emerge, i.e. for governance to be arranged in particular ways.

From this literature, it can be gathered that environmental politics as a specific domain can be conceptualized as underpinned by a particular green political rationality, displaying similarities with the neoliberal political rationality analyzed by Wendy Brown. It highlights how particular power-knowledge regimes have increasingly come to encompass environmental governance across environmental policy fields, instituting particular governance arrangements. Consequently, when analyzing specific environmental governance arrangements, these can productively be read as co-constitutive of such a broader green political rationality.

\section{Conceptualizing smart energy experimentation as co-constituting green political rationality}

Within literature specifically concerned with smart city and smart energy experimentation, certain scholars emphasize how particular political rationalities come to underpin such interventions, displaying similarities with the broader green political rationality outlined above. In such a vein, research on smart city experimentation has highlighted how specific programs of government are entangled with attempts at constructing smart cities, especially through the widespread deployment of ICT to govern cities to become more sustainable. ${ }^{164}$ From this literature, we can gather that experimentation has special salience in relation to smart, both since dominant visions and many experiments on smart energy are heavily technologically imprinted through a focus on ICT, and since smart in itself is a contested term which necessitates experimentation in actual places to narrow down the meaning of smart.

Part of the literature has been concerned with the wider implications of smart city initiatives, illustrating risks of increased corporate control over urban spaces while questioning the sustainability implications of such initiatives, often highlighting how such initiatives seem to dovetail with neoliberalization processes. ${ }^{165}$ This literature has increasingly moved toward

${ }^{164}$ Vanolo 2014. Smartmentality; Gabrys 2014. Programming Environments: Environmentality and Citizen Sensing in the Smart City. Environment and Planning D: Society and Space, 32(1); Söderström, Paasche, and Klauser 2014. Smart cities as corporate storytelling. City, 18(3); Marvin \& Luque-Ayala 2016. Urban Operating Systems: Diagramming the City. International Journal of Urban and Regional Research, 41(4); Schindler \& Marvin 2018. Constructing a universal logic of urban control? City, 22(2); Haarstad 2016. Where are urban energy transitions governed? Conceptualizing the complex governance arrangements for low-carbon mobility in Europe. Cities, 54; Levenda 2018. Urban Living Labs for the Smart Grid: Experimentation, governmentality and urban energy transitions. In Marvin et al. (eds). Urban Living Labs; Levenda 2019. Thinking critically about smart city experimentation: entrepreneurialism and responsibilization in urban living labs. Local Environment, 24(7).

${ }^{165}$ See e.g. Hollands 2008. Will the Real Smart City Please Stand Up?; Söderström et al. 2014. Smart cities as corporate storytelling; Vanolo 2014. Smartmentality; Gabrys 2014. Programming Environments; Cardullo \& Kitchin 2019. Smart urbanism and smart citizenship: The neoliberal logic of 'citizen-focused' 
examining "the actually existing smart city", i.e. following smart city initiatives across an array of urban contexts to find out how the smart city becomes enacted in practice through different initiatives. ${ }^{166}$ Such studies underscore how turning promises of smart cities into reality tends to happen through experiments, and drawing on STS sentiments of attending closely to practices they show how the variegated incarnations of smart cities depend on a multitude of discursive and material factors. For this thesis, such detailed cases studies of experiments by environmental and STS researchers Anna Wallsten and Darcy Parks have special significance. Wallsten closely investigated the demonstration project Smart Grid Gotland as it unfolded, while Parks attended to how the ambition of turning Hyllie into a climate-smart city district played out in practice and influenced urban environmental governance in Malmö. ${ }^{167}$ Through their detailed accounts of the processes within Smart Grid Gotland and Hyllie, the knowledge generated in these studies is of great importance for this thesis. They provide deep knowledge of the particularities within both of these endeavors, and highlight the need to further attend to how specific experiments come to arrange environmental governance echoed across literature concerned with experimentation.

Within the literature on smart, a sub-field where smart energy experiments constitute the main empirical focus is emerging. This literature tends to emphasize the place-based specificities of smart energy experiments, i.e. the embeddedness of experiments within specific socio-material textures. ${ }^{168}$ Within this literature, research concerned with the mobilization of singular experiments and their impact on broader sustainability agendas is also emerging, using the concept of policy mobilities. For instance, geographer Anthony Levenda analyzes how political rationalities are embedded in experimentation and moved across smart grid experiments, thereby shaping policy. ${ }^{169}$ Anything can be politicized, as Foucault once

smart cities in Europe. Environment And Planning C: Politics And Space, 37(5); Levenda, Mahmoudi, and Sussman 2015. The Neoliberal Politics of "Smart": Electricity Consumption, Household Monitoring, and the Enterprise Form. Canadian Journal of Communication, 40(4); Karvonen \& Van Heur 2014. Urban laboratories: Experiments in reworking cities. International Journal of Urban and Regional Research, 38(2). 166 Taylor, Zook, and Wiig 2015. The 'Actually Existing Smart City'. Cambridge Journal of Regions, Economy and Society, 8(1); Karvonen et al. (eds.) 2019. Inside Smart Cities; Parks 2018. The Sustainable City Becomes Climate-Smart.

${ }^{167}$ Wallsten 2017. Assembling the Smart Grid: On the Mobilization of Imaginaries, Users and Materialities in a Swedish Demonstration Project. Diss. Linköping : Linköping University; Parks 2018. The Sustainable City Becomes Climate-Smart.

${ }^{168}$ Wallsten \& Parks 2020. The Struggles of Smart Energy Places: Regulatory Lock-In and the Swedish Electricity Market. Annals of the American Association of Geographers, 110(2); Cugurullo 2018. Exposing smart cities and eco-cities: Frankenstein urbanism and the sustainability challenges of the experimental city. Environment and Planning A: Economy and Space, 50(1); Stripple \& Bulkeley 2019. Towards a material politics of socio-technical transitions: Navigating decarbonisation pathways in Malmö. Political Geography, 72.

${ }^{169}$ Levenda 2019. Mobilizing smart grid experiments: Policy mobilities and urban energy governance. Environment and Planning C: Politics and Space, 37(4). 
claimed, and one need not look long for politics in infrastructural endeavors. ${ }^{170}$ Smart energy experiments are no exception; they are thoroughly permeated by politics. Many actors ascribe smart grids great importance in the transformation toward a sustainable future energy system, and since the meaning of smart grids has yet to be stabilized, the struggle to define what a smart grid is, discursively and materially, is interwoven with defining the future sustainable society. ${ }^{171}$ Since experiments are explicitly viewed as important steps toward the future sustainable society, they are ascribed importance in deciding which futures come to pass and which do not. Consequently, they are imbued with politics and configure power relations, as they contribute to shaping how environmental issues become governed in the present, forming specific futures. ${ }^{172}$

Experiments are political since they:

[...] provide critical junctures through which new configurations are assembled, mobilized, normalized and contested. [...] Yet it can also serve to sustain existing forms of inequality, reproducing divisions or fostering new forms of exclusion [...]. ${ }^{173}$

As governmentality studies underline, governance is an expansive activity entailing indeterminacy related to whether and how conditions, such as the climate condition, can be improved. ${ }^{174}$ In the case of experiments such uncertainty is amplified, since not only the outcomes of an intervention are unknown but the parameters against which such interventions should be judged are also up for contestation. Consequently, experiments work through this indeterminacy to demonstrate the viability of futures by enacting these futures in the present, i.e. through their articulation as pathways to low-carbon cities, or as the sustainable electricity

${ }^{170}$ See e.g. Easterling 2016. Extrastatecraft: the power of infrastructure space. London: Verso; Avelino, Grin, Pel, and Jhagroe 2016. The politics of sustainability transitions. Journal of Environmental Policy \& Planning, 18(5); Winner 1980. Do artefacts have politics? Daedalus, 109(1); Kall 2011. Förnyelse med förhinder. Dissertation. Linköping: Linköping University; Hultman 2015. Den inställda omställningen: omställningen: svensk energi- och miljöpolitik i möjligheternas tid 1980-1991. Möklinta: Gidlund; Anshelm 2000. Mellan frälsning och domedag: om kärnkraftens politiska idéhistoria i Sverige 1945-1999. Eslöv: Brutus Östlings bokförlag Symposion; Larkin 2013. The Politics and Poetics of Infrastructure. Annual Review of Anthropology, 42; Ahlborg 2017. Towards a conceptualization of power in energy transitions. Environmental Innovation and Societal Transitions, 25; Summerton 2004. Do Electrons Have Politics? Constructing User Identities in Swedish Electricity. Science, Technology, \& Human Values, 29(4).

${ }^{171}$ Cf. Stephens et al. 2015. Smart Grid (R)Evolution; Bulkeley et al. 2015. An Urban Politics of Climate Change; Edwards \& Bulkeley 2017. Heterotopia and the urban politics of climate change experimentation; Wallsten 2017. Assembling the Smart Grid.

${ }^{172}$ Edwards \& Bulkeley 2017. Heterotopia and the urban politics of climate change experimentation; cf. Adam 1998. Timescapes of modernity: the environment and invisible hazards. London: Routledge; Andersson \& Westholm 2019. Slaget om framtiden: forskningens roll i konflikten mellan tillväxt och miljö. Stockholm: Santérus förlag.

${ }^{173}$ Bulkeley et al. 2015. An Urban Politics of Climate Change. p. 254.

${ }^{174}$ Murray Li 2007. The Will to Improve; cf. Bulkeley 2016. Accomplishing Climate Governance. 
grid of the future. This reiterates the political character of experiments. Experiments cannot be considered neutral sites where optimum technical and social solutions are arrived at; they are political endeavors since they actively constitute certain futures at the expense of other possible futures.

Since experiments are granted the ability to navigate uncertain terrain, they contribute to forming horizons of expectation and the conduct of conduct. In the words of anthropologist Andrés Luque-Ayala and colleagues, experimentation and learning serve to open up new political spaces. ${ }^{175}$ At the same time, experimentation serves to close down other political spaces, or at least make new political spaces unlikely. ${ }^{176}$ Thus, experiments provide content for smart energy, carving out its nebulous contours, and making certain pathways of energy transformation more or less likely through their socio-technical configuration and circulation. ${ }^{177}$ In particular, Anthony Levenda has highlighted how smart energy experimentation tends to draw upon and re-constitute a broader political rationality. He has shown how knowledge generated in experiments is packaged as best practice by elite actors and circulated across experimental sites, for example by travelling technocrats, embedding and re-embedding a neoliberal political rationality. ${ }^{178}$

This literature highlights how, in order to analyze governance arrangements emerging through smart energy experimentation, scholars need to adopt analytical frameworks that are able to grasp both the contingencies and specificities of particular experimental sites and the reconfigurations unfolding there, while also attending to the conditions of possibility for such experiments.

\section{Concluding discussion}

This chapter has highlighted how governance is continuously arranged across multiple sites, or spaces of governance, encompassing aspects such as mundane techniques, city councils, various test sites such as so-called urban living labs, and policy networks. It has further highlighted overlaps and interplay, or at least compatibility, between a broader political rationality, and smart energy experimentation. These insights show how one can fruitfully analyze environmental governance as shaping and being reshaped by smart energy experiments, through conceptualizing smart energy experimentation as underpinned by such a broader political rationality. Conditions of possibility for governance arrangements emerging across smart energy experiments can thus be adequately accounted for. The discussed literature has,

\footnotetext{
${ }^{175}$ Luque-Ayala, Bulkeley, and Marvin 2018. Rethinking Urban Transitions: An analytical framework. p. 31. In Luque-Ayala et al. (eds.). Rethinking Urban Transitions. pp. 13-36.

${ }^{176}$ Edwards \& Bulkeley 2017. Heterotopia and the urban politics of climate change experimentation.

${ }^{177}$ Cf. Luque-Ayala et al. 2018. Rethinking Urban Transitions.

${ }^{178}$ See e.g. Levenda 2019. Mobilizing smart grid experiments; Levenda 2019. Thinking critically about smart city experimentation.
} 
however, also underlined how governance cannot be conceptualized as a rolling out and implementation of idealized schemes from a distance. To grasp how environmental governance is arranged through smart energy experimentation, and the politics of such unfolding processes, analysis also needs to consider dynamics of governance, such as how governance becomes arranged across concrete cases of experiments. Consequently, following how governance is arranged by different actors across different spaces of governance is a pressing task for research.

Such an analysis is attuned to calls for following governance as it is produced by attending closely to the particularities of specific experiments, echoing across literature concerned with experimentation, particularly the knowledge politics of experiments. It is equally attuned to the calls for attending to the broader governance arrangements instituted through experimentation. Sociologist Lea Fuenfschilling and colleagues state that:

In particular, the roles of different actors in experimenting should be more closely examined in order to understand the type of governance created through experimentation. ${ }^{179}$

The discussed literature has further illustrated benefits of taking up a research approach sensitized to space, power and politics, and interlinkages between experimentation across governance spaces, i.e. how governance is continuously produced and arranged through experimentation. This requires paying attention to who experiments; since experimentation has become a prominent modality of environmental governance, this is not the preserve of niche actors. ${ }^{180}$ Large, incumbent regime actors surely experiment as well in a landscape where environmental governance is increasingly pursued through experimentation, while the broader governance landscape is thoroughly projectified and governance thus pursued largely through latching on to different project funding infrastructures. This requires granularity when analyzing experimentation, to take into account how it institutes new arrangements, becomes woven into, and potentially reconfigures broader political rationality.

This is precisely where the contribution of this study lies, both through focusing on how smart energy experimentation becomes nested across governmental institutions and policy networks, i.e. incorporated into a governmental apparatus, co-constituting environmental governance in particular ways, and through highlighting how specific cases of experiments contribute to particular governance arrangements. Thus, dynamics of unfolding environmental governance processes can be unpacked. In the following chapter, I endeavor to develop a theoretical approach fit for this task, building on the insights outlined throughout this chapter.

\footnotetext{
${ }^{179}$ Fuenfschilling, Frantzeskaki, and Coenen 2018. Urban experimentation and sustainability transitions. European Planning Studies, 27(2).

${ }^{180}$ Cf. Luque-Ayala et al. 2018. Rethinking Urban Transitions: An analytical framework. p. 20.
} 



\section{Studying experimentation as governance: operationalizing theoretical conceptualizations}

In this chapter I will highlight the specific concepts that will be enrolled for my analytical endeavor and explain how these will be operationalized.

Building on insights from the previous chapter, I will conceptualize smart energy experimentation as an element of a broader governmental apparatus underpinned by a political rationality. Further, I will discuss Harriet Bulkeley's approach of accomplishing governance, particularly the concepts of authorization and assembling intervention, and I will additionally discuss circulations. These concepts contribute by focusing the analytical gaze on how governance is arranged through and beyond cases of experiments, to avoid falling into the trap of conceptualizing governance as simply rolled out from a distance.

This approach can highlight dynamic processes of governing, allowing for an analysis of how governance is entwined with specific problematizations around which programs of government become enacted through particular technologies. Such an analysis can unpack experimentation as a specific mode of environmental governance and its implications, by attending to both the conditions of possibility for particular governance arrangements through the concept of political rationality, and the contingencies and particularities of how governance is produced in and through cases of experiments.

The chapter is structured as follows. First, I will specify how I will analytically approach and operationalize the concept of political rationality, building on the previous chapter. Then, I will flesh out the concepts of authorization, assembling intervention, and circulations, before finally summarizing the theoretical approach and how its constituent parts will be put to work in the empirical analysis.

\section{Politics of experimentation: configuring knowledge, configuring power}

Political rationality is a central concept for the analytical endeavor. I conceptualize political rationality in line with Wendy Brown and Luigi Pellizzoni, as a historically situated, contingent order that is generative of broader social systems, constituting conditions of possibility for particular relations to enter into force. Thus, political rationality is conceptualized not as an instrument of governmental intervention, but rather as the conditions of possibility for particular instruments and the field of reason from which such governance arrangements emanate. A political rationality entails the forms of reasoning, conditions, and dissemination of particular power-knowledge regimes, underpinning and encompassing social life, although it is constituted and crystallized in different ways across social fields, such as particular policy 
domains. Further, political rationality is generative of and crystallized into particular practices such as policy programs, constitutive of political fields, summarized in the term "governmental apparatus".

I will conceptualize smart energy experimentation as constituting an important part of a governmental apparatus underpinned by a broader green political rationality, which was shown in the previous chapter to dovetail with neoliberalization processes. ${ }^{181}$ Consequently, I conceptualize contemporary Swedish environmental, energy, and climate politics as underpinned by a broader, dominant political rationality, characterized by market logic and instituting market solutions, public-private partnership arrangements, consensus-seeking, and techno-economic expertise. This political rationality will be further fleshed out through empirical analysis, but for now I will conceptualize it in line with political rationality as described in the previous chapter. As also shown in the preceding chapters, experimentation has become increasingly intertwined with this political rationality, fulfilling particular functions. We saw how projectification, iterative testing rather than central planning, and particular notions of change were central characteristics of experiments, displaying striking compatibility with the broader political rationality.

I will investigate how the political rationality influences smart energy experimentation, and how experimentation arranges environmental governance. Thus, smart energy constitutes a particular empirical domain, with its own institutional conditions, historically sedimented power relations, and socio-technical infrastructure, which also influence how governance becomes arranged through experimentation. Political rationality conceptualized in this particular way, however, allows the co-constitution of smart energy experimentation and environmental governance to be analyzed; experimentation shapes environmental governance, instituting particular arrangements, but the existing, broader political rationality that envelopes fields such as environmental politics also shapes smart energy experimentation. Thus, I will investigate how experimentation arranges environmental governance in a historically specific situated green political rationality, compatible with neoliberalization processes, but with specific characteristics and specific preconditions in the empirical domain of smart energy. Such a conceptualization is similar to political ecologist Bruce Braun's analysis of new urban climate governance dispositions. He argues that resilience has come to constitute a central mode of government, but is reshaped as climate increasingly becomes governed in urban settings:

Viewed through the broadest of lenses, we might posit that resilience is a mode of government proper to neoliberalism, in which government seeks not to punish, nor to prevent or discipline, but

\footnotetext{
${ }^{181}$ It must be noted that uncovering and describing such a governmental apparatus in a structured manner would be too ambitious and wide-ranging an endeavor for a single study. Thus, I will build upon other scholars who have accomplished excellent work doing so, and conceptualize experimentation as increasingly becoming embedded within such an apparatus, underpinned by a broader political rationality which produces and is reproduced through acts of governing.
} 
rather to modulate 'natural processes' by creating a 'milieu', whether at the scale of the gas consumption meter or the scale of the environmental surrounds of the city. But if so, in the face of climate change this takes new and unique forms, from the introduction of 'economy' into technological systems (understood as a kind of second nature) to the incorporation of the 'natural processes' of nature itself as part of the critical infrastructure of urban life. ${ }^{182}$

Braun further underscores that the value of the concept of governmental apparatus is that it enables the analysis of both the various forms of contemporary administration and government, and the ad-hoc nature of the institutions, practices, and forms of knowledge that are continuously stitched together to constitute what comes to be apprehended as totalities. According to Braun, such totalities have no internal consistency other than the network which connects the constituent elements together, which in his analysis is the concept of resilience that posits feedbacks between diverse scales and actors. ${ }^{183}$ Following such a conceptualization, I will occasionally refer to the governmental apparatus of smart energy experimentation, besides referring to experimentation as incorporated into a broader governmental apparatus, to unpack specific associated features.

In line with Braun, I conceptualize experiments as contingent activities nested within and reshaping specific political rationality, co-constituting environmental governance. Following processes of governance consequently emerges as a relevant analytical strategy. Specifically, the concept of political rationality can act as a locus through which to analyze what experimentation does to environmental governance, and what the broader political rationality does to smart energy experimentation. Put differently, it can highlight how such governance is instituted in practice through establishing a correct disposition of things through experimentation - even though such an analytics works on an aggregate level, removed from the particularities of specific experiments. Political rationality as a concept can highlight how the field of intervention for environmental governance is constituted through the governmental apparatus generative of and reconstituted through experimentation. As STS researchers Andreas Lösch and Christoph Schneider show, the digitalization of the energy system can be analyzed productively through such a conceptual lens. They argue that unfolding digitalization processes potentially mean a radical reconfiguration of actor relations, social practices, and institutional frameworks, and consequently smart grids can be understood as contributing to a reorganization of power-knowledge assemblages in the energy system, instituting a new power disposition where experimentation constitutes a central norm. ${ }^{184}$

Analyzing political rationality in this vein entails an analysis of the forms of reason underpinning particular political fields and programs, forming a governmental apparatus. In Tania Murray Li's words, this involves analyzing the procedures, plans, maps, and techniques

\footnotetext{
${ }^{182}$ Braun 2014. A new urban dispositif? p. 61.

${ }^{183}$ Ibid. p. 61.

${ }^{184}$ Lösch \& Schneider 2017. Transforming power/knowledge apparatuses: the smart grid in the German energy transition. Innovation: The European Journal of Social Science Research, 29(3).
} 
of governing. ${ }^{185}$ In the case of smart energy experimentation, such a governmental apparatus consists of elements such as governmental agencies, funders of experiments, funding calls, research funding strategies, techniques for evaluating experiments, set-up of experiments, energy policy documents, and regulations, as well as actor constellations and relations within and across experiments. It also includes practical reasoning and notions about experimentation among the actors involved. Analyzing the co-constitution of smart energy experimentation and environmental governance through distinguishing such a political rationality necessitates building the analysis on previous literature. In the empirical analysis, however, I will focus on which actors are cast as central for experimentation, implicit and explicit assumptions that can be traced across the material, delineations and demarcations e.g. in terms of how boundaries around experiments are conceptualized in the material, the knowledge claims that are rendered central for experiments and the knowledge orders that are created through experimentation, and rendering technical, i.e. the problems and solutions of experimentation posited by particular actors. These aspects can be fruitfully approached through the concept of political rationality, highlighting how a broader political rationality underpins smart energy experimentation, and how it takes on particular forms. Consequently, I will conceptualize political rationality as a power-knowledge regime with power effects in terms of particular orderings of fields of intervention.

Analyzing smart energy experimentation in this way entails highlighting the knowledge politics of experimentation, to make explicit and analyze questions such as who gets to experiment, who gets access to knowledge generated through experiments, which knowledge claims are viewed as legitimate and robust, and which are neglected. As pointed out by development studies scholar Ian Scoones and colleagues, knowledge generation related to debates about green transformations always entails politics. ${ }^{186}$ They state that this includes both:

$[\ldots]$ what we think we know (consensus and uncertainties) and [...] who knows it (whose knowledge counts). ${ }^{187}$

Environmental social scientist Matthew Cashmore and colleagues extend this by stating:

We contend that contemporary urban "political rationalities" (or ways of knowing, thinking and acting) are intrinsically connected to the specific knowledge-configuring activities employed in rendering urban systems as intelligible and governable concerns. ${ }^{188}$

The concept of political rationality underscores that knowledge, including scientific knowledge, embeds and is embedded within practices, conventions, instruments, and institutions. Emphasizing knowledge politics can make this explicit through sensitizing the

\footnotetext{
${ }^{185}$ Murray Li 2007. The Will to Improve. pp. 28-29.

${ }^{186}$ Scoones, Newell, and Leach 2015. The politics of green transformations. In Scoones, Leach, and Newell (eds.). The politics of green transformations.

${ }^{187}$ Ibid. p. 4.

${ }^{188}$ Cashmore et al. 2019. Introduction. p. 2.
} 
analysis to, for instance, who gets to contribute to knowledge generation through experiments, by which criteria experiments become viewed as legitimate, and how learning and the diffusion of results from experiments are organized in practice. Thus, arranging environmental governance through smart energy experimentation creates specific types of knowledge politics through the inclusion and exclusion of certain forms of knowledge-making, of certain actors, and of certain problem formulations, through appellation to certain authorities, and through embedding in specific institutions, rendering particular knowledge claims central and others irrelevant.

Cashmore and colleagues state that the politics of knowledge generation can be discerned both in the concrete practices of knowledge generation and through empowering and disempowering actors and actions through these practices. ${ }^{189}$ Specifically, they argue that knowledge generation necessarily entails turning complex realities into governable issues by constructing boundaries, creating specific relations, and filtering out that which is deemed irrelevant or unknowable, and thereby that knowledge generation is a productive process. ${ }^{190}$ They draw on governmentality studies and STS to substantiate their argument, and claim that political rationalities underpin specific knowledge generation practices and provide practical reasoning which guides governance. Thus, knowledge claims are central to political rationalities, producing specific forms of governance. Cashmore and colleagues state that:

Political rationalities are important because they determine, for example, the institutionally embedded ways of specifying what is problematic in a city and the methods of calculation that delimit how solutions to these problems are constructed. ${ }^{191}$

Analytical attention to knowledge politics sensitizes the analysis to which actors get to define problems and solutions, how expertise is distributed among actors in and across experiments, and whether or not experiments appear to transform established ways of knowing sociotechnical systems and environmental issues. ${ }^{192}$ If experiments are viewed as future-shaping, emphasizing knowledge politics allows for analyzing how such futures are made intelligible and by whom.

The concept of political rationality, then, works to analyze the governmental apparatus around smart energy experimentation in this study. It allows for conceptualizing experimentation as underpinned by a broader political rationality, and probes how it comes to co-constitute environmental governance through positing particular actors, knowledges, and techniques as central for improving the environmental condition. This approach can highlight how such a political rationality becomes nested across governmental institutions and policy networks,

\footnotetext{
${ }^{189}$ Ibid. p. 9.

${ }^{190}$ Ibid.

${ }^{191}$ Ibid. p. 9.

192 Ibid. p. 10.
} 
forming a governmental apparatus, thus illuminating how the field of intervention for environmental governance becomes constituted through experimentation. ${ }^{193}$

However such an analytical approach would still be insufficient, considering the calls within previous research to follow "the actually existing" smart city, and to take seriously the contingencies of how specific experiments institute governance arrangements on a micro level. As governmentality studies underline, governance is not rolled out from a distance through calculative centers, but political rationality as a concept does not provide an analytical language suited for moving closer to sites of experiments. ${ }^{194}$ Murray $\mathrm{Li}$ argues that analysis of governmental intervention on an aggregate level can be productively undertaken in conjunction with unfolding processes, i.e. focusing on what happens when such interventions hit the ground and become ensnared in processes they were meant to regulate and improve, in contrast to an impulse within sections of governmentality studies to stay at an analytical level emphasizing governmental apparatuses from a distance. ${ }^{195}$ Keeping these two analytical endeavors apart would mean missing a link between the many different spaces of governance, contrary to the general impulse of governmentality as a concept, and contrary to studies underlining how experimentation arranges governance through particular orderings across sites of experiments.

I understand political rationality as underpinning and becoming re-constituted through smart energy experimentation. However, I do not view political rationality as monolithic, absolute, or impossible to reconfigure or challenge. It creates certain conditions of possibility for how environmental governance is arranged through experimentation, but as Murray Li and the previously discussed micro-inclined literature highlight, unexpected things will always happen as processes unfold in concrete experiments. In Braun's words:

For Deleuze, we belong to apparatuses [dispositifs] and act within them. But apparatuses are

${ }^{193}$ Here, it is important to note that I do not view political rationality as a monolithic entity detached from specific experiments, as such a view would be entirely at odds with the conceptual foundations of governmentality. I am rather interested in the interplay, or the dynamic, between situated experiments and the governmental apparatus where smart energy experimentation is becoming increasingly important. Experiments come into being in specific spatio-temporal settings, with specific histories, meaning they are permeated and conditioned from the outset by both place-specific aspects such as governance structures and power relations, as well as funding structures and notions of how best to set up experiments, and the socio-technical configuration of the electricity grid infrastructure. They are embedded within, but also serve to re-embed, a broader green political rationality. The field of intervention for environmental governance that is shaped through smart energy experiments is conditioned by the political rationality generative of such experiments, but unexpected things always happen and the field of intervention may be constituted in ways unthought of in planning offices, bending the will to improve in unexpected ways. This forms an interplay between the broader political rationality underpinning experimentation, thus potentially reshaping it in small, unexpected ways. Cf. Murray Li 2007. The Will to Improve.

${ }^{194}$ Bulkeley 2016. Accomplishing Climate Governance.

${ }^{195}$ Murray Li 2007. The Will to Improve. p. 27. 
never without lines of flight, never without possibilities for the production of something new. This is why, for Deleuze, Foucault is best read as a pragmatist, someone who thinks politics in terms of actualizing possibilities found in the current moment, "attentive to the unknown which knocks at the door". ${ }^{196}$

This quotation nicely captures how I conceptualize political rationality; it creates certain conditions of possibility for arranging environmental governance through smart energy experimentation, but these are not absolute or impossible to reconfigure. In line with the literature discussed in the previous chapter, I understand governance as unfolding dynamically, i.e. specific experiments as contributing to (re-)constitute a broader green political rationality. I understand governmental apparatus as it was outlined in the previous chapter, i.e. as a wideranging system of relations between elements such as administrative procedures, policy instruments, institutions, practices, and forms of knowledge. Such a governmental apparatus is always underpinned and permeated by a political rationality, which is also generative of it. Thus, unpacking how experimentation arranges governance requires historicizing to elucidate how the forging of certain relations, foregrounding of certain knowledge claims, and positioning of certain actors is facilitated by experimentation. This can be productively appraised through the concept of political rationality, and how such political rationality is crystallized into a governmental apparatus, focusing for example on institutional arrangements and policy instruments. Outlining the governmental apparatus that experimentation is incorporated into is achieved by building on previous research, as outlined in the previous chapter, in combination with empirical analysis.

The field of intervention for environmental governance is conditioned by the political rationality underpinning the governmental apparatus which smart energy experimentation is incorporated into, but how governance unfolds in practice is always unpredictable and contingent, thus the field of intervention can become constituted in unexpected ways in concrete cases of experiments. This, in turn, interplays with and may reshape the broader political rationality, as highlighted in Braun's quotation. While a broader political rationality underpins experimentation, in the case of specific experiments positions can be reworked as interventions are assembled. ${ }^{197}$ Experiments can thus work around the edges of political rationality, reconfiguring it in the process, or in some cases challenge the dominant political rationality through embodying a different political rationality in the microcosm of the experiment, in a sense working as heterotopias. ${ }^{198}$

\footnotetext{
${ }^{196}$ Braun 2014. A new urban dispositif? p. 62. This possibly alludes to Foucault's concept of heterotopia, which Edwards and Bulkeley use to analyze urban climate governance experiments as places "which challenge modes of thinking, which embody in themselves the changes required to reorder society". See Edwards \& Bulkeley 2017. Heterotopia and the urban politics of climate change experimentation. p. 9. For Foucault's original formulation of heterotopia, see Foucault 1986. Of Other Spaces. Diacritics, 16(1). ${ }^{197}$ Murray Li 2007. The Will to Improve; Bulkeley 2016. Accomplishing Climate Governance.

${ }^{198}$ Edwards \& Bulkeley 2017. Heterotopia and the urban politics of climate change experimentation.
} 
Therefore, further concepts are needed to analyze how governance becomes arranged through specific instances of experiments on a more granular level than political rationality as a concept allows for. I will turn to Harriet Bulkeley's approach to governance, mobilizing in particular the central concepts of authorization and assembling intervention, before explicating how circulations will also work toward such analytical purposes. Bulkeley's concepts allow for analyzing how governance is produced in and through specific cases of experimentation, i.e. focusing on practices of governing. The concept of circulations is present across many literatures, not least Foucault's own writings, but is not always developed systematically. I will take a specific conceptualization of circulations as a point of departure from which to analyze interlinkages between cases of experiments and the broader political rationality of experimentation. This is a central move for the analysis, as it can highlight how a governmental apparatus is stitched together as circulations, especially of knowledge, establishes connection points, or nodes, solidifying relations between socio-material elements.

\section{Accomplishing environmental governance}

In this section I will briefly sketch out Bulkeley's approach to climate governance, before outlining the specific concepts of authorization and assembling intervention which form a part of Bulkeley's approach to governance. These concepts are suited to analyzing how environmental governance is arranged through specific experiments, e.g. taking place-based specificities into analytical consideration, particularly focusing on how relations are forged.

Bulkeley has developed a specific approach to studying climate governance, through synthesizing insights from poststructuralist governmentality studies, STS, and spatial sensibilities from geography. ${ }^{199}$ Essentially, she argues that in order to understand climate governance it is necessary to attend to how specific interventions are accomplished across different spaces, to how these interventions are practiced and contested. The argument is built around the fact that climate governance has become embedded as an issue which many actors across spaces engage with, illustrating how climate governance is continuously accomplished across a wide range of arenas and sites through contingent unfolding processes. ${ }^{200}$ Bulkeley

\footnotetext{
${ }^{199}$ Transferring Bulkeley's approach to environmental issue areas other than the climate does not pose any significant issues. The overarching object of study is still the same, i.e. how the ambiguous concept of the environment, be it the climate, seas, forests, natural resource management, waste, or smart energy experimentation, as is the case in this study, becomes enacted as a governable object through specific interventions and the interlinking of governance spaces. So whether the main interest is climate or environmental governance more broadly is not an issue, especially as these boundaries tend to blur and overlap in practice. This is also in line with the expanded conceptualization of governance outlined previously. See also e.g. Stripple \& Bulkeley (eds.) 2013. Governing the climate; Bulkeley, Paterson, and Stripple 2016. Toward a cultural politics of climate change: devices, desires, and dissent. Cambridge: Cambridge University Press.

${ }^{200}$ Bulkeley 2016. Accomplishing Climate Governance. p. 49.
} 
argues that climate governance unfolds iteratively between the discursive constitution of the problem to be governed and how this plays out in practice in different arenas across society, in line with governmentality studies and an STS emphasis on practices. Such orchestrations are always contingent, argues Bulkeley, as they involve assembling disparate socio-material relations across spaces. Therefore, these processes are thoroughly permeated by power, as they configure relations in specific ways which could always be otherwise.

Bulkeley's approach to governance is largely in line with how governance is conceptualized within governmentality studies. Clearly echoing Foucault, she states that:

Governing is then not a matter of implementing solutions to predefined problems, but rather of the constitution and configuration of what should be governed and what it means to govern in tandem. ${ }^{201}$

This quotation illuminates how Bulkeley's approach is apt for studying how environmental governance is produced in and through specific smart energy experiments. It points to how, in order to interrogate the way in which environmental governance is arranged through specific experiments, or accomplished rather, an important analytical avenue is to investigate how the field of intervention is itself constituted through processes of governing, i.e. what it is that should be governed and how this should be done, inviting a rather inductive approach. ${ }^{202}$ This also indicates how power can take on different modalities through distinct orderings of relations across spatio-temporal scales - from domination or coercion to authority and seduction. ${ }^{203}$ Bulkeley quotes Foucault and states that the conduct of conduct is arranged through the disposition of things: "arranging things so that this or that end may be achieved through a certain number of means". ${ }^{204}$ Along these lines, Bulkeley summarizes her view on accomplishment, the key word of her approach, thus:

$[\ldots]$ a critical engagement requires that we examine the dynamics through which governing is produced - to the ways in which climate governance is accomplished. [...] Understanding how governance is accomplished is then a matter of examining how it is performed, fulfilled and completed in relation to different desires and objectives through the acquisition and honing of particular skills and techniques. ${ }^{205}$

This underlines how environmental governance can productively be understood as the assembling of diverse elements into relations, and how these specific configurations are always contingent and in flux, as they might be opened up or closed down through processes of

\footnotetext{
${ }^{201}$ Bulkeley 2016. Accomplishing Climate Governance. p. 11.

202 Ibid. p. 10.

${ }^{203}$ Ibid. p. 9; cf. Allen 2003. The Whereabouts of Power: Politics, Government and Space. Geografiska Annaler B, 86(1).

${ }^{204}$ Bulkeley 2016. Accomplishing Climate Governance. p. 12.

${ }^{205}$ Ibid. p. 14.
} 
governing. ${ }^{206}$ Tracing how environmental governance is accomplished through experiments, then, requires attending to how entities are brought into alignment and configured through specific spatial relations, and how these processes of experimentation shape governing of the environment through case studies of different experiments. ${ }^{207}$ This highlights how Bulkeley's approach differs somewhat from governmentality studies. Such studies often tend to focus on encompassing programs of governance rather than specific interventions on a smaller scale, and Bulkeley's approach is rather attuned to the micro-inclined literature discussed in the previous chapter. It is more granular, with micro-practices as the main empirical locus, compared to much of the governmentality literature. Together with the concept of political rationality, understanding governance as accomplishment provides an approach that is finetuned toward studying spaces of governance and their interlinking. ${ }^{208}$

\section{Authorization and assembling intervention}

Bulkeley mobilizes several concepts, developed through case studies, which she argues constitute integral parts of governing the climate. Two central concepts are authorization and assembling intervention. These will be incorporated into the theoretical framework of this study, to analyze how governance is produced in and through specific experiments.

The concept of authority lies at the heart of governance, according to Bulkeley. ${ }^{209}$ She defines authority as "the recognized orchestration of power", i.e. governance that is perceived as rightful and not carried out through outright coercion. ${ }^{210}$ Further, she conceives of authorization as a practice rather than a held capacity, meaning that authorization must be practiced in any given intervention to improve the climate condition. Authorization requires defining a specific problem to devise solutions that are legitimate, through drawing on different problematics, illustrating its linkage with the concept of assembling intervention. This means utilizing different strategies, programs, and techniques. Understanding authorization as practice highlights what becomes recognized and what is ignored as interventions are assembled. ${ }^{211}$

Consequently, authority is reconsidered based on the overarching outlook of accomplishing governance, and Bulkeley mobilizes it to interrogate how power is generated through authorization practices, stating that it can take on different modalities. She works out the three

\footnotetext{
${ }^{206}$ Ibid. p. 17.

${ }^{207}$ Ibid. p. 19; cf. Asdal 2011. Politikkens Natur - Naturens Politikk. Oslo: Univ. forl.

${ }^{208}$ Cf. Cashmore et al 2019. Introduction. p. 7.

${ }^{209}$ Bulkeley 2016. Accomplishing Climate Governance. pp. 54-58.

${ }^{210}$ Ibid. p. 54.

${ }^{211}$ Ibid. p. 73
} 
ideal type modalities of consent, consensus, and concord. ${ }^{212}$ Through case studies of various climate interventions, Bulkeley shows how these modalities of authorization have played out across different sites in the UK. Authorization as consent is equated with the consent of the governed, the ability to enlist voluntary agreement, or acquiescence in what another proposes or desires. Drawing on John Allen's work on the geographies of power, Bulkeley states that authorization as consent is designed to make others act in ways they would not have done otherwise. ${ }^{213}$ She adds that authority as consent is relational, since it requires more than putting into place mechanisms or techniques to persuade constituents to comply; it requires that such governmental intent is deemed worthy of acceptance, i.e. regarded as legitimate and worthwhile of compliance. It is "formed in the working through of techniques for generating acquiescence and the practice of compliance". ${ }^{214}$ This can be done by aligning goals and agendas, e.g. through the creation of governmental programs:

As UK government and corporate bodies have come to regard communities as a site through which climate change ambitions can and should be realised, programmes have been devised through which

to enrol such constituents in the work of accomplishing climate governance. Realising such programmes has required the practice of consent, whereby community groups seeking funding must

comply with governmental ambitions, particularly those to demonstrate measurable carbon reductions, and those engaged in the orchestration of such programmes are required to actively monitor and ensure compliance. ${ }^{215}$

Authorization as concord entails bringing into agreement heterogeneous elements so they become taken for granted in shaping conduct. ${ }^{216}$ Bulkeley states that authorization as concord is not very visible in the UK climate governance interventions explored in her study. She argues instead that climate governance has mainly tended to be accomplished through consensus, albeit not in an a-political manner since contestation has continually emerged in different forms alongside consensus, threating to destabilize it. ${ }^{217}$ Consensus as a modality of authorization is defined as being mutually constituted through the association of constituents with one another as heterogeneous elements are reworked into a common position on the nature of the problem at hand and thus the reasonable solution. ${ }^{218}$ Further, it is a constant process which requires work, an accomplishment in the making, in terms of both what the

${ }^{212}$ Bulkeley 2016. Accomplishing Climate Governance. p. 57. Bulkeley points out that viewing authority in these terms necessarily renders the three modalities as ideal types, but these can help unpack how authority is articulated and contested in practice.

${ }^{213}$ Ibid. p. 59.

${ }^{214}$ Ibid. p. 59.

${ }^{215}$ Ibid. p. 64.

${ }^{216}$ Ibid. p. 58.

${ }^{217}$ Ibid. p. 58.

${ }^{218}$ Ibid. p. 65. 
climate problem is and how it should be addressed. ${ }^{219}$ Reaching consensus thus requires ongoing mediation and negotiation, providing opportunities for contestations. Bulkeley further elaborates that authorization in the modality of consensus tends to develop through an emphasis on the opportunities that improving the climate condition offers to different actors, providing a diagnosis of possibilities. ${ }^{220}$ Understanding authorization as practice, then, entails a close analytical focus on how authorization is practiced, maintained, and troubled in empirical cases, inviting a focus on fine-grained aspects which tend to elude conceptualizations of governance painted in broader brushstrokes. In the case of experiments, such aspects could include instituting coordinating mechanisms to link actors across experiments, e.g. through the provision of dialogue forums, or persuading participating households as well as nonparticipating stakeholders through the demonstrative capacities of experiments, e.g. by circulating particular stories told through experiments at conferences or public presentations.

There is a principal difference, then, between authorization in the modality of consent and consensus. Authorization as consent entails putting mechanisms into place, often signaling a more active form of top-down state intervention. Although this is a matter of degrees; as the examples highlight it is not a matter of rigidly imposing limitations or regulations from above, but rather of putting mechanisms into place that are deemed worthy to comply with by the governed. Authorization as consensus, on the other hand, entails reworking divergent interests into a common position, an act always prone to destabilization. Rather than putting mechanisms into place, this is a matter of socio-material bricolage. Both modalities of authorization are based on voluntariness, but can be understood as entailing different degrees of the rigidity of state intervention. Consent entails instituting formal mechanisms, whereas consensus is more ad-hoc.

The concept of assembling intervention is thoroughly intertwined with and further builds upon Bulkeley's theorizing of authorization as practice. Assembling intervention as a concept aims to capture:

$[\ldots]$ the ways and means through which alignments are forged in and through the practice of assemblage [...] the ways in which climate change comes to be problematised and ordered through practices of bricolage that serve to draw into alignment a host of sociomaterial entities and in turn realign existing assemblages - communities, rivers, businesses - around climate change. ${ }^{221}$

Analyzing how interventions are assembled, then, means analyzing how climate change is neither everywhere nor nowhere, but comes to be related to specific objects and moments. ${ }^{222}$

\footnotetext{
${ }^{219}$ Ibid. p. 74.

${ }^{220}$ Ibid. p. 68.

${ }^{221}$ Ibid. p. 80.

222 Ibid. p. 75.
} 
These can include anything from polar bears, energy systems, houses, or whole cities, to meatfree Mondays. Bulkeley states that in order to analyze how governance is accomplished, it is imperative to attend to why, how, by whom, and with what consequences some parts of the world come to be framed and reconfigured as parts of the climate problem while others do not. ${ }^{223}$ This is the main analytical thrust that assembling intervention adds to my conceptualization of how smart energy experimentation arranges environmental governance - a detailed focus on questions of how relations are assembled, and by whom, and governance thus becomes constituted through experiments. The concept is based on an understanding of governance as an inherently problematizing activity, in line with governmentality studies. Bulkeley uses the example of a micro-hydro project connected to Transition Towns to show that:

Rather than springing fully formed from the intention to address climate change, micro-hydro had to be summoned: assembled through the articulation of various entities and intentions that had to be aligned into a coherent ordering of the space of intervention. Rather than being any kind of problem, climate change emerged in the relation amongst different concerns for energy - as an issue of security, economy and environment. ${ }^{224}$

Assembling intervention, then, is specified as contingent assemblages of objectives, knowledges, techniques, and practices, formed through bricolage, which extends to an analysis of how different elements and entities come to be mobilized in relation to each other through and beyond specific interventions. ${ }^{225}$ Bulkeley's analysis of how climate governance is accomplished through assembling intervention extends across actors, discourses, materials, artefacts, devices, and infrastructures, to underline how climate change becomes problematized in specific ways across different interventions through practices of bricolage where such disparate elements are brought into relation around climate change. ${ }^{226}$ Importantly, assembling intervention is about aligning separate, often pre-existing, issues and socio-material entities through which climate becomes governed whilst other goals can be pursued simultaneously. ${ }^{227}$ This highlights the value of bringing the concept of political rationality into the analysis, as this can elucidate precisely such conditions of possibility, which assembling intervention will then help probe further through analysis of how governance is accomplished through specific experiments. Particular constituent elements of the political rationality underpinning environmental politics might be drawn into specific experiments as interventions are assembled, which can reveal how smart energy experimentation institutes

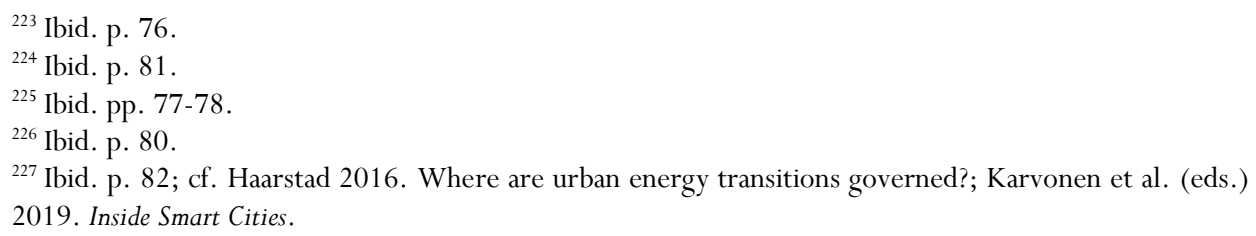


environmental governance in specific ways that can be described and analyzed empirically. Further, as we saw previously, experimentation often entails pursuing a wide variety of different goals, not least in specific experiments, bearing in mind the specificities of particular places. Bulkeley claims that:

How energy should be provided, how customers should shop, how cities should be renovated and how banks should go about their business [...] come to be considered as matters that should be comprehended in relation to climate change. This is not a seamless endeavor, but rather a process of bricolage $[\ldots]$ Yet to attend to the ways in which accomplishing climate governance happens through these practices of assemblage is not to deny its purposeful nature. Some entities are enrolled and aligned, bought into a climate order and rendered both intelligible and sensible in climate change terms. Others either struggle to be accommodated or are neglected altogether. Moreover, climate change comes to be ordered in different ways. ${ }^{228}$

What this tells us is, effectively, that the specific interventions constitute the field of intervention, i.e. the problem to be solved, through contingent orderings of climate change in order to make it governable in distinct ways. This underscores the analytical value of the concept of assembling intervention in this study. It can highlight specifically how relations are ordered through experiments, which elements are drawn into and excluded from experiments, and crucially who the authoritative actors doing the ordering are. It illuminates the ways in which experiments are constituted to contribute to transformative change, as well as which specific problematizations of the environment they shape. Do they tell us that electricity consumption needs to be reduced, or is it a matter of shifting use to optimize the grid, for instance, and what are the repercussions of such orchestrations?

I interpret authorization and assembling intervention as two sides of the same coin, as interlinked processes which are in practice enmeshed. Authorization is an integral feature of any intervention, and assembling intervention requires authorization of the intervention. They work in tandem but can be separated analytically. The boundaries between the concepts are however not explicitly demarcated by Bulkeley, and come across as rather blurred. In the empirical chapters of this study, I will keep the two concepts separated for analytical clarity, but in practice I view them as interlinked dynamics of accomplishing environmental governance. The concept of political rationality works on a higher level of analytical abstraction, analyzing how smart energy experimentation is incorporated into a governmental apparatus underpinned by such political rationality and co-constitutes environmental governance through instituting particular governance arrangements. Meanwhile, the concepts of authorization and assembling intervention work on a lower level of analytical abstraction, and can serve to highlight how governance arrangements are instituted through and across specific experiments. The political rationality underpinning smart energy experimentation

${ }^{228}$ Bulkeley 2016. Accomplishing Climate Governance. p. 100. 
will likely condition experimentation, prescribing or facilitating particular orderings. How this actually unfolds can be elicited empirically through the concepts of authorization and assembling intervention.

All interventions, and not least experimentation with a stated goal of achieving transformative change, entail the reconfiguration of e.g. infrastructural composition as a central goal, and unexpected twists and turns will always occur when accomplishing governance. Authorization and assembling intervention make a significant contribution to the empirical analysis of smart energy experimentation in relation to this; since they fine-tune the analysis toward how relations are authorized and assembled in practice, they contribute by illuminating how environmental governance is accomplished in particular ways across cases of experiments. The concepts can elicit how governance is arranged not so much as rolling out a rigid program imposed by political rationality from a distance, but rather as a dynamic interplay between how particular relations become assembled, maintained, and troubled in and beyond concrete experiments. This can be productively understood in line with Bruce Braun, who stated that totalities, such as a particular governance arrangement, do not exist in and of themselves, but are rather stitched together through the establishment of interconnections between entities, or the assemblage of disparate socio-material elements, in line with Bulkeley. This approach can highlight how environmental governance is arranged, and by whom, beyond singular experiments, through elucidating the relations established between socio-material elements and actors beyond the experimental site by focusing on contingent assembling and authorization practices, and, crucially, how these are conditioned by and potentially reconfigure a broader green political rationality.

Authorization and assembling intervention contribute analytical attention to how the right disposition of things is accomplished through cases of smart energy experiments, then. The concepts can highlight interlinkages between different problematics pre-existing and created through specific cases of experiments, by emphasizing authorization as a practice and the assembling of diverse elements as interventions unfold. Together, they allow for an analysis of how the field of intervention for environmental governance is delineated through such cases, as well as which relations are forged and which actors become central and excluded as a consequence. Through these concepts, analytical attention is directed toward the contingencies and particularities of arranging governance through concrete experiments. Thus, authorization and assembling intervention are concepts which take sensibilities from STS seriously and allow for analytically zooming in to understand how governance is produced in and through specific experiments.

Bulkeley's analysis of climate governance entails additional concepts, but the concepts of political rationality, authorization, and assembling intervention suit my interest of analyzing how smart energy experimentation arranges environmental governance beyond singular experiments. If the analytical approach had been completely bottom-up, focusing more 
ethnographically on one or two experiments or attending ethnographically to the intricacies of accomplishing governance in City Councils or the Government Offices, it might have been beneficial to flesh out Bulkeley's theoretical apparatus in full. What is lacking in the theoretical framework developed here, however, is a concept that ties the analysis together by elucidating how governance arrangements become durable and change. This is the role fulfilled by the concept of circulations, which we will turn to next.

\section{Accomplishing governance through circulations}

One of the main reasons articulated for instituting smart energy experimentation as an environmental governance strategy is the assumed contribution of experiments to transformative change of energy infrastructure. This is often conceptualized in research as occurring through upscaling, and upscaling is a prominent focus of smart energy experimentation, as we saw previously. ${ }^{229}$ As discussed, upscaling as a concept can be problematic since it tends to be linked to technology-centric and mechanic notions of change, which might not be suited to analyzing cases which are diverse and involve social practices, such as smart energy experimentation. Literature concerned with upscaling in smart energy experimentation is regularly oriented toward policy input, rather than pursuing critical research. ${ }^{230}$ Consequently, scholars interested in experimentation as governance arrangement have claimed that upscaling is an insufficient notion for understanding experiments' eventual contribution to transformative change, suggesting instead the concept of circulations to remain open to unfolding dynamics of governance. ${ }^{231}$ In this section I will explain how circulations is a suitable concept for analyzing how smart energy experimentation arranges environmental governance, making explicit how it will be used in empirical analysis.

Essentially, circulations contributes with analytical sensibility towards who generates knowledge in experiments, how, and which knowledge claims that gain traction - thus impacting how environmental issues are perceived and how the environmental condition can be improved. Therefore circulations can further elucidate knowledge politics of smart energy experimentation. Circulations is a broad concept, deployed across a vast literature spanning fields such as governmentality studies, STS, and policy mobilities. The concept of circulations is central to the analysis pursued in this study, as it provides an analytics through which to explicitly engage with how contingent, ad-hoc accomplishments are crystallized into governance arrangements. Circulations highlight how interlinkages between elements are

\footnotetext{
${ }^{229}$ See e.g. Naber et al. 2017. Scaling up sustainable energy innovations.

${ }^{230}$ Cf. Ibid.

${ }^{231}$ See Castán Broto \& Bulkeley 2018. Realigning Circulations: How Urban Climate Change Experiments Gain Traction. In Turnheim et al. (eds). Innovating Climate Governance. pp. 69-84; Bulkeley et al. 2015. An Urban Politics of Climate Change. pp. 240-243.
} 
established so that governance arrangements extending beyond singular experiments are stabilized, or changed for that matter. Recall Braun's sentiment that institutions, practices, and forms of knowledge must be continuously assembled to be apprehended as totalities, displaying no internal consistency other than the networks that connect constituent elements. Circulations can highlight precisely such interlinkages. In particular, they can elucidate how ideas about and attempts at achieving transformative change through experiments, often expressed as moving beyond experiments, are organized in practice. This includes, for instance, whether the broader political rationality underpinning smart energy experimentation facilitates the creation of particular channels for establishing relations through experiments, e.g. whether certain actors gain access to policy arenas through participating in experiments, or whether particular notions of change are packed into the setup of experiments which creates certain pathways for stories to be told through experiments.

A concrete example of a circulation could be a participant in an experiment travelling to conferences or similar settings to talk about the experiment, highlighting certain aspects whilst others are consigned to the background, thus in practice making particular knowledge claims through the experiment whilst filtering out aspects of reality that are deemed irrelevant. Put differently, an actor in the field may actively package specific knowledge gained from an experiment into knowledge claims and try to circulate such claims into policy through project evaluations, speaking at conferences, or acting as a policy advisor, whilst simultaneously circulating knowledge gained through the experiment, a new product developed through the experiment, or the use of particular actor constellations, within their own network as means of strategic change. This highlights how embodied knowledge can circulate through the movement of particular personnel within or across organizations and policy networks, persons possessing know-how and representing particular actor relations established through experiments, enabling the stitching together of particular networks of actors and anchoring particular knowledge claims in different policy forums. Circulations as a concept can further shed light on how learning is organized in practice between sites of experimentation and policymakers, for example whether knowledge becomes circulated from experiments to public administrations and, if so, how and what type of knowledge, or whether knowledge is circulated to reach national policymakers. This could cement particular knowledge orders through experimentation. Another example could be the institutionalization of particular orders for transferring knowledge or experiences from one experimental setting to another. These are all examples of governance arrangements that can be studied empirically through the concept of circulations. Circulations as a concept extend beyond rigid notions of upscaling, and as the examples provided underline, knowledge can be circulated in many forms beyond codified knowledge. 
Circulations, then, refer to "the actions of making something movable or capable of movement”. ${ }^{232}$ Such an overarching conceptualization of circulations draws upon STS to analyze how temporarily stabilized socio-material formations are moved from one setting to another. ${ }^{233}$ STS researchers have shown that experiments cannot simply be transferred into policy or replicated from a template; this requires translation and circulation. According to anthropologist Bruno Latour, circulations are integral to the workings of science, as chains of transformations producing reductions and amplifications. Latour shows how moving from a field site where soil samples were extracted into scientific reports is entirely dependent upon such transformations in the form of circulations:

From forest to expedition report, we have consistently represented the forest-savanna transition as if drawing two isosceles triangles covering each other in reverse. Stage by stage, we lost locality, particularity, materiality, multiplicity, and continuity, such that, in the end, there was scarcely anything left but a few leaves of paper. [...] But at each stage we have not only reduced, we have also gained or regained, since, with the same work of re-representation, we have been able to obtain much greater compatibility, standardization, text, calculation, circulation, and relative universality, such that by the end, inside the field report, we hold not only all of Boa Vista (to which we can return), but also the explanation of its dynamic. ${ }^{234}$

This illustrates how STS tends to analyze circulations as an integral part of micro-practices which make up the world, in infinitely more complex ways than is often imagined. It highlights the socio-material relations enacted through circulations, as well as the devices necessary to make e.g. knowledge circulate and the circuits of knowledge circulation. Latour's elaboration underscores how complex situations can be made into context-independent objects of knowledge, enabling comparison with knowledge produced in other complex settings, rendering invisible the messiness of situations in the forest where soil samples were taken.

Another relevant conceptualization of circulations comes from literature on policy mobilities. Drawing upon geographical sensibilities to space, governmentality, and assemblage thinking, such literature stresses that the generation and circulation of knowledge that address how cities are governed "develop in, are conditioned by, travel through, connect, and shape various

\footnotetext{
${ }^{232}$ Stripple (undated), unpublished manuscript. Mobilising climate-smart Malmö: Encountering three forms of circulation; see also Callon \& Law 2004. Guest Editorial - Introduction: Absence-Presence, Circulation, and Encountering in Complex Space. Environment and Planning D: Society and Space, 22(1); Latour 1988. The Pasteurization of France. Cambridge, MA: Harvard University Press.

${ }^{233}$ See e.g. Latour \& Woolgar 1986. Laboratory life: the construction of scientific facts. [New ed.] Princeton, N.J.: Princeton Univ. Press; Knorr Cetina 1999. Epistemic Cultures: how the sciences make knowledge. Cambridge, Mass.: Harvard University Press.

${ }^{234}$ Latour 1999. Pandora's Hope: Essays on the Reality of Science Studies. Cambridge: Harvard University Press. pp. 70-71.
} 
places, spatial scales, networks, policy communities, and institutional contexts”. ${ }^{235}$ This literature is concerned with the ways in which governance works through "tensions between fixities and mobilities and between local embeddings and global interconnection". ${ }^{236}$ Thus, it shares a family resemblance with the STS interest in circulations. In policy mobilities literature, however, the analytical gaze is rather focused upon how policies are moved across cities, for instance through best practice benchmarking, constituting assemblages of practices, expertise, and models, and as they change when adopted in specific contexts and woven into the urban fabric of the sites where they touch down. ${ }^{237}$ This literature urges researchers to follow particular policies as they become circulated through various channels, and to analyze the practices developed through these processes as well as their politics. ${ }^{238}$

Principally, policy mobilities literature is concerned with knowledge as an object of study; its transfer, translation, and transformation as it is circulated. As an example, geographer Jennifer Robinson analyzes how the use of city strategies - policies containing strategic visions of urban development - are mobilized by actors and circulated across a wide range of urban contexts, prescribing specific approaches to development which are presented as replicable. ${ }^{239}$ She elucidates that policies are made different in different localities, through analytically attending to a range of sites where city strategies are circulated, including agencies, networks of consultants and theorists, as well as city-specific agents engaged in policy circulation. ${ }^{240}$ Geographers Cristina Temenos and Eugene McCann identify several empirical avenues of research within the policy mobilities literature. This includes how best practice policy models reflect ideological contexts of their production, the role of specific actors for packaging knowledge and circulating policies, the influence on actual governance through study trips to well-advertised sites of e.g. sustainable urban development ("policy tourism"), and the mutations of policies as they become implemented elsewhere. ${ }^{241}$ Anthony Levenda utilizes insights from policy mobilities literature in a study on smart grid experiments and their mobilization. He shows how specific governmental rationalities are shaped in experiments, and further how these are circulated through practices such as energy pricing schemes and

\footnotetext{
${ }^{235}$ Jonas, McCann and Thomas 2015. Urban Geography: A Critical Introduction. Chichester, West Sussex: Wiley Blackwell. p. 94.

${ }^{236}$ Ibid. Urban Geography. p. 95.

${ }^{237}$ Ibid. Urban Geography. p. 95; Robinson 2011. The Spaces of Circulating Knowledge: City Strategies and Global Urban Governmentality. In McCann \& Ward (eds.). Mobile Urbanism: Cities and Policymaking in the Global Age. Minneapolis: University of Minnesota Press. pp. 15-40.

${ }^{238}$ See e.g. McCann 2011. Urban Policy Mobilities and Global Circuits of Knowledge: Toward a Research Agenda. Annals of the Association of American Geographers, 101(1); Temenos \& McCann 2013. Geographies of Policy Mobilities. Geography Compass, 7(5).

${ }^{239}$ Robinson 2011. The Spaces of Circulating Knowledge.

${ }^{240}$ Ibid.

${ }^{241}$ Temenos \& McCann 2013. Geographies of Policy Mobilities.
} 
discourses of choice. ${ }^{242}$ Through an emphasis on circulations, he shows how smart grid experiments were shaped by and reshaped practices of intercity referencing, the work of traveling technocrats, and benchmarking best practices. ${ }^{243}$

Building on a recent contribution by Bulkeley and Castán Broto, circulations can be conceptualized as infrastructures that enable movement. ${ }^{244}$ This adds another layer to my conceptualization of circulations. Analytically, this means being attuned to the processes which enable aspects of experiments to become moved, the channels of this movement, and the actors who move them. The concept of circulations highlights that it is not a matter of simply moving a stable "thing" from one place to another, for instance in order to scale up an experiment, since such an endeavor would require tucking the specific ideas and technologies into other socio-material webs of relations. ${ }^{245}$ Rather, elements of an experiment can be extracted, packaged, assembled, and then circulated, for instance by highlighting a specific technology and marketing it as innovative through the creation of showrooms. Circulations are not equivalent to learning, then, but rather a process of accomplishing governance which can shed further light on orderings within contingent, unfolding governance processes. Learning through circulation of knowledge can be a form of circulation. However, as highlighted by the concept of circulations this does not happen in a straightforward manner, but rather through knowledge becoming packaged and moved by specific actors through specific channels. Additionally, the broader political rationality underpinning smart energy experimentation may enable the creation of particular infrastructures of circulation, whilst constraining other possibilities.

From this we can gather that an analytics of accomplishing governance through cases of experiments can benefit from an explicit conceptualization of circulations, since it adds an emphasis on the actors mobilizing e.g. knowledge and the channels through which knowledge becomes mobilized. Additionally, circulations contribute an analytics with which to investigate interlinkages between specific experiments and the broader political rationality underpinning experimentation. They can shed light on ideas about as well as how attempts to "move beyond" experiments are organized in practice, further elucidating how environmental governance is arranged through smart energy experimentation. Circulations as a concept emphasizes that this is not a coherent unitary process, and highlights e.g. which actors are able to put their

\footnotetext{
${ }^{242}$ Levenda 2019. Mobilizing smart grid experiments.

${ }^{243}$ Ibid.

${ }^{244}$ Castán Broto \& Bulkeley 2018. Realigning Circulations.

${ }^{245}$ Bulkeley et al. 2015. An Urban Politics of Climate Change. pp. 240-243; cf. Karvonen et al. (eds.) 2019. Inside Smart Cities; Temenos \& McCann 2013. Geographies of policy mobilities; McCann \& Ward (eds.) 2011. Mobile Urbanism.
} 
stamp on environmental governance by circulating knowledge claims through extracting particular knowledge from smart energy experiments, and moving it along particular infrastructures of circulation. It can also highlight which knowledge generated through experiments that finds it more difficult to gain traction and become mobile, and which forms of learning associated with experiments are favored among policymakers and other actors. Circulations as a concept can direct analytical attentiveness toward how experiments come to have an impact beyond their confines, either by instigating change or by consolidating specific orderings of environmental governance, elucidating order within unfolding governance processes. Such infrastructures of circulation stitches a governmental apparatus together, establishing channels between separate socio-material elements to consolidate particular orderings of environmental governance.

The concept of political rationality highlights how experiments are likely to include specific ideas and practices related to how they are supposed to contribute to transformative change, which is then packed into specific configurations of experiments from the point at which they are designed and set up. Thus, we find politics in the set-up and evaluation of experiments, for instance through the forms and organization of learning associated with them. Circulations as an analytical concept can help illuminate these aspects, by focusing on the practices related to experiments' contribution to transformative change such as societal learning, upscaling, or replication, as well as by drawing analytical attentiveness toward how actors tap into established channels of circulation or emerging infrastructures that enable movement of e.g. knowledge claims instituted through experiments. The concept of circulations therefore further illuminates the dynamics of unfolding governance processes, showing how smart energy experimentation arranges environmental governance in particular ways.

\section{Concluding remarks}

All of the analytical concepts introduced depart from similar theoretical ground, so even though they will be put to work in different parts of the study they share a family resemblance. Political rationality, authorization, and assembling intervention, as well as circulations, all take as their point of departure - or synthesize insights from - poststructuralism and STS.

I view authorization and assembling intervention as two sides of the same coin, which can elucidate dynamics of how experimentation arranges governance within and beyond specific experiments. The concepts presuppose one another, although they will be analytically separated for clarity in the empirical chapters. Authorization works through more discursively cognitive registers, whereas assembling intervention is a concept which can elucidate practices more hands-on. Through authorization practices different interests can be reworked into a common position, thus defining and delimiting a specific problem and devise solutions that are relationally constituted as legitimate, ensuring the rightful orchestration of power. Such authorization is always relational, and when it plays out through the modality of consensus it 
requires constant negotiations and reworking, inviting contestations. Assembling intervention is a matter of practically forging alignments through socio-material assembling, thus assembling intervention can be approached as practices of bricolage, realigning existing assemblages around improving the environmental condition.

Political rationality prefigures and conditions authorization \& assembling practices in specific experiments, making certain ways of authorization and assembling intervention smoother while smothering others. The broader political rationality which underpins the governmental apparatus enveloping smart energy experimentation institutes particular assumptions, delineations, knowledge claims, and techniques as central for governance. Political rationality underpins experimentation also in the case of specific experiments, although in the case of specific experiments positions can be reworked, as Bulkeley shows, as intervention is assembled. Experiments can work around and reconfigure political rationality in particular places, or, in some cases, perhaps attempt to challenge the dominant political rationality by embodying a different political rationality. In a sense, then, experiments might constitute heterotopias, i.e. embodiments of future possibilities which deviate from status quo.

So, political rationality might grease the wheels of certain governance arrangements while inhibiting others, e.g. favoring instituting experiments in project-form, setting up experiments in line with neoliberalization processes - e.g. prioritizing profit motive, large companies, export orientation, citizens as customers, public-private partnerships, consensusseeking, foregrounding rationality - in line with the broader governmental apparatus which the political rationality underpins, encompassing e.g. government agencies, funding structures, research strategies, policy documents, and regulations. Thus, political rationality prefigures, or institutes conditions of possibility for specific accomplishments through smart energy experiments. Consequently, political rationality highlights the situatedness of how smart energy experimentation arranges environmental governance, emphasizing its co-production within specific historical and cultural moments and sites. ${ }^{246}$ Additionally, knowledge politics of and within experiments can be highlighted through emphasizing political rationality, for example whether and how experiments are conditioned by institutionally embedded ways of specifying problems and the construction of solutions to such problematics, and how certain types of knowledge might be perceived as more valuable than others and thus become circulated. Political rationality also impacts circulations. Certain routes or channels of circulation might be rigged into experiments from the outset, e.g. favoring implementation of new technologies in the current power grid by incumbent private companies. However as governance is accomplished new infrastructures of circulation can be established, or actors can tap into dispositions already in place which enable the creation or consolidation of such infrastructures of circulation. Such place-based specificities might entail historically sedimented power relations or actor constellations on a local level, for instance. 
Socio-technical systems researcher Frank Geels has stated that it is necessary to scrutinize not only change but also permanence, i.e. to investigate and develop theoretical approaches to understand the "stickiness" of socio-technical regimes, which I concur with. ${ }^{247}$ The approach of accomplishing governance is more attuned to analyzing processes of change, lacking concepts which can help analytically to discern how there might yet be order in the chaos of governance processes unfolding through twists and turns. Concepts are needed which can further analyze whether and how experiments contribute to transformative change, for example by reverberating across society through processes of circulation, the conditions of possibility for such circulations, who is actually allowed to participate in knowledge-making through experiments, and how knowledge dissemination is organized in practice. This highlights how the concept of political rationality can be complementary to the more granular concepts of authorization, assembling intervention, and circulations. At the same time, experiments co-constitute political rationality, which is also an accomplishment. Put differently, governance is always an accomplishment in the making, no matter where one looks empirically; governance is accomplished across spaces of governance ranging from the production, publication, and circulation of policy documents to the installation of smart meters, or energy use in households.

This theoretical framework answers calls by other scholars, making it possible to analyze the broader governance arrangements constituted through smart energy experimentation without losing sight of the particularities of situated experiments. The approach moves on an analytical middle level, focusing on interlinkages between specific experiments with environmental governance in a broader sense. Through this approach, experimentation can be conceptualized as shaped by and shaping specific political rationality, by creating relations between diverse socio-material elements as interventions are assembled and knowledge claims circulated.

${ }^{247}$ Geels 2014. Regime Resistance against Low-Carbon Transitions: Introducing Politics and Power into the Multi-Level Perspective. Theory, Culture \& Society, 31(5). 


\section{Method and material}

As shown in previous chapters, experimentation has become increasingly prominent as a mode of arranging environmental governance, however experiments tend to be discussed as singular, isolated interventions. Taking the oft-repeated question of what happens "beyond experiments" seriously implies conceptualizing experimentation as instituting particular governance arrangements, underpinned for example by ideas about how to achieve transformative change extending further than singular experiments and surrounding arrangements set up accordingly, and creating specific orders of knowledge where some knowledge claims are valued higher than others. Conceptualized thus, smart energy experimentation can be conceived as shaping power relations, making it possible to ask what kind of environmental politics becomes possible through experimentation.

This entails investigating experimentation both through interviews with experts across governmental institutions and other organizations and document analysis, ${ }^{248}$ and by examining how governance is accomplished through different cases of experiments. Thus, analysis in this study pertains to how smart energy experimentation arranges environmental governance, and the politics of these processes, rather than uncovering causal chains of cause and effect. ${ }^{249}$ An important focus is to compare different cases, to examine whether governance is accomplished differently across experiments, as well as whether there are different ideas about and attempts to instigate transformative change extending beyond singular experiments, e.g. through upscaling, both in relation to specific experiments and among national and international actors. $^{250}$

To achieve these analytical goals, I will mainly utilize text analysis and interviews, supplemented with observations and site visits across different spaces of governance. According to Castán Broto and Bulkeley, it is important to reflect on an experiment's

${ }^{248}$ Cf. Foss Ballo 2015. Imagining energy futures: Sociotechnical imaginaries of the future Smart Grid in Norway. Energy Research \& Social Science, 9. Foss Ballo terms the network of experts engaged in smart energy in Norway a "techno-epistemic network", to convey how a specific constellation of actors mainly residing within governmental agencies and private companies has taken up prominent positions of agendasetting. Similarly, I will conduct an analysis of central actors and institutions which, in different ways, have a bearing on and make their mark on smart energy experimentation in Sweden, and can thus be considered central parts of a governmental apparatus around smart energy. This is an integral part of enabling the dynamic interplay between broader political rationality and specific experiments to be analyzed, instituting particular environmental governance arrangements.

${ }^{249}$ Cf. van der Heijden 2019. Studying urban climate governance: Where to begin, what to look for, and how to make a meaningful contribution to scholarship and practice. Earth System Governance, 1. p. 6.

${ }^{250}$ Cf. Ibid. p. 7. 
embeddedness within policy contexts. They state that in order to gain a deeper understanding of how such experiments can reconfigure infrastructure regimes, the notion of a unified policy context or governance landscape must be problematized. ${ }^{251}$ It is vital to understand that experiments emerge in multi-scalar landscapes, or within an ecology of interventions as they write, and that experiments can relate to each other in different ways which may occasionally become systematized or incorporated into specific strategic programs. ${ }^{252}$ As discussed in the theory chapter, the concepts of political rationality and circulations enable such an analysis.

Interviewees work, for instance, at the government offices, government agencies, public administration in the vicinity of experiments, energy companies, national interest organizations, and international organizations. Texts include national and local policy documents, reports by different actors, and project documents. Site visits and observations include sites of experiments as well as public dialogue forums, hearings, workshops, and presentations. In line with my Foucauldian-inspired conceptualization of governance, I take these to represent spaces of governance, i.e. sites where governance is arranged in practice. ${ }^{253}$ This answers to Castán Broto and Bulkeley's call for analytical sensibility to the embeddedness of specific experiments, as well as constituting a link between the particularities of individual experiments and broader governance arrangements.

In the following, I will account for the analytical process and discuss the specific methods utilized in the study, before ending the chapter with some methodological reflections.

\section{The analytical process}

For the sake of transparency, and in order to recount my own steps to try and get to grips with the important choices made along the analytical process, I intend to give a brief overview of this process. As any researcher - or student, for that matter - will know, such reconstructions are not to be taken at face value. Recall Bulkeley's description of climate governance as an iterative process developing through twists and turns rather than along any straightforward linear process - research is always full of similar twists and turns, unfolding in an iterative interplay between the intellectual backpack one carries as a person into the process, entering a new field and encountering empirics, and attempting to make sense of these empirics through different theoretical constructs. Vitally, it is a process unfolding over a long stretch of time, and it is thus virtually impossible to rationally recall every choice made throughout the analytical process. Rather than attempting to construct any afterthought-based illusions of a

\footnotetext{
${ }^{251}$ Castán Broto \& Bulkeley 2018. Realigning circulations.

252 Ibid.

${ }^{253}$ Cf. Asdal 2011. Politikkens natur-naturens politikk. p. 216.
} 
linear or concerted research process, then, this section constitutes an attempt to reflexively recount for the choices, inclusions, and exclusions made throughout the process.

The first step in the analytical process was to perform a discursive mapping of the field, loosely based on Hajer's argumentative discourse analysis. In practical terms, this was achieved through a compilation of empirics of different provenances which could help illuminate the Swedish smart energy field, with a special focus on experimentation. In this endeavor I was guided by academic literature on the subject, following Foucault's statement that it is impossible to account for an entire discursive field in any analysis. I tried to take Hajer and others seriously, thinking that the discursive constitution of a problem is not only achieved in the parliament but also in other arenas and through other means. Thus the search was not confined only to parliamentary debate and political documents, for example, but also included the mass media and the trade press, reports by NGOs, future scenarios related to energy system change published by different actors, reports by government agencies, governmental reports (SOUs), etc. Through this discursive mapping, I tried to understand how smart energy had been and was currently discursively constituted in the Swedish context. With the help of Hajer's argumentative discourse analysis, I tried to trace discursive shifts during the time period that smart has been connected to energy in Sweden, and which actors and central themes could be discerned. A theme forms a nexus in text material, and can be identified through attention to e.g. recurring statements, lines of conflict and consensus, and notions which appear to be taken for granted. This is similar to qualitative content analysis. ${ }^{254}$

Text analysis was complemented with site visits and attendance at dialogue forums, hearings, presentations, and workshops, as well as following several hearings and presentations which were broadcast online. A large part of the empirics consists of interviews with different actors. These include actors involved in smart energy experiments, different governmental agencies, the government offices, actors in the local administrations where the experiments were carried out, and actors occupying prominent positions in the Swedish energy sector and international organizations. The ambition with this methodological approach was to follow smart energy experimentation through different spaces empirically, to allow for an inductive inquiry focused on the relational embedding and circulation of aspects of experiments, as well as ideas about and attempts at instigating broader change beyond singular experiments. Such an empirical analysis makes it possible to highlight how experimentation arranges environmental

\footnotetext{
${ }^{254}$ Mayring 2004. Qualitative content analysis. In Flick, von Kardorff, and Steinke (eds.). A companion to qualitative research. Sage.
} 
governance across different spaces. This can shed light on the dynamics between broader political rationality and accomplishing governance through experiments. ${ }^{255}$

This design allows for unpacking how experimentation contributes to governance arrangements, which are rarely named or explicitly described, by analyzing how experimentation arranges governance across different spaces. The analysis entails highlighting how governance is arranged as attempts are made by various actors to "go beyond" singular experiments. As described in the previous chapters, governance is arranged on both the level of governmental institutions and the micro level through specific experiments, arrangements which can be fruitfully unpacked through the concepts of political rationality, authorization and assembling intervention, and circulations. I will follow how processes of arranging governance unfold in practice, that is how governance arrangements become constituted in practice both across cases of experiments and across governmental institutions and policy networks.

In practical terms, the textual mapping and analysis of documents has unfolded over a longer period of time, together with a couple of pilot interviews to test interview guides and start a snowballing process. Two pilot interviews were conducted in February 2017. Most of the interviews, site visits, and observations took place during a more intensive empirical period, autumn 2017, after which I switched the field for the office to take a step back and work with the material. After working through the material and drafting text, a second empirical period commenced in autumn 2018, including some additional interviews, follow-up interviews, observations, and site visits. The final interview took place in May 2019.

\section{Choosing cases}

Specifically, I took three large experiments, often called demonstration projects, as a starting point. These are the two urban development projects of Norra Djurgårdsstaden in Stockholm and Hyllie in Malmö, both including smart energy experiments as integral elements, and the case of Smart Grid Gotland, where a consortium of actors aimed to modernize the rural grid on the island of Gotland. The decision to use these as focal points in the study was a result of

${ }^{255}$ Cf. Pellizoni \& Ylönen 2012. Conclusion. In Pellizoni \& Ylönen (eds.) 2012. Neoliberalism and Technoscience. p. 232. Pellizoni \& Ylönen argue that there is no inherent contradiction between drawing on detailed cases studies and the embeddedness of such cases within e.g. regulatory arrangements, historical trends, or policy fields. Rather, they argue, detailed case studies help avoid unwarranted abstractions, while drawing out broader implications requires "a sensible approach" to e.g. policy fields and ideational perspectives, which in turn does not prevent but rather benefits from delving into concrete examples. See also Roth 1987. Meaning and method in the social sciences: a case for methodological pluralism. Ithaca, N.Y.: Cornell Univ. Press. 
my mapping of the field. They are also interesting in principle, as they are the three first coherent smart energy demonstration projects in Sweden. ${ }^{256}$ Considering their high profile as reference points in Swedish smart grid development, these three projects emerged at the beginning of this study in 2015 as a relevant starting point. They are also interesting since all three can be conceived as socio-technical experiments, involving e.g. users, social practices, technologies, and actor constellations. In the respective pre-studies for the projects, for example, all three are expressed as steps along the way toward a completely implemented smart grid, and they are all argued to be of importance with respect to their assumed contribution to energy transformation. Further, they are all explicitly tied to reaching environmental goals in their pre-studies. There is an explicit emphasis in all three endeavors on utilizing ICT both to improve technical grid operations and to influence or test the behavior of energy users. Thus, they were envisioned and portrayed from the outset as socio-technical sustainability experiments.

As I gained further insights into the field of smart energy in Sweden, additional empirical cases were added. One case revolves around attempts to make Gotland an energy pilot region, providing an energy transformation blueprint for the rest of Sweden to emulate. This relates to the decision by Svenska Kraftnät (SvK), the Swedish transmission system operator (TSO), to cancel the long-planned construction of a new transmission cable to the island of Gotland, following a new socio-economic assessment of this infrastructure project. As previously described, Gotland's distribution grid is connected to the transmission grid with two HVDC cables which are argued today to be close to maximum transmission capacity, creating a bottleneck for the integration of further electricity production to the grid on the island. The decision was announced in relation to the annual gathering of politicians on Gotland in June 2017, Almedalen Week, and was met with exasperation on the island. Several policy documents from the public administration on Gotland, stipulating goals for e.g. developing the business sector as well as energy and climate goals, were predicated on the assumption that a new cable was going to be constructed eventually. Around the same time, former Minister of Policy Coordination and Energy Ibrahim Baylan tasked the Energy Agency with investigating how Gotland could become a pilot model in the transition to a smart and sustainable energy system. It was explicitly stated that knowledge gained in previous Swedish smart grid projects

\footnotetext{
256 Another project, Kraftsamling smarta nät i Västra Götalandsregionen, was started around the same time. However, this is a coalition of actors looking to promote smart grid development in western Sweden rather than a specific pilot project. This would also have been interesting, but through the discursive mapping and snowballing the three large demonstration projects stood out as central anchoring points in the smart energy field at the time, so I decided to start with these three.
} 
was to be taken into account in the Gotland investigation, and the Energy Agency was given a mandate to suggest changes in regulations if deemed necessary.

Considering the close proximity in time to the experiments I had started looking into, with the actors in Smart Grid Gotland (SGG) delivering the final report around the same time, I was interested in following the Gotland investigation more closely. This came across as an interesting empirical avenue through which to scrutinize whether and how previous experiments such as SGG would come into play in a more encompassing initiative, constituting an important part of the policy formation around smart energy. The Gotland investigation was also interesting in view of the potentially large impacts its different outcomes could evoke; for instance, it was within the Energy Agency's remit to suggest regulatory changes. It could therefore become a defining moment in the shaping of the future energy system, as it could potentially create precedential effects related to the construction of new energy infrastructure. It was also especially interesting as an empirical case, since it involves ambivalences in its very formulation. It is articulated as both a pilot and a model simultaneously, i.e. with implications of both testing and showing what works, including a substantial emphasis on upscaling; the government's directive states that what is tested on Gotland should be scalable to the rest of Sweden. Further, it could conceivably be understood as an attempt to go beyond singular experiments because of its broadened scope, both geographically and concerning the contents of the initiative, e.g. it is not confined only to the power grid. The initiative turned out to be interesting enough that SGG faded into the background, and should be read as an important background to the energy pilot region initiative rather than a case study in its own right. In the empirical chapter on Gotland, the section on SGG thus contributes with important insights that deepens the analysis of the energy pilot initiative.

Finally, after actively searching for alternative smart energy experiments, including experiments which were different in terms of setup, stated goals, actor constellations, and size, I added the additional case of a smart energy experiment in Västerås. This is significantly smaller empirically than the other cases, consisting mainly of one interview and a site visit to an experimental site where different renewable energy technologies are tested and put on display in Katrineholm. Rather than specifically being about the experiment in Västerås, however, the case is about an actor in the energy sector who wishes to conduct experiments in very different ways compared to the other experiments analyzed in this study. This came across as a relevant contrast to the other experiments in Malmö and Stockholm, and on Gotland. The need to search actively for different types of smart energy experiments should be considered a result in itself.

Through this design, I have been able to follow different experiments across spaces. The legitimacy for this study derives from its empirical breadth, analyzing specific instances of experimentation and bridging it with an account of how smart energy experimentation 
arranges environmental governance more broadly, through the text analysis and interviews with actors across spaces of governance. Thus, my intention is to follow how experimentation arranges governance across the different cases, rather than providing an exhaustive, ethnographic in-depth account of the cases. Of course, there are many possible spaces of governance to study. The chosen ones constitute important sites where governance is produced, in terms of e.g. organizing learning from experiments in practice and with regard to whether and how experiments come to matter beyond single interventions. Following such acts of governance in the making by attending to specific processes where the role of experiments is discussed and consolidated or challenged provides an opportunity to trace whether and how experimentation arranges environmental governance in specific ways. Utilizing these cases is justified since they can say something relevant about the broader societal phenomenon of how experimentation arranges environmental governance, even though the study is not designed symmetrically or to be generalizable in a straightforward sense. ${ }^{257}$

In terms of choosing cases, Glynos and Howarth offer some relevant viewpoints. They distinguish a typology of cases, based on geographer Bent Flyvbjerg, to illustrate the value of choosing different types of cases. ${ }^{258}$ Deviant cases, they claim, can highlight particular phenomena through dramatic juxtaposition. They make their case with the example of Foucault's use of different treatment methods from different historical epochs. ${ }^{259}$ Another type of case is the paradigmatic case, which can serve to illustrate exemplary embodiments of a broader phenomenon. ${ }^{260}$ In the most basic sense, Västerås constitutes a deviant case, whereas Stockholm and Malmö are to be considered paradigmatic cases. Gotland as an energy pilot is more difficult to characterize. Glynos and Howarth go on to state that comparison is a key methodological device in case studies, not least in critical research, as deviant cases can expose aspects which are usually so taken for granted that they fade into the background, whereas paradigmatic cases can be highly relevant to contrast against each other to highlight similarities and differences. ${ }^{261}$ It is in this vein that the cases were chosen in this study.

The empirical emphasis is, however, also weighted toward actors on the national level, to be able to situate the specific experiments and follow how experimentation arranges environmental governance, both by analyzing experiments as an abstract phenomenon in texts as well as more specifically through interviews, and by following circulations within and

${ }^{257}$ Cf. Flyvbjerg 2001. Making Social Science Matter. Cambridge: Cambridge University Press; Franzén Hertting, and Thörn 2016. Stad till salu: Entreprenörsurbanismen och det offentliga rummets värde. Göteborg: Daidalos. p. 258.

${ }^{258}$ Glynos \& Howarth 2007. Logics of Critical Explanation in Social and Political Theory. pp. 203-204.

${ }^{259}$ Ibid. p. 203.

${ }^{260}$ Ibid. p. 203.

${ }^{261}$ Ibid. p. 205. 
beyond specific experiments, for instance whether actors involved in experiments use them to influence policymaking or whether personnel are moved within companies to change strategic direction. Empirical emphasis related to the specific experiments is further weighted mainly toward the cases of Stockholm and Gotland, i.e. there is a more substantial body of empirical material related to these cases compared to Malmö, and especially Västerås. This has been a result of the inductive analytical process. The case of Gotland was particularly interesting for the reasons outlined above, while Stockholm was frequently described in early interviews as a failure and had encountered criticism in both the mass media and the trade press, making it an interesting case to look into more closely. Naturally, the choice of cases is also always a question of access. Further, considering the risk of snowballing concerning representation combined with my interest in politics of experimentation, I also searched actively for interviewees engaged in deviant smart energy experimentation. As mentioned, this resulted in one additional interview and a site visit to an experimental site in Katrineholm.

My intention is to study how smart energy experimentation arranges environmental governance by attending to the particularities of these cases, as well as how governance is arranged more broadly by looking across different spaces of governance and circulations of e.g. knowledge claims through specific experiments. This is the central aspect of the study design; it allows me to unpack how smart energy experimentation arranges environmental governance in a broader way, precisely through analyzing "the policy landscape" and different cases of experiments. Or, put differently, the design allows me to analyze different spaces of governance and their interlinkage. To summarize, snowballing is an important keyword to understand how the analytical process started, and after encountering the field and learning more about smart energy through the discourse analysis I actively searched for deviant experiments. ${ }^{262}$ The analytical process has, however, been iterative, moving back and forth between e.g. analytical ideas and preconceptions, encountering empirics, analysis, and testing different theoretical approaches. ${ }^{263}$

In the following sections, I will discuss discourse analysis, interviews, observations, and site visits, as well as coding and analysis.

\section{Discourse analysis of documents}

Discourse analysis of documents constitutes an important part of analyzing the broader political rationality and the governmental apparatus it underpins. I am guided by Hajer's argumentative discourse analysis, since it provides a practical analytical framework to analyze

\footnotetext{
${ }^{262}$ Cf. Noy 2008. Sampling Knowledge: The Hermeneutics of Snowball Sampling in Qualitative Research. International Journal of Social Research Methodology, 11(4).

${ }^{263}$ See Glynos \& Howarth 2007. Logics of Critical Explanation in Social and Political Theory.
} 
material on a middle level between situated experiments and governmental institutions and policy networks, thus making it a useful starting point. In line with my theoretical approach, I will depart from Hajer's focus on discourse coalitions and storylines to instead highlight the political rationality underpinning smart energy experimentation. This entails analyzing the forms of reason underpinning particular programs and techniques of governing, inviting an empirical focus on assumptions, demarcations, and how the field of intervention is rendered technical through empirical analysis of e.g. governmental agencies, research funding strategies, energy policy documents, actor relations and relations within and across experiments, and the knowledge claims positioned as relevant as governance is arranged through experimentation.

I have included historical and contemporary energy policy SOUs and political decisions to gain a deeper understanding of the energy policy field in Sweden, reports from different government agencies pertaining to energy in general and pilot and demonstration projects in particular, mass media and trade press material, propositions by the government, strategies published by the Swedish Smart Grid Forum, energy future scenarios published by governmental actors, reports from NGOs and interest organizations, and project documents and reports related to the four experiments which form the focus of the study. For the analysis of press material, I used the database Retriever, covering both the mass media and the trade press in Sweden, to search for keywords such as "smart grid", "pilot project", "demonstration", "experiment", and similar terms in different constellations. This rendered 170 initial hits, and after an initial search I ended up with 77 articles since it turned out that many were either duplicates or irrelevant. Since the purpose of this analysis was to discern the public debate around smart energy, I mainly looked for differences of opinion and contestations. With a few exceptions which focused on nuclear power, generally in opinion pieces and debate articles, it turned out that there was virtually no debate on smart energy experiments. There were a few articles where the experiment in Norra Djurgårdsstaden was singled out for criticism, mainly in the trade press, but overall my findings were very sparse - including in terms of debate on smart energy in general. Consequently, the analytical point which can be made from this is that smart energy in general is not a hotly debated issue in Sweden outside the energy sector, and this is even more the case with experimentation.

The empirical bank has been constantly expanded, generally through cross-referencing between documents as well as referencing of documents by interviewees. From a political science perspective, many of the documents chosen are central energy policy documents. Of course, more material could have been added, or other material chosen, but I would argue that the chosen material provides a solid basis on which to examine the discursive constitution of smart energy in Sweden. I view smart energy as a distinct discursive terrain imprinted by a broader political rationality, as discussed in the previous chapter. I understand discourse in line with Hajer, as a historically and culturally situated ensemble of ideas, concepts, and 
categorizations which is produced and reproduced through practices. This conceptualization of discourses thus moves beyond single statements. ${ }^{264}$ Discourses structure how the world is interpreted and understood, and consequently what it is reasonable to think and do in certain places at certain times. ${ }^{265}$ Foucault insisted that discourses contribute to defining conditions of possibility, making some ways of ordering webs of relations easier and others difficult or impossible, and making certain subject positions more or less accessible for individuals. ${ }^{266}$ According to environmental social scientist Johan Hedrén, the relation between discourse and practice can be conceptualized dialectically, i.e. discourses become enacted in practices, but these practices come into existence in the discourse. ${ }^{267} \mathrm{~A}$ practice is thus established and maintained through discourse, and discourse becomes produced and reproduced through practices. $^{268}$

I concur with this view of discourse; I do not view discourse as something that floats around freely, detached from the material world and its relations. ${ }^{269}$ Nor do I view discourse as something powerful actors can straightforwardly create and use instrumentally in order to gain support for a political agenda, and then simply discard and form a new discourse if the first does not work. ${ }^{270}$ I understand discourses as historically specific relational systems of meaning, i.e. situated systems of practices and relations. In other words, it is through discourses that the world can be understood and thus how options for action are enabled and constrained. Discourses are anchored in institutions, and they form and are reshaped through practices. ${ }^{271}$ Accordingly, concepts and knowledge are derived from concrete contexts and historical

\footnotetext{
${ }^{264}$ See Winther Jørgensen \& Phillips 2000. Diskursanalys som teori och metod. Lund: Studentlitteratur.

${ }^{265}$ Dryzek 2013. The Politics of the Earth.

${ }^{266}$ E.g. Foucault 1972. The archaeology of knowledge. Note that discourses does not impose such conditions of possibility, but contributes to defining them in particular spatio-temporal settings.

${ }^{267}$ Hedrén 1994. Miljöpolitikens natur. Dissertation. Linköping: Linköping University. p. 32.

${ }^{268}$ Alm 2006. Nationell kraft och lokal motkraft: En diskursanalys av konflikten kring SwePol Link. Dissertation. Linköping: Linköping University. p. 15. Hajer proposes a similar conceptualization through the example of a police officer; people tend to stop in front of a police officer, or traffic-light, not because of the power possessed by the individual officer or traffic-light, but because of the discourse through which the role of the police and traffic-light gets defined and reproduced. Consequently, power is not an inherent property or something that e.g. an institution "has", but rather an outcome defined through the relations a discourse enacts. See Hajer 1995. The Politics of Environmental Discourse. p. 49.

${ }^{269}$ For a similar view, see Anshelm 2012. Kampen om klimatet. Storå: Pärspektiv Förlag.

${ }^{270}$ Which is not to say that actors cannot latch on to specific discourses to gain support for specific positions or policy programs; see e.g. Laclau and Mouffe 1985. Hegemony and Socialist Strategy; Hay 2002. Political Analysis: a critical introduction. Basingstoke: Palgrave. pp. 257-260.

${ }^{271}$ See e.g. Hajer 1995. The Politics of Environmental Discourse.
} 
sedimentations. ${ }^{272}$ Thus, in this study, discourses are in a sense understood as language rules, while discourses are viewed as playing out within a broader political rationality. ${ }^{273}$

The concept of political rationality, then, aims to capture something broader than discourse, extending to how the phenomenon of smart energy experimentation makes up the field of intervention for environmental governance, whereas discourse is an integral part of such political rationality. The analytical framework of this study is geared toward analyzing the broader governance arrangements emerging around smart energy experimentation, and the interplay between specific experiments and such broader arrangements. The concept of political rationality allows for such an analysis, as discussed in the theory chapter. Through discourse analysis, the contours of smart energy experimentation's political rationality can be discerned. I make no claim to provide "the full picture" of smart energy; rather, I present a snapshot of a discursive terrain which is detailed enough to embed the four experiments within. ${ }^{274}$ This approach, together with the conceptualization of governance as accomplishment, is highly relevant since the policy formation around smart energy is currently unfolding; thus this snapshot provides insight into such unfolding processes. Specifically, I have attempted to discern central themes, by focusing on recurrent statements which are shared by many actors and form nexuses in the text material. Such nexuses function as a shorthand means for actors to gather around in specific spatio-temporal settings. Further, I have paid attention to groups of actors who align around such themes, structuring the discursive field. Consequently, themes and actors have been discerned through iterations of analysis, relating specific texts to the expanding empirical bank.

Finally, I do not view discourses as something that can be found in texts, passively awaiting discovery through a researcher's sharp gaze. Rather than something I uncover, the discursive constitution of smart energy experimentation is my analytical construct. ${ }^{275}$ There is good reason to consider my characterization as reasonable, I would argue, since it is based on a thorough, close reading of a large textual material in an iterative process, moving back and forth between the expanding empirical bank and individual texts. ${ }^{276}$ Further details about this process are provided in the section on coding and analysis.

\footnotetext{
${ }^{272}$ Howarth 2013. Poststructuralism and after; Anshelm 2012. Kampen om klimatet.

${ }^{273}$ Cf. Foucault. 2011. Vetandets Arkeologi. 2nd ed. Lund: Arkiv; Hajer 1995. The Politics of Environmental Discourse; Pellizzoni 2015. Ontological Politics in a Disposable World; Brown 2015. Undoing the Demos.

${ }^{274}$ Cf. Alm 2006. Nationell kraft och lokal motkraft. p. 38.

${ }^{275}$ Cf. Winther Jørgensen \& Phillips 2000. Diskursanalys som teori och metod. pp. 136-137.

${ }^{276}$ Cf. Anshelm 2012. Kampen om klimatet. p. 18.
} 


\section{Interviews}

Choosing interviews as an empirical avenue is relevant for several reasons. First, the policy formation around smart energy in Sweden is currently unfolding, meaning there is not an abundance of text material. Second, since it is currently unfolding, interviews constitute a primary avenue into processes of accomplishing governance. They provide snapshots of unfolding processes from different actors' perspectives, which together with documents and observations comprise a rich basis for analyzing how smart energy experimentation arranges environmental governance, and the politics of these processes.

A total of 31 interviews have been conducted. One interview was conducted by telephone, and two interviews included two interviewees at the same time. The rest of the interviews were individual interviews. They mainly took place at the offices of different organizations, often in conference rooms, but in a few cases I met the interviewees at quiet cafés, and in one case an interviewee came to my university department where the interview was conducted in a meeting room. Two interviewees were interviewed twice, during different empirical phases. The second interview functioned as a follow-up in both cases, to gain additional insight into unfolding processes connected to the Gotland investigation. The initial choice of interviewees was based on the aforementioned mapping, and then snowballing. The idea was to map and conduct interviews with central actors in the field, to gain substantial empirical material covering some central spaces of governance where experiments were discussed as well as some sites of specific experiments. Consequently, many of the interviewed actors can be considered experts in the field of smart energy. In general, I approached interviewees via e-mail.

The interviews were semi-structured, and the point of departure for the creation of interview guides was to create clusters of questions around the core of my research questions but without steering the conversations too much. ${ }^{277}$ I tried to specify questions beforehand that opened up avenues for the interviewee, and also to specify different possible follow-up questions. Through this design I intended to let the interviewee's conceptualizations guide the conversation, but still be prepared to steer the conversation slightly if I deemed it necessary, for example if the interviewee strayed too far into technical details. The intention was to keep the discussion open if the interview took a different route than I had anticipated when drafting the interview guides, but nonetheless appeared interesting and relevant in relation to my research interest. ${ }^{278}$ This is especially relevant when the interest lies in unfolding processes. Additionally, considering how interviews are in a sense performances, if an interviewee is very

\footnotetext{
277 An example of an interview guide can be found in Appendix. The specific questions differed depending on whom I was interviewing and how far into the research process the interview took place, however they were formulated around similar clusters of questions.

${ }^{278}$ Cf. Kvale \& Brinkmann 2014. Den kvalitativa forskningsintervjun. Lund: Studentlitteratur. pp. 172-182.
} 
keen on steering the conversation in a specific direction this can be of value for the analysis. ${ }^{279}$ It might highlight certain aspects of a discussed issue being more relevant to the interviewee than others, and it might highlight other aspects that are considered off-limits for discussion for various reasons. ${ }^{280}$ This turned out to be a successful strategy, since the inclusion of the Gotland as an energy pilot region case partly resulted from this strategy.

The interviews were recorded, with the permission of the interviewees, and then transcribed. When quoting, I have edited text from the transcripts slightly in some instances to make them more readable. There is a difference between colloquial language and written language, so for example words used as filler in conversations have been removed. As this study is not based on a conversation analysis of the ethnomethodological tradition, filler words or pauses do not need to be included for analytical purposes. When listening to interviews and transcribing them, I have tried to be attentive to features such as pauses or laughter that seem significant, such as instances where they appear to convey a tension, but I have reflected upon this in the text related to the quotations rather than in the actual quotations themselves, simply to improve the readability of the text. I have included a table of abbreviations for interviewees and specified which organizations they represent. Certain interviewees represent more than one organization. In these instances, I have chosen to either call them energy field experts, or abbreviate based on the organization they were mainly affiliated with at the time of the interview or the organization whose affiliation is mainly relevant for this study. The interviewees were interviewed specifically with their roles in relation to smart energy experimentation in mind, so it is not them as individuals per se that are of interest but rather the organizations they are affiliated with and the positions they hold. Consequently, I utilize abbreviations or titles instead of names of individuals.

As a final note, I sent quotations to interviewees who requested this before publication, and some wished to edit their quotations. I chose to accept semantic alterations which did not change the meaning of the quotations, to avoid the risk of ending up with interviews being withdrawn. Some interviewees insisted on changing formulations in a way that altered the meaning of the quotations. In such cases, I have chosen to paraphrase rather than quoting, with careful consideration of the changes the interviewees wished to make. One interviewee decided to withdraw the entire interview, however. Full transcripts of all interviews exist, in line with generally agreed good research ethics.

\footnotetext{
${ }^{279}$ Atkinson \& Silverman 1997. Kundera's immortality: The interview society and the invention of the self. Qualitative Inquiry, 3(3).

${ }^{280}$ Charmaz 2014. Constructing Grounded Theory. 2nd edition. Thousand Oaks, CA: Sage Publications. p. 80 .
} 


\begin{tabular}{|c|c|c|c|}
\hline Organization & $\begin{array}{l}\text { Number of } \\
\text { interviewees }\end{array}$ & $\begin{array}{l}\text { Number of } \\
\text { interviews }\end{array}$ & Abbreviations \\
\hline $\begin{array}{l}\text { Ministry of The } \\
\text { Environment and } \\
\text { Energy }\end{array}$ & 2 & 1 & $\begin{array}{l}\text { EXMEE1, EXMEE2 (Experts, Ministry } \\
\text { of The Environment and Energy) }\end{array}$ \\
\hline $\begin{array}{l}\text { The Energy } \\
\text { Commission }\end{array}$ & 1 & 1 & EEC (Expert, the Energy Commission) \\
\hline $\begin{array}{l}\text { The Energy Markets } \\
\text { Inspectorate }\end{array}$ & 1 & 1 & $\begin{array}{l}\text { EXEI (Expert, the Energy Markets } \\
\text { Inspectorate) }\end{array}$ \\
\hline The Energy Agency & 5 & 6 & $\begin{array}{l}\text { EXEA1, EXEA2, EXEA3, EXEA4, } \\
\text { EXEA5 (Experts, the Energy Agency) }\end{array}$ \\
\hline $\begin{array}{l}\text { The Swedish Smart } \\
\text { Grid Forum }\end{array}$ & 2 & 2 & $\begin{array}{l}\text { CM Swedish Smart Grid Forum 1, CM } \\
\text { Swedish Smart Grid Forum } 2 \text { (Cabinet } \\
\text { members) }\end{array}$ \\
\hline Energy field experts & 3 & 3 & EXE1, EXE2, EXE3 (Energy experts) \\
\hline Svenska Kraftnät & 2 & 1 & $\begin{array}{l}\text { EXSvK1, EXSvK2 (Experts, Svenska } \\
\text { Kraftnät) }\end{array}$ \\
\hline Region Gotland & 2 & 2 & $\begin{array}{l}\text { EE Region Gotland (Energy Expert), } \\
\text { EnvE Region Gotland (Environmental } \\
\text { expert) }\end{array}$ \\
\hline $\begin{array}{l}\text { Gotland County } \\
\text { Administrative Board }\end{array}$ & 1 & 2 & $\begin{array}{l}\text { EE Gotland County Administrative } \\
\text { Board (Energy Expert, Länsstyrelsen } \\
\text { Gotland) }\end{array}$ \\
\hline $\begin{array}{l}\text { GEAB (Gotlands Energi } \\
\text { AB, local grid operator) }\end{array}$ & 2 & 2 & $\begin{array}{l}\text { CEO GEAB, GM GEAB (Grid } \\
\text { manager) }\end{array}$ \\
\hline Vattenfall & 2 & 2 & $\begin{array}{l}\text { PM1 Vattenfall, PM2 Vattenfall } \\
\text { (Project managers) }\end{array}$ \\
\hline ABB & 1 & 1 & PM ABB (Project manager) \\
\hline E.ON & 1 & 1 & PM E.ON (Project manager) \\
\hline Fortum & 1 & 1 & RM Fortum (Research manager) \\
\hline City of Stockholm & 2 & 2 & $\begin{array}{l}\text { PM City of Stockholm (Project } \\
\text { manager), EnvE City of Stockholm City } \\
\text { of Stockholm (Environmental expert) }\end{array}$ \\
\hline Ericsson & 1 & 1 & PM Ericsson (Project manager) \\
\hline Ellevio & 1 & 1 & PM Ellevio (Project manager) \\
\hline ETC & 1 & 1 & SETC (Spokesperson ETC) \\
\hline
\end{tabular}

Table 1. List of interviewees 


\section{Observations and site visits}

I consider site visits and observations to offer immersion into different spaces, to follow the empirical phenomenon of smart energy experiments up close in order to create a close relationship to the empirical material in the form of physical places, encountering and conversing with different actors. Put differently, this has enabled me to follow experimentation through different places. I view site visits and observations as complementary to interviews and texts, as a means of discovering new relevant themes and finding new analytical avenues, for instance through more informal conversations with different actors to complement the semi-structured interviews. Further, they add richness to the empirical bank and a robustness to my interpretation through triangulation between documents, interviews, and observations.

The site visits and observations have taken different formats. Three were part of other research projects, and thus gathered more actors in the field of smart energy both from the Swedish context and from elsewhere. Two of these, which took place in Hyllie, were quite formal in the sense that they included agendas, specific tours, and so on. Several observations were undertaken on Gotland, through my participation in public hearings, dialogue forums cohosted by the Municipality of Gotland and the County Administrative Board on Gotland, and presentations by different actors on initiatives related to the wider initiative of making Gotland an energy pilot region. I also attended a couple of conferences, one on urban futures and one on the energy transformation, gathering different researchers as well as actors from the public and private sectors working with energy transformation. These occasions provided opportunities for informal conversations with many different actors, both on Gotland and across the Swedish energy sector. I view these as complementary to the semi-structured, more formal interviews, providing additional insights into the empirical field of study and in some cases strengthening, as well as discouraging, analytical ideas which I was developing. Thus, they have contributed to the overarching analytical process in a complementary way.

\section{Coding and analysis}

After transcribing interviews, and compiling and reading through documents and field notes, I began coding using the qualitative data analysis software Atlas.ti. This coding helped me see certain aspects in the material that stood out as relevant. This was not a linear process 
occurring once; rather, as qualitative researcher Johnny Saldaña states, coding is cyclical. ${ }^{281}$ Generally, coding has functioned as an analytical device, in line with Saldaña's sentiment that:

\section{[...] coding is the transitional process between data collection and more extensive data analysis. ${ }^{282}$}

I do not conceive of coding as a linear process, but rather as a set of guidelines and a heuristic device to help a researcher to delve deeper into empirical material. Coding in Atlas.ti provided a way of exploring and working through the material. It acted as an analytical device and a reminder not to rush the analytical process, to let it take time and allow myself to reformulate the ideas and concepts that I brought with me into the research process. The most important contribution of coding to the analytical process, then, was to slow me down and allow me to delve deeper into the material. I think of this in a manner akin to how sociologist Kathy Charmaz describes the coding process. In her description of coding, it is a device that simultaneously helps provide a deeper understanding of empirical material and opens up an avenue for theoretical playfulness, i.e. for testing out whether analytical ideas appear to work, what they do in relation to the material, and where they lead. ${ }^{283}$ This mode of thinking helped me avoid conceptualizing coding in a mechanical sense, which risks hampering one's analytical imagination. ${ }^{284}$ Doing analysis is as much about mindset and finding zones to think through as it is about having the right tools, such as a specific coding framework. I thus stuck closely to Saldaña's advice to be pragmatic when practicing qualitative coding and doing "what works" in a given analysis. ${ }^{285}$ I took another piece of advice from Saldaña seriously in respect of doing what works, namely writing analytical memos extensively. This has also been a device for staying with the material, and for building a bridge between developing the more abstract analysis out of the concrete empirical material. In given periods, coding moved out of the computer software and onto the floor, in a combination of brainstorming, post-it writing, and sorting printed material, while writing analytical notes.

After coding, I moved between theoretical concepts and the coded material, to allow an analysis to take form, guided by my research questions. In practical terms, the analysis was accomplished by relating pieces of the empirical material to the expanding empirical bank, and by thinking through the theoretical framework. The process was iterative, moving through close reading of text, coding, writing analytical memos, encountering new empirics, going back to coding, and so on. Thus, I treated the material symmetrically, although staying vigilant

\footnotetext{
${ }^{281}$ Saldaña 2015. The coding manual for qualitative researchers. 3rd edition Thousand Oaks, CA: Sage Publications.

${ }^{282}$ Ibid. p. 5.

${ }^{283}$ See Charmaz 2014. Constructing Grounded Theory. pp. 136-137.

${ }^{284}$ Cf. Saldaña 2015. The coding manual for qualitative researchers. p. 15.

${ }^{285}$ Ibid. pp. 44-45.
} 
to the different provenances of the material. An interview can illuminate certain aspects, and documents others, as discussed above. In the analytical process, I looked for recurring central meanings and ideas, as well as central actors. I also looked for contradictions and strong statements, as well as the roles and meanings ascribed to specific experiments and experimentation in general by different actors. Paul Ricœur's hermeneutics of suspicion and sympathy was a guideline in the analysis.

\section{Methodological reflections}

Through this research design, particularities of a select few experiments can be highlighted whilst interlinking these with how smart energy experimentation arranges environmental governance more broadly in Sweden. The breadth and variety of material serves to strengthen validity. ${ }^{286}$ As with any analytical endeavor, there are blind spots and exclusions with this research design.

One weakness, in a sense, is connected to the description of methods as crafts, which is recurrent in almost all literature on qualitative methods. To learn a craft, one must practice. At the beginning of a $\mathrm{PhD}$, no one is a master of these crafts. However, any $\mathrm{PhD}$ student has practiced these crafts and learned along the way. When looking at transcripts from early interviews, I find that I would probably have approached certain questions in these interviews somewhat differently, and identified instances where I failed to follow up on interesting threads. Especially in the later stages of finishing the thesis, when the picture of the overarching intentions was clearer, questions in early interviews would have been posed differently. Having said this, the early interviews were not meaningless; they were important in an explorative sense to enhance my understanding of the empirical field and pinpoint relevant focus points for the dissertation, which were crystallized partly because of these interviews. This is a constant condition of interviews, which can be considered both a strength and a weakness. What it does illustrate, however, is some strengths of an abductive approach moving back and forth constantly throughout the research process in a pendulum-like movement between material, preconceptions, and theoretical resources, with the analysis being worked out through this movement, forces researchers to change their questions and analytical focus along the way.

Finally, I will only be able to say as much as my interpretations of the empirical material allow, and it is essentially impossible to cover an entire discursive field in one analytical endeavor. One aspect of this particular empirical area is, as I stress as a rationale for the study, that the policy formation around smart energy is currently unfolding. This comes not only with advantages, but also with considerable risks. It is quite possible that experiments will come to

\footnotetext{
${ }^{286}$ George \& Bennet 2005. Case studies and theory development in the social sciences. Cambridge, Mass.: MIT Press.
} 
be viewed differently, their role reinterpreted, at another time and place. As with most phenomena, the benefit of hindsight can certainly make something appear otherwise. Consequently, this study should be read as a historical document as well - it highlights aspects of how smart energy experimentation arranges environmental governance in a particular place at a particular time. ${ }^{287}$ This can be valuable in order to understand how smart energy experimentation arranges environmental governance in a situated way, if nothing else as a historical artefact, even if the role of smart energy experiments comes to be reinterpreted. It is certainly the case, however, that any research is a product of circumstance to some extent. I brought my own concerns for environmental issues into deciding on an analytical direction. Scrutinizing smart energy experimentation appeared important at this moment in time because of how this experimentation is strongly argued by central actors and institutions as a solution to deteriorating biophysical systems and an unfolding climate crisis. Interrogating how experimentation arranges governance, then, is a product of these concerns I harbor both as a researcher and as a citizen.

${ }^{287}$ Cf. Alvesson \& Sköldberg 2017. Tolkning och reflektion: vetenskapsfilosofi och kvalitativ metod. 3rd ed. Lund: Studentlitteratur. p. 49. 


\section{Setting the scene: Swedish energy politics, green political rationality, and experimentation}

This chapter is intended to situate smart energy experimentation as a mode of environmental governance by providing relevant background. The chapter therefore briefly explicates how experimentation has figured historically in Swedish energy politics, before moving on to describe smart energy as a sub-field of energy politics and the apparent salience of experimentation for smart energy in particular. Throughout the chapter, a broader political rationality underpinning Swedish environmental and energy politics will be elaborated.

\section{Experimentation as innovation instrument in Swedish energy politics}

It has been argued that energy policy became actualized as an issue area in its own right in Sweden after the 1970s oil crisis, mainly revolving around how to reduce oil dependency. ${ }^{288}$ The energy crisis transpired at the same time as changes were occurring in terms of how energy was perceived and handled by the Swedish government, and likely spurred on these changes, including embedding energy policy within urban and regional planning, the widespread use of forecasting, and crucially the development of large government-funded energy research programs. ${ }^{289}$ Energy policy became increasingly intertwined with environmental issues in Swedish politics, symbolized in political contestation over nuclear power, and since 1990 especially climate change. ${ }^{290}$ After the popular vote on nuclear power in 1980, overarching goals for energy policy were explicated, including dismantling nuclear power, decreasing oil dependency, increasing energy planning, and future energy supply becoming mainly based on renewable energy sources. ${ }^{291}$

Contemporary energy policy centers on the three overarching goals of ecological sustainability, security of supply, and competitiveness, with specific goals of net-zero greenhouse gas emissions by 2045 , specific shares of renewable energy sources, and increased energy

\footnotetext{
${ }^{288}$ Andersson \& Klevard Setterwall 1995. Energiboken: kunskapsläge och forskningsfront. Stockholm: Statens råd för byggnadsforskning.

${ }^{289}$ Wittrock \& Lindström 1984. De stora programmens tid - forskning och energi i svensk politik. Stockholm: Akademilitteratur.

${ }^{290}$ See e.g. Anshelm 2000. Mellan frälsning och domedag; Kall 2011. Förnyelse med förhinder; Anshelm 2012. Kampen om klimatet.

${ }^{291}$ Ingelstam \& Kaijser 1982. Kommer vackra mål att dränkas i el och kol? PLAN, 1-2.
} 
efficiency. ${ }^{292}$ The Swedish electricity system is characterized by large-scale electricity production with nuclear power, hydropower, wind power, and electricity from combined heat and power (CHP) transferred unidirectionally to energy users through large-scale transmission and distribution grids. The share of renewable energy is increasing, particularly through the establishment of large-scale wind power parks. ${ }^{293}$ The system is also centralized, operated mainly by large private companies, although a state-owned company (Svenska Kraftnät, SvK) owns and operates the high-voltage transmission grid. ${ }^{294}$ Further, the electricity system is interconnected to other Nordic countries and to the European electricity grid. ${ }^{295}$ The energy sector was marketized during the mid-1990s, introducing the Nordic electricity trading market Nord Pool, and eventually dividing Sweden into four bidding areas. ${ }^{296}$

Throughout its history, Swedish energy politics has been characterized by intense conflict and controversy. ${ }^{297}$ Three governments have had to resign at least partly as a result of intense conflict over energy politics. ${ }^{298}$ This might at first glance seem peculiar, since Sweden is often described as a nation where consensus-based governance prevails. ${ }^{299}$ On the contrary, there have been at least two strongly opposed discourses of how the energy system ought to be constituted, both within official parliamentary politics and through sub-politics. ${ }^{300}$ One of these discourses, an industrial-modern discourse, is aligned with how the energy system has developed historically, with an emphasis on large-scale solutions and centralization, while the other discourse, an ecological discourse, constitutes its opposite and instead revolves around

${ }^{292}$ SOU 2017:2. Kraftsamling för framtidens energi. Stockholm: Miljö- och energidepartementet. pp. 147149 .

${ }^{293}$ Energimyndigheten 2020. Energiläget 2020. ET 2020:1. Arkitektkopia: Bromma. p. 7.

${ }^{294}$ Wangel 2015. Developing Sweden's transmission grid: What are the drivers and barriers? Stockholm: Stockholm Environment Institute.

${ }^{295}$ Wangel 2015. Developing Sweden's transmission grid.

${ }^{296}$ See Högselius \& Kaijser 2007. När folkhemselen blev internationell: Elavregleringen i ett historiskt perspektiv. Stockholm: SNS Förlag; Magnusson 2013. District heating in a liberalized energy market: A new order? Dissertation. Linköping: Linköping University; Wallsten 2017. Assembling the Smart Grid. pp. 70-74.

${ }^{297}$ See e.g. Anshelm 2000. Mellan frälsning och domedag; Storm 2014. Post-industrial landscape scars. New York, NY: Palgrave Macmillan; Hultman 2015. Den Inställda Omställningen.

298 Anshelm 2000. Mellan frälsning och domedag.

${ }^{299}$ See e.g. Lewin 1998. Majoritarian and Consensus Democracy: the Swedish Experience. Scandinavian Political Studies, 21(3).

${ }^{300}$ Sub-politics is a term popularized by Ulrich Beck, see e.g. Beck 1997. Subpolitics: Ecology and the Disintegration of Institutional Power. Organization \& Environment, 10 (1). p. 64. The term highlights how an understanding of politics confined to the domains of official institutions will always be inadequate, broadening the search for politics to actors and processes outside these institutions. Examples provided by Beck include social movements, NGOs, scientists, and news media, as he argues that all of these actors and arenas shape politics as well as influencing parliamentary politics. Cf. Hajer \& Wagenaar (eds.) 2003. Deliberative Policy Analysis: Understanding governance in the network society. Cambridge: Cambridge University Press. 
small-scale solutions and decentralization. ${ }^{301}$ Closely aligned with these discourses, the actor coalitions furthering them, and the institutions where they have been anchored, two radically different visions of the ideal society can be distinguished. A progress-oriented, economic growth driven, expert-centered, and expansive view of society can be identified with the industrial-modern discourse, while a vision advocating participatory engagement, small-scale solutions, decentralization, self-sufficiency, and equilibrium is tied to its ecological counterdiscourse. ${ }^{302}$ During the 1970 s, the ecological counter-discourse's view of the ideal society crystallized in the vision of "the low energy society", which was directly opposed to the dominant industrial-modern discourse's outlook on the ideal society. ${ }^{303}$ The vision of the low energy society embodied the ecological counter-discourse's ideals, including decentralization, radically decreased energy use, small-scale solutions, and local democratic participation.

The volatile debates of the 1970s did not have a lasting imprint on the development of the energy system, however, with the industrial-modern discourse clearly being dominant over time, visible in the dominance of traits such as large-scale solutions, centralization, expansion, and economic growth. The energy system has developed materially along such lines, as described. The actor coalitions furthering the dominant industrial-modern discourse managed to outmaneuver the ecological counter-discourse's subscribers during the 1990s, retaining dominance and ensuring the continued existence of a large-scale, centralized energy system. ${ }^{304}$ Energy has remained an area prone to conflict and controversy, however, with nuclear power reemerging over time as a battleline both in parliament and through sub-politics, while questions connected to energy transformation have occasionally sparked debate. The dominant industrial-modern discourse has to a large extent relied on techno-economic expertise to assert itself and remain dominant; rationality, expertise, and marking a distance toward the ecological counter-discourse's claimed emotion-driven and irrational arguments have been hallmarks of the dominant discourse. ${ }^{305}$ During the nuclear power debate, techno-economic experts came to play an increasingly important role, with the language of the debate and the subjects debated moving steadily toward issues of a technical and economic character rather than social or political. ${ }^{306}$ Techno-economic expertise is deeply intertwined with the dominant industrial-modern discourse, and such experts are prominent figures in the public debate on energy while retaining prominent positions within the actual energy system. ${ }^{307}$

${ }^{301}$ Cf. Anshelm, 2000. Mellan frälsning och domedag; Kall 2011. Förnyelse med förhinder; Hultman 2015. Den Inställda Omställningen.

${ }^{302}$ See Anshelm 2000. Mellan frälsning och domedag; Kall 2011. Förnyelse med förhinder.

${ }^{303}$ Anshelm 2000. Mellan frälsning och domedag. pp. 150-151.

${ }^{304}$ See Hultman 2015. Den Inställda Omställningen.

${ }^{305}$ Kall 2011. Förnyelse med förhinder.

${ }^{306}$ Anshelm 2000. Mellan frälsning och domedag; Anshelm 2006. Bergsäkert eller våghalsigt? Frågan om kärnavfallets hantering i det offentliga samtalet i Sverige 1950-2002. Lund: Arkiv.

${ }^{307}$ Högselius \& Kaijser 2007. När folkhemselen blev internationell; cf. Pellizzoni \& Ylönen (eds.) 2012. Neoliberalism and Technoscience. 
In the contemporary energy policy landscape, small-scale renewable energy has increasingly come to be associated with concepts and practices that were previously the exclusive preserve of the dominant discourse. Rather than being a symbol of a radically different society, from the 1990s onwards renewable energy has increasingly come to signify progress and development, and has been highlighted as an instrument of increased economic growth. ${ }^{308}$ This gradual shift elucidates a broader shift in energy politics, from controversy and political rifts toward emphasizing consensus, or at least toning down such rifts. ${ }^{309}$ This pattern can be observed across environmental policy areas in Sweden, although conflicts occasionally flare up in relation to specific political decisions or the planned establishment of extractive industries. ${ }^{310}$ Contemporary governance arrangements spanning environmental policy areas include public-private partnership constellations, an emphasis on consensus and cooperation, instituting market solutions across policy areas, and techno-economic knowledge claims. ${ }^{311}$ Consequently, it can be argued that a broader political rationality envelops and underpins contemporary Swedish environmental politics, despite being prone to instances of repoliticization.

Experimentation has played a prominent role within the setting of Swedish energy politics, historically as well as in contemporary settings. Since the oil crisis of the 1970s, energy policy in Sweden has recurrently been shaped through the use of politically appointed committees, with the purpose of investigating specific broader energy-related issues to stake out policy directions. One such committee was appointed directly after the oil crisis, and it was through this committee's work that experimentation rose to prominence in Swedish energy policy. Historically, pilot and demonstration projects have fulfilled the role of supporting technological innovation in the industrial sector in Sweden. ${ }^{312}$ Within the energy sector, research and development in the form of such pilot projects increasingly came to be articulated

\footnotetext{
${ }^{308}$ Kall 2011. Förnyelse med förhinder; Hultman 2015. Den Inställda Omställningen.

${ }^{309}$ Kall 2011. Förnyelse med förhinder.

${ }^{310}$ For recent scholarly contributions emphasizing such aspects in relation to mining, see Anshelm, Haikola, and Wallsten 2018. Svensk gruvpolitik i omvandling: Aktörer, kontroverser, möjliga världar. Gidlunds förlag; Haikola \& Anshelm 2018. Depoliticization, Repoliticization, and Environmental Concerns Swedish Mining Politics as an Instance of Environmental Politicization. ACME: An International Journal for Critical Geographies, 17(2). Another such extractive conflict recently played out, as Preem's plans to expand operations in a refinery in Lysekil became the object of much scrutiny, sparking intense debate. The plans were eventually cancelled.

${ }^{311}$ See e.g. Hultman \& Anshelm 2014. Discourses of Global Climate Change: apocalyptic framing and political antagonisms. Abingdon, Oxon: Routledge; Holgersen \& Malm 2015. "Green fix" as crisis management. Or, In which world is Malmö the world's greenest city? Geografiska Annaler Series B Human Geography, 97(4); Lidskog \& Elander 2012. Ecological modernization in practice? The case of sustainable development in Sweden. Journal of Environmental Policy \& Planning, 14(4); Hysing 2014. A Green Star Fading? A Critical Assessment of Swedish Environmental Policy Change. Environmental Policy and Governance, 24. p. 271; Hult 2017. Unpacking Swedish Sustainability: The promotion and circulation of sustainable urbanism. Diss. KTH: Stockholm; cf. Hedrén 1994. Miljöpolitikens Natur.

${ }^{312}$ Wittrock \& Lindström 1984. De stora programmens tid.
} 
as an arrangement for transforming the energy system in the wake of the 1970s oil crisis. ${ }^{313}$ Coalescing energy and environmental concerns spurred extensive policy activity, resulting in a national energy research and development program in the mid-1970s. ${ }^{314}$ In addition to the creation of energy taxes and municipal energy planning, the energy research agenda soon developed further into a broad family of research programs related to energy. This was largely the result of the committee appointed after the 1970s oil crisis. ${ }^{315}$ A large proportion of the funds channeled by the state into energy-related R\&D were used to develop pilot and demonstration plants. ${ }^{316}$ The development of a national energy program continued and was consolidated further during the 1980s. ${ }^{317}$

As mentioned, appointing committees to investigate specific questions or issue areas has long been - and still is - common practice for Swedish governments, not least in the field of energy. Looking historically at such investigations (Swedish Government Official Reports, or SOUs) can reveal meaning horizons of how energy was constructed as an issue at particular times, and thus the role ascribed to experimentation in energy policy. This can be especially illuminating since several such committees focused on energy have been appointed since the 1970s, in order to advise the government on how to develop energy policy and regulations. Moving forward from the 1970s and the 1980s, in an energy SOU published in 1995, experimentation in the form of pilot and demonstration projects was ascribed great importance for energy transformation, and was articulated as necessary due to environmental concerns. ${ }^{318}$ The energy policy bill following on from this investigation put great emphasis on research and development in the form of pilot and demonstration projects, argued to be vital for the longterm transition of the energy system. ${ }^{319}$ It was posited in the government bill that research and development was a prerequisite for ecologically sustainable economic growth, and that the role of the state should be to guarantee long-term commitment and catalyze private actors through research funding. ${ }^{320}$ So while the state tasked itself with creating favorable conditions for energy transformation, private companies were designated as central actors for accomplishing this transformation. Cooperation between the state, the private sector, and the

\footnotetext{
${ }^{313}$ Bergquist \& Söderholm 2014. Industry Strategies for Energy Transition in the Wake of the Oil Crisis. Business and Economic History On-Line, 12.

${ }^{314}$ Prop. 1975:30. Regeringens proposition om enerighushållningen m.m. Stockholm; see Wittrock \& Lindström 1984. De stora programmens tid. pp. 111-125.

${ }^{315}$ Wittrock \& Lindström 1984. De stora programmens tid.

${ }^{316}$ Bergquist \& Söderholm 2014. Industry Strategies for Energy Transition in the Wake of the Oil Crisis; cf. Torregrosa-Hetland, Pelkonen, Oksanen, and Kander 2019. The prevalence of publicly stimulated innovations - A comparison of Finland and Sweden, 1970-2013. Research Policy, 48(6).

${ }^{317}$ Bergquist \& Söderholm 2014. Industry Strategies for Energy Transition in the Wake of the Oil Crisis; see also Wittrock \& Lindström 1984. De stora programmens tid.

${ }^{318}$ SOU 1995:39. Omställning av energisystemet. Näringsdepartementet: Stockholm. pp. 208; 212; 219; 223-224.

${ }^{319}$ Prop. 1996/97:84. En uthållig energiförsörjning. Stockholm.

${ }^{320}$ Prop. 1996/97:84. En uthållig energiförsörjning.
} 
research community was described as vital in order to support technological and market developments simultaneously, and pilot and demonstration projects were given a very prominent role for transforming the energy system. ${ }^{321}$ Consequently, energy politics came to be increasingly intertwined with environmental politics during the 1990s, especially climate change, as highlighted in the $1995 \mathrm{SOU}$ and the subsequent energy policy bill.

The substantial emphasis on research and development during the 1990s shifted somewhat in the following energy SOU, dating from 2003. There, it was stated that too much importance and faith was being afforded to research and development to realize the sought-after energy transformation in the 1997 energy policy bill. Instead, it was claimed, while research and development is an important prerequisite to enable a transformation of the energy system, it could never constitute the engine of this transformation. ${ }^{322}$ Instead, other policy instruments such as taxes and regulatory frameworks for firms were articulated as being more important to consider. Still, there was a substantial emphasis on the need for cooperation between industry, the state, and the research community in the SOU. ${ }^{323}$ It was stated that the state's opportunities to actively intervene in energy transformation had been dramatically reduced as a result of the deregulation of the electricity sector, competition legislation, and the development of the EU. ${ }^{324}$

Within Swedish energy policy, concepts such as rationality, credibility, and long-term thinking have generally been historically employed as virtues. In line with these virtues and the overarching constitution of the energy system, experiments have tended to take the form of major state-funded industrial innovation projects, often demonstration plants owned by large energy companies. ${ }^{325}$ There is often an eagerness to demonstrate a distance from an implicitly, and sometimes explicitly, characterized irrational and emotionally driven debate of the past, at least since a future-oriented SOU from 1974 in which concepts such as the low energy society were mentioned. ${ }^{326}$ As environmental and STS researcher Martin Hultman states, in concurrence with scholar of intellectual history Jonas Anshelm, energy was debated in the 1970s in terms of societal ideals and the future constitution of society in Sweden, and this is mirrored to some extent in the 1974 SOU, even though it is not engaged with to any great

${ }^{321}$ Prop. 1996/97:84. En uthållig energiförsörjning.

${ }^{322}$ SOU 2003:80 EFUD - en del i omställningen av energisystemet. p. 14. Stockholm.

${ }^{323}$ Ibid.

${ }^{324}$ Ibid. p. 24.

${ }^{325}$ Wittrock \& Lindström 1984. De stora programmens tid.

${ }^{326}$ See e.g. SOU 1984:61; SOU 1995:39; SOU 2003:80; cf. SOU 1974:76. See also Kall 2011. Förnyelse med forrhinder. Kall offers a thorough historical analysis of the parliamentary debate and policy documents related to renewable energy. 
degree. ${ }^{327}$ This indicates that the energy debate in Sweden has long been waged largely in techno-economic rather than explicitly political terms.

This is underscored by environmental and STS researcher Ann-Sofie Kall, who points out that in energy SOUs after the mid-1970s there is an eagerness to signify a distance from the previous energy policy and energy debate, which is described as emotionally driven and irrational. ${ }^{328}$ Energy policy since the mid-1970s has rather focused on technological development and system optimization, not least through the use of demonstration and pilot projects, and has eventually shifted into making Sweden a frontrunner through exporting green technology and articulating energy transformation as an opportunity to boost economic growth. ${ }^{329}$ In this endeavor, research and development has been granted an important role, in conjunction with realizing a transformation of the energy system; as stated above, there has historically been a seemingly adamant belief in the possibilities of applied research and new technology in Swedish energy policy. ${ }^{330}$

This brief historical section illuminates two central points. First, that experiments in the form of pilot and demonstration projects have been ascribed a central role to enable energy system change since the $1970 \mathrm{~s}$ in the Swedish context. Second, experiments have tended to be launched in the form of large-scale initiatives in cooperative arrangements between the state and private companies, in line with how experiments have been mainly described in SOUs as development and commercialization of new technology by private actors, aided by the state through research funding. This overarching description of experiments as enablers of transformation seems to be in line with the evolution of environmental and energy discourse in Sweden, which has come to heavily emphasize the development and export of green energy technology and increased economic growth as solutions to environmental issues, despite the slight shift of emphasis in the SOU from 2003. ${ }^{331}$ Since its inception in the international political arena, environmental sustainability has, however, been conceptualized differently over time and policy responses to environmental degradation have also varied. ${ }^{332}$ Currently, sustainability is often conceptualized as a possible win-win situation, where political goals linked to the global political economy, such as economic growth, are considered an impetus for sustainability. This discourse has been called ecological modernization, and while it comes in different guises, the dominant version mainly revolves around a problem-solving approach

${ }^{327}$ Hultman 2010. Full gas mot en (o)hållbar framtid. Diss. Linköping: Linköping University. p. 40ff; Anshelm 2000. Mellan frälsning och domedag.

${ }^{328}$ Kall 2011. Förnyelse med förhinder.

${ }^{329}$ Ibid.

${ }^{330} \mathrm{Cf}$. Ibid.

${ }^{331}$ See e.g. Ibid; Anshelm 2000. Mellan frälsning och domedag; cf. Hajer 1995. The politics of environmental discourse.

${ }^{332}$ Dryzek 2013. The Politics of the Earth; Bulkeley 2016. Accomplishing Climate Governance. 
where environmental issues are believed to be best handled through market approaches connected to technological innovation, consumer choices, and increased economic growth in the "green" sectors of society, such as renewable energy and "green" goods and services. ${ }^{333}$ Several researchers have shown how this particular brand of ecological modernization, often termed "ecomodernism", came to the fore as the dominant environmental discourse in Sweden. ${ }^{334}$

Sweden provides a clear example of this line of thinking and arranging environmental governance, expressed for example through policy programs connected to the desire to become the world's first fossil-free welfare state. This has deep historical roots, especially within the Social Democratic Party, which has long been the dominant political party in Sweden. ${ }^{335}$ During the mid-1990s, ecological modernization became woven into official political rhetoric and anchored in governmental institutions as prominent social democrats explicitly referred to ecological modernization as the next big societal project. ${ }^{336}$ This has engaged and mobilized many across governmental institutions since, to the extent that ecological modernization can be argued to have guided Swedish environmental and economic policy since the mid-1990s - focusing on technological solutions, exports, and green economic growth, all based on the notion that environmental considerations can act as an impetus to and strengthen Swedish private companies, and boost national economic growth.

As stated, it can certainly be argued that contemporary Swedish environmental politics is underpinned by a particular political rationality, characterized by instituting market arrangements across environmental policy fields, public-private partnership constellations, consensus-seeking, and an emphasis on techno-economic expertise. In international politics, Sweden is often viewed as a frontrunner when it comes to climate governance, and Swedish governments have been keen to promote this picture of Sweden as well. ${ }^{337}$ Contemporary politicians often claim that Sweden is actually close to becoming the world's first fossil-free welfare state, i.e. a state which has managed to decouple increasing environmental pollution from economic growth through policy programs prescribed by ecomodernism, often related to consumer choices and the development and export of new technologies. Considering this,

\footnotetext{
${ }^{333}$ Hajer 1995. The Politics of Environmental Discourse; Dryzek 2013. The Politics of the Earth.

${ }^{334}$ See e.g. Lidskog \& Elander 2012. Ecological Modernization in Practice?; Lundqvist 2004. Sweden and ecological governance: straddling the fence. Manchester: Manchester University Press.

${ }^{335}$ See Anshelm 1995. Socialdemokraterna och miljöfrågan: en studie av framstegstankens paradoxer. Stockholm: B. Östlings bokförl. Symposion.

${ }^{336}$ Anshelm 2002. Det gröna folkhemmet - Striden om den ekologiska moderniseringen av Sverige. In Hedrén (ed.). Naturen som brytpunkt: om miljöfrågans mystifieringar, konflikter och motsägelser. Eslöv: B. Östlings bokförl. Symposion. pp. 34-61.

${ }^{337}$ See e.g. Anshelm \& Hultman 2014. Discourses of global climate change; Anshelm 2012. Kampen om klimatet; Hysing 2014. A Green Star Fading?
} 
it does not seem unfair to state that Sweden is in many ways the epitome of ecomodernism, as many actors in different parts of Swedish society wish for Sweden to be a frontrunner by showing the rest of the world that it is essentially possible to reconcile deep decarbonization with economic growth. ${ }^{338}$ Worryingly, the policy mix has been deemed nowhere near enough by the independent Climate Policy Council to realize these ambitions. With mitigation slowing down, neither the overarching net-zero emissions by 2045 goal nor the more detailed intermediate targets are considered possible to reach. ${ }^{339}$

\section{The salience of experimentation for smart energy}

In the midst of these ambitions and contradictions sits the ambition to develop a smart energy system. The ongoing attempts to transform the energy system through socio-technical experiments can be viewed as a crucial step toward actually realizing Sweden's political ambitions of becoming an environmental frontrunner, leading the way toward sustainability for others to follow. Therefore it is perhaps unsurprising to find echoes of the ambition to turn Sweden into the world's first fossil-free welfare state in relation to smart energy, nor is it surprising to note that smart energy is also an explicit element of the government's export strategy through the now dissolved governmental agency the Swedish Smart Grid Forum.

"Smart" is, however, an ambiguous term, requiring deliberation before moving on. In the words of environmental social scientist Jennie C. Stephens and colleagues, "smart grid" is an umbrella term encompassing different technical and social changes of energy systems, and different individuals and institutions harbor different perceptions of smart grids. ${ }^{340}$ In other words, there are diverse views on what actually constitutes a smart grid, but a widespread application of information and communications technology (ICT) in different parts of the energy system is usually considered the backbone of turning the "dumb" grid into a smart counterpart. ${ }^{341}$ How to configure a smart grid in practice, though, is fraught with uncertainties. Smart grid is thus an interpretatively flexible concept, since there are many different views on what distinguishes a smart grid from a "dumb" grid and how to demarcate the concept. Should it include only the production, transmission, and distribution of electricity, or are users of electricity also included in the concept? Perhaps it is not enough to focus on electricity, since integration between different parts of energy systems could be

\footnotetext{
${ }^{338}$ See e.g. Anshelm \& Hultman 2014. Discourses of global climate change.

${ }^{339}$ Bonde et al. 2019. Klimatpolitiska rådets rapport 2019. Stockholm.

${ }^{340}$ Stephens et al. 2015. Smart Grid (R)evolution. p. 4.

${ }^{341}$ This can be applied for different purposes in different parts of the energy system, e.g. enhanced surveillance and error detection for grid operators through the utilization of smart meters and deployment of sensors in electricity transmission and distribution grids, or increased information about energy use for private households via smartphone applications. This will be discussed further below.
} 
considered smart. This has resulted in a preference for some actors to speak about the smart energy system rather than the smart grid. ${ }^{342}$

Certain features do, however, recur in different descriptions of smart grids. A smart grid is often contrasted to the contemporary energy system, since it is usually described as a system where energy flows in different directions as a result of the extensive integration of decentralized and large-scale renewable energy sources, often enabled through the application of ICT in different parts of the energy system. ${ }^{343}$ Thus, smart grid as a concept usually contains both hardware and software. Importantly, the motivations for a smart energy system differ greatly between different actors. ${ }^{344}$ In Sweden, it is intimately interconnected with achieving environmental goals, with energy and climate policy often articulated as the main policy areas where smart energy is important. This can be illuminated through the following quotation:

Sweden has decided on ambitious energy and climate policy goals. For example, Sweden's electricity production shall be $100 \%$ renewable in 2040, and Sweden will become one of the world's first fossil-free welfare states. This places new demands on the power grids. Smart grids grant grid operators, producers, and electricity users new opportunities to contribute to a sustainable system that utilizes the energy smarter. ${ }^{345}$

This quotation is taken from the website of the now dissolved government agency the Swedish Smart Grid Forum, and it underlines how smart energy is considered an integral element of the transformation of Swedish society toward sustainability. Smart energy is ascribed the possibility of solving additional issues related to the greening of power grid infrastructure, primarily connected to capacity limitations and the lack of available power in an increasingly intermittent system. It should be emphasized that while different reasons tend to be outlined as causes for capacity and power limitations, most explanations spring from continued growth - including the expansion of cities, but mainly connected to the construction of large, electricity-devouring server halls. ${ }^{346}$ Smart energy is mainly described as alleviating such concerns through the optimization of the electricity grid by interlacing it with ICT equipment, e.g. shaving peak loads through load-shifting by financially incentivizing households to become

\footnotetext{
${ }^{342}$ In this study, we will move across forums where discussions such as these are ongoing, as well as approaching experiments which are not primarily concerned with electricity. I will use both the terms "smart grid" and "smart energy", but "smart energy" will be mainly used as the preferred umbrella term.

${ }^{343}$ Stephens et al. 2015. Smart Grid (R)evolution.

${ }^{344}$ Lovell 2018. The promise of smart grids. Local Environment, 24(7); Stephens et al. 2015. Smart Grid (R)evolution.

${ }^{345}$ Forum för smarta elnät (undated). Varför smarta elnät. http://swedishsmartgrid.se/varfor-smartaelnat/ [2018-02-28]. All Swedish quotations have been translated into English by the author.

${ }^{346}$ See e.g. Axberg et al. 2020. Kapacitetsutmaningen i elnäten. Ei R2020:06. Energimarknadsinspektionen: Eskilstuna. p. 24. It should be noted that the Energy Markets Inspectorate formulates the issue the other way around, so that a lack of available grid capacity is framed as a threat to the establishment of new server halls.
} 
more flexible in their energy use, or by installing automated solutions, as well as shifting loads through storing energy by various means, enabled by different smart technologies. Such ambitions tend to be described as being best achieved by instituting governance arrangements such as different market solutions, the export orientation of smart energy policy, an emphasis on consensus and cooperation, techno-economic expertise, and techno-managerialism. In other words, smart energy as a sub-field of energy policy also appears to be underpinned by the broader political rationality enveloping Swedish environmental politics.

The political salience afforded to smart energy is further underscored by the choice of thenMinister for Policy Coordination and Energy Ibrahim Baylan as the forum's chairperson. However, the Swedish Smart Grid Forum is by no means alone in this assessment of smart energy. Many actors from different parts of society refer to smart grids as key elements of a societal transformation toward increased sustainability. Further, as environmental social scientist Amelia Mutter has illustrated, the notion that society needs to become increasingly electrified as a remedy to environmental harm is gaining widespread support across Sweden and beyond. ${ }^{347}$ Electrification is regularly connected to smart energy, since electrification as an environmental policy must be based on intermittent renewable energy sources. This is argued to necessitate the utilization of more digital technologies to coordinate electricity production and use, as enshrined in the quotation above.

A policy formation around smart energy is currently ongoing in Sweden, and many smart energy and smart city experiments such as pilot and demonstration projects are being carried out. In policy documents, smart grids are described as being important in relation to green transformation, and there is an explicit dedication to fostering pilot and demonstration projects. ${ }^{348}$ There are ongoing discussions on how to further facilitate the conditions for pilot projects through regulation, within regulatory agencies as well as within industry, for example on how to create so-called policy labs. ${ }^{349}$ Smart energy is a clear example of systemic sociotechnical change, as it is not clear how a smart grid would interact with the current energy infrastructure or whether it would necessitate replacing the current configuration. This

\footnotetext{
${ }^{347}$ Mutter 2019. Mobilizing sociotechnical imaginaries of fossil-free futures - Electricity and biogas in public transport in Linköping, Sweden. Energy Research \& Social Science, 49.

${ }^{348}$ SOU 2014:84. Planera för effekt!. Stockholm: Näringsdepartementet; SOU 2017:2. Kraftsamling för framtidens energi; SOU 2018:76. Mindre aktörer i energilandskapet - förslag med effekt. Stockholm: Miljö- och energidepartementet. p. 275; Prop. 2016/17:66. Forskning och innovation på energiområdet för ekologisk hållbarhet, konkurrenskraft och försörjningstrygghet. Stockholm: Miljö- och energidepartementet; Forum för smarta elnät 2017. Strategin från forskning till internationalisering: rekommendationer. Stockholm: Regeringskansliet.

${ }^{349}$ E.g. Forum för smarta elnät 2017. Strategin från forskning till internationalisering; Wolf \& Andersson 2018. Elnätets roll i framtidens energisystem: Möjligheter, hinder och drivkrafter för smarta elnätslösningar. Power Circle. Stockholm.
} 
uncertainty grants socio-technical experimentation, in its various guises, a key role in relation to smart energy, as such experiments are justified particularly with the belief that they will reduce uncertainty by showing which configurations work in practice and which do not. Following on from this, there are several funding schemes and policy initiatives related to smart energy and smart city experimentation, facilitating the actual ongoing experiments in the Swedish context. 


\section{Reducing uncertainty, ensuring prosperity: the discursive constitution of smart energy experimentation in Sweden}

In this chapter, I will analyze smart energy in Sweden as a discursive space where meaning is made about experimentation in relation to developing a smart energy system. I will focus on broader governance arrangements, mainly on a national level, drawing on the concept of political rationality. The chapter thus constitutes a critical interrogation of the governmental apparatus in which smart energy experimentation is becoming incorporated, and the political rationality which underpins it. ${ }^{350}$ I will attend to the discursive embeddedness of smart energy experimentation, mainly through analysis of texts and interviews. In practice, the chapter is built upon a discourse analysis of materials of different provenances, including policy documents, reports by public, non-governmental, and private actors, and interviews with actors from government offices, governmental agencies, and industry. These actors and documents occupy important policy roles and were recurrently described as pivotal in interviews.

The analysis can elucidate the boundaries of smart energy experimentation by highlighting which practices become reasonable within experiments, for example which problems experiments are described as solutions to. Thus, this chapter analyzes the political rationality underpinning smart energy experimentation, pre-existing but co-evolving with individual experiments, likely influencing the setup and practices of experiments, and potentially being reshaped by experiments. The analysis will be developed in relation to the situatedness of smart energy experimentation, through the lineage of experimentation in Swedish energy policy described in the previous chapter. There, we saw how ideals of centralization and large scale have been historically dominant in Swedish energy politics, and how this has been an area marked by intense conflict over time. Additionally, we saw how an ecomodern approach to

\footnotetext{
${ }^{350}$ As discussed in the methods chapter, I do not view discursive elements as something inherent in empirical material to be discovered. I rather understand these as constructed in the analytical process. Nonetheless I would maintain that there are good reasons to accept my description of the discursive constitution of smart energy experimentation, since it is the result of an abductive interplay between theoretically informed analysis developed over long time of extensive empirical material, including many re-visits of empirical material. For similar arguments, see e.g. Glynos \& Howarth 2007. Logics of Critical Explanation in Social and Political Theory; Saldaña 2015. The Coding Manual for Qualitative Researchers; Anshelm 2012. Kampen om klimatet.
} 
environmental issues has been deeply rooted in Swedish governmental institutions since the mid-1990s.

\section{Swedish energy experimentation - cooperation, consensus, and exporting green energy technology}

In this section, I will analyze contemporary Swedish energy policy, by way of a few central documents and political decisions. These will serve to elaborate on the discursive constitution within which smart energy has become cast as a sub-field of energy policy. Since smart energy experiments are embedded within this discursive setting, it is relevant to dig further into its formation. The following section then disentangles how smart has become a sub-field, its discursive characteristics, and the role ascribed to experimentation within this sphere.

Two interconnected endeavors which are often mentioned in interviews and documents as being central for the constitution of smart energy in Sweden, albeit not directly concerned with smart, are the 2016 Energy Agreement and an Energy Commission tasked in 2015 with developing the basis for this agreement, and which delivered its final report in the form of an SOU in early 2017. The Energy Commission was a parliamentary committee tasked with laying the foundations for a broad energy policy agreement. ${ }^{351}$ This was said to be necessary in order to reach both energy and climate policy goals, and especially in relation to the changes the energy system was experiencing. It was explicitly stated in the directive to the Energy Commission that in order to encourage necessary investments, there was an urgent need for broad consensus and clear long-term energy policy goals. ${ }^{352}$ The directive focused on active customers, making Sweden a frontrunner in the development and export of green energy technology, and reaching climate and energy policy goals through exports and boosting economic growth. ${ }^{353}$

The Energy Agreement is a 2016 political agreement between five of the eight political parties in the Swedish parliament: the Social Democratic Party, the Moderate Party, the Green Party, the Centre Party, and the Christian Democrats. Consequently, it spans the political spectrum, albeit not the entire spectrum. The agreement was constructed around the same basic elements as the energy collaboration within the EU, i.e. ecological sustainability, competitiveness, and security of supply. ${ }^{354}$ The specific goals of the agreement revolve around creating a renewable

\footnotetext{
351 Miljö- och energidepartementet 2015. Kommittédirektiv: Översyn av energipolitiken. Dir. 2015:2. Stockholm.

${ }^{352}$ Ibid. p. 7.

${ }^{353}$ Ibid. p. 7.

${ }^{354}$ Miljö- och energidepartementet 2016. Ramöverenskommelse mellan Socialdemokraterna, Moderaterna, Miljöpartiet de gröna, Centerpartiet och Kristdemokraterna. Stockholm.
} 
and sustainable energy system with net-zero emissions of $\mathrm{CO}_{2}$ by 2045. The agreement explicitly states that the goal of renewable electricity production does not exclude nuclear power, and that nuclear power will not be shut down by political decisions. ${ }^{355}$ The overarching goals are also connected to creating new jobs and boosting economic growth, and this is reflected in the role assigned to energy experiments in the agreement. It is stated that research will be centered on efforts that contribute to reaching climate and energy policy goals and have the potential for economic growth and export. ${ }^{356}$ It is further stated that energy research will continue to focus on technology development, and on demonstration and pilot projects, since energy research plays a decisive role in making sure that new and innovative technical solutions are developed for all renewable energy sources. ${ }^{357}$

The three parties that are not part of the agreement - the Sweden Democrats, the Liberal party, and the Left party - gave different reasons for not subscribing to it. The Sweden Democrats left the negotiations at an early phase, claiming that the Green Party was given too much power in forming the agreement. According to the Sweden Democrats, this would lead to an energy system that was dependent on the weather due to intermittent energy sources, and thus to Sweden forsaking the all-important goal of security of supply. ${ }^{358}$ The Left Party stated that there were positive aspects to the agreement, but decided not to sign up because the Social Democratic Party had conceded too much in order to get the Moderate Party on board. The Left Party's leader, Jonas Sjöstedt, argued that since the agreement did not stipulate a definitive expiration date for nuclear power, no renewable energy system was in sight. ${ }^{359}$ The Liberal Party left the negotiations early, like the Sweden Democrats, because it could not accept what were perceived as excessive subsidies for renewable energy. ${ }^{360}$ Nuclear power has been a hotly debated political issue in Sweden since at least the 1970s, and the indecisiveness regarding nuclear power in the Energy Agreement could be interpreted as a result of the parties' different positions on the question of nuclear power. ${ }^{361}$ An Energy Commission cabinet member stated in an interview that this vagueness on nuclear power enabled the Moderate Party to claim that nuclear power had been saved, while the Green Party

${ }^{355}$ Ibid.

${ }^{356}$ Ibid. p. 6.

${ }^{357}$ Ibid.

${ }^{358}$ SVT Nyheter 2016. Kritik från V och SD. 2016-06-10. https://www.svt.se/nyheter/inrikes/kritikfran-v-och-sd [2018-05-02].

359 Sveriges Radio 2016. Energiuppgörelse klar mellan fem partier. 2016-06-10. https: / / sverigesradio.se/sida/artikel. aspx?programid=83\&artikel=6450597 [2018-05-02].

${ }^{360} \mathrm{Ibid}$.

${ }^{361}$ See e.g. Anshelm 2000. Mellan frälsning och domedag; Anshelm 2006. Bergsäkert eller våghalsigt? 
could simultaneously claim that goals for reaching a 100\% renewable energy system had been established, and that both were actually right. ${ }^{362}$

The Energy Agreement and the Energy Commission reflect a broad discursive theme within energy policy: that of making Sweden an environmental frontrunner, achieving climate and energy policy goals by exporting green energy technology. An emphasis on consensus and cooperation is repeatedly articulated in relation to this theme, and it appears to unite many actors. This is in line with the ecomodern environmental discourse which has long been a prominent feature of Swedish environmental politics. ${ }^{363}$ In other words, it appears that the Energy Commission played an important role in reaffirming agreement on making Sweden an environmental frontrunner through greening the capitalist political economy. The Energy Agreement reflects a strong emphasis on the need for consensus and cooperation to realize these goals, which is prevalent in Swedish energy policy. Still, there are clearly divergent views between the political parties in the agreement, as shown.

Several interviewees claimed that the Energy Commission and the Energy Agreement managed to establish a consensus in the energy sector, and described how the energy sector has come together and is now pulling in the same direction. The theme of making Sweden a frontrunner and reaching climate and energy goals through export is also mirrored in statements on energy research in both the Energy Agreement and the Energy Commission's SOU. For example, the SOU states that energy research should center on efforts which can contribute to reaching climate and energy policy goals, and that have the potential to increase economic growth and export revenue. ${ }^{364}$ The following quotation is illuminating for the language on experiments in the SOU:

The efforts in the energy research area will remain focused on technology development, and on demonstration and pilot projects in all areas of energy research. Energy research plays a crucial role in developing technology and services which can be commercialized through the Swedish business sector, and thereby contributes to sustainable growth and the transition and development of the energy system in Sweden as well as in other markets. The Swedish business sector has significant opportunities to develop and provide these goods and services in a global market to meet the environmental and climate challenges. ${ }^{365}$

Consequently, experiments are ascribed an important role in transforming the energy system, whilst cooperation and consensus are articulated as virtues that seem necessary in order to

\footnotetext{
${ }^{362}$ Interview EEC.

${ }^{363}$ See e.g. Anshelm \& Hultman 2014. Discourses of Global Climate Change; Anshelm 2002. Det gröna folkhemmet - Striden om den ekologiska moderniseringen av Sverige.

${ }^{364}$ SOU 2017:2. Kraftsamling för framtidens energi. p. 306.

${ }^{365}$ Ibid. pp. 306-307.
} 
sustain the overarching ambitions. Energy transformation is described as being best led by the business sector, by carrying out innovative experiments to develop new green energy technology which can be exported. Connected to such lines of reasoning, science and a scientific approach are regularly mobilized as central virtues in energy politics. ${ }^{366}$ Experiments appear to derive much credibility and become important precisely in this regard, as they are described as a scientific instrument to inform policymaking. Governance can thereby become evidence-based, it is argued. This notion is widespread across the material, and can be illustrated by the following quotation:

Most of us want to see evidence-based policymaking that is based upon verifying the use of this new development or the development of regulations, as far as possible. ${ }^{367}$

This highlights how experiments are seen to provide policymaking with a scientific basis, through scientifically testing what it is possible to do, thus marking out reasonable courses of action to transform the energy system. This mirrors the increasingly central role technoscientific expertise has been afforded in Swedish energy politics, gradually displacing political debate about future ideals into the realms of techno-economics. ${ }^{368}$ Further, the role ascribed to experiments tallies with the importance granted to consensus and cooperation across central policy documents, as experiments are tasked with scientifically asserting routes for policymaking.

In line with the history of Swedish energy politics, which is characterized by conflict and controversy rather than consensus, it is however quite clear that diverging views exist in the field, despite this emphasis on consensus, cooperation, and evidence-based policymaking. For instance, in an interview with representatives from the Swedish TSO, Svenska Kraftnät, it was stated that the TSO was concerned about the overarching energy policy goal of security of supply, and had voiced this concern repeatedly in the Energy Commission without any effect. ${ }^{369}$ The argument was that it is disruptive and potentially harmful to the system to remove plannable electricity production, such as nuclear power, as it provides the main base load as well as crucial balancing for the system. ${ }^{370}$ This cannot simply be replaced by weather-

\footnotetext{
${ }^{366}$ Cf. Kall 2011. Förnyelse med förhinder.

${ }^{367}$ Interview CM2 Swedish Smart Grid Forum.

${ }^{368}$ As discussed in the background chapter. Cf. Anshelm 2000. Mellan frälsning och domedag; Anshelm \& Hultman 2014. Discourses of global climate change; Birch 2017. Techno-economic assumptions.

${ }^{369}$ Interview EXSvK.

370 This relates to the material constitution of electricity infrastructure and the properties of power plants. It is infused with hotly debated capacity issues, which extend beyond e.g. grid limitations in cities which could potentially be solved by constructing new transmission lines. It also encompasses capacity issues engendered by the geography of the Swedish energy system, since a large proportion of electricity production is concentrated in northern areas while a large proportion of consumption is concentrated in southern Sweden, and power plants that supply important services such as rotational energy and balancing frequency in the grid are being removed. See Bakke 2017. The Grid: the fraying wires between Americans and
} 
dependent electricity production, it was argued. The Confederation of Swedish Enterprise has put forward similar opinions. ${ }^{371}$ According to the representatives from Svenska Kraftnät, the removal of plannable electricity production jeopardizes the goal of security of supply, and this was disregarded in the Energy Commission and the Energy Agreement. ${ }^{372}$ An interviewee who was involved in the Energy Commission claimed that distribution system operators (DSOs) will most likely find themselves more important in a future energy system based on renewable energy sources. However, this would not necessarily be a smooth process:

So the regional grid owners will become very important, that seems pretty clear. How that's going to happen and which competencies they will have, and how much SvK [Svenska Kraftnät] will let go of are big questions which are far from settled. And they're not very keen on letting go of their power, either. ${ }^{373}$

These examples show that there are choices to be made with regard to the future energy system architecture, and that these choices have political consequences. Despite these instances, the overarching discursive theme across the material is that of a shared consensus within the energy policy field, albeit a shallow consensus. It should be noted that neither the Energy Agreement nor the Energy Commission are the only empirical instances where cooperation and consensus are emphasized. There are a number of other contributing initiatives, actors, and documents, including the Royal Academy of Engineering Sciences' (IVA) ${ }^{374}$ Choosing Electricity Pathway project. This project was set up to operate in parallel with the Energy Commission. ${ }^{375}$ The theme can also be traced across joint Nordic endeavors, such as a 2016 report on Nordic Energy Technology Perspectives, and the Swedish government's strategic research and cooperation platform on smart cities. ${ }^{376}$ I have focused on the Energy Agreement and the Energy Commission in this section, as they were both frequently mentioned in interviews as important for creating consensus and bring the energy sector together, to paraphrase several interviewees.

our energy future. New York, NY: Bloomsbury Publishing Plc. p. 5-8. This relates to smart energy experimentation, since hope is pinned on experiments to develop new products and services which can supply similar services to stabilize the grid, enabling increased electrification while making radical alterations to the current energy system infrastructure redundant.

${ }^{371}$ See e.g. Sunér Fleming 2017. Remissvar Kraftsamling för framtidens energi SOU 2017:02. Svenskt Näringsliv. Stockholm.

${ }^{372}$ Interview EXSvK.

${ }^{373}$ Interview EEC.

${ }^{374}$ In Swedish: Kungliga Ingenjörsvetenskapsakademien.

${ }^{375}$ Interview EXE2.

${ }^{376}$ Both the report and the government's platforms will appear frequently throughout this study. 
This excursion via central energy policy documents and interviews shows that consensus and cooperation are recurrently articulated as central virtues, and are often described as necessary in order to achieve a transformation of the energy system. The business community is singled out as central for such a transformation, by conducting experiments via state-sponsored schemes to develop new green energy technology which can then be exported. Further, experiments are tasked with scientifically evidence-basing policymaking, echoing the perceived need for consensus.

\section{Political rationality underpinning smart energy experimentation - reaching climate policy goals through export}

Within Swedish energy policy, as in many other areas, "smart" has emerged as a prominent sub-field. ${ }^{377}$ As per the introductory chapter, smart does not signify a neatly delineated field of activity; rather, it entails different visions of the future energy system. ${ }^{378}$ Generally speaking, a common thread that runs through initiatives to make energy systems smart is the use of digital technologies, mainly ICT, and experimentation appears to have substantial salience in relation to smart energy. In the following, we will dig deeper into how smart has become cast as a sub-field of Swedish energy policy by focusing on its discursive constitution.

The first governmental initiative related to smart energy was to appoint a committee in 2012, named the Coordination Council for Smart Grids. ${ }^{379}$ It was disbanded in late 2014 after fulfilling its mission of delivering an official report to the government (SOU). ${ }^{380}$ Since many actors point to the Coordination Council as being central for the formation of smart energy as a sub-field of energy policy, and since it was the first governmental effort explicitly articulated as smart energy policy, it constitutes a relevant focus point. Judging by several interviewees' stories, the genealogy of smart energy in Sweden stretches back further than the Coordination Council, however. Former US president Barack Obama's Recovery Plan and its focus on smart grids was mentioned several times as an important part of smart grid development which shaped Swedish interest in smart energy, while some mentioned discussions between Swedish and American diplomats during the George W. Bush administration as an important early

377 Cf. Strengers 2013. Smart Energy Technologies in Everyday Life; Stephens et al. 2015. Smart Grid (R)Evolution; Marvin, Luque-Ayala, and McFarlane (eds.) 2016. Smart Urbanism - Utopian vision or false dawn? Abingdon, Oxon: Routledge.

${ }^{378}$ Stephens et al. 2015. Smart Grid (R)Evolution.

${ }^{379}$ In Swedish: Samordningsrådet för smarta elnät.

${ }^{380}$ SOU 2014:84. Planera för effekt! 
moment of smart energy in Sweden. ${ }^{381}$ These events were mainly articulated as creating preconditions for smart energy to become a sub-field, however, and the central role of the Coordination Council as a starting point for the formation of smart energy into an issue area in Sweden was articulated in several interviews as well as on the website of the subsequent Swedish Smart Grid Forum. ${ }^{382}$ Given this, I intend to organize this part of the chapter largely around the Coordination Council.

Because of the Coordination Council's central position, the rationale underpinning the formation of the council is an important element in the discursive formation of smart energy in Sweden. This rationale is made explicit in the government's directive, the foundational document that stipulates the mission and orientation of the committee. ${ }^{383}$ The directive states that smart grids constitute the grids of the future, and that Sweden is in a good position to take advantage of the opportunities associated with the development of these future grids. These opportunities are specified as achieving climate and energy policy goals, giving customers more influence in the electricity market, making Sweden a prominent export nation in smart grids and thus creating new jobs and export revenue. ${ }^{384}$ Evidently, this is in line with the aforementioned emphasis on developing and commercializing green energy technology for export in Swedish energy and environmental policy.

As discussed previously, initiatives to realize environmental ambitions have increasingly come to revolve around experimentation, for example within the UN climate regime, and initiatives are often intimately connected to research communities through national and EU funding infrastructures, which is also the case with smart energy. Importantly, experiments are regularly articulated as being imperative in order to reduce uncertainty and lead the way forward, which is significant specifically in relation to energy transformation since this tends to be described as a fundamentally uncertain process. ${ }^{385}$ Put differently, experiments are important for carving out specific pathways of transformation, i.e. to define and develop a specific version of a smart energy system. In the directive for the Coordination Council, smart grids are defined as the "modern grid of the future", enabled through increased use of ICT in

\footnotetext{
${ }^{381}$ Interview EXE1; Interview EXE2; Interview EXMEE. Recall further how scholars have highlighted the kinship between "smart" and preceding notions of connected, creative, green, and digital cities.

${ }^{382}$ Interview CM1 Swedish Smart Grid Forum; Interview EXMEE; Forum för smarta elnät (undated). Bakgrund - Samordningsrådet för smarta elnät. http://swedishsmartgrid.se/om-oss/bakgrund-samordningsradet-for-smarta-elnat/ [2019-10-22].

${ }^{383}$ Näringsdepartementet 2012. Kommittédirektiv: Samordningsråd med kunskapsplattform för smarta elnät. Dir. 2012:48. Stockholm.

${ }^{384}$ Ibid. p. 9.

${ }^{385}$ See e.g. Verbong \& Geels 2010. Exploring sustainability transitions in the electricity sector with sociotechnical pathways; Hojckova, Sandén, and Ahlborg 2018. Three electricity futures: Monitoring the emergence of alternative system architectures. Futures, 98.
} 
the energy system, and are associated with concepts such as active customers, flexibility, efficiency, and costs. ${ }^{386}$ The following quotation is representative of the directive:

Thereby [through increased integration of ICT into the energy system and thus more information] it becomes easier for electricity producers and consumers to adapt their electricity production and consumption to price signals from the market. ${ }^{387}$

There is a great emphasis on enabling consumers, or customers as they are often referred to, to become active through the provision of more information which enables them to act in accordance with market logic. This is articulated in the directive as being highly important to facilitate increased integration of renewable energy sources; price signals are cast as a mechanism to address their intermittency. ${ }^{388}$ The appointment of the Coordination Council was preceded by a report from the Energy Markets Inspectorate in 2010, and a 2011 government bill. ${ }^{389}$ Both the report and the bill offer similar descriptions of smart grids, as well as assessments of the opportunities provided by smart grids. In both the Energy Markets Inspectorate report and the government bill, it is claimed that there is an urgent need to coordinate and spread results from research, development, and demonstration. ${ }^{390}$ Both documents further reinforce the recurrent notion that it is necessary to coordinate the development of smart grids to realize the presumed opportunities. This is also reproduced in the directive for the Coordination Council. There is an emphasis on the need for experiments to achieve this, and a civil servant from the Energy Agency claimed in an interview that the Coordination Council's very existence was partly predicated upon three large demonstration projects which were ongoing. ${ }^{391}$ These projects were Smart Grid Gotland, the smart grid demonstration project in Norra Djurgårdsstaden (not yet named Smart Energy City at the time), and the smart grid demonstration in Hyllie. Both Norra Djurgårdsstaden and Smart Grid Gotland are mentioned explicitly in the Coordination Council's directive as well. ${ }^{392}$

The mission and specific tasks of the Coordination Council, as outlined in the directive, mainly relate to seizing the opportunities provided by smart grids to reach climate and energy policy goals whilst boosting economic growth and job creation by making smart grids a prominent

\footnotetext{
${ }^{386}$ Näringsdepartementet 2012. Kommittédirektiv: Samordningsråd med kunskapsplattform för smarta elnät. p. 2; cf. Wallsten 2017. Assembling the Smart Grid.

${ }^{387}$ Näringsdepartementet 2012. Kommittédirektiv: Samordningsråd med kunskapsplattform för smarta elnät. p. 2. ${ }^{388}$ Ibid.

${ }^{389}$ Energimarknadsinspektionen 2010. Anpassning av elnäten till ett uthålligt energisystem. EIR R2010:18. Eskilstuna: Energimarknadsinspektionen; Regeringens proposition 2010/11:153. Stärkt konsumentroll för utvecklad elmarknad och uthålligt energisystem. Stockholm.

${ }^{390}$ Ibid.

${ }^{391}$ Interview EXEA2.

${ }^{392}$ Näringsdepartementet 2012. Kommittédirektiv: Samordningsråd med kunskapsplattform för smarta elnät. p. 3.
} 
Swedish export industry. The role of the Coordination Council is stated as assuming the role of coordinator to facilitate seizing the opportunities of smart grids, as implied by the council's name. Importantly, a core task for the Coordination Council was to disseminate knowledge from experiments, in addition to being tasked with drafting up a national action plan for smart grids. ${ }^{393}$ This use of a committee as a coordinating actor reflects the importance afforded to cooperation between actors from the public, private, and research sectors in Swedish energy policy, and the significance ascribed to spreading knowledge from experiments to realize the perceived environmental and economic potential of smart energy in the Coordination Council's directive mirrors the increasingly important position of experimentation as environmental governance strategy.

The Coordination Council's SOU is permeated by the same market emphasis as the directive, and concepts referred to as central in the directive - such as active customers - also take center stage in the SOU. ${ }^{394}$ It is stated that the driving forces for developing a smart grid are first and foremost marked-based. ${ }^{395}$ This market emphasis is mirrored in interviews as well, such as when a representative from a state agency claimed that the energy transition was entirely driven by market forces. ${ }^{396}$ Another interviewee stated that no matter how the future architecture of the energy system was configured it would result in some kind of business model. ${ }^{397}$ In another interview, an interviewee working within the private sector described the development of a new energy system as a competition, one which should take place not through political decisions but through energy technologies proving themselves in the market. ${ }^{398}$ In the Coordination Council's SOU, the emphasis on market and energy users as customers is accentuated to a higher degree than other energy policy SOUs.

In the SOU, energy research and experiments are highlighted as being important to realize goals related to smart energy. ${ }^{399}$ For instance, it is stated that demonstration projects are especially important as enablers of innovation-driven economic growth, and it is therefore imperative that such initiatives are supported as they can facilitate the development of new market arrangements. ${ }^{400}$ Experiments are described as necessary since they are argued to reduce uncertainty by showing what works in practice, and can facilitate cooperation between different actors, as well as marketing Sweden internationally as a prominent smart grid nation

${ }^{393}$ Ibid. p. 9.

${ }^{394}$ SOU 2014:84. Planera för effekt!; cf. Wallsten 2017. Assembling the Smart Grid.

${ }^{395}$ SOU 2014:84. Planera för effekt! p. 12.

${ }^{396}$ Interview EXEA4.

${ }^{397}$ Interview EXEA3.

${ }^{398}$ Interview EEC.

${ }^{399}$ SOU 2014:84. Planera för effekt!

${ }^{400}$ Ibid. p. 16. 
to enhance export revenue. ${ }^{401}$ Consequently, experiments are tasked with providing input for policy to make the right decisions to fulfill the ambition of achieving climate and energy policy goals through exporting smart energy technology. ${ }^{402}$ Importantly, as we saw previously, experiments are described as providing a scientific basis for policymaking, which in turn appears important to foster the sought-after cooperation and consensus. The following quotation captures the overarching language in the Coordination Council's SOU:

The energy and climate policy goals at national and EU levels constitute an important point of departure. To manage these challenges, an electricity system that is considerably more flexible than the current one is needed. New technology and market models contributing to increased flexibility in the entire electricity system are clear improvements. The new opportunities associated with developments in IT and communications technology are also an important factor for the development of the whole electricity system that is expected to be increasingly important. ${ }^{403}$

As illustrated in the above quotation, opportunities associated with new technology especially related to digitalization - are expected to contribute to the development of smart grids, and climate and energy policy goals can thereby be reached. ${ }^{404}$ According to the Coordination Council, it is through active energy users participating as customers in the electricity market that the potential of smart grids can be unlocked, being facilitated through new technology and digitalization. As the quotation shows, this is argued to contribute to reaching energy and climate goals, by making Sweden a prominent export nation in smart energy. The emphasis on coordination is also present in the council's SOU, as shown by the following quotation:

For smart grids to become a successful Swedish growth industry, there is a need to coordinate and prioritize the initiatives in the area supported by a clear national innovation strategy. The strategy will lead to better coordination of private and public funding and better cooperation between different industries. Many comparable countries to Sweden have some sort of prioritization and coordination of research and innovation efforts for smart grids. ${ }^{405}$

The perceived need to coordinate the field of smart energy, as underlined in the Coordination Council's name, is intertwined with research and demonstration projects, as per the quotation. Overall research and demonstration are explicitly connected to economic growth in the SOU, and demonstration and pilot projects are considered important in this respect as

\footnotetext{
${ }^{401}$ SOU 2014:84. Planera för effekt!

${ }^{402}$ As mentioned, such a policy approach of pursuing green growth is entirely aligned with the historical prevalence of ecomodernism in Sweden.

${ }^{403}$ SOU 2014:84. Planera for effekt! p. 32.

${ }^{404}$ See also Wallsten 2017. Assembling the smart grid. Wallsten draws similar conclusions based on an analysis of the Coordination Council's publications, including its SOU.

${ }^{405}$ SOU 2014:84. Planera for effekt! p. 148.
} 
well. Nevertheless, it is stated that tests and demonstration projects are very different, depending for example on how many actors participate, the complexity of the project, and the project's focus, ${ }^{406}$ and there is explicit recognition that innovation is not a linear process. Still, there appears to be an implicit assumption that the purpose of research and demonstration projects on smart energy is to culminate in commercialization. ${ }^{407}$ It is explicitly stated that there is great potential in utilizing ongoing collaborative projects better; Norra Djurgårdsstaden, Hyllie, and Smart Grid Gotland are mentioned explicitly as examples of such projects to be used more actively as flagships to showcase Swedish proficiency in smart grids for the purposes of international marketing. ${ }^{408}$

This highlights how particular forms of demonstration become valued through an emphasis on making Sweden an environmental frontrunner, structuring particular forms of demonstration as desirable. During observations at several conferences and presentations, a number of prominent actors engaged in smart energy utilized metaphors of both trains and marathons to illustrate how important it was that Sweden, and especially Swedish firms, leads the way to the future. Sweden should lead the train, otherwise we will be left standing at the station, and Sweden has to take the lead in the global energy transition race in order for others to follow, or as a representative of a municipal energy company expressed it: "Either we jump on the train or entrepreneurs will come and take our business away from us.” To be a frontrunner, you need to demonstrate your proficiency.

\section{Coordination as an instrument of ordering: from the Coordination Council to the Swedish Smart Grid Forum}

The Coordination Council's SOU included an action plan for smart grids which recommended one regulatory change, pertaining to electricity customers' access to metering data. When the Coordination Council delivered its SOU to the government, it also recommended that a new organization responsible for coordination in the field of smart energy be established, to make sure the opportunities offered by smart grids are seized. The emphasis on utilizing experiments as marketing within the Coordination Council's work appears to have struck a chord with the government, as a new coordinating body was established explicitly as part of the government's export strategy. This organization was the aforementioned Swedish Smart Grid Forum, formally a governmental organization in the form of a so-called special project within the Government Offices, sorted under the Energy Agency. The Forum was active until the end of 2019. Its task was both similar to and different from that of its predecessors in the

\footnotetext{
${ }^{406}$ Ibid. p. 152.

${ }^{407}$ Ibid. pp. 153-154.

${ }^{408}$ Ibid. p. 155.
} 
Coordination Council. It was similar in the sense that the Forum was supposed to continue as the main coordinating body in the field of smart energy, but different as its work was not supposed to culminate in a report to the government (SOU). In that sense, it had a more operational role than the Coordination Council. ${ }^{409}$

Discursively, the same language and concepts that characterized the Coordination Council followed into the work of the Forum. There was a similar emphasis on market solutions, users as customers, digitalization, and flexibility. ${ }^{410}$ One difference, however, as revealed in the interviews, is that there was a shift in emphasis from smart grids to smart energy, as many actors claim that smart grids imply power grids and that including only electricity is too narrow to capture what smart grids are about. It was stated in several interviews that smart grids used to be a buzzword, but that maturity has now been reached. Paradoxically, the same actors also stated that smart grids are too vague a concept. ${ }^{411}$ In the government's directive to the Swedish Smart Grid Forum, several relevant aspects can be observed which illustrate a continuity between the Coordination Council and the Forum. The same expressions related to electricity users as customers are present in the directive, and the notion that customers can gain more power over their costs through smart grids. ${ }^{412}$ There is also an expectation that customers will become more active, based on their individual interests and needs. ${ }^{413}$ It appears quite unclear, however, what it actually means to be an active energy user, or a customer. The following quotation is illustrative of the language used in the directive:

An efficient utilization of resources, including energy, is the basis for economic growth and sustainable development. Energy efficiency is adjudged to be able to contribute to increased competitiveness for Swedish industry and security of supply. ${ }^{414}$

Essentially, the goals articulated in the quotation are guiding principles which have been connected to the energy sector for a long time, and in line with the contemporary politically established overarching energy policy goals. ${ }^{415}$ There is much emphasis in the directive on the Forum being a part of the government's export strategy. This is reflected in three goals that the Swedish Smart Grid Forum established for its work. The first is about achieving an

\footnotetext{
${ }^{409}$ Interview CM1 Swedish Smart Grid Forum.

${ }^{410}$ Ibid; Interview EXE1; see also Stephens et al. 2015. Smart grid (R)evolution; Wallsten 2017. Assembling the Smart Grid.

${ }^{411}$ E.g. Interview RM Fortum; Interview CM1 Swedish Smart Grid Forum.

${ }^{412}$ Miljö- och energidepartementet 2015. Inrättande av forum för smarta elnät. Protokoll II:6 vid regeringssammanträde. Stockholm. p. 3.

${ }^{413}$ Ibid. p. 4.

${ }^{414}$ Ibid. p. 5.

${ }^{415}$ See e.g. Bladh. 2007. El nära och långt borta: hur kan hushållen agera på elmarknaden? Linköping: Tema T, Linköping University.
} 
electricity market with active customers, and robust and efficient integration of 100 percent renewable energy. The second is about Sweden becoming a hub and an obvious testbed for smart grids, with internationally recognized competence. The third goal proclaims that Sweden should have an increased number and variation of smart grid exporting firms, services, and products. ${ }^{416}$ Two of the three goals are thus directly related to the Smart Grid Forum as part of the government's export strategy.

This is also mirrored in several texts published by the Forum, as well as in interviews with actors within and with connections to the Forum. ${ }^{417}$ For instance, the Forum published a strategy for increased flexibility through smart grids in 2017. ${ }^{418}$ This strategy contains concrete recommendations for an increasingly flexible electricity market. One of these recommendations is explicitly about creating more favorable conditions for testbeds and pilots, or policy labs, to enable firms to try out new ideas which can then be evaluated on the basis of their societal value. ${ }^{419}$ It is explicitly stated that it is imperative to disseminate the results of these tests. ${ }^{420}$ Besides the flexibility strategy, the Forum also published a strategy titled "From research to internationalization". ${ }^{421}$ This strategy focuses on how to turn Swedish smart energy experiments into international commercialization through export. In line with the recommendation in the flexibility strategy to create favorable conditions for smart energy experiments such as testbeds and policy labs, it appears that smart energy experiments are considered important in relation to the goal of making Sweden a prominent smart energy export nation.

The necessity of consensus and cooperation between actors is also emphasized in the strategy, since this is claimed to be a prerequisite for international success in terms of exports. ${ }^{422}$ Related to this, increased funding of experiments in Sweden is argued for in the strategy, and this is explicitly connected to the goal of showcasing Swedish proficiency in smart grids internationally. ${ }^{423}$ The strategy argues that future experiments should be governed toward increased packaging of the results for an international audience, that standardization of smart energy should be pursued since this would facilitate Sweden's export ambitions, and that Sweden needs to be active in different international forums so that the design of research

\footnotetext{
${ }^{416}$ See e.g. Forum för smarta elnät 2017. Strategi för en ökad flexibilitet i elsystemet genom smarta elnät. p. 2.

${ }^{417} \mathrm{Ibid}$; Forum för smarta elnät 2017. Strategin från forskning till internationalisering; Interview CM1 Swedish Smart Grid Forum; Interview EXE1; Interview CM2 Swedish Smart Grid Forum.

${ }^{418}$ Forum för smarta elnät 2017. Strategi för en ökad flexibilitet i elsystemet genom smarta elnät.

${ }^{419}$ Ibid. pp. 23-24.

${ }^{420}$ Ibid.; Interview EXE2.

${ }^{421}$ Forum för smarta elnät 2017. Strategin från forskning till internationalisering.

${ }^{422}$ Ibid. p. 20.

${ }^{423}$ Ibid. p. 31.
} 
funding can benefit Sweden's export ambitions. ${ }^{424}$ The following quotation highlights these ambitions:

The image of Sweden plays an important role for supporting export and internationalization. An important task is to create a strong and clear brand to market Swedish competence in smart grids in different international contexts. It is also important to convey the Swedish vision to the world in a

way that creates interest and enables different actors to use the material for marketing and

knowledge purposes. Therefore, Sweden needs to work systematically to convey an image of competence, firms, and research and innovation toward foreign markets and actors, and to facilitate meetings and exchange of experiences between different actors who are active in the field of smart grids. $^{425}$

Similar views surfaced in interviews with the Forum's cabinet members. ${ }^{426}$ The quotation captures a particular notion of achieving transformation of energy infrastructures through experiments. Public and private actors travel together around the globe, to forge contacts and market Sweden's competence as a smart energy nation, thereby greasing the wheels of the export machine. This notion is akin to how policy development is described in literature on policy mobilities, although in the case of smart energy, experiments appear to be ascribed a central role through generating knowledge and being staged as open for the public to see, thus providing credibility to the visions of travelling corporate and policymaking actors.

The Forum was also assigned an important role of coordinating the smart energy field, similar to that of the Coordination Council. An interviewee from the Ministry of the Environment and Energy stated that it is necessary to harmonize different regulatory frameworks to connect different sectors of society that need to be involved in the creation of smart grids, such as the construction sector. The interviewee said that:

That's the background to the existence of this Forum, to interlink these questions because I mean it's easy to run off in different directions and then you can't extract the value that's there if you don't do it in a coordinated way. And pilot projects can definitely play a big part in showing that value. $^{427}$

Smart energy experiments are thus necessary to demonstrate the potential value for different actors if they engage collectively in a cooperative manner to transform the energy system, according to the interviewee. Such notions of the need to coordinate the smart energy field through experimentation are also in line with the emphasis on cooperation interlaced with the prevalent discursive theme of making Sweden an environmental frontrunner through smart

${ }^{424}$ Ibid. pp. $31 ; 34 ; 36$.

425 Ibid. p. 38.

${ }^{426}$ Interview CM1 Swedish Smart Grid Forum; Interview CM2 Swedish Smart Grid Forum.

${ }^{427}$ Interview EXMEE, EXMEE1. 
energy export, visible through the interviewee's expression that it is necessary to get different actors to cooperate and pull in the same direction. In line with such notions of demonstration through experiments, demonstration in the form of marketing was regularly described as an important aspect of experiments in interviews. Marketing seems to work on several levels, however. One of the most salient ways of talking about experiments as marketing is clearly intertwined with the discursive theme of Sweden becoming an environmental frontrunner through export. This was a prevalent feature in an interview with a cabinet member from the Swedish Smart Grid Forum, for instance. This is perhaps unsurprising, considering that the Forum was explicitly part of the government's export strategy. Since the Forum was the primary institution tasked with coordinating and promoting smart energy as a field in Sweden, the fact that it was created as part of the government's export strategy tells us something about the political rationality underpinning smart energy experimentation, and consequently how the field of intervention for environmental governance becomes structured through such experimentation. This is highlighted by the following quotation:

Well, we are not involved in funding those kinds of projects [smart energy experiments]. [...] So our role when it comes to demonstrations, as I see it, is partly to have a dialogue with those who allocate funds precisely about the need to disseminate results. [...] But then it is above all about disseminating results from demonstrations and tests, and to push for demonstrations and tests to be carried out. There is also this need when it comes to internationalization, to be able to test technology in other countries, since it is important to show that it works here, and it works there as well. ${ }^{428}$

This quotation illustrates how experiments are ascribed the role of marketing, both where the cabinet member calls for stricter demands for the dissemination of results from funders of experiments, and where experiments are articulated as being important for internationalization where they are explicitly connected to the export strategy. Again, a connection can be traced to the idea that it is important to demonstrate, to show that a technical component and a business model work, for example, in order to convince others to buy this product or service from Swedish firms. Similarly, another interviewee stated that a central cause for launching the three large flagship projects in Stockholm, in Malmö, and on Gotland could be traced to a mapping of smart energy experiments across the EU, where Sweden had comparatively few ongoing experiments. The interviewee stated that the Swedish claims of environmental prominence through smart energy had to be substantiated by launching more experiments, explicitly connecting experimentation to the ambitions of becoming an environmental frontrunner through smart energy export. ${ }^{429}$

\footnotetext{
${ }^{428}$ Interview CM1 Swedish Smart Grid Forum.

${ }^{429}$ Interview EXE2.
} 
Making the Swedish Smart Grid Forum an explicit part of the government's export strategy seems to be an expression of the direction taken by Swedish environmental and economic policy during the mid-1990s, when ecomodernism became nested across governmental institutions. There is certainly reflexivity in the field about how to assess whether or not an experiment has been successful, but showcasing through experiments was regularly connected to Sweden's export ambitions, as seen in the following quotation:

I mean, those projects [the flagship projects of Norra Djurgårdsstaden, Hyllie, and Smart Grid Gotland] have been able to engage early adopters, those who are interested in the area and who engage voluntarily. The thing is then to engage the other 95 percent of humanity, and then it would be preferable if these early adopters could show that, well, this was of actual use, in our household

or in our small general store or whatever it might be. That is what I think. It is quite a big step.

There are many who are prepared to make an effort due to a conviction that they have to do something for the environment or climate or something like that, but the entire population isn't that altruistic, in a manner of speaking, so then you have to show that there is a point to it. ${ }^{430}$

Smart energy experiments are described as needing to be successful because otherwise it will be difficult to engage the public. This is frequently emphasized in the interviews, where the three large demonstration projects of Norra Djurgårdsstaden, Hyllie, and Smart Grid Gotland are expressed as being vital to show the benefits of the smart grid in order to interest more people. This poses the question of how socio-technical experiments function as tests. Is it possible to experiment, with uncertain outcomes, and perhaps fail if the goal is both to persuade and to export, with experiments having to succeed to legitimize such ambitions? The following quotation further illuminates how demonstration through socio-technical experiments was recurrently described as necessary:

And well, you can't fulfill the export ambitions if you can't show that we have tried that, the business model or service in question and it works, we got successful results. You have to have that in some way. ${ }^{431}$

If we cannot show that we are good at this in Sweden, our credibility as an export nation might be at risk. The following quotation implies an interrelated line of reasoning:

[...] but then Ibrahim Baylan [Minister for Energy and Policy Coordination at the time] chose to take the [Smart Grid ] Forum himself, as he views it as a continuation of the discussion with the actors after the Energy Commission, to be able to be out there listening and to drive the development forward. And above all he sees that if we are to have anything to export and be strong outwards, we have to be proficient on our home ground. ${ }^{432}$

\footnotetext{
${ }^{430}$ Interview EXMEE, EXMEE2.

${ }^{431}$ Ibid.

${ }^{432}$ Interview EXMEE, EXMEE1.
} 
Without proving Sweden's proficiency in the field of smart energy through experiments, no credible claims of being a frontrunner can be made, it is stated. Through such a conceptualization, actors with techno-economic expertise and the organizational capacity to raise awareness and showcase competence in smart energy are implicitly positioned as central for doing experiments. When interviewees talk about the need for coordination, it is noticeable how it tends to be the energy industry that is seen to require coordination. It is these actors who possess organizational infrastructures fit for showcasing in the desired way, and together with municipalities and research institutes can muster enough resources to conduct such large experiments and ensure they get publicity. Certainly, this involves risks too. If not everything goes according to plan (and, if everything was to work out as planned, it would be hard to call the endeavor an experiment), it becomes difficult to sustain commercial interest and this would jeopardize dreams of exporting new products. Nonetheless, smart energy experimentation creates a specific knowledge order, illuminated through the empirical examples. Certain actors become positioned as central because of their capacity for making knowledge claims through experiments in the manner described as necessary; actors with vast techno-economic expertise, deep knowledge of funding infrastructures, wide-reaching contact networks, established brands, and in-house R\&D departments.

A prominent tension surfaced in relation to whether or not socio-technical experiments have to be successful and what it means to succeed, however. A civil servant from the Energy Agency reflected explicitly on the difficulties of measuring success in experiments, and problematized the idea that success should mainly be assessed through quantitative measures such as products introduced to the market. ${ }^{433}$ Similarly, an energy field expert criticized the dichotomy between successful and unsuccessful, and also stated that there is too great a fear of failure, as failures are often great learning experiences if acted upon. ${ }^{434}$ Still, even though there appears to be several uncertainties regarding how to measure success in experiments, and some of the interviewees were very reflexive about the dichotomy of successful or unsuccessful, there appears to be a widespread perception that smart energy experiments must be successful across the material. If smart energy experimentation entails configuring environmental governance as solving problems through exporting green energy technology, then private companies, cities, and regions need something to showcase. Additionally, it is rarely rendered explicit whose task it actually is to learn from experiments, or how such

\footnotetext{
${ }^{433}$ Interview EXEA3.

${ }^{434}$ Interview EXE2.
} 
lessons could be arrived at, further indicating that showcasing tends to be more important in practice.

The prominence afforded to experiments is reflected in the wider significance experiments have taken on in environmental governance. As we saw previously, institutions such as the UN and the EU both strongly emphasize experimentation through research funding and broader governance setups to achieve environmental policy goals. In the Swedish context, the current energy research bill also includes an emphasis on experiments. It is stated that experiments are important in order to support innovation processes, change behavior, and create knowledge about new alternatives. ${ }^{435}$ The following quotation is illustrative of this:

To demonstrate technology, systems, and the interplay between users (so-called living labs), new technology and policy instruments are an important step in order to utilize research, through the implementation and commercialization of new knowledge and new products, systems, and services. ${ }^{436}$

This underlines how a transformation of the energy system is considered an opportunity to enhance export revenues, and the central role afforded to experiments in realizing this. Experiments become important as innovation instruments, in order to catalyze product development and achieve the sought-after export revenue while demonstrating Swedish proficiency. It is also explicitly stated in the document that energy research and the energy sector are considered to offer major possibilities to generate export revenue, and the Swedish Smart Grid Forum - through its connection to the government's export strategy - can be a favorable way of pursuing such export-enhancing initiatives. ${ }^{437}$ Sweden is also articulated as a successful frontrunner related to energy transformation and climate policy. In the document, it is stated that the overarching goal for research and innovation in the energy sector should be to contribute to realizing climate, energy, and environmental goals, and that initiatives in energy research which show potential for economic growth and export will be prioritized. ${ }^{438}$ In this document, a report from the Nordic Council of Energy Ministers and the International Energy Agency (IEA) is explicitly referenced as important for Swedish energy policy, since it is considered to be an important background for strategic planning of energy research in Sweden. ${ }^{439}$

${ }^{435}$ Prop. 2016/17: 66. Forskning och innovation på energiområdet för ekologisk hållbarhet, konkurrenskraft och försörjningstrygghet.

${ }^{436}$ Ibid. p. 66.

${ }^{437}$ Ibid. p. 41.

${ }^{438}$ Ibid. p. 55.

${ }^{439}$ Ibid. p. 39. 
The IEA report outlines regional long-term technology pathways for a low-carbon transition, with a special focus on cities and electricity systems in the Nordic countries. In the report, experiments are described as central for energy transformation, especially through upscaling and replication of smart energy experiments. ${ }^{440}$ It is stated that Nordic cities in particular have the opportunity to become innovation hubs, where sustainable smart city concepts can be demonstrated, multiplied, and exported. ${ }^{441}$ The report argues that, in order to achieve this, Nordic countries have to learn from each other and help other regions by exporting smart city concepts. ${ }^{442}$ Consequently, the report reflects descriptions of experiments in the Swedish context, especially the particular notion of change embodied by experiments described previously. This includes instituting experiments as endeavors through which knowledge claims can be made, constituting a right disposition of things where such knowledge can travel across the Nordic countries to scale up experiments and achieve export-driven economic growth.

The organization Power Circle, a Swedish umbrella organization bringing together different actors engaged in electrification, assigns similar attributes to experiments in a recent report. In the report, experiments, called pilots and testbeds, are described as being vital to enable a transformation of the energy system. ${ }^{443}$ Experiments are necessary, it is claimed, to show what works in practice, in order to enable exports. In this report, however, an implicit support for experiments managed by incumbent actors can be observed. It is stated that energy companies should be granted more leeway to conduct experiments, such as being allowed to allocate part of their revenue framework ${ }^{444}$ to experiments, and a concern is expressed that microgrids and local energy systems might become competitors to the electricity grid if regulations are not designed properly. ${ }^{445}$ Besides illustrating the importance afforded to experiments as arrangements to both realize a transformation of the energy system and enhance export revenues, this also illuminates an ongoing struggle to define the future smart energy system. This struggle does not come across as an apparent struggle, however, as we have seen that there is rather a strong tendency to emphasize consensus and cooperation. Nonetheless, the

${ }^{440}$ IEA 2016. Nordic Energy Technology Perspectives 2016: Cities, flexibility and pathways to carbon-neutrality. Paris. p. 13.

${ }^{441}$ Ibid. p. 108.

${ }^{442}$ Ibid. p. 150.

${ }^{443}$ Wolf \& Andersson 2018. Elnätets roll i framtidens energisystem. pp. 22-23.

${ }^{444}$ The electricity system was privatized during the mid-1990s in Sweden, however since power grid infrastructure is a natural monopoly the Energy Markets Inspectorate calculate acceptable revenue for grid owners based on different parameters. This constitutes a grid owners "revenue framework" for a fouryear period. Recently, grid owners have successfully taken the Energy Markets Inspectorate to court, allowing them to increase their revenue and increase grid tariffs for consumers, prompting the government to alter the regulations.

${ }_{445}$ Wolf \& Andersson 2018. Elnätets roll i framtidens energisystem. pp. 23; 28. 
architecture of the future energy system is an open question, and in the Power Circle report some options seem to be implicitly endorsed as more reasonable and desirable than others. ${ }^{446}$ The point here is not to criticize Power Circle based on its report, which consists of a survey and interviews with actors in the power industry. Rather, the report illustrates, perhaps unintentionally, how there are political choices connected to the transformation of the energy system, and that these choices are not rendered visible in discussions about smart energy experimentation. ${ }^{447}$

Considering the history of energy politics in Sweden, this absence of open contestations is noticeable in relation to both smart energy in general and the Swedish Smart Grid Forum in particular. Historically, the environmental movement has engaged with energy as an issue area to a great extent, both on the barricades as vocal opponents to governmental energy policy and by taking part in committees and governmental investigations. ${ }^{448}$ The Smart Grid Forum presents itself as including a very broad representation of actors, from all parts of society, within its steering group and its working groups, and in its work as a coordinator. ${ }^{449}$ There are, however, no representatives from environmental organizations in the steering group. Only a few civil society organizations are involved in the Smart Grid Forum, and none of these are related to the environmental movement. Overall, environmental organizations are peculiarly quiet when it comes to smart energy in general and experimentation in particular. According to one of the Forum's cabinet members, one of the largest professionalized environmental organizations in Sweden, the Swedish Society for Nature Conservation, expressed interested in smart energy, but mainly engaged with the Forum from a distance, for example through bilateral discussions. ${ }^{450}$

As we saw previously, the historical political rifts within energy politics have certainly not disappeared, although they are not explicitly articulated with any regularity. In general, questions about societal ideals are not reflected or debated in relation to smart energy. Several interviewees explicitly stated that the question of energy supply has been solved, or that with

\footnotetext{
${ }^{446}$ Cf. Stephens et al. 2015. Smart Grid (R)Evolution.

${ }^{447}$ On political aspects of energy systems, see e.g. Boyer 2019. Energopolitics; Mitchell 2013. Carbon Democracy; Mulvaney 2019. Solar Power: innovation, sustainability, and environmental justice. Oakland, California: University of California Press; Stephens et al. 2015. Smart Grid (R)Evolution; Malm 2016. Fossil Capital.

${ }^{448}$ See e.g. Tarasova 2017. Anti-nuclear movements in discursive and political contexts: between expert voices and local protests. Diss. Huddinge: Södertörns högskola; Anshelm 2000. Mellan frälsning och domedag; Hultman 2015. Den Inställda Omställningen.

${ }^{449}$ Interview CM1 Swedish Smart Grid Forum; Interview CM2 Swedish Smart Grid Forum.

${ }^{450}$ Interview CM2 Swedish Smart Grid Forum. The Swedish Society for Nature Conservation published a report on energy futures in 2012, in which smart grid is briefly mentioned. See Wolf 2012. Dags att välja framtidens energisystem. Naturskyddsföreningen, Stockholm.
} 
renewables there is no need for a low energy society; the problem now is rather one of systematic coordination within the energy system in order to make power available at the right place and time due to the intermittency of renewable energy sources. ${ }^{451}$ Such a course of reasoning is certainly in line with the emphasis on consensus and cooperation reverberating across the smart energy field. As a cabinet member of the 2015-2017 Energy Commission put it, "no one can be against smart grids". ${ }^{452}$ Experimentation appears to be assigned particular value in relation to such wishes for consensus, and to the Forum's coordinating role. Recall how one of the Forum's cabinet members stated that experiments were necessary not only to guide policymaking, but also to evidence-base policymaking. Experiments are articulated as an instrument to uncover scientifically asserted paths to transform the energy system, often through endeavors emphasizing cooperation in public-private partnership constellations, such as in the cases of Norra Djurgårdsstaden, Hyllie, and Smart Grid Gotland.

Despite the recurrent emphasis on consensus and cooperation, there are diverging views on smart energy in general in the material, albeit rarely rendered explicit. In a written response to the Coordination Council's SOU from 2014, for instance, the Swedish Environmental Protection Agency stated that it is impossible to know whether or not smart grids will contribute to reaching climate policy goals, as they are described in the SOU. ${ }^{453}$ This contention does not appear to have gained any traction, since the notion that smart grids will contribute to achieving climate and environmental policy goals seems virtually taken for granted. We will have reason to return to this apparent lack of open contestation and controversies related to smart energy in general and smart energy experiments in particular.

\section{The governmental apparatus of experimentation: coordination, consensus, and techno-economic knowledge claims}

Taking the material analyzed thus far into account, the outlines of an emerging governmental apparatus of smart energy experimentation can be discerned. ${ }^{454}$ Central pillars include a preference for devising smart energy experimentation through market measures, and an emphasis on consensus and cooperation. The Smart Grid Forum and its predecessor, the Coordination Council, have been designated as central, authoritative actors to coordinate the

\footnotetext{
${ }^{451}$ E.g. Interview EXE1; Interview EXEA3; Interview RM Fortum.

${ }^{452}$ Interview EEC.

${ }^{453}$ Javelius \& Backman Hannerz 2015. Yttrande över slutbetänkande från Samordningsrådet för smarta elnätPlanera för effekt! (SOU 2014:84). Stockholm: Naturvårdsverket.

${ }^{454}$ To be clear, in this section I will describe what I perceive as an emerging governmental apparatus of smart energy experimentation, to disentangle its associated features. I do however, as already mentioned, conceptualize smart energy experimentation as increasingly incorporated into a broader, already existing governmental apparatus. Cf. Braun 2014. A New Urban Dispositif?
} 
field, constituting a central mechanism of the governmental apparatus through dialogue forums, publication of reports, bilateral cooperation, etc. Within this apparatus, experiments are assigned the role of marketing Swedish competence in smart energy, to fulfill hopes of becoming an environmental frontrunner through exporting smart energy technology. Further, experiments are articulated as being crucial to evidence-basing policymaking, i.e. staking out scientifically asserted policy directions, thereby maintaining the sought-after consensus. We have also seen how there appears to be a preference for large-scale experiments run by incumbent energy companies, both in policy documents and in practice, e.g. in the case of the "flagship projects" of Norra Djurgårdsstaden, Smart Grid Gotland, and Hyllie. The emphasis on Sweden becoming a frontrunner by exporting smart energy technology, thereby boosting economic growth whilst achieving climate and energy policy goals, constitutes a central discursive theme. Actors spanning industry and public organizations gather around this theme, although all can be argued to constitute elite and expert actors in the energy field, such as energy utilities, technology developers, and policymakers. ${ }^{455}$ It also includes interest organizations representing expert groups, e.g. Swedenergy ${ }^{456}$ which represents different energy actors such as utilities, as well as property developers and the Swedish Homeowners Association $^{457}$.

This governmental apparatus is underpinned by a broader political rationality, which hinges upon a perceived need to concentrate efforts in the same direction, as enshrined in the work of the Coordination Council and the Swedish Smart Grid Forum, and further reflected in the Energy Agreement and the Energy Commission's SOU. In interviews with prominent actors in the policy sector, it was stated for instance that the Energy Agreement epitomizes a united energy sector that is now striving toward the same goal, and that the Energy Commission has managed to increase the level of knowledge in the energy sector. ${ }^{458}$ Government officials at the Ministry of the Environment and Energy stated that former Minister for Energy and Policy Coordination Ibrahim Baylan elected to chair the Swedish Smart Grid Forum in order to continue the work of the Energy Commission, thus facilitating continued cooperation between actors. ${ }^{459}$ Through this language focused on unity, often linked to the development of new energy technology for commercialization, smart energy experimentation is molded into a non-

${ }^{455}$ Cf. Foss Ballo. 2015. Imagining energy futures. Foss Ballo shows how a similar tendency can be discerned in Norway. She uses the term "techno-epistemic network" to illustrate how the main actors are knowledgeable experts in the energy field who are well versed in techno-economic knowledge, and whose prominent positions grant them special authority to influence the development of the energy system.

${ }^{456}$ In Swedish: Energiföretagen Sverige.

${ }^{457}$ In Swedish: Villaägarnas Riksförbund.

${ }^{458}$ E.g. Interview CM1 Swedish Smart Grid Forum.

${ }^{459}$ Interview EXMEE. 
controversial issue. ${ }^{460}$ As highlighted by the Energy Agreement and the Energy Commission, as much as in the work of the Coordination Council and the Smart Grid Forum, the future smart energy system appears to be imagined as necessitating very few changes, and energy transformation is constituted mainly as a matter of technological design best left to the industry and the market, facilitated by coordinating governmental bodies.

This reflects how the political rationality underpinning experimentation configures environmental governance in particular ways. The dominant discursive theme positions experiments as being necessary to legitimize Swedish export ambitions. Large demonstration projects run by big private firms with broad marketing reach and global brands naturally fit better if the intention is to market Swedish proficiency in smart energy, at least in terms of making specific locations into marketing nodes. ${ }^{461}$ This is also in line with how several interviewees talked about the need to package smart energy, for example by coupling it to smart cities, to persuade actors of the value of engaging with smart energy as well as substantiating Swedish export ambitions through marketing and demonstration.

The need for consensus is also emphasized, as can be illustrated by the following quotation from a government official at the Ministry of the Environment and Energy:

Now we pretty much know what type of technology we might need, it's just a matter of getting it together, well in a sense networking so that we get all these sectors that we just talked about to cooperate, to move in the same direction $[\ldots]^{462}$

This quotation conveys that cooperation between different actors is of the essence to achieve the sought-after transformation of the energy system. The need for consensus appears to be intertwined with a techno-economic language which permeates smart energy experimentation, as such a language tends to frame the issue at hand in technical terms rather than as a contentious political issue, i.e. as a matter of agreeing upon the rationally optimal route toward a consensually agreed goal. Consequently, knowledge claims made in relation to smart energy experimentation are characterized by a largely techno-economic language.

This techno-economic framing is also mirrored through recurrent concepts in documents and interviews, e.g. price signals and cost efficiency, and the idea that it is through active customers' choices in a market that the smart energy system will be instituted. The language used in policy documents and interviews is often imbued with technical concepts that are

\footnotetext{
${ }^{460}$ Cf. Kall 2011. Förnyelse med förhinder.

${ }^{461}$ Cf. Harvey 1989. From Managerialism to Entrepreneurialism; Kotler, Haider, and Rein 2002. Marketing Places. New York: Free Press.

${ }^{462}$ Interview EXMEE1.
} 
assumed to be understood and shared across the field of smart energy. Many of the experts interviewed are also mainly defined as experts through their expert knowledge of technology and economics. The following quotation illustrates the techno-economic language underpinning smart energy experimentation:

[...] it is correctly observed what you say, that we grant the public a large role, the individual so to speak. But we are not sure that individuals themselves will search for these opportunities, broadly speaking. [...] and the strategy [the Forum's flexibility strategy] tries to create conditions for new types of services and new kinds of firms, which in turn can address the public, so I think that our idea is that we need to find the right conditions for others to take this to the public. The assessment today is that the majority of the population might not become very active in terms of checking their consumption, broadly speaking, so you need someone else to do that for you. Being an active customer might mean granting someone access to information about my [energy] use, and giving me tips or even steer [energy use]. ${ }^{463}$

Further, the interviewee exemplified that - in practice - increasing flexibility in the energy system could be organized through aggregators, or by appliance manufacturers. The key, the interviewee explained, would be to devise simple solutions, preferably delivered to energy users in the capacity of customers. The quotation also underlines how the techno-economic framing appears to have been strengthened over time, given how the interviewee describes the shift in the conceptualization of energy users from being active and engaged toward being passively governed through automatization and service companies. ${ }^{464}$ The same interviewee stated that the Coordination Council might have pinned too much hope on customers wanting to become active, and that it is more feasible for the energy system to try to create new business opportunities based on automated control and aggregation of many users' electricity loads instead. ${ }^{465}$ This viewpoint is shared across interviews, including interviewees who were engaged in the Coordination Council. One interviewee expressed this as the industry "coming to its senses". ${ }^{466}$ A shift has occurred from talking about how to engage and create active customers to how many customers need to become active, as reflected in the quotation. It is not a question of what being an active energy user entails, i.e. how one can be active, as the political rationality underpinning smart energy experimentation revolves around the notion that the development of a smart energy system hinges upon devising the correct market solutions, and therefore being an active energy user is synonymous with being a customer. Another interviewee stated that it was imperative to get customers to accept that issues

\footnotetext{
${ }^{463}$ Interview CM1 Swedish Smart Grid Forum.

${ }^{464}$ Albeit this is a tension which was present in the Coordination Council's work as well, see Wallsten 2017. Assembling the Smart Grid. It is also a prevalent theme in smart energy across different contexts. See e.g. Sadowski \& Levenda 2020. The anti-politics of smart energy regimes. Political Geography, 81.

${ }^{465}$ Interview CM1 Swedish Smart Grid Forum.

${ }^{466}$ Interview EXE2.
} 
connected to smart energy would be best solved through system optimization. ${ }^{467}$ Both of these examples underscore the techno-economic language shared across the smart energy field. Empowering energy users tends to be described as a goal. However, it is mainly discussed in terms of shaping behavior that is beneficial to the current energy system architecture, i.e. conducting conduct, with the exception that it would be more intermittent, or utilizing automatization and aggregators instead. So it is discussed mainly as an issue of technological design and market design, i.e. as a techno-economic issue.

The political rationality underpinning smart energy experimentation entails instituting the field of intervention for environmental governance in specific ways, enshrined in the analyzed material. A central aspect is this discursive constitution of what it entails to be an active user, i.e. in terms of whether and how to engage different publics and afford possibilities for political participation. It appears that the notion of an active user has increasingly turned into an obstacle, and there have been attempts to sidestep this, as shown by the quotation above. ${ }^{468}$ Smart energy experimentation revolves around attempts to create order through market solutions, users as customers, and an overarching techno-economic language in which control and system optimization are stressed, which appears to cement that being an active user is synonymous with acting individually in a market, even though this may take different forms. Another relevant aspect, which is also discernible in the quotation above, is the articulated need for simple solutions. Taking into account the wider conversation within which the quotation is embedded, simple solutions appear to be synonymous with specific market solutions and in line with the techno-economic sentiments on the needs of the energy system. This also resonates with the export goal.

This political rationality hinges upon the goal of Sweden becoming a frontrunner, achieving climate and energy policy goals by exporting smart energy technology, which is shared by many actors. This has created a shared understanding of the development of the future smart energy system as mainly driven through market solutions, and it is discussed overall as a business opportunity. The coordinating roles of governmental bodies constitute important political technologies instituted around smart energy experimentation, whereas private companies are positioned as authoritative actors to generate knowledge through experiments in the form of product development. As we have seen, experiments are described in documents and interviews in line with such a political rationality. We can discern that statefunded research and development projects for the industry constitute a prime form of experimentation, in line with the preference for market solutions and techno-economic

\footnotetext{
${ }^{467}$ Interview EXE1.

${ }^{468}$ Cf. Wallsten 2017. Assembling the Smart Grid.
} 
knowledge claims. Experiments are described as a way of scientifically asserting optimal routes toward energy transformation, whilst showcasing Swedish competence and granting marketing opportunities to export firms. Further, cities are described as research hubs where experiments can be carried out, and where new products can be developed and then scaled up in the form of commercialization. Related to cities, policy discussions have increasingly become concentrated around smart energy as a way of enabling increased growth in terms of expanding electricity use by building new city districts, establishing new firms, and especially positioning electricity-devouring server halls across Sweden.

There is however a friction here, related to implicit notions of socio-technical change. On the one hand, this development is argued to be best served through market solutions, implying a notion of change as self-organizing through individuals making choices in a market. On the other hand, the techno-economic language, centered on system optimization, implies a rather mechanical notion of change necessitating planning. This becomes evident in attempts to sidestep making customers active through automatization, for instance. There are additional empirical examples of this tension across the smart energy landscape. The previously mentioned report on electricity pathways by IVA is a case in point. It is stated that it is imperative not to tie policy down to one single solution; flexibility and cost efficiency should be the guiding principles. ${ }^{469}$ Changes in the energy sector are described as market-driven, implying a notion of change through self-organization. ${ }^{470}$ In the same report, however, it is stated that long-term planning and a clear political vision are absolutely necessary for the development of electricity grids, in order to ensure that the grids are developed "in the right way". ${ }^{471}$

So it is claimed, simultaneously, that change is market-driven and occurs through selforganizing processes in which it is imperative for policymakers to be flexible, and that change must be facilitated through long-term planning and a clear political vision. This might not be intrinsically contradictory, but it points to a tension inherent in the broader governmental apparatus which smart energy experimentation is being incorporated into. Thus, it appears as though change must be governed in specific directions, so as to "decrease the risk of sub-

\footnotetext{
${ }^{469}$ Byman 2016. Fem vägval för Sverige - Syntesrapport: IVA-projektet Vägval el. IVA. Stockholm. p. 12.

${ }^{470}$ It should be noted that this notion of organic change through markets harbors inherent contradictions of its own, so in practice the dichotomy between mechanic and organic notions of change might not be rigid. For instance, it takes quite a lot of administrative work, often by state actors, to create and facilitate markets. See e.g. Dryzek 2013. The Politics of the Earth. p. 143; MacKenzie 2006. An engine not a camera. Cambridge, Mass.: MIT Press.

${ }^{471}$ Byman 2016. Fem vägval for Sverige. p. 46. As mentioned, there are many other examples of this tension; see e.g. SOU 2014:84; SOU 2017:2; Tillväxtanalys 2015. Innovationspolitik för framtidens energisystem. Rapport 2015:05. Östersund; cf. Wallsten 2017. Assembling the Smart Grid. Chapter 7.
} 
optimization", to use a phrase from the government directive to the Coordination Council. Change cannot be allowed to simply happen by its own accord; it must be governed, albeit not directly by the state but rather through state agencies working to align agendas through coordination to forge a consensus.

This tension related to how change of energy infrastructure is described is further reflected in descriptions of experiments. Experimentation is ascribed key functions within this setting, both as a dissolver of uncertainty to evidence-base policymaking, and as an instrument for marketing Swedish competence to facilitate exports. There is thus an implicit notion of sociotechnical change through experiments, which is characterized by testing and learning, but there is clearly also a notion that socio-technical change needs to be coordinated to realize ambitions of making Sweden a prominent smart energy export nation. This notion of sociotechnical change can be illustrated by the following quotation, from an interview with government officials at the Ministry of the Environment and Energy:

[...] here we have also put forward a mission this summer, which will be like a big pilot project, perhaps not in terms of practically doing a pilot project, but the mission focused on how Gotland can be an important role model for the transition. So that shows that there is an interest not only in building new capacity but also in utilizing the built capacity, and in using technology to make more efficient use of the grids and thereby connecting more wind and solar power, and so on. ${ }^{472}$

In this instance, experimentation is described as revolving around replication and upscaling, prominent notions related to smart energy experimentation. ${ }^{473}$ Put differently, the initiative involving making Gotland a pilot model, as alluded to in the quotation, is predicated upon the idea that something can be tested and showcased on a smaller scale in one place and then transferred to another place, or rolled-out and scaled up in this terminology. The quotation also shows how this idea of upscaling and replication is a central feature of the political rationality underpinning smart energy experimentation, interconnected with the goal of Sweden becoming an environmental frontrunner through smart energy technology export.

This perspective of experiments being important for marketing and their straightforward transfer to other locations can be conceived as rather instrumental. ${ }^{474}$ The contrasting view, where experiments are understood to be fundamentally uncertain endeavors with the main purpose of testing and learning, could be argued to encompass a different understanding of socio-technical change. So on the one hand, energy transformation needs to be governed and coordinated to ensure long-term success, but on the other hand these processes are envisioned as occurring through self-organizing market-driven processes. Consequently, a friction can be

\footnotetext{
${ }^{472}$ Interview EXMEE, EXMEE1.

${ }^{473}$ Cf. Castán Broto \& Bulkeley 2018. Realigning circulations.

${ }^{474}$ See e.g. Luque-Ayala et al. 2018. Rethinking Urban Transitions: An analytical framework. pp. 17-18.
} 
observed between marketing and testing. Experiments are discussed as rather instrumental endeavors, with the main purpose of marketing Sweden, while at the same time being conceived of as uncertain tests with uncertain outcomes, which can guide policy through learning. Experiments are ascribed the abilities of open testing, thereby reducing uncertainty, but they are also described as clearly delineated entities which can be scaled up and replicated, as well as marketing Sweden internationally.

\section{Analytical discussion}

Thus far, we have seen how experimentation in the shape of demonstration projects has long held sway as an instrument for technological innovation in Swedish energy policy, not least through state-funded research programs. In contemporary energy politics, the meaning of experimentation has opened up to include many different types of interventions with the aim of transforming the energy system. These different interventions can be characterized as sociotechnical experiments, including both social and technical aspects. For instance, they intend to change energy users' behavior through the introduction of IT equipment in households, as well as developing digital solutions for grid surveillance and error detection, and paving the way for regulatory changes. Smart grids, or smart energy, has emerged as a distinct sub-field within Swedish energy politics, similarly to other places across the globe. ${ }^{475}$ As this chapter has shown, socio-technical experiments are imbued with particular salience in the field of smart energy. The chapter has explored the political rationality underpinning smart energy experimentation, and how it constitutes environmental governance. In particular, I have sketched out the discursive constitution of smart energy experimentation in Sweden throughout this chapter, illustrating discursive affinities of Swedish smart energy experimentation. ${ }^{476}$ There are bound to be interconnections between policy development and experimentation across different contexts, albeit forming in a complex interplay and becoming transformed through interactions and movement across the globe. ${ }^{477} \mathrm{I}$ have endeavored to show how a distinct political rationality underpinning smart energy experimentation can be discerned through an analysis of the governmental apparatus emerging around experimentation in Sweden.

This political rationality hinges upon the goal of Sweden becoming a frontrunner through exporting smart energy technology, thereby boosting economic growth whilst achieving climate and energy policy goals. A plethora of actors gather around this goal, and despite

\footnotetext{
${ }^{475}$ See e.g. Karvonen et al. (eds.) 2019. Inside smart cities; Marvin et al. (eds.) 2016. Smart Urbanism; Stephens et al. 2015. Smart Grid (R)Evolution.

${ }^{476}$ See Hajer 1995. The Politics of Environmental Discourse.

477 See e.g. McCann and Ward (eds.) 2011. Mobile Urbanism; Karvonen et al. (eds.) 2019. Inside Smart Cities; Bulkeley et al. 2015. An Urban Politics of Climate Change. pp. 240-243.
} 
having different political priorities they find unity with regard to the goal. As we have seen, this unity might be superficial, but it seems to be enough to create and sustain a shallow consensus. Central discursive concepts include flexibility, digitalization, and users as customers. Further, the political rationality devises market solutions as central features of instituting environmental governance through experimentation. Consensus and cooperation are accentuated as central values, thus suppressing the conflictual past of Swedish energy politics and subduing political rifts. Experimentation is ascribed a key role in achieving the ambition of making smart energy an export and growth industry for Sweden that will simultaneously contribute to achieving climate and energy policy goals. Smart energy experimentation is thoroughly projectified, and is institutionalized through EU and Swedish research funding infrastructure.

In documents including strategies published by the Swedish Smart Grid Forum, the Coordination Council's SOU, the current energy research bill, the Energy Commission's SOU, reports by interest organizations such as Power Circle, and a report by the Nordic Council of Ministers and the IEA, experiments are assigned a central role for developing new technology to facilitate the integration of renewables, export smart energy technology, and thereby boost economic growth and realize Sweden's environmental frontrunner ambitions by achieving climate, energy, and environmental policy goals. The political rationality facilitates large-scale experiments funded by the state and run by private companies, preferably through public-private partnerships. Experiments are ascribed the task of staking out scientifically asserted directions for policymaking, while also being described as crucial for marketing Swedish proficiency and contributing to reaching the export goal. There are notions of transforming the energy system through experimentation in hubs, especially in cities, which can then be replicated and scaled up, for example through Nordic cooperation and exchanges of knowledge generated through experiments. Coordination by governmental bodies constitutes a central political technology, embodied in the Coordination Council for Smart Grids and then the Swedish Smart Grid Forum. These actors were regularly ascribed a central role for initiating cooperation and acting as intermediaries between different smart energy actors. As shown, other energy policy initiatives such as the Energy Commission have also been important for the ensuing policy formation on smart energy, and appear to have contributed to the shallow consensus, despite obvious political rifts.

A central feature of this political rationality which underpins smart energy experimentation in Sweden is the casting of smart energy as a techno-economic issue. This institutes environmental governance in particular ways through such experimentation, as we saw with respect to how attempts to enroll energy users and make them active were described in the material. The language used in the 2017 energy SOU is illustrative of the techno-economic framework through which energy is discussed, stating that it is market actors who are 
responsible for planning and financing energy infrastructure based on the market's needs. ${ }^{478}$ Wallsten claims that smart energy as an issue space in the Swedish context can be defined to a large extent through its constitution as an economic issue, rather than a social or political issue. ${ }^{479}$ Simultaneously, smart energy is also discussed as an issue of technical design and optimization of the existing energy system, as shown throughout this chapter. Technical and economic aspects are generally bundled together in discussions of smart energy in the material analyzed for this chapter, thus contributing to the story of smart energy and energy transformation as a matter of techno-economic design and expertise. This tells us something about experiments as well, or at least about the way in which experiments are described in the material. Generally, as this chapter has shown, experiments are described as neutral technoscientific tests, and they seem to be taken for granted to a certain extent in the material; there is a specific way of talking about and describing experiments in documents which chimes with the constitution of smart energy as a techno-economic issue. ${ }^{480}$ Particularly in the Swedish context, this is in line with how energy politics have been dominated historically by ideals of large scale and centralization. Despite the intensely conflictual history of energy politics, this dominance has been asserted and upheld to a large extent through the casting of energy as primarily a techno-economic issue, by appealing to techno-economic expertise.

Experiments, then, become necessary in order to realize the export goal through showcasing Swedish proficiency and developing new energy products and services to export. Additionally, experiments become important to allow for increased growth of cities and establishing server halls. Experiments also become important in order to address perceived uncertainties in energy transformation processes, as discussed previously, since they are ascribed the ability to reduce such uncertainties by showing what works in reality. Because of these ascribed abilities, experiments can potentially suppress the political conflicts detected in the material, as uncertainties related to the future architecture of the electric grid, for example, is made into a matter of neutral technoscientific tests through experiments. As discussed, there are many possible ways to change the configuration of the energy system to align it with environmental

\footnotetext{
${ }^{478}$ SOU 2017:2. Kraftsamling för framtidens energi. pp. 298-299.

${ }^{479}$ Wallsten 2017. Assembling the Smart Grid.

${ }^{480}$ This is also a prevalent feature of governmental decarbonization agendas and energy transformation processes in places other than Sweden. See e.g. Pallesen \& Jacobsen 2018. Solving infrastructural concerns through a market reorganization: A case study of a Danish smart grid demonstration. Energy Research \& Social Science, 41; Foss Ballo 2015. Imagining energy futures; Tozer \& Klenk 2018. Discourses of carbon neutrality and imaginaries of urban futures. Energy Research \& Social Science, 35. As in the Swedish context, this techno-economic language is also often coupled with an emphasis on the need for consensus and cooperation between actors engaged in energy transformation endeavors and other environmental governance processes, see e.g. Blühdorn \& Deflorian 2019. The Collaborative Management of Sustained Unsustainability: On the performance of Participatory Forms of Environmental Governance. Sustainability, 11(4).
} 
policy goals. However, this is not explicitly debated as a matter of political choice in the Swedish context. Instead, the need for consensus and testing through experiments is emphasized, contributing to evidence-based policymaking. As we saw throughout the chapter, some options appear more desirable to specific actors than others, and these can be influenced by the specific ordering of the field of intervention through experimentation, for example in terms of who is positioned as authoritative and central for conducting experiments, who gets access to the knowledge generated, and which knowledge claims gain traction.

Experiments get to lead the way toward the future energy system by demonstrating future configurations in the present, and thus also by implicitly excluding alternative pathways or alternative configurations. ${ }^{481}$ Experiments are assigned the role of reducing uncertainty and complexity, by showing what works in reality, although this entails specific forms of experimentation aligned with the overarching export goal. Experiments are described as journeys of gradual technoscientific exploration and adaptive learning, while simultaneously being given the role of marketing Sweden internationally and being rather instrumentally described in terms of replication and upscaling. It is private companies who, in part through research funding provided by the state, are designated as the main agents. Experiments will contribute to transformative change by showing what works in practice, and can then be upscaled and replicated to facilitate the export of new smart energy technology developed by Swedish firms. As we saw, such specific notions of changing energy infrastructure embody a tension between marketing and testing through experiments. Change was described as selforganizing and market-driven, whilst the need for planning and long-term visions was underlined in the material.

In the following chapter, we will move closer to experiments by disentangling notions of experimentation among different experts in the smart energy field, before following different cases of experimentation across Sweden. 


\section{Ordering governance through smart energy experimentation: political rationality and experts' notions of experimentation}

The previous chapter analyzed the political rationality underpinning smart energy experimentation, and the governmental apparatus into which such experimentation is becoming incorporated, from an aggregated analytical perspective. This chapter will focus on how experts across governmental institutions and policy networks reason in practice about smart energy experimentation, including how they make sense of, negotiate, and attempt to handle smart energy experimentation. The group of experts includes funders of smart energy experiments, policymakers, experts overseeing energy research strategies, regulators, experts involved in the dissemination of results from experiments, energy interest organizations, the Swedish transmission system operator, and energy experts occupying multiple roles in national and international organizations. Because of their central roles in the energy policy landscape, these actors are important when it comes to organizing smart energy experimentation. Heuristically, the previous chapter honed in on a macro level, while this chapter focuses on a meso level.

Thus, their accounts of experiments are important in order to understand how experimentation arranges environmental governance. What are the reasons behind such experiments, according to these actors? How is the use of experiments to govern the environment legitimized, and why is it necessary to conduct socio-technical experiments to transform infrastructures such as the energy system? How do they think about and attempt to organize efforts to achieve transformative change beyond individual experiments? The chapter elucidates how experts across governmental institutions and policy networks deliberate on experimentation and attempts to handle it in practice, revealing how the political rationality unearthed in the previous chapter creates certain conditions of possibility for these experts. ${ }^{482}$ For instance, particular theories of change and infrastructures of circulation taking root among experts across governmental institutions will be highlighted. Further, frictions that appear as experts grapple with experimentation in practice will be highlighted. The chapter also

\footnotetext{
${ }^{482}$ Put differently, if the previous chapter revolved around the plans, maps, and techniques of governance, the analysis in this chapter zooms in on the "mentalité" of governmentality, to paraphrase Tomas Lemke, i.e. the assumptions, demarcations, notions, and knowledge claims underpinning and emanating from the governmental apparatus around smart energy experimentation. See Lemke 2011. 'The birth of biopolitics'.
} 
provides an insight into how governing is less about chasing one dogmatic goal, and rather about a whole series of specific finalities, to paraphrase Foucault. Sensitizing the analysis to this can highlight the complexities and contingencies of governance, its dynamic nature and its constant reconfiguration, as well as how - despite such contingencies - governance is not directionless, and creates certain power-knowledge orders.

\section{Socio-technical experimentation: setting up experiments}

Interviewees regularly deliberated upon which qualities make an intervention experimental. A plethora of terms were used to discuss smart energy experimentation, with pilot projects, demonstrations, test beds, experimenting, reference plants, full-scale application, and commercialization constituting common terms. However, despite this ambiguity, certain recurrent patterns when talking about experiments emerged across a number of interviews. In this section, I will disentangle some of these meanings ascribed to experiments, by focusing on how interviewees reflect on the setup of experiments and the terms they use to signify experimental endeavors.

An initial remark is that the term "experiment" is noticeably absent in the material. The term surfaces in interviews, but only rarely. Instances where experimentation is explicated in positive terms are even rarer. In e-mail correspondence with an actor involved in a large smart energy experiment, it was stated that the consortium of actors actively refrained from using the term "experiment" throughout the initiative's duration, since it was perceived to carry negative connotations in a project which included households and thus people's private lives. The preference was rather for the terms "innovation project" or "research study". This line of reasoning reveals how the term "experimentation" has not necessarily gained favor in Swedish environmental politics, although concepts associated with experimentation - such as "scientific studies" and "innovation projects" - seems more attractive. And, as we shall see, it is possible to speak about experimentation even if the term itself is deemed risky.

\section{Experiments as catalysts of incremental change}

One characteristic often ascribed to experimentation across interviews was a notion of experiments as catalysts for infrastructural change in an incremental way. One example came up in an interview with an energy field expert:

[...] the large pilot projects, they are useful because they mobilize, but you also need these earlier steps in this staircase, the research and innovation scale. It would be good if you could see this chain, that these solutions, we think these are important to develop Sweden's electricity system. This type of technology is something we should go for, and then we go for it with test beds, and then we make products, and then we make reference plants, so we do the entire side. And it's not, it's a bit ad-hoc 
now, I mean what is it that is demonstrated in the pilots, it's the private companies themselves who look at what they think is interesting. ${ }^{483}$

Critique is aimed at experimentation for being too ad-hoc, and at too much leeway being granted to private companies to decide for themselves on the direction of experiments. The quotation also illustrates a specific way of conceptualizing change through experimentation, and a specific sequential order through which experimentation is envisioned to unfold. It conveys an emphasis on product development through experiments, but it is argued that this should be driven by a direction which is not exclusively decided on by private companies. Further, a seemingly taken-for-granted research and innovation scale is referred to, in which test beds, product development, and reference plants are described as important steps in a staircase. In similar articulations, a scale called the Technology Readiness Level (TRL) scale was regularly brought up by interviewees, for instance in the following example:

The pilot [the Gotland as energy pilot initiative] will be the entire span, I hope, not basic research, do you know about the TRL scale? So I hope that we will be on the other half of that. ${ }^{484}$

The notion of change through experimentation, which is visualized in this instance, and more broadly through references to the TRL scale across interviews, tallies with the quotation above describing a sequence of endeavors, mainly focused on technology development. ${ }^{485}$ The following example can further elucidate how the TRL scale was leaned on to support a specific notion of infrastructural change, in which experiments provide catalyzation:

But if you see what I mean, the further down this scale you are, the less mature the technology is and thus the greater the risk of failure. But it's wrong really to say fail, I mean you need to learn and build upon that. But of course, if you are higher up on the scale, like now this technology is pretty much finished, then perhaps you don't want too much of [that]. A long time ago I used to work on one of these projects at [a large firm], where they did lots of basic research. And then they said that well, at least 95 percent of all the ideas you start working on should fail. But then you're on a really basic level, then it develops the higher and higher [you are on the scale]. ${ }^{486}$

Considering how the TRL scale appears to structure the way many experts think about smart energy experimentation, it can be conceptualized as an expression of a particular political rationality that shapes how experimentation arranges environmental governance. This illustrates how, despite the aforementioned ambiguity in terms of how concepts such as "experiment", "pilot project", and "demonstration" are articulated, there is a degree of coherence as well. Experimentation is coupled with initiatives to develop new energy technology to a significant extent across interviews, imagined as unfolding in a sequential

\footnotetext{
${ }^{483}$ Interview EXE1.

${ }^{484}$ Interview EXEA4.

${ }^{485}$ Interview CM1 Swedish Smart Grid Forum.

${ }^{486}$ Ibid.
} 
manner, crystallized in the TRL scale. This tallies with the techno-economic language permeating energy as an issue area in Sweden, as detailed in the previous chapter, since it is also in line with an ideal-type view of science where experiments essentially constitute neutral technoscientific tests which reduce uncertainty. The TRL scale and notions of infrastructural change coupled with it thus appear to structure the field of intervention in particular ways, rendering intervention technical by defining a problem of sequential technological development and outlining solutions which particular experts, mainly within certain private companies, stand ready to provide. Here, a knowledge politics can be discerned, as knowledge generation processes in experiments are configured in line with the TRL scale, engendering particular knowledge orders of smart energy experimentation.

Another example of expressing socio-technical experiments as a way of achieving incremental change can be gleaned in this quotation:

I think that it's wrong to lock yourself in too much, you don't know how we need to develop the electricity grid and that will happen continuously. [...] Depending on how far ahead you look, if you compare today with a certain number of years ahead there will surely be significant changes, but I don't think that, I mean it's dangerous to [be] too radical as well, too fast, because then you might make the wrong decision or lock yourself into a technology which is bad. ${ }^{487}$

Here, a civil servant from the Energy Markets Inspectorate outlines a notion of infrastructure change as an incremental, long-term process, with reference to the risk of investments in unfavorable energy technology which will lead to lock-in. The interviewee continued:

Well it is a shift, smart grids, it starts something, but at the same time where it works you keep it of course, and make wise decisions, economically motivated decisions. Our view is that you don't do things just for the sake of it, there has to be value. But it is an important area, so in that sense pilot projects and such are good. I mean, the electricity grids are something one shouldn't forget in the climate transition, it's not just about investing in different renewables or electric cars, the infrastructure is very important, and it's an area where lots of research is needed, so that should be kept in mind when research funding is allocated. [...] And also integration with smart, new technology and such, so pilot projects are good there. ${ }^{488}$

The quotation illustrates the viewpoint that developing smart grids constitutes a shift for the energy sector, but it is important to avoid overly drastic decisions or rapid change since this might lead to technological lock-in or poor, uneconomical decisions. Therefore, sociotechnical experiments offer an appropriate way of integrating smart technology with existing electricity grid infrastructure, i.e. a form of incremental change through testing and adapting, which is articulated as economically sound. This is in line with the widespread tendency to

\footnotetext{
${ }^{487}$ Interview EXEI.

${ }^{488}$ Ibid.
} 
discuss energy transformation in techno-economic terms. Consequently, socio-technical change is also implicitly described as a stepwise process in this instance, where experiments constitute a way to support incremental change. Another interviewee talked about how the popularity of small scale is increasing within the energy landscape, and distribution system operators (DSOs) are becoming increasingly important, partly as a result of new EU energy policy. ${ }^{489}$ But at the same time, according to the interviewee, there are parallel processes which steer toward large scale as well, and there is no broad shift toward small scale. Rather, according to the interviewee, both small scale and large scale must be able to function in parallel and fulfill different roles. ${ }^{490}$ Considering the battle-lines between the proponents of small-scale and large-scale configurations of the energy system historically in Sweden, this statement illuminates how the discursive terrain of smart energy experimentation is dominated by the theme of Sweden as an environmental frontrunner, particularly the emphasis on consensus and cooperation. ${ }^{491}$ It also further reinforces a notion of experiments as catalysts of incremental change, since the interviewee explicitly stated that both large and small scales must be able to co-exist and there is no far-reaching transformation in terms of socio-technical configuration of the energy system in sight. As mentioned, socio-technical experiments are commonly assigned the role of realizing such incremental changes. Another example can be discerned in the following quotation, in an interview with representatives from Svenska Kraftnät:

I don't know if any conclusions have been drawn [from the smart energy experiments in Norra Djurgårdsstaden, Hyllie, or Smart Grid Gotland] or if anything can be concluded yet, but what one can see approaching now is this large trend of societal urbanization where people move to cities, and I suspect some conclusions can be drawn from these projects [...] It's very difficult to construct grids in and around cities, and if it's possible with the help of these pilot projects to avoid some grid investments then that is a good conclusion and output from a project like this, by using consumption instead to offload certain critical hours. ${ }^{492}$

As discussed previously, avoiding large investments in the electricity grid is one of the rationales for smart energy technology often stressed by its advocates, particularly governments and grid operators, as is smart energy's contribution to reducing power issues and capacity limitations in the grid, for example through load-shifting. ${ }^{493}$ Further, it

489 The so-called Winter Package, or the Clean Energy for all Europeans package. See: https://ec.europa.eu/energy/en/topics/energy-strategy-and-energy-union/clean-energy-alleuropeans [2019-05-24].

${ }^{490}$ Interview EEC.

${ }^{491}$ Cf. Kall 2011. Förnyelse med förhinder; Anshelm 2000. Mellan frälsning och domedag; Hultman 2015. Den Inställda Omställningen.

${ }^{492}$ Interview EXSvK, EXSvK1.

${ }^{493}$ Cf. Stephens et al. 2015. Smart Grid (R)Evolution. 
underscores how smart energy experiments are increasingly ascribed the role of enabling growth since they are imagined to uncover means of stabilizing and balancing the grid in ways that are compatible with rapidly expanding cities and electricity-devouring activities such as large server halls. In the quotation, it seems that smart energy experiments are considered to be a method for instigating incremental change of energy infrastructure, adapting the existing infrastructure as cost-efficiently as possible rather than making large investments to reinforce or drastically change grid infrastructure. Similarly, an interviewee connected to the Swedish Smart Grid Forum stated that socio-technical experiments are vital to verify technologies, because the financial and credibility values at stake if a technology is simply implemented without verification are too great. ${ }^{494}$ An interviewee from the Energy Markets Inspectorate also expressed that socio-technical experiments are important to verify technology, because investments should be made only if a technology is the most cost-efficient option and provides the best security of supply for electricity customers. ${ }^{495}$ Both the cabinet member at the Smart Grid Forum and the civil servant from the Energy Markets Inspectorate refer to technology development in terms of scale or level, i.e. that experiments are necessary to move a technology along a scale and when it is economically efficient and mature it can be implemented, in line with the aforementioned TRL scale. The interviewee from the Energy Markets Inspectorate also referred to how the grid operators are essentially private companies in a monopoly situation, so experiments are a convenient way of making sure they do not let customers pay for arbitrary research and development projects - it is important that such endeavors are pursued through a governmental agency such as the Energy Agency, where funding can be applied for in competition with others through project funding calls. ${ }^{496}$

These examples illustrate how socio-technical experiments are articulated as a method for instigating incremental change across the material, for different reasons. They provide insights into how the political rationality underpinning smart energy experimentation entails certain conditions of possibility, as experts across governmental institutions grapple with smart energy experimentation, in practice arranging governance. Changing infrastructures is linked to market solutions, through developing new energy technology in experiments. Private companies are assigned the central role of developing products, deriving funding for projects from governmental agencies, whereas coordinating bodies such as the Swedish Smart Grid Forum structure the smart energy field through dialogue forums, drafting up strategies and policy proposals, and providing opportunities for exchanges between actors in the energy system, for example by arranging conferences. This particular order of things appears to be

\footnotetext{
${ }^{494}$ Interview CM1 Swedish Smart Grid Forum.

${ }^{495}$ Interview EXEI.

${ }^{496}$ Ibid.
} 
based on a particular notion of change linked to innovation practices, crystallized in the TRL scale. The political rationality underpinning contemporary environmental politics appears to have explanatory value here. There are clear affinities with a broader preference for projectified forms of governing in environmental governance, as well as neoliberal inclinations of turning environmental issues into opportunities for expanding capital's reach by developing new markets. Thus, the political rationality underpinning smart energy experimentation comes to influence how experts arrange governance in practice, constituting the field of intervention for environmental governance in this particular way.

A tension can be discerned in relation to articulations of socio-technical experiments as promoting incremental change, or as keeping options open, rather than deciding on specific directions. Instead of incremental change, some experts call for clear political visions, directions, and long-term planning. ${ }^{497}$ One interviewee stated that:

[...] kind of like we think this is something for Sweden. One would like to see more of that kind of choice. [...] It can be perceived as a bit centrally planned, but it's some kind of strategic choices, that it's this type of solution we need from start to finish. ${ }^{498}$

This interviewee would like to see a clearly articulated vision for the energy system and political choices to be made. A similar perspective emerged in an interview with an energy field expert. The interviewee criticized a perceived lack of political courage and a lack of political visions. It was claimed that incremental regulatory changes were also necessary, but were far from enough, and the interviewee called for a comprehensive political approach and clear directions:

[...] basically I think that something like that is necessary, that you point out a completely new regulatory framework. Then it will happen. ${ }^{499}$

Here, the interviewee states that there is a need to change regulatory frameworks drastically, to facilitate the development of a future smart energy system. Further, the interviewee stated that the large experiments in Norra Djurgårdsstaden, Hyllie, and Smart Grid Gotland have not affected the discussion on regulations as much as they could or should have. In the following exchange, the interviewee reflected upon how the three large experiments have influenced the planning for the future energy system:

Not much. Not much I would say, and that's not being mean or anything, and I return to what I said before. [...] in the Energy Commission and in IVA's project Choosing Electricity Pathway, people wanted to show how modern and knowledgeable they were, so they said that really it should be called a Power Commission rather than an Energy Commission. And I say okay, if that's the case, if

\footnotetext{
${ }^{497}$ Wolf \& Andersson 2018. Elnätets roll i framtidens energisystem; Interview EXE1; Interview EXE2.

${ }^{498}$ Interview EXE1.

${ }^{499}$ Interview EXE2.
} 
that's what it's all about, if the future challenge is the power issue, then you have to think about how the regulations have to change if we are to handle this power issue in the most efficient way $[\ldots] .{ }^{500}$

The interviewed expert connects this line of reasoning, about the lack of profound regulatory changes and the experiments' modest influence on policymaking, with a perceived lack of clear political visions:

I think that we have a basic problem, and that is that we actually lack this vision that we talked about, about how things will look. We don't have that. Because, and this is what I've been saying, if you have a vision about how this will look, then the time scale can always be discussed. And you could always discuss how you get there as well, but if you are clear about where you will end up, that makes it a lot easier and that's when you can make these drastic decisions. [...] I mean think about the construction of the fiber infrastructure, I think that it's fantastic that when it comes to communications we've really gone for it. When we built the mobile phone grids, those are huge investments. [...] Fiber is the same thing, and then I say why couldn't that be done in the energy

system, I mean something similar? Like, now we decide. [...] I mean we will still need pilot projects, but if I were to set the demands for new pilot projects, I would be clearer about them having to describe how they will be scaled up. Because that question was never posed to these pilot projects. ${ }^{501}$

The notion of upscaling recurs across the interviews, seemingly as an integral part of how transformative change beyond singular experiments is imagined. Thus, we will return to the question of scaling up later in this chapter. Highlighting a lack of clear political vision, as the interviewee does, can be seen as existing in friction with pursuing incremental change through experiments. The energy field expert did, however, also explicitly emphasize that there is a need to include and provide support for smaller firms in the energy transition, perhaps illustrating a compatibility between incremental change and staking out a clear political direction. This would mean shifting research funding toward smaller firms, based on an idea that these actors would be more innovative and able to drive transformation, compared to established, incumbent actors. ${ }^{502}$ Still, there is a greater tension in the material that can be visualized through this example, related to notions of incremental change and the calls for a clear political direction and political vision. This becomes clear in the following instance:

We still construct grids in the same way [as before], and then I say perhaps they should be stronger or weaker. Have we, for example, considered what this will look like when we have a million electric vehicles in Sweden, which we will have in 2025? I mean a million chargeable, there is no, I see no foresight in this [...]. I mean I think that we don't have a vision for this, we lack a vision. ${ }^{503}$

This quotation illuminates the tension between articulating socio-technical experiments as incremental change and as policy input. On the one hand, experiments are ascribed the role

\footnotetext{
${ }^{500}$ Interview EXE2.

${ }^{501}$ Ibid.

502 Ibid.

${ }^{503}$ Ibid.
} 
of speeding up a transformation of the energy system by feeding into policy and guiding regulatory change. In several instances, this was connected to a perceived lack of a political vision and long-term planning, i.e. calls for staking out a clear political direction. On the other hand, experiments are articulated as a method for achieving incremental changes, gradually transforming the energy system. These two notions of the role of experimentation for energy transformation illustrate two different programs of action: on the one hand they are articulated as guidance for policy to stake out a political direction, while on the other they are articulated as best left to the energy industry to achieve incremental changes of energy infrastructure. It is important to be careful here, to avoid painting a picture of a simple either/or choice. However, the instances accounted for in this section clearly illustrate two rather different roles for smart energy experiments in energy transformation endeavors. Thus, within the broad discursive theme of Sweden becoming an environmental frontrunner, a tension related to achieving socio-technical change through experimentation can be discerned. This can be interpreted as a consequence of the political rationality underpinning smart energy experimentation, creating such tensions among experts who are tasked with organizing experimentation in practice; the political rationality entails projectification in an ad-hoc manner, where new experiments are always necessary to develop new green energy technology. ${ }^{504}$

\section{The setup of experimentation}

The interviewees regularly discussed how best to set up experiments. The setup of experiments is a central part of the governmental apparatus of smart energy experimentation, which can further elucidate how the political rationality underpinning it renders intervention technical in specific ways. Consequently, we will linger on the setup of experimentation for a while. Several interviewees referred explicitly to the large flagship projects of Norra Djurgårdsstaden, Hyllie, and Smart Grid Gotland. Two civil servants at the Energy Agency and an energy field expert talked about the difficulties in setting up and performing experimental and innovative projects in which it is mainly the conventional, large energy sector actors who participate. ${ }^{505}$ The following quotation makes this point clear:

Then another experience that I see is that, and that is also a problem, but to be able to launch such a large project you need big, safe actors who can finance and take the risk. But that also means that you end up in the lap of the established actors and you know from every transition [that significant changes are rarely accomplished by incumbent actors]. Some will survive, but the biggest changes come from entirely new actors. So how do we reach them? And then you need to create the conditions to be able to get them in, and we tried that clearly at the beginning of these projects, but

\footnotetext{
${ }^{504}$ Cf. Murray Li 2019. Problematising the project system.
}

${ }^{505}$ Interview EXEA3; Interview EXEA2; Interview EXE3. 
I can tell you that we suffered setbacks several times. This was because when we pushed this too hard, the projects almost fell apart since it comes down to the funding. ${ }^{506}$

The statement that it is difficult to create projects where smaller private firms and the large energy companies work together ties in with a claim made by many of the interviewees, including among the big energy utilities in question, that the conventional actors are reluctant to change. An illustration of this logic is offered by the Smart Energy City experiment in Norra Djurgårdsstaden, where a smaller firm eventually became involved, but one of the larger project partners bought this company. ${ }^{507}$ Related specifically to the notion of experimentation, several of the interviewees were somewhat skeptical about how experimental the three large demonstration projects could actually become, considering how all three of them were mainly run by large incumbent utilities. In an interview with an energy field expert, it was even expressed that the three demonstration projects were large and heavy, and consequently not very innovative, which according to the interviewee explained why the Coordination Council for Smart Grids came to emphasize the need for funding test beds besides large demonstration projects. ${ }^{508}$ The interviewee clearly differentiated between test beds and demonstration projects, claiming that smaller pilot projects within test beds had the potential to be more innovative. Such a classification seems to be in line with the notion of experiments as catalysts for incremental change, as outlined above, where different initiatives were regularly inscribed and classified according to the TRL scale. The notion that experimentation should be pioneering or innovative is prevalent in the empirical material as well, and besides the instance above it was also expressed by several interviewees at the Energy Agency who explained how they came to alter their research funding strategy for electricity grid projects toward focusing on smaller projects rather than large demonstrations. ${ }^{509}$ This prevalence of the TRL scale as well as the notions of change and innovativeness frames knowledge generation through experiments and positions specific actors as primary knowledge generators.

Articulations such as the one above, in which different types of experiments are characterized, can illuminate how the political rationality underpinning smart energy experimentation influences the way in which experts demarcate and delineate the field of intervention to filter out complexity, rendering intervention technical. The following example can further illustrate this point:

What I think pilot projects should do, often there are so many different goals so it can become a bit unclear. But a pilot is about having a technology that works on a lab scale or in a non-real practical

\footnotetext{
${ }^{506}$ Interview EXEA2.

${ }^{507}$ Interview PM ABB.

${ }^{508}$ Interview EXE1.

${ }^{509}$ Interview EXEA1; Interview EXEA2; Interview EXEA3.
} 
setting. [...] Well, this works in some kind of artificial environment, and the pilot is supposed to make this work in a live environment where there are regular customers and regular conditions and the physical environment, with all the complications that can occur when it is out there in a commercial reality. ${ }^{510}$

A clear delineation between the "lab scale" and "commercial reality" is drawn, and pilot projects constitute a link between these different spaces. This illustrates a particular notion of spatial boundaries of socio-technical experiments. Here, experiments are articulated as tests in a live environment, which is contrasted with a clearly delineated artificial environment. So experiments are assigned the role of testing a socio-technical configuration in a live environment, to paraphrase the interviewee. The following instance provides another illuminating example:

I: You show for example that, look this is possible, or you show that this didn't go too well? CM: Yes, and I mean, [...] There are probably few people who would buy a technology and experiment with their electricity supply simply from the drawing board. ${ }^{511}$

This quotation highlights how experiments are ascribed the role of trailblazing by showing what works in practice. Socio-technical experiments are viewed as endeavors to bridge a perceived gap between experimentation on the drawing board and the reality out there, by showing what works. In the quotation, it is stated that experiments are important for changes to be instigated, as such endeavors appear to be imagined to dissolve uncertainty. Experiments are described as necessary precisely by virtue of being tests in a live environment, as opposed to an artificial environment. However, experiments are also described in other instances as being necessary exactly because they take place in artificial circumstances. Consider the following quotation:

[...] well we [the Energy Markets Inspectorate] would be an obstacle if they imagine that they were going to charge their customers for experimenting, but if they are granted funding from the Energy Agency $[\ldots]$ we will not interfere $\left[\ldots . .{ }^{512}\right.$

Here, socio-technical experiments are ascribed importance since they take place within a delineated boundary, so that energy users are protected from experimentation at the mercy of energy utilities. Experiments are important because they offer a space for testing something specifically in an artificial environment, rather than the other way around.

The tensions related to experiments discussed here illustrate how there are many different modalities of conducting experiments, despite this not seemingly being very prominent in

\footnotetext{
${ }^{510}$ Interview EXE1.

${ }^{511}$ Interview CM1 Swedish Smart Grid Forum.

${ }^{512}$ Interview EXEI.
} 
policy. Constituting environmental governance through experimentation is not so much about chasing one dogmatic goal, but rather an amalgamation of different finalities, to paraphrase Foucault. For some, the relevance lies in testing in a protected space, whereas for others it is precisely the opposite that is the point of experiments. These different boundaries being drawn around experiments reflect how the governmental apparatus of smart energy experimentation is imbued with differences, rather than a monolithic entity imposing a single goal. One interviewee, a cabinet member at the Energy Commission, talked about the set-up of sociotechnical experiments in a problematizing way:

I guess pilot projects are a great way to start. But then the difficulty, I don't know, it's a question of method how you set up these projects, I think that it's very important, in Smart Grid Gotland, without being entirely knowledgeable I have understood that it was possible to sign up by interest, and the risk then is that you get customers who aren't representative. These could be customers who are already very active and choose to act, who are not representative of the broader customer collective, so when you do a pilot project [it's important] to get a representative sample to really understand what the potential is. ${ }^{513}$

There is an implicit appeal to scientific authority in this quotation, as is often the case in experiments, but the interviewee's main point is that it is important to give proper thought to the setup of socio-technical experiments. The interviewee questions whether Smart Grid Gotland was set up in a neutral fashion, and what this entails. In a somewhat similar fashion, an interviewee from the Energy Agency also discussed the possibility to set up experiments in different ways:

I mean you have different types of pilot projects. You have these large demo projects, then you have different kinds of pilot studies that you apply for to develop a product or test this solution or whatever it might be. And that is very interesting, so to speak. And then you have some kind of, I don't know where the boundary is between because, demo is about demonstration, the other is perhaps more focused on implementation projects. So there are different types of project funding. ${ }^{514}$

Almost in passing, this interviewee discusses the possibility of carrying out different types of socio-technical experiments. It seems, however, that all of the examples are closely connected to the ambition of turning Sweden into an environmental frontrunner by exporting smart energy technology, since all the examples brought up by the interviewee are discussed within a commercial framework. In an interview with a civil servant from the Energy Agency, it was stated that socio-technical experiments play an important role for energy transformation:

We have talked about this a little bit already, the firms have special circumstances, they should rather be delivering black figures, not red figures. And that means that they cannot invest any

\footnotetext{
${ }^{513}$ Interview EEC.

${ }^{514}$ Interview EXEA3.
} 
amount of money in research and development, they can't take huge risks. But at the same time, considering how fast things are happening, not least on the transport side, it's also a matter of survival. It's a matter of strategy, if they are to remain you have to engage, so to speak, which everyone does I suppose, but there I think these demonstrations and our cooperation with universities and industry is important to offload risk for them to dare to take these steps. So I am pretty sure these demonstrations are very significant. But it's up to us to choose the right demonstrations, and that it's demonstrations that are not close to business as usual but rather quite far off. ${ }^{515}$

Here, we can see how the interviewee describes the importance of experiments being experimental, in the sense that they cannot be too close to business as usual. Further, the quotation emphasizes cooperation and public-private partnerships as being integral to experimentation. It is also articulated that experiments are important to offload risks for private companies, illustrating a particular view of infrastructural change through experiments in which private companies developing commercial products are central. Across the interviews, there appears to be substantial agreement about the need to enroll different actors, although it is mainly private companies that are brought up specifically in interviews and documents, and it seems to be implicitly recognized that these actors operate under special circumstances, to paraphrase the interviewee, which means that they should preferably earn money from experimenting. Incumbent energy companies are often the ones who are mentioned explicitly. Of course, it is impossible to ignore the socio-material composition of the Swedish electricity grid infrastructure when understanding the insistence on the importance of these actors for smart energy experimentation. It is a large-scale, centralized infrastructure with particular material properties, bringing certain modes of infrastructural change closer to hand than others. Further, these actors have long held prominent positions within the actor constellations across the energy system, and can certainly be considered powerful. Nonetheless, it is notable that these actors are positioned as central for generating knowledge through experiments. In particular, the preference for proprietary knowledge reveals how the political rationality underpinning smart energy experimentation is reflected through ways of thinking about experimentation among experts across governmental institutions and policy networks. Developing new products, thus creating new market opportunities abroad as well as within Sweden by interlacing the energy system with ICT, is also significative of this political rationality.

These instances underline how, despite inherent tensions and pulls in different directions, the political rationality underpinning smart energy experimentation has centered around a particular order of things, where experimentation is central for instituting environmental governance within a market framework. The widespread consensus around the discursive

\footnotetext{
${ }^{515}$ Interview EXEA4.
} 
theme of making Sweden into an environmental frontrunner through smart energy technology export, and the notions of change crystallized in the TRL scale underpinning it, has seemingly structured the smart energy field in terms of which actors become authoritative and which knowledge claims are deemed reasonable. This highlights how smart energy experimentation is becoming incorporated into a broader governmental apparatus. Within this disposition, public project funding emerges as a central instrument of governing, shaping practices of experimentation such as funding schemes, calls, and setting up specific experiments in line with the sequential notion of experimentation expressed through, for example, the TRL scale and the goal of smart energy exports. This is nested across EU funding structures through widespread projectification, which is also prevalent in the case of Swedish smart energy experimentation, as seen in the emphasis on cooperation and the preference for public-private partnerships in individual experiments. Experimentation is almost exclusively discussed in market terms, expressed for example through the ultimate goal of commercializing new technology. There is a clear emphasis on such aspects across the empirical material. Interviewees problematize aspects connected to experimentation, but the political rationality underpinning smart energy experimentation clearly contributes to framing certain ways of arranging governance as more reasonable. Despite several interviewees problematizing experimentation under the auspices of large, incumbent energy companies, it is noticeable how it is precisely these actors that are frequently described as being necessary in order to instigate infrastructural change through experimentation. The notions of incremental technical, innovation-driven change underpinning the political rationality of smart energy experimentation, as crystallized in the TRL scale, structure the field of intervention in this particular way. The knowledge claims mobilized as being central for instituting environmental governance through experimentation can mainly be generated by R\&D departments at large, private energy companies. The TRL scale, and the underlying theory of change upon which it is premised, exemplify the influence of the political rationality, since the assumptions highlighted appear to be taken for granted, while obviously influencing thinking about experimentation among different experts, inferring particular knowledge politics.

\section{Socio-technical experimentation as tests: learning through experiments}

One of the most common ways of talking about socio-technical experiments across the material is as tests, with an emphasis on the importance of learning from these tests. This partly overlaps with another prevalent notion, that of experiments as trailblazers, reducing uncertainty and thus pointing the way to the future. However, such notions tend to draw upon rigid conceptualizations of objective science, where experiments can scientifically assert the way forward, as we shall soon see. When experiments are discussed as tests, there is instead a 
greater emphasis on uncertainty and iterative learning. One example of this appears in an interview with two employees at the Swedish TSO, Svenska Kraftnät:

EXSvK2: My thinking is that they have an important role, since they provide an opportunity to try out new solutions on a smaller scale without having too much effect. Then you can evaluate to allow for implementation on a larger scale later. So it is an important step to develop, well, for development simply.

EXSvK1: Yes, and that was kind of the motivation and background for us joining Smart Grid Gotland, that we saw it as maybe a small Sweden in miniature where one could do these tests and then it could be upscaled to conclusions for Sweden as a whole. And I think that we have to, it's very important, when we are facing such big changes that we have to do pilot projects or tests in sharp situations to gain knowledge and learn how the system reacts. I think it's easy to sit at the desk and work out what we think, but I think we have to test as well and then pilot projects are an important part of that.

EXSvK2: Yes and then you might encounter things that couldn't be foreseen. ${ }^{516}$

This reflection on behalf of the two employees at SvK conveys the notion of experiments as tests, with an emphasis on trying out technologies, or rather socio-technical configurations, learning from these tests, and thus reducing uncertainty. The quotation also reflects the techno-economic language prevalent in smart energy discussions, as detailed in the previous chapter, for example by describing experiments as a way of learning how the system reacts. This is in line with articulations by SvK about the need for control over the energy system and the need for plannable power, as detailed in the previous chapter. Upscaling is then described as a logical next step after an experiment, made possible by casting Gotland as "a Sweden in miniature", which enables lessons to be learned for the rest of Sweden. One of the interviewee's emphasis on uncertainty in experiments contrasts with this line of reasoning, however, claiming that unforeseen things tend to be encountered in experiments. This highlights a contradiction as we saw above, in the section about setting up experiments, between emphasizing uncertain testing through experiments on the one hand, and determining a direction through evidence-basing policy via experiments on the other.

Another example of talking about experiments as tests surfaced in an interview with a civil servant from the Energy Agency:

And the idea behind these projects is to test new systems, larger systems, and see how they work. Which lessons can be learned from that and then implemented on a larger scale. ${ }^{517}$

Here, socio-technical experiments are expressed as experimental since they are envisioned as trying out something new, with unknown outcomes, and then learning from it. This is,

\footnotetext{
${ }^{516}$ Interview EXSvK.

${ }^{517}$ Interview EXEA1.
} 
however, also in line with the prevalent notion of experiments as unfolding sequentially, since learning lessons and then implementing a socio-technical configuration is described as a sequential process of testing, learning, and upscaling. There is thus an implicit tension illustrated in this quotation, as on the one hand it illustrates how learning is imagined to happen iteratively through tests with uncertain outcomes, while on the other hand experiments are stepping stones in a sequential process of innovation, whereby change occurs step-wise through testing, learning, and upscaling. Again, such notions of change through experiments appear to constitute an integral part of the political rationality underpinning smart energy experimentation, crystallized in the TRL scale and favoring experimentation in the form of product development for commercialization. Such a notion of socio-technical change sometimes resembles well-worn ideas of stages of growth. ${ }^{518}$ It certainly sits uneasily with the idea that experiments should function as uncertain tests in which learning and adaptation occur continuously, highlighting a friction imbued by the political rationality underpinning smart energy experimentation and the governmental apparatus it is being incorporated into, as experimentation is imbued with different potentially contradictory goals. Similarly, a civil servant from the Energy Agency stated that:

There you can try out different solutions, you can test on a smaller scale, test different things on a small controlled scale, and there is a focus actually on including end-consumers and trying business models and how things could work, so it's a test environment basically. Which is very important, and you can get different actors on board, so eventually it leads to the implementation of some kind of product or solution somewhere. [...] So they [socio-technical experiments] play a large role, a pivotal role even, I would say. ${ }^{519}$

This articulation seems to be in line with a notion of incremental change through experimentation, as discussed previously. Similarly, an expert from the Energy Markets Inspectorate stated that:

I think it's very important as a step in between, because often [...] you have experience of something at the university, and it gets very theoretical and quite far from implementation, and then the grid operators have their own business, but in between there I think it's important to test technology. And also for the role of Sweden, I mean this is an important future business area. To increase the knowledge in Sweden and perhaps export. [...] Yes, so I think that pilot projects are really good, and also negative results are useful, to exclude things or to do projects better the next time. ${ }^{520}$

\footnotetext{
${ }^{518}$ See e.g. Rostow 1960. The stages of economic growth: a non-communist manifesto. Cambridge: Cambridge at the University Press.

${ }^{519}$ Interview EXEA3.

${ }^{520}$ Interview EXEI.
} 
This interviewee describes experiments as a step in between theoretical application at universities and commercial implementation for grid operators, a conceptualization of socio technical experiments which is not uncommon across the material. Research as an institution appears to be assigned a somewhat instrumental role of technology development in the quotation, in line with the widespread techno-economic language used to describe smart energy experimentation. It seems to be less about evidence-basing policymaking in this quotation, however, and more akin to how another interviewee called for researchers to participate in international business conferences to legitimize Swedish claims of competence in smart energy. Further, the notion that negative results are also important is common across the material, as they are described as providing important lessons for the development of a sustainable smart energy system. The key question, however, is how such knowledge is arrived at, who gets to draw conclusions from experiments, and which knowledge claims based on experiments manages to gain traction. Such questions are rarely, if ever, touched upon by experts across governmental institutions.

The interviewee continued by saying that the initiative involving using Gotland as a pilot model is a good example of an experiment which can test regulations one step in advance, before issues such as capacity limitations in the grid create an acute situation. So, in this instance, experiments are described as being important in order to test existing legislation, to probe the limits of these regulations. The interviewee explicitly referred to a task on Gotland which the Energy Markets Inspectorate had on its agenda at the time of the interview, relating to whether or not the regional grid operator is allowed to deny micro-production of electricity connection to the grid under current legislation, with reference to capacity issues. In this instance, testing also seems to be connected to the prevalent discursive theme and Swedish export ambitions, and the interviewee mainly points to a perceived gap between research at universities and the commercial operations of grid owners which socio-technical experiments can fill.

Through these notions of experimentation, we can see how smart energy experimentation appears to create a particular knowledge order, by positioning certain actors and their knowledge claims as central. In the instance above, it seems clear that it is mainly up to private companies carrying out experiments to learn through experimentation, while specific goals connected to exports and product development appear to permeate the setup of experimentation. Consequently, the idea of testing through experiments seems conditioned by the widespread discursive theme of making Sweden an environmental frontrunner through smart energy technology export, since most of the interviewees talk about experiments as something that needs to happen on a commercial basis, with private companies designated as central for conducting and learning from experiments.

An energy field expert, however, stated that socio-technical experiments such as pilot projects never decide a course of events, although experiences gained from an experiment can 
contribute to specific courses of events. ${ }^{521}$ The same interviewee also said that results from experiments could conceivably be implemented in locations with similar characteristics to the one where the experiment was carried out. The interviewee referred to Gotland and stated that perhaps the solutions trialed in experiments on Gotland could be used on Öland, or in remote parts of northern Sweden, if the experience on Gotland proves to be successful. ${ }^{522}$ Here, socio-technical experiments are described as explorative tests, and learning from them is articulated as being imperative in order to implement new technical solutions in similar locations. This illustrates a more differentiated understanding of learning through experiments than notions of straightforward upscaling, for example. In this instance, experiences from situated experiments are described as being impossible to simply adopt somewhere else, unless it is a place with similarities to the site of the experiment. Experiments were frequently described as explorative learning experiences across other interviews as well. ${ }^{523}$

A different take on socio-technical experiments can be discerned in an interview with an employee at the Energy Agency. This interviewee stated that experiments are indeed learning experiences, but emphasized different aspects of testing than other interviewees:

Yes exactly, the goals [of the flagship projects Norra Djurgårdsstaden, Hyllie, and on Gotland], and I think there's a big discrepancy between what the goals were, as I see it in any case between what the goals were and where the interesting results showed. [...] what has been interesting has been the development during the project. Goals rather connected to the format and the processes would have been more interesting than technical end-goals. [...] especially in Norra Djurgårdsstaden where you have ABB, Ericsson, Fortum, Electrolux, all these giants are supposed to be involved in the same project, and do something together, and I think the most interesting effects, which we emphasized when we granted the project funding as one of the unique parts, how did these companies cooperate and what happened along the way? ${ }^{524}$

This interviewee tones down the development of technical components or products, which is often stressed as the main goal of socio-technical experiments, and instead articulates such experiments as tests of social arrangements. What happens when large, incumbent private actors are supposed to work together in a project, as the interviewee put it, is the interesting part of testing through an experiment.

The political rationality underpinning smart energy experimentation seems to embed a need to making experiments appear successful, to fulfill Swedish export ambitions, within the governmental apparatus. As we have seen, this creates contradictions and tensions when

\footnotetext{
${ }^{521}$ Interview EXE3.

${ }^{522}$ Ibid.

${ }^{523}$ E.g. Interview EEC.

${ }^{524}$ Interview EXEA2.
} 
experts deliberate upon experimentation, but it appears to constitute a prevalent part of the political rationality underpinning experimentation nonetheless, as it is an assumption that permeates much thinking about experimentation.

\section{Socio-technical experimentation as mobilization for change}

In the following sections, I will disentangle different ways of ascribing the role of mobilization to experiments and how this informs my analysis of how the political rationality underpinning smart energy experimentation enables and constrains ways of thinking about experimentation, and arranging governance, among experts across governmental institutions and policy networks. The section is divided into three main sub-sections, which illustrate prevalent ways of talking about experimentation as mobilization for change.

\section{Experiments as creating pressure for change in the energy industry}

A prevalent notion is that experiments constitute mobilization by virtue of creating pressure for change in the energy industry, generally in line with ideas of momentum and inertia in large technical systems. ${ }^{525}$ A civil servant from the Energy Agency described how the role of the Energy Agency is specifically to "instigate development" through demonstrations of different sorts. ${ }^{526}$ According to the interviewee:

I think the more you can combine universities with the firms who might see opportunities in the technology, it's really them who have a key role, at the stage where we are now, as I see it. So our role is supposed to be instigating and enabling demonstrations, so to speak, or whatever it might be, but if we are a facilitator then it is up to others to take it from theory to practice $[\ldots] .{ }^{527}$

This quotation highlights how the interviewee conceptualizes the field of intervention in line with central assumptions inferred by the political rationality underpinning smart energy experimentation. Certain actors are tasked with facilitating specific interventions, e.g. through research funding in the form of projects, whilst others are designated as the active interventionists. ${ }^{528}$ It also further underscores the perceived need for consensus and cooperation, and for favoring public-private partnerships in experiments. Transformation of the energy system is described as a matter of cooperation between universities and private firms, and there seems to be an idea of change unfolding sequentially in stages. Understanding

\footnotetext{
${ }^{525}$ Cf. Hughes 1983. Networks of power; Högselius \& Kaijser 2007. När folkhemselen blev internationell.

${ }^{526}$ Interview EXEA4.

${ }^{527}$ Ibid.

${ }^{528}$ Cf. Murray Li 2019. Problematising the project system.
} 
socio-technical change as a process unfolding in different stages is also prevalent across the material, and tallies with academic literature on socio-technical transitions. ${ }^{529}$ This relates to experiments as mobilization, since the interviewee appears to ascribe experiments the ability to drive change on a smaller scale which will then create ripple effects. Through public project funding mechanisms, experiments mobilize private companies and universities to change energy infrastructure through developing new products and services, according to this description. This is also in line with understanding experiments as catalysts of incremental change. Related to how socio-technical experiments are often described as trailblazers, leading the way toward the future, a government official from the Ministry of the Environment and Energy spoke in similar terms:

And in this specific sector, since it's a natural monopoly, these kinds of projects that can show how something can be done differently might be of extra importance. ${ }^{530}$

The interviewee ascribes experiments an important role for instigating change, based on the notion that the electricity sector is reluctant to change. Consequently, experiments become important to show that it is possible to do things differently, to create pressure for change which, according to the interviewee, is non-existent since electricity grids do not work as a competitive market and thus are never pressured into change. ${ }^{531}$ This viewpoint of the energy industry as conservative is present throughout the material, including in some of the interviews with representatives of this industry. It also illustrates how the political rationality underpinning smart energy experimentation is premised on and embeds assumptions about market logic. ${ }^{532}$

Similarly, a civil servant from the Energy Agency stated that:

It [socio-technical experiments] accelerates development, I think. Especially if it's a conservative industry and you don't really dare to take the first step, then it can be beneficial if someone does that so to speak, and then we might have to support it as a government agency. ${ }^{533}$

Here, socio-technical experiments are described as mobilization in the sense that they can persuade a conservative energy industry to instigate incremental changes. Experiments make things happen, so to speak, or accelerate development, to paraphrase the interviewee. As we have seen, this is a widespread way of talking about socio-technical experiments among experts. The line of reasoning offered reflects the theory of change that flows like an

\footnotetext{
${ }^{529}$ See the chapter on conceptualizing experimentation as governance arrangement.

${ }^{530}$ Interview EXMEE, EXMEE1.

${ }^{531}$ Ibid.

${ }^{532}$ Cf. Wallsten 2017. Assembling the Smart Grid; Foss Ballo 2015. Imagining energy futures.

${ }^{533}$ Interview EXEA1.
} 
undercurrent among experts across governmental institutions, engendered by the political rationality. Cooperation is key while state actors set up, finance, monitor, and evaluate experiments, and governmental bodies act as coordinators, while private companies and sometimes universities are ascribed the role of change agents. Product development and commercialization are regularly emphasized as the means for successful transformation of the energy system through this disposition. In the instances described above, it seems that experiments often fulfill the role of persuading private companies that changing established business practices can be economically beneficial, while offloading risk through co-funding via the public sector. ${ }^{534}$

\section{Experiments as arenas for mobilization}

Another way of talking about socio-technical experiments as mobilization, which is prominent across the material, can be discerned in the following quotation:

So I mean, the actual results of Norra Djurgårdsstaden are actually quite limited. I'm sure you've seen that if you have looked at it, too. What has really been implemented? Well it's some things, but it wasn't that remarkable now was it? I think rather that the real value with that whole project was that you gathered around a project and hade common ideas, there was a lot of discussions and it sparked interest $[\ldots] .{ }^{535}$

This interviewee points to the positive impacts of gathering around a common endeavor, since it sparks interest and discussion. Experiments are described as creating attention around specific issues, which initiates discussion reaching beyond the specific experiment. ${ }^{536}$ The interviewee also stated that:

And then you can think about how large an impact these so-called flagship projects have, and that isn't like clockwork, it's the criticism I get back to how they haven't meant a lot for smaller firms, they have had an indirect impact through increased knowledge, but in a direct sense they have mattered precious little. [...] Yes, it's more like that [actualizing an issue]. ${ }^{537}$

Assessing the importance or impact of specific experiments in a direct sense is notoriously difficult, especially since the experiments discussed in this instance were all conducted recently, but the interviewee again points to how flagship projects have managed to raise

\footnotetext{
${ }^{534}$ Whether or not incumbent energy companies really need this kind of persuasion is a matter for the upcoming empirical chapters. However, it should be noted at this stage that experimentation is described in the literature as constituting opportunities for engaging in governance processes also by incumbents, although how this unfolds is also a matter for the empirical chapters. See e.g. Luque-Ayala et al. 2018. Rethinking Urban Transitions: An analytical framework. p. 20.

${ }^{535}$ Interview EXE2.

${ }^{536}$ Interview EXE1.

${ }^{537}$ Interview EXE2.
} 
attention around specific issues, and thus worked as mobilization. ${ }^{538}$ A civil servant from the Energy Agency described socio-technical experiments as mobilization in a similar fashion, and expanded on such aspects:

I think above all it has contributed to a dialogue. [...] it's difficult to measure, but I think that has been one of the absolutely largest effects [...] in both Norra Djurgårdsstaden and Smart Grid Gotland they had in their pre-studies and at the beginning of the projects in those reference groups, mainly during the pre-studies I should say, there were representatives from different governmental agencies, including the Energy Markets Inspectorate, and this was while they were doing their [metering] investigation [...]. And then these projects became a clear exponent and channel for the industry actors and the different governmental agencies to discuss this question related to this ongoing investigation by the Energy Markets Inspectorate, but also to keep up interest politically. So I am convinced that [the experiments] contributed very much to certain issues that were raised in the project, that this isn't possible to do, it came through to the decision-makers and put pressure on the Energy Markets Inspectorate, they have iterated their way forward so there it had a significant importance, it was good timing. ${ }^{539}$

Experiments are described here as having served as mobilization in terms of creating linkages between a network of actors across industry and the public sector, to facilitate dialogue on issues deemed important for transforming the energy system. This mobilization also had impacts in a more direct sense, according to the interviewee:

And then if you look at our work and Sweden's international cooperation, I think it has also been of great importance. I don't know if you're familiar with KIC InnoEnergy, [but] they have these different nodes across Europe, and the smart grid and energy storage node [...] was placed in Sweden and that was very much thanks to these projects being in the works. So there was an interesting arena to offer. [...] and also many who have done research on these projects, so they helped create an interesting environment for those who worked in this area, so there was a lively discussion, a cooperation with many relevant actors. [...] the way I see it, these grid-owner projects, there is a need to create new linkages between new actors, to understand, you don't know which way you are going, you need to share risk, and then you need a dialogue including the decision-makers you need to create attention, and I think those have been the big effects. ${ }^{540}$

Mobilization through socio-technical experiments is here described in terms of creating an arena, which meant not only that a longer-term interest in issues connected to energy transformation and smart energy experimentation could be sustained, but also that it had more direct effects such as a EU innovation hub deciding to locate one of their offices in Sweden. The description of this chain of events was similarly described by another interviewee, who also claimed that KIC InnoEnergy established its so-called smart grid and energy storage node

\footnotetext{
${ }^{538}$ Cf. also Marres \& Stark 2020. Put to the test.

${ }^{539}$ Interview EXEA2.

${ }^{540}$ Ibid.
} 
in Sweden because of the flagship smart energy projects. This assessment was repeated by another interviewee, who stated that:

[...] writing the application to the EU. There we accentuated how great we are when it comes to smart grids, we have many smart meters and we had these pilot projects, and already back then people started discussing, we are good at this. So I can tell you that that's an example of how Sweden was sold in as proficient in smart grids, and InnoEnergy - it was not a coincidence - [...] were given responsibility for smart grids and energy storage in Sweden. That was simply because well, people thought that yes, that seems correct, they're probably good at that. ${ }^{541}$

So mobilization through socio-technical experiments in these instances is described as actualizing specific issues through the creation of a dedicated space for discussing these issues and providing linkages between actors through the creation of an arena. The civil servant from the Energy Agency quoted above further expanded on socio-technical experiments as mobilization:

They [socio-technical experiments] facilitate dialogue and handling of uncertainties, really. And it is difficult to measure, but ideally it means that barriers can be removed early. To make the right choices, from a societal perspective but also from the perspective of the respective actors. The companies involved have hopefully learnt more about which priorities to make, and as a whole it reduces the inertia in the system. I believe that, but it is really difficult to measure it. [...] I believe that the area [smart grids] in itself, since it links to both digitalization and the energy transformation, is an important business sector, so there the right choice was probably made from the beginning both politically and in terms of economics [...] it's a way of actualizing an issue, I mean that arena. ${ }^{542}$

Here, the interviewee describes experiments as trailblazers, since they are envisioned to reduce uncertainties, but also as mobilization since they are argued to constitute an arena where actors can gather for energy transformation to gain momentum. This is also a widespread idea across the material, and it can be further illustrated through this quotation:

But then I think [...] as an arena, and that arena can be set up in different ways, but there I think it's extremely important when you have these huge development questions, then you need to create arenas. And there again, the Coordination Council, I would almost like to claim that one of the reasons for its very existence was these demonstration projects, without them maybe we wouldn't have had the Coordination Council. You can always discuss what the Coordination Council accomplished, but these projects are part of a snowball effect. ${ }^{543}$

\footnotetext{
${ }^{541}$ Interview EXE2.

${ }^{542}$ Interview EXEA2.

${ }^{543}$ Ibid.
} 
A specific notion of change as happening through the creation of arenas interlinking actors, where experiments play an integral part, is laid out in the quotation. The interviewee continued:

[...] the politicians felt pressured to actually answer them [questions raised through the large demonstration projects and other linked initiatives], and because of that all of these governmental investigations were appointed. [...] They built momentum. [...] in the bigger picture, back to our role, through launching initiatives that are this big, we contribute to building momentum, so maybe that's one of the big lessons learned if we see that this is an area that should be prioritized more, it's

important to get a discussion going around it, through launching demo projects which aren't completely, it can't be entirely conventional and familiar for the others, because then there is no new contribution [...] then we put our stamp that we think this is important, and then a discussion starts rolling which might become broader. Some will say this is not important at all, and then you have managed to start this discussion that's needed. ${ }^{544}$

Through this quotation, specific ideas of how socio-technical change occurs can be gleaned. Even though the interviewee says explicitly that arenas can be set up differently, it seems quite clear that to get the attention that is perceived to be necessary, socio-technical experiments need to be large in order to attract attention to get a discussion going, to paraphrase the interviewee. This entails a specific idea of change as necessitating large experiments to create momentum, which then creates a snowball effect. As we have seen, and as this specific interviewee problematized, this entails specific modes of arranging these arenas, however. It tends to include large incumbent energy utilities, mainly private actors, and seemingly includes potential commercial gains for these actors. There is thus a specific knowledge politics attached to this mode of arranging environmental governance through smart energy experiments. Change is described as occurring in stages, where large socio-technical experiments are needed initially to set this change process in motion, and this is argued to be beneficial in order to reach environmental policy goals as well as realizing Swedish export ambitions. This creates a particular knowledge order, through positioning these specific actors as central for carrying out experiments, and they thus become central for developing a smart energy system. Their knowledge claims become foregrounded; the knowledge generated in and appealed to through large experiments is mainly their techno-economic and proprietary knowledge. Put differently, these actors are positioned as central knowledge-makers through the political rationality underpinning smart energy experimentation.

This highlights how experimentation arranges environmental governance at national level, which becomes visible through these different experts' attempts to handle smart energy experimentation, especially the theories of change and assumptions such articulations are 
premised upon, which clearly reflects the broader political rationality underpinning smart energy experimentation. However, many questions are left unanswered. When does a change process begin and end, for instance, and what happens after a large socio-technical experiment? Is it necessarily so that this mode of governance entails creating opportunities for change, by assigning central roles to incumbent private actors in terms of conducting experiments as well as providing linkages between these incumbents and decision-makers? All of these are questions to which we will return throughout the subsequent chapters.

\section{Mobilization through knowledge generation and enrollment of actors}

Another articulation of socio-technical experiments as mobilization can be discerned in the following quotation:

[...] they [socio-technical experiments] matter [since] they have pinpointed several, they haven't solved them, but they have pinpointed these questions, for instance this thing about customer involvement because, I would argue that the pilot projects helped us [...] there's been a sobering up there $[\ldots]$ they have also mattered in relation to getting a better understanding of who these stakeholders really are. For instance about property owners contra construction companies and so on, a lot of those questions, I think that wouldn't have been so clear without these projects. ${ }^{545}$

This description seems to be in line with the argument of a civil servant from the Energy Agency, i.e. that through large socio-technical experiments such as Norra Djurgårdsstaden, Hyllie, and Smart Grid Gotland, specific issues deemed as important for constructing a smart energy system were pinpointed. This interviewee refers to who the important actors really are, with reference to how property owners and construction companies were not initially involved in the smart energy experiment in Norra Djurgårdsstaden and how this became a problem for the whole experiment. More on that later; the important point here is how sociotechnical experiments are argued to pinpoint specific issues which can then be taken into consideration, for example when developing new regulations or deciding which actors actually need to be involved when constructing a smart energy system. This sheds further light on how the field of intervention for environmental governance is constituted through smart energy experimentation, since it tells us how such endeavors are designated as important avenues for locating and enrolling specific actors in the endeavor to construct a smart energy system. Thus, they contribute to establishing the right disposition of environmental governance in terms of inclusion and exclusion of specific actors.

\footnotetext{
${ }^{545}$ Interview EXE2.
} 
Related to this, critical reflections on which actors actually tend to become engaged in smart energy experiments surfaced from time to time in interviews with experts across governmental institutions and policy networks. A civil servant from the Energy Agency stated that:

[...] then it depends on which context you think about, because if you think important in the form of those who have been operating these pilot projects that you are following, well there it's the big actors, I mean that's where there is capital, and that's where there have been collaborations, established collaborations that have been furthered, it's EON and it's been the City of Malmö, and $\mathrm{ABB}$, and Fortum, and Vattenfall, and GEAB, and so on, Svenska Kraftnät, KTH, it's the traditional players who have collaborated specifically in those pilots. But then you also need to care for the innovation power and the ideas that come from the smaller companies that pop up. ${ }^{546}$

This interviewee is careful to point out that the large smart energy experiments in Norra Djurgårdsstaden, Hyllie, and Smart Grid Gotland constitute a specific type of experiment, and that it is imperative to also utilize advantages provided by smaller firms since it is argued that innovation usually comes from there, similar to how several employees at the Energy Agency expressed themselves. Once again, this quotation underscores a specific conceptualization of how mobilization works through large socio-technical experiments, such as the three cases mentioned, since that is where there is enough capital and established collaboration between actors. The same interviewee also detailed the tight interlinkages between Vattenfall and ABB, formerly ASEA, which are described as relevant in relation to changing energy infrastructure. ${ }^{547}$ This highlights how historically sedimented power relations in the Swedish energy system influence experimentation, particularly through a centralization of ownership and control of energy infrastructure. Another interviewee offered similar lines of reasoning:

[...] it's a constant dilemma how to get smaller companies on board. It's always the big ones. And that's a limitation in itself. Because, I mean, large firms, what they mainly want is to sell what they [already] have, right. Maybe tweak something a little bit, while, I can see that at [...] InnoEnergy, I mean the most dynamic, that is often young companies. [...] So that is a dilemma I think with all these projects, I mean how to locate and get these smaller fast-growing companies on board [...] it's more likely that they will embrace this stuff. ${ }^{548}$

This interviewee states that there is a tendency when setting up socio-technical experiments to mainly include large, established private companies. This tendency has already been discussed, but it is worth lingering on a little longer. All across the empirical material, the discursive theme of making Sweden an environmental frontrunner through smart energy

\footnotetext{
${ }^{546}$ Interview EXEA1.

547 See e.g. Kaijser \& Kander 2013. Framtida energiomställningar i historiskt perspektiv. Rapport 6550. Naturvårdsverket. Stockholm. p. 24.

${ }^{548}$ Interview EXE2.
} 
export appears to be widely shared, with an emphasis on consensus and cooperation, as well as on techno-economic language. In this instance, where the set-up of experiments is problematized to an extent, similar assumptions also permeate the conversation. What differs from some other accounts in interviews and documents is the path toward this goal; whereas this interviewee claims that smaller firms are more innovative than established actors and need to be prioritized when funding smart energy experiments, others argue that it is necessary to fund large experiments since the big actors have capital and established collaborations, and these are needed for mobilization to happen. Consequently, there seems to be widespread agreement that infrastructural change through experimentation must mainly be commercially driven, i.e. unfolding through market imperatives.

Through such statements and lines of thought, we can glean how experimentation arranges governance, and how the articulations mirror the political rationality, instituting knowledge politics through experimentation. Smart energy experimentation appears tightly intertwined with a political rationality which configures environmental governance as a matter of market solutions in the form of new products provided through experiments set up as public-private partnerships, in which it is mainly large, incumbent private companies who develop products. Further, techno-economic language is utilized, and sequentially unfolding innovation is constituted as a central arrangement, enabled through such public-private partnership constellations and coordinating governmental bodies. Considering calls within academia as much as within international institutions such as the EU for a just transition, including energy justice, user empowerment, and community engagement, this constitution of smart energy experimentation and the concepts, assumptions, and arguments underpinning it comes across as remarkable. ${ }^{549}$ There are socio-material aspects that cannot be ignored when understanding this, however. The electricity grid infrastructure in Sweden is set up as a large-scale system where electricity is transferred across vast distances through a high-voltage transmission grid, whereas owning grid infrastructure is premised upon concession rights, underscoring the centralized ownership structures. Nonetheless, it is remarkable that smart energy, which tends to be intertwined specifically with hopes for energy system decentralization and user empowerment, is characterized rather by these aspects. It is even more remarkable considering how experimentation, which at least superficially embodies attempts at changing the status quo, or should at least be set apart from the status quo, as often pointed out by interviewees, seems so close precisely to the status quo, even predisposing smart energy experiments in line with such historically sedimented socio-material constellations.

\footnotetext{
${ }^{549}$ See e.g. Szulecki 2018. Conceptualizing energy democracy. Environmental Politics, 27(1); cf. Burke \& Stephens 2016. Political power and renewable energy futures.
} 
Further examples of how socio-technical experiments are discussed in terms of mobilization can be seen in the following quotation:

[...] and as for demonstration projects, it is also about, I mean it doesn't matter if the [Energy] Agency says okay, this was a fun project, we'll sponsor 25 percent of it, if the business community doesn't invest the other 75 percent. If they are not ready to do it or not interested enough to formulate a pilot or a demo project, it isn't possible to launch one. In that sense demonstration projects cannot be planned, you can't say that well 2019 sounds good, let's have a large-scale demonstration by then. It depends on when the actors who we are supposed to support in this are ready to come together, and there are often many different actors who have to join in the same project and say that yes we'll take this part, and so on. So it is very hard work network-wise to formulate these projects. [...] for a pilot project or demonstration to start, you need to have these actors who invest their time and their resources, otherwise there won't be a project. And either, often you have a core group who invest the money or the work, and that can be Vattenfall or

Gotland Energi or whatever, but it can also be suppliers of separate technologies to be implemented into this system, and then there is often a broader group who are very interested and follow this work closely and offer their opinions, so every project has its own quite well-defined group of interested parties who have declared themselves that this is interesting for us, because otherwise there will be no project. ${ }^{550}$

As the quotation highlights, the interviewed government official suggests that experiments are difficult to plan for since they have to emerge organically in a sense, when the business community is ready. ${ }^{551}$ This elucidates how smart energy experimentation arranges environmental governance. The interviewee refers to the actors the state is supposed to support in energy transformation endeavors, highlighting how the state assigns itself the role of supporting private companies in developing new products. This elucidates particular actor relations manifested as experimentation constitutes environmental governance, displaying affinities with a broader political rationality that envelops contemporary environmental governance. Who are the actors that can muster enough resources to create mobilization in the sense described in the material? It seems clear that, based on how experts talk about sociotechnical experiments as mobilization, it seems to be predisposed for large, incumbent private companies. As highlighted by the above quotation - as well as the example provided by another interviewee previously, referring to Vattenfall and ABB as an constituting a long-established collaboration through ASEA - it is necessary to be well-connected and have established collaborations, which means that in practice some voices find it easier to be heard than others. There seems to be a notion that in order to change energy infrastructure, an issue must first be actualized and momentum built through large experiments run by established, large, private companies. Then, when things have started rolling, to paraphrase one interviewee, or

\footnotetext{
${ }^{550}$ Interview EXMEE, EXMEE2.

${ }^{551}$ Cf. Murray Li 2019. Problematising the project system.
} 
when the first step has been taken, to paraphrase another interviewee, more actors can be enrolled and it becomes possible to diversify.

There is a clear risk, however, that this first step will cement specific meaning formations and actor constellations, such as the interlinkages between private energy companies and policymakers in formal and informal policy networks described as central throughout this chapter, which become difficult to alter. In particular, it highlights how large, incumbent energy companies become authoritative actors whose knowledge claims carry a significant import. The knowledge claims which can be generated through such large experiments are difficult for other actors to access, as might be such policy arenas in the first place. This points to a knowledge politics of smart energy experimentation, illuminated through notions of experiments as mobilization for change. This order of things comes across as somewhat remarkable, considering how experiments are often described across the material, and in academic literature, as being further from business as usual, whereas in the case of Swedish smart energy experimentation, almost the opposite seems to be the case. ${ }^{552}$

\section{Socio-technical experimentation as policy input}

Another prominent way of talking about socio-technical experiments among experts was to describe how the results of such experiments should feed into policy. This often overlap with discussing experiments as trailblazers, as it is frequently inferred that through their reduction of uncertainty in relation to the future, socio-technical experiments should also inform policymaking. This can be discerned in the following quotation:

No, but I think they are absolutely crucial. I mean we need to learn, we need empirics to start from. It's difficult for politics or for EI [the Energy Markets Inspectorate] to sit down and write a perfect regulation without knowing how it works or how customers react. We need pilot projects where we can observe how customers behave and what their drivers are. So I think that they are extremely important. ${ }^{553}$

\footnotetext{
${ }^{552}$ Of course, the validity of this point hinges upon how one defines "business as usual". Considering the very valid point pushed for example by Svenska Kraftnät about the new circumstances of the electricity system, such as difficulties maintaining balance as plannable power is removed and the penetration of intermittent renewables increases, where smart energy is imagined as a possible solution, smart energy experimentation can certainly be argued as being far from business as usual. On the other hand, smart energy experimentation is very clearly and firmly embedded within, and appears to strengthen, an ecomodern environmental politics which has generated very dubious results historically, it must be said, and in that sense comes very close to business as usual, including in terms of the constitution of the Swedish energy system. See e.g. Dauvergne 2016. Environmentalism of the Rich; Malm 2016. Fossil Capital.

${ }^{553}$ Interview EEC.
} 
The view represented in this quotation, that experiments should produce new knowledge through testing, which then informs policymaking, was common among the interviewed experts. Recall how a cabinet member of the Smart Grid Forum underlined how experiments were necessary to evidence-base policymaking. Another interviewee expressed similar views:

I think they are important because, I mean who will benefit from these experiences? I think that, I would like to move faster, but it's important for policymakers, for them it's very important to get these experiences. ${ }^{554}$

Socio-technical experiments are described as being important to dissolve uncertainty by showing what works in reality, and thus guiding policymaking through the knowledge produced. Consequently, the knowledge produced through experimentation is articulated as being central specifically for policymakers. Another interviewee described how sociotechnical experiments can be used either to identify the need to develop new regulations, or to test existing regulations, i.e. as policy input in quite straightforward terms. ${ }^{555}$ These examples illustrate how socio-technical experiments are articulated as important for policymaking, as they provide input so that regulations can be changed to facilitate transforming the energy system.

Connected to the previous section on experiments as mobilization, an interviewee at the Ministry of the Environment and Energy stated that it is possible for actors to influence politics through membership of organizations such as the Swedish Smart Grid Forum. ${ }^{556}$ This appears to grant a channel to politicians which is reserved for certain actors. The same interviewee also said that it is always possible for different actors to influence politics, although:

Right now there's no larger pilot project running like that, as far as I know. ${ }^{57}$

This seems to imply that it is easier for actors involved in large socio-technical experiments to gain access to and influence policymakers, which might be a reflection of the prevalent idea of mobilization which appears to favor large, commercial actors with the organizational capacity to run such large experiments.

Nonetheless, several other articulations of how socio-technical experiments can, and should, influence policymaking also appeared. Several actors mentioned the policy importance of the International Smart Grids Action Network (ISGAN), a sub-organization of the IEA, initiated by the Clean Energy Ministerial (CEM). CEM was founded in the aftermath of the COP

\footnotetext{
${ }^{554}$ Interview EXE2.

${ }^{555}$ Interview EXEI.

${ }^{556}$ Interview EXMEE, EXMEE1.

${ }^{557}$ Ibid.
} 
meeting in Copenhagen in 2009, and presents itself as "a high-level global forum to promote policies and programs that advance clean energy technology, to share lessons learned and best practices", and is made up of a number of countries described as leaders in developing clean energy technology, as well as "leaders" in terms of low greenhouse gas emissions. ${ }^{558}$ ISGAN was founded at the first convening of CEM in 2010, and describes itself as "a strategic platform to support high-level government attention and action for the accelerated development and deployment of smarter, cleaner electricity grids around the world". ${ }^{559}$ ISGAN wishes to promote smart energy policies and programs among its members to "accelerate the global transition to clean energy", illustrating how it is set up as a platform for knowledge exchange and policy transfer. ${ }^{560}$

Several of the experts connected to smart energy policymaking in Sweden stated that ISGAN is a central channel for disseminating results from socio-technical experiments. ${ }^{561}$ They often described how experiments are intended to be scaled up and replicated through the creation of new networks via ISGAN, similar to notions of changing energy infrastructure by creating interlinkages between actors, including through the use of dialogue forums in Sweden. However, a clear emphasis on marketing experiments is also prevalent in relation to ISGAN. One interviewee stated that it would be beneficial if socio-technical experiments carried out in Sweden were to produce better marketing materials, and summaries for policymakers in the form of short bullet points were specifically called for to facilitate policy transfer through ISGAN. ${ }^{562}$ This highlights how ideas about how experimentation contributes to change are inscribed into the governmental apparatus of smart energy experimentation. A particular infrastructure of knowledge circulation can be discerned, where lessons learned from experiments can be shared by experts within ISGAN, creating new interlinkages to facilitate scaling up experiments. Benchmarking within ISGAN appears to be a prominent modality of such knowledge circulation. Thus, we can again see how particular theories of change flow like an undercurrent among experts as they reason about smart energy experimentation,

558 Clean Energy Ministerial (undated). ABOUT THE CLEAN ENERGY MINISTERIAL. http:/ / www.cleanenergyministerial.org/about-clean-energy-ministerial [2019-05-23].

${ }_{559}$ ISGAN (undated). About Us. https://www.iea-isgan.org/about-us/ [2019-05-23].

${ }^{560} \mathrm{Ibid}$. This also resonates with the concept of policy mobility, which was discussed in the theory chapters, i.e. how policies often travel through more or less diffuse channels, often carried and championed by individuals. The policy mobility concept, however, is an attempt to analyze how policies change shape as they travel, and morph as they become embedded within local contexts, complicating the idea of straightforward policy transfer. See e.g. McCann \& Ward (eds.) 2011. Mobile Urbanism.

${ }^{561}$ E.g. Interview EXEA2; Interview EXEA3; Interview EXE1.

${ }^{562}$ Interview EXE1. 
shaping specific infrastructures of circulation, and thus arranging governance through experimentation in particular ways.

Assumptions about which types of knowledge are relevant to policymakers can be discerned across the material. There is a broad emphasis on conducting scientific experiments, often in an instrumental sense, to aid policymakers by evidence-basing policy as one interviewee expressed it, while carrying out large, high-profile experiments appears to grant access to arenas where policymaking can be influenced. This seems to be the case both nationally in Sweden and in international forums, such as ISGAN. Consequently, it is mainly large organizations with in-house R\&D capacity and know-how about the project funding world who are positioned as capable of providing the desired knowledge, or evidence, on which to base policy. ${ }^{563}$ It is rather peculiar that there is not even more outright deliberation on precisely how experiments are supposed to influence policy among policymakers, considering how this was often described as a key rationale of experiments. This aspect seemed so taken for granted that interviewees tended to get confused when questioned further on the topic. This can be interpreted as a central assumption infused by the political rationality underpinning smart energy experimentation, and consequently of the knowledge politics of this experimentation; large, private companies with in-house $\mathrm{R} \& \mathrm{D}$ capacity and well-established links to policymakers are positioned as central for generating the desired knowledge, so by extension their knowledge claims become central for policymaking. Or, rather, it is knowledge generated through public-private partnership consortiums that seems sought after and incorporated into the setup of experimentation, although the emphasis on making Sweden an environmental frontrunner through smart energy technology export assigns private companies a central position within the field of intervention that is constituted through experimentation, by virtue of their possibility to make knowledge claims that are deemed relevant.

\section{Socio-technical experimentation as demonstration}

Edwards and Bulkeley describe how socio-technical experiments tend to be assigned the role of dissolving uncertainty, by showing "what works in reality". ${ }^{564}$ They state that consequently, experiments are political spaces where future socio-technical configurations become folded into the present by virtue of material demonstrations and discursive storytelling. ${ }^{565}$ In the

\footnotetext{
${ }^{563}$ On the world of project funding within the EU, see Büttner 2019. The European Dimension of Projectification: Implications of the Project Approach in EU Funding Policy. In Hodgson et al. (eds.) 2019. The Projectification of the Public Sector. pp. 169-188.

${ }^{564}$ Edwards \& Bulkeley 2017. Heterotopia and the urban politics of climate change experimentation.

${ }^{565}$ Cf. Segal 1986. The Technological Utopians. In Corn (ed.). Imagining Tomorrow: History, Technology, and the American Future. Cambridge, MA: MIT Press; Nikoleris 2018. On the role of envisioned futures in sustainability transitions. Diss. Lund: Lund University.
} 
previous chapter, we saw that this is a prevalent feature of the political rationality underpinning smart energy experimentation in the Swedish context as well, since experiments have recurrently been assigned the role of dissolving uncertainty and leading the way toward the future. In this section, I will disentangle notions which surfaced when experiments were assigned the role of demonstration, to further analyze how experts designate roles for experiments when deliberating upon experimentation. This can further elucidate how experimentation arranges environmental governance, and how the political rationality enables and constrains certain arrangements through embedding specific assumptions, notions, and political technologies across governmental institutions and policy networks.

\section{Experimentation as showcasing the viability of futures}

An interviewee at the Energy Agency stated that experiments can illustrate the potential for different types of solutions:

It can be important to show opportunities [...] it is definitely mentioned in the initiatives we have, for instance connected to SamspEl [research and innovation program for electricity grids], we have said that we need to show new concepts. ${ }^{56}$

Here, socio-technical experiments are described as being necessary in order to show, or to demonstrate, new opportunities arising in the transformation of the energy system. The perceived need to show, or demonstrate, is palpable across the empirical material. In an interview with government officials from the Ministry of the Environment and Energy, it is explicitly stated that smart grid is a measure to face the future, and the interviewees describe pilot and demonstration projects as a crucial step in order to know what works. ${ }^{567}$ This is illustrated in the following quotation about the role of experiments in moving toward a sustainable energy system and society:

They are necessary. I mean, we can't change society through research reports. [...] And it has to be introduced to the market or the equivalent, otherwise it isn't an innovation and if it's not an innovation it has no contribution to the energy system. To get there you have to show somehow that it works, and especially when we talk about systems you have to show that the concept works. ${ }^{568}$

The interviewed government official is careful to point out that research results from experiments can benefit society in different ways. The quoted example of a product introduced on the market is not necessarily the only favorable outcome. The interviewee provided the example of guidelines for sustainable extraction of biomass as knowledge that can

\footnotetext{
${ }^{566}$ Interview EXEA1.

${ }^{567}$ Interview EXMEE.

${ }^{568}$ Interview EXMEE, EXMEE2.
} 
be utilized, argued to be just as valid an outcome from a research project as a product on the market. ${ }^{569}$ The same interviewee further stated that:

If it is just a thing which has been demonstrated in a lab it's an invention, not an innovation. To become an innovation it must get out and prove itself to work. ${ }^{570}$

The act of demonstrating is thus constructed as an integral part of leading the way toward the future through experiments, i.e. of trailblazing. The interviewee also offers a glimpse into how boundaries of experiments are constructed. There is a clear delineation between the figure of the lab and its outside, and the proof of the pudding for any innovation lies in demonstration. The importance ascribed to demonstration is unsurprising, considering the argument developed by Shapin and Schaffer about how experiments came to gain traction as a method for cementing truth claims. According to them, showing something publicly has long been a key feature of experiments which grant them legitimacy. ${ }^{571}$ This has been argued to constitute an integral feature of socio-technical experiments, for similar reasons. ${ }^{572}$ As the examples above show, demonstration also seems to be considered an integral component of smart energy experimentation. An additional example of this comes from an interview with a cabinet member of the Swedish Smart Grid Forum:

Yes, and I mean, if a housing association is thinking about going off-grid, their inclination to do so will increase I think if they can find an example showing that this works. ${ }^{573}$

The quotation highlights how demonstration entails persuasion, by providing an example of something that works "in reality" in order to persuade others to pursue similar lines of action. Thus, demonstration appears to be constituted as a central activity through the governmental apparatus of smart energy experimentation, since the demonstrative effect is intended to affect others to behave in specific ways, and to convince others that the configuration trialed in the experiment encompasses a future worth pursuing.

Connected to showcasing through experiments, an interviewee at the Ministry of the Environment and Energy stated that:

[...] a demonstration project is the end point of what can be done through research, development, and innovation tools per definition, since when you have managed to demonstrate something there

\footnotetext{
${ }^{569}$ Ibid.

${ }^{570}$ Ibid. Note that the Swedish word used by the interviewee was "visa", which means both literally "to show" and figuratively "to prove" in this instance.

${ }^{571}$ Shapin \& Schaffer 1985. Leviathan and the air-pump.

${ }^{572}$ See e.g. Laurent 2016. Political experiments that matter; Nikoleris 2018. On the role of envisioned futures in sustainability transitions.

${ }^{573}$ Interview CM1 Swedish Smart Grid Forum.
} 
is no news value in doing it again and therefore you can't continue with that instrument, you need other activities then. [...] but that is essentially another set of tools, for the research, development, and demonstration regulations it [demonstration] is the end. It's the grand finale, to show that something works, hopefully. Sometimes you show that something doesn't work, and that isn't as fun I suppose. ${ }^{574}$

Experiments are described as important to demonstrate something in this passage as well, but the final sentence brings out something new. The statement that it is less fun to show that something does not work is likely to be true in a trivial sense, i.e. that actors have invested time, money, and perhaps prestige in something which turned out not to work in the way it was imagined or hoped. It does however also speak to how the political rationality underpinning smart energy experimentation preformats experiments in particular ways: experiments play a central role in showcasing Swedish proficiency to substantiate the ambitions of becoming an environmental frontrunner through exporting smart energy technology. This was another aspect of demonstration recurrent in interviews, i.e. that sociotechnical experiments are important to showcase Sweden's proficiency through material demonstrations. This likely explains why a prominent viewpoint held across interviews with experts was the idea that experiments should be successful. Showing what works becomes a necessary precondition in order to build credibility as an export nation.

Connected to such notions, it was repeatedly emphasized in the same interview how smart energy demonstration projects are important in terms of having something concrete to show visitors, for example international delegations. ${ }^{575}$ The interviewees claimed that it is important to package smart energy experiments and to have something more than a substation present materially to show interested parties, in order for experiments to contribute to marketing and ultimately achieving the export goal. ${ }^{576}$ The shrouded character of a technical infrastructure such as a smart energy system complicate its widespread implementation, as it is difficult to engage individuals on a personal level in the development of this system, according to the interviewees. A shrouded technological infrastructure, such as smart energy, does not send a clear social signal in the same way that buying a new electric vehicle does. ${ }^{577}$ Consequently, the cultural value or symbolism is granted an important role in the development of a smart energy system. It needs to be made tangible in order to function symbolically, by showing that individuals are environmentally aware through installing solar panels and buying new electric

\footnotetext{
${ }^{574}$ Interview EXMEE, EXMEE2.

${ }^{575}$ Ibid.

${ }^{576}$ Interview EXMEE.

${ }^{577}$ Ibid.
} 
cars. ${ }^{578}$ Consequently, the interviewees suggest that a smart energy system needs to be made visible, to persuade others to change their behavior, or conducting conduct, and experiments are ascribed an important role here. Again, this points to a tension between testing through smart energy experiments and the stated goal of using experiments as a means of persuasion and to substantiate claims of Swedish proficiency in smart energy. In this instance, smart energy experimentation entails positioning private companies as central for engaging citizens in energy transformation endeavors, by introducing new technology at the disposal of these citizens, or rather customers, and thus highlighting how the market inclinations of the political rationality underpinning such experimentation influence practical reasoning on experimentation among experts.

The order of things described here, where experiments are articulated as being vital to showcase Swedish proficiency, ties in to showcasing the viability of futures through experimenting. A clear example of experiments as leading the way toward the future can be observed in the following phrasing:

Yes, they are important to show what works, and once you know what works you can actually use them in reality, and that's what you want. That's the whole point of investing in science and innovation, to transition to a sustainable energy system and for better, cleaner, more efficient products, services, and technologies to be applied..$^{579}$

Experiments are supposed to show what works in reality, and therefore map previously uncharted terrain. What they are tasked with is thus a folding of the future into the present, since they are supposed to be demonstrations of a future that is yet to be realized, but still have to negotiate the conditions of the present. ${ }^{580}$ When experiments are described as being vital for showcasing Swedish proficiency, however, it seems that there is less room for uncertainty or testing, since a desired future has in a sense already been decided on through the demarcations and assumptions contained in the political rationality underpinning smart energy experimentation. Showcasing through experiments to substantiate Swedish ambitions of becoming an environmental frontrunner through smart energy export, and the articulated need for testing and learning through experiments, constitute a tension that runs through the interviews with experts at various governmental institutions and policy networks. In the

578 Cf. Bauman 2007. Consuming life. Cambridge: Polity; Larkin 2013. The Politics and Poetics of Infrastructure.

${ }^{579}$ Interview EXMEE, EXMEE2.

${ }^{580}$ Of course, they also take place in the present in actual physical spaces, and must cope with all the sociomaterial conditions that come with that. Such aspects will be discussed in subsequent chapters on specific experiments. For more on this, see Wallsten 2017. Assembling the Smart Grid; Bulkeley 2016. Accomplishing Climate Governance; Stripple \& Bulkeley 2019. Towards a material politics of socio-technical transitions. 
following instance, an expert from the Energy Agency problematized the notion of experiments as leading the way to the future by demonstrating specific futures in the present:

I mean my main conclusions, specifically related to demonstration projects, in these complex projects with many actors you need to be incredibly humble about what a technical system should look like at the end. You need to focus much more on process goals and create preconditions for a development that favors innovation or sustainability, or whatever it is that you want. But if you start to specify what this should look like at the end, that's when you make a mistake. It's kind of similar to this thing with Svenska Kraftnät, which is a totally different question, but if you decide not to build a cable based on an idea of how things will look later, then you make that mistake because it's not how it will look later that should guide us, we need to think rather about how the development might look [...] the path is what's interesting and will affect so many things in a society which is not centrally planned..$^{581}$

In the quotation, the notion that socio-technical experiments are supposed to lead the way toward the future by showing what works is problematized, since techno-economically motivated decisions such as SvK's decision not to build a new transmission cable to Gotland is based on a rigid idea of how the future will look, extrapolated from the present, according to the interviewee. ${ }^{582}$ Socio-technical experiments should therefore be designed to take uncertainties, twists, and turns into account, rather than specifying a desirable future beforehand which should then be demonstrated. To some extent, this problematizes how experiments are ascribed the role of trailblazers, since the future is described as being too uncertain to capture in that manner. The interviewee rather emphasizes testing and adapting along the way through experiments. This provides a concrete example of tensions that the political rationality underpinning smart energy experimentation engenders as governance is arranged in practice, echoing frictions outlined in the previous chapter.

The overarching view that pilot and demonstration projects are supposed to decrease uncertainty, by showing what works in reality and thus paving the way toward the future, is however widespread. This idea surfaces in interviews with representatives from organizations such as the Energy Agency, the Swedish Smart Grid Forum, and the Energy Commission, as well as several energy field experts working for private, public, national, and international organizations. ${ }^{583}$ This is perhaps unsurprising, as the idea of testing something on a smaller scale, often with an emphasis on testing scientifically, to ascertain what works and what does not, is certainly not a new phenomenon. As we saw previously, contemporary society is often described as increasingly permeated by experimentation, for example describing cities as

\footnotetext{
${ }^{581}$ EXEA2.

${ }^{582}$ Cf. Adam 1998 Timescapes of modernity; Andersson \& Westholm 2019. Slaget om Framtiden.

${ }^{583}$ Interview EXEA1; Interview EXEA2; Interview CM1 Swedish Smart Grid Forum; Interview EEC; Interview EXE3; Interview EXE1; Interview EXE2.
} 
central change agents and arenas in terms of the experimental city. ${ }^{584}$ The pervasive projectification of the public sector further underscores how notions of testing something on a small scale and then scaling up are widespread. ${ }^{585}$ This is further reflected in contemporary environmental governance arrangements, emphasizing bottom-up efforts by cities and regions as central agents and arenas of change, where upscaling is an integral notion, as shown previously.

As socio-technical experiments are afforded this ability to show what works, however, they also implicitly show what does not work and thus they make certain futures more likely at the expense of others. ${ }^{586}$ Consequently, this ability that experiments are afforded in the Swedish context, of showing what works and what does not, tells us something about how power is configured as smart energy experimentation arranges environmental governance. As Edwards and Bulkeley argue, socio-technical experiments are not neutral journeys of exploration in which social and technical optimums are discovered objectively, but rather value-laden processes that influence how actual futures may come to pass through shaping "planning, infrastructure, bureaucracy, and indeed governance in the present". ${ }^{587}$ This seems to be verified by how different experts tasked with central roles within environmental governance through smart energy experiments reason about such experiments, since they are ascribed the ability to show what works and what does not, and are described as necessary to transform the energy system.

The political rationality underpinning smart energy experimentation appears to leave precious little room for uncertainty and testing, however. The knowledge that is made central through this political rationality is, as we have seen, foremost proprietary in the shape of product development by private companies, described as being necessary to reach the Swedish export ambitions. Seemingly, this demarcates what becomes possible, or at least desirable, to showcase through experiments. Criticisms of this order of things did however surface in the field, further illustrating the tension between testing and showcasing engendered by the political rationality of smart energy experimentation. An energy field expert stated that two primary purposes of pilot projects can be described as follows:

A pilot project is supposed to be the first test in a fully commercial environment, where you don't have commercial demands for results, but it is a commercial environment that you test. So I think that should be the primary purpose. The secondary purpose is almost always to showcase, which is

\footnotetext{
${ }^{584}$ Evans et al. (eds.) 2016. The Experimental City.

${ }^{585}$ Hodgson et al. (eds.) 2019. The Projectification of the Public Sector.

${ }^{586}$ Cf. Edwards \& Bulkeley 2017. Heterotopia and the urban politics of climate change experimentation. ${ }^{587}$ Ibid. p. 7.
} 
more of a demo than a pilot, to showcase a technology or to showcase a company's competence and innovative outward face, so pilot projects are also showcase projects. ${ }^{58}$

The interviewee continued by saying that for socio-technical experiments to function as intended, knowledge cannot be allowed to stay within the project consortium - it has to be shared with others:

$[\ldots]$ there are problems with this silo-thinking, which data you deliver outwards and I think that, if I am to be critical I think that the pilots we have, I think it's difficult to find examples of other grid operators who have said that well, this is interesting, they did this thing on Gotland, we should do that as well. I think it would be difficult to find examples of such firms. [...] Well, within the projects and as marketing windows [is where the projects have played a role]. ${ }^{589}$

Connected to this, the interviewee also said that:

No, I don't think it's the most important instrument. I think, I mean of course pilot projects are important, but pilot projects it tends to be, it easily becomes an island if it's not followed up at both ends, so to speak. [...] it becomes too much storefront and too little new technology. ${ }^{590}$

The interviewee is essentially saying that pilot projects are intended to showcase, but that means running the risk of putting too much emphasis on showcasing and too little on testing new socio-technical configurations. Connected to this, critique is also expressed against how knowledge generated through smart energy experiments often remains with participating firms. There is thus a criticism here of both experiments as demonstrations if they become "too much storefront", as the interviewee put it, and of knowledge not being disseminated outside the firms conducting experiments. The interviewee is very knowledgeable about the energy field, and has been involved in several smart energy policy initiatives, so there is most likely merit in this statement.

This highlights that the emerging governmental apparatus of smart energy experimentation is interlaced with a knowledge politics, which becomes visible through the deliberations offered by experts across governmental institutions and policy networks. The quotations above clearly illustrate how the governance arrangements around smart energy experimentation position certain actors as central and make certain knowledge claims more relevant than others. This is underlined in the tension between testing and showcasing through experiments, as the interviewee claims that experiments tend to become "too much storefront and too little new technology", highlighting how the emphasis on marketing Swedish proficiency and exporting smart energy technology conditions experiments. ${ }^{591}$ The critique expressed in the quotations

\footnotetext{
${ }^{588}$ Interview EXE1.

${ }^{589}$ Ibid.

${ }^{590}$ Ibid,

591 This could also be argued to arise as a consequence of projectification. See Ylijoki 2016. Projectification and conflicting temporalities in academic knowledge production. Theory of Science, 38(1). Ylijoki
} 
is articulated by a prominent actor in the energy field, but it is not a criticism that is prevalent beyond this actor and, importantly, it does not seem to have impacted the constitution of smart energy experimentation, at least not yet.

\section{Socio-technical experimentation as marketing}

Positioning Sweden in an international context through means of marketing, made possible by experiments, is often expressed as an important goal of experimentation across the material. The following quotation is indicative of such a line of reasoning:

When I go to a conference, I don't go to academic conferences, but if I go to one of these international conferences about smart grids, the other countries have professors and $\mathrm{PhDs}$ with them to talk. And that creates credibility. I mean, we have established a goal that Sweden is going to become a recognized knowledge nation in smart grids, and we can't achieve that only with people like me who are bureaucrats, or only private companies. You need academia on board as well, and obviously companies that have done the demonstrations. ${ }^{592}$

The quotation also highlights the idea that consensus and cooperation are necessary to achieve the ambition of turning Sweden into a prominent smart energy export nation. It should be noted, though, that the interviewee in this instance also referred to other motivations for both smart energy in general and experiments in particular, for instance as trailblazers, but the marketing aspect was repeatedly emphasized in the interview. Again, the contours of a knowledge politics of experimentation can be gleaned here, through the interviewee assigning researchers the role of joining coalitions of public and private actors at business conferences to market Swedish proficiency in smart energy, to grant legitimacy to claims of Sweden as a prominent smart energy nation. A connection to academic research seems to be considered necessary to provide credibility and gain influence internationally as a smart energy knowledge nation, which is in a sense a somewhat instrumental role reminiscent of articulating experimentation as technoscientific neutral tests. Science becomes important for credibility reasons, and for staking out the correct pathway forward through experiments. Not so much through testing, it seems, but more by establishing a consensus and aligning agendas in experiments, scientifically evidence-basing policy whilst contributing to marketing Swedish competence.

underlines how projects tend to stifle academic curiosity in knowledge generation processes, since there is precious little room for surprises in the controlled world of projects.

${ }^{592}$ Interview CM1 Swedish Smart Grid Forum; cf. Hall 2019. Why is innovation policy projectified? Political causes in the case of Sweden. pp. 39-41. In Hodgson et al. (eds.). The Projectification of the Public Sector. 
In another interview, it was stated that it is necessary to package projects for them to market Swedish competence in smart energy:

EXMEE1: Then it fulfills a purpose to visit these places, because otherwise it can be a little, when you integrate it with the entire society and smart cities it becomes a package. Otherwise, visiting a substation might not be very interesting, well here you can measure or get that information, but if you see the entire structure with charging cars or buses [...].

EXMEE2: And that also shows up conversely, when a minister travels to visit someone else, to have the experiences of that and perhaps accompanying companies, to market Sweden, I mean, it is this export idea. If you haven't shown anything you can't take up any position at all. [...] we have talked about solar panels and electric cars, and those are components of a future smart system, so it can be a matter of depiction. I mean, people are interested in electric cars, solar panels, and so on, so you could market them as parts of a smart system to a greater extent, rather than as separate components, and that can be kind of a message that politicians want to express. ${ }^{593}$

The government officials' reasoning in these quotations underlines the importance attributed to marketing through experiments, but also how experiments can be used for marketing purposes in conjunction with smart cities, for example. It is also connected to the perceived need for demonstration through experiments, to make something tangible, by way of presenting solar panels and electric cars as parts of a smart system, to paraphrase the interviewee.

This notion of packaging aspects of experiments for demonstration purposes, or for marketing, is prevalent in the material. The need for coordination is often articulated in connection with such ambitions. A cabinet member from the Smart Grid Forum explicitly brought up the importance of coordination and demonstration in conjunction with each other:

It is pretty fragmented today, actually. [...] smart grids, I'm sure you've noticed in your work that it pops up here and there, but there is no coordinated image. And that also leads to the need to make Sweden visible as a smart grid nation. [...] Creating visibility in the world is a big task as well [...] but it's also about making visible within Sweden. ${ }^{594}$

Here, the interviewee touches upon the need to conduct experiments, both to showcase Sweden internationally and to visualize smart energy as a sub-field of energy policy within Sweden. The first aspect, of showcasing Sweden, is connected to Swedish export ambitions. The perceived need to coordinate and cultivate a coherent image is in line with the argument that consensus is necessary for Sweden to realize its ambitions of becoming an environmental frontrunner through green energy technology export. The second aspect, of demonstrating within Sweden, speaks to a perceived need to showcase socio-technical configurations through

\footnotetext{
${ }^{593}$ Interview EXMEE.

${ }^{594}$ Interview CM1 Swedish Smart Grid Forum.
} 
experiments, since the Forum has been tasked with creating a knowledge platform. This feeds back to the perceived need to coordinate the development of smart energy in Sweden, reflected in the directive for the Swedish Smart Grid Forum as well as the preceding Coordination Council. The interviewee also argued for the need to disseminate results and knowledge from experiments, and stated that the Forum was engaged in a dialogue with research funders about this:

CM: It is partly about proactive initiatives, to talk to the funders of projects. Ideally you want it to be clearly stated in the call, I mean somewhat higher requirements related to reporting and participation in conferences to talk about what has been done. So that's one thing, that we have a dialogue, mainly with the Energy Agency to get the ones who have participated in projects to talk about them to a larger extent. And outside of academic circles [...] I think that experience shows we need to get better at spreading knowledge and making use of lessons learned. I mean, that is something that is already done, you make use of lessons learned in the next project, but also specifically for the dissemination of results. [...]

I: To whom should it be addressed?

CM: Well it is partly users of technology [...] let's say it's a technology that brings improvements for grid operators, it might decrease their maintenance, increase quality, robustness $[\ldots]$ which is then the value of it, it can increase customer satisfaction, then you want to reach the grid operators

[...] So that's one group, and then of course it's buyers in other countries. [...] To be able to demonstrate. ${ }^{595}$

The interviewee also stated that, as well as disseminating results from demonstrations and tests, it is also necessary to continue to push for more demonstrations and tests. ${ }^{596}$ This illuminates a knowledge politics of smart energy experimentation. It is described as being important to coordinate the development of smart energy, for two main reasons. First, in order to cultivate a coherent image of Sweden as a competent export nation in smart grids, where environmental issues are solved through optimization of the electricity grid and exports of new energy technology. Second, to arrive at a consensus on how to develop a smart energy system, by aligning actors in cooperative public-private partnership constellations. Consequently, it seems that spreading knowledge from experiments revolves to a significant extent around marketing Swedish competence internationally via the Forum and other actors, and around marketing specific companies' competence in terms of commercial smart energy products. There also seems to be an implicit assumption that after an experiment comes more experiments, which is in line with the export emphasis engendered by the political rationality, as it depends upon both developing new products and services, and also demonstrating these new products and services. ${ }^{597}$ The interviewee also quite clearly advances specific recipients

\footnotetext{
595 Ibid.

${ }^{596}$ Ibid.

${ }^{597}$ Murray Li 2019. Problematising the project system.
} 
and expected uses of these results, i.e. who experiments are supposed to demonstrate to, which also highlights a knowledge politics of experiments. It is mainly electricity utilities who can improve their customer relations, or buyers in other countries, who are described as recipients and users of knowledge generated through experiments. This highlights how smart energy experimentation is arranged in line with the broader green political rationality, crystallized in projectification, public-private partnerships, and neoliberal policies. Thus, it appears reasonable to claim that such experimentation is increasingly becoming incorporated into a broader, pre-existing governmental apparatus, lending further credibility to governance arrangements aligned with this apparatus.

A similar picture emerged in another interview, where marketing was described as a central aspect of experimentation:

Well both yes and no [if the Norra Djurgårdsstaden, Hyllie, and Smart Grid Gotland experiments have realized their purpose]. Because one purpose was about showcasing Sweden, this is how good we are and all that. And there I would say that even if the results aren't fantastic, that purpose has been realized. These projects have travelled, and they have been talked about, they have worked to show that Sweden is a frontrunner, as they say. In that sense they worked. ${ }^{598}$

As the quotation illustrates, the so-called flagships' main achievement is articulated as contributing to positioning Sweden by demonstrating a competence in the field of smart energy. It is also stated that the actual results of the projects are perhaps less interesting, but the marketing aspect is of such importance that this may not be a matter of great concern, since one of the goals was specifically to market Sweden, according to the interviewee. Additionally, the emphasis on how the experiments have travelled highlights how marketing seems to be a prominent mode of circulation of experiments in and beyond the Swedish context.

In an interview with another energy field expert, it was even claimed that the three large smart energy experiments of Norra Djurgårdsstaden, Hyllie, and Smart Grid Gotland were not sufficiently marketed:

EXE1: Yes, of course people who participated in the pilot projects and then became involved with the [Smart Grid] Forum, they have brought their knowledge with them. But there is no, there's nothing explicit. That's indirect knowledge that comes in. However, we have this working group for internationalization, from research to internationalization, and there one of the suggestions is precisely that the results from pilot projects should be disseminated more. If the goal is to showcase Sweden's knowledge in this field, and the pilot projects are of course also supposed to contribute to knowledge accumulation in Sweden, but it is also a way to showcase Sweden.

\footnotetext{
${ }^{598}$ Interview EXE2.
} 
I: Right. This export strategy?

EXE1: Export strategy. Then at least you have to make sure you have sensible material available in English to show who you are so that it's not just people coming there to visit from time to time.$^{599}$

In this instance, the interviewee argues that actors in the three smart energy experiments did not manage to market their efforts enough, which is considered important in relation to the export goal. It is also stated that the experiments are important for knowledge accumulation, but according to the interviewee this has not been realized to the extent it could have been:

Exactly, it stops there, and of course it is also an internal knowledge accumulation within the organization which I think is very important, but one expects the pilot projects, if they are to be marketed, they need to have clear messages. If you look at other countries and compare internationally, other pilot projects have been carried out and there you are supplied with something like, ten conclusions, this is what we've learnt. There is a need for a thorough marketing strategy, and the Forum, in that strategy from research to internationalization, it is pointed out that these are

silos. That pilot projects should have a clear marketing channel, and the material should be presented in English so that others can read it. But that strategy has been specifically focused on facilitation, and not so much on internal learning. But even the internal learning, I mean the reporting within Sweden, what other grid operators can learn from Norra Djurgårdsstaden, we don't have that either really. ${ }^{600}$

Here, the interviewee is critical of the participants in the flagship experiments, as they have been unsuccessful in marketing their projects. As the quotation illustrates, this is explicitly connected to the export strategy. It is also stated that the experiments have likely been great learning experiences for the involved companies, but the knowledge generated appears to have stayed within these companies to a large extent. This is similar to the opinions expressed by a cabinet member of the Smart Grid Forum, accounted for previously, who stated that the dissemination of results was an integral aspect of experiments which can be improved. Here, we can discern the contours of a knowledge politics of smart energy experimentation. As the interviewee stated, the firms involved in socio-technical experiments have probably learnt a lot, but this knowledge tends to move inwards rather than outwards. As we have seen, the knowledge generated is seemingly often expressed to possess value mainly as a persuasion tool, to get others to buy in to specific socio-technical configurations tested in experiments, or to get others to buy smart energy products from Swedish firms. Additionally, as this quotation highlights, it is often knowledge of a proprietary nature that is valued and positioned as central, as such knowledge is imperative both for the development of new products for export, and to make knowledge claims about Swedish competence in smart energy. Thus, knowledge generated through smart energy experiments mainly appears to be considered valuable in

\footnotetext{
${ }^{599}$ Interview EXE1.

${ }^{600}$ Ibid.
} 
commercial terms, to market Sweden or to persuade others to buy products from competent Swedish firms. However, the interviewed energy field expert appears to be critical of such knowledge politics, as it is stated that there is a lack of internal learning within Sweden, such as other grid operators learning from the smart energy experiment in Norra Djurgårdsstaden.

As illustrated in this section, the idea that experiments are important for marketing recurred frequently in interviews with experts across governmental institutions and policy networks, often interlinked with the goal of making smart energy into an export industry and Sweden into a prominent smart energy nation, in line with the political rationality underpinning smart energy experimentation. This articulation of experiments, however, highlights a tension within smart energy experimentation. This tension surfaced in an interview with a civil servant from the Energy Agency:

They [socio-technical experiments] are important for society I would say, I mean for the development of the business sector and, well politics, especially related to sustainability [...] But then, I mean, to nuance that picture, in parallel with Smart Grid Gotland and Norra Djurgårdsstaden, similar projects have been carried out all over the world. And, looking at it from a negative perspective, I think they know very little about each other, even though they've actually

met, and that makes you think about and evaluate how important the marketing is and how important the actual results are. And there, I think, the marketing might be, unfortunately, a bit too important. Those who have been good at marketing, they have greater influence than those who actually have the good results. At least in the short term - it remains to be seen in the long term. In Korea, for instance, there is an example, Jeju Island, which was an enormous project, a lot bigger than these, and it was hugely publicized, but as a technical project I don't think it achieved anything other than a gigantic PR campaign $[\ldots] .{ }^{601}$

Connected to this, the interviewee also problematized how socio-technical experiments are often inscribed with many different goals since these might clash:

And they, as researchers and as someone who is going to sell a product, and this is kind of somewhere in between, there are researchers involved but the actual project might be too focused on selling it to governmental agencies or policy, and then it doesn't, well you might not do that homework as well $[\ldots]{ }^{602}$

The civil servant states here that experiments might become problematic as the involved actors might have very different goals, and these can be difficult to align. He points to how there might be different priorities within experiments, between different actors involved in experiments. This line of reasoning is also reminiscent of how one of the energy field experts talked about the many different goals ascribed to experiments, as detailed previously. ${ }^{603}$ One

\footnotetext{
${ }^{601}$ Interview EXEA2.

${ }^{602}$ Ibid.

${ }^{603}$ Interview EXE1.
} 
of the issues connected to this concerns how experiments are expected to create certainty, through folding the future into the present and showing what is possible to do. This might be difficult to achieve if too many different goals are ascribed to experiments, since it might blur the lines in terms of what they are supposed to achieve and whom they are actually for. Connected to the frequent and often emphatic emphasis on marketing and export goals, this might risk displacing other goals, which the civil servant from the Energy Agency seems to hint at. It is stated that marketing often becomes more important than other goals, and this becomes problematic since the political rationality underpinning the governmental apparatus of smart energy experimentation primarily predisposes experiments to fulfill the role of marketing. Importantly, marketing operates on several levels, which the quotation above illustrates. It is a matter of marketing Sweden to fulfill the export ambition, but also a matter of marketing for individual private companies. It remains to be seen in upcoming chapters whether such goals are expressed across and beyond specific smart energy experiments as well, and if so, how this contributes to accomplishing environmental governance.

\section{Moving beyond experiments? Achieving transformative change through experimentation}

Throughout the chapter, implicit assumptions about how to achieve transformative change through experimentation can be traced across interviewees' articulations. Such notions constitute an integral part of how smart energy experimentation institutes environmental governance, since they structure, or at least inform, how experimentation is set up and thus how the field of intervention for environmental governance is constituted. In this part of the chapter, we will look more closely at some examples of where interviewees explicitly reflect on how to achieve transformative change through experiments, often phrased as "moving beyond" experiments.

In the instances accounted for thus far, we have seen how moving beyond experiments is often phrased as scaling up experiments. This is often connected to the TRL scale, embodying a sequential order of innovation. One interviewee stated that Sweden currently lacks a coherent approach to smart energy experimentation, and called for the utilization of the entire chain, or staircase, on the research and innovation scale, as accounted for previously. This interviewee referred to large pilot and demonstration projects as one particular step on such a staircase, but stated that the Swedish approach to experimentation was currently too ad hoc, and that there was no clear political direction marked out which involved the entire innovation chain. There is a need for test beds, product development, and reference plants, according to the interviewee, otherwise there is always the risk that it will be the private companies who simply decide themselves what to do in experiments. This constitutes a clear criticism of a particular ordering of smart energy experimentation, in terms of setting up and following up on experiments. The interviewee further stated that: 
It can be interpreted as centrally planned but, it's some kind of strategic choice [that is needed], that it's a type of solution that we need from start to finish. ${ }^{604}$

Here, the interviewee clearly calls for the state to take a more active role in ordering smart energy experimentation. Even more clearly expressed, it was stated in the same interview that:

What's missing is what comes after the pilot. What I think should be done in a pilot is to test a new technology that is not yet commercialized, if you show that it works you need to follow it up in some way. [...] Commercially available but untried technology in Sweden, that part is neglected, which was discussed in the Coordination Council. Just because something was successfully installed in Canada, for instance, doesn't mean that Swedish grid operators will go for it, there may be tons of practical issues. [...] it often stays at pilots, but we need reference plants that are really commercial. ${ }^{605}$

The quotation highlights a critique of the setup of experimentation. In particular, the lack of following up on, or moving beyond, experiments is singled out. It is relevant to note that the interviewee stated that this was an issue discussed in the Coordination Council, but one which still seemed problematic from the interviewee's perspective, several years later. It is, however, important to note that the criticism is not aimed at the implicit notion of how to achieve transformative change through experimentation. Energy transformation is still depicted in terms of market solutions, where the TRL scale constitute a central organizing political technology along which the field of intervention is structured. Remedying environmental issues is still a matter of technological innovation in this depiction, albeit more clearly guided by the state. So environmental governance arranged through smart energy experimentation becomes a matter of developing new products, commercializing them to optimize the current energy system, often depicted as interlacing it with ICT, and then exporting such solutions abroad.

This interviewee was not alone in such an assessment. Recall also how several interviewees stated that smart energy was currently fragmented, and the recurrent emphasis on cooperation and making the energy industry and public administration come together and pull in the same direction. To achieve this, coordination was frequently depicted as necessary, embodied in the Coordination Council and the Smart Grid Forum. Coordination was often coupled to a perceived need to cultivate a coherent image of Swedish proficiency in smart energy to realize export ambitions. Even though some interviewees problematized the "chain of innovation" crystallized in the TRL scale, smart energy experimentation is largely ordered along such lines, as both this and the previous chapter have shown. This means that transformative change is constituted as being achieved through mobilizing actors in public-private partnership constellations in experiments, to develop new smart energy products and services which can then be commercialized. As we have seen, this order of things is predicated upon particular notions of socio-technical change, particularly as interviewees described large-scale

\footnotetext{
${ }^{604}$ Interview EXE1.

${ }^{605}$ Ibid.
} 
experiments run by large, incumbent private companies as being necessary for mobilization. This is partly a result of the grid infrastructure and historically sedimented actor constellations, as highlighted in the background chapter, but it is also very much in line with the political rationality underpinning smart energy experimentation. As a project manager at ABB stated, now that new technical solutions had been developed through the experiments in Norra Djurgårdsstaden and Smart Grid Gotland, it is up to the private companies, primarily the grid operators, to buy and implement these solutions. ${ }^{606}$ Moving beyond experiments entails the commercialization of new products. This highlights a particular mode of circulation embedded within assumptions about experimentation, as an experiment is intended to achieve change through new products being circulated and implemented into the energy system by grid operators.

Another interviewee, an energy field expert, repeatedly stated that there was a lack of political vision for transforming the energy system, as accounted for throughout the chapter. In the following quotation, there is an explicit reference to a lack of following up on experiments, in line with the calls for more active governing by the state outlined above:

I listened to a great presentation about public-private, who does what, and he said that of course the public has a role to play in terms of basic research, but then he said that the public's most important task is to create a market by regulation. The rules and regulations are not supposed to be a hindrance, they should support this. ${ }^{607}$

The quotation highlights a perceived need to change regulations in order for a smart energy system to be developed, which the interviewee stated had been lacking after the flagship projects. Rather, it was stated, the flagship projects contributed new knowledge, or pinpointed important issues to paraphrase the interviewee. The experiments showed that it is impossible to focus only on technology, a mistake which was initially made in all the projects, according to the interviewee. In practice, they had not managed to spread, other than to position Sweden favorably in an international context as a proficient smart energy nation. The interviewee stated that despite the hectic construction work going on all around Stockholm, no Norra Djurgårdsstaden 2.0 could be seen, despite the explicit hope that the smart energy experiment could provide a blueprint for how to build smart homes and optimize urban electricity grids. ${ }^{608}$ This highlights a critique, again, related to achieving transformative change through experiments. As another interviewee stated, if experiments are not followed up on, they can easily become lonely islands. ${ }^{609}$ The case of making Gotland into an energy pilot region was, however, explicitly referenced as a great way of moving beyond experiments, and explicitly framed as a form of upscaling of the preceding Smart Grid Gotland experiment. ${ }^{610}$

\footnotetext{
${ }^{606}$ Interview PM ABB.

${ }^{607}$ Interview EXE2.

${ }^{608}$ Ibid.

${ }^{609}$ Interview EXE1.

${ }^{610}$ Interview EXE2.
} 
The key to moving beyond experiments in this case was expressed as the Energy Agency's mandate to propose changed regulations in the Gotland investigation, as this could really make things happen, to paraphrase the interviewee. ${ }^{611}$

Another energy field expert expressed a similar viewpoint, stating that people involved in research and innovation tend to highlight the need to first conduct small-scale projects, then large-scale projects, but perhaps it would be more efficient to change the regulations to allow for legislative exceptions in smaller projects, for example related to tariff structures. ${ }^{612}$ Thus, it is rather legislative changes that are deemed necessary to transform the energy system, or at least are articulated as a central instrument rather than experiments. In contrast to this, a government official at the Ministry of the Environment and Energy stated that it is impossible to understand energy transformation as a causal process of taking step after step. Instead, it was described as more interactive and creative. ${ }^{613}$ Nonetheless, the need to follow up on experiments stands out as an almost unilateral consensus across the material, despite this instance hinting at something messier.

It is noticeable that there is almost complete consensus across the material of the need to carry out experiments to transform the energy system. As the instances above have shown, concerns were however raised regarding what comes after an experiment, or how to achieve transformative change extending beyond individual experiments. A lack of following up on experiments was expressed. Across interviews, it was often pointed out that responsibility for this should primarily be placed with the Energy Agency, as a funder of experiments. ${ }^{614}$ In concrete terms, following up on experiments was often characterized as learning from experiments and spreading such knowledge. A civil servant stated that the main result of the three flagship projects for the Energy Agency was feeding into its internal renewal of the research funding strategy for the electricity grid area. ${ }^{615}$ This renewed strategy meant a decreased focus on large pilot and demonstration projects, making smaller experiments a higher priority, according to the interviewee. It was pointed out during the interview that there were still possibilities to continuously apply for funding for large demonstration projects, but that this was no longer a priority. The reasons given for this were both a specific notion of socio-technical change, as discussed previously, where large demonstrations are assigned a central role for mobilizing actors and creating arenas, and the fact that running such large projects with many actors involved over a long period of time had proved extremely difficult. According to the interviewee, temporality was one of the central challenges of running such large projects, since technology development and regulatory change occurred simultaneously

\footnotetext{
${ }^{611}$ Interview EXE2.

${ }^{612}$ Interview EXE3.

${ }^{613}$ Interview EXMEE, EXMEE2.

${ }^{614}$ E.g. Interview EXE3; Interview EXSvK.

${ }^{615}$ Interview EXEA1.
} 
as the projects were ongoing, and thus ideas that were deemed innovative at the start of the projects became markedly less so during their running time. ${ }^{616}$

The civil servant also made the point that learning from smart energy experiments was not primarily a matter for the Energy Agency, but rather for the companies involved:

We specify interventions, we don't run the projects, so in that sense we might not be the primary target in terms of learning from projects. That's rather for those who run the projects, or those whose operations are impacted by the results of the project. ${ }^{617}$

Further, it was stated that the Energy Agency had organized a meeting where actors from the consortiums of the three flagship projects had met to discuss experiences and lessons, described as a knowledge transfer project, and then the final reports of the projects were assessed by the relevant civil servants. ${ }^{618}$ On this topic, the interviewee stated that:

I mean we talk across department boundaries [within the Energy Agency], but we haven't organized any specific effort where these large pilots were discussed, or at least not to my knowledge. This has mainly been for those at the Agency who are responsible for these types of projects [...]. We haven't had any specific knowledge diffusion activity, it's within the organization, but how many know about the experiences from these specific pilots I don't know. That's difficult to say ${ }^{619}$

Another civil servant from the Energy Agency painted a similar picture, stating that a lot had been learnt through the three flagship projects, but it was not the agency's task of summarizing or packaging these experiences; this was rather a task for the companies involved. ${ }^{620}$ The interviewee stated that the Energy Agency's task is to kickstart things, providing opportunities for the energy industry to test technologies, rather than learning specific things from the experiments themselves. The civil servant also stated that sharing lessons and new knowledge from experiments occurred through policy networks, referring specifically to ISGAN as an important channel for sharing knowledge from experiments which could provide policy input. ${ }^{621}$ However, another interviewee, with wide-ranging insight into ISGAN, stated that this is not entirely true, since discussions within ISGAN are kept at a more aggregated level, meaning that results and experiences from specific experiments do not usually filter through or make it into discussions in that forum. ${ }^{622}$

The relevant point here is that it highlights how there is no clear answer to the burning question of how to achieve wide-ranging change through experimentation. It was repeatedly stated across interviews that experiments are vital, but no organization claimed responsibility for following up on experiments. As the instance with ISGAN above highlights, this seems rather

\footnotetext{
${ }^{616}$ Ibid.

${ }^{617}$ Ibid.

${ }^{618}$ Ibid.

${ }^{619}$ Ibid.

${ }^{620}$ Interview EXEA3.

${ }^{621}$ Ibid.

${ }^{622}$ Interview EXE1.
} 
fragmented. Most interviewees placed the responsibility for learning from and moving beyond experiments firmly with an organization other than their own. Apart from the Energy Agency, the Energy Markets Inspectorate - as the regulatory agency - is often assigned the role of learning from experiments. ${ }^{623}$ A civil servant from the Energy Markets Inspectorate, however, stated clearly that learning from experiments is a matter for the Energy Agency. ${ }^{624}$ Additionally, it was stated that:

More indirectly, it's the overall state of knowledge [rather than the flagship projects having provided policy input to the Energy Markets Inspectorate]. I would say that if you want to describe it as if the pilot projects have had a big impact, I don't think that's the case for us as of yet. [...] We are rather disconnected from the pilot projects. ${ }^{625}$

The interviewee underlined that experiments have a role to play in transforming the energy system, but learning from experiments is a matter for the Energy Agency, not the Energy Markets Inspectorate. At the Ministry of the Environment and Energy, an interviewee stated that the Smart Grid Forum plays a central role in learning from experiments and then conveying this knowledge to the Ministry of the Environment and Energy. ${ }^{626}$ A cabinet member at the Forum, however, stated that this is a task for the funders of experiments, i.e. the Energy Agency, rather than the Forum. ${ }^{627}$

This section has underscored that experts certainly think about how to achieve transformative impacts through experimentation, beyond instrumental notions of upscaling, even though such notions are also present in the material. Several interviewees pointed out issues in the current setup of experimentation which make it difficult to achieve transformative change. Nonetheless, it seems that the political rationality underpinning smart energy experimentation constrains such a reconfiguration of governance. The governmental apparatus that smart energy experimentation is being incorporated into is rigged in favor of marketing Swedish competence in smart energy to pave the way for exports, giving private companies a prominent position to market themselves as well. Coupled with the recurrent emphasis on the need for consensus and cooperation, it seems difficult to achieve the broader changes imagined to be brought about through mobilization within and beyond experiments, as desired by policy experts. This also holds true for the techno-economic language widely used in the field of smart energy, constituting techno-economic knowledge claims as being central for experimentation, thus casting energy transformation as a question that is uninteresting for common citizens, positioning people mainly as customers.

Further, a prevalent feature of the political rationality is that it becomes difficult to allocate responsibility in settings marked by public-private partnerships and projectification, as visible

\footnotetext{
${ }^{623}$ E.g. Interview EXE3; Interview EEC; Interview EXE1.

${ }^{624}$ Interview EXEI.

${ }^{625}$ Ibid.

${ }^{626}$ Interview EXMEE, EXMEE2.

${ }^{627}$ Interview CM1 Swedish Smart Grid Forum.
} 
in the section where different actors firmly placed the responsibility of learning from experiments with actors other than themselves. Despite a regular insistence on systematicity in policy documents and allusions to a scientific approach through experiments, such systematicity is not visible in conceptualizations of following up on experiments. A panel was organized at a conference, asking the question of how to scale up, where one of the speakers briefly alluded to networking and finding each other through arenas such as the one provided by the conference. This might seem trivial, but none of the other panelists had any clearer ideas about how to achieve transformative change through experiments, indicating perhaps that such ideas are not abundant or made peripheral. The order of things emerging, encompassing the assumptions and delineations permeating the political rationality underpinning smart energy experimentation, seems to make knowledge generation and knowledge claims through experiments a matter mainly for private companies, as one interviewee critically remarked above.

The analytical point to highlight through this section is that while experts clearly reflect on how to achieve transformative change, there are no clear ideas about how to move beyond experiments expressed or described across the governmental apparatus. The political rationality underpinning smart energy experimentation makes energy transformation a matter of introducing new products and services to the market and through profiling Sweden as a prominent export nation, implicitly requiring new experiments to constantly develop such new products and maintain the newly achieved status as a proficient smart energy nation. The field of intervention for environmental governance is thus delineated to solutions that are ready to be provided by experts within $\mathrm{R} \& \mathrm{D}$ and marketing departments at private energy companies, often in partnership constellations with municipalities. Solving environmental issues is thus cast as a matter of developing new products and services, introducing these to the market for customers and grid operators to buy and implement, interlacing the energy system with ICT whilst exporting smart energy technology abroad. As we have seen, this constitutes a particular way through which experimentation arranges environmental governance, reflecting the broader political rationality.

\section{Analytical discussion}

We can gather that arranging environmental governance through smart energy experimentation entails specific notions of change and is ordered in line with a broader emphasis on market solutions in environmental politics. The TRL scale embodies such notions of change, rendering the field of intervention technical via a notion of innovation as unfolding sequentially. This positions certain actors as central, as described, whilst delineating the field within which environmental governance is configured in line with a broader political rationality. Efforts to achieve consensus and cooperation, often in public-private partnership constellations, are central in the field of intervention constituted through smart energy experimentation. Experiments are often depicted as neutral, technoscientific tests which can guide the way forward. There is no wider public debate, or even open debates within the 
energy sector, although opinions clearly differ, as shown, on the role and constitution of smart energy experimentation. Experiments seem to be largely viewed as neutral scientific tests, to discover techno-economically optimal routes forward toward a seemingly inevitable energy transition. Some interviewees stated that it is impossible to stop the energy transition, and that no one can be against smart grids. ${ }^{628}$ Others claimed that the Energy Commission had raised the knowledge level in energy policy, making everyone strive in the same direction, whilst experiments were assigned the role of evidence-basing policymaking. Large-scale experiments in line with the centralized electricity system architecture which has been prevalent in Sweden for a long time are a preferred mode of experimentation. This highlights the importance of socio-material factors, such as the grid infrastructure in Sweden, and historically sedimented power relations that have co-evolved with the development of this infrastructure. The substantial market emphasis and export orientation reveals a lineage with an ecomodern environmental politics, deeply rooted in the Swedish state since the mid-1990s.

A political rationality underpinning smart energy experimentation, laden with a knowledge politics, can also be discerned as experts deliberate on experimentation. The emphasis on public-private partnerships, experimentation as thoroughly projectified, and a preference for neoliberal governance arrangements highlight the influence of such a political rationality. It is further visible in the positioning of actors through the emerging governmental apparatus of smart energy experimentation. Large, incumbent private energy companies are very well positioned to utilize the techno-economic framing of smart energy, since they have in-house $\mathrm{R} \& \mathrm{D}$ departments with technical expertise, social networks, access to funders, knowledge of research funding infrastructure, access to key policy arenas, and thus the ability to run largescale experiments, which seems to be favored. A clear expression of how the knowledgeconfiguring activities constituted through experimentation entail delineations and structure the field of intervention was discerned in relation to achieving transformative change through experiments. While experts clearly reflected on how to profoundly transform the energy system through experiments, no clear ideas about how to move beyond experiments could be discerned across the material. The political rationality underpinning experimentation casts energy transformation as mainly a matter for the market. Achieving environmental goals is constituted as developing and commercializing new products and services, as well as profiling Sweden as a prominent smart energy export nation, and it thus follows that after an experiment comes more experiments. The field of intervention for environmental governance is consequently rendered technical as it is delineated to solutions ready to be provided by experts at private energy companies, often in partnership with public actors. Developing new

${ }^{628}$ Cf. Andersson \& Westholm 2019. Slaget om framtiden; Adam 1998. Timescapes of Modernity; Edwards \& Bulkeley 2017. Heterotopia and the urban politics of climate change experimentation. 
products and services for introduction to the market becomes the prime method for solving environmental issues, casting energy users as customers.

The trailblazing ability ascribed to experiments by interviewees can serve as an example to further illuminate how the political rationality conditions the way experts across governmental institutions and policy networks think about and handle smart energy experimentation in practice. Trailblazing, leading the way into the future by reducing uncertainties, is clearly connected to how experiments are also often articulated as mobilization for change, being described in terms of efforts which mobilize actors to achieve change. We saw how there seemed to be a knowledge politics at play, related to which actors actually have the resources required for mobilization, e.g. in terms of internal $R \& D$ infrastructure, know-how, capital, social networks, and access to policy arenas. Related to articulations from experts connected to policymaking across the energy sector, mobilization through experiments often seemed to be imagined as necessitating arrangements favoring large incumbent private companies. The assumptions that can be discerned here highlight a specific notion of socio-technical change. First, an issue must be highlighted and momentum built through large experiments, such as demonstration projects with established actors, and then when the ball has been set rolling, as one interviewee expressed it, experimental initiatives can be widened to enroll more actors through changed research funding strategies. In spite of some ambiguities, as well as reflexivity among interviewees, the chapter has elucidated how the political rationality enables and constrains experts as they grapple with smart energy experimentation. The frequent references to the TRL scale are in line with the notion of socio-technical change as outlined above, and the setup of programs such as project funding provides a further illustration of this. The contours of a knowledge politics of smart energy can also be glimpsed in connection with this disposition, where knowledge generation within private companies and knowledge claims by such companies become central, and actors are positioned in particular ways, such as state agencies functioning as facilitators through launching large experiments with the intention of creating arenas for cooperation and discussion for private firms, the public sector, and academia, while other governmental bodies are assigned the task of coordinating the field, stitching together this order of things.

Taking the trailblazing ability of experiments seriously, however, there is a risk that with such an approach - emphasizing how enrolling large, incumbent private companies is a necessary first step in achieving socio-technical change - meaning formations connected to smart energy will already have been sedimented through the experiments, if they fold the future into the present convincingly enough. It is therefore important to pose the question whether experiments govern in specific directions, rather than being structured and performed as exploratory, iterative, and adaptive learning experiences. This is a question for subsequent 
chapters, but it is important to point out the obvious risks of such a setup of environmental governance through experiments, as detailed in numerous other studies. ${ }^{629}$

As we saw throughout the chapter, experts were reflexive about the setup of experimentation, and sometimes expressed outright criticism. One interviewee, for instance, criticized how private companies were granted too much leeway in deciding the content of experiments, as well as keeping generated knowledge proprietary. Tensions appeared in discussions about whether socio-technical experiments can actually be considered tests, and how to set up experiments to also include smaller firms. There seemed to be recognition among the interviewees that experiments are often about muddling through, although experiments are ascribed an important role in environmental governance, to facilitate achieving climate and energy policy goals. One interviewee from the Energy Agency made a point of emphasizing the uncertainties surrounding experiments, arguing that uncertainties related to smart energy experiments had actually generated interesting results from the Energy Agency's perspective. This interviewee also articulated how it is imperative not to focus too much on specific technological goals during the course of a project, as this can be detrimental to knowledge generation through experiments.

This line of reasoning hints at certain risks with socio-technical experimentation when organized through projects, however, when viewed in the light of Tania Murray Li's analysis of projects as a mode of organization in the public sector. She argues that the project form tends to displace political debate about possible futures, which through the project form is often replaced with piecemeal interventions. She writes that:

After a project is over, no one expects to see a lasting result of the kind anticipated in the technical matrix that served to legitimize it. A successful project is one that generates a flow of revenue, and more projects. ${ }^{630}$

Additionally, it was also articulated that in order to manage to assemble the three so-called flagship projects, large incumbent actors had to be persuaded by setting up the experiments in favor of these actors developing new technology to sell. The question then is what space is left for uncertain testing, especially in terms of attempts to achieve transformative change beyond singular experiments, if economic growth and exports are given precedence over other goals, as implied in the instance referred to here. This tension also surfaced when experiments were discussed in terms of demonstration, particularly in the form of marketing. It seems that despite reflexivity among experts, smart energy experimentation currently configures

${ }^{629}$ Cf. Murray Li 2019. Problematising the project system; Hultman 2015. Den Inställda Omställningen.

${ }^{630}$ Murray Li 2019. Problematising the project system. p. 62. 
environmental governance in line with a political rationality which renders such concerns superfluous, constituting commercialization, techno-economic expertise, consensus, and cooperation as central modi. Highlighting the broader political rationality underpinning experimentation and how experimentation is incorporated into a broader governmental apparatus, can illustrate the conditions of possibility for experimenting for change and, importantly, moving beyond experiments in the Swedish context. These first two empirical chapters have excavated the playing field in a sense, or set the scene, which allows for an analysis of the dynamics of how environmental governance is produced through and beyond smart energy experiments. We have seen how particular notions, practices, and arrangements of experimentation seem nested across governmental institutions and policy networks, as well as frictions generated by the political rationality as experts deliberate upon experimentation.

Taken together, the analysis in these two chapters provides insights into how smart energy experimentation arranges environmental governance. They show how such experimentation can be analytically approached both as an emerging governmental apparatus in its own right, but also how it is becoming incorporated into a broader, pre-existing governmental apparatus and might thus be productively interpreted as constituting an important element in wider contemporary governance structures. We have seen how smart energy experimentation dovetails with, draws upon, and gives impetus to neoliberalization processes, primarily leaning into public-private partnership constellations pursuing green economic growth in a projectified setting, and how it is underpinned by a broader political rationality. The next chapter will attend to how governance is produced, or accomplished, in specific urban experiments. This will allow for an analysis of whether different experiments re-embed, reconfigure, or challenge the political rationality underpinning smart energy experimentation. Are different boundaries being drawn in different cases of experiments, and which actor relations are assembled in practice? How is the field of intervention for environmental governance constituted through and beyond different experiments? How do actors within experiments attempt to achieve transformative change beyond singular experiments? Answering these questions can highlight interlinkages between spaces of governance, elucidating the reach of the political rationality, and can consequently highlight how smart energy experimentation arranges environmental governance as interventions are assembled. ${ }^{631}$ Thus, the dynamic of how environmental governance is arranged through concrete cases of experiments as well as the broader governmental apparatus of experimentation can be empirically described and interpreted. 


\title{
Shaping smart energy futures: accomplishing environmental governance through urban experiments
}

\begin{abstract}
Cities have increasingly been afforded a central role as both actors and arenas of environmental action, not least as locations of sustainability-oriented experiments. Sweden is no exception; many smart energy experiments are currently undertaken in urban contexts across Sweden. This chapter analyzes how environmental governance is accomplished through three such urban experiments in Stockholm, Malmö, and Västerås. Smart Energy City in Norra Djurgårdsstaden constitutes the main empirical focus of the chapter, while smart energy experimentation in the city district of Hyllie in Malmö, and in the city of Västerås, are contrasting cases. The chapter includes continuous comparative analysis between the cases, ending with an analytical discussion to summarize key points made in the comparative analysis. Empirically, the analysis is based on texts such as local policy documents and project documents, as well as interviews with actors participating in experiments and working within local public administrations, complemented by observations and site visits.
\end{abstract}

The focus is on how governance is accomplished through these experiments, as different problematics are drawn upon and heterogeneous elements are assembled into dispositions of people and things. Conceptualizing environmental governance as accomplishment entails the assumption that such specific accomplishments create linkages between spaces of governance, and through these processes delineate the problem to be solved by drawing upon and potentially reconfiguring broader political rationality. Consequently, the analysis addresses a lower level of analytical abstraction than the previous chapters to contrast unfolding governance processes, thus highlighting how governance is an accomplishment in the making that is continuously arranged across different spaces. The analysis centers on how governance is arranged beyond imagined spatio-temporal confines of individual urban experiments, tracing how relations are assembled and showing which actor constellations are forged through and beyond different experiments, how certain actors are positioned as authoritative for experimenting, how certain knowledge claims are foregrounded across settings, which infrastructures of circulation are created, and which power-knowledge orders are shaped. Thus, the chapter empirically zooms in on actual sites of experiments and the relations forged through and beyond such sites.

The analysis illuminates dynamics that arise as governance is accomplished through experimentation across concrete places, conditioned by socio-technical infrastructure, actor constellations, and historically sedimented power relations. In particular, the significance of the political rationality underpinning smart energy experimentation will be scrutinized across 
cases. This is used to highlight how the broader political rationality, as outlined in previous chapters, is reconstituted and possibly reconfigured as governance is arranged through and beyond specific experiments.

\section{Norra Djurgårdsstaden - Smart Energy City}

This section will focus on the Smart Energy City experiment, which was conducted within a new city district in Stockholm called Norra Djurgårdsstaden (NDS). ${ }^{632}$ This urban development project will also be examined to probe the relations forged between the smart energy experiment, urban development, and environmental governance. Analytically, the section zooms in on how the intervention undertaken in the experiment is authorized and assembled, how aspects of it is circulated, and how these processes arrange environmental governance in specific ways. It also investigates how these processes, which take place in a local setting to a significant extent, are conditioned by and co-constitute the broader political rationality. Thus, the focus is on how diverse elements are assembled through the experiment and how the actors involved draw on specific problematics to elucidate contingent accomplishments constituting the field of intervention for environmental governance, as well as how the broader political rationality conditions such accomplishments. Initially, a brief background to urban development in Stockholm will be provided.

Contemporary urban development in Stockholm is focused on ensuring continued growth of the city, to enhance its international position and increase competitiveness. ${ }^{633}$ Sustainability is also a significant focus of urban development in Stockholm, reflecting the contemporary emphasis on cities as crucial actors and arenas of environmental governance. In the contemporary political landscape, where governance is often arranged in loose netw orks, the capital of a country with far-ranging environmental ambitions occupies a central position in terms of realizing environmental goals. Urban development is also dispersed to a large extent. Since Sweden is characterized by de- (or rather re-)regulated electricity and housing sectors, governance tends to be arranged through public-private partnerships in which private companies are responsible for realizing national environmental goals. ${ }^{634}$ This overarching mode of urban development, intertwining economic and environmental policy, reflects the broader green political rationality. Arranging governance in loose networks across privatized sectors, making environmental issues an impetus for expanding capital's reach, is clearly aligned with neoliberalization processes. Consequently, urban development processes in Stockholm are underpinned by the broader political rationality. Perhaps as a convergence

\footnotetext{
${ }^{632}$ The city district is called Stockholm Royal Seaport in marketing material aimed at an international audience.

${ }^{633}$ See e.g. Stockholms stad 2018. Översiktsplan för Stockholm. Stockholm.

${ }^{634}$ Green 2006. Hållbar energianvändning i svensk stadsplanering. Dissertation. Linköping: Linköping University. p. 18; von Bergmann-Winberg \& Wihlborg (eds.) 2011. Politikens entreprenörskap - kreativ problemlösning och förändring. Malmö: Liber.
} 
between the two trends of market-led environmental politics and continuous attempts to enhance Stockholm's competitiveness through marketing, large urban development projects with sustainability profiles have become established practice in Stockholm. ${ }^{65}$ Scholars have shown how the city district of Hammarby Sjöstad, often cited as an emblematic example of sustainable urban development, became a reference point for this development. ${ }^{636}$ According to researcher Anna Green, Hammarby Sjöstad's environmental ambitions were interrelated with Stockholm's bid to host the 2004 Olympic Games, with the aim of marketing Stockholm as an environmental frontrunner to strengthen the bid. ${ }^{637}$ Enhancing the visibility of the city in a global arena was connected to sustainable urban development in a concrete project, devising a direction for years to come.

Such entanglements between constructing new city districts with a prolific sustainability profile and a willingness to market cities as a measure to increase their competitiveness, and thus a notion of competition between cities, is interlinked with the Fordist crisis ${ }^{638}$ Since at least the 1990s, urban development in parts of Sweden has revolved to a significant extent around urban regeneration because of the Fordist crisis. Urban regeneration has, however, taken on specific modes, and as described above, urban development processes in Stockholm are clearly aligned with the broader political rationality, expressed through the dispersed mode of governance favoring public-private partnership constellations that pursue economic profit by improving the environmental condition across privatized sectors. Further, Stockholm was not hit as hard by the Fordist crisis as many other industrial Swedish cities. During the 1970s and 1980s, the foundations were laid for moving toward a post-Fordist economy in Stockholm, accentuating creativity, communication, and knowledge while strengthening ties between the public and private sectors. ${ }^{639}$ Stockholm's approach is compatible with entrepreneurial urbanism, an approach to urban governance sprung from the Fordist crisis, focused on placebranding to achieve economic success. ${ }^{640}$ This includes establishing public-private partnerships

${ }^{635}$ See e.g. Hult 2017. Unpacking Swedish Sustainability: The promotion and circulation of sustainable urbanism; Wangel 2013. Hur hållbara är Hammarby sjöstad och Norra Djurgårdstaden? In Teleman (ed.). Hållbarhetens villkor. Arena: Malmö, Sweden.

${ }^{636}$ See e.g. Green 2006. Hållbar energianvändning i svensk stadsplanering; Bylund 2006. Planning, Projects, Practice: A Human Geography of the Stockholm Local Investment Programme in Hammarby Sjöstad. Diss. Stockholm: Stockholm University.

${ }^{637}$ Green 2006. Hållbar energianvändning i svensk stadsplanering.

${ }^{638}$ On the Fordist crisis, see e.g. Harvey 1989. From Managerialism to Entrepreneurialism. For a Swedish perspective, see Franzén et al. 2016. Stad till salu.

${ }^{639}$ Franzén et al. 2016. Stad till Salu. It has been argued that these events took place partly because the state decided to relocate government activity that had previously been based in Stockholm, severing an implicit contract between the state and the city of Stockholm. See Kåring-Wågman 2008. När staten flyttade från sta'n. In Gullberg \& Lilja (eds.). Makten i stadshuset. Stockholms lokalpolitik under 1900-talet. Stockholm: Stockholmia förlag. pp. 265-283; Andersson 1985. Kreativitet - StorStadens framtid: en bok om Stockholm. Stockholm: Prisma. See Franzén et al. 2016. Stad till Salu. pp. 71-73 for a discussion on the impacts of the investigation on urban development in Stockholm.

${ }^{640}$ Harvey 1989. From Managerialism to Entrepreneurialism. 
in order to develop and "sell" specific parts of the city, often in the form of large flagship projects such as sports events or new city districts. Since the economic crises of the 1990s, Stockholm has continued to expand and display renewed economic growth, and is sometimes lauded as Sweden's growth engine. ${ }^{641}$

Contemporary urban development in Stockholm is centered around smart and sustainable solutions to environmental issues, particularly by establishing large environmentally profiled urban development projects. ${ }^{642}$ In the comprehensive plan for Stockholm, developing the global attractiveness of Stockholm whilst reducing environmental impact is articulated as a key goal, and urban development is argued to constitute a powerful tool for achieving this goal. ${ }^{643}$ Norra Djurgårdsstaden is presented as one such sustainable urban development project, and a lineage to Hammarby Sjöstad is regularly articulated. ${ }^{644}$ The approach of constructing sustainable city districts to enhance Stockholm's competitiveness clearly mirrors the broader political rationality, touting new green technical solutions as solutions to environmental issues whilst boosting economic growth. The environmental profile area of Norra Djurgårdsstaden, which is emphasized as being central for Stockholm's environmental ambitions whilst attracting large numbers of visitors, consists of an old industrial area and a former harbor, located by the waterfront in the northeastern parts of central Stockholm, close to a national park. ${ }^{645}$

${ }^{641}$ Franzén et al. 2016. Stad till Salu. p. 74. It has been argued that this success story disguises continuously deepening differences in social relations and inequalities produced through the described course of action, e.g. by contributing to growing ethnic and class-based housing segregation and gentrification. See Franzén et al. 2016. Stad till Salu. pp. 75-76.

${ }^{642}$ See: https://vaxer.stockholm/ [2019-06-17]; https://vaxer.stockholm/tema/hallbara-och-smartalosningar/ [2019-06-17].

${ }^{643}$ Stockholms stad 2018. Översiktsplan för Stockholm. Stockholm. p. 6. In the words of the Swedish National Board of Housing, Building and Planning, which is a central government authority, a comprehensive plan is a document which municipalities are mandated to establish by law. It must include an overall intention for land and water use, plans for the built environment, public interests, how national interests and environmental quality standards are to be met, and how different national and regional goals related to sustainable development are to be taken into account by the municipality. See Boverket 2018. Planning Process. https://www.boverket.se/en/start/building-in-sweden/swedish-market/laws-andregulations/planning-process/ [2019-06-17].

${ }^{644}$ See e.g. Stockholms stad 2019. Hållbar stadsutveckling drar många besökare till Stockholm. https: / /vaxer.stockholm/nyheter/2019/03/hallbar-stadsutveckling-drar-manga-besokare-tillstockholm/ [2019-06-17].

${ }^{645}$ Stockholms stad 2019. Hållbar stadsutveckling drar många besökare till Stockholm. https://vaxer.stockholm/nyheter/2019/03/hallbar-stadsutveckling-drar-manga-besokare-till-

stockholm/ [2019-06-17]. It must be mentioned, however, that large sustainable urban development projects are not without their critics; questions have been raised about whether they actually contribute to realizing environmental goals and for whom the city districts are being constructed. See e.g. Stiernstedt 2019. Stockholm en förebild - med brister. Dagens Industri 2019-06-10. Available online: https://www.di.se/hallbart-naringsliv/stockholm-en-forebild-med- 
The means for achieving the stated goals of urban competitiveness and environmental sustainability are, at least partly, a substantial emphasis on innovation, research and development, and testing in Norra Djurgårdsstaden. The city district has essentially been tasked by the City Council with testing what it is possible to do now and stretching the boundaries where possible, in the hope of making NDS a role model for sustainable city development. ${ }^{646}$ Consequently, research and development projects are very important in NDS. The Smart Energy City experiment was one such project, running from 2009 until $2018 .{ }^{647}$ It was funded partly through the Swedish Energy Agency - in the final report, the project consortium describes it as a research program. ${ }^{648}$ The consortium include the Swedish Energy Agency, the ICT company Ericsson, the energy company Fortum (and later Ellevio, when Fortum divested its grid operations and Ellevio was formed to take over as grid operator), the Royal Institute of Technology (KTH), ABB, and Electrolux. ${ }^{649}$ Smart Energy City focused on the behaviors of household energy users as well as technical smart grid solutions intended to support behavioral changes. ${ }^{650}$ In its early stages, a pre-study was conducted and one single apartment was subsequently fitted with smart home technology. After a hiatus, it was revamped to include 154 households in newly constructed buildings in Norra Djurgårdsstaden, which were equipped with new smart home technology as well as digital technology in the electricity grid. ${ }^{651}$ Smart Energy City is a clear example of a socio-technical experiment intended to improve the environmental condition, and as a prominent initiative connected to urban environmental governance in Stockholm as well as policymaking at national level, it provides a relevant case.

brister/?fbclid=IwAR1 yMBBUR06olFcomLpcaOT65r8Uk1R4HPZBORboO89hgNDqsN2tyFNx52U [2019-06-17]; Green 2006. Hållbar energianvändning i svensk stadsplanering. p. 21; Hult 2017. Unpacking Swedish Sustainability; Wangel 2013. Hur hållbara är Hammarby sjöstad och Norra Djurgårdstaden? For a similar critique in the Malmö context, see Holgersen \& Malm 2016. "Green fix" as crisis management.

${ }^{646}$ See e.g. Stockholms stad 2017. Program för hållbar stadsutveckling: Norra Djurgårdsstaden visar vägen mot en hållbar framtid; Stockholms stad 2019. Norra Djurgårdsstaden. https://vaxer.stockholm/omraden/norradjurgardsstaden/?page-21-1243=0\#page-21-1243 [2019-06-17].

${ }_{647}$ This period includes the total duration of the experiment, also extending over a period of time when the experiment was put on hiatus. A more detailed explanation will follow throughout the chapter.

${ }^{648}$ Ander 2019. Smarta elnät i stadsmiljö i Norra Djurgårdsstaden - slutrapport. Eskilstuna: Energimyndigheten. The terminology is not insignificant. Besides obviously drawing on popularized notions of rigid, objective science, as is common in such endeavors, in correspondence with a project member it was explicitly stated that the consortium avoided the term "experiment" throughout the duration of the project. This was described as necessary to avoid negative connotations of experimentation, especially since the project involved households and thus people's daily lives.

${ }^{649}$ Ander 2019. Smarta elnät i stadsmiljö i Norra Djurgårdsstaden- slutrapport. The Energy Agency did not participate operatively in the experiment, but provided funding.

${ }^{650}$ Ibid. p. 7.

${ }^{651}$ Interview EXEA2; Ander 2019. Smarta elnät i stadsmiljö i Norra Djurgårdsstaden-slutrapport. p. 7. 


\section{Authorizing and assembling intervention: triggering green transformation through an innovative city district}

This section will focus on how different actors authorize the Smart Energy City experiment and how they assemble diverse elements, thereby stitching the intervention together. Interlinkages created between different problematics and spaces of governance through the processes of authorizing and assembling intervention will be highlighted to elucidate how environmental governance is accomplished through and beyond the experiment, paying particular analytical attention to how the broader political rationality comes into play in and beyond Smart Energy City. I will treat authorization and assembling intervention as intimately linked processes, presupposing one another. Consequently, I will interweave both concepts into the analysis rather than symmetrically splitting it into separate sub-sections focused on one concept at a time. Authorization entails ensuring the consent of the governed, often through reworking interests into a common position, and thus defining a problem and devising a solution which is relationally constituted as legitimate, so I will treat authorization as a discursively cognitive process expressed through practices. Assembling intervention is a matter of practically forging alignments between socio-material elements through assembling practices, i.e. practices of bricolage which realign existing assemblages around improving the environmental condition in specific ways. Political rationality conditions such processes, instituting particular assumptions and knowledge claims, for example, which facilitates certain accomplishments while constraining others, although contingencies may occur as intervention is assembled, meaning that experiments can work around or reconfigure the political rationality.

According to the City of Stockholm, Norra Djurgårdsstaden is one of Europe's largest urban development projects. ${ }^{652}$ In one of the first public documents about Norra Djurgårdsstaden, published in 2009, produced by the City of Stockholm, and signed by several private actors such as a financial institute and an energy company, a common vision of the future city district is outlined. It is stated that globalization creates increased pressure and competition which Stockholm must face, whilst new business opportunities are simultaneously created by expanding markets. Norra Djurgårdsstaden is articulated as an answer to both avoiding such dangers of international competition and reaping the benefits of expanding markets. The sustainable city district will take into account knowledge from Hammarby Sjöstad, and not only consolidate Stockholm's position as an environmental frontrunner, but also support the marketing of Swedish green technology and provide a platform for the development of new technology which will benefit all of Sweden, according to the document. ${ }^{653}$ Planning started long before the publication of this document, as constructing an entirely new city district is a

\footnotetext{
${ }^{652}$ https: //vaxer.stockholm/omraden/norra-djurgardsstaden/?page-21-1243=0\#page-21-1243 [201906-17].

${ }^{653}$ Stockholms stad 2009. Norra Djurgårdsstaden - Vision 2030. Stockholm.
} 
lengthy process. ${ }^{654}$ Still, this document, which outlines the vision for the future city district, constitutes an important moment for authorizing the Smart Energy City experiment, which was still in a pre-study phase in 2009. It illustrates how NDS is drawn into a specific problematization, in line with the broader green political rationality, which came to be of significance for Smart Energy City. The vision explicated in the document is of NDS as an innovative city district, where new green technology is developed by private companies, consolidating Stockholm's position as an environmental frontrunner city, whilst the technology developed can be disseminated for the benefit of Swedish spatial planning and exported to reach the aforementioned expanding markets. ${ }^{65}$ Consequently, we can observe how the broader political rationality influences authorization practices from an early stage; authorization relies upon embedded assumptions about improving the environmental condition as a growth-enhancing opportunity, defining the problem to be solved through urban development in line with solutions ready to be provided by private companies developing new green products for implementation and export in green city districts.

The document was soon followed by an overarching program for sustainable urban development in the city district. ${ }^{656}$ The program was developed by the City of Stockholm's administrative unit responsible for urban development, in collaboration with other parts of the administration and in dialogue with other actors. ${ }^{657}$ It was intended to function as an overarching governance document for sustainable urban development in NDS, including specific goals. ${ }^{658}$ The ambition of making NDS into a world-class environmental city district and an international role model for sustainable urban development is reiterated, as is the emphasis on utilizing knowledge from Hammarby Sjöstad. ${ }^{659}$ It is stated that because of increased urbanization, cities are the central sites of long-term environmental and climate action, with an emphasis on reduced energy and resource use, and on a growing economy through the development of new green technology. ${ }^{660}$

The term "world-class" is commonly used to describe Norra Djurgårdsstaden throughout the document. ${ }^{661}$ It is stated that the environmentally conscious planning associated with NDS will be transferred to other urban development initiatives across Stockholm. ${ }^{662}$ Cooperation is a substantial focus of the document - it is stated that since the City of Stockholm does not have formal authority over key aspects of urban development, an integral part of NDS will consist

\footnotetext{
${ }^{654}$ Interview PM City of Stockholm.

${ }^{655}$ Stockholms stad 2009. Norra Djurgårdsstaden - Vision 2030.

${ }^{656}$ Stockholms stad 2010. Övergripande program för hållbar stadsutveckling. Stockholm.

${ }^{657}$ Ibid. p. 5.

${ }^{658}$ Ibid. p. 10

${ }^{659}$ Ibid. p. 4.

${ }^{660}$ Ibid. p. 4.

${ }^{661}$ Ibid. pp. 5; 11; 30; 39; 44.

${ }^{662}$ Ibid. p. 6.
} 
of initiatives introduced and run by private companies, actualizing a need for cooperation. ${ }^{663}$ Further, it is stated that NDS will constitute an arena for developing smart system solutions which will help realize sustainability goals, with a special focus on ICT. ${ }^{664}$ It is stated that:

Norra Djurgårdsstaden will contribute to innovation, development and marketing of Swedish green technology and expertise in sustainable urban development. ${ }^{665}$

Hopes are expressed in the document that Norra Djurgårdsstaden will become an international role model for sustainable city development, and that Swedish knowledge will serve as inspiration whilst Swedish technology developed in NDS will be exported. ${ }^{666}$ This emphasis on solving environmental issues through testing, developing, and exporting new green technology, thus making private companies authoritative actors, elucidates how the City of Stockholm aligned NDS with the broader green political rationality from an early stage. The emphasis on testing is reflected further in the subsequent overarching program for sustainable urban development, dating from 2017. Making Norra Djurgårdsstaden into an innovative city district through testing is more evident in this document. It is stated that an overarching goal for the City is that NDS becomes a natural place for testing innovative new work modes, methods, and solutions, which can then be disseminated to the rest of Stockholm to benefit further urban development. ${ }^{667}$ In this document, strategies for urban development in NDS are concretized, with a substantial focus on learning and cooperation between actors through different projects. ${ }^{668}$

The sentiments expressed in guiding documents for Norra Djurgårdsstaden are also mirrored in environmental policy documents encompassing the whole of Stockholm, extending beyond specific urban development projects. For instance, the Environmental Program for the City of Stockholm - a policy document outlining environmental goals and their implementation for 2016-2019, and developed by a working group cutting across the public administration reflects such ambitions. Innovation aimed at creating new forms of cooperation between different actors is articulated as being central for realizing sustainability goals. ${ }^{669}$ Specifically regarding energy goals, demonstration projects are given an important role. ${ }^{670}$ It is stated that through demonstration projects the city can become an international role model, as well as a driving force strengthening economic growth through the development of green technology and thus job creation. ${ }^{671}$ Further, it is stated that demonstration projects can contribute to

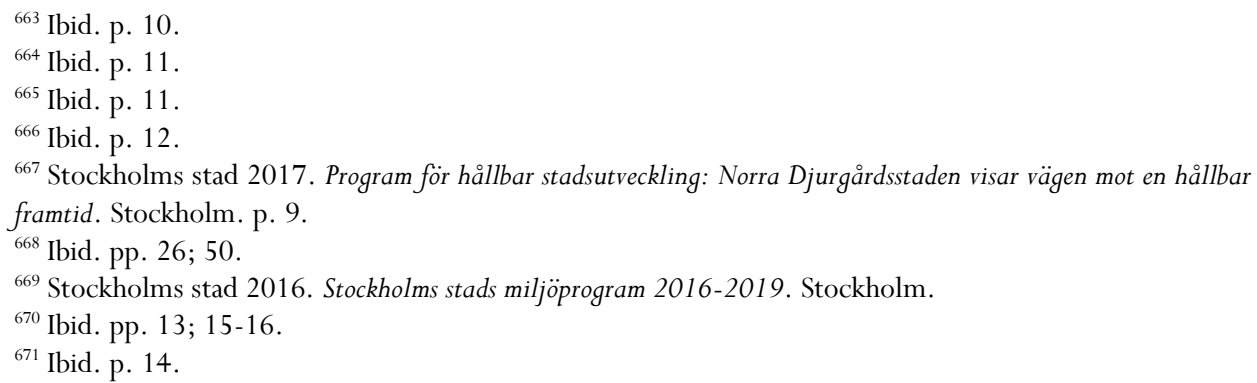


Stockholm's frontrunner status by illustrating new opportunities ${ }^{672}$ Such expressions mirror notions among experts at national level, emphasizing the demonstrative qualities of experiments as well as their importance for marketing.

The overarching ambition of making Norra Djurgårdsstaden into an innovation arena, where new technologies and social arrangements are tested, has been central throughout the process of planning and constructing the new district. This is an important moment for authorizing Smart Energy City. Testing, developing new technologies, and trying out new forms of organization for urban development, which the rest of Stockholm will then benefit from while the developed technologies contribute to export revenue, is continuously articulated as the key method for achieving environmental goals and making NDS into a world-class sustainable city district. This clearly draws upon notions of experimentation as testing, as discussed in the previous chapter, and is in line with the substantial focus on export in policies related to smart energy experimentation. Consequently, authorization of the experiment relied from an early stage upon providing a diagnosis of possibilities in the vein of the broader political rationality, where private companies and public administration iteratively work toward making NDS an innovative district where new green technologies can be developed to further the ambitions of the city, private companies, and Sweden as a whole. It also includes specific ideas about the circulation of experiments, which we will return to.

The aforementioned emphasis on consensus and cooperation is also present in the documents outlining Stockholm's environmental governance, as well as in documents pertaining specifically to Norra Djurgårdsstaden. Thus, authorizing the large urban development project of Norra Djurgårdsstaden has leaned into the modality of consensus since the advent of the project. Issuing the document outlining a future vision for the city district, which was signed by different private actors, illustrates how consensus was mobilized as the authorizing modality from an early stage. Authorization is however a constant process, requiring ongoing work to define and delineate what the problem at hand is and how it should be rightfully addressed, i.e. how to rework dispersed interests into a common position around improving the environmental condition in a specific way. ${ }^{673}$ In light of this recognition, it makes sense to see how the modality of consensus as an authorizing practice extends through the key policy documents of NDS. The imminent new city district has continuously been articulated as a project for green transformation, which will generate green economic growth for the benefit of Stockholm and Sweden. ${ }^{674}$ Evidently, such ambitions tap into the broader green political rationality. In these documents, realizing the promises offered by the new city district relies upon testing and learning. It is not explicitly defined as an experimental mode of urban development, but the language reflects notions of experimentation expressed across

\footnotetext{
${ }^{672}$ Ibid. pp. 15-16.

${ }^{673}$ Bulkeley 2016. Accomplishing Climate Governance. p. 74.

${ }^{674}$ Cf. Wangel 2013. Hur hållbara är Hammarby sjöstad och Norra Djurgårdstaden?; Hult 2017. Unpacking Swedish Sustainability.
} 
governmental institutions and policy networks. It is stated that Norra Djurgårdsstaden will become a platform and an innovation hub, where new methods of urban development will be tested and new green technologies developed. Specific experiments, often articulated as pilot projects, demonstrations, or research and development projects in documents, are thus afforded a key role in making NDS into the desired sustainable district.

Importantly, authorization - or the rightful orchestration of power - is also substantiated through reference to previous urban development projects, such as Hammarby Sjöstad, which is referenced regularly in documents and interviews as an important role model for Norra Djurgårdsstaden. It is stated that experiences from Hammarby Sjöstad will feed into NDS, with the implicit recognition that the mode of urban development associated with Hammarby Sjöstad, also centered on innovation and testing for sustainability by both public and private actors, constitutes the right disposition of things for sustainable urban development. It could therefore also be argued that the circulation of a particular storyline of successful urban development interlinked with environmental ambitions was initiated before breaking ground at the planned new district. Elements of the broader political rationality - such as consensusbuilding through public-private partnership constellations engaging in collaborative projects, thereby enabling the generation of new knowledge - were drawn upon, albeit repackaged to fit the urban development context in Stockholm. This occurred before Smart Energy City was initiated, as part of the authorization for the larger urban development project which the smart energy experiment would be tucked into.

This elucidates how the political rationality underpinning smart energy experimentation, as analyzed in previous chapters, creates certain conditions of possibility for Smart Energy City. It is already evident at this early stage that a particular power-knowledge assemblage was shaped through processes of authorization, drawing upon elements of the political rationality, where new knowledge is imagined to be generated through collaboration in experiments which can then be transferred to inform other sustainable urban development projects. Making NDS into an innovative city district where private companies are assigned central responsibility for generating said knowledge lays the groundwork for particular knowledge politics and channels of circulation, as we will see.

\section{Configuring the Smart Energy City: delineations and interlinkages}

The Smart Energy City Experiment is situated at this nexus of urban development aiming for sustainability and increasing Stockholm's competitiveness. The pre-study from 2011 mirrors the aspirations tied to Norra Djurgårdsstaden. ${ }^{675}$ It is claimed that developing smart grids is a necessary precondition for the transformation to a sustainable energy system, which will both empower energy customers and enable the Swedish business sector to assume a leading

\footnotetext{
${ }^{675}$ It should be mentioned that the experiment was not named Smart Energy City until several years later, after a hiatus.
} 
international position, thus strengthening the export industry and contributing to economic growth. ${ }^{676}$ Smart grid research and development projects conducted in close collaboration between private companies, academia, and the public sector are said to be of vital importance in order to realize these opportunities. ${ }^{677}$ This can contribute vital lessons and experiences, it is argued, and NDS is articulated as an ideal space for establishing research, testing, and demonstration programs which will enable an innovation process to strengthen the Swedish export industry and academia. ${ }^{678}$ Hammarby Sjöstad is also explicitly mentioned as a reference point. This illuminates the process of assembling intervention for Smart Energy City. The consortium behind the experiment mobilizes arguments attuned to the green political rationality, reflecting smart energy policy on a national level. Arguments about reaching environmental goals through the development of new green technology via collaborative endeavors are frequently expressed in the pre-study, illustrating how the consortium invokes elements of and reinforces the political rationality. There are also frequent references to science in the pre-study, especially technoscience. For instance, it is stated that NDS is a central enabler of and catalyst for world-class smart grid and sustainable city research, creating a forum for cooperation between industry, academia, and the public sector in which scientific and industrially relevant research and development projects can be hatched and implemented. ${ }^{679}$

Load management - in the form of a demand-response solution, enhanced surveillance of the mid- and low-voltage grid, and in-home displays - is expressed in the pre-study as an interesting and pursuable option. ${ }^{600}$ Such IT-focused smart energy ambitions evolved into an initial project often referred to as the "active apartment" project, funded by the Swedish innovation agency Vinnova, revolving around the introduction of smart energy solutions in a single apartment in Norra Djurgårdsstaden. ${ }^{681}$ The project was met with criticism in the industry press, especially emphasizing a shaky collaboration between the different parties of the project, which were described as acting more like business competitors than project partners. ${ }^{682}$ An interviewee with insight into the smart energy experiment in NDS stated that

\footnotetext{
${ }^{676}$ Fortum et al. (undated). Norra Djurgårdsstaden - smart elnät i stadsmiljö: Förstudie. p. 4.

${ }^{677}$ Ibid. pp. 7; 8.

${ }^{678}$ Ibid. p. 8.

${ }^{679}$ Ibid. p. 7.

${ }^{680}$ There were other aspects, such as the electrification of naval transport through a ship to shore solution and testing battery storage, which were later described in an interview with a project manager as "enormous plans" which were ultimately discarded since there "is no unlimited supply of money". Interview PM ABB.

${ }^{681}$ See: https://www.vinnova.se/p//Aktiva-huset-i-den-hallbara-staden/ [2019-06-18]

${ }^{682}$ Ahlbom 2015. Smarta fiaskot för prestigebygget i Norra Djurgårdsstaden. NyTeknik 2015-02-14. https: / / www.nyteknik.se/nyheter/smarta-fiaskot-for-prestigebygget-i-norra-djurgardsstaden6336033 [2019-06-18]. This was mirrored in an interview with an energy field expert, who raised the risks of diverging commercial interests in smart energy experiments, as accounted for in the previous chapter.
} 
Vinnova was underwhelmed by the "active apartment" project and decided not to engage further. ${ }^{683}$ The entire smart energy experiment in Norra Djurgårdsstaden came to a halt at this stage. Several different explanations for this surface across interviews with different actors within or connected to Smart Energy City, e.g. conservationist concerns over biological diversity which led to construction in Norra Djurgårdsstaden being halted, ${ }^{684}$ and a re-shuffling of roles within the project. ${ }^{685}$ According to a civil servant at the Energy Agency, the stoppage and subsequent reboot of the project came about as a result of the experiment's setup. The interviewee's explanation for the hiatus provides a glimpse into processes of assembling intervention. When the consortium outlined a common vision, the vision was based on the commercial interests of individual private companies, i.e. that every actor would be able to develop and sell its own products. However, no actual customers were involved in the project. ${ }^{686}$ It turned out that when the consortium approached construction companies and property owners, these actors thought the smart grid solutions they were being asked to implement were too expensive. According to the civil servant at the Energy Agency:

That also meant that in tough negotiations [within the consortium], it created a situation of competition between the different companies. Well ABB's product was too expensive so we have to get rid of them, or no, why should we have a smart washing machine [illustrating the negotiations], and then the joints for the entire cooperation started to creak. ${ }^{67}$

This highlights tensions infused by the broader political rationality, as proprietary knowledge generation with the goal of commercializing new technology does not necessarily sit easily alongside the goals of testing, learning, and openly sharing these experiences, as also expressed by governmental actors at national level. The converse argument could also be made, i.e. that the moves made and the intricacies that emerge as intervention is assembled create frictions with the broader political rationality. In a sense, then, the hiatus also underlines the contingencies of socio-material assemblage, seen for example when property owners and construction companies did not agree to be enrolled in any straightforward sense. The experiment was later rebooted under the name Smart Energy City, with newly signed deals between the project partners. According to the civil servant, even though this was a tough process, a lot was learnt, and essentially the solution developed for the "active apartment" project was too expensive, so several years later when other technology options were available which were much cheaper, the consortium managed to get property owners involved. ${ }^{68}$ Smart Energy City was officially inaugurated in 2016 by the then Minister of Enterprise, Social Democrat Mikael Damberg, who referred to it as a very interesting and important experiment, which according to him illustrated how innovation in cooperation between industry,

\footnotetext{
${ }^{683}$ Interview EXEA2.

${ }^{684}$ Interview PM Ellevio.

${ }^{685}$ Interview PM ABB.

${ }^{686}$ Interview EXEA2.

${ }^{687}$ Ibid.

${ }^{688}$ Ibid.
} 
government agencies, and academia can solve the climate challenge. ${ }^{689}$ In a press release from the government, Smart Energy City is explicitly described as an experiment, and is tied to an innovation initiative launched by the government called strategic collaboration programs, specifically a program for smart cities. ${ }^{690}$

In documents and interviews about the experiment, which was concluded in late 2018, it is usually divided into two subprojects: one called the "active house", and another called "smart grid”. ${ }^{691}$ In the final report to the Energy Agency, Smart Energy City is termed a research program, with a stated focus on exploring behavior change and technical solutions that enable such changes. ${ }^{692}$ For the "active house", 154 apartments - a mix of rental and tenant-owned apartments - were fitted with smart home technology such as smart meters, smart devices in the form of in-house displays and a smartphone app, and smart home appliances such as programmable washer and tumble dryers, which were connected to an IT platform described as an internet of things (IoT) platform. ${ }^{693}$ The goals were stated as investigating drivers for changed energy behavior of households, as well as load-shifting through price and environmental signals and decreasing households' climate footprints by incentivizing changed behavior. ${ }^{694}$ The "active house" element included visualizations of electricity use as well as indoor and water heating, but feedback in the form of a price signal was tied solely to household electricity use. ${ }^{695}$

A demand-response algorithm was developed and used in the experiment as a price signal to schedule EV charging, dryers, and washing machines, based on hourly day-ahead spot prices from the Nord Pool market, while home appliances were connected to smart plugs to allow

\footnotetext{
${ }^{689}$ Näringsdepartementet 2016. Mikael Damberg inviger "Smart Energy City" på Norra Djurgårdsstaden i Stockholm. Press release. https://www.regeringen.se/pressmeddelanden/2016/11/mikael-damberginviger-smart-energy-city-pa-norra-djurgardsstaden-i-stockholm/ [2019-06-18].

${ }^{690}$ See Näringsdepartementet 2017. Regeringens strategiska samverkansprogram. Fact sheet.

N2017.40. Stockholm. These strategic collaboration programs constitute an important part of the government's innovation policy, with the explicit goal of facilitating cooperation between public and private actors and academia, to find solutions to complex societal issues - or "challenges", which is the preferred term in documents - whilst strengthening Sweden's global competitiveness. In an evaluation of these programs published by Vinnova, it is explicitly stated that a major policy challenge connected to smart cities is meeting the immense need for experimentation to address complex societal challenges. It is stated that innovation labs or policy labs must be implemented, to develop new, explorative methods, in collaboration with citizens and other actors across entire value chains, on all levels. It is explicitly stated that this goal of increasing experimentation mirrors the emphasis on experimentation in Agenda 2030, reflecting the dispersed bottom-up character of much contemporary environmental governance. See Vinnova 2019. Uppdrag att bistå i arbetet med regeringens samverkansprogram för innovation. Stockholm.

${ }^{691}$ See e.g. Ander 2019. Smarta elnät i stadsmiljö i Norra Djurgårdsstaden-slutrapport; Interview RM Fortum; Interview PM Ellevio; Interview PM ABB.

${ }^{692}$ Ander 2019. Smarta elnät i stadsmiljö i Norra Djurgårdsstaden-slutrapport.

${ }^{693}$ Ibid.

${ }^{694}$ Ibid. p. 12.

${ }^{695}$ Interview PM ABB; Ander 2019. Smarta elnät i stadsmiljö i Norra Djurgårdsstaden-slutrapport.
} 
for monitoring electricity use in real-time. ${ }^{696}$ The demand-response solution was an attempt to test the energy behavior of households both through smart home features, e.g. the scheduling mechanism for EV and washing machines, and through visualization of energy use as well as price and environmental signals. The households were separated into different categories, so that some received the price signal and some the environmental signal, with the main difference being that emission rights were purchased for the sum saved through load shifting for the households with the environmental signal. There was also a benchmarking function in the system, so that households could see their energy use over time as well as that of their neighbors. Solar panels were installed on the roofs, and electricity production from these could be viewed on the in-house display. However, they were not connected to the smart energy system solution in the experiment. ${ }^{697}$

In the "smart grid" element, the power grid was fitted with smart technology, e.g. substations equipped to reduce no-load losses, an automated switch-over software solution between two substations to reduce power supply interruptions, and error indicators and sensors. Gathered information was forwarded to the control system (SCADA), whilst equipment connected to both the active house and the smart grid relayed data for analytics to KTH. ${ }^{698}$ An important aim in the smart grid subproject was to use big data analytics to increase reliability and reduce maintenance costs, through the installation of monitoring equipment in substations and connecting this to the network operation center.

These measures suggest arranging environmental governance in specific ways, noticeably in line with the centralized, large-scale infrastructure of the contemporary energy system. The actors enrolled in the experiment were mainly traditional players - large incumbent energy companies - reflecting historically sedimented power relations in the Swedish energy system. Automated solutions to optimize the electricity grid are proposed, which are developed by private companies, whereas it is stated that behavior among households can be tested and asserted scientifically. The market solution developed configures political participation for energy users in particular ways, mainly in the shape of assumedly rational customers. Obviously, this configuration is far from the ideals of user empowerment and energy democracy regularly attached to smart energy. Techno-economic expertise and knowledge become central in such a setting, making established large energy companies authoritative actors. The field of intervention for environmental governance that is shaped through Smart Energy City, then, appears to mirror the political rationality underpinning smart energy experimentation, underlining how assembling intervention appears to be conditioned by the political rationality. The final report to the Energy Agency mirrors the goals stipulated for Norra Djurgårdsstaden by the City of Stockholm. NDS is described as a pioneering sustainable urban development project, and an innovation arena where technology for sustainable cities is

\footnotetext{
${ }^{696}$ Ander 2019. Smarta elnät i stadsmiljö i Norra Djurgårdsstaden-slutrapport. pp. 16-21.

${ }^{697}$ Ibid; Interview PM Ellevio.

${ }^{698}$ Ander 2019. Smarta elnät i stadsmiljö i Norra Djurgårdsstaden-slutrapport. pp. 21-27. 
developed in collaboration between private and public actors and academia. ${ }^{699}$ There is also a substantial focus on cities as prominent arenas for meaningful environmental action, and multiple goals are connected to the creation of a smart energy system, such as increased efficiency, reduced costs, and security of supply. Sustainability is expressed as the overarching goal in the project report. ${ }^{700}$ However, as already shown, accomplishing governance always entails contingency - authorization unfolded through the modality of consensus drawing upon local circumstances such as long-lasting urban development practices in Stockholm, whereas assembling intervention entailed twists and turns such as the unwillingness of property owners to simply be enrolled and the unplanned hiatus of the experiment.

\section{An array of tests: urban environmental governance through an innovation hub}

Within the City of Stockholm, similar points surface across interviews. However, despite the substantial emphasis on cooperation between actors across different sectors, interviewees regularly delineated the Smart Energy City experiment from the broader urban development project of Norra Djurgårdsstaden, while in the final project report, Smart Energy City is described as one of many research programs in NDS. This provides an insight into processes of authorizing and assembling intervention. According to a project manager working with urban development at the City of Stockholm, planning for developing Norra Djurgårdsstaden began back in 2001, and during the planning process the City Council decided that NDS would become a new environmental profile area. According to the project manager, politicians in Stockholm saw an opportunity to make NDS into the new flagship area for sustainable urban development in Stockholm and consequently assume the role previously played by Hammarby Sjöstad. ${ }^{701}$ This attracted much attention from different stakeholders across the region, including the energy company Fortum which held concession rights for the electricity grid in Stockholm, who were interested in shaving peak loads. According to the project manager, Fortum made its wishes explicit; working with technology developers and utilizing the "good name of Norra Djurgårdsstaden” to showcase its competence to an international market was considered attractive. ${ }^{702}$

Since one of the City of Stockholm's goals for Norra Djurgårdsstaden was to help Swedish cleantech companies test solutions, it agreed in principle with Fortum. ${ }^{703}$ However, the interviewee was keen to point out that the City did not feel obliged to liaise with Fortum in particular, or with any other specific actor for that matter. In fact, it was suggested that it was

\footnotetext{
${ }^{699}$ Ibid. p. 10.

${ }^{700}$ Ibid.

${ }^{701}$ Interview PM City of Stockholm.

${ }^{702}$ In 2015, Fortum sold the grid operations to the then newly formed company Ellevio, which owns the grid today. As a result, both Fortum and Ellevio were part of the project consortium in Smart Energy City.

${ }^{703}$ Despite Fortum not really being a Swedish company, as the interviewed project manager remarked.
} 
important for the City not to grant unfair advantages within NDS to specific actors; the City's aim for NDS was expressed as shaping the district into an innovation arena where any actor is allowed to develop and test different technical solutions. ${ }^{704}$ The project manager stated that the City intended not to give priority to any specific technical solution related to energy, or in terms of building materials for the urban development project. The interviewee said:

We have felt that our task is to test things and see, get an array of different technologies here which can then be evaluated. If something proves to be better than something else, then they can fly. We haven't felt that we need to be super loyal to one or the other. And that's where we are now, they are doing their testing, this Smart Energy City [...]. ${ }^{705}$

It is however relevant to note that the actors involved in Smart Energy City are all large, traditional players in the energy system, reflecting historically sedimented power relations in Swedish energy politics. The actor constellation is made up exclusively of incumbent for-profit energy companies which own substantial portions of the large-scale power grid as well as the district heating grid. Recall how several civil servants at the Energy Agency stated that it is among these private companies there is enough capital, established collaboration, and knowledge of the research funding system to launch such large smart energy experiments. Further, it could certainly be argued that the broader political rationality, in tandem with neoliberalization processes, establishes thresholds that are very difficult for other actors to surmount in practice, even if the door to smart energy experimentation is kept open in principle. The emphasis on instituting consensus-seeking public-private partnership projects to pursue increased economic growth through the development and export of green energy technology means that, in practice, smart energy experimentation is not necessarily open to anyone and everyone. For a small startup firm or a civil society organization, access to smart energy experimentation might in practice be rather constricted because of dynamics such as a lack of capital, knowledge of research funding infrastructure, and access to policy networks.

The project manager also explained that the role of the City of Stockholm in Smart Energy City became rather marginal. The City laid out broad framework demands, including overall energy use for newly built houses, but with no further specification on how to achieve these goals. This mirrors how another interviewee, a public servant at the City of Stockholm working with environmental issues and urban development, described how the development office, which is responsible for urban development in NDS, works:

What we do in Norra Djurgårdsstaden is that we have been appointed as an environmental profile area, which means that we are supposed to try and develop new ideas, new methods, which we do in collaboration with the departments within the city administration, breaking these goals down into different types of demands. [...] So the development office is the land owner, entering into civil

\footnotetext{
${ }^{704}$ Interview PM City of Stockholm.

${ }^{705}$ Ibid.
} 
contracts with construction companies, where functional requirements for the construction companies are set. ${ }^{706}$

This elucidates the overarching strategy for the City of Stockholm in NDS, which is partly a result of the administration not owning infrastructure but rather being a land owner, according to interviewees. ${ }^{707}$ Regarding Smart Energy City, the project manager stated that the City let the project consortium utilize the City's brand, so the project partners could claim that they were conducting the project together with the City. ${ }^{708}$ The interviewee repeated several times that many different projects were ongoing in NDS, to test other things besides energy. ${ }^{709}$

Another interviewee stated that it was the status of NDS as an innovation arena with ambitious environmental goals that triggered projects such as Smart Energy City. ${ }^{710}$ The interviewee explained that many different actors, such as construction companies and energy companies, view NDS as a springboard for implementing different ideas and solutions which can then be disseminated by these actors. ${ }^{711}$ Private actors are interested in carrying out experiments in NDS because of its status as a platform for testing different solutions, and since it is labeled a frontrunner in sustainable urban development and has a prolific public profile it also provides a platform for marketing, according to the interviewee. ${ }^{712}$ Consequently, quite clear boundaries are drawn between the urban development project NDS and the Smart Energy City experiment, stating that the actors in the smart energy experiment have probably learnt a lot through their endeavors. This is also an important part of assembling intervention, since this statement by the interviewee implicitly underscores that it is not primarily a task for the City to learn from the experiment; this is rather a task for the private companies involved in the experiment. Experimentation is also described as a space which triggers new ideas. Making NDS into an innovation arena where new technologies and collaborations can be tested serves to align the goals and instruments of different actors, bearing the imprint of the political rationality underpinning smart energy experimentation - it is mainly proprietary knowledge generation by private companies that is emphasized.

I will discuss circulations at length later, although here we can already glimpse the foundations of an infrastructure of circulations, where private companies are implicitly assigned primary responsibility for disseminating knowledge through their own established channels as a primary way of achieving transformative change through experimentation. In line with such notions of change, the marketing aspect of a high-profile area like Norra Djurgårdsstaden also comes across as important, with an interviewee stating that:

\footnotetext{
${ }^{706}$ Interview EnvE (Environmental Expert) City of Stockholm.

${ }^{707}$ Ibid; Interview PM City of Stockholm.

${ }^{708}$ Interview PM City of Stockholm.

${ }^{709}$ Ibid.

${ }^{710}$ Interview EnvE City of Stockholm.

${ }^{711}$ Ibid.

${ }^{712}$ Ibid.
} 
$[\ldots]$ here we have an area where the same ideas that we work with are being applied, triggered through very ambitious goals. And then they are transferred to other, quite profiled areas like GrowSmarter, which is an EU project [...], and also there we see that private companies are very interested in profiling themselves in these areas, because it is from there that you can market yourself..$^{713}$

This highlights how marketing is articulated as an important element of experimentation in NDS and other large sustainable urban development projects across Stockholm, especially for private companies. Here, a prominent friction created by the political rationality underpinning smart energy experimentation can be observed. Emphasizing testing constitutes a central element of assembling intervention in Smart Energy City. NDS is cast as an innovation arena for urban sustainability where new technology is developed and solutions are tested. An experiment cannot really fail if it is construed as a test, as long as something is learned through it. However, this does not sit entirely easily with the articulations of Norra Djurgårdsstaden as a global frontrunner in urban development and environmental sustainability, especially in connection with such ambitions of utilizing NDS as a marketing platform because of its profile. This tension was explicitly brought up by interviewees from governmental agencies, as we saw in the previous chapter. The blurred and often unclear designation of responsibility for actually learning from experiments appears to further accentuate how marketing and product development might gain precedence over testing and learning in practice. This illuminates how the broader political rationality underpinning smart energy experimentation produces tensions when ambitions are to become reality in a concrete experiment. The political rationality also appears to facilitate the shaping of particular infrastructures of circulation, as well as knowledge politics, as highlighted.

A project manager at the City of Stockholm also emphasized how the City prefers to see commercial projects that can sustain themselves in Norra Djurgårdsstaden, i.e. without funding from the City. ${ }^{714}$ This further underscores the constitution of NDS as an innovation arena, where private actors are invited to conduct many different experiments to test and develop new green technology. The interviewee stated that the City aimed to create a spirit of innovation in NDS, and thus endeavors not to govern too strictly, choosing to focus on setting technologically neutral framework demands, for example in terms of the energy performance of buildings. ${ }^{715}$ These articulations highlight an important element of authorizing and assembling the intervention in NDS. Emphasizing testing appears to be central for authorizing the experiment in terms of earning the consent of the governed, making the intervention rightful and legitimate, and as an element connected to assembling practices. For instance, a project manager at the City invoked testing as a central element when discussing

\footnotetext{
${ }^{713}$ Ibid.

${ }^{714}$ Interview PM City of Stockholm.

${ }^{715}$ Interview EnvE City of Stockholm.
} 
issues that arose in connection with the single apartment fitted with smart home technology, funded by Vinnova between 2011 and 2013:

Well, I don't think it's a problem that someone tries. I mean that's what a development project is, that you try something, that someone dares to have someone live there for two years and then we'll see, is it possible to steer [...] or what happened? And then you've learned that, and that's not the end of the world. It was said that this is something that we try $[\ldots]$ that doesn't bother me at all. ${ }^{716}$

In this quotation, the aforementioned articulations about Norra Djurgårdsstaden as an innovation arena where tests are performed, expressed in policy documents and project documents, is echoed. The project manager stated that what was described in the industry press as failures of the smart energy experiment were actually important learning experiences, in line with NDS as an innovation arena:

I don't place any personal pride in that working. Really. I think that if you have said that it is a test, some tests go badly so then you try again..$^{717}$

The interviewee frequently referred to the whole of Norra Djurgårdsstaden as a test in itself, where new knowledge is generated continuously which then feeds back into the urban development process. A public servant working with environmental issues and urban development at the City of Stockholm expressed similar viewpoints:

[...] we see Norra Djurgårdsstaden as a brand, as a [...] marketing argument, so we venture in Norra Djurgårdsstaden, test new ideas particularly in Norra Djurgårdsstaden, since there is a platform there, to market yourself from as well. [...] Create, or trigger new ideas, most often they

work very iteratively I think in these types of projects, you learn continuously throughout the process. So I think they have probably learnt quite a bit about how to govern these types of projects and how important it is to have different parties involved. ${ }^{718}$

Here, the interviewee describes NDS as an innovation arena where ideas can be tested, and importantly also as a marketing platform, in line with policy documents and project documents for Smart Energy City describing NDS as a frontrunner of sustainable urban development. Invoking testing as an important element when intervention is assembled for Smart Energy City, and NDS as an urban development project, appears to have a strong rationale from the perspective of the City of Stockholm:

But we are only the development office, and our task is only to set requirements for the construction companies in our own contracts as smartly as possible. But then we can, we call for [...] doing LCA calculations on stuff, we should also be tasked with encouraging residents here to have a different lifestyle. But that has been like, oh no we don't want to do that. There our politicians $[\ldots]$ no that feels a bit risky, if you were to say live in a different way. ${ }^{719}$

\footnotetext{
${ }^{716}$ Interview PM City of Stockholm.

${ }^{717}$ Ibid.

${ }^{718}$ Interview EnvE City of Stockholm.

${ }^{719}$ Interview PM City of Stockholm.
} 
Since Norra Djurgårdsstaden is a very large urban development project, with a prolific public profile including claims of world-class sustainability, it has attracted its fair share of criticism. In the instance above, the project manager was asked about how different obstacles in the overall urban development project NDS has been handled, and what the City thinks about the criticisms raised. His response constitutes a way of shifting responsibility to other actors, but it also speaks to how NDS as a sustainable urban development project is authorized and how intervention is assembled. Since the City has a limited repertoire of formal instruments at its disposal, casting NDS as an innovation arena constitutes a way of authorizing the particular setup, inviting different constellations of actors to test new technology labeled as green, constituting a specific approach pursued in the name of world-class sustainable urban development. This works through the modality of consensus, since everyone appears to agree that this course of action is suitable for addressing environmental issues, thus contributing to accomplishing environmental governance in a particular way. The project manager continued:

So you're really careful politically to tell people how they should do that [live], that has to come from somewhere else. ${ }^{720}$

Judging from this quotation, it makes sense for the public administration to cast Norra Djurgårdsstaden as an innovation arena where private actors are invited to experiment with green technology. It becomes a method of coping with the political goals of making NDS into a world-class sustainable city district, considering the City's repertoire of instruments, for example that they do not own the electricity grid. The project manager stated that it would be desirable for the City to be allowed to engage with other issues in NDS, such as consumption and transportation. ${ }^{721}$ Drawing testing as an integral element of sustainable urban development into NDS, then, constitutes a way of assembling intervention which aligns different problem complexes. The emphasis on research, development, and testing primarily led by private actors can be viewed in light of the broader green political rationality, visible in attempts to reconcile market-based governance with ambitions of enhancing Stockholm's global competitiveness through marketing. ${ }^{722}$ Further, it presents a way for the City to balance the claims of world-class sustainability with the conditions instituted through the broader political rationality, such as projectification and dispersed responsibilities, while providing a way to escape criticism. Testing means that it is possible to not reach set targets, indicating that new tests are needed. It constitutes a particular way of accomplishing environmental governance, since it makes the environment into a field of intervention in specific ways through specific actions, including invoking large problem complexes, such as the ones just mentioned, as well as local problem complexes in Stockholm, and drawing testing as an integral element into sustainable urban development.

\footnotetext{
${ }^{720}$ Ibid.

${ }^{721}$ Ibid.

${ }^{722}$ Cf. Dryzek 2013. The Politics of the Earth; Franzén et al. 2016. Stad till Salu.
} 
To further underscore how - despite the emphasis on consensus in both project documents for the Smart Energy City experiment and policy documents for NDS - the sought-after collaboration between actors seems less close in practice, consider the following quotation:

I mean Norra Djurgårdsstaden has attracted a lot of interest from different private companies, researchers and so on, and therefore there are a bunch of R\&D projects which are run by the City on the one hand, and then there are R\&D projects run entirely outside the City, and then it's rather different types of private companies and construction companies who try to test different things. Smart Energy City is one of those, where we at the City of Stockholm are not at all engaged, it has been run by private companies and construction companies [...] So our involvement in Smart

Energy City is really not existent, we try to be, well, set requirements for the construction companies in a way so that they develop an innovative work method themselves, and if that happens to be developing apps, or developing some kind of visualization system for residents to affect their own behavior, that's something we entrust the construction companies and the private industry with, really. We are not part of this project. ${ }^{723}$

This lengthy quotation underscores several points. It reiterates the point made above, about how the new city district NDS is constituted as a green innovation arena, representing a specific mode of accomplishing environmental governance which is clearly influenced by the broader green political rationality. For the City of Stockholm, it represents a way of handling expectations from local politicians and living up to dreams of world-class sustainable urban development and marketing of Stockholm, in a manner that is consistent with available instruments. There are clear boundaries drawn between the Smart Energy City experiment and the broader urban development project, since Smart Energy City is described by the City of Stockholm as one of many innovative, green technology research projects ongoing in the city district. The interviewee stated, for instance, that smart grid is really not an issue for the City, but rather for Fortum and other energy suppliers in the city. ${ }^{724}$ It is claimed that cooperation is of key importance, but the question of smart grid development rests with Fortum rather than the City of Stockholm. This was also mirrored by the interviewed project manager at the City, who said that the City is not involved in any smart grid network, such as the Swedish Smart Grid Forum, but Fortum is likely to be. These articulations show how particular boundaries between the smart energy experiment and the larger sustainable urban development project are drawn. This is an important part of assembling intervention, since smart energy experimentation is turned into a question to be dealt with by private companies. This configuration mirrors the broader political rationality underpinning smart energy experimentation, highlighting how governance is arranged through projectification, where public-private partnership constellations attempt to develop new green products and services. However, it is private companies who are mainly designated "doers" in the case of NDS and Smart Energy City.

\footnotetext{
${ }^{723}$ Interview EnvE City of Stockholm.

${ }^{724}$ Ibid.
} 
Importantly, the interviewed public servant also stated that the City has a close relationship with Fortum, and that they are very interested in seeing the results of the Smart Energy City experiment to gain an understanding of how residents' energy behavior can be affected, potentially guiding future endeavors pursued by the City. ${ }^{725}$ This assigns an impetus to performing experiments, with an emphasis on techno-economic research, which can then guide policy, in line with so-called evidence-based policymaking, a notion that stood out as central for the political rationality underpinning smart energy experimentation across governmental institutions and policy networks. It thus appears that science as an institution is afforded credibility, in line with ascribing experiments the ability to find out what works in practice and consequently guide further action. This prominence afforded to science also highlights the importance of the affiliation with the Royal Institute of Technology (KTH), which was emphasized by interviewees.

The political rationality underpinning smart energy experimentation exerts considerable influence on the configuration of Smart Energy City. Environmental issues, such as those connected to energy use, waste, and climate change, are articulated as being best solved by developing new green technologies which can be exported, boosting Swedish economic growth. Specifically, it is through making NDS into an innovation arena where many different private companies are invited to test different solutions that the goals of world-class sustainable urban development can be achieved, whilst Stockholm is marketed as a frontrunner. The articulations in documents and interviews accounted for captures a double move working as authorization for a particular line of action pursued by the City of Stockholm, and indeed of a broader problematization of the environment. According to the interviewed project manager, the role of experiments should be to showcase the viability of different ideas, and to illuminate how different systems need to be transformed for change to take place and more projects to be rolled out. ${ }^{726}$ Identifying necessary regulatory changes and new business models is also expressed as important. Accordingly, there is a specific idea of how to achieve desired changes through experiments implicit in the statement; it involves testing ideas and identifying regulatory barriers, and then new, better experiments can be designed to contribute to change. This notion of how to achieve change through experiments fits neatly into the articulations of Norra Djurgårdsstaden as an innovation arena, and importantly with allusions to science recurrent in descriptions of both the urban development project NDS and the Smart Energy City experiment. The project manager stated:

I think that what is being done, it's self-evident, you do it because you can make money out of it. You don't have to be an idealist, it's widely accepted to work with sustainability, you don't have to be a muppet to do it $[\ldots]]^{727}$

\footnotetext{
${ }^{725}$ Interview EnvE City of Stockholm.

${ }^{726}$ Interview PM City of Stockholm.

${ }^{727}$ Ibid.
} 
Working with environmental issues is described as common sense, something that everyone does in order to make money, in line with the broader green political rationality. Thus, the quotation underscores how authorization unfolded through the modality of consensus; everyone agrees that it is important and you do it to raise revenue, not because you are an idealist. However, the project manager proceeds to problematize overconsumption and norms related to high material standards, which are described as problematic and very rooted in Sweden. ${ }^{728}$ He also stated that decision-makers should take alternative trends seriously, such as reduced private consumption, and be more proactive in making new laws to create the necessary preconditions which allow such trends to grow. Somewhat in line with alluding to how the public administration office for city development has not been tasked with handling consumption, building materials, or transportation in NDS, then, the project manager simultaneously legitimizes the administration's own approach to NDS as an innovation arena, and problematize how the necessary preconditions are not always in place, which makes handling the ambitions of world-class sustainable urban development in NDS difficult. It seems as if invoking testing, by constituting NDS as an innovation arena, provides a way of coping with these difficulties. It is also clearly reminiscent of how scholars concerned with governance have pointed out that responsibility is often difficult to locate in fragmented, network-based governance arrangements, where it is generally unclear who does what, i.e. it also serves as a way of dispersing responsibility to many different actors rather than putting the onus on the City of Stockholm. ${ }^{729}$ Such network-based governance is a central feature of neoliberalization processes, and as we saw previously it is a prevalent feature of the political rationality underpinning smart energy experimentation.

Within the sustainable urban development project of Norra Djurgårdsstaden, there is a clear emphasis on cooperation, illustrating how authorization works through the modality of consensus. The cooperation appears to be loosely constituted between different actors: the City provides a platform for private companies, while taking a distanced stance toward the Smart Energy City experiment. The City works by setting framework requirements for construction companies, while expressing that it is important to remain neutral toward different technological solutions, so it is up to private actors to come to NDS and carry out experiments, such as Smart Energy City, to test their solutions and "see what flies", as the project manager expressed it. This illuminates a particular knowledge politics, where the public administration is actually quite removed from smart energy experimentation, making private companies the principal actors for generating knowledge and making knowledge claims, implicitly rendering techno-economic knowledge central for improving the environmental condition. This order further underscores the conditions of possibility created by the broader political rationality, as it has clearly facilitated such knowledge politics.

\footnotetext{
${ }^{728}$ Ibid.

${ }^{729}$ See e.g. Brown 2015. Undoing the Demos; Morrison, Adger. Brown et al. 2019. The black box of power in polycentric environmental governance. Global Environmental Change, 57.
} 


\section{Smart Energy City: arranging governance through science, testing, and green innovation}

After the reboot and name change to Smart Energy City in 2016, the experiment revolved around smart home applications in 154 apartments and digitalized solutions in the electricity grid, with KTH conducting follow-up research on the behavior of energy users. The project partners in the Smart Energy City experiment draw upon different problematics to authorize their specific intervention, including as a method for transforming the energy system in response to climate change. Across interviews and project documents, renewable energy sources are described as being necessary to mitigate carbon emissions, but are also described as problematic for the current energy system configuration because of their intermittency, hence the need to test household flexibility to shave peaks in the power grid and maintain system stability. All of the interviewed participants in Smart Energy City were keen to point out that they are involved in many different smart energy experiments. This highlights how experimentation arranges governance based on a particular notion of change, where new experiments are always necessary to develop new products, and allows for marketing, in line with the broader political rationality underpinning smart energy experimentation.

This makes the smart grid into a specific solution to such problems, by extension casting experiments as tests as an arrangement to test what works in reality to narrow down the possible configurations of the smart grid. This constitutes a specific way of assembling intervention, mobilizing elements such as scientifically testing smart energy solutions, specifically in urban settings, through loosely arranged cooperative endeavors where different private companies are allowed to pursue individual agendas as long as they cooperate in a common experiment. The positioning of these actors as central for environmental governance, while foregrounding techno-economic knowledge claims they are best suited to produce, elucidates knowledge politics associated with the broader political rationality, clearly reflected in Smart Energy City. It specifically positions such actors as principal generators of knowledge.

The Smart Energy City experiment consisted of a consortium of private actors with somewhat different goals, mainly of a commercial character. These goals all tie in with constituting Smart Energy City as a test. According to a project manager at ABB, the overarching goal of the project was for KTH to analyze "how customers react" by testing the equipment in Smart Energy City; as mentioned previously, scientific tests are ascribed the highest importance by interviewees and in project documents, thus constituting an integral element as intervention is assembled through Smart Energy City. ${ }^{730}$ It also highlights KTH's role in the experiment, i.e. providing data and producing new research. ${ }^{731}$ An interviewee from an energy company described how knowledge generated through Smart Energy City feeds into a so-called smart living concept, since utilizing smart home technology in households is described as an

\footnotetext{
${ }^{730}$ Interview PM ABB.

${ }^{731}$ Ander 2019. Smarta elnät i stadsmiljö i Norra Djurgårdsstaden - slutrapport; Interview PM ABB. 
important way of unlocking flexibility in the energy system, which is required due to the increased integration of intermittent renewables. ${ }^{732} \mathrm{ABB}$ was interested in testing different technologies for surveillance of the grid and demand-response, while Electrolux tested how its appliances interacted with the IT equipment and how customers used them. ${ }^{733}$ Such an emphasis on testing scientifically further mirrors the political rationality underpinning smart energy experimentation; as shown in previous chapters, notions of scientific testing leading the way toward the future is a central element of the political rationality, especially testing and developing new green products, foregrounding techno-economic knowledge claims.

A project manager at an energy company participating in the experiment expressed several rationales for participation. These included testing digital technology for surveillance of the low-voltage grid to reduce error frequency and maintenance costs, and keeping tabs on new developments in the energy sector, as demanded by the company's board. ${ }^{734}$ The interviewee stated that benchmarking was an important function of the experiment, since being best practice was considered vital, while also articulating keeping down costs as a reason to engage. Specifically, electricity market regulations currently favor low error frequency through the use of different indexes calculating the annual average power outage duration per customer, for instance, which is then used as input for energy companies' revenue framework since they are monopolists. Smart Energy City provided ample opportunity to test digital technologies to enhance such indexes and thus increase revenue. ${ }^{735}$ Several of the actors involved also articulated how marketing was an integral aspect of participating in the experiment. A project manager at an energy company stated that branding was one of the main underlying reasons for engaging in smart energy experiments. Working with pilot projects had rendered it easier to attract young people, making recruitment processes cheaper. ${ }^{736}$ Being perceived as working with "the right issues", the issues of the future, was integral to this, the interviewee explained, thus emphasizing how the experiment helped to project an image of the company as innovative and green. ${ }^{737}$ According to the project manager, experiments such as Smart Energy City also play an important role in making smart grids commercially viable, which according to the interviewee can be pushed for by sharing experiences across different experiments. ${ }^{738} \mathrm{~A}$ project manager at $\mathrm{ABB}$ also expressed how marketing was an important reason for engaging in Smart Energy City, besides testing new technology. ${ }^{739}$ These examples illustrate how the partners within the consortium draw on different problematics to authorize the intervention assembled through the experiment. By tapping into climate change as a broad societal issue,

\footnotetext{
${ }^{732}$ Interview RM Fortum.

${ }^{733}$ Interview PM ABB.

${ }^{734}$ Interview PM Ellevio.

${ }^{735}$ Ibid.

${ }^{736}$ Ibid.

${ }^{737}$ Ibid.

${ }^{738}$ Ibid.

${ }^{739}$ Interview PM ABB.
} 
and by presenting electrification and digitalization as solutions, transforming the energy system through the development of an IT platform is presented as a rightful and legitimate course of action. A representative of Fortum described how households provide a key to unlocking more flexibility in the energy system, while a representative of Ellevio described how smart grids can provide a way of cutting costs in different ways.

Related to invoking testing as a central element of Smart Energy City, a representative of an energy company stated:

Well, you need some kind of project [to change the energy system], but whether we should call it pilot projects or demonstrations or research, I'm not sure. There could be very different parts depending on the maturity of technology or possible market perspectives. ${ }^{740}$

Here, different types of experimentation are described in terms of technological maturity or market perspectives, echoing the so-called TRL scale which was regularly referred to by experts across governmental institutions and policy networks. However, Smart Energy City does not appear to be easily pinned down in TRL terms, since it has variously been called an experiment (albeit not by the project consortium), a living lab, a demonstration project, a pilot project, a research program, and a flagship project. Still, these terms are mainly discussed using techno-economic language in Smart Energy City. A project manager at Ellevio used similar expressions, related to the TRL scale:

I always say that there is a staircase and here, at the bottom, you have basic R\&D. And then you have technology demos, what does it look like, how does it work, not that it has to be profitable but you've got to see that, right, and then maybe you have pilots, and I mean pilots on a small scale not a full scale $[\ldots]$ and then suddenly you're out in the market. ${ }^{741}$

The role of experiments for technological development crystallized in the TRL scale is disseminated through the EU's research funding platforms, as discussed previously. In the above quotation we can see how such a notion of technological change is invoked in Smart Energy City as a way of authorizing it; in order to climb higher up the staircase, the preceding steps must be taken first. This notion of change frames the Smart Energy City experiment, thus making certain courses of action more relevant and pursuable than others, constituting an important part of delineating the problem to be solved and thus of accomplishing environmental governance. Environmental governance becomes synonymous with private actors developing new technical solutions, following logics and implicit notions of technological change as enshrined through the TRL scale.

Describing Norra Djurgårdsstaden as an innovation arena, where private companies are invited to test and develop new technologies, seems to fit the notions of change implicit in the TRL scale. So despite the broader political rationality instituting consensus-seeking and cooperative efforts in public-private partnership projects, and despite this being commonly reflected in

\footnotetext{
${ }^{740}$ Interview RM Fortum.

${ }^{741}$ Interview PM Ellevio.
} 
documents pertaining to Smart Energy City, we have already observed how interviewees at the City of Stockholm clearly delineate NDS as an urban development project from Smart Energy City. Such demarcations are further reflected among actors in the project consortium, as well as in the final project report. This also elucidates how authorizing through the modality of consensus can take on different forms in concrete experiments. It appears quite clear that all involved actors endeavor to constitute NDS in this specific way, although cross-sector collaboration between the City and other actors conducting experiments, such as the private companies and academia in Smart Energy City, is rather loosely arranged. This is a clear example of how experimentation arranges governance - a particular actor constellation was established through experiments such as Smart Energy City, where private companies become central knowledge generators and their knowledge claims are foregrounded as central. Thus, the environmental condition is cast as being improved through testing and developing new products for commercialization, and actors invoke elements such as scientific testing for evidence-basing policy.

Centering science as authoritative expertise while emphasizing consensus and cooperation chimes with the notions of change implicit in the TRL scale. This institutes testing of a particular kind, focused on developing new green products and services which can hopefully become commercially viable, positioning private companies as authoritative actors and foregrounding techno-economic knowledge claims. This governance disposition entails notions of change which implicitly and continuously construe new experiments as the correct way of improving the environmental condition and achieving transformative change, by developing ever more new green products and services. Providing a general direction was described by an interviewee as a valuable and important contribution of experiments, more important than from specific companies' perspectives. ${ }^{742}$ This reflects how experiments can narrow down the pathways of energy transformation, mirroring descriptions of experiments as trailblazers and mobilization across governmental institutions and policy networks, i.e. as unearthing the right pathway toward the future smart sustainable energy system. This serves to obscure politics of experimentation, despite clearly instituting particular power-knowledge assemblages in line with the political rationality underpinning smart energy experimentation.

For example, Smart Energy City was regularly described as a scientific test, and sometimes even as interdisciplinary due to the involvement of different private companies, where science constitutes an integral element for authorizing the experiment. ${ }^{743}$ In particular, it was frequently expressed that Smart Energy City tested and researched energy users' behavior in order to assess the potential of flexibility among energy users, which would then feed into planning for the future energy system, echoing calls for evidence-basing policymaking on national level. Testing is inevitably predicated upon assumptions about energy users. Several

\footnotetext{
${ }^{742}$ Interview RM Fortum.

${ }^{743}$ Ibid; Ander 2019. Smarta elnät i stadsmiljö i Norra Djurgårdsstaden - slutrapport.
} 
interviewees pointed out that it was important for engaging with the equipment and devices installed in the apartments to be voluntary, in order to properly test whether people wanted to become more active. However, it was often emphasized that solutions had to be as simple and easy to engage with as possible, implicitly assigning rather passive roles to households. This entails politics since it facilitates specific positions for citizens to occupy, thus configuring environmental governance in specific ways. For instance, a project manager at an energy company stated that:

$[\ldots]$ the program decided that anything that makes it too complicated for the consumers, these are small-scale consumers who use maybe 3-4000 kWh [per year], they're not big, they have no heat load, it's all district heating. It's not good for the project [making things complicated], it doesn't work, you have to keep it simple. ${ }^{744}$

The project manager stated that the goal would be for energy users, or customers in his words, to voluntarily engage and act in a way that makes their lives more comfortable. He added that their environmental footprint could be changed and that customers could save money, but overall customers are not interested in understanding the different parts of a smart energy program. ${ }^{745}$ This idea, of keeping it simple since people were not perceived as being interested in energy as an issue area, recurred across interviews. ${ }^{746}$ This also constitutes an important element of assembling intervention, since preferring automated solutions which energy users notice as little as possible becomes a logic consequence of considering energy users to be uninterested in energy. ${ }^{747}$ This further elucidates knowledge politics of Smart Energy City, passivizing energy users and implicitly designating particular private companies as knowledge generators and producers of technical devices. Further, the quotation illustrates how technoeconomic knowledge claims made through the experiment risk solidifying comparatively high levels of energy use, since it was deemed to be too complicated to institute smart energy solutions regulating energy use at such low levels. This also mirrors the large-scale and centralized socio-technical infrastructure of the Swedish energy system; solutions on a large scale have long been preferred by the incumbent energy utilities. ${ }^{748}$

Taken together, these empirical examples elucidate how the involved actors are pursuing different avenues, albeit mainly of a commercial character. This constitutes different elements in assembling intervention, gathered under the large umbrella of Norra Djurgårdsstaden as an innovation arena, i.e. the specific mode of authorizing intervention through the modality of consensus, which allows for these diverse practices of assembling intervention. Cons ensus-

\footnotetext{
${ }^{744}$ Interview PM Ellevio.

${ }^{745}$ Ibid.

${ }^{746}$ Interview RM Fortum; Interview PM ABB.

${ }^{747}$ Cf. Schick \& Winterheik 2013. Innovating Relations - or Why Smart Grid is not too Complex for the Public. Science \& Technology Studies, 26(3).

${ }^{748}$ There are many reasons for such preferences, ranging from technical and economic to political. See e.g. Anshelm 2000. Mellan frälsning och domedag; Hultman 2015. Den Inställda Omställningen; Kall 2011. Förnyelse med förhinder; cf. Bakke 2017. The Grid.
} 
seeking and cooperation are generally employed as virtues in contemporary energy policy, often coupled to ideas of rationality, and as we have seen these notions are reflected in Smart Energy City. The experiment seems to have revolved mainly around different private companies being allowed to test, develop, and potentially sell green products and services as a solution to environmental issues, through the city administration tasking itself with establishing green, innovative city districts, enabling this course of action. This could be conceived of as accomplishing environmental governance in a specific way, with authorization unfolding to a large extent by associating improving the environmental condition with the broader green political rationality, for example by emphasizing product development and world-class sustainability through green innovation and exports, creating frictions between testing and marketing. Assembling intervention has entailed forging alignments between actors and realigning existing agendas in line with the problematization and solution devised through authorization. As we have seen, arranging governance through Smart Energy City has entailed positioning actors into a constellation where smart energy experimentation is more or less separated from the public administration, making private companies central agents.

\section{Issues, frictions, and contestations: setup of socio-technical experiments as a point of concern}

As Bulkeley underlines, contestation tends to emerge continuously alongside consensus, albeit not necessarily visibly manifested. In this section, a few central issues and frictions that emerged as authorization unfolded and intervention was assembled in Smart Energy City will be outlined. These tell an additional story about how the actors involved continuously maneuvered to stitch the experiment together, further illuminating how specific elements are continuously drawn into the experiment, and new problematics interlinked, in order to contain the experiment and uphold the intervention. Analytical attention to issues and contestations can tease out the politics of Smart Energy City, especially since it was authorized through the modality of consensus, which tends to shroud political contestation. ${ }^{749}$ Adding this focus can also shed light on how environmental governance is accomplished through and beyond Smart Energy City. However, it needs to be mentioned immediately that very few, if any, outright contestations surfaced in the material.

A few issues were mentioned in interviews as rather straightforward ones, such as apartments being bought on speculation which made it difficult to get accurate measurements of electricity use among residents. It is difficult not to view this in the light of criticism of smart energy experimentation, for tending to cater more to the wants of segments of the upper middle class and to increase profits, rather than achieving environmental improvements. ${ }^{750}$ Additionally,

\footnotetext{
${ }^{749}$ See Mouffe 2005. On the Political.

${ }^{750}$ See e.g. McLaren \& Agyeman 2019. Smart for a reason; cf. Dauvergne 2016. Environmentalism of the Rich.
} 
quite a few residents seemed completely uninterested in using the installed devices. ${ }^{751}$ Another issue appeared to relate to the experiment taking place in a city. The consortium wanted to install a switch in the basement of the apartment buildings, but this would have made too much noise so they had to find a different solution. ${ }^{752}$ This illustrates how materiality conditioned Smart Energy City, since the material particularities of layered, large-scale electricity infrastructure in the city provided obstacles to the consortium's plans. ${ }^{753}$

A central friction, as described by several interviewees, was that the technical solution tested in the single "active apartment" in the early stages of the experiment was too expensive and difficult to install. Thus, construction companies and property owners simply rejected installing the solution in their buildings. ${ }^{754}$ Representatives of the City stated that a fair amount of difficulty arose in relation to the different interests of the commercial actors involved in the experiment at an early stage, ${ }^{755}$ whilst a project manager at an energy company offered a similar description to that of the aforementioned civil servant at the Energy Agency, i.e. that ABB wanted to leave the project if it would be unable to test and sell its technical solution. ${ }^{756}$ Thus, friction occurred since one of the commercial actors might not be able to use the project for commercialization, and since builders and property owners were not actively involved. As previously described, all the actors in the consortium claimed later on that the pause and reboot of the experiment this resulted in turned out to be very good, since new, cheaper technology was available, construction companies could be involved from the start, and ABB was able to engage in the smart grid subproject rather than the smart home component. This illustrates how environmental action in essence depends on managing to reconcile different private companies' profit interests, when governance is arranged as in Smart Energy City. Historically, similar governance dispositions - in line with policy programs associated with the broader green political rationality - have at best delivered ambiguous results. ${ }^{757}$

There were also some frictions related to the setup of the experiment, which elucidates processes of accomplishing environmental governance. While emphasizing how successful the

\footnotetext{
${ }^{751}$ Interview PM ABB.

752 Ibid.

${ }^{753}$ Cf. Bulkeley, McGuirk, and Dowling 2016. Making a smart city for the smart grid? The urban material politics of actualizing smart electricity networks. Environment and Planning A, 48(9); Barry 2001. Political Machines.

${ }^{754}$ Interview RM Fortum; Interview PM Ellevio; Interview EXEA2.

${ }^{755}$ Interview EnvE City of Stockholm; Interview PM City of Stockholm.

${ }^{756}$ Interview PM Ellevio; Interview EXEA2. It was ABB's technical solution that was installed for the apartment test, i.e. the equipment in the household rather than the equipment they later installed in the grid such as substations and the demand-response solution.

${ }^{757}$ See e.g. Dauvergne 2016. Environmentalism of the Rich; Pirani 2019. Burning Up; Irvine 2019. Carbon. Especially chapter 3; Burke and Stephens 2016. Political power and renewable energy futures; Malm 2016. Fossil Capital.
} 
experiment had been with regard to how much had actually been learnt by the actors involved, a research manager at an energy company also described something similar to fatigue:

RM: Speaking in a broad concept of smart grids, I don't think we will do another project this huge with the Energy Agency and big partners and everything. [...]

\section{I: Because?}

RM: Well sometimes it gets a bit heavy. Sometimes there's too many compromises. Every partner wants their share and when you enter into a cooperation like this it's like, sometimes you decided that you want to dance with someone and when you're up there dancing suddenly you want to do different dances and that doesn't always turn out great. So I think it's easier and quicker to rather look at, that this will rather be run through more of a fleet-footed, agile and innovative perspective. Maybe not such a large, heavy project like this. ${ }^{758}$

This quotation illustrates several frictions, for instance related to temporal aspects and the size of experiments. Similarly, several interviewees stated that one issue with such big experiments is that the ideas which formed the basis of the experiment at an early stage might already be outdated before the project ends. An interviewee from the City of Stockholm stated that interest in smart grids as an issue area was very high during 2010-2011, but that it quickly cooled off thereafter. According to the interviewee, the City stopped receiving virtually any questions at all about Smart Energy City after an initial boom. ${ }^{759}$ This seems to underline a concern expressed by experts across governmental institutions and policy networks, that marketing becomes too important a value of experiments. Viewed in the light of the broader political rationality, this is an unavoidable risk, since developing new products sits at the core of improving the environmental condition.

In the quotation above, the specific actor constellation in the experiment is also problematized, essentially because of the interests of the different private companies. This also echoes how a civil servant at the Energy Agency expressed that the experiment was basically constructed as a compromise between the different private companies, so that everyone would be able to sell their products. ${ }^{760}$ Similarly, another interviewee from the City of Stockholm stated that it had been something of a thorny issue that the City wanted to install solar panels and solar collectors, since a private energy company involved owned the district heating grid. ${ }^{761}$ Connected to how there were mainly private companies involved in the experiment, the research manager at Fortum also stated that it is vital to be careful with trademarks when conducting experiments, so that the experiment does not end up hurting them:

\footnotetext{
${ }^{758}$ Interview RM Fortum.

${ }^{759}$ Interview EnvE City of Stockholm.

${ }^{760}$ Interview EXEA2.

${ }^{761}$ Interview EnvE City of Stockholm.
} 
How do you handle the trademark, how do you handle that, I mean in a project such as this which is for real, it is not just like a playground, these are real people living in real apartments that they have bought. So how do you handle prototypes and real products when you put it out to the customer? ${ }^{762}$

This further underlines the tension between marketing and testing, since it actualizes the question of whether it is possible to perform uncertain tests with uncertain outcomes if the intended goal is to utilize the experiment as marketing to sell products. Again, this illustrates how environmental governance arranged through Smart Energy City entails uncertainties, especially since it hinges on managing to reconcile different private actors' interests. Connected to this, a friction which appeared regularly in interviews relates to uncertainties about who is actually responsible for financing the development of a smart energy system, especially in terms of who pays and who reaps the benefits. ${ }^{763}$ The following quotation highlights this:

And then the business models, if the energy company sees opportunities to save a lot of energy who will take part in that and who will enable it to happen? Should the City demand that construction companies invest in something, or should they bid for it? Should consumers get more expensive apartments? There you need to decide who should take the risk, that hasn't been possible so far. And there we have felt the entire time that, well it's not up to the City in any case. But maybe the others have been thinking like that as well. ${ }^{764}$

Connected to this line of reasoning, the project manager at the City briefly expressed criticism against market-driven environmental governance:

Yeah, sure, those smart apartments could be introduced all over if anyone would be willing to pay for it. But up until now it's been like, the market will solve this, and then it gets [...] it delimits quite a lot what can actually be done. [...] Sometimes you have really high hopes that things will just happen. ${ }^{765}$

These sentiments present a critique of the sustainable urban development project of Norra Djurgårdsstaden and Smart Energy City, and essentially of the largely market-focused Swedish environmental governance, and thus the political rationality underpinning smart energy experimentation.

This brief foray into tensions and frictions highlights how contestations emerged alongside attempts to forge a consensus to authorize the experiment. This shows how consensus is always an accomplishment in the making, and how the broader political rationality creates tensions in a concrete experiment. Further, as illuminated by the critique expressed above, contradictions appear when experimentation is aligned with the broader political rationality underpinning smart energy experimentation.

\footnotetext{
${ }^{762}$ Interview RM Fortum.

${ }^{763}$ E.g. Interview PM Ellevio; Interview PM City of Stockholm.

${ }^{764}$ Interview PM City of Stockholm.

${ }^{765}$ Ibid.
} 


\section{Accomplishing environmental governance through Smart Energy City in NDS: green growth through an innovation district}

As we have seen, the Smart Energy City experiment constitutes a site through which different elements are woven through practices of bricolage, thus accomplishing environmental governance. This occurs through interlinkages between different problematics and problem complexes, such as urban development and enhancing the city's competitiveness, as well as digital methods for surveillance of the low-voltage electricity grid and shaping energy users' behavior through the use of ICT. We have seen how the experiment contributes to shaping the field of intervention for environmental governance, making the issue at hand intelligible and governable, thus delineating the field of intervention in specific ways through these practices. ${ }^{766}$ Through the constitution of Norra Djurgårdsstaden as an innovation arena by the City of Stockholm, elements are drawn into the experiment and associated with contemporary problem complexes, such as urbanization, notions of competition between cities, digitalization, energy transformation, and households as nodes of flexibility that can contribute to balancing the large-scale electricity system, and these elements are connected to the specific solutions produced through Smart Energy City. We can thus discern a specific problematization, with specific solutions attached. In other words, experimentation arranges environmental governance in particular ways.

Authorizing Smart Energy City appears to have hinged upon aligning the experiment with the broader political rationality underpinning smart energy experimentation to a large extent, focused on technological innovation by private companies. This taps into both the dominant political rationality, as discussed in previous chapters, and Stockholm's local circumstances. An emphasis on testing is a common element in Norra Djurgårdsstaden and the Smart Energy City experiment. There is also a strong emphasis on consensus and rationality, often through alluding to scientific testing, which also tallies with calls for evidence-basing policymaking and paving the way forward through experiments. The language when experiments are discussed by interviewees, and when they are described in documents, displayed a degree of fragmentation. The sustainable urban development project of NDS was mainly described as an innovation arena or a platform for tests, but Smart Energy City was variously referred to as a test, a demonstration project, a pilot project, a flagship project, a living lab, an experiment, a testbed, and a research program. As mentioned previously, the project consortium members were, however, careful not to call it an experiment themselves.

Assembling intervention included casting the city as an optimal site of environmental action, mainly climate action, with reference to urbanization and the large environmental footprint of cities. Developing innovative methods for organizations as well as new green technologies were mobilized as central elements, which fed into constituting Norra Djurgårdsstaden as a

${ }^{766}$ Cf. Bulkeley 2016. Accomplishing Climate Governance. 
sustainable city district. Construction companies, new apartment buildings, IT systems, and learning and testing as central goals were then drawn into the experiment. For the City of Stockholm, an emphasis on iterative learning and testing through many different experiments became a way of coping with political goals of world-class sustainable urban development, while certain issue areas, such as consumption and transportation, were excluded from intervention. Testing and learning, mainly performed by private companies, provided a method for shifting some responsibility of action onto other actors, whilst goals of world-class sustainability could be upheld despite some obvious areas of intervention being off limits. This also makes the field of intervention for environmental governance intelligible and governable in specific ways through experimentation, while other possibilities are excluded, as the examples highlight. Importantly, through drawing on notions of testing and learning, it became possible to escape certain criticism that arose against the Smart Energy City experiment and Norra Djurgårdsstaden, since it was articulated that an important part of testing was to learn from mistakes and then try again. So the story of Norra Djurgårdsstaden as an innovative sustainable city district is partly told through experiments such as Smart Energy City, which also constitutes a method of coping with political goals of sustainability in NDS while staying away from issues such as transportation and residents' lifestyles (at least beyond temporary shifts in electricity use over time). Such a line of action can then be selfreferentially confirmed as the correct route through the techno-economic knowledge claims made by private companies through experiments, in the capacity of authoritative actors.

In the process of assembling intervention in Smart Energy City, demarcations were continuously made. The urban development project of Norra Djurgårdsstaden was articulated as an innovation arena in which different experiments were ongoing, but also as an experiment in itself since it is supposed to "try what is possible now and stretch limits where possible, to become a role model for sustainable urban development" ${ }^{767}$ This underlines contingencies of assembling intervention, also reflected in the final report submitted to the Energy Agency by the Smart Energy City consortium, through a timeline where the initial single "active apartment" test is excluded, which reinforces how it might be difficult to articulate mistakes or lessons learned in a large, strongly profiled experiment that is partially intended to market specific companies and strengthen their brand as well as a new city district - and, by extension, an entire city. This might run the risk of the endeavor being viewed as a failure, which may negatively impact marketing goals. Recall how a civil servant at the Energy Agency reflected that unfortunately socio-technical experiments with the biggest impact and visibility are often well-marketed ones, rather than ones with interesting results. Another boundary was drawn by a representative of an energy company, who stated that urban development was not the company's main skill - this was rather energy system development, which seems to tally with how representatives of the City of Stockholm drew quite clear boundaries when proclaiming

\footnotetext{
${ }^{767}$ https: / / vaxer.stockholm/omraden/norra-djurgardsstaden/?page-21-1243=0\#page-21-1243 [201906-26].
} 
that smart grid development is a question for energy companies, whilst urban development was construed as the City's issue. This underlines how despite public-private partnership collaborations constituting a central tenet of the broader political rationality, actor constellations might rather reflect local place-based specificities and histories, in the case of NDS and Smart Energy City reflecting a lineage in how the City has worked with establishing green innovation districts as part of economic and environmental policy.

Smart Energy City institutes specific knowledge politics, since the actors with the capacity to carry out smart energy experiments in a setting characterized by marketing and export as central goals, and to attract the attention of the City through their broad contact networks and their expertise in writing applications for funding, are large, established private companies. When intervention is assembled thus, it might be more difficult for actors with different circumstances to come across as relevant; for example, one small firm brought into the Smart Energy City experiment was acquired by one of the large energy companies involved, and the question is what scope there is for grassroots initiatives in such a setting. ${ }^{768} \mathrm{~A}$ mismatch between the rhetoric and practice of experimentation as environmental governance strategy can be observed here; the political rationality underpinning smart energy experimentation leaves precious little space for bottom-up efforts which invite broader political participation in energy transformation endeavors. While NDS is argued to be open to anyone wanting to experiment with smart energy, it seems that in practice there are actually few who manage to pass the threshold. This can be interpreted in light of neoliberalization processes, historically sedimented power relations in the energy system, and the broader political rationality, constituting brand-making to substantiate claims of world-class sustainability in Stockholm and Sweden as central, while catering to the national export orientation, and emphasizing consensus rather than envisioning and materializing alternative modes of organizing energy systems through experimentation.

\section{Knowledge circulation within organizations and marketing through networks}

This section will focus on circulations connected to Smart Energy City. As discussed in the theory chapter, in the broadest sense the concept of circulations aims to capture the activities and processes of making something movable. Of particular interest is whether Smart Energy City facilitates the creation of infrastructures that enable movement, the channels of movement, and the actors facilitating movement. Elements of experiments can be extracted, packaged, and then circulated; practices that might be enabled or constrained by the political rationality underpinning smart energy experimentation - for instance foregrounding particular knowledge claims. The broader political rationality might facilitate rigging certain routes or channels of circulation into an experiment from the outset. However, as governance

${ }^{768}$ Cf. Crouch 2011. The strange non-death of neoliberalism. Cambridge: Polity. 
is accomplished new infrastructures of circulation may be created, while actors can utilize existing place-based dispositions to facilitate circulations. Consequently, circulations can help analytically distinguish how elements of a governmental apparatus are stitched together.

Circulations may occur in different ways. This section is therefore structured along forms of circulations that emerged through empirical analysis, based on a conceptualization of circulations as outlined in the theory chapter. Specific projections of how the future smart energy system is imagined could conceivably be shaped or reinforced through experiments and circulated among actors through e.g. participation in policy networks such as the Swedish Smart Grid Forum, cementing or unsettling specific configurations shaped through experiments. Specific constellations and roles of actors could be also transferred to other experiments or endeavors, i.e. circulations of specific social arrangements, or circulations of technological devices into other experiments or everyday operations of energy companies. Further, it includes analyzing whether certain actors gain access to policy arenas through participating in experiments, or whether particular notions of change are packed into the setup of experiments, which creates certain pathways for stories to be told through experiments. Actors in the field may actively package knowledge claims based on experiments and attempt to circulate them in different policy forums, thus in practice foregrounding particular knowledge claims through the experiment whilst filtering out aspects of reality that are deemed irrelevant.

As we have seen in previous chapters, there is a widespread idea about how experiments contribute to transforming energy infrastructure embedded across governmental institutions and policy networks, informed by the broader political rationality. Articulated in documents as well as by experts in such institutions and networks, experiments tend to be framed as sites for generating knowledge and learning which can be transferred to other places, informing policy while developing new green technology, and thus contributing to changing the energy system. To unpack how experiments arrange environmental governance in practice, circulations as a more generic term allows for remaining open to where, how, and through which channels different types of knowledge and knowledge claims are circulated beyond single experiments, thus pinpointing different political effects of experiments such as consolidating or unsettling assumptions embedded by the broader political rationality, stitching the governmental apparatus together. As we will see, circulations better capture the diverse ways in which experimentation arranges environmental governance beyond the dominant narrative.

Thus, circulations as a concept can better illuminate how experimentation arranges governance and the power relations resulting from such arrangements than, for instance, upscaling. Recall how a civil servant at the Energy Agency lamented how it is not always the experiments with interesting results that manage to gain traction; rather, it is often the successfully marketed ones. This underlines how circulation goes beyond learning, even if it can include learning, for example that certain involved actors might have learned something whilst knowledge might be closed off to others. Recall how an energy field expert expressed 
concern about precisely this, i.e. that knowledge generated through experiments tends to stay within participating private companies, thereby strengthening their position. Actors with access to established marketing channels or policy-relevant forums might have an easier time gaining traction through experiments than others, highlighting the analytical value of thinking through infrastructures of circulation, whilst moving a technological component might be successful if it can be tucked into a suitable socio-material web of relations in another place. This illustrates how experiments' contribution to transformative change might happen in unexpected ways through circulations, while circulations might also contribute to upholding impasses, rendering environmental ambitions difficult to reach.

\section{Circulations by private companies: learning within organizations, marketing through networks}

A distinguishing feature of Smart Energy City is that circulations of different aspects of the experiment appear largely to be performed by individual actors through their own established channels, in line with how Norra Djurgårdsstaden is configured as an innovative green city district where many different initiatives are carried out individually rather than being carefully coordinated. Naturally, common project presentations including several of the partners in the Smart Energy City consortium or project partners and representatives of the City of Stockholm have also taken place, for example at seminars or conferences. Several interviewees emphasized how the City of Stockholm initiated a visitor initiative, where many different people from all over the world come to take guided tours of the city district. ${ }^{769}$ Interviewees underlined that heads of state and other high-level policymakers often came to witness Norra Djurgårdsstaden, and this often included hearing presentations of the Smart Energy City experiment from actors involved. ${ }^{770}$ This could be construed as circulations taking place within the site of the experiment, i.e. the physical space, by circulating the narrative of Norra Djurgårdsstaden as a pioneering, innovative sustainable urban development project, showcasing specific technological components and drawing upon the narrative of testing through experiments. This ties in to circulating a specific image of the experiment, extracted from the broader intervention assembled, and substantiated through claims of excellence in sustainable urban development by the City of Stockholm and the national level, in line with understanding experiments as being important for marketing and policy transfer. It tallies with the aforementioned importance afforded to marketing Swedish excellence in sustainability, Stockholm as an environmental frontrunner city, and the involved companies' expertise in green energy technology. Further, it runs parallel with longstanding trends of "policy tourism"

\footnotetext{
${ }^{769}$ Interview PM City of Stockholm; Interview RM Fortum.

${ }^{770}$ Interview RM Fortum.
} 
and best practice benchmarking, which are integral aspects of contemporary governance processes pertaining to urban space and environmental issues. ${ }^{771}$

Overall, many different ways of spreading knowledge were articulated by interviewees, which seemed to be synonymous with disseminating results from the Smart Energy City experiment, the implicit assumption being that it was beneficial to reach as many forums and audiences as possible. Further, scientific publications connected to Smart Energy City were highlighted as being important, indicating the circulation of particular knowledge into academic publishing. This seems to imply that circulation to gain traction for an experiment is assumed to work best when the results of an experiment are disseminated in as many forums as possible, tailored to fit the intended receiver. A project manager at $\mathrm{ABB}$ stated that the consortium would have liked to reach wider publics through news media, mentioning some of Sweden's largest daily newspapers, but that the news value was limited and the logics of the media prevented publicity among the broader public, pointing to how people in general are not very interested in energy. ${ }^{772}$

Representatives of both energy companies involved in Smart Energy City, Fortum and Ellevio, explained how the experiment had generated important new knowledge as well as contributing to developing new products. In the case of Fortum, an interviewee stated that Smart Energy City had provided input for the development of a so-called smart living concept, which Fortum launched as a commercial service for households. ${ }^{773}$ Similarly, a project manager at Ellevio stated that the experiment had provided new insights related to cyber security in an increasingly digitalized grid, which is of relevance for grid operators such as Ellevio when interlacing the grid with smart technology. ${ }^{774} \mathrm{~A}$ project manager at $\mathrm{ABB}$ highlighted that participation in Smart Energy City and similar endeavors had contributed to the development of new products, which $\mathrm{ABB}$ was now ready to roll out on a commercial basis. ${ }^{775}$ Such statements are clearly in line with the overarching narrative of experiments' contribution to transformative change through learning and developing new products, although in these cases learning is reserved for the specific companies involved. Consequently, experiments are articulated as being important for both business development and internal learning, elucidating circulations of new knowledge within the involved companies as an important infrastructure of circulation. This certainly tallies with the frequent descriptions of Norra Djurgårdsstaden as a green innovation hub, as well as aligning with the export orientation imbued by the broader political rationality underpinning smart energy experimentation.

${ }^{771}$ E.g. McCann \& Ward (eds.) 2011. Mobile Urbanism. As already discussed, such governance is significative of neoliberalism as a political rationality. See Brown 2015. Undoing the Demos.

${ }^{772}$ Interview PM ABB. As we have seen, this seems to be a widespread assertion among energy companies.

${ }^{773}$ Interview RM Fortum.

${ }^{774}$ Interview PM Ellevio.

${ }^{775}$ Interview PM ABB. 
Marketing and branding were often highlighted as central aspects of experimentation, in concurrence with NDS as an urban development project. ${ }^{776}$ Benchmarking in particular can be considered a specific form of circulation among energy companies, which constitute a specific group of actors. Experiments were described by a representative of Ellevio as a form of situational analysis, of making sure that they are best practice. ${ }^{777}$ Thus, extracting particular knowledge from experiments to circulate, or simply making it known to other energy companies that they are participating in experiments, seems to be important. This could be compared to how energy users in Smart Energy City were encouraged to benchmark their electricity use against themselves and their neighbors over time, which scholars have argued runs the risk of creating non-negotiable baseline levels of electricity use. ${ }^{778}$ This form of circulation, of metrics comparing performance between energy companies, creates an impetus for conducting experiments, as the quoted project manager implicitly states. If the main participants in experiments are large, private actors who make comparisons for benchmarking among themselves, this does not necessarily lead to environmental improvements. Specific levels of energy use, for example, could become cemented as best practice among energy companies, but these levels might not be sustainable in the long run at all, taking into consideration the wider socio-technical infrastructures of which they are part. ${ }^{779}$ This underlines how the political rationality underpinning smart energy experimentation facilitates particular forms of circulation through particular channels, where knowledge claims that can amplify marketing efforts and produce a specific image of innovative testing in the new city district are centered, running the risk of contributing to sustaining unsustainability rather than achieving transformative change. ${ }^{780}$

The scattered examples of circulations as marketing make sense when viewed in the light of the constitution of NDS as an innovate green city district focused on testing new technology, not least when considering the City of Stockholm's emphasis on NDS as a flagship area to make Stockholm a global environmental frontrunner city. The Smart Energy City experiment, along with other experiments in NDS, creates interlinkages with these goals, as we saw in the sections on assembling intervention, and consequently a larger infrastructure of circulations as marketing can be discerned. Smart Energy City is part of a patchwork of experiments which create grounds for marketing NDS as an innovative green city district, which as we have seen creates marketing opportunities for different private companies' products and proficiency in

\footnotetext{
${ }^{776}$ E.g. Interview PM ABB; Interview PM Ellevio.

${ }^{777}$ Interview PM Ellevio.

${ }^{778}$ See e.g. Hargreaves, Nye, and Burgess 2013. Keeping energy visible? Exploring how householders interact with feedback from smart energy monitors in the longer term. Energy Policy, 52; Strengers 2013. Smart energy technology in everyday life.

${ }^{779}$ Cf. Dauvergne 2016. Environmentalism of the Rich; Pirani 2019. Burning $U_{P}$; Dunlap 2019. Renewing Destruction; Boyer 2019. Energopolitics.

${ }^{780}$ Cf. Blühdorn \& Welsh (eds.) 2014. The politics of unsustainability: eco-politics in the post-ecologist era. London: Routledge.
} 
building the smart energy system of the future. The marketing of NDS as a pioneering sustainable urban development project substantiates the City of Stockholm's sustainable city ambitions, which in turn corroborates Swedish ambitions of green economic growth through innovation and export, in line with the broader green political rationality. Such an infrastructure of circulation, producing an image of green innovation and place-branding NDS as a green innovation hub, can also be interpreted as an expression of the demonstrative capacities of experiments - i.e. as a way of convincing particular publics of specific future smart energy system configurations. As expressed by several interviewees, however, the news value of experiments tends to fade quickly, and thus marketing and place-branding become risky forms of circulation. For example, an employee at the City of Stockholm stated that the number of visitors to Norra Djurgårdsstaden who were interested in Smart Energy City decreased dramatically over a period of time. ${ }^{781}$

It is important to emphasize how circulations of the Smart Energy City experiment overall mainly occur through individual actors' own channels, seemingly often in the form of generating attention for the experiment and circulating a narrative of an innovative city district and forward-thinking firms. Ericsson, for instance, built an in-house studio at its headquarters, where Smart Energy City was demonstrated. As we have seen, circulations also appear to take place as learning within the individual private companies. Recall how, according to a research manager, experiences from Smart Energy City fed into Fortum's smart living concept. ${ }^{782}$ There seems to be less focus on knowledge circulation between organizations, as the previously discussed boundaries drawn between the City of Stockholm and the Smart Energy City consortium might suggest. The project manager at ABB remarked how there were many different people within the company engaged in their "smart grid concept", and described a continuous dialogue with the research manager at $\mathrm{ABB}$, illustrating how the research department was interested in the results of Smart Energy City. ${ }^{783}$ However, the project manager also stated that it was difficult to answer the question of what ABB would do with the experiences gained through Smart Energy City, other than gauging interest in using the products developed partly through the experiment. ${ }^{784}$ For Ellevio, knowledge related to digitalized surveillance of the grid was articulated as an important result of the experiment which was disseminated within the company. This shows how a great deal of hope is pinned on individual private companies learning from experiments, and then moving in a sustainable direction based on this new knowledge, which appears to be a central aspect of how environmental governance is accomplished through Smart Energy City and the setup of smart energy experimentation in Norra Djurgårdsstaden.

\footnotetext{
${ }^{781}$ Interview EnvE City of Stockholm.

${ }^{782}$ Interview RM Fortum.

${ }^{783}$ Interview PM ABB.

${ }^{784}$ Ibid.
} 
Considering how experiments are attributed with scientifically asserting optimal routes to energy transformation, the techno-economic knowledge claims private companies are poised to make through experiments gain considerable weight in not only gauging development or carrying out tests, but also consolidating the route toward a smart energy system in line with such business strategies through circulations. As a concrete example, Ericsson installed a permanent showroom at its own headquarters to display its Smart Energy City technologies to visitors and employees. This ties in with experiments as demonstrations, i.e. as showcasing technologies. Together with the examples above, this highlights how particular infrastructures of circulation were shaped or tapped into through Smart Energy City, among other smart energy experiments. This contributes to arranging governance in specific ways, since implicit assumptions stemming from the broader political rationality are consolidated through such knowledge claims, thus indirectly steering energy transformation in specific directions. The dominant political rationality evidently conditions circulations of Smart Energy City, as marketing infrastructures are set up among large private companies to facilitate achieving export ambitions and greening economic growth. Inadvertently, this seems to cause much of the knowledge generated through Smart Energy City to remain within companies in proprietary form, whereas these actors are designated as central for energy transformation through the foregrounding of their knowledge claims in this setting. As we saw, this shrouds important, implicit assumptions about improving the environmental condition that are irresolute at best, while passivizing energy users.

\section{Circulations within the City: NDS as a frontrunner}

As alluded to previously, it was often articulated through policy documents and interviews with civil servants that Norra Djurgårdsstaden is a continuation of Hammarby Sjöstad, in the sense that it is intended to build upon experiences gained when constructing the previous large green innovation district. This highlights how Smart Energy City is incorporated from the outset into a specific infrastructure of knowledge circulations, not only producing new such infrastructures. The experiment's integration into the production of a particular image thus becomes clear; it substantiates the story of Stockholm's green innovative city districts where private companies are invited to iteratively test their way toward the development of new green energy technology, while cooperative learning is undertaken which can then inform the construction of new green innovation districts, as a way of improving the environmental condition. The circulation of such an image is accomplished through participating in transnational environmental forums such as $\mathrm{C} 40$ or the "policy tourism" operation in NDS, for instance. This is an important part of the story the City of Stockholm wishes to tell with its green innovation districts, which in turn clearly taps into dominant narratives of smart energy experimentation, emphasizing testing, learning, transferring knowledge, and scaling up, and thus providing an important function for place-branding Stockholm as the testing, learning city at the frontline of green technology development. Such infrastructures of circulation, in which Smart Energy City plays an important role, highlight particular governance arrangements, improving the environmental condition in specific ways. This is clearly attuned to the broader 
political rationality, as it substantiates Swedish green smart energy export ambitions, while positioning private companies as principal agents of environmental governance and supplying public funding for their smart energy experiments.

Another infrastructure of circulations that appeared to be central was between administrative departments within the City. As we saw previously, the City of Stockholm was keen to articulate NDS as an innovative urban arena where not only new technologies were tested, but also new methods of urban development, which would then be disseminated across the city and shape urban development practices. According to an interviewee at the City of Stockholm, spreading knowledge from specific experiments such as Smart Energy City across Stockholm mainly happens through a specific method developed in NDS. Several thematic areas for NDS were identified by the City, including energy, which were then bracketed and organized into focus groups consisting of different parts of the public administration, in order to "break up silos", to paraphrase the interviewee. ${ }^{785}$ One person is assigned to coordinating these different groups, to make sure that common questions which span the different focus areas are discussed in all groups and knitted together to avoid issues with silos such as myopia. ${ }^{786}$ Who was responsible for sharing results from specific experiments with the other experts in the focus groups, such as from Smart Energy City, was not entirely clear. The interviewee stated that:

And all these experts in these focus groups, who in practice belong to other administrations or companies, they take the knowledge and spread it to their other projects. So it creates ripples on the water. That's how we work, and that's how we make sure that the good experiences are disseminated. ${ }^{787}$

This could perhaps be conceived of as a microcosm of the broader sustainable urban development project of Norra Djurgårdsstaden, as well as a reflection of the Smart Energy City experiment. Circulations are staged through the creation of different groups, or forums, where experts within public administration and from private firms meet and share results and experiences, which can then feed into additional experiments. Circulations are thus arranged in the image of experimentation in NDS, i.e. through loosely arranged networks and forums, with the hopes of dissemination resting on individual actors utilizing their own channels. Thus, transformative change from experiments appears to be expected to emanate from the development of new green energy technologies within the city district, which can then be commercialized and thereby have an impact. Another interviewee expressed a particular notion of change, which further elucidates this infrastructure of circulations; through lessons learned and knowledge generated in initiatives such as Smart Energy City, more new projects could be rolled out, building upon gained experiences. This implies an organic notion of circulation of knowledge, where the City is not primarily responsible for learning or

\footnotetext{
${ }^{785}$ Interview EnvE City of Stockholm.

786 Ibid; Stockholms stad 2017. Program för hållbar stadsutveckling.

${ }^{787}$ Interview EnvE City of Stockholm.
} 
organizing learning processes. This serves to further underline the separation between Smart Energy City and the City of Stockholm.

Importantly, it seems to be mainly experts within the public administration and private companies who are described as being important within these groups, rather than environmental NGOs, for example. One could ask where critics of Smart Energy City and NDS are allowed to float their opinions, which could inform smart energy experimentation e.g. in terms of setting up new experiments. The consensus-seeking and emphasis on cooperation instituted through the broader political rationality seems to be reflected in the case of NDS and Smart Energy City - we saw in previous chapters how, as experimentation arranges environmental governance, the state's role is configured mainly as coordinator and funder, and collaboration is centered around public-private partnership constellations. Such an ordering of environmental governance seems to be strengthened in practice through experiments such as Smart Energy City, which reflects the fact that while smart energy experimentation might be open to anyone in principle (a recurrent argument from the public administration related to NDS), it seems to be primarily reserved for large, established companies in practice. Consequently, the infrastructures of circulations outlined above arrange environmental governance in line with the broader political rationality, providing impetus for neoliberalization processes; the export orientation which foregrounds the profit motive for smart energy experimentation, positioning large private companies as central agents, as well as consensus-seeking and emphasizing cooperation while foregrounding technoeconomic knowledge claims which suppress potential conflicts and controversies over the form and substance of smart energy experiments. This further underscores how the broader political rationality underpinning smart energy experimentation conditions the creation of channels for circulation. Instituting NDS as a green, innovative city district where the City remains distant from most of the experiments carried out entails placing the onus for achieving transformative change mainly with certain private companies, thereby making circulations mainly a matter for these actors. As discussed, the instruments at the City's disposal, combined with a widespread projectification of the public sector, which also tallies with the broader political rationality, further reinforce such tendencies.

\section{Circulations through knowledge-networks: organizing learning, influencing policy}

Interviewees also remarked how experiments should feed into policy, and inform regulatory development, concurring with many experts across governmental institutions and policy networks. ${ }^{788}$ These interviewees also articulated their active participation in different policyrelevant forums, attempting to spread the results of Smart Energy City. ${ }^{789}$ This constitutes another type of circulation: circulation through participation in different political forums,

\footnotetext{
${ }^{788}$ E.g. Interview PM ABB; Interview RM Fortum.

${ }^{789}$ Interview RM Fortum; Interview PM Ellevio; Interview PM ABB.
} 
utilizing results and knowledge from the experiment. Such participation in different policy networks can be conceptualized as a particular form of circulation, which might facilitate particular pathways of energy transformation to gain traction through linking to different political goals and engaging in policy discussions, foregrounding knowledge claims that can be substantiated through participation in experiments. ${ }^{790}$

As learning from experiments is regularly framed as a prerequisite for policy input, it is relevant to disentangle who is made responsible for learning. As we saw on the national level, divergent views surfaced across governmental agencies and other actors. A research manager at Fortum assigned the main responsibility for spreading results of Smart Energy City to involved actors, since this was required by the Energy Agency. The interviewee also ascribed the Energy Agency with some responsibility, however, stating that they attempt to spread knowledge through open dialogues and sessions. ${ }^{791}$ A project manager at ABB expressed similar sentiments, articulating that ABB used the Smart Energy City experiment to engage with and lobby policymakers in different forums. Examples mentioned included inviting politicians and Energy Agency employees to visit the experiment site, pursuing discussions with the Energy Markets Inspectorate regarding regulatory development, and engaging in the Swedish Smart Grid Forum. ${ }^{792}$ The project manager stated that this was mainly pursued during the course of the experiment, i.e. attempts at influencing policymakers, and would not be something ABB would devote resources to once the experiment was finished.

This highlights a temporality of circulating knowledge from an experiment, or utilizing experiments as marketing, which speaks to a wider problematic of smart energy experimentation. Since Smart Energy City taps into a strong marketing and place-branding emphasis connected to the broader political rationality as well as particularities in Stockholm, by testing cutting-edge technology, experiments run the risk of losing newsworthiness very quickly, thus driving a need for further, new experiments. If showcasing is the goal, the technologies showcased must be up to date and perceived as modern. Being at the forefront of technology development - or at least projecting an image of being so, as an interviewee at an energy company put it - thus creates legitimacy and grants access to policy networks.

This ties in to how circulations of Smart Energy City institute a knowledge politics. The knowledge generated through the experiment is to a large extent proprietary, since there was an emphasis on developing and commercializing new products for different actors. Circulation is thus often described as upscaling, in the specific vein of market dissemination of new products. ${ }^{793}$ It seems quite clear that the circulations of Smart Energy City build upon individual actors utilizing their own channels and circulating knowledge within their own

\footnotetext{
${ }^{790}$ Cf. Edwards \& Bulkeley 2017; Castán Broto \& Bulkeley 2018. Realigning Circulations.

${ }^{791}$ Interview RM Fortum.

${ }^{792}$ Interview PM ABB.

${ }^{793}$ Ibid; Interview RM Fortum.
} 
organizations, not least proprietary knowledge, despite the significant emphasis on collaboration in Norra Djurgårdsstaden. This can be highlighted further through a quotation from a project manager at the City of Stockholm:

I thought it was very interesting when we went down to Malmö, and you saw this whole, E.ON had built that house which was crystal clear $[\ldots]$ That was not done here $[\ldots]$ that would have been nice if you had gone for showing this technology thing in Stockholm. ${ }^{794}$

The project manager suggests that it would have been beneficial to have a physical place to showcase the technologies tested in Smart Energy City, which illustrates how circulations largely relied upon individual actors' own initiatives. Recall, for instance, that Ericsson had a showroom for demonstrating its own technologies tested in Smart Energy City in-house. This illustrates an integral part of accomplishing environmental governance through Smart Energy City: it is embedded in the broader sustainable urban development project of Norra Djurgårdsstaden as one of many experiments, primarily run by private companies and organized through loosely arranged public-private partnerships. It is then mainly up to the private companies to learn through experiments, and thereby develop new green energy technology for the benefit of Swedish green economic growth, in line with the political rationality underpinning smart energy experimentation. This risks leading to only particular types of knowledge being generated, and rendering particular actors central for producing this knowledge. As previously described, participants in Smart Energy City explained how sharing knowledge and results was integral, in line with experts at the national level. Such knowledge sharing was frequently problematized by interviewees, however. A project manager at the City problematized such aspects when stating that:

That is quite funny too; for them [private companies involved in Smart Energy City] all of this becomes business instantly. That, like you said that two competitors try to do a project together, then they don't always open up to each other. It can be a bit like that. ${ }^{795}$

This quotation seems to problematize certain aspects of how intervention was assembled in Smart Energy City, and by extension in Norra Djurgårdsstaden. Making the urban development project into an innovation platform, where private companies develop and test new green technology, seems to come with the drawback of knowledge not necessarily being shared between companies working together in experiments since they might be competitors. Correspondingly, a project manager at $\mathrm{ABB}$ stated that knowledge sharing between the different large smart energy experiments in Sweden was difficult since they included different constellations of actors who were actually competitors. ${ }^{796}$ Recall how this was brought up by several energy field experts in national and international organizations as a central issue of smart energy experimentation. Again, knowledge politics of the smart energy experiment in

\footnotetext{
${ }^{794}$ Interview PM City of Stockholm. The house referred to by the interviewee is a visitor center run by E. ON in Hyllie, which will be discussed later in the chapter.

${ }^{795}$ Ibid.

${ }^{796}$ Interview PM ABB.
} 
NDS can be discerned. The proprietary nature and commercial interests of different actors appear to shape knowledge circulation as mainly occurring either as marketing and branding, or as internal learning within the respective organizations. It should also be noted that circulations connected to place-branding of NDS do not constitute proprietary knowledge, for instance through the City's attempts at producing an image of NDS as a green innovation district by using experiments such as Smart Energy City. Still, as shown above, this also draws upon the broader political rationality, reproducing it through such infrastructures of circulation while providing impetus for neoliberalization processes.

Interestingly, considering how different actors emphasized that they were carrying out many different experiments besides Smart Energy City, a project manager at an energy company lamented that "everyone is doing experiments", rather than using public funding more wisely on fewer experiments and then openly sharing what has been done and the results, i.e. problematizing circulation as marketing and the lack of openly sharing knowledge inferred through the commercial nature of much smart energy experimentation. ${ }^{797}$ Ironically, the same interviewee emphasized how his company also used the experiment for marketing purposes. Additionally, the knowledge politics of Smart Energy City is interlinked with processes of assembling intervention. As we saw in the previous section, a marketing emphasis, a focus on commercialization, assumptions about the need to keep energy technologies simple for people, and contributing to comfortable lives all lead to the generation of specific forms of knowledge which is suitable for these purposes, whilst other modes of circulations or engaging with energy users are excluded from the experiment. The marketing emphasis might also explain why many of the actors involved, in both Norra Djurgårdsstaden and Smart Energy City, generously shared reflections about issues, learning from mistakes, and difficult considerations in interviews, but these are nowhere to be found in materials such as the final report to the Energy Agency (which is a public document).

Finally, since many of the actors involved in Smart Energy City explained how they circulated the experiment to use as policy input, the knowledge politics of Smart Energy City also seems to include foregrounding knowledge claims perceived by decision-makers to be valuable and credible, granting access to different policy networks and a way of having an impact in these forums. Taken together, this section has illustrated several infrastructures of circulation. Learning within private companies, and the circulation of a story of NDS as an innovative city district at the forefront of developing sustainable technology, often for the purposes of marketing at different levels and place-branding, constitute central forms of circulation. Besides principal generators of knowledge, large established private firms are thus also positioned as central recipients of knowledge through Smart Energy City, while making knowledge claims through experiments that consolidate specific governance arrangements. There seems to be a widely shared perception of knowledge being spread and others learning

\footnotetext{
${ }^{797}$ Interview PM Ellevio.
} 
important lessons, as long as many different forums and actors can be reached through communication efforts. This reflects the political rationality underpinning smart energy experimentation to a large extent, although there is a tension related to the emphasis on publicprivate partnerships and learning through testing.

\section{Summarizing reflections}

Intervention to improve the environmental condition through Smart Energy City is accomplished as it is woven into the urban fabric of Stockholm's new city district, drawing on different global, national, and local problematics, invoking different socio-material elements to establish relations, and thus arranging governance beyond the confines of the individual experiment. The City of Stockholm is attempting to create arenas for innovation in the form of large sustainable urban development projects, such as Norra Djurgårdsstaden, where private companies develop and test new green technology for commercialization. Actors in the Smart Energy City experiment informed households of their energy use, or rather their electricity use, to incentivize load-shifting in order to shave peaks in the power grid while interlacing the grid with ICT for optimization purposes. The intervention makes cities into central arenas of environmental governance, whilst the environmental condition is problematized in a specific way in relation to the intervention. The focus of improving the environmental condition is on optimizing electricity flows in the city's power grid by making households into flexibility resources, aimed at mitigating climate change, through the efforts of private companies developing new green energy technology. It is through loosely arranged networks, where different actors can pursue their own agendas in experiments in a green innovative city district, that the environmental condition can be improved, since this triggers sustainable innovations.

The City of Stockholm attempts to use NDS, drawing on notions of the district as a node where new methods and technologies can be tested, which can then be circulated throughout the city through the use of focus groups extending across different parts of the public administration. This resembles notions of experiments as mobilization among experts at the national level. In practice, however, learning and acting on new knowledge resided with individual organizations, and often with individuals. In the local context, it constitutes an attempt on behalf of the City to move NDS in a sustainable direction, without interfering in issue areas that are deemed off limits, such as lifestyles, consumption, and transportation. Private companies can use NDS as an arena for testing new technologies and as a marketing platform, generating knowledge which is then circulated within the respective organizations. Smart Energy City sits in the midst of this arrangement, drawing on these and other problematics, such as electrification, energy transformation, urbanization, and prevalent ideas of collaborative public-private partnership arrangements. Elements such as households as flexibility resources were drawn into the experiment while, crucially, iterative testing and learning was mobilized as a central goal of the experiment and the broader urban development project. Science and rationality were frequently drawn into the experiment as an element in conjunction with testing as intervention was assembled, leading to an emphasis on scientific 
testing. Specifically, there are many allusions throughout documents and interviews to how the ordinary Swedish household was the subject of testing, to rigidly assess the potential for flexibility among energy users. ${ }^{798}$ However, a civil servant at the Energy Agency and a project manager at an energy company involved in Smart Energy City both pointed to how residents in Norra Djurgårdsstaden are actually affluent upper middle class people, considering the price of the new apartments. ${ }^{799}$ Thus, questions could be asked about for whom the future smart energy system in Smart Energy City actually was constructed, as well as how to interpret the potential for flexibility based on the specific group of people involved in the test. ${ }^{800}$ The broader political rationality underpinning smart energy experimentation is thoroughly reflected in Smart Energy City. The ambition of making Sweden an environmental frontrunner by exporting smart energy technology is recurrently mirrored in documents and interviews. Mobilizing experiments as tests, especially through invoking science, is also manifested in Smart Energy City. Specifically, the idea of achieving transformative change through experiments - carried out in a stepwise process, with reference to notions of innovation such as the TRL scale - is prevalent, highlighting how techno-economic knowledge is foregrounded through the experiment. The experiment also appears to confirm the concerns of some experts at governmental agencies about experiments sometimes becoming overloaded with too many different goals, and about marketing crowding out other goals.

In particular, arranging governance through public-private partnership collaborations in projects in the case of Smart Energy City appears to cause fragmentation, as shown. This fragmentation manifests in circulations related to the experiment, for example. Circulations seem to occur to a large extent as circulations of proprietary knowledge within individual organizations, or connected to marketing, and through individual actors' channels. The relationship between the City and the Smart Energy City consortium is loosely arranged overall; the City is not actively involved in the experiment, and articulates it as one of many ongoing green innovation projects. Another relevant aspect of how environmental governance is accomplished through circulations relates to temporalities of circulation. Smart Energy City was circulated in the early stages of the experiment, often in the form of marketing, which seems to have gradually decreased over time. Several of the actors involved also emphasized how they used the experiment in policy-relevant forums during the course of the experiment. This seems to complicate the idea of scaling up experiments, which in literature is often described as occurring after an experiment, as a means of "moving beyond" experiments. Spatial boundaries were also continuously negotiated throughout the course of the experiment. As also shown, the City and the involved private companies also collaborated to circulate an image of NDS as a green innovation district in different forums, contributing to place-branding.

\footnotetext{
${ }^{798}$ E.g. Ander 2019. Smarta elnät i stadsmiljö i Norra Djurgårdsstaden - slutrapport; Interview RM Fortum; Interview PM ABB.

${ }^{799}$ Interview PM Ellevio; Interview EXEA4.

${ }^{800}$ Recall how an expert at the national level expressed a similar remark.
} 
Such efforts are based upon knowledge claims generated through experiments such as Smart Energy City, substantiating claims of environmental excellence in Stockholm as well as among the involved private companies, underlining how knowledge circulation is not necessarily proprietary.

Taken together, these aspects highlight knowledge politics of Smart Energy City. Most of the interviewees spoke about how their organizations are involved in many different experiments. As a project manager at an energy company remarked, everyone seems to be involved in experiments, but there seems to be a lack of collective knowledge-sharing and learning from the endeavors, apart from within the specific organizations involved ${ }^{801}$ Several actors pointed to others, such as the Energy Agency, as being primarily responsible for organizing learning from experiments, although they also stated that this is a difficult task for the agency. A project manager at ABB made the case that learning from experiments such as Smart Energy City is the task of the regulatory agency, to inform regulatory change. Representatives of the City of Stockholm pointed to how learning and disseminating knowledge are mainly questions for the companies involved in the experiment. They also reiterated how smart grid development is a question for energy companies rather than the City. Knowledge generated in Smart Energy City is largely proprietary, and appears to primarily stay within private companies.

Norra Djurgårdsstaden is cast as an arena for innovation for green transformation, and in the words of a project manager at the City, this arena is open to anyone. Questions could be posed, however, about who actually gains access to conduct smart energy experiments. Considering the required knowledge of complicated research funding infrastructures, and the necessary skill set for writing applications, it is likely that only a few actors will succeed in a context where projects are the main form of organization. The question of how experimental an experiment can actually be in a context dominated by goals of marketing and turning Stockholm and Sweden into smart energy frontrunners also resurfaces. Is it possible to experiment with uncertain outcomes, as interviewees tend to claim is necessary, if a central goal is to become world-class and export smart energy technology? Do experiments become part of city-making or city-branding in this context? Consequently, Smart Energy City appears to be largely configured along the lines of the broader political rationality underpinning smart energy experimentation. Despite being clearly conditioned by the political rationality, reconstituting it in processes of accomplishing governance, frictions and contradictions created by this political rationality also continuously surfaced in Smart Energy City, as shown. Besides the apparent tension between marketing and testing, we saw how - despite the best efforts of

\footnotetext{
${ }^{801}$ Recall that in the previous chapter, several of the experts across governmental institutions and policy networks expressed similar concerns. In a similar vein, many experts at the national level also expressed concerns that marketing risks becoming an overarching goal in smart energy experiments, displacing other goals, and as we have seen throughout the analysis of Smart Energy City, this risk seems largely to have become a reality.
} 
all involved actors to arrive at consensus - contestations emerged continuously along the way, for example as a result of the different commercial interests of the private companies involved.

\section{Hyllie - Smart grids for a sustainable energy system in Hyllie and beyond}

In this part of the chapter, smart energy experimentation in the city district of Hyllie in Malmö will be introduced as a contrasting case to Smart Energy City. Like Norra Djurgårdsstaden in Stockholm, Hyllie is an area of Malmö where a new city district is being constructed. A significant difference compared to Stockholm, however, is that Malmö was severely hit by the post-Fordist crisis. ${ }^{802}$ Previously a strong industrial city, not least because of the successful shipyard in the Western Harbor, Malmö's fortunes were hit hard after the 1970s crisis. ${ }^{803}$ During the 1990s, the City of Malmö attempted to lay out a new vision for Malmö, moving away from post-industrial crisis to alternative futures. ${ }^{804}$ Making Malmö into a creative city became a core strategy, tapping into ideas of a knowledge and information society as the logical continuation of an industrial society, in line with entrepreneurial urbanism. ${ }^{805}$ This ambition was closely coupled to efforts to turn Malmö into a green city. ${ }^{806}$

The City of Malmö's efforts to interlink environmental action and urban development is mirrored in Hyllie, where the City wants to make the new district a global role model for sustainable urban development, similar to the City of Stockholm's environmental ambitions for NDS. The "Smart grids for a sustainable energy system in Hyllie" experiment was undertaken within this setting, and finished in 2016. It was partly funded by the Swedish Energy Agency, and was operated by a consortium of private and public actors, including the City of Malmö, the multinational energy company E.ON, and a local infrastructure actor responsible for water and waste called VA Syd, as well as a local property owner. ${ }^{807}$ Other participants included KTH, Lund University, and two property developers. The participants aimed to make Hyllie a "full-scale testbed for solutions for the future", ${ }^{808}$ specifically through testing smart grid and smart home solutions.

\footnotetext{
${ }^{802}$ Holgersen \& Malm 2016. “Green fix” as crisis management.

${ }^{803}$ Ibid.

${ }^{804}$ See e.g. Dannestam 2009. Stadspolitik i Malmö: Politikens meningsskapande och materialitet. Diss. Lund: Lund University.

${ }^{805}$ Madureira 2013. Physical Planning in Entrepreneurial Urban Governance - Experiences from the Bo01 and Brunnshög Projects, Sweden. European Planning Studies, 22(11).

${ }^{806}$ Dannestam 2009. Stadspolitik i Malmö; Holgersen \& Malm 2016. "Green fix" as crisis management; Green 2006. Hållbar energianvändning i svensk stadsplanering. pp. 105-107.

${ }^{807}$ Johansson \& Berne 2016. Smarta nät för ett hållbart energisystem i Hyllie - slutrapport. Eskilstuna: Energimyndigheten.

${ }^{808}$ Ibid. p. 7.
} 
The main part of the experiment revolved around using the thermic inertia of buildings as a demand-response mechanism to reduce bottlenecks in the district heating and district cooling grids. Related to this, E.ON's smart grid platform - its customer energy and system optimization platform (CESO) - is regularly highlighted as the main thrust of the experiment. It is an ICT platform that, when integrated to a property's building management system, can communicate and optimize flows in the energy system. ${ }^{809}$ Based on this platform, tests such as dynamic pricing for district heating and temperature regulation based on optimization principles were carried out. Consequently, load-shifting through demand-response is underscored in documents, interviews, observations, and site visits as an important result of the experiment, realized through the integration of EON's IT platform into building management systems. The experiment also included a smart home component focused on developing a home energy management system, allowing energy users to see their energy use in real-time and providing information about energy prices. According to the final report, this resulted in the commercial service "100koll" provided by E.ON ${ }^{810} 100 \mathrm{koll}$ basically consists of a so-called optical eye that is installed on a smart electricity meter, and a smart plug, which connects to a smartphone application providing energy users with information about their household energy use, allowing them to schedule different patterns of energy use such as laundry based on spot prices or using a calendar function. ${ }^{811}$

The smart energy experiments in Hyllie and Norra Djurgårdsstaden are evidently quite similar on the surface. As the analysis will show, however, significant differences appeared when looking more closely into Hyllie, including in terms of actor constellations and channels for and practices of circulations that were shaped through the experiment. Circulations in particular stood out in empirical analysis in relation to NDS, so the majority of the analysis will therefore be dedicated to contrasting circulations of Hyllie with those of Smart Energy City.

\section{Authorizing and assembling intervention: making a post-industrial city green through coordinated experimentation}

As in Stockholm, different problematics were drawn upon to authorize and delineate the intervention in Hyllie. The experiment is explicitly articulated as a means by which to face future challenges, climate change generally being most prominently expressed, through creating a sustainable energy system, in the project report as well as in interviews and during

\footnotetext{
${ }^{809}$ Ibid. p. 8; Interview PM E.ON.

${ }^{810}$ Johansson \& Berne 2016. Smarta nät för ett hållbart energisystem i Hyllie - slutrapport. p. 9.

${ }^{811}$ See: https://www.eon.se/privat/for-hemmet/100koll/om-100koll.html [2019-10-22]; Interview PM E.ON.
} 
site visits and observations. ${ }^{812}$ An important background related to this, which is emphasized by the actors involved, is a document called the climate contract, which was signed by E.ON, the City of Malmö, and VA SYD in 2011, and another document called the environmental program for Hyllie dating from 2015. The climate contract is tied to environmental and energy policy goals established by the City of Malmö. Essentially, it is an agreement between E.ON, the City of Malmö, and VA Syd, stipulating that Hyllie is to become the most climate-smart city district in the Öresund region as well as a global role model for sustainable urban development. ${ }^{813}$ These two documents constitute central elements of how the intervention in Hyllie was authorized and assembled.

The climate contract is not a legally binding document, but it is nonetheless emphasized as an important document, both in interviews and by actors during site visits as well as in other documents related to the project. The environmental program for Hyllie was published by the City of Malmö, and was intended to constitute a platform gathering all the sustainabilityrelated documents and processes emerging from Hyllie, concretizing these into specific goals. ${ }^{814}$ In both documents, developing a smart grid and implementing smart homes are stressed as key factors in achieving the climate, environmental, and energy goals for Hyllie and Malmö. Consequently, smart grids and smart homes are constituted as important aspects of developing a sustainable energy system, and authorization of the smart energy experiment is performed through drawing on specific environmental problematics. Hyllie is also explicitly articulated as a testbed in the document, where new climate-smart solutions and technology are developed in close cooperation between private companies and the City of Malmö. ${ }^{815}$ The overall picture painted by these documents is largely similar to Norra Djurgårdsstaden and Smart Energy City. According to the actors involved, the smart energy experiment in Hyllie resulted in turning the vision of smart grids into reality. ${ }^{816}$ It is stated in the final report that a broad collaboration was created through the experiment, which allows for rolling out sustainable infrastructure solutions and testbed efforts on different levels, for the benefit of all

${ }^{812}$ For a more detailed, in-depth study of how the smart energy experiment unfolded in Hyllie, see Parks 2018. The Sustainable City Becomes Climate-Smart. Parks takes an ethnographically inspired approach, including observations from meetings during the course of the smart energy experiment, to closely attend to the twists and turns which such an endeavor inevitably entails. Since my interest lies in how experimentation arranges governance, focusing on the interlinkages created across different sites and policy levels, I will draw on Parks' study as an important source of knowledge, enabling a nuanced understanding of the smart energy experiment in Hyllie.

${ }^{813}$ E.ON, VA SYD, and City of Malmö 2011. Klimatkontrakt för Hyllie.

${ }^{814}$ Malmö stad 2015. Miljöprogram Hyllie: Mål och åtgärder för förverkligandet av Öresundsregionens klimatsmartaste stadsdel. Malm. p. 5.

${ }^{815}$ Ibid. p. 6.

${ }^{816}$ Johansson \& Berne 2016. Smarta nät för ett hållbart energisystem i Hyllie - slutrapport. p. 2. 
the parties involved ${ }^{817}$ Evidently, such a description is also aligned with the broader political rationality underpinning smart energy experimentation, as visible in the emphasis on consensus-building public-private partnership engagement in different projects, as well as the underlying notion of change achieved through multiple experiments resulting in the commercialization of new green products and services.

Descriptions of the smart energy experiment in Hyllie as successful echo across the empirical material; of the three flagship projects, ${ }^{818}$ Hyllie was most commonly described as a success by interviewees. One of the success factors regularly underlined by experts at the national level was that the smart energy experiment in Hyllie entailed a more encompassing approach than the other two experiments, and this was regularly connected to a differentiation between smart grid and smart energy system among the interviewees. This was also stressed by a project manager at E.ON, as well as in project documents. However the opposite could also be claimed, i.e. that Hyllie entailed a narrower approach compared to Smart Energy City. The smart energy experiment did not involve households to the same extent as Smart Energy City, since the main application developed was for optimizing district heating distribution. It was also emphasized by a civil servant at the Energy Agency that the Hyllie project had a different background compared to Norra Djurgårdsstaden and Smart Grid Gotland. The interviewee stated that while Smart Energy City and Smart Grid Gotland were financed specifically as electricity grid projects, Hyllie's funding came from another Energy Agency department focused on energy efficiency. ${ }^{819}$

The civil servant stated that this fact, combined with the experiment being dealt with by a farsighted individual at the agency, meant in practice that from the outset, the Hyllie experiment included a broader scope than the electricity grid and a freer model for cooperation. The interviewee claimed that this was important in terms of how the Hyllie project developed. ${ }^{820}$ This illustrates how what on the surface might come across as minor details can have important repercussions for how an experiment unfolds, illustrating the contingencies of how experimentation arranges governance. A representative from an energy company involved in Smart Energy City also mentioned how the consortium in the Hyllie experiment "were very good at opening up", and had used an external reference group, in contrast with Smart Energy City's own approach. ${ }^{821}$ Here, it can be seen that it is possible to

\footnotetext{
${ }^{817}$ Ibid. p. 9.

${ }^{818}$ Smart Energy City in Norra Djurgårdsstaden, Smart Grid Gotland, and the Hyllie experiment.

${ }^{819}$ Interview EXEA2.

${ }^{820}$ Ibid.

${ }^{821}$ Interview RM Fortum.
} 
set up smart energy experiments in different ways, showing how the political rationality underpinning smart energy experimentation is not all-encompassing or entirely homogenizing. Authorizing the experiment relies on appellations to urbanization, visible for example in project documents, alongside the description of Hyllie as a role model for sustainable urban development. Thus, the actors involved drew on similar problematics as in the case of NDS, where urbanization was also described as a strong trend demanding action, whilst cities were described as central arenas for environmental action. The picture that emerges from the climate contract and the environmental program for Hyllie reinforces this description, but is also in line with the overarching direction of urban development in Malmö, emphasizing sustainability as an impetus for urban regeneration and development. For the City of Malmö, however, there are also other rationales for engaging in experimentation. According to a representative of the City, giving a presentation in the neighboring city of Lund on Malmö's engagement in urban experimentation, the City had to find new modes of environmental governance since $90 \%$ of energy use is beyond the direct control of the City.

It was articulated that the goal was for Malmö to become a beacon, signaling to other actors to come and work on sustainable development together with the City of Malmö. In concrete terms, it was stated that an important goal for the City is for a sustainable energy system to be a fully commercialized product by 2020 , and that the City intends for this to happen through experiments such as in Hyllie. The representative of the City stated that by making Hyllie into a testbed, a smart energy system had been developed, referring to E.ON's IT platform CESO, with the possibility to balance loads in the district heating grid. There was a clear emphasis on cooperation in the presentation; the representative stated that the achievements in Hyllie were largely down to vibrant partnerships between central actors. The rhetoric employed is similar to the case of Smart Energy City and Norra Djurgårdsstaden, but as we shall see the actual setup of the partnerships constitutes a central difference between the cases. Authorization unfolded through the modality of consensus, as in NDS, and the overarching program for action outlined by the representative of the City and by the actors implicitly designated as central is in line with the broader political rationality underpinning smart energy experimentation.

Additionally, like with the case of the City of Stockholm and Smart Energy City, one logic for engaging in experimentation seems to be that it is considered difficult to fail when experimenting. The representative of the City of Malmö stated during the presentation that the City's focus was on trying something and if it works, they attempt to replicate and scale up this solution, and if not then no one would be criticized. The representative also mentioned, however, that experimentation as a mode of environmental governance was vulnerable, since it was driven more by specific individuals than institutionally, and that how to scale something up was unknown in advance; it was presented as a question of muddling through. This 
illuminates that how experimentation arranges environmental governance is conditioned by the broader political rationality, instituting projectification and networked governance through commercially oriented collaborative projects - hallmarks of neoliberalization processes. During the presentation, however, specific meanings seemed to be attached to concepts connected to experimentation, e.g. testbeds as geographically delineated city areas where experiments could be conducted, and then scaled up. This highlights a difference compared to NDS and Smart Energy City, as in Malmö the City appears to take a more hands on approach and work systematically with experimentation, whereas the City of Stockholm tasks itself with creating green innovation districts such as NDS for private actors and assumes less of an operative role. According to the representative of the City, continuity was the key for successful experimentation, especially involving E.ON in more experiments beyond Hyllie, since "they own the solution".

This highlights how knowledge generated in the smart energy experiment in Hyllie is largely proprietary, similarly to Smart Energy City, in line with the emphasis on developing new commercially viable products and services at the core of the political rationality underpinning smart energy experimentation. It also underlines the aforementioned emphasis on collaboration and coordination, which seems to be an integral part of assembling intervention in Hyllie. The interlinkage between the City and E.ON highlights how environmental governance is accomplished differently in NDS and Hyllie, since in NDS the City explicitly stated that it was important not to become locked into collaborations with any specific actors, instead encouraging the involvement of many different experiments and actors across the green innovation districts. Thus, ways of knowing and governing environmental issues in urban settings are configured differently, despite some obvious resemblances between NDS and Hyllie. In Hyllie, while clearly conditioned by the broader political rationality, experimentation seems to arrange governance in a way that resembles traditional corporatist setups, likely due to the historically strong relationship between the local energy company Sydkraft (now E.ON) and the City.

However, similarly to Norra Djurgårdsstaden and among experts at the national level, there was a significant emphasis on speeding up technological innovation, reflecting the Swedish frontrunner ambitions. This can be illustrated through the frequent use of the metaphor of "not missing the train". This metaphor, or variations such as "taking on the leader's shirt in the global race", was frequently used by experts across governmental institutions and policy networks, and also during site visits in Hyllie. ${ }^{822}$ During one site visit, almost every actor involved in the experiment used the metaphor of not missing the train. These actors

${ }^{822}$ Cf. Wallsten 2017. Assembling the Smart Grid. pp. 91-93. 
emphasized how important it was to be on top of the development and engage early, otherwise the train would be missed. This metaphor appeared to justify and explain engaging in what were perceived to be the early stages of developing new infrastructure. The train metaphor seems to align with the urgency afforded to smart energy by the government, as well as the export orientation. In order to become a frontrunner, as the government - and by extension the Swedish Smart Grid Forum - explicitly aims for Sweden to become, it was stated in Hyllie that it was imperative to engage early in the development of a smart energy system, otherwise the train would have left the station and it would be too late to become a frontrunner. The use of such metaphors demonstrates how the political rationality underpinning smart energy experimentation imposes certain implicit assumptions and delineations; the environmental condition is best improved through the development and commercialization of new green energy technology for export, allowing Sweden to become a global environmental frontrunner. Questions about whether this actually entails becoming greener in practice are not asked, as such assumptions flows as an undercurrent through the broader political rationality.

\section{Frictions of establishing common goals}

As with most experiments, frictions appeared in Hyllie. During a site visit, questions were asked to employees working with environmental issues at the City of Malmö about why there was a goal of $100 \%$ renewable or recycled energy for Malmö rather than simply $100 \%$ renewable, making the representatives visibly uncomfortable. It appeared that the representatives were not entirely satisfied with the addition of recycled energy, as they explained how the goal had previously been phrased as 100\% renewable energy. Parks describes in his study of the smart energy experiment in Hyllie how this was a constant point of negotiation, since the City wanted $100 \%$ renewable energy as a goal, whereas E.ON which owns the district heating grid in Malmö - also wanted to include district heating from waste incineration in the goal. ${ }^{823}$ During one of my site visits, an employee from the City stated that this question had only been temporarily resolved, and was still under negotiation. Despite this apparent tension, the picture that emerges across the material is one of close cooperation between the actors involved in the Hyllie experiment, in marked contrast to Smart Energy City.

During site visits and observations, several representatives from the City stated that defining the energy goal for Hyllie was a difficult political question. It is definitely political, both in the sense of the negotiations within the Hyllie experiment between E.ON and the City, and within the City Council where such decisions are ultimately made. It is also political in a wider sense, since the two different goals would necessitate different courses of action, arranging

\footnotetext{
${ }^{823}$ Parks 2018. The Sustainable City Becomes Climate-Smart.
} 
environmental governance in different ways through experimentation. Thus, the smart energy experiment arranged governance in a particular way that allowed the district heating infrastructure to become an integral element of the green energy transformation. This shows how an essentially political question was dismantled through seemingly minor twists and turns as intervention was assembled in Hyllie, consolidating the knowledge claim that district heating from waste incineration is green. ${ }^{824}$ Apart from underlining how authorization through the modality of consensus is an accomplishment in the making, with the threat of contestations always lurking, this highlights the knowledge politics of the Hyllie experiment. Drawing upon the political rationality underpinning smart energy experimentation, Hyllie is cast as a cooperative testbed where spatio-temporally confined projects are pursued in tightly interlinked public-private partnership constellations to develop and commercialize new green energy products and services. Further, by invoking testing as an essential element as intervention was assembled, much like in Smart Energy City, essentially political questions about the sustainability of different energy infrastructure configurations and about desirable energy futures could be dismantled and consolidated into common positions, crystallized in knowledge claims as seen in the final project report.

\section{Shaping the smart energy system in Hyllie: developing partnerships, developing business opportunities}

Despite such frictions, the picture of close collaboration in Hyllie is further strengthened by a project manager at E.ON. When asked about how E. ON came to be involved in the Hyllie smart energy experiment, the project manager said:

I have been involved from quite an early stage in conceptualizing what we call our sustainable city portfolio, how E.ON can be a relevant actor in different urban development projects and especially related to the area of sustainable urban development. [...] And that effort is to a large extent about how we can perhaps especially, at least initially as an infrastructure actor, participate in helping our cities transition to more sustainable energy systems primarily based on renewable energy ${ }^{825}$

The project manager explained how the problem largely revolves around using new technology without driving costs, for example to avoid reinforcing the physical grid infrastructure with new cables. ${ }^{826}$ Viewing itself as an infrastructure actor that wants to be active in sustainable urban development contrasts E.ON with one of the energy companies involved in Smart Energy City which refrained from such a course of action, arguing that its area of expertise was energy rather than urban development. The project manager went on to state that E.ON aims to achieve this mainly through working on digitalization. This has some

\footnotetext{
${ }^{824}$ For a detailed account of these negotiations, see Parks 2018. The Sustainable City Becomes Climate-Smart. ${ }^{825}$ Interview PM E. ON.

${ }^{826}$ Ibid.
} 
significance for authorizing and assembling the intervention in Hyllie. The project manager draws on similar problematics to those in policy documents related to Hyllie, describing cities as key arenas for climate action. ${ }^{827}$ The interviewee stated that:

And then we naturally have integrated a kind of business development perspective in our work, which to a large extent is based in our infrastructure business, and together with partners, for example in Hyllie with the City of Malmö [...] actors entered into different joint development projects, where we formulate goals and test solutions to see what's possible. And we have valued this extremely highly, and it has proven to be very relevant to build this type of testbed if you want to call it that, it can be defined in many different ways, but testbeds really to test new technology together with different partners in a real environment such as Hyllie. ${ }^{828}$

Here, the project manager explains how E.ON is attempting to achieve the aforementioned goals. The smart energy experiment in Hyllie and similar initiatives across Sweden and internationally are described as an important part of E.ON's business development strategy, whilst there is an emphasis on experimentation as a form of testing. There is also an emphasis on testing technology through partnerships, which is a big difference compared to the Smart Energy City experiment, where technology was tested by private companies rather than in close collaboration between public administration and private companies. The following quotation further illuminates how E.ON authorizes the intervention in Hyllie, as well as how the intervention was assembled:

[...] it revolves around, to a large extent, creating a flexibility in our energy systems which enables the transition to a sustainable energy system $[\ldots]$ and also enables an efficient energy system where we reduce losses and make better use of the residual flows in our cities, for instance. [...] that means we need smart grid solutions to adapt and optimize [...] it's about smart grid solutions to utilize as much local production or surplus energy as possible, which comes from the prosumer $[\ldots]$. And that also means that we optimize the distribution of our different energy carrier systems, district cooling, district heating, power grid, perhaps gas as well [...] and there are several values there, it's about redundancy, it's about dealing with bottlenecks, it's about utilizing energy that is available in places where perhaps the grids aren't designed to receive this energy, from both heating and power grid perspectives. ${ }^{829}$

Through this quotation, an emerging order of things which E.ON is attempting to establish can be glimpsed. E. ON is attempting to develop a smart energy system, as the project manager explained, by combining building a sustainable energy system with expanding E.ON's business portfolio through engaging in smart energy experiments. ${ }^{830}$ It was also described how, besides optimizing distribution, creating flexibility on the consumption side was integral, for example

\footnotetext{
${ }^{827}$ Ibid

${ }^{828}$ Ibid.

${ }^{829}$ Ibid.

${ }^{830}$ Ibid.
} 
by interlinking different energy carriers when heating buildings. The quotation illustrates how E.ON is interlinking different problematics, and is thereby shaping a specific problem to be solved through a smart energy system. Environmental issues, especially in the guise of climate mitigation and energy optimization, are molded into issues that can be governed productively in cities, especially city districts labeled testbeds where collaborative public-private partnership constellations pursue different projects together to improve the environmental condition by developing green energy technology, in line with the broader political rationality underpinning smart energy experimentation. This positions E. ON as a central actor both for environmental governance and for infrastructure development, greasing the wheels of this order by optimizing district heating flows and by providing platforms for prosumers to become agents in future, digitalized urban energy systems. This demonstrates how E. ON was careful not to delineate smart grid only to electricity:

[...] we're thinking, how one can create a parallel infrastructure, which it is to a large extent, to be able to utilize information flows between different points in the energy system, I mean consumer, property, distribution, production, and prosumer information which sits in our different grids and in our different nodes in the energy system. ${ }^{831}$

The project manager mentioned that smart grid can be many different things depending on who was asked, but the common denominator boils down to finding new ways of using information:

[...] for some it's dynamic line rating solutions [...] another, which is essentially what we're working with, is how to link the different, really, points in an energy system from consumer to distribution and production and prosumer, and how one can create interaction in between. Specifically the interface between the nodes, where there has not been a lot of exchange of information previously. ${ }^{832}$

This quotation shows how a specific smart energy system configuration becomes a solution to the problem as defined above, where the interface for optimizing the parts of different energy systems described by the project manager becomes central. This is where E.ON's technical smart grid solution, the customer energy and system optimization platform (CESO), enters. Whilst it is emphasized in the project documents and by the project manager at E.ON that many different things were achieved in Hyllie, it was mainly E.ON's IT platform CESO that was the main attraction during site visits. The project manager also highlighted CESO as the most important result:

${ }^{831}$ Ibid.

${ }^{832}$ Ibid. 
And there [in the project's final report] we quite thoroughly review results, how we have worked with solutions at the customer level, how we have worked with the property interface, how we have worked with infrastructure solutions and what has perhaps been the most important thing, these different integration interfaces and solutions between these segments, if it can be called that. ${ }^{83}$

This quotation demonstrates how E.ON conceives of its IT platform and its integration with building management systems as probably the most important result of the project. Recall how in Smart Energy City, developing such an IT platform was also the main goal for ICT company Ericsson. This underscores that while accomplishing environmental governance is contingent, it is not aimless; actors attempt to push for certain directions to be taken, and the political rationality underpinning smart energy experimentation facilitates positioning private companies in a favorable position for doing so. This is especially true of large, incumbent companies, considering the history of the large-scale, centralized Swedish energy system, where a small number of energy companies have long held privileged positions. The project manager also stated that:

There we have, together with the Energy Agency [...] developed this smart grid platform that we call CESO [...]. And what we have learned from that specific project, which was one of several different development projects in Hyllie, is that there is a great deal of potential in developing this informative bridge where we can communicate with properties' automation systems, I mean the buildings' computers or BMS [building management system] or whatever you want to call them. ${ }^{834}$

The emphasis on the IT platform in the quotation is in line with project documents, especially the final report where the platform is described as perhaps the key aspect of the project. ${ }^{835}$ The project manager continued:

And there we have developed a $[\ldots]$ hardware solution that $[\ldots]$ enables us to create this communicative interface, but above all also the software with a number of functions, which allows us to create the right conditions for optimization of our district heating and district cooling systems

in particular, and also the electricity grid system. At the same time, we also create the right conditions for the customers to optimize their energy use $[\ldots] .{ }^{836}$

The quotation illustrates the importance ascribed to the IT platform by E.ON, described as constituting the central node in the smart energy experiment. The project manager also mentioned that it allowed the company to deal with bottlenecks in the distribution system for district heating and cooling, as also emphasized in the final report. ${ }^{837}$ Additionally, E.ON was on the verge of entering other sustainable urban development projects to keep developing its

\footnotetext{
${ }^{833}$ Ibid.

${ }^{834}$ Ibid.

${ }^{835}$ Johansson \& Berne 2016. Smarta nät för ett hållbart energisystem i Hyllie - slutrapport.

${ }^{836}$ Interview PM E. ON.

${ }^{837}$ Ibid; Johansson \& Berne 2016. Smarta nät för ett hållbart energisystem i Hyllie - slutrapport.
} 
IT platform at the time of the interview, whilst simultaneously attempting to roll out the solution developed in Hyllie both across Malmö and in other energy systems beyond Malmö on a commercial basis. ${ }^{838}$ Taken together, E.ON intentionally seems to use initiatives such as the smart energy experiment in Hyllie to move toward becoming an IT infrastructure actor as well as being more active in sustainable urban development projects. The company is mainly attempting to do this by utilizing its digital platform CESO, with the intended function of acting as an interface between different parts of a smart energy system. This illustrates how E.ON is actively tapping into different problematics, and in the process defining a reasonable solution which it can provide. E. ON and the City of Malmö are also pursuing a specific version of a smart energy system, focused on digitalization of the current grid infrastructure, providing a node between the different parts of such an energy system - or, to paraphrase E.ON, putting E.ON in a prominent position. Thus, we can discern how E.ON is authorizing the intervention in Hyllie by drawing different problematics such as climate change, urbanization, digitalization, and electrification into the intervention in a manner that makes E. ON an important actor for transforming existing energy infrastructure in cities. E. ON has assumed an important role for assembling the intervention in Hyllie, especially through developing the hardware and software infrastructure of CESO, which is intended to provide the link between different parts of energy systems that E. ON wants to establish.

Another prominent feature of assembling intervention in Hyllie has been the partnership structure, which largely differs from Smart Energy City in Norra Djurgårdsstaden. In moving toward E.ON's goals, the project manager explained how important close-knit collaboration with different actors has been thus far, and especially emphasized the successful partnership with the City of Malmö:

Hyllie has been interesting because there we started quite early and there was a real mobilization in Hyllie to really show how we can develop solutions that allow for Malmö to actually meet its very ambitious climate targets. Among other things, all of Malmö is going to be supplied by renewable energy in 2030, and that was based on the climate contract that we signed in 2011, of which utilizing Hyllie as a testbed for innovation in smart grids was a part. ${ }^{839}$

The importance afforded to the climate contract, and to the cooperation between E.ON and the City it epitomizes, is also in line with how representatives of the City described the contract. It illuminates how close cooperation appears to have been a central component of the Hyllie experiment, and thus the partnership contract constitutes an integral element of assembling intervention in Hyllie. The quotation also further elucidates how E.ON, as well as the City, articulate the smart energy experiment in Hyllie as a form of mobilization for change,

\footnotetext{
${ }^{838}$ Interview PM E.ON.

${ }^{839}$ Ibid.
} 
in line with how experiments were regularly described as mobilization by experts across governmental institutions. Collaboration is described as a virtue by actors involved in the smart energy experiment in Hyllie, similar to Smart Energy City and Norra Djurgårdsstaden. However, it seems to constitute a central component of experimentation in a different way in Hyllie. ${ }^{840}$ The project manager at E. ON stated that:

Hyllie as a project started with us signing this climate contract together with the City of Malmö in 2011, and that laid the foundation for cooperation between E.ON, the City of Malmö, and VA Syd, who are also part of the climate contract. And of course we have many points of contact with the City of Malmö, but the climate contract meant that we entered into a common development project with a common agenda, a common objective that was and is clearly articulated, for Hyllie, so in that sense it has also become a tighter cooperation in terms of how to run an operative urban development process, at least in this case, but then there are loads of other projects in Malmö which involve us cooperating with the City. But Hyllie has shown and is a clear node for driving development and innovation, in cooperation, and it is a common agenda that we discuss and drive primarily with the City of Malmö but also with VA Syd. [...] and that has also been one of the ambitions of Hyllie as a project, how can Hyllie show the way for Malmö, in terms of how Malmö can achieve its ambitious environmental goals. ${ }^{841}$

This quotation shows how the climate contract constitutes a central element of assembling intervention in Hyllie, and how Hyllie has been integral in developing a closer partnership primarily between the City and E.ON, which was also echoed by representatives from the City. It also elucidates how E.ON and the City practice experimentation in the form of common endeavors focused on developing infrastructure together through partnerships in clearly delineated geographical areas, such as the city district of Hyllie, which the project manager and a representative from the City referred to as testbeds. This illuminates a specific mode of accomplishing environmental governance, where different actors are assigned specific roles and specific modes of organization are actualized. The project manager at E. ON said that:

Yes definitely, that is the whole, that's one of the basic purposes of mobilizing in an area and running demonstration projects. It's a very important focus for our work to always take scalability into consideration in the work we do in local testbeds. And that's why it's also [...] very relevant to run development initiatives in urban development areas, because you can get new solutions on board at an early stage and you can drive a cooperation process in early stages, for instance with those who might be the other most important group in this context, the property developers. Because it is, without creating this cooperation between system and properties and end-consumers, we don't make it all the way, and that means we have to do things together with property owners and the properties control the volume, or the ownership limit if you can call it that. It has been very significant with the cooperation that the climate contract and the smart grid Hyllie project have also

\footnotetext{
${ }^{840}$ See also Parks 2018. The Sustainable City Becomes Climate-Smart.

${ }^{841}$ Interview PM E. ON.
} 
laid the foundation for, how we can get property developers and property owners on board when testing new solutions. ${ }^{842}$

The quotation underscores E.ON's attempts to create an interface between different parts of urban energy systems, and how property owners and property developers also become important actors in the smart energy system configuration tested in Hyllie. This illustrates how authorization has worked through the modality of consensus in Hyllie, established by using the climate contract, which has also helped to persuade other actors, such as property owners, to become engaged. The project manager at E. ON emphasized how the mobilization achieved in Hyllie, including the climate contract, made it possible for property owners to get easier access to external funding. ${ }^{843}$ Consequently, property developers and property owners were drawn into the Hyllie experiment as intervention was assembled from an early stage. The emphasis on cooperation and the inclusion of property owners from an early stage also contrast with Smart Energy City. In connection with this, the project manager at E. ON also stated that:

So definitely, Hyllie has contributed to creating a relevant network around digitalization, smart grids, and sustainable urban development. Definitely. ${ }^{844}$

A final important aspect of authorizing and assembling intervention in Hyllie was a clear emphasis on making it easy for energy users. This echoes how some actors in Smart Energy City, as well as policymakers at the national level, stated that people in general are not interested in energy and thus new solutions must be made as simple as possible. In Smart Energy City, there was an emphasis on making people's lives more comfortable, which was also present in the Hyllie experiment:

Digitalization is a common theme throughout it, and also how we can create better conditions for our customers and make their lives easier. ${ }^{845}$

This illustrates how in the smart energy experiment in Hyllie, similarly to Smart Energy City, the intervention was geared toward optimizing existing technical systems, rather than engaging with energy users, based on assumptions that people value comfortable lives and are not interested in energy. ${ }^{846}$ This is also in line with the ecomodern elements of the broader political rationality underpinning smart energy experimentation, with inclinations toward

\footnotetext{
${ }^{842}$ Ibid.

${ }^{843}$ Ibid.

${ }^{844}$ Ibid.

${ }^{845}$ Ibid,

${ }^{846}$ Cf. Parks 2018. The Sustainable City Becomes Climate-Smart; Wallsten 2017. Assembling the Smart Grid; Strengers 2013. Smart energy technologies in everyday life.
} 
commercializing technical solutions for the upper middle class as solutions to environmental issues, which fits neatly into the contemporary capitalist political economy. ${ }^{847}$

In contrast to the Smart Energy City experiment, however, the language of experimentation displays more internal coherence in Hyllie. For instance, the term "testbed" seems to entail specific, defined features, visible during the formal interview with the project manager at E.ON as well as in informal interviews during site visits and observations, especially during a presentation on urban experimentation given by an employee at the City of Malmö. "Testbed" seems to imply entering public-private partnerships where technologies and new social arrangements can be tested and consolidated in delineated geographical areas such as Hyllie, with the intention of disseminating these and thereby developing urban infrastructure together. The representative from the City described Malmö as an experimentation arena during his presentation, where testbeds were being developed in which experiments took place. Experimentation also seemed to carry the connotation of finding new modes of working for the City, for example by entering into partnerships with actors who own energy infrastructure in order to achieve national environmental, climate, and energy policy goals, as well as environmental policy goals established by the City Council. The reoccurrence of the metaphor of not missing the train, which was also prevalent among experts at the national level, might also say something about the strength of the export orientation implied by the broader green political rationality underpinning smart energy experimentation, as might E.ON's intentions of expanding its business portfolio by branching into IT infrastructure and urban development to a larger extent.

While there are clear points of overlap and similarities between the Hyllie experiment and Smart Energy City, there are also clear differences. Through the focus on close and coordinated cooperation between a few actors - which gather around Malmö as an urban experimentation arena, marking a significant difference compared to Smart Energy City and Norra Djurgårdsstaden - a particular disposition appears to have been consolidated through the Hyllie experiment. First, an actor constellation, consisting of close cooperation, primarily between E.ON and the City of Malmö, but also including VA Syd and a property owner. This was achieved in part through the use of partnership contracts as a central feature when intervention was assembled in Hyllie. Second, a specific approach to experimentation emphasizing testbeds, and E.ON's technical solution CESO. Third, implicit assumptions about urban infrastructure development, where close partnerships between public and private actors are established and further endeavors beyond individual experiments are pursued together. In

\footnotetext{
${ }^{847}$ See e.g. Hult 2017. Unpacking Swedish Sustainability; Anshelm \& Hultman 2014. Discourses of global climate change; cf. Dryzek 2013. The Politics of the Earth.
} 
Norra Djurgårdsstaden, the focus was on establishing platforms for private companies to develop new green technology, highlighting a separation between the City of Stockholm and the consortium in Smart Energy City, which was articulated as one of many different ongoing innovation projects in NDS. In Hyllie, the smart energy experiment appears to a greater extent to have shaped urban governance and infrastructure development through the close partnership primarily between E.ON and the City. ${ }^{848}$

The disposition consolidated through the Hyllie experiment shows how environmental governance has been accomplished in a specific way, through processes of authorizing and assembling intervention. Analytical attention to processes of authorization and assembling intervention reveals how accomplishing governance is contingent to some extent, excavating differences across experiments that on the surface might appear subtle, but in practice entail constituting the field of intervention for environmental governance in different ways. The power-knowledge assemblages shaped through smart energy experimentation in Hyllie and NDS clearly differ, as has been shown. This highlights that the broader political rationality underpinning smart energy experimentation is indeed pliable, at least to some degree, since urban energy experiments that originally appear very similar end up accomplishing governance in different ways. Although it is necessary to emphasize that the Hyllie experiment also draws upon the broader political rationality to a large extent in authorizing and assembling intervention, for example through elements such as public-private partnership constellations pursuing consensus-seeking projects, green growth through development and export of new energy technology, positioning private companies as central for environmental governance, and centering techno-economic expertise. This is especially evident in E.ON's emphasis on making it easy to do the right thing, which is mirrored in the preference for keeping things simple among actors involved in Smart Energy City. This indicates that both experiments arrange environmental governance in particular ways, drawing upon the broader political rationality underpinning smart energy experimentation, and assigning agency mainly to techno-economic experts to optimize the current energy system infrastructure through the use of ICT.

\section{Shaping urban infrastructure development and environmental governance through orchestrated circulations}

In this section, I will address different forms of circulation associated with the Hyllie experiment. There were many different processes of circulation in Hyllie, where the actors involved attempted to circulate knowledge claims and actor constellations across and beyond Malmö. The processes of circulation visible in the material differ to a large extent from Smart

${ }^{848}$ Cf. Parks 2018. The Sustainable City Becomes Climate-Smart. 
Energy City, which makes it interesting to compare how governance is accomplished across the two cases through circulations.

As we saw previously, the City of Malmö is circulating a story about Malmö as an urban experimentation arena, including through presentations in Hyllie and at conferences. This seems to a large extent to arrange environmental governance in particular ways: a representative from the City explained during a presentation how the City is attempting to position Malmö as a central place for climate action, or as a beacon in his words, where other actors outside the city will want to come and work together with the City. This was partly born out of pragmatism, as we saw, since the City does not have formal jurisdiction over some sectors deemed necessary for environmental initiatives - the representative mentioned, for instance, that E. ON owns and operates the electricity grid in Malmö. Connected to this, both the City representative and the project manager at E. ON explained how the use of voluntary partnership contracts, such as the climate contract, had become important in other areas of Malmö beyond Hyllie. They both described how the same model was re-used across Malmö, with new partnership contracts being signed for different urban areas. The City representative stated that a climate contract covering the whole of Malmö would most likely be developed and signed in the future, which would then be followed by sub-contracts for different city districts. It should be noted that this is due to specific characteristics of Malmö as a location, even though the Hyllie experiment has certainly contributed to extending such processes. Historically, the City and Sydkraft - which was subsequently acquired by E. ON following the deregulation of the electricity sector - have developed a close relationship, while the City of Malmö initiated collaborative sustainable urban planning processes with property developers in a previous sustainable urban district called Västra Hamnen which were also utilized in Hyllie. ${ }^{849}$ Thus, Hyllie was already part of existing infrastructures of circulation from the outset.

As a result of the smart energy experiment in Hyllie, the use of partnership contracts is being circulated across Malmö, and according to the representative from the City it is now easier to bring property developers on board in new experiments because of the experiences in Hyllie. This shapes urban environmental governance toward specific modes of action, as the mode of cooperation used in Hyllie is being circulated across Malmö. Through the experiment, trust and a relationship with infrastructure system owners was built up, according to the City representative, which led to further collaborations across Malmö in the shape of new contracts and projects, which the project manager at E.ON also emphasized. According to the project manager:

What can also be said about that is that Malmö, or Hyllie as a cooperation model, has been re-used as well. [...] Hyllie as a node and showing the way for the rest of Malmö, it's about partly showing 
which technical solutions are needed to achieve these goals and then it's also relevant for the entire city and not just Hyllie as an area. ${ }^{850}$

The quotation highlights how such circulations have consolidated relations established through Hyllie, and a particular mode of urban environmental governance and infrastructure development has thereby been consolidated in Malmö. The project manager articulated how building a more sustainable energy system was a central goal for E.ON, by creating flexibility in the energy system which is stated as necessary when intermittent renewables are integrated, and that:

It is important to handle energy solutions in cities and there Malmö has been an important place for us to be active, not least because we are an infrastructure actor in Malmö, but also because Malmö is expanding, Malmö has extremely ambitious environmental goals and so on, so good conditions have been established for running these types of testbed initiatives, where Hyllie is one of them, in Malmö. But then we scale it up, I mean a lot of these experiences and lessons learned form the basis for our work in Täby, in Järfälla, in Norrköping and Örebro, and so on, where we see that it can actually help in the transition and face these challenges that cities are faced with such as urbanization, the climate footprints of cities [...] and there I think we were on the right track early on when we formulated this work for Hyllie to really hit the right parts that we saw as important [...] about an integrated energy perspective where we're not just looking at electricity, not just at heat, but rather we're looking at the energy system in our cities, in our districts in the cities. ${ }^{851}$

This quotation further underlines how E.ON is drawing different problematics into the intervention assembled in the experiment in Hyllie, but essentially also how the company is attempting to re-use the cooperation model developed in Hyllie. The project manager emphasized how E.ON is actively re-using this mode of urban development through partnerships with cities in other places, extending across Sweden and in other countries. ${ }^{852}$ Again, this illustrates how environmental governance is accomplished through Hyllie; it is through testbed initiatives where mobilization can be achieved, working as nodes, set up as close partnerships between large private companies and municipalities, as well as other relevant actors, where an IT-based technology for linking different parts of energy systems can be tested as well as social arrangements such as the climate contract that was developed. The technology and social setup are then circulated to other places, shaping environmental governance in the city and extending beyond Malmö.

Despite obviously presenting a polished picture, this illustrates how the smart energy experiment in Hyllie has contributed to accomplishing environmental governance through forming a specific disposition where a tight coalition of actors gathers around a specific problematization, configuring how to improve the environmental condition by rendering intervention technical. This disposition is centered around an actor constellation positioned

\footnotetext{
${ }^{850}$ Interview PM E. ON.

${ }^{851}$ Ibid.

${ }^{852}$ Ibid.
} 
on the regional level, and this accomplishment shapes urban governance and infrastructure development in specific ways, which differs significantly from Smart Energy City and Norra Djurgårdsstaden. The project manager from E.ON stated that the smart energy experiment in Hyllie had ended as a project, but new initiatives had been launched to:

[...] keep developing Hyllie's force as a node for development initiatives in Malmö. But there is also lots of thinking going on about, well, how do we scale these solutions from Malmö and to other areas $[\ldots] .{ }^{853}$

There are also circulations that create interlinkages extending beyond the regional context. For instance, the project manager at E.ON described how the experiment in and of itself contributed to creating access to various relevant forums:

Indirectly, I believe that the value of the Hyllie project and lessons from it have surely contributed for instance to E.ON being part of the cooperation group for smart cities, the government's cooperation group [...]. [E.ON] has participated in several different working groups within this cooperation program, for instance, which have turned out very well with the government, including a working group where we have produced a number of reports linked to digitalization of the urban development process, because a number of aspects are relevant from the energy perspectives. [...] But it could be said that the importance of cooperation, and I think that has been noticed, and that's also viewpoints which we have concretized for the Energy Agency, the value we have seen in the setup, for instance the framework for how we worked within the Hyllie smart grids project. I mean, a very important success factor for us was, for instance, that we were able to get property developers on board, and that is about how you shape the frameworks around, for instance, external funding in demonstration projects and how you design testbeds. ${ }^{854}$

The project manager stated that it is impossible to claim that a specific policy has been developed as a direct result of the Hyllie experiment, but it was quite clear that knowledge claims derived from the experiment had an impact in terms of providing input to and affecting policy discussions. The interviewee also mentioned how the strategic innovation programs had received input from the three large smart energy demonstration projects funded by the Energy Agency, i.e. Hyllie, Norra Djurgårdsstaden, and Smart Grid Gotland, especially in relation to regulatory aspects such as the pricing of electric power. Additionally, it was mentioned how E.ON was also active in the Swedish Smart Grid Forum, as well as in the Energy Commission active between 2015 and 2017, sharing experiences from the Hyllie experiment. ${ }^{855}$ This illuminates how E.ON has been able to use the experiment to access forums where the company can participate in policy discussions, and circulate its specific problematization and solution. Essentially, certain channels of circulation were created or consolidated through the Hyllie experiment. As the quotation illustrates, the establishment of such channels was largely conditioned by the broader political rationality underpinning smart energy experimentation, through underlining cooperation and consensus-building as an integral part of public-private

\footnotetext{
${ }^{853}$ Ibid.

${ }^{854}$ Ibid.

${ }^{855}$ Ibid.
} 
partnership constellations pursuing different experiments together. Thus, an infrastructure of circulations that arranges governance in particular ways was strengthened through circulations associated with the Hyllie experiment. This appears to be similar to how representatives of the private companies in Smart Energy City described how they were using their experiment to access policy networks and exert influence.

E.ON also attempts to circulate its specific technical solution, i.e. the software and hardware infrastructures connected to the IT platform CESO, for instance by entering into new partnership contracts with the City of Malmö and through other experiments. The project manager at E.ON stated that:

We have gotten far enough so that we are now rolling out this solution that we have developed in Hyllie, and have been doing so for a while now, in other parts of Malmö but also in other energy systems outside Malmö. And there we are about to use this on a commercial basis. [...] it has been an important pre-requisite for us when we have developed this smart grid platform, among other things, that we have to be able to use it in existing neighborhoods, for example to connect existing properties with less sophisticated management systems [compared to Hyllie]. ${ }^{856}$

The project manager also mentioned how E.ON is attempting to use CESO in other experiments, both in the Malmö region and elsewhere. This illustrates how the circulation of the specific technical solution is also an important part of accomplishing environmental governance, as it positions E.ON as a central IT infrastructure actor in a specific smart energy system configuration, with the aim of embedding the solution in different contexts through close cooperation with partners such as the City of Malmö. There is an emphasis on scaling up experiments, both from the City and from E.ON, and judging by the quotations from the project manager scaling up seems to entail circulating the specific organizational mode of cooperation from Hyllie to other locations, as well as commercializing the technical solution CESO, and consequently moving E.ON toward urban development with a sustainability profile as well as an IT infrastructure actor. The project manager stated that:

One part of it is the smart grid, I mean it's both about technology but also the results that were generated in Hyllie, and one part is how can we create these communicative bridges between the energy system and the building, where we have developed a smart grid platform that is based on both a hardware and a software infrastructure that enables this. And we are scaling this up outside of

Hyllie now as well, and we are looking at these functions in Simris too, and whether at least components of this solution can be used there, and also how it can be further developed to become more modular and fit different projects and different areas' more specific circumstances. ${ }^{857}$

Whereas E.ON and the City of Malmö are certainly very active in their attempts to circulate aspects of the Hyllie experiment, the emphasis not only on circulation as establishing and consolidating actor constellations and modes of infrastructure development through publicprivate partnership but also on commercialization through scaling up via additional 
experiments, indicating the centrality of projectification, appears to be very compatible with the broader political rationality underpinning smart energy experimentation. As shown, other actors in the energy field regularly referred to Hyllie as the most successful of the three large flagship smart energy experiments. Making the experiment reverberate through establishing new infrastructures of circulation, as well as latching on to existing ones, aligning knowledge claims stemming from Hyllie with the broader political rationality, has allowed E.ON and the City of Malmö to gain traction for a particular disposition of environmental governance arranged through Hyllie.

Besides E.ON's circulations of the technical solution into additional experiments, another prominent form of circulation was marketing the experiment, much like in Smart Energy City. As expressed in policy documents, the City of Malmö intended to use Hyllie as a space for showcasing innovative solutions for the future, which could then be scaled up, making demonstration a central feature of such place-branding. Similarly, E.ON also wanted to showcase its specific technical solution, which becomes clear through the marketing infrastructure created around the experiment on-site in Hyllie. Much like the rest of the experiment, this visitor operation was run in close cooperation between E.ON and the City, although E.ON operated the center, and site visits often included presentations by actors involved such as a property owner. There is a building in Hyllie which is the focal point of this visitor operation, previously referred to by an employee at the City of Stockholm. During site visits, this building was used to show a short movie about the Hyllie experiment, and in addition to personnel from E.ON there were often other involved actors present who gave presentations. There was also a guided tour of Hyllie, on which E.ON demonstrated its IT platform in one of the buildings, as well as visits to the premises of involved property owners. The project manager at E. ON stated that this operation was of great importance for marketing the project:

[...] there has been great interest in what we're doing in Hyllie among other things, and that has also been a part of the smart grid project to actually communicate and package experiences and knowledges and results from the projects, and our information facility that has been kind of the node of the visitor operation in Hyllie. [...] And there we've had quite a lot of visits from governmental agencies, municipalities, and other actors in the business sector and academia and so on, so that has been an important part of our visitor operation, and then of course participants have also attended Energiutblick [an annual energy conference hosted by the Energy Agency] several times and talked about what we do, and so on. ${ }^{858}$

This importance afforded to marketing and packaging knowledge from the experiment also resonates with how other interviewees perceive Hyllie. For example, a project manager in Norra Djurgårdsstaden mentioned that substantial amounts of money and effort appeared to 
be poured into the marketing infrastructure around Hyllie. ${ }^{859}$ It is, however, important to note that the marketing also differs from Smart Energy City, since the marketing of Hyllie appeared to unfold through very coordinated processes, constituting an additional component of the close cooperation between E. ON and the City of Malmö. Finally, E. ON also circulated aspects of the Hyllie experiment within its own organization. According to the project manager, this was an attempt to link different business areas together in line with the business development strategy of making E.ON a more prominent actor in sustainable urban development and IT infrastructure. ${ }^{860}$ One way of achieving this was to circulate personnel within the organization, to spread the organizational model developed through the Hyllie experiment to other parts of E.ON. This elucidates an internal circulation of embodied knowledge, moving an actual person who was involved in Hyllie and who possesses knowledge about how the experiment was set up and unfolded, with the hope of initiating similar experiments in other places.

Taken together, these examples illustrate how different types of circulations can be discerned through the Hyllie experiment, extending beyond the specific experiment. These examples elucidate how circulations contribute to accomplishing environmental governance, arranging governance in specific ways. Circulations in the case of Hyllie consolidated a discursive constitution of the problems that the future smart energy system is supposed to solve. Taking the implications of conceptualizing governance as accomplishment seriously, the circulations undertaken by E.ON and the City of Malmö contribute to stitching together a specific, contingent socio-material disposition which configures what environmental governance entails in practice. This is evident in the case of E.ON's IT platform and the company's attempt to circulate the organizational form for collaboration with municipalities between contexts, since E. ON is actively taking up a position in the governance of sustainable urban development through the particular mode of infrastructure development developed in Hyllie. This is intrinsically linked to environmental governance, as epitomized in the climate contract, for example. Through this process, E.ON and the City of Malmö are also discursively influencing what it entails to govern the environment by circulating the devices and organizational constellations from the Hyllie project. This is done by drawing disparate elements together into specific configurations, and by establishing particular infrastructures of circulation operating across formal and informal spaces of governance simultaneously, interlinking knowledge claims, technical components, and social arrangements of the Hyllie experiment with policy networks, different parts of E.ON's internal organizational infrastructure, and the everyday environmental work of the City of Malmö.

\section{Summarizing reflections}

This section has highlighted similarities and differences between unfolding processes as smart

\footnotetext{
${ }^{859}$ Interview PM City of Stockholm.

${ }^{860}$ Interview PM E. ON.
} 
energy experimentation arranges environmental governance in Stockholm and Malmö. There are some striking differences between Hyllie and Norra Djurgårdsstaden, demonstrating how the political rationality underpinning smart energy experimentation conditions experiments in particular ways but is nevertheless far from monolithic or impenetrable.

Through the smart energy experiment in Hyllie, a specific governance disposition seems to have been created. The involved actors attempt, quite successfully, to circulate aspects of this disposition, for example through E.ON's attempts at implementing similar experimental setups in different places and the City's intention to re-use partner contracts across multiple sites in Malmö. In line with Edwards and Bulkeley, the experiment constitutes an example of folding the future into the present, especially through the different forms of circulation extending beyond the Hyllie experiment. By consolidating a specific disposition and then attempting to move central aspects of it to other places, specific governance arrangements can potentially be consolidated while the meaning of a smart energy system can potentially be narrowed down and crowd out alternative ways of accomplishing environmental governance through experimentation, and a specific energy future is thus shaped through these activities. The attempts at coordinated circulation of the experiment highlight a significant difference compared to Smart Energy City. There are clearly very different ideas about how to scale up an experiment at work across the two different experiments, not least visible through E.ON and the City of Malmö's reflections on how to manage to scale up an experiment and insert it into different context-specific circumstances and materialities, something that did not seem to be considered an issue in the case of Smart Energy City. Perhaps it was also an issue there, albeit an issue for individual actors rather than a common endeavor, if it was considered. Overall, the close-knit cooperation between E.ON and the City of Malmö contrasts significantly with Smart Energy City and Norra Djurgårdsstaden, illuminating how environmental governance is accomplished differently across the two smart energy experiments.

A specific knowledge politics can also be discerned in the case of Hyllie. E. ON owns the solution, as a representative of the City put it, although there seems to be a more open and institutionalized process of knowledge-sharing between E. ON and the City compared to Smart Energy City in Norra Djurgårdsstaden. This is evident in the character of the regular meetings throughout the duration of the experiment. ${ }^{861}$ In the case of Smart Energy City and NDS, there was a clear separation between the urban development project and the smart energy experiment. As the frictions outlined highlight, however, the question of what constitutes the proper means to improve the environmental condition for different actors is far from closed. For E.ON, it is clearly the smart grid solution, and especially the software and hardware for its IT platform CESO, which can constitute a device to integrate IT with different infrastructure activities in the city in the future for E.ON. For the City, environmental

\footnotetext{
${ }^{861}$ See Parks 2018. The Sustainable City Becomes Climate-Smart.
} 
governance through smart energy experimentation need not necessarily be tied to E.ON's specific technical solution; considering how Ericsson, and others, are developing similar platforms and solutions, E.ON's might well be replaceable in direct terms. Further, recall how a representative of the City described Malmö as an experimentation arena, hinting at other possible modes of arranging governance through smart energy experimentation. However, the close cooperation between E.ON and the City, strengthened through the Hyllie experiment, has served to consolidate a specific disposition where E.ON's IT platform currently constitutes a central element of environmental governance in the city and beyond. The experiment has established a particular power-knowledge assemblage, in line with the broader political rationality underpinning smart energy experimentation. As shown, questions about how to improve the environmental condition which are essentially political questions were filtered out, whereas knowledge claims of achieving sustainability goals through the disposition enshrined in Hyllie were foregrounded, even though it is thoroughly unclear to what extent district heating from waste incineration can be considered part of a green energy future, which is also the case with commercialization of new IT equipment integrated into the current energy infrastructure. ${ }^{862}$

The foregrounding of such knowledge claims, establishing a discursive constitution of what the problem to be governed is, elucidates knowledge politics. Accomplishing environmental governance through smart energy experiments is implicitly framed as necessitating the creation of relations between specific actors who becomes important through a specific problematization, and aligning these actors' interests through large experiments, labelled testbeds to function as nodes, as is evident in frequent statements by representatives of both the City and E.ON. The use of the term "nodes" reveals a particular notion of change. For the City, scaling up seemed to be synonymous with carrying out more experiments and implementing E.ON's technical solutions in more places other than Hyllie on a commercial basis. So in the case of the Hyllie experiment, environmental governance is accomplished through a specific disposition of things, which the creation of new infrastructures of circulation and tapping into existing ones sits at the heart of. These circulations implicitly rely on, and reconstitute, a notion of transformative change being best achieved through more experiments. This underlines how a particular notion of change flows as an undercurrent through the Hyllie experiment, aligned with the political rationality underpinning smart energy experimentation by emphasizing the export orientation and practices of marketing in Hyllie, thus contributing to strengthening implicit assumptions of solving environmental issues through green economic growth inherent in the political rationality.

By accomplishing environmental governance in this particular way, E.ON is positioned as a central actor in the future smart energy system, as an IT infrastructure actor that provides the

\footnotetext{
${ }^{862}$ See e.g. Eriksson \& Finnveden 2009. Plastic waste as a fuel - $\mathrm{CO}_{2}$-neutral or not? Energy \& Environmental Science, 2(9). Cf. Bonnedahl 2012. Från ekonomiskt till hållbart, från exploatering till samexistens: en bok om att tänka om. Lund: Studentlitteratur; Sadowski 2020. Too Smart.
} 
platform interlinking different parts of urban energy systems. According to a representative of the City of Malmö, experimentation entails uncertain testing, but overall progress is made toward environmental goals. However, it is important to consider whether that is actually the case; the re-negotiation of the goal of renewable energy into recyclable energy might hint toward moving in circles rather than moving forward, and - as mentioned by the project manager at E.ON - cities currently have a massive environmental footprint. ${ }^{863}$ The risk of moving in circles rather than forward should at least be taken seriously. Nonetheless, the smart energy experiment in Hyllie appears to have been important in establishing specific knowledge claims of how to improve the environmental condition. Improving the environmental condition hinges upon optimizing energy flows in the city and beyond, while making it "easy to do the right thing" for customers, consolidating E.ON's position as an authoritative actor in the future smart energy system and cementing a close partnership between E.ON and the City of Malmö.

\section{Västerås - experimentation as tinkering and expanding imagination}

The final part of this chapter is set in the city of Västerås. The smart energy experiment in Västerås provides a stark contrast to the two preceding urban experiments. Locating it required actively searching - it was neither publicized nor talked about in the field to the same extent as NDS or Hyllie. This could be explained by the absence of physical construction within the Västerås experiment at the time, although both the Hyllie and Norra Djurgårdsstaden experiments were widely publicized before they started, and were well known in the energy sector in contrast to the Västerås experiment. The experiment in Västerås is mainly carried out by ETC, a self-described climate activist, antiracist, feminist enterprise which started as a leftist newspaper in the 1970s and now includes several branches. Alongside the newspaper, perhaps most prominently of these is its involvement in producing electricity from renewable energy sources, especially in so-called solar parks. This part of the chapter is based on an interview with a key individual within the ETC organization, and a site visit to ETC's solar park in Katrineholm where ETC tests and showcases different types of renewable energy technologies. Since the Västerås experiment has in a sense not begun yet, with buildings currently under construction, this part of the chapter will focus on the process thus far, and the interviewee's ideas about smart energy experiments and those displayed in Katrineholm.

\footnotetext{
${ }^{863}$ See e.g. IRP 2018. The weight of cities: resource requirements of future urbanization. Swilling et al. A Report by the International Resource Panel. United Nations Environment Programme. Nairobi: Kenya; Holgersen \& Malm 2016. "Green fix" as crisis management; Ernstson \& Swyngedouw (eds.) 2019. Urban Political Ecology in the Anthropo-Obscene: Interruptions and Possibilities. Abingdon, Oxon: Routledge.
} 
Similar to Malmö, Västerås is a former industrial city, previously the primary seat of ASEA, which is now Vattenfall and $\mathrm{ABB} .{ }^{864} \mathrm{ABB}$ still has offices in Västerås. The smart energy experiment in Västerås is located in an urban development area, where the new city district Öster Mälarstrand is under construction. Like Hyllie and Norra Djurgårdsstaden, the location is a former industrial area, including a harbor. ${ }^{865}$ While it is imperative not to get stuck in binaries, the smart energy experiment in Västerås differs from Hyllie and Smart Energy City in the sense that it is more grassroots-driven. The main actor, ETC, has evolved into an enterprise encompassing different companies, including a construction company. The smart energy experiment is run by the construction company, with the explicit ambition of providing affordable housing with low environmental impact by building passive houses made of wood. ${ }^{866}$ The experiment is partly financed through crowdfunding, i.e. individuals lending money to the project on a long-term basis in return for an annual fixed interest rate. At the time of the interview, the plan was for the houses to be connected to a local solar-powered DC grid using a power converter system, with the hope of extending the local grid to neighboring buildings. Later, however, the Energy Markets Inspectorate clarified that current regulations only allow for transmission of electricity between buildings by concession rights holders, i.e. grid operators. ${ }^{867}$

Since this section is intended to provide a contrasting case and is based on substantially less material than the preceding cases, it will be kept short under one main headline. Since circulations do not appear to have taken place to a great extent yet, the focus will rather be on the interviewee's ideas about the circulation of experiments.

\section{Authorizing and assembling intervention through tinkering: showing that different energy futures are possible}

Thus far, the processes of authorizing and assembling intervention in the smart energy experiment in Västerås differ from Hyllie and Smart Energy City. A spokesperson for ETC expressed in an interview that:

\footnotetext{
${ }^{864}$ See e.g. Granberg 2003. Kommunikativ process eller beslutsentreprenad? Politiker, planerare och medborgare i samhällsplaneringen. Örebro University, Centrum för stadsmiljöforsknings skriftserie, report no. 57.

865 Mälarstrandens utveckling AB (undated). Projektet Öster Mälarstrand. https: //www.ostermalarstrand.se/projektet/ [2019-07-03].

${ }^{866}$ ETC 2022 [sic]. Presentation av ETC Hyreshus. Published 2022-01-01 [sic]. https://www.etc.se/etc-hyreshus/presentation-av-etc-hyreshus [2019-07-03].

${ }^{867}$ The Energy Markets Inspectorate 2020. Tillstånd behövs för ledningar som överför solenergi mellan flerbostadshus. Published 2020-06-26. https://www.ei.se/sv/nyhetsrum/nyheter/nyheter2020/tillstand-behovs-for-ledningar-som-overfor-solenergi-mellan-flerbostadshus/ [2020-10-13]. This is currently being evaluated and intensely discussed further, since it is interpreted by many as a barrier to the widespread establishment of energy communities and therefore clashes with EU legislation. Thus far, however, EI's stance remains firm.
} 
What we're doing in Västerås I guess is a smart grid in a way, but it's a DC grid. [...] our rental apartment buildings are entirely based on self-produced electricity. We won't take any district heating, which will be very interesting when they understand that, they don't get that yet. They can lay a cable, but we won't connect to it. Instead, we will build a DC grid between our buildings and to the neighbors. I mean the buildings are pretty big, it's schools and an elderly care home which are owned by the municipality, and then there are housing associations. So we will connect a grid of our own, on the DC side, simply because we are not allowed to transfer AC between the houses. ${ }^{868}$

The vision of a smart energy system presented in the quotation differs significantly from Hyllie and Smart Energy City, with the interviewee stating that ETC wishes to build a DC-based nanogrid to provide its own buildings with self-produced renewable electricity and with the intention of connecting other buildings in the vicinity, aiming to sidestep concession rights legislation. ${ }^{869}$ ETC intended to use a power converter system, and heating would mainly be provided for through thick insulation of the buildings. ${ }^{870}$ The attitude toward smart energy experimentation expressed by the interviewee also differs significantly from actors involved in the other two urban experiments. The interviewed spokesperson for ETC said that there was a genuine desire to get the municipality and others on board as well. However, since the municipal-owned energy company might take issue with ETC's plans not to connect to the district heating grid, it might choose to disengage from the experiment. According to the interviewee, this would not represent a big issue, however, since the experiment would still work even if restricted to ETC's own apartment buildings. ${ }^{871}$ This illustrates how the interviewee appeared to perceive of experimentation as tinkering, i.e. as working around the edges of current socio-technical configurations in order to subvert or change them. The interviewee stated, for instance, that it would be great to own some grid infrastructure, because that would allow for "doing lots of fun things":

But one has to do the fun things you can $!^{872}$

This underscores how experimentation is articulated as tinkering by the interviewee; working within constraints but attempting to go creatively beyond such constraints. It could possibly even be argued that the Västerås experiment works as a heterotopia, embodying a different political rationality. On an ideational level, this argument could certainly be made. It would however necessitate a more thorough empirical analysis of the Västerås case, following it more closely as it unfolds. At the time of the interview, it remained mainly on an ideational level, with construction yet to be commenced. In connection with this, the interviewee also expressed testing as a central part of experimentation, in line with how many experts across governmental agencies and policy networks spoke about experiments. The interviewee

\footnotetext{
${ }^{868}$ Interview SETC [Spokesperson ETC].

${ }^{869}$ As stated above, this did not pan out the way ETC hoped. This will be further discussed below, when drawing the comparative analysis together at the end of the chapter.

${ }^{870}$ Interview SETC.

${ }^{871}$ Ibid,

${ }^{872}$ Ibid.
} 
emphasized how tests are by definition uncertain, visible for example in the terms of cooperation in the Västerås experiment described above. Further, the interviewee explained how the solar park in Katrineholm was a major experiment in itself, since ETC had continuously tried different solar-PV technologies and wind turbines, with the intention of learning from these tests:

I mean, that is important for people when they think about building something, it's actual experiences as well. We learned pretty quickly that [...] solar trackers were useless, which was an expensive lesson. But it has saved enormous amounts of money for people. [...] I thought that we should try everything before we said that it's bad. [...] It's not the idea, because then the mechanics and engineering skills come in $[\ldots] .{ }^{873}$

Here, experimentation is expressed as testing technologies in line with prevalent notions across the field of smart energy. However, uncertainty is emphasized in contrast to the knowledge claims foregrounded in Smart Energy City and Hyllie. As mentioned, the solar park in Katrineholm was articulated as an experiment in itself, since ETC had tried many different techniques for constructing wind turbines, different renewable energy technologies and so on, mainly based on revenue raised from the newspaper. The interviewee stated that the goal was resolutely not commercial, although it was of course important that the park sustained itself in order to make responsible use of readers' money. ${ }^{874}$ This is also a significant contrast to Hyllie and Smart Energy City, both of which included commercialization as a central goal.

Besides articulating experimentation as tinkering and uncertain tests, the interviewee also displayed a significantly different way of thinking about experiments compared to actors involved in the other two urban experiments:

I mean use it [the solar park in Katrineholm] to say that another world is possible, another energy world is possible. ${ }^{875}$

The interviewee expressed how experiments are essentially about expanding the imagination, or broadening the perceived horizon of possibilities, by showing that another energy world is possible and within reach. This is akin to articulating experiments as demonstration, although with the focus shifted from marketing specific technologies or consolidating actor constellations toward expanding the imaginative horizon. This clearly differs from Hyllie and NDS, since it essentially entails outright challenging the current configuration of the energy system and the politics of this configuration. ${ }^{876}$ As stated, the Västerås experiment could perhaps be conceived of as a heterotopia embodying a different political rationality.

\footnotetext{
${ }^{873}$ Ibid.

${ }^{874}$ Ibid.

875 Ibid.

${ }^{876}$ Cf. Burke \& Stephens 2016. Political power and renewable energy futures.
} 
Additionally, the interviewee stated that the purpose of carrying out experiments, such as in Västerås, was also:

To frighten them [incumbent energy companies] a bit. They get scared, you know. ${ }^{877}$

This also illustrates a fundamental difference between the notions of experimentation articulated by other actors and the spokesperson for ETC. While most actors express experiments as spaces of cooperation, which the spokesperson for ETC also does, stating that there is a desire on behalf of ETC to work with other companies and actors as well, there are significant differences in how such cooperation is described. The quotation above, on using experiments to "scare" the established energy companies, is also in line with how the interviewee said that experiments are largely about showing that a different energy world is possible, and thus illuminates a counter-model of smart energy experimentation to the other two urban energy experiments. Consequently, the politics and orchestration of power flowing from current energy system infrastructure is basically brought into the light of day.

Here, smart energy experimentation becomes a way of drawing upon the broader political rationality, invoking testing and cooperation as central elements as intervention is assembled, but rather than reinforcing the political rationality, defining features such as commercialization are highlighted as emblematic of problems with dominant modes of smart energy experimentation.

\section{Circulations as knowledge-sharing and inspiration for grassroots mobilization}

Specific notions of circulation also surfaced in the interview. One type of circulation had actually already commenced, through disseminating knowledge about the experiment, such as blueprints, use of funds, and plans through the ETC newspapers and website. According to the interviewee, this was mainly to provide transparency for readers, so they were informed about every step taken and how their funds were being used. ${ }^{878}$ Thus, this circulation occurred before the experiment, i.e. before the construction of any buildings. Another circulation of both the Västerås experiment and ETC's broader engagement in smart energy experimentation was through the solar park in Katrineholm, according to the interviewee. At the time of our interview, a school was being built, with plans to arrange courses on different aspects related to energy transformation, drawing on ETC's own energy initiatives. Speaking specifically about upscaling, the spokesperson for ETC said that performing tests in the form of experiments in the solar park and being transparent about these tests:

\footnotetext{
${ }^{877}$ Interview SETC.

${ }^{878}$ Ibid.
} 
[...] has a practical value. But it's a practical value that is not aimed at the Energy Agency or some company, it's aimed at these people who are themselves going to try to transition $[\ldots]{ }^{879}$

Through this quotation, another type of circulation can be glimpsed. The idea seems to be that when people come to the solar park in Katrineholm, or the smart energy experiment in Västerås, they can learn about different renewable energy technologies, what works under which conditions and so on, and then mobilize themselves at a grassroots level. The interviewee stated that:

I think that this, everything we do in Västerås, building massive wooden houses and supplying them with our own production for the vast majority, ferment waste from them, clean water in a different

way, re-using energy with FTX systems, all those things, that won't mean that I will build ten thousand houses. But [...] some smart municipal company will go there and say, this is cheaper. So in that way you can achieve an upscaling. ${ }^{880}$

The quotation illustrates how the interviewee appears to view upscaling in a similar sense to Hyllie and NDS, based on an idea of spreading awareness for the experiment and initiating "policy tourism". However, the knowledge politics differ significantly from Hyllie and NDS. In this experiment, information is openly available and there is a clear ambition of spreading knowledge, which is quite far from marketing, and instead intends to challenge the current energy system regime by activating citizens. The interviewee continued by stating that:

But I don't think upscaling will be about companies [...] that's what you often think, that new technology has to be patented and packaged in a venture capital firm, and then it will grow big after five years. I think that only slows it down. I think that you do things, and then others will do the same if you have done something good. And what will force a more democratic grid is that consumers become aware. And don't accept this passive role they have, but demand to own the solar panels on the roof of the apartment building or school. [...] I think that will come, and then the grids and the smart will be forced to adapt. So politics is the method of regular people, but to change politics people must have done this first. It's really, first people put up solar panels, then politics changes, because then people can make demands of the politics [... ${ }^{881}$

In the two quotations, a specific notion of socio-technical change through circulations can be distinguished, driven by experiments, which renders energy transformation explicitly political. Consequently, these notions of circulations were linked to an underlying idea of how to achieve socio-technical change, which also drew on the notions of experimentation as expanding imagination. See for instance the following quotation:

It's a way of, I mean all change is based on, it's not based on companies, it's based on enough people who think that this is important. ${ }^{882}$

${ }^{879}$ Ibid.
${ }^{880}$ Ibid.
${ }^{881}$ Ibid.
${ }^{882}$ Ibid. 
Rather than generating proprietary knowledge or place-branding through smart energy experimentation, then, the spokesperson for ETC seems to view knowledge circulation as something that happens organically through transparency. In the example above, it was stated that upscaling of experiments could be achieved, for instance, when municipal planners come to visit the Västerås experiment, taking fresh ideas about how to construct houses and energy systems back to their municipalities. This is not so different from Norra Djurgårdsstaden or Hyllie, where the actors involved also emphasized how interested parties came to visit and took inspiration home. However, the notions of grassroots mobilization through experimentation that the spokesperson for ETC talked about seem far removed from the smart energy experiments in Hyllie and Norra Djurgårdsstaden. The interviewee explicitly stated that those large urban experiments did not have a significant reach, or a low spread, to paraphrase, since they were mainly aimed at experts. ${ }^{883}$ Changing the energy system, for the ETC spokesperson, entails grassroots mobilization toward a democratic electricity grid, and in this process experiments play the key role of expanding imagination and providing impetus for such grassroots mobilization. Compared to NDS or Hyllie, this is thus a significantly different mode of accomplishing environmental governance, drawing on other ideas of sociotechnical change through circulations and assigning central roles to other actors.

\section{Making the politics of energy infrastructure change visible: hopes of democratizing the energy system}

The interviewee was also explicitly critical of market-led environmental governance, perhaps unsurprisingly considering the affiliations with a leftist newspaper, although this critique was frequently connected to energy transformation and attempts to develop a smart energy system. The interviewee stated that:

Well we need to nationalize the grid. [...] Then we need to expand the grid locally. And by that I mean that it's better to build ten thousand microgrids in Sweden [...] perhaps with battery storage or hydrogen storage or some, whatever you want, like small reserve plants or storage or expanding

pump-storage hydroelectricity along the lakes, to create a really local, sustainable, balanced electricity grid. ${ }^{884}$

The vision of the future energy system laid out by the interviewee differs significantly from both NDS and Hyllie. The interviewee is careful to point out, however, that the envisioned future energy system is not an off-grid variant, but rather one where many microgrids are built and interlinked through the existing large-scale grid infrastructure. The spokesperson for ETC claimed that:

Because those who want to do these smart grids, they own the production, they own the grid, and most often they own the electricity trading. For them, a smart grid is merely a way of increasing

\footnotetext{
${ }^{883}$ Ibid.

${ }^{884}$ Ibid.
} 
profit on their own production or consumption in the grid. [...] So smart grids are not, today it's not a way of increasing consumers' power, it's rather a way of protecting the lock-in. ${ }^{885}$

The view expressed on developing a smart energy system is connected to the interviewee's strong critique of market-led environmental governance, and thus provides an important element for authorizing and assembling intervention in Västerås. Assembling intervention in the smart energy experiment in Västerås builds on this criticism, and thus provides legitimacy for pursuing a non-commercial pathway toward a future smart energy system, including the aforementioned specific ideas about gaining traction through circulations. As mentioned, this contains a more or less outright challenge to the current energy system regime and the central actors, mainly incumbent, large energy companies. The interviewee stated that the biggest issue currently holding back a widespread energy transformation is the unwillingness of politicians to govern the market:

It's the politicians who say that this will be done by the market, and the market never does that. The market can be fantastic for developing mobile phones [...] But this is infrastructure. This isn't something that the market solves. If the market gets hold of it, it becomes a conservative force, and stops development because that's what enabled them to make money, that you have control, the monopoly. ${ }^{886}$

Connected to this critique, the interviewee also stated that energy companies have long used techno-economic language to make energy as complex an issue as possible, in order to shut down debate. The interviewee was highly critical of the Energy Commission and the 2016 Energy Agreement for this reason, in contrast to other actors accounted for in earlier parts of this study who were very positive toward the Energy Agreement, since it was articulated as an important moment for establishing consensus in the energy sector. A key difference between the smart energy experiment in Västerås and the ones in Norra Djurgårdsstaden and Hyllie is thus that commercialization is not a stated goal of the Västerås experiment, nor of ETC's solar park in Katrineholm. The interviewee stated that a large-scale move toward the vision of a future smart energy system outlined previously is perceived as impossible by many people, because it would threaten the profitability of currently powerful actors. ${ }^{887}$ The interviewee stated that the biggest difference between ETC's experiments and initiatives such as Hyllie or Smart Energy City was that ETC did not have the goal of commercialization, but rather of knowledge generation. ${ }^{888}$ Additionally, as we have seen, of catalyzing grassroots mobilization. According to the spokesperson for ETC, the smart energy experiment in Västerås, and other experiments carried out by ETC such as the solar park in Katrineholm, had encountered significant difficulties when applying for funding. According to the interviewee, several applications had been declined, often by the same civil servants at the Energy Agency, with

\footnotetext{
885 Ibid.

${ }^{886}$ Ibid.

${ }^{887}$ Ibid.

${ }^{888}$ Ibid.
} 
reference to the commercial unfeasibility and the lack of previous experience of similar projects. ${ }^{889}$ The precedence granted to commercialization in the other two urban smart energy experiments is in line with the ecomodern orientation of Swedish environmental politics, and thus the broader political rationality underpinning smart energy experimentation, while ETC's mode of experimentation presents a challenge to market-led environmental politics.

Authorizing the experiment in Västerås also differs significantly from the other two urban smart energy experiments. The Västerås experiment and the solar park in Katrineholm are both based on specific ideas of knowledge circulation, contrasting with Hyllie and Smart Energy City. ETC's ambition of achieving net-zero carbon emissions through its buildings and the DC nanogrid, and the explicit intention to influence construction norms in Sweden, through a non-profit scheme results in a significantly different mode of authorizing the experiment. Power is channeled through ETC, although it is dispersed through the circulations based on an idea of organic dissemination of knowledge through transparency. Thus, the orchestration of power through the Västerås experiment is also different from the other two urban energy experiments, not least in terms of knowledge politics.

\section{Summarizing reflections}

Despite many differences, there is also common ground between the urban experiments in Hyllie and Norra Djurgårdsstaden, which the ETC spokesperson clearly does not share. For ETC, experiments are about showing that a different energy future is possible, and that experiments have to be genuinely uncertain and explorative to have a raison d'être. Actors involved in Smart Energy City also described the energy sector as conservative, however the criticism against the unwillingness of politicians to govern the market, as the ETC spokesperson put it, clearly differs as well. The smart energy experimentation undertaken by ETC seems to revolve largely around infrastructural tinkering, in the sense of pushing norms and regulations by testing new socio-technical configurations on the margins of what is reasonable within the broader political rationality, as the Västerås experiment highlights. It also entails an outright challenge to current environmental politics, and calls for re-imagining and reconstituting the energy system dramatically.

Consequently, we can discern a different mode of knowledge politics compared to Smart Energy City and Hyllie. In Västerås, there is an explicit ambition to generate different knowledge about how energy systems can be arranged, as well as how and by whom the knowledge is generated, and the intention is to circulate the arrangement to municipal planners and catalyze grassroots mobilization among the public, alongside the explicit ambition to influence politics. Thus, there is a clear difference in terms of who owns the knowledge. In

${ }^{889} \mathrm{Ibid}$. Of course, it is very difficult to check the validity of this statement. 
Västerås, the knowledge generated is available for anyone; knowledge is not proprietary as it is to some extent in Hyllie and Smart Energy City.

Including the case of Västerås, despite the limited material compared to the other cases, is justified since it illustrates how smart energy experimentation can arrange environmental governance very differently, including within the conditions of possibility that the broader political rationality imposes. Having to actively search for a clearly contrasting case, however, signals the dominance of the political rationality, in terms of conditioning smart energy experiments to take on particular forms. Of course, this is also due to the socio-technical infrastructure of the Swedish energy system, signified by large-scale infrastructure, as well as historically sedimented power relations through centralized ownership structures in the energy system.

\section{Analytical discussion}

The three experiments explored in this chapter contribute to accomplishing environmental governance in significantly different ways, despite Hyllie and Smart Energy City being very similar from a distance and all three being firmly based in post-industrial urban development projects. They encompass different discursive constitutions of the problem to be governed, different actor constellations, different knowledge generation practices and knowledge ownership, and different types of circulations. Consequently, analytical attention to processes of accomplishing environmental governance through smart energy experiments has shown how experimentation can arrange governance differently. This is the case despite the political rationality underpinning smart energy experimentation clearly conditioning the experiments - visible especially in processes of authorization, assembling intervention, and circulations related to Hyllie and Smart Energy City, where elements compatible with the political rationality are invoked, such as the emphasis on consensus, cooperation, and techno-economic knowledge claims, and the focus on green growth through exporting energy technology.

The analysis has shown how experiments shape urban governance and modes of infrastructure development, and these three experiments exemplify different modes of accomplishing environmental governance. In Norra Djurgårdsstaden, the City is trying to create arenas for private actors to develop technology to achieve change, while the intervention in Hyllie relies on the articulation of common goals between public and private actors in close cooperation, and in Västerås the experiment constitutes an attempt at grassroots mobilization to influence politics. These three experiments illustrate the ongoing struggle to define what a smart energy system can become, through different enactments of urban environmental governance and different attempts to define how low-carbon transformation in cities should be accomplished.

The Västerås experiment presents an outright challenge to the current configuration of the energy system, with an explicit focus on power relations. In Hyllie, we can see a gradual reconfiguration of actor positions, forming an attempt to change the energy system through a coordinated public-private partnership mode of infrastructure development. In Norra 
Djurgårdsstaden, smart energy experimentation displays a rather fragmented character based on reconciliation of different actors' interests. As shown, the three urban experiments exemplify different knowledge politics. In Stockholm, a story of green innovation districts is molded and circulated, where private actors are positioned as central for generating and to an extent appropriating knowledge. Hyllie is characterized by a specific mode of governance through close cooperation between E.ON and the City of Malmö, using partner contracts and circulating E. ON's technical solution, as well as the use of partner contracts across and beyond Malmö. In Västerås, we see attempts at grassroots mobilization and ambitions of openly sharing knowledge. Thus, the cases present three different types of knowledge generation, producing different knowledge claims, as well as different types of circulation.

The two experiments in NDS and Hyllie both appear clearly conditioned by and attuned to the broader political rationality underpinning smart energy experimentation, although more clearly so in the case of NDS and Smart Energy City. Nonetheless, in processes of authorization and assembling intervention in both cities, elements derived from the broader political rationality are drawn upon, such as ambitions of positioning Sweden as an environmental frontrunner through developing and exporting smart energy technology, which is not the case in Västerås. As such elements are drawn into assembling practices, and authorization processes take on the modality of consensus, the political rationality is continuously re-constituted through experiments. The case of Västerås, however, illustrates that it is possible to work around the edges of the political rationality, and to use smart energy experiments to potentially subvert such conditions of possibility. Perhaps it could even be argued that the Västerås experiment constitutes a heterotopia, embodying a different political rationality which challenges the contemporary dominant one, although this would require more thorough empirical analysis as the experiment unfolds in practice. Considering the different publicity profiles of the three experiments, this might tell us something about the constraints imposed by the political rationality, which at least partly shape different experiments, especially the ability to gain traction. The case of Västerås underlines the strength of the political rationality - despite attempts at subversion, the construction of a DC nanogrid proved impossible in the end. The three experiments further illustrate the tension between uncertain testing and marketing imposed by the political rationality, and especially how marketing tends to take precedence and thus obstruct uncertain testing.

Still, despite the experiments in NDS and Hyllie being more aligned with the broader political rationality than Västerås, the analysis has shown how all three illustrate that it is possible to experiment with smart energy differently, thus showing how environmental governance can be accomplished in different ways through experiments. Consequently, there is a range of options when setting up experiments. Further, the case of Västerås allows for a deeper questioning of seemingly dominant modes of experimentation. Nature, however we wish to conceptualize this complicated notion, is rather distant in both Smart Energy City and 
Hyllie. ${ }^{890}$ When the environmental condition is explicitly discussed, it is mainly dressed in techno-economic terms as something to improve, i.e. as something pliable. ${ }^{891}$ There are many discussions on bending demand curves and optimizing energy flows, although the material aspects of environmental issues such as resource and material flows are rarely part of the problematization that is reconfigured through processes of accomplishing governance, nor does reduced energy use seem to have a place in smart energy experimentation. Rather, the cases of Smart Energy City and Hyllie serve to foreground knowledge claims which consolidate assumptions that are taken for granted in ecomodern policy programs, whilst filtering out political questions such as the sustainability of waste incineration, or the consumption and transportation practices of the upper middle class - in other words of the desirability of different possible energy futures. The case of Västerås is a clear exception, as environmental impacts of construction are explicitly problematized and considered, in tandem with the provision of affordable housing, urban gardening and plantation, and ownership structures and the scale of energy systems.

The three experiments thus arrange environmental governance in specific ways, with specific power effects, regardless of the intentions of different actors. The field of intervention for environmental governance is constituted in the specific ways described throughout the chapter, with the risk of crowding out other, possibly greener modes of smart energy experimentation.

\footnotetext{
${ }^{890}$ For studies where notions of nature are succinctly unpacked, see e.g. Andersson 2020. Artificial Earth: On the Genealogy of Planetary Technicity. Dissertation. Linköping: Linköping University; Warde etl. 2018. The environment.

${ }^{891}$ Cf. Pellizzoni 2015. Ontological Politics in a Disposable World.
} 


\section{Gotland as an energy pilot region: becoming an environmental frontrunner through experimentation?}

This chapter focuses on the case of the governmental initiative whereby Gotland has been designated a pilot region for a 100\% renewable energy system and achieving environmental policy goals before the rest of Sweden, against the backdrop of the preceding smart energy experiment Smart Grid Gotland (SGG). The Energy Agency was appointed by the government to be responsible for facilitating the initiative in 2017. The energy pilot initiative is of a different character than SGG, since it is not spatially delineated as a confined smart energy experiment, rather encompassing an ecology of interventions on Gotland that extend beyond but also include smart energy. Despite the governmental energy pilot initiative's significantly broader scope compared with Smart Grid Gotland, it includes a similar emphasis on smart energy and concepts connected to experimentation such as piloting, testing, and upscaling, leading the way for the rest of Sweden to follow. ${ }^{892}$

It was explicitly stated in the government's directive to the Energy Agency that experiences and knowledge from previous experiments were to be incorporated into the energy pilot initiative. Importantly, the energy pilot is not as clearly temporally delineated as SGG was no material construction has commenced yet, but networks of actors are being assembled, plans are being drawn up, and pre-studies are being published. It therefore presents a compelling opportunity to investigate an attempt to instigate transformative change by "moving beyond" experiments as it unfolds, and what this implies in terms of how smart energy experimentation arranges environmental governance. The interrelation between SGG and the energy pilot initiative constitutes a prominent avenue to explore to this end, in order to investigate how SGG comes into play in the energy pilot initiative. Empirically, the chapter is based on interviews with key actors involved in the energy pilot initiative and Smart Grid Gotland, such as representatives of private companies, employees at the public administration on Gotland, and governmental agencies, as well as central documents pertaining to the two initiatives. The analysis is complemented by observations from public hearings, workshops, presentations, and similar events on the island.

\footnotetext{
${ }^{892}$ Regeringskansliet 2017. Smart och förnybart energisystem på Gotland. Regeringsbeslut. Miljö- och energidepartementet: Stockholm; Regeringskansliet 2018. Uppdrag till Statens energimyndighet att möjliggöra att Gotland blir en pilot för ett hållbart energisystem. Regeringsbeslut. Miljö- och energidepartementet: Stockholm.
} 
While the last chapter aimed to contrast how experimentation arranged environmental governance across three urban experiments, this chapter follows slightly different analytical aims. Rather than focusing on the individual endeavors for comparison, the primary analytical aim is to dig deeper into the large energy pilot initiative, which can be conceptualized as an ecology of interventions, to study unfolding processes of attempting to instigate transformative change beyond an individual experiment. As mentioned, analyzing how Smart Grid Gotland comes into play in the energy pilot initiative provides a relevant empirical avenue to explore for this purpose. By highlighting interlinkages between SGG and the energy pilot initiative, it is possible to gain a deeper understanding of both how experimentation arranges environmental governance and how attempts to instigate far-reaching change beyond individual experiments play out, which can reveal what scaling up appears to entail both as a notion and in practice, for instance. The chapter elucidates how relations are continuously assembled as the meaning and range of the governmental initiative are opened up and closed down, highlighting dynamics between the broader political rationality and aspirations and practices on the island of Gotland.

\section{Prelude to making Gotland an energy pilot region: Smart Grid Gotland}

Smart Grid Gotland was a smart energy experiment on the island between 2012 and 2017, and like the experiments in Norra Djurgårdsstaden and Hyllie it was partly funded by the Energy Agency. ${ }^{893}$ The actors involved were Vattenfall, ABB, the regional grid operator (DSO) Gotlands Energi AB (GEAB), Schneider Electric, and the Swedish transmission system operator (TSO) Svenska Kraftnät (SvK).

This section is grounded in rich empirical work, but it will be kept brief. ${ }^{894}$ Considering the primary analytical aims just outlined, it is relevant to include a shorter section outlining Smart Grid Gotland to lay the groundwork for the main analytical thrust of the chapter. This is motivated for two reasons. First, since it adds a layer of understanding the interrelation between SGG and the energy pilot initiative, elucidating central aspects related to which elements are subsequently drawn into the energy pilot initiative and which actors become central, for example. Second, it provides some background and a deeper understanding of the local context in which the energy pilot initiative is currently playing out, thus adding nuance to the palette for painting the analytical picture of the initiative. Additionally, including such

\footnotetext{
${ }^{893}$ As mentioned, these three experiments are regularly referred to as Sweden's flagship projects on smart energy.

${ }^{894}$ For an in-depth study of the user-oriented part of SGG, Smart Customer Gotland, see Wallsten 2017. Assembling the Smart Grid. Wallsten closely followed Smart Customer Gotland as it unfolded, examining subtle processes of exclusion as households were enrolled as principal actors for developing a smart energy system in SGG. Wallsten's study provides an important source of knowledge, informing my analysis especially in terms of a deepened understanding of SGG.
} 
a section provides an opportunity to contrast the three so-called flagship projects, to investigate whether environmental governance is accomplished differently across these cases. To be clear, then, this section on SGG should not be read as a separate case study in the same vein as Norra Djurgårdsstaden or the energy pilot initiative, but rather as an important background allowing for a nuanced analysis of the energy pilot. It will therefore be structured around some important analytical points that add to the analysis of the energy pilot, rather than being structured along the main analytical concepts as in the previous chapter.

To understand SGG and the energy pilot initiative, it is relevant to begin by briefly outlining the situation on Gotland. The electricity grid on the island is connected to the mainland largescale transmission grid via two HVDC cables. In 2009, it was decided that a new transmission cable would be constructed, financed by Svenska Kraftnät. According to Mikael Odenberg, the then Director General of SvK, this was justified since it was considered a substantial infrastructural endeavor interconnected with national environmental and energy policy goals of expanding renewable electricity production. ${ }^{895}$ Energy and environmental policy on Gotland was largely based on such a new transmission cable for several reasons, for example since the goal of substantially increasing local renewable electricity production was considered to necessitate a new link to the large-scale transmission grid. The two existing cables are considered to eventually be approaching their end of life, while not being constructed for two way transmission, thus a new link is argued to be necessary in order to export excess electricity production to the transmission grid and thus avoid capacity issues in the grid on Gotland. It was against this background that SGG came about, partly as an attempt to investigate how additional wind power could be integrated into the regional power grid without risking hitting capacity limits. ${ }^{896}$ Essentially, the main goal of SGG was to modernize the existing power grid on Gotland through the use of ICT, marking a difference compared to the new city districts of Hyllie and Norra Djurgårdsstaden. It consisted of three overarching sub-projects, each corresponding to a specific goal of the experiment. First, to enable increased wind power capacity in the grid through ICT applications, as mentioned; second, to increase power quality through the use of ICT equipment in the grid; and third, encouraging private households to load-shift through automated and active steering of electricity use. ${ }^{897}$

However, in early summer 2017, SvK announced after an internal economic analysis that the plans to construct the new transmission cable were being abandoned. This caused strong reactions on Gotland, with politicians and actors within the energy sector expressing

895 Widegren 2017. Politikerna tar strid för elkabel. SVT Nyheter 2017-06-17. https: / / www.svt.se/nyheter/lokalt/ost/politikerna-tar-strid-for-elkabel [2019-08-29].

${ }^{896}$ Cf. Wallsten 2017. Assembling the Smart Grid.

${ }^{897}$ Gustavsson \& Wedberg 2017. Smart Grid Gotland - slutrapport. Eskilstuna: Energimyndigheten. 
frustration and concern for the future of the island. ${ }^{898}$ This underscores how while SGG was performed against the backdrop of certain capacity limitations in the grid, because of the technical limitations of the two HVDC transmission cables, the energy pilot initiative came about in relation to a more pressing situation. During the lifespan of SGG, SvK was still planning to construct a new transmission cable connecting the island's regional grid to the national large-scale transmission grid. As of the inception of the energy pilot initiative, these plans are up in the air, which explains why many Gotlanders feel that there is more at stake in the energy pilot initiative.

Before delving deeper into the case of the energy pilot itself, let us take a look at SGG to lay the groundwork for such an analysis.

\section{Technology development, environmental benefits, and place- branding through smart energy experimentation}

From a first glance, it is already clear that Smart Grid Gotland was conceived of, planned, and executed in different circumstances than Norra Djurgårdsstaden and Hyllie. Norra Djurgårdsstaden and Hyllie are new city districts in two of Sweden's main urban hubs, whereas SGG intended to interlace an already existing grid with ICT in primarily rural settings on an island. Across policy documents and interviews with employees of the public administration on Gotland working with environmental issues, several different goals of experiments are expressed. In policy documents, a generally positive outlook to locating experiments such as pilot and demonstration projects on Gotland is articulated. ${ }^{899}$ It is expressed in the Region's environmental program and a document called Vision Gotland 2025, for instance, that an overarching goal is for Gotland to become a world-leading island region, leading the way toward ecological sustainability. ${ }^{900}$ In connection with this goal, it is stated that there are several renewable energy projects at the forefront on the island, which is described as a springboard to an ecologically sustainable society. ${ }^{901}$ Thus, experiments are mobilized as catalysts for achieving environmental goals, similarly to national policy, alongside other initiatives and policy instruments.

This is further echoed in other policy documents. In the Region's energy plan, working toward the establishment of more renewable energy pilot projects on Gotland is specifically expressed

\footnotetext{
${ }^{898}$ See e.g. Widegren 2019. Gotland ger inte upp kampen för en ny elkabel till fastlandet. SVT Nyheter 2019-07-03. https://www.svt.se/nyheter/lokalt/ost/gotland-ger-inte-upp-kampen-for-en-ny-elkabel [2019-08-26].

${ }^{899}$ Länsstyrelsen Gotland 2012. Klimat- och energimål för Gotland 2012-2020. Gotland: Visby; Region Gotland 2014. Energi 2020: energiplan för Gotland. Gotland: Visby; Länsstyrelsen Gotland 2019. Tillsammans mot 2030: En energi- och klimatstrategi för Gotland. Gotland: Visby. Dnr: 485-2019.

${ }^{900}$ Region Gotland 2015. Miljöprogram. Gotland: Visby; Region Gotland 2008. Vision Gotland 2025: Regionalt utvecklingsprogram för Gotland - RUP. Gotland: Visby.

${ }^{901}$ Region Gotland 2015. Miljöprogram. p. 9.
} 
as a goal. ${ }^{902}$ The County Administrative Board recently revised its energy and climate strategy for Gotland, and in the new strategy experiments (or "energy and climate projects", which is the term used) are assigned key functions for achieving environmental policy goals. It is stated that for Gotland to be a frontrunner, research and innovation projects are necessary to develop, demonstrate, and commercialize new technology, whilst projects closely tied to the local community are described as equally necessary. ${ }^{903}$ At first glance, tying such environmental frontrunner ambitions to experiments does not seem particularly different to Norra Djurgårdsstaden or Hyllie. However, as we will soon see, this is not a matter of place-branding in the vein of entrepreneurial urbanism - there are different dynamics at play on Gotland. We can already see how the socio-technical electricity grid infrastructure creates a certain precarity on Gotland, manifested in the fraying connection between the regional grid and the national large-scale transmission grid. Further, Gotland is characterized as a rural region in project documents connected to SGG, while the region's public administration consists of the single administrative unit of Region Gotland, rather than being split between a municipality and a region as is the case across Sweden, underlining the (economic) conditions of the region. Additionally, Gotland is regularly described as a region fraught with depopulation. ${ }^{904}$

The generally favorable outlook on experiments makes sense when interpreted against this backdrop, i.e. it constitutes a way of place-branding, of telling a positive story about Gotland as an innovative region, submitting to the "innovation imperative". ${ }^{905}$ This does not seem primarily to be a matter of tapping into and exploiting neoliberalization processes, but rather an attempt at conforming with such logics to specific local ends. This highlights how the broader political rationality institutes certain truth claims and assumptions, i.e. conditions of possibility, that seem difficult to entirely escape, although these trigger very different outcomes in different local settings. This favorable outlook on experiments is echoed in interviews with employees across the public administration on Gotland, specifically expressed in relation to Smart Grid Gotland. An interviewee stated that pilot projects:

\footnotetext{
${ }^{902}$ Region Gotland 2014. Energi 2020. p. 13.

${ }^{903}$ Länsstyrelsen Gotland 2019. Tillsammans mot 2030. p. 12.

${ }^{904}$ Whether or not depopulation must always be a problem can certainly be discussed, see e.g. Ringel 2018. Back to the Postindustrial Future - An Ethnography of Germany's Fastest-Shrinking City. Berghahn Books. Nonetheless, depopulation creates economic issues in terms of a shrinking tax base, and underlines a situation that can certainly be described as precarious in some ways.

905 On the innovation imperative, see Pfotenhauer, Juhl, and Aarden 2019. Challenging the "deficit model” of innovation: Framing policy issues under the innovation imperative. Research Policy, 48(4). On a very basic level, the "innovation imperative" refers to how innovation as a notion has become all the more ubiquitous as a policy response to widely different social issues, mirroring the increased importance of experimentation as environmental governance strategy. This tends to reframe heterogeneous issues into problems of an innovation deficit, i.e. a lack of innovation, implying a pro-innovation bias that risks shrouding politics and marginalizing other rationales, while placing undue power with technical innovation experts. Cf. also Godin \& Vinck (eds.) 2017. Critical studies of innovation: alternative approaches to the proinnovation bias. Cheltenham, UK: Edward Elgar Publishing.
} 
[...] are supposed to show what it is possible to do. Then they are supposed to, more slowly, develop products that can become commercially viable. [...] They're a step in the development. ${ }^{906}$

This quotation highlights notions of experimentation which are widely shared across the material, primarily as a matter of product development and of showcasing what it is possible to do. The notion that they are a step in a technological development process finds resonance across the material, for example as discussed in previous chapters in relation to the so-called technology readiness level (TRL) scale. The emphasis on product development underscores a prevalent delineation of responsibility, where energy experiments are mainly made into a matter for private companies to develop products, similarly to Norra Djurgårdsstaden. Further, the interviewed environmental expert at the Region stated - with reference to Smart Grid Gotland - that the Region took a positive view of SGG, as it constituted an example of the type of pilot project that the Region would like to see more of on the island. The interviewee described SGG as a technology development project, and thus not very relevant for the Region other than in a general sense. It was stated that:

[...] we'll see if the Smart Grid Gotland pilot project will give us access to technology or the possibility to choose technical solutions which were developed thanks to the project, but during the duration of the project it didn't really matter that it existed, other than as I said previously that it's

very good to have pilot projects taking place here which draw positive attention to the energy system on Gotland. ${ }^{907}$

This echoes how employees at the City of Stockholm described Smart Energy City as one of many innovative projects ongoing in Norra Djurgårdsstaden, but not really a question for the City. There seemed to have been a clear delineation between the public administration that was not involved in SGG and the consortium engaged in the experiment, similarly to NDS. The interviewee also stated that there was publicity about SGG in the early stages of the experiment, but that this decreased during the course of the experiment, and additionally that SGG did not really have a "public part". ${ }^{908}$ The goal of SGG, from the environmental expert's perspective, was essentially not tied up with the Region:

What I saw of Smart Grid Gotland was really that the power grid on Gotland was an excellent location to investigate the possibilities of different smart grid technologies which could then become a commercial product for the private companies involved. ${ }^{909}$

This underscores how the physical properties of the island, and especially the socio-technical power grid infrastructure, provided the raison d'être for SGG. ${ }^{910}$ A central goal of SGG was to facilitate increased integration of wind power by interlacing the current grid infrastructure

\footnotetext{
${ }^{906}$ Interview EnvE Region Gotland (environmental expert).

${ }^{907}$ Ibid.

${ }^{908}$ Ibid.

${ }^{909}$ Ibid.

${ }^{910}$ See also Gustavsson \& Wedberg 2017. Smart Grid Gotland - slutrapport; cf. Wallsten 2017. Assembling the smart grid.
} 
with ICT, actualized through the regional grid's strained condition because of the state of the connection to the large-scale mainland transmission grid. Thus, the physical characteristics of the island, such as the prime conditions for wind power and the connection to the mainland grid, constituted important elements of SGG, highlighting how experimentation on the island is loaded with both hope and precarity. The clear separation of SGG from the public administration underscores how the experiment contributed to positioning private companies as principal agents through their techno-economic expertise and their ability to develop new products to interlace the energy system with ICT. This is also reflected in the energy pilot initiative to some extent, as we will see.

Similar sentiments were expressed among energy and environmental experts across the Region and the County Administrative Board. An energy expert at Region Gotland stated that SGG was too narrow for the Region, since the Region does not own the electricity grid, and that the results of SGG were not very widely reported or discussed on the island. ${ }^{911}$ An energy expert at the County Administrative Board expressed similar sentiments, i.e. that the results of SGG were not widely reported by the consortium, or publicized in the media. ${ }^{912}$ Both interviewees also expressed themselves in similar terms with regard to the overarching goals of carrying out experiments, in relation to environmental ambitions. Both interviewees described how experiments were vital for learning, and that conducting experiments on a small scale was vital:

I think it [carrying out experiments] is super important, because otherwise where would you start? [...] there needs to be pilot projects because you can't start building on a large scale immediately, it has to happen in stages and start somewhere. ${ }^{913}$

The energy expert at the County Administrative Board said that:

I think they [experiments] are important, mainly to test what actually works in reality and you don't know how something will be perceived. You will encounter situations that, okay this was the wrong way to go, and then it's important that you haven't scaled it up yet. Rather you test it, and in the cases where it is perceived as positive and what works gets spread, so I see that as an important part, and also this story about the positive examples, that can be spread around the world [...] If you hear that it has worked somewhere else you dare to think bigger, I think that's important. ${ }^{914}$

These quotations reflect how experiments were ascribed the ability to navigate uncertain terrain, to show what it is possible to do, among experts across governmental institutions and policy networks. Specifically, experiments are assigned the role of initiators of stepwise change, reminiscent of notions of change which flow as an undercurrent through governance arrangements instituted by experimentation. The importance afforded to spreading positive examples is also relevant, considered in the light of place-branding Gotland to manage

\footnotetext{
${ }^{911}$ Interview EE (energy expert) Region Gotland.

${ }^{912}$ Interview EE (energy expert) Gotland County Administrative Board.

${ }^{913}$ Interview EE Region Gotland.

${ }^{914}$ Interview EE Gotland County Administrative Board.
} 
different dynamics of precarity highlighted above. Such notions of experiments as part of sequential socio-technical change seem to be prevalent among employees in the public administration on Gotland. ${ }^{915}$ Similar abilities were afforded to the urban experiments of the previous chapter, underlining how the political rationality underpinning smart energy experimentation conditions different experiments in similar ways, instituting political technologies such as the TRL scale which embodies assumptions central for the political rationality.

As the quotations and the policy documents also illustrate, there seems to be a connection between experimentation and the articulation of Gotland as an environmental frontrunner, similarly to Hyllie and NDS, since experiments are afforded a central role in realizing such frontrunner ambitions in these places, as evidenced by the Region's goal of ever more experiments on Gotland. An energy expert at the County Administrative Board stated that:

The picture I have is that to get a large-scale transition, it has to be viewed as positive, you have to want to do it. And also we [Gotland] are supposed to be frontrunners for others, so the results from pilot projects have to be, for upscaling, viewed as positive [...] when you do it on a large scale, it has to be viewed as positive. Otherwise you can't be a frontrunner of anything. ${ }^{916}$

As the quotation illustrates, experiments are thus assigned the role of marketing, or placebranding, Gotland as an environmental frontrunner. Considering how interviewees across the public administration stated that the subject SGG had turned remarkably quiet, even after its completion when results might be expected to reach such actors, perhaps learning from experiments was reserved for a few actors in practice. One might glean as much from the quotation from the environmental expert at the Region, who stated that learning from SGG was a task for the private companies involved.

This section has shown how local dynamics on Gotland were mirrored in the setup of Smart Grid Gotland, dynamics that will be important for understanding the energy pilot initiative in a nuanced way. Further, it has illuminated how SGG only involved the public administration on Gotland to a minor extent.

\section{Frictions of SGG: experimentation as allure and danger}

Amid the generally positive outlook on experimentation expressed in policy documents and among interviewees on Gotland, some frictions related to notions of experimentation appeared during fieldwork, constituting a flipside to the coin of experimentation. Such frictions reveal further aspects that are important for interpreting the energy pilot initiative in a nuanced way.

\footnotetext{
${ }^{915}$ As discussed previously, this conceptualization of experiments is also widespread within academia, e.g. in literature on sustainability transitions such as the multi-level perspective and strategic niche management.

${ }^{916}$ Interview EE Gotland County Administrative Board.
} 
One such tension appeared in relation to testing through experiments. An energy expert at Region Gotland, for instance, stated that:

I think that sometimes Gotland is too quick off the mark and sometimes too slow off the mark. Maybe you shouldn't be first every time, because it can easily become expensive and you might make many mistakes, but on the other hand you might get [financial] support when you are first. And Gotland is a great place for testing. ${ }^{917}$

The interviewee highlights how it can be beneficial to have experiments take place on Gotland, although risks are also highlighted. There is a danger with experimenting, since it might lead to unnecessary costs and mistakes. The interviewee further articulated that the energy pilot initiative needs to become broader and bigger than SGG, and that it must incite action to a greater extent than SGG, which was described as being too narrow. ${ }^{918}$ A grid manager at GEAB reasoned in a similar way, explaining how:

It's more about how we can solve this everyday [situation] facing many grid operators. This research and development stuff is a bit further away. ${ }^{919}$

The grid manager further underscored how there were real issues connected to capacity in the regional grid on Gotland, which meant that GEAB had been working in reality for several years with smart grids and not only on the research level as in SGG. The delineation between ordinary operations and experiments such as SGG, as expressed by the grid manager, is further reinforced by a project manager at Vattenfall who stated that KTH was involved in SGG as an adjunct part to create a connection to the research community, implicitly described as a necessity, which was also the reason for talking to me. ${ }^{920}$ Drawing science as a necessary element into SGG resembles how science was frequently drawn upon as intervention was assembled in Smart Energy City in Norra Djurgårdsstaden. This also reveals part of the knowledge politics of smart energy experiments, i.e. that explicit connections to the research community are considered necessary to substantiate knowledge claims made through experiments by appealing to science as an authoritative source of knowledge.

Related to such delineations of SGG, an environmental expert at Region Gotland stated that the experiment was much larger than "a lab bench". ${ }^{921}$ This resonates with how interviewees at GEAB problematized the extent of SGG, stating that the size of SGG was problematic since a large organization had to be maintained and kept in line for a long time, and this was described as very difficult for all the parties involved. ${ }^{922}$ A grid manager at GEAB stated that having so many different parties involved in the experiment created difficulties and uncertainties, since there were very large organizations with separate interests involved, and

\footnotetext{
${ }^{917}$ Interview EE Region Gotland.

918 Ibid.

${ }^{919}$ Interview GM GEAB.

${ }^{920}$ Interview PM2 Vattenfall.

${ }^{921}$ Interview EnvE Region Gotland.

${ }^{922}$ Interview CEO GEAB; Interview GM GEAB.
} 
some actors were very keen on being able to develop and test their own products which created difficulties for GEAB on the receiving end. ${ }^{923}$ Further, the grid manager explained how uncertainties arose related to whether or not specific technology tests were to be carried out, which was problematic for GEAB who operates the grid. ${ }^{924}$ These actor relations, and the tensions infused among the constellation by experimentation, are also an important piece of the puzzle of sensitizing the analysis of the energy pilot region initiative.

Such uncertainties created through SGG appear counterintuitive, since experiments were often ascribed the ability to dissolve uncertainty among experts at the national level, as well as on Gotland. However, as we saw in previous chapters, experiments can create as much uncertainty as they dissolve. The fissures related to experimentation as testing which appeared in relation to SGG reflect how experimentation sometimes has connotations of uncertainty, and in some cases even danger, as exemplified previously when some actors were reluctant to even use the word "experiment". Through the case of SGG, it becomes clear that concerns connected to regional politics, which have been touched on previously, and the socio-technical grid infrastructure shaped notions of experimentation as testing - both as something promising which can benefit Gotland, and as an endeavor fraught with risks, which rather highlights the precarity resulting from capacity limitations in the grid, for instance. As we will soon see, such tensions coupled to notions of testing through experimentation were amplified and expressed more forcefully in relation to the energy pilot initiative.

\section{Initiating change through experimentation: knowledge politics of testing and learning}

Several of the actors involved in SGG agreed that experiments are necessary to achieve energy system change; it was often articulated that it is a conservative sector and there are no real economic incentives to change. This view of experimentation was widespread among interviewees across the different experiments and among experts at the national level, i.e. that such endeavors are necessary to initiate stepwise change processes. There is an obvious clash between how some experts at the national level expressed that experiments are supposed to test contemporary legislation and provide input on whether regulations need to be changed, and an emphasis among certain actors within SGG who expressed that for experiments to have value they need to be allowed exceptions from certain regulations to test new technologies. ${ }^{925}$ This is reminiscent of the ongoing discussion on policy labs and regulatory sandboxes among experts across governmental institutions and policy networks, as touched upon previously. Clearly, testing new technology and user behavior was articulated among interviewees as a central goal of Smart Grid Gotland.

\footnotetext{
${ }^{923}$ Interview GM GEAB.

${ }^{924}$ Ibid.

${ }^{925}$ E.g. Interview PM2 Vattenfall; Interview PM1 Vattenfall; Interview PM ABB.
} 
In project documents, several additional problematics which elucidate local dynamics are invoked, serving to delineate and formulate the problem at hand as manageable, legitimizing and providing the rationale for testing new technology and user behavior in Smart Grid Gotland. SGG, regularly labeled the world's most modern grid in documents and on websites, is presented as an energy transformation endeavor, with explicit reference to both EU and Swedish environmental policy goals, for example stating that new technological solutions which contribute to an intelligent grid are required in order to enable increased electricity production from wind power. ${ }^{926}$ It is emphasized that this has acute relevance on Gotland; since transmission capacity to the power grid on the mainland is limited, new technology is necessary to increase production of wind power generated electricity on the island without jeopardizing power quality and potentially causing blackouts. ${ }^{927}$ As stated above, this highlights how the material characteristics of the electricity grid and the island of Gotland are drawn upon in a specific way by the consortium in SGG. Further, it is stated in the final project report that the experiment contributes relevant knowledge about how the large-scale electricity grid of the future can be developed most efficiently within the framework of existing market models. ${ }^{928}$ This formulation contains specific ideas about the constitution of the future smart energy system, seemingly in line with the contemporary marketized electricity system and the large-scale grid, indicating how SGG entailed drawing upon particular problematics and thus constituting a specific, manageable problem to be solved, in line with the broader political rationality underpinning smart energy experimentation and reinforcing the historical constitution of the Swedish electricity system and power relations between actors in this system. ${ }^{929}$

Further, it is stated that experiments such as SGG can serve to postpone investments in physical grid infrastructure, echoing experts at the national level; since the electricity system is a large socio-technical system, it is more economically viable to gradually change its constitution. ${ }^{930}$ Smart Grid Gotland is described as a step on the road toward full-scale implementation of the smart grid in Sweden. ${ }^{931}$ This serves to legitimize the specific approach to experimentation taken in SGG, potentially narrowing down the field of intervention by consolidating a particular configuration as the smart energy system of the future. There is also an emphasis on differentiating the smart grid from the old grid in project documents, visible e.g. through emphasizing modernization and upgrading the grid using ICT, and through reference to smart grid technology as "a natural technological development in line with

\footnotetext{
${ }^{926}$ Gustavsson \& Wedberg 2017. Smart Grid Gotland - slutrapport. p. 5.

${ }^{927}$ Ibid.

${ }^{928}$ Ibid. p. 7.

${ }^{929}$ This becomes visible e.g. when interviewees express that SGG was a "pure grid-owner project". Cf. Wallsten 2017. Assembling the Smart Grid. Wallsten shows how micro-producers of renewable electricity, i.e. local civil society actors, were excluded from SGG.

${ }^{930}$ Gustavsson \& Wedberg 2017. Smart Grid Gotland - slutrapport.

${ }^{931}$ Ibid. p. 30.
} 
television and telephones". ${ }^{932}$ It is explicitly stated that this modernization of the power grid will contribute to increased system efficiency, customer empowerment, enhanced safety, and productivity increases. ${ }^{933}$ Replication and upscaling are also emphasized as key goals of the experiment. ${ }^{934}$ The final project report thus illustrates how Smart Grid Gotland delineated a field of intervention, making a problem intelligible in a specific way. This was done, for example, by latching on to different problematics with reference to both EU and Swedish environmental policy goals, as well as local circumstances on Gotland. It was stated that to construct a smart energy system for the future, integration of renewable energy - mainly wind power generated electricity - into an existing large-scale energy system infrastructure must be achieved, and this can be done by developing new products and using ICT in the grid. Such an order of things mirrors the broader political rationality, arranging governance in line with the export orientation of smart energy policy.

Some of the goals of SGG expressed in documents were echoed in interviews. However, several aspects which complicated the picture described in project documents also appeared. Through such instances, complexities of conducting a smart energy experiment can be glimpsed, as can the politics of such endeavors. This can reveal more about the socio-material webs of relations where the energy pilot initiative would eventually end up, allowing for richer analysis. For instance, it is quite clear that marketing is often inscribed as a vital aspect of smart energy experiments, reflected among experts at the national level as well as in Norra Djurgårdsstaden and Hyllie, with ambitions of becoming an environmental frontrunner echoing across these spaces of governance. As shown above, this was also reflected on Gotland, albeit probably for different reasons. Norra Djurgårdsstaden and Hyllie are new city districts in two of Sweden's three largest urban areas, whilst Gotland is an island that is often labeled as rural and faces issues of depopulation. An employee at GEAB, for instance, stated that a central issue for the company was to hire new personnel with the right competence and an interest in living on the island. ${ }^{935}$ This might indicate how the environmental frontrunner ambitions are interconnected with the Region's goal of more experiments on the island, i.e. as a measure interlinked with regional politics. It was quite clear across the interviews that the consortium involved in Smart Grid Gotland was also keen on marketing SGG as a cutting-edge experiment. ${ }^{936}$

These reciprocal goals of marketing, or place-branding, Gotland as an innovative region and marketing the private companies participating in SGG also created problems, however. As a project manager at Vattenfall remarked:

\footnotetext{
932 Ibid. p. 7.

933 Ibid. p. 30.

${ }^{934}$ Ibid. pp. 26-27.

${ }^{935}$ Interview GM GEAB (grid manager). GEAB is the local energy company on Gotland, 25\% owned by Region Gotland and 75\% owned by Vattenfall.

${ }^{936}$ E.g. Interview PM ABB; Interview PM Vattenfall 2; cf. Wallsten 2017. Assembling the Smart Grid.
} 
I joke sometimes and say that it [the pre-study for SGG] is written high above the clouds. It is very forward-looking so to speak, had high ambitions $[\ldots] \cdot{ }^{937}$

The project manager stated that the pre-study was perhaps too ambitious, similarly to how a project manager at $\mathrm{ABB}$ remarked that the pre-study for the smart energy experiment in Norra Djurgårdsstaden was unrealistic. The project manager at Vattenfall reflexively stated further that:

[...] and there we probably need to look at ourselves in the mirror a bit because, as I said, we went in quite hard from the start and then we ran into trouble with funding, so some things were excluded [from the experiment] and interest disappeared for some, I would guess. Or I know it did. ${ }^{938}$

Here, marketing as a central goal of experimentation is essentially problematized. It is stated that since the consortium was quite bullish in its presentation of SGG from the very beginning, which it might have felt compelled to be, as soon as the consortium ran into trouble interest completely cooled off among many previously interested parties. This, again, poses the question of what the significant marketing emphasis does to smart energy experimentation, particularly in terms of what can actually be tested and learnt through experiments. As we saw above, a tension between experimentation for learning and an emphasis on experiments needing to be perceived as successful to work as positive stories appeared in an interview with an employee at the public administration on Gotland. This further underscores how there seems to be a knowledge politics of smart energy experiments, interconnected with the broader political rationality and the emphasis on making Sweden an environmental frontrunner by developing and exporting green energy technology. The knowledge that becomes valuable in these settings appears to be proprietary to a significant extent, and to be packaged in order to spread positive stories of successful experiments where private companies have managed to develop new technology. As we saw in previous chapters, this seems to condition what is actually learnt from experiments, and who learns.

Further reflecting the knowledge politics of SGG, an interviewee stated that his involvement in the experiment emanated from his knowledge of the research funding system and his prior experience of writing successful research applications. It was stated that he had innate knowledge of the difficulties and hurdles of writing applications, and of running that type of project. This illustrates, as mentioned in previous chapters, that carrying out smart energy experiments largely seems to be skewed toward a select few large, resourceful actors with organizational infrastructures adapted for attracting research funding, including extensive

\footnotetext{
${ }^{937}$ Interview PM2 Vattenfall. The Swedish metaphor used in the quotation is not easily translatable. Perhaps the closest translation would be "written with the head up in the clouds", as in high-flying and unrealistic, although this would imply a negative connotation that I wish to avoid ascribing to the consortium. Therefore I went with "high above the clouds" to capture how the interviewee described the pre-study as unrealistic, while avoiding such negative connotations. ${ }^{938}$ Ibid.
} 
knowledge of how the research funding system is set up and works in practice, as well as links to policy networks, which conducting experiments can further facilitate. This seems to perpetuate practices of smart energy experimentation, consolidating a particular order of things where knowledge primarily stays within the bounds of a few resourceful actors. Such an order, where particular knowledge claims are foregrounded, appears to be clearly conditioned by the broader political rationality, perpetuating an ecomodern environmental politics and contributing to processes of neoliberalization. It also highlights how experiments, when set up as in the case of Smart Grid Gotland, tend to consolidate historically sedimented power relations in the Swedish energy system. The point that learning from experiments seems in practice to be the reserve of a few actors is further echoed by a project manager at Vattenfall, who stated that:

I think it is representatives of the kind of private company which I did not describe just now, I mean Vattenfall, Ellevio, E.ON. Those who have a research department, those who have the possibility to sit and think about these types of ideas, those who can afford to have people working in a visionary way and with a future focus. They are interested in this. [...] I don't think you should believe that the Energy Agency is an agency where people are reading reports and learning. They are funding

this for the energy companies to learn, they distribute funds for competence to be built in the organizations who receive the funding. [...] I think that's how they see it as well, that competence needs to be built up within the private companies. ${ }^{939}$

This quotation illuminates that smart energy experimentation seems indeed to be skewed in favor of certain actors, and that knowledge generated in experiments might be considered mainly a matter for the private companies involved, primarily to learn about the development and implementation of new technology. As we saw in the previous chapter, there are even varying ideas within the Energy Agency about who should actually learn from smart energy experiments - overall, it is clear that actors have different ideas about who is supposed to learn from experiments, and also what is supposed to be learnt. In practice, experimentation appears to arrange governance which facilitates keeping knowledge within certain private firms. The analysis further illuminates how goals of testing risk being crowded out by goals of marketing in practice, a risk that is also detected among experts at the national level. In relation to who learns from experiments, an interviewee involved in SGG reflected that:

[...] no, we haven't [engaged with the public through SGG], there we got lost along the way I think, because a focus on the public has not existed apart from the customer test. And that is a problematic in this kind of project, what is official and what is not official, and in principle what is official and for the public's eyes is what we have reported to the Energy Agency, in principle. Then there are a number of reports that we consider internal to the project, and they are really only available to the parties [in the consortium]. And there is a problematic here. ${ }^{940}$

\footnotetext{
${ }^{939}$ Interview PM1 Vattenfall.

${ }^{940}$ Interview PM2 Vattenfall.
} 
The interviewee reflexively highlights a tension that we have seen across several smart energy experiments; when they are principally run by actors whose main interest is to sell products, boundaries are created between what is considered knowledge best kept within the participating organizations and what can be publicly released, facilitating proprietary knowledge generation. As will become evident in the analysis of the governmental initiative of making Gotland an energy pilot region, such knowledge politics are however also an accomplishment in the making, meaning that they can be challenged or circumvented.

Further elucidating knowledge politics instituted through SGG, interviewees from the SGG consortium exclusively describe the experiment as a pure technological development project, or as a pure grid-owner project, as was also evident among interviewees from the public administration on Gotland. ${ }^{941}$ The CEO of GEAB, for instance, explicitly stated that SGG did not really have much to do with energy transformation, but rather with how to make the current energy system as robust and effective as possible. This was described as important as well, but not really a matter of energy transformation. ${ }^{942}$ This designates specific actors as stakeholders and principal actors of governing the environment, while at the same time risking undermining the environmental ambitions of smart energy experimentation, since while SGG was defined as an energy transformation endeavor in project documents, the actors involved rather defined goals of product development, technology implementation, and marketing as central. Further, it could certainly be argued that reduced total energy use is necessary to initiate a meaningful transformation. ${ }^{943}$ However, it was explicitly stated that shifting loads over time to ensure grid stability was one of the central goals of SGG, including both decreasing and increasing electricity use according to weather patterns and system requirements to ensure system stability and balance. A project manager at Vattenfall explained how difficult it was to increase electricity use at given times, stating that the consortium had approached the cement producer Cementa, inviting them to use more electricity during specific hours. Increasing electricity use is not necessarily easily compatible with ecological concerns, even through renewable sources, since it tends to be intimately connected to increased resource use and environmental impact. ${ }^{944}$ It also actualizes specific types of knowledge generation practices, related to the development of sophisticated ICT equipment and grid optimization, foregrounding specific knowledge claims which confirm that improving the environmental condition is essentially a matter of developing new products to implement in the existing socio-technical grid infrastructure, as well as exporting such green energy

\footnotetext{
${ }^{941}$ Interview PM1 Vattenfall; Interview PM2 Vattenfall; Interview CEO GEAB; Interview GM GEAB; Interview PM ABB.

${ }^{942}$ Interview CEO GEAB.

${ }^{943}$ See e.g. Kallis 2018. Degrowth. Newcastle upon Tyne: Agenda Publishing; Dunlap 2019. Renewing Destruction.

${ }^{944}$ See e.g. Boyer 2019. Energopolitics; Schlosberg \& Coles 2016. The new environmentalism of everyday life; Krausman et al. 2018. From resource extraction to outflows of wastes and emissions; Hickel \& Kallis 2020. Is Green Growth Possible?
} 
technology. Smart energy experimentation is made into a matter of concern for incumbent energy companies rather than the public administration.

To summarize this section, both the public administration on Gotland and the private companies involved in the experiment described SGG as a commercial technology development project, despite it being mainly framed with reference to energy transformation and environmental concerns in project documents. Such delineations, expressed for example as SGG being termed a pure grid-owner project, elucidate how the experiment made environmental issues mainly an issue to be dealt with using techno-economic expertise. ${ }^{945} \mathrm{An}$ energy expert at the County Administrative Board stated that smart grid is an area which is technically advanced and difficult to understand for those who are not technical experts, reinforcing the notion that responsibility for executing and learning from the experiment rested firmly with the consortium. ${ }^{946}$ The interviewee also mentioned that it would be highly relevant to be informed of the results of SGG, which as mentioned had not occurred. This provides important insights into how smart energy experimentation had arranged environmental governance before the launch of the energy pilot initiative, and the micropolitics of such processes, especially knowledge politics. As the energy pilot initiative unfolds, such actor constellations, delineations, and positioning of actors become reconfigured although it is important to note that this was the local context where the initiative was launched, to analyze how such reconfigurations became possible.

\section{Confrontational critique and subtle politics of experiments}

Through the smart energy experiment in Västerås, a forceful critique of Sweden's market-led environmental politics in general and of the discursive constitution of smart energy in particular was articulated, as we saw in the previous chapter. Similar criticism surfaced in relation to Smart Grid Gotland. Highlighting such critique further elucidates the ground where the energy pilot initiative would come to land, especially in terms of explicating latent political energies on the island. The critique expressed on Gotland was less head-on, but essentially similar aspects to those criticized through the Västerås experiment were targeted. A project manager at Vattenfall expressed how policymakers seemed to want a change of the energy system, but from his perspective they were reluctant to change the regulations and simply hoped that change would occur almost by itself, similar to the criticism expressed by a project manager at the City of Stockholm in the previous chapter. ${ }^{947}$ This was echoed by a grid manager at GEAB, who stated that experiments are necessary, but larger political initiatives

\footnotetext{
${ }^{945}$ Cf. Wallsten 2017. Assembling the Smart Grid.

${ }^{946}$ Interview EE Gotland County Administrative Board.

${ }^{947}$ Interview PM1 Vattenfall.
} 
were also resolutely needed for the development of a smart energy system, in order to govern the market. ${ }^{948}$ Additionally, the CEO of GEAB said that:

[...] many people have expressed how demand flexibility is the solution to a lot of, or the market will solve our problems. And of course if you are imprinted with a neoliberal view then that's the answer to every question in this world. ${ }^{949}$

The interviewee was critical of what he perceived to be an over-enthusiasm about user flexibility on market terms, since SGG had shown that this was "the long, difficult road". 950 Taking such a critique further, a grid manager at GEAB stated that:

$[\ldots]$ then you release that part of smart grid development to market actors. That means that it must be entirely profitable the day it needs to be done. [...] Electricity and power grid, it's an important infrastructure, but it's dealt with on market terms. Which means that it gets stuck in between a bit, in this case. It's a bit like saying, well a freeway up to the north of Sweden, you'll have to pay for that yourselves. [...] I'm not sure that's how we should do it. ${ }^{951}$

The interviewee expressed stark skepticism about leaving the development of a smart energy system in the hands of market actors, with reference to infrastructural endeavors being too large and complex, as well as not necessarily being profitable in the short term, to be dealt with on market terms. The interviewee further expressed that it would be very difficult to imagine contemporary market mechanisms governing an energy system without nuclear power, which was described as being likely to be phased out. ${ }^{952}$ Criticism is thus expressed against faith in market-driven infrastructure change, similarly to the critique voiced in the case of Västerås. The grid manager stated that:

I don't think that Ringhals [a nuclear power plant] have paid for their four cables. ${ }^{953}$

Through these examples, politics of energy transformation are made explicit as the current mode of governing energy infrastructure change is critiqued. For instance, viewing households as flexibility resources in a smart energy system, and conducting conduct accordingly, is criticized and labeled as a neoliberal project, and as being very difficult. This underlines how the political rationality underpinning smart energy experimentation conditions experiments in particular ways, inducing market solutions and the development of green energy technology for export, and how tensions surface as intervention hits the ground. The outright critique expressed illustrates how experimentation could arrange environmental governance differently, which would actualize different programs of action and make different types of knowledge relevant. There is plenty of desire for this on the island of Gotland, which would

\footnotetext{
${ }^{948}$ Interview GM GEAB.

${ }^{949}$ Interview CEO GEAB.

${ }^{950}$ Ibid.

${ }^{951}$ Interview GM GEAB.

${ }^{952} \mathrm{Ibid}$.

${ }^{953}$ Ibid.
} 
come to be explicitly articulated in relation to the energy pilot initiative, as we will soon see. As we saw in the case of Västerås, it is possible to base smart energy experimentation on other logics and accomplishing governance differently through experimentation.

Besides these instances of contestation regarding the way in which the political rationality conditions how experiments constitute the field of intervention, where politics of energy transformation are laid bare and contested, examples of subtle politics of smart energy experimentation also appeared in relation to SGG. For instance, an energy expert at the County Administrative Board described SGG as a complex technical project, and called for the results to be translated through technical expertise to guide and inform the actions of the County Administrative Board and the Region in relation to smart energy. ${ }^{954}$ The interviewee stated that:

When I have been reading, I have thought a lot about how much individuals should have to do, I mean how active do individuals need to be. Perhaps the Region and the County Administrative Board have a role to play with information related to what's needed by the public, to engage and create understanding for that part [...] then maybe the County Administrative Board and the municipalities can come in and try to establish an information project about that for the public. So I would like to discuss this, for example, with those who have developed this [in SGG]. Is it stuff like this that we should go for [information to the general public], or should we go for smart grids which necessitate as little involvement from individuals as possible? Or is it really important to involve individuals? [...] someone who could translate this technical language, to show what does this mean? How should we proceed? ${ }^{95}$

The interviewee also reflected:

And is it necessary to have active users, or is it possible to make it smart without individuals having to do things consciously? It should be so easy to do the right thing that it becomes impossible, or difficult, to do the wrong thing. ${ }^{956}$

This highlights a subtle politics of accomplishing environmental governance through smart energy experiments, since certain actors are made knowledgeable and relevant to inform the public administration how to engage with smart energy, for example whether or not members of the public would need to be active, and - as we saw previously - what becoming active entails. It also underlines similarities across cases of experiments, since the emphasis on making it easy to do the right thing echoes across both Hyllie and Smart Energy City, as well as on Gotland. The energy expert at the County Administrative Board, however, proceeded to reflexively discuss the difficulties in aligning a bottom-up approach to energy transformation with a need for wide-ranging political initiatives, illustrating some difficulties with making specific actors responsible, although experiments such as SGG were made into an expert issue which could then inform the public administration's actions. Such a relation grants influence

\footnotetext{
${ }^{954}$ Interview EE Gotland County Administrative Board.

${ }_{955}$ Ibid.

${ }^{956}$ Ibid.
} 
to technical experts, and as we have seen this expertise often resides within large private companies, positioning such actors with the power to define and delineate specific problems to be solved through experiments. Consequently, there is a knowledge politics of experiments in terms of who gets to define issues and generate relevant knowledge, which shapes how experimentation arranges environmental governance.

Politics connected to specific delineations made through experiments also appeared in the case of SGG, including in terms of delineating participation in SGG with reference to technical prerequisites. For instance, a project manager stated that there are many different types of heating systems, and it would have been too complex and expensive to adapt certain interested people's homes to suit the setup of the experiment. Similarly, micro-producers of electricity and industries were also excluded from the experiment with reference to technical difficulties. In relation to such delineations made through $\mathrm{SGG}$, Wallsten has argued that this essentially constitutes exclusions that are important political acts; since SGG and other experiments contribute to shaping energy system change in specific directions, or along specific pathways, such exclusions might entail the exclusion of different system configurations and of certain types of political participation in energy transformation. ${ }^{957}$ This can be seen in frequent references to the need for control among the consortium. A project manager stated that:

$[\ldots]$ and then people will do it by themselves [install solar panels] anyway. And then we'll completely lose control, the only thing we can control then is our grid [...] the control apparatus is an incredibly relevant part, having control of the flows in the grid will be incredibly important in the energy transition as I see it. ${ }^{958}$

Here, it is expressed that a grid operator wants to keep control of the grid, whilst a widespread adoption of decentralized renewable electricity production by households is described as chaotic and implicitly undesirable. Such a desire for control on behalf of the grid operator illustrates how energy transformation is a political and essentially contested process, which experiments can serve to narrow down, as highlighted through the examples above.

These examples illustrate the tensions and politics of accomplishing environmental governance through experiments that arose in relation to SGG, shaping horizons of meaning, for example by telling specific stories about the future, and making certain types of knowledge relevant and valuable, which empowers certain actors at the expense of others. The political rationality underpinning smart energy experimentation caused such tensions, which becomes visible through these instances of critique, illuminating how experiments can alter or reinforce specific orchestrations of power through the arrangements produced in and beyond experiments. This section has highlighted how critical voices appeared in relation to SGG, as well as how alternative voices such as those of micro-producers of renewable energy, desiring

\footnotetext{
${ }^{957}$ See Wallsten 2017. Assembling the Smart Grid; cf. Burke \& Stephens 2016. Political power and renewable energy futures.

${ }^{958}$ Interview PM2 Vattenfall.
} 
a different energy system, had to be outmaneuvered and marginalized. These political energies came across as firmly nested in local pockets on Gotland - understanding this, as these examples have shown, is highly relevant for analyzing the energy pilot initiative. As we will see in the case of the energy pilot, processes of accomplishing environmental governance through experimentation continuously underwent such processes of opening up and closing down relations, horizons of meaning, and specific practices. ${ }^{959}$

\section{After SGG: knowledge circulations and dismantling}

One of the central constituent elements of SGG was the ambition to make the experiment scalable. When analyzing the empirical material, what upscaling actually means in practice came across as far from self-evident, however. It seemed difficult for interviewees to pinpoint what was going to be scaled up or how. Two project managers at Vattenfall both stated that they really did not know what will happen after SGG, if anything. ${ }^{960}$ Several interviewees expressed how SGG was finished, and with the conclusion of the experiment the parties involved would move on in separate directions. The CEO of GEAB, for instance, stated that:

Again, now the project is dismantled so there is nothing left. ${ }^{961}$

This was reflected by a civil servant at the Energy Agency, who also expressed how SGG was now finished and had been debriefed. ${ }^{962}$ Perhaps this is a reflection of the specific character of the experiment on Gotland, which was carried out across different parts of the island, in contrast to the urban experiments of the previous chapter which all took place in newly constructed city districts. It does, however, complicate the idea of scaling up an experiment, since there appeared to be a taken-for-granted notion among interviewees that when an experiment was concluded it was finished, so to speak. The grid manager at GEAB stated that:

I know too little about the world of academia and research to really see how this type of pilot project is used in the next step. Where is this generated knowledge picked up on the level you are talking about? I don't know that. I'm too down to earth for all that, I pick up the things I see that I need. ${ }^{963}$

This quotation shows how taking care of knowledge generated through SGG was considered someone else's task. These examples illustrate a need to dig deeper into what it means to scale up an experiment, for instance in terms of what is supposed to be scaled up, how, and by whom. As we saw in previous chapters, most actors engaged in smart energy experimentation

959 Bulkeley 2016. Accomplishing Climate Governance; Haikola \& Anshelm 2018. Depoliticization, Repoliticization, and Environmental Concerns.

${ }^{960}$ Interview PM1 Vattenfall; Interview PM2 Vattenfall.

${ }^{961}$ Interview CEO GEAB.

${ }^{962}$ Interview EXEA4.

${ }^{963}$ Interview GM GEAB. 
appear to place responsibility for learning from experiments with actors other than themselves. However, in relation to upscaling, the grid manager at GEAB further claimed that:

My understanding of the upscaling that was supposed to follow on from Smart Grid Gotland was really that Vattenfall's vision was to test in a limited area and in a controlled environment how existing grids could be made smarter. Because they own a lot of grids of the type they tested on here, mainly in the north of Sweden and similar regions, where there are no economic opportunities to rebuild all this in the time horizon that would be necessary if you look at quality parameters and stuff like that, so that was the upscaling I was aware of there. ${ }^{964}$

This resonates with how two project managers at Vattenfall described SGG as successful, since Vattenfall had immediately decided to implement the solution for monitoring the low-voltage grid in other parts of their own grid across Sweden. Vattenfall's decision to implement solutions for monitoring the low-voltage grid implies a circulation of knowledge within the organization as well as a circulation of a technical configuration to other parts of Vattenfall's grid. Interviewees at GEAB also described how a lot was learnt through SGG, although the knowledge generated was described as technically advanced and mainly interesting for GEAB itself. The grid manager described how GEAB decided to keep certain technological components from the experiment installed, for example in connection with monitoring and maintaining the grid to reduce error frequency and improve power quality. ${ }^{965}$ The system for increased customer information and demand-response developed through SGG was also commercialized. However, as an employee at Region Gotland remarked, this was relatively unknown on the island. ${ }^{966}$ According to the grid manager and the CEO of GEAB, electricity prices were too low to make such a system successful. ${ }^{967}$ The interviewees explained how GEAB had also developed smart church and smart summer home services based on SGG, which were essentially systems for monitoring electrical appliances in summer homes and ensuring an appropriate indoor climate in stone-built churches. ${ }^{968}$ Consequently, the knowledge generated in SGG seems to have resulted in certain new products being developed, indicating a circulation of knowledge within GEAB. However, a lot of the equipment used in SGG was dismantled, as both the CEO and grid manager stated. The new SCADA was described as entirely disproportionate for a grid operator the size of GEAB, for example, and was thus not kept; instead, GEAB decided to invest in a different new SCADA. ${ }^{969}$

As mentioned previously, interviewees from the public administration on Gotland tended to state either that learning from SGG was not really a matter for them, or that they had not been informed of the outcomes of the experiment. In a presentation during a public event called the Energy Dialogue in 2018, a politician on Gotland expressed that things had gone quiet in

\footnotetext{
${ }^{964}$ Interview GM GEAB.

965 Ibid.

${ }^{966}$ Interview EE Region Gotland.

${ }^{967}$ Interview GM GEAB; Interview CEO GEAB.

${ }^{968}$ Interview GM GEAB.

${ }^{969}$ Ibid.
} 
relation to SGG, and that even after the experiment was finished no briefing was held or input provided for the County Administrative Board or politicians on Gotland. Knowledge circulations thus appear to have occurred largely within the private companies involved in SGG. A further complication of the idea of scaling up an experiment surfaced in an interview with a project manager at Vattenfall. The interviewee expressed that when an experiment carried on for a long time, many of the aspects the consortium wanted to test had become regular features in the energy system. Certain elements that were considered forward-looking when SGG started had become incorporated into legislation during the course of the experiment, according to the project manager. ${ }^{970}$ This highlights how experiments focused on technological development are often conditioned by demands of showcasing technology that is perceived as cutting-edge, as discussed in previous chapters, which also underlines the strong marketing emphasis across the studied smart energy experiments, highlighting how the broader political rationality conditions experiments. The project manager at Vattenfall said:

Development projects cannot go on for too long [...] and I think we are a borderline case with regard to going on for too long. ${ }^{971}$

If the focus of upscaling is on market dissemination of technologies, it makes certain types of smart energy experiments relevant, mainly experiments with a strong publicity profile focused on product development which are not allowed to go on for longer periods of time. This further illuminates how the political rationality underpinning smart energy experimentation in practice facilitated SGG, infusing a knowledge politics as specific actors and types of knowledge are designated as relevant in such a setting while others become irrelevant. It contributes to positioning large private companies as principal agents of energy transformation by virtue of their capacity to make particular knowledge claims.

To summarize this section, considering the close proximity in time between SGG and the governmental initiative of making Gotland an energy pilot region, as well as the different scopes of the two initiatives, a substantial opportunity for upscaling should be present, according to the hope pinned on experiments for achieving transformative change through upscaling among experts at the national level. However, the dismantling of most of the constituent parts of SGG, and the prevalent notion that the experiment is a closed case, coupled with the notions of SGG as a narrow technology development project on the island, might complicate the picture. In the following section on Gotland as energy pilot, the interrelation between SGG and the governmental initiative will be explored further, building on the analysis in this section.

\footnotetext{
${ }^{970}$ Interview PM2 Vattenfall.

${ }^{971}$ Ibid.
} 


\section{Gotland as an energy pilot region}

The inception of the governmental initiative of making Gotland an energy pilot region, initially described by the government as piloting the transition to a smart and renewable energy system, must be viewed in the light of Svenska Kraftnät's decision not to construct a new transmission cable linking the regional power grid on Gotland to the large-scale national transmission grid. The decision, announced in 2017, caused uproar and exasperation on the island - which cannot have come as a surprise, considering how much of Gotland's environmental and economic policy goals were predicated upon the construction of a new cable, as we have seen. It can certainly be interpreted as a symbol of a distant state whose neoliberal shadow Gotland endures. While Smart Grid Gotland was launched against the backdrop of a constricted transmission capacity, thus aligned from the outset with the large-scale socio-technical grid infrastructure, SvK's decision raised the stakes forcefully. Suddenly, new, alternative solutions for the electricity system on Gotland had to be implemented, and urgently.

In conjunction with the annual gathering of politicians on Gotland in 2017, Almedalen Week, the government announced the initial decision that the Energy Agency had been commissioned to investigate how Gotland could become a pilot in the transition to a smart and renewable energy system in Sweden. ${ }^{972}$ Some actors engaged in energy transformation endeavors on Gotland greeted this announcement with optimism, claiming that this constituted an exciting opportunity to significantly alter the configuration of the energy system, moving from a largescale grid and large wind power parks toward a small-scale, decentralized energy system. ${ }^{973}$ This makes sense in view of the situation on the island outlined in the previous section. The then Director General of the Energy Agency Erik Brandsma expressed a positive outlook on the initiative, claiming that Gotland could become a model for Sweden and the whole world to replicate. ${ }^{974}$

It was specified in the government's directive that the Energy Agency should describe "how the project can be performed on a full scale", appoint actors responsible for different suggested measures, and propose regulatory changes if deemed necessary. ${ }^{975} \mathrm{~A}$ few weeks earlier, the final report of Smart Grid Gotland had been submitted to the Energy Agency, and it was explicitly stated in the governmental decision that lessons and experiences from previous smart grid projects were to be taken into account in the energy pilot initiative. ${ }^{976}$ Additionally, it was

\footnotetext{
${ }^{972}$ Regeringskansliet 2017. Smart och förnybart energisystem på Gotland.

${ }^{973}$ See e.g. Neuman 2018. Gilla läget och satsa på alternativ till tredje elkabeln. Sveriges Radio P4 Gotland. 2018-11-06. https://sverigesradio.se/sida/artikel.aspx?programid=94\&artikel=7079704 [2019-0826].

974 Alestig 2017. "Gotland en förebild för Sverige - och världen". Svenska Dagbladet - SVD Näringsliv. 201709-20. https://www.svd.se/gotland-kan-bli-en-forebild-for-sverige-och-varlden [2019-08-26].

${ }^{975}$ Regeringskansliet 2017. Smart och förnybart energisystem på Gotland. p. 1.

${ }^{976}$ Ibid. p. 2.
} 
stipulated that the investigation was to be carried out in collaboration with the Swedish Smart Grid Forum and other relevant actors. ${ }^{977}$ In September 2017, the regional grid operator on Gotland, GEAB, announced that new electricity production would not be allowed to connect to the grid with reference to grid stability, including connecting micro-produced solar power, explicitly referencing SvK's abandonment of its construction plans. ${ }^{978}$ The Energy Agency presented the pre-study on Gotland in mid-2018, and soon afterwards the government issued a new assignment for the Energy Agency: helping to make Gotland a pilot region to lead the way in the transformation to a sustainable energy system. ${ }^{979}$ The renewed initiative included developing a roadmap for such a transformation together with relevant actors, and to act as a coordinator in realizing the roadmap after its publication, as well as making use of lessons learned during the transition and publishing these every other year. ${ }^{980}$ The Energy Agency announced its roadmap at a public seminar on Gotland in mid-2019.

In this part of the chapter, I will discuss these processes, following the initiative from its inception up until just after the roadmap was published in mid-2019. It must be emphasized that the energy pilot initiative is of a different character compared to the other cases in this study - in the sense that no physical construction has commenced, the scope is much broader, and it is not spatio-temporally confined in the same way as the other experiments. Thus, when speaking about circulations of the initiative, for instance, it is rather attempts at circulation before any physical construction has taken place and ideas of circulation that I unpack. Despite the broadened scope compared to SGG and the urban smart energy experiments in the previous chapter, there are traces on the surface of the political rationality underpinning smart energy experimentation. There is, for example, an emphasis on public-private partnership constellations, projects, coordination, cooperation, testing, learning, upscaling, and replication. Nonetheless, it is significantly broader in scope than the other cases of smart energy experimentation accounted for in this study, comprising an ecology of interventions rather than an individual pilot project.

Empirically, the chapter builds on analysis of the pre-study published in 2018 and the roadmap from 2019, as well as interviews with key actors from governmental agencies involved in the energy pilot initiative and actors on Gotland, and observations during public events, workshops, and presentations connected to the energy pilot initiative. Analytically, the focus will be directed toward how this ecology of interventions arranges environmental governance by attending to processes of authorizing and assembling intervention, as well as attempts at making the initiative circulate. Further, analytical attention will be directed toward how SGG

\footnotetext{
977 Ibid.

${ }^{978}$ See Widegren \& Lindskog 2017. Stopp för ny elproduktion på Gotland. SVT Nyheter. 2017-09-05. https://www.svt.se/nyheter/lokalt/ost/stopp-for-ny-elproduktion-pa-gotland [2019-08-26].

${ }^{979}$ Regeringskansliet 2018. Uppdrag till Statens energimyndighet att möjliggöra att Gotland blir en pilot för ett hållbart energisystem.

${ }^{980}$ Ibid.
} 
comes into play in the governmental initiative. It is thus an analysis of how actors become involved, how they assign meaning to the initiative, how it is given form, and how environmental governance is accomplished through the initiative. The analytical aim is to gain a deeper understanding of how smart energy experimentation arranges governance by scrutinizing the energy pilot initiative, and further investigating the politics of such processes. Consequently, the chapter represents a snapshot of an accomplishment in the making, providing an insight into how such processes unfold. First, we will delve deeper into how different actors made sense of and positioned themselves as the initiative was announced in 2017.

\section{Becoming a pilot region as opportunity and concern: opening up and closing down relations through authorizing and assembling intervention}

This section will analyze how intervention was authorized and assembled from the energy pilot initiative's inception in 2017 up until mid-2019, after the Energy Agency presented its roadmap. Accordingly, it will follow a chronological structure. Attention will be paid to the interrelation between Smart Grid Gotland and the energy pilot initiative, consequently building upon the preceding part of the chapter. The first section focuses on 2017-2018. It revolves around how the governmental initiative was initially received among key actors on the island, and how these actors positioned themselves in relation to it. It also zooms in on how the Energy Agency made sense of its new task. Thus, the section begins to unpack how intervention was authorized and assembled during the inception of the initiative, accomplishing environmental governance in specific ways.

\section{The perils and promises of being frontrunner: experimentation as a solution or a problem?}

The governmental initiative of making Gotland an energy pilot region was unveiled in somewhat tumultuous circumstances. This was reflected in interviews with key actors on Gotland and among experts across governmental institutions and policy networks. A prominent tension that appeared regularly during interviews in 2017 connects explicitly to experimentation as testing, and the term "experiment". It clearly resembles what surfaced in relation to Smart Grid Gotland, of how experimentation was cast simultaneously as something risky and promising. In relation to the energy pilot initiative, however, such tensions were clearly amplified. For instance, the grid operator GEAB's CEO stated that whilst SGG had been instructive in relation to reducing the occurrence of errors in the grid using ICT-enabled automation, the situation caused by SvK's decision to withdraw its plans for a new transmission cable was of a different degree. ${ }^{981}$ According to the interviewee, because of the large share of renewable electricity production on the island which would risk grid stability during

\footnotetext{
${ }^{981}$ Interview CEO GEAB.
} 
production peaks, the decision not to build a new cable resulted in a bottleneck and put GEAB in a difficult situation. Regulations require a grid operator to allow new electricity production to be connected to the grid whilst other regulations stipulate limits regarding errors such as power outages. The new situation forced GEAB to take extraordinary measures such as refusing connection to the grid for new renewable electricity production, according to interviewees. ${ }^{982}$

Similarly, an interviewee from Region Gotland remarked that without a new transmission cable the Region's energy plan would be impossible to realize, and that this necessitated some kind of decision within the framework of the energy pilot initiative. ${ }^{983}$ SvK's decision was described as catastrophic by the interviewee, since it would derail plans for expanding renewable electricity production on Gotland. ${ }^{984}$ From these articulations, a demarcation between SGG and the energy pilot initiative can be observed. Illustrating such delineations, GEAB's CEO stated that:

Before we can allow new production [to be connected] we have to have some solutions we actually believe in. Because we can't jeopardize, this is a society for god's sake, it's not a laboratory, which I have said a few times and created some irritation, I'm aware of that. But I would still like to say that this is a society, not a laboratory. And then it's very important when we are moving in to test new technology and risk everything, that we do it in a careful and safe manner. And that we don't do it until we actually know that this works. ${ }^{985}$

Here, the CEO articulates the new situation more as a peril connected to the abandonment of the previous infrastructure plans, rather than being full of promises connected to becoming an environmental frontrunner. Testing through experimentation is expressed in quite clear terms as something dangerous which cannot be allowed in the current situation, since it would be irresponsible. In particular, describing Gotland as a society rather than a laboratory draws attention to questions of politics of arranging environmental governance through experimentation, as highlighted previously in the section on SGG but more openly laid bare through the energy pilot initiative. It also highlights an inverse logic compared to how experimentation is often described as testing, where GEAB wants to be reassured before trying new solutions. The CEO stated that Gotland is a part of Sweden and should be afforded similar conditions to the rest of Sweden, and that a new transmission cable is needed to balance a renewable-based large-scale grid, not just for the sake of Gotland but for the sake of Sweden. ${ }^{986}$ The interviewee repeatedly stated that Gotland is not a laboratory, and that the solutions

\footnotetext{
${ }^{982}$ Ibid; Interview PM2 Vattenfall.

${ }^{983}$ Interview EnvE Region Gotland. Similar viewpoints also surfaced in an interview with GEAB's grid manager.

${ }^{984}$ Interview EnvE Region Gotland.

${ }^{985}$ Interview CEO GEAB.

986 Ibid.
} 
devised through the governmental initiative have to be safe. ${ }^{987}$ Experimentation appears to be risky and fraught with tensions.

Consequently, the initiative immediately provoked strong reactions. There are likely several reasons for this, not least in terms of regional politics. The decision not to construct the cable can be conceived of as signaling a distant and disinterested state, feeding into a brewing conflict between urban and rural settings. Further, it highlights precarity for Gotland because of the socio-technical constitution of the electricity grid, potentially leaving the islanders with severely limited access to the large-scale transmission grid and thus left fending for themselves, putting energy and environmental policy goals at risk. As we saw previously, similar fears played into the specific setup of SGG, although in the case of the energy pilot initiative they were substantially amplified. What these tensions also highlight is that the energy pilot region initiative was interpreted as opening the door to different energy futures, potentially forcing new energy system architectures. Recall how this was an explicit hope pinned to the initiative by some experts in governmental institutions and international policy networks, as accounted for in previous chapters. Similar hopes also surfaced on Gotland, for instance during the Energy Dialogue in 2017. The Energy Dialogues are recurring public events, organized by the County Administrative Board, to bring together actors involved in energy on Gotland in any way.

The theme for the dialogue in 2017, which took place in late October, was "the transition to a smart and sustainable energy system" to achieve energy and climate policy goals, i.e. referencing the energy pilot initiative. The event included presentations from politicians and different actors on Gotland, as well as a presentation from the Energy Agency, and workshops in smaller groups on the topic of the event. Specifically, questions about how to embed a transition locally and hopes and risks associated with transformation were discussed. During the event, actors engaged primarily in comparatively small-scale energy transformation endeavors voiced how the energy pilot initiative could be conceived as an opportunity to change the large-scale, centralized grid infrastructure, thus challenging the historically strong socio-technical energy system configuration. Such hopes shine a different light on the articulations from the $\mathrm{CEO}$ of GEAB, and the fears expressed by a project manager at Vattenfall about losing control of the energy system if decentralized solar power gains momentum.

This underlines how the broader political rationality underpinning smart energy experimentation, which clearly conditioned SGG, risks being brought into the open and thus challenged here. The stakes come across as higher when compared to Västerås, since the governmental initiative of making Gotland an energy pilot region is significantly more wideranging in scope and much more publicized, encompassing an ecology of interventions. Consequently, in its initial stage the initiative appeared to have opened the door to alternative 
energy futures, as further underlined by the grid operator's fear of losing control of the system. As we saw in the previous section on SGG, politics abound as experimentation arranges environmental governance on Gotland. Lines of conflict became clearly accentuated through the energy pilot initiative at this stage in 2017.

An expert from the Energy Agency offered this reflection on SvK's decision not to construct a new transmission cable:

So the question SvK should ask themselves, rather than what's efficient, is how can we assess whether people would like to build wind power and solar on Gotland, what do Gotlanders want? And if you view it from a societal perspective, in our energy policy, which preconditions do we think collectively that we should afford different actors, and do you want Gotland to have different conditions compared to the mainland? Should there be less of a possibility to install solar panels on Gotland than in Småland? That's what the discussion should be about, not what's efficient. So it's rather the social sustainability aspect maybe and the economic question that's, well the basis now in the political debate is the technical so you might easily, you might carry out a techno-economic analysis. But you should really carry out a socio-economic analysis. ${ }^{988}$

This articulation reveals the dominance of a techno-economic language and market rationality in the energy sector, reflections of the broader political rationality, and how this political rationality create frictions "on the ground" as smart energy experimentation arranges environmental governance. Further, it underlines how environmental governance rests upon techno-economic knowledge claims generated through economic cost-benefit analysis, illuminating the prevalence of techno-economic rationality in the energy sector. As we have seen, experiments are clearly conditioned by this through the broader political rationality and tend to perpetuate this order further, instituting particular knowledge politics as we have seen throughout the study. This did not necessarily seem to be the case, however, with the energy pilot initiative at this early stage:

With different actors connected [to electricity and district heating grids operated by GEAB], who

have their own ideas about how to drive and work and create a good future. [...] Smart Grid

Gotland was a research project where you tested a number of technologies and extended them as far as possible. It was not so much about how you manage a system consisting of all these operators here and there. And that is what we are really faced with now. ${ }^{989}$

This quotation echoes how a project manager at Vattenfall reflected upon how control of the energy system could potentially slip out of the hands of grid operators in the future. Taken together, the examples cited above convey a more direct urgency, however, with reference to the acute situation, charging experimentation with negative connotations as something risky. This illustrates how the process of assembling intervention, here at a nascent stage, is essentially an open process and that governance can be accomplished in many different ways. For GEAB, it seems that the energy pilot initiative presents a real risk of losing control of the

\footnotetext{
${ }^{988}$ Interview EXEA2.

${ }^{989}$ Interview CEO GEAB.
} 
energy system, prompting a demarcation between SGG and the energy pilot initiative. A grid manager at GEAB stated that the energy pilot initiative entailed a completely different perspective than SGG:

A lot is done within that, pilot projects and the research world and so on, so of course it's important that that exists. But I also think that it's important that it's complemented by the kind of investigations that the Energy Agency has got on its hands now. That really takes a real problem as starting point, and [the Energy Agency] is supposed to put its foot down in questions, because research without taking a stance on the things that appear, well then not much will happen. So, it has to be captured especially on a political and regulatory level, so that the lessons learned are really picked up on in the right place. ${ }^{990}$

Here, demarcations surface, similar to how the CEO of GEAB clearly delineated SGG from the governmental initiative shown in the previous section on SGG. The articulations underline how SGG was construed as a clearly delineated endeavor mainly concerning the involved private companies; the insistence that knowledge generated in SGG is not primarily aimed at policymakers is telling in that regard. Thus, the field of intervention is constituted differently through the energy pilot initiative - if such a field became demarcated and tightened through SGG, the energy pilot initiative would rather appear to blow it wide open, with possibilities of arranging governance through experimentation seemingly endless at this point in time. And, as we have seen, this is a cause both for hope and concern.

The grid manager further stated that the energy pilot initiative needs to include a review of rules and regulations, for example with reference to how the market works, which was connected to a criticism against putting too much faith in market solutions, as discussed previously. The interviewee mirrored concerns echoing across the island, claiming that:

I don't think that Gotland will thrive or make it without a strong connection to the mainland. [...] considering how it takes 13 years to build a new high-voltage power line, so that's no time perspective, this has to be decided now anyway, what it will look like in the long term. If you were to arrive at that solution, that no new cable will be built, then a lot of other things need to be transformed. So lots of other rules and legislation will really need to change. And then I fear that it will mostly take a lot of time. That's the fear out here [on Gotland], that it's not enough time to do it in a proper way. ${ }^{991}$

Despite not explicitly referring to experimentation as something risky, like the CEO, it is clear that the decision not to construct a cable is considered to have created a potential threat, highlighting regional political concerns of precarity as discussed above, as well as politics in terms of the roles and capacities of different actors in a future smart energy system, such as specific grid operators risking losing control of the system, control they have long enjoyed and become accustomed to. ${ }^{992}$

\footnotetext{
${ }^{990}$ Interview GM GEAB.

${ }^{991}$ Ibid.

${ }^{992}$ Cf. Stephens et al. 2017. Smart Grid (R)Evolution; Bakke 2017. The Grid.
} 
The initial reactions toward the energy pilot initiative provide insights into how smart energy experimentation arranges environmental governance. First, they illustrate how accomplishing governance through experimentation is in principle an open process, indicated by different actors strategically maneuvering to position themselves and shift the terms of debate. For instance, neither the line of reasoning offered by the grid manager nor the CEO of GEAB indicate that the question of a whether or not a new transmission cable will be constructed is a settled question; rather, the opposite is true. Both are attempting, in conjunction with many other actors on Gotland, including politicians, to open up the issue, almost immediately after it seemed to have been closed by Svenska Kraftnät. They do this by drawing on specific problematics, and enrolling certain socio-material elements, mainly related to grid stability, local circumstances, and regional politics, and with reference to environmental issues when claiming that grid connections have to be expanded in order to avoid capacity issues and balance the regional energy system to allow for extensive expansion of renewable electricity production.

This illustrates how the energy pilot initiative actualized different aspects compared to SGG, and how much more was perceived to be at stake, as illuminated by the demarcations between the two endeavors. Further, it underlines how accomplishing governance through experimentation is a constant struggle to establish specific dispositions through the dynamics of authorization and assembling intervention, and an attempt to contain the assembled elements in relation to each other and make them coherent. Such processes of opening up and closing down relations appear to have commenced almost as soon as the energy pilot initiative was launched in 2017. 993 This also illustrates how environmental governance does not necessarily hone in on improving the environmental condition as its primary goal. Through practices of bricolage, different elements and problematics are drawn into the intervention to align different agendas, and possibly reshape them in the process. This is clearly a political process, brimming with contestations in the case of the energy pilot initiative.

Among the public administration, articulations similar to those expressed by the interviewees from GEAB resurfaced at this stage of the energy pilot initiative. Public administration employees also characterized SGG and the energy pilot initiative as two inherently different types of intervention. Further, according to an environmental expert at Region Gotland, the entire energy plan of Region Gotland hinges upon being able to export large amounts of electricity produced by wind power, making it possible to account for such clean electricity as replacing dirty coal power in Europe, as a way of cancelling out the large fossil footprint of the cement producer Cementa on Gotland. ${ }^{994}$ Besides illustrating the importance of calculative practices for environmental governance, this articulation underscores the ramifications of the energy pilot initiative. The interviewee continued:

${ }^{993}$ Cf. Bulkeley 2016. Accomplishing Climate Governance. p. 19.

${ }^{994}$ Interview EnvE Region Gotland. 
And then it's going to be the same thing now if the Energy Agency manages to come up with such good project proposals and find such good financing opportunities that it, then it won't be a pilot

project. It will be, Gotland is a full-scale society, what happens in a city, what happens in the countryside, what happens in a large, in an industrial area? It's big enough here so it is beyond, it's considerably larger than the lab bench. And considerably larger than a pilot project in a city district. So then it's already a full-scale project, although a pilot area since that hasn't been done anywhere before [...] a pilot project is if you test whether something works, but this task that they [the Energy Agency] have been given here is to suggest things that are supposed to work in reality. ${ }^{995}$

As we saw in the previous section on SGG, the interviewee ascribed similar attributes to SGG, i.e. that it was done "on a full scale"; however, a clear boundary between the public administration and SGG was upheld in that instance. The environmental expert at the Region stated that the purpose of SGG did not seem to revolve around developing the power grid on Gotland, but was rather located on the island because Gotland provided a suitable cradle for developing products to sell somewhere else. Connected to this line of reasoning, the interviewee also differentiated the energy pilot initiative:

However, the Energy Agency's initiative to make Gotland a pilot area for renewable energy, that's a full-scale project and not a pilot project I would say, which will have a decisive role if they come up with things that we can do here. ${ }^{996}$

The quotation underlines how the energy pilot initiative allows for casting a wider field of intervention than SGG. Whereas SGG was made into a matter for techno-economic energy experts, mainly in private firms, the energy pilot initiative was initially cast as a matter of concern also for the public administration. ${ }^{997}$ Or, in accordance with Bulkeley, the energy pilot initiative was constituted as a matter that more clearly aligned the public administration's interests, for instance connected to the energy and regional development plans, with those of GEAB, and potentially the Energy Agency. Similar viewpoints surfaced in other interviews as well, for example an energy expert at the Region who pinned hopes on the energy pilot initiative being broader and larger in scope, and amounting to more action than SGG. ${ }^{99}$

However, the environmental expert at Region Gotland stated that:

A sustainable [society] is much more than the energy system, since it builds upon sustainable consumption, sustainable use of land and water, and so on, but the energy system is a very large cause of our negative impact, so it will be a giant leap if we can get a sustainable energy system which is also entirely independent from fossil fuels. So it's a fantastic development opportunity. ${ }^{999}$

995 Ibid.

${ }^{996}$ Ibid.

${ }^{997}$ Cf. Latour 2004. Politics of Nature.

${ }^{998}$ Interview EE Region Gotland.

${ }^{999}$ Interview EnvE Region Gotland. 
In this instance, the energy pilot initiative is described as an opportunity rather than something problematic. Here, assembling intervention takes the form of diagnosis of possibilities. ${ }^{1000}$ Improving the environmental condition by developing an entirely renewable-based energy system - albeit far from rectifying all environmental issues, as the interviewee notes - presents significant opportunities. Thus, intervention is authorized as presenting a window of opportunity, allowing assembling intervention to realign specific elements and agendas. It should also be noted that certain parts of the world were blocked off as out of reach as the intervention was assembled, such as Cementa's operations, at least in terms of delimiting or regulating in any way. Similarly, we saw previously how changes which would require a dramatic transformation of the configuration of the energy system would not be favored by some actors on the island, and nor would dramatic reductions in energy use.

There were also others on Gotland who described the energy pilot initiative as an opportunity. An energy expert at the County Administrative Board, for example, stated that while it is a matter of interpretation what the energy pilot initiative will entail:

I want to be positive, that this initiative can help, because Gotland has had goals for a long time within renewable energy if you go back and look at the energy plans. It has been a vision on Gotland since way back, and now perhaps we will receive help to accomplish that. And as I said, there are significant hopes pinned to it [...] and the size and that it's taken seriously at the national level and that there are funds and so on to do things on a larger scale, so I hope so. ${ }^{1001}$

This quotation conveys how the energy pilot initiative entails possibilities of realigning existing visions and political goals on Gotland. The interviewee also stated that:

Many people hope so. But many people are also scared that it's just, that it will become just another investigation and how far will we get with this pre-study? Will there be real action afterwards? [...] As I said, they [the Energy Agency] have a really difficult task, lots of expectations [...] from every

direction who wish that they will include [this and that]. But the government initiative says specifically that smart grids are one of those things. ${ }^{1002}$

This further underscores some of the tensions connected to the energy pilot initiative, and how for actors on Gotland it was a source of both concern and hope in 2017. Another important moment in the processes of accomplishing environmental governance through the energy pilot initiative, where further dynamics of the initiative unfolded, was the Energy Dialogue in 2017, which I attended as an opportunity for observations and informal conversations. During the dialogue, especially in workshop constellations including representatives from different organizations and citizens, hopes and fears connected to the energy pilot initiative were expressed clearly. It was stated repeatedly that participants feared that Gotland might become "just an experiment" or a "playground" as a result of the initiative,

\footnotetext{
${ }^{1000}$ Bulkeley 2016. Accomplishing Climate Governance.

${ }^{1001}$ Interview EE Gotland County Administrative Board.

${ }^{1002}$ Ibid.
} 
echoing tensions related to experimentation as testing described above. ${ }^{1003}$ One striking statement related to a fear that the pre-study might become nothing but a shackle, because it could be perceived as easy to experiment with a small island, and the burning question is what happens afterwards. ${ }^{1004}$ During the workshops, widely different viewpoints on the initiative were articulated, ranging from the need for strong political governance to focusing on individuals, and local ownership of electricity production as a counterpoint to corporate control of the energy system as well as an emphasis on marketing and pilot facilities to make sure Gotland becomes a widely known frontrunner. ${ }^{1005}$ The frequent emphasis on becoming a frontrunner, echoed across national policy, regions, cities, and the island of Gotland, underlines how the broader political rationality infuses smart energy experimentation with notions of competition between places, necessitating place-branding, thus incorporating smart energy experimentation into neoliberalization processes.

These instances further elucidate dynamic processes of accomplishing environmental governance through smart energy experimentation. They also illustrate how different actors on Gotland immediately began to mobilize, positioning themselves in relation to the initiative, and how practices of bricolage ensued. This ranged from examples such as GEAB's decision not to allow new electricity production to be connected to the grid, with reference to grid stability, to presentations during the Energy Dialogue and the Energy Agency activities such as arranging meetings with actors on Gotland. Here, interlinkages began to take form, and as shown above an initial alignment of different agendas and problematics unfolded. It appears that the authorization of the intervention in 2017 largely revolved around making it an opportunity for Gotland. Consequently, one might expect to see attempts to forge a consensus, as supported by quotations from interviews and an emphasis on including everyone and making the energy pilot an opportunity for everyone on Gotland during the Energy Dialogue. In such an interpretation, the early signs during the energy pilot initiative seem to point toward governance being accomplished through a diagnosis of possibility; intervention was thus assembled by drawing on the desirability of improving the environmental condition and simultaneously achieving other goals among different actors. ${ }^{1006}$

However, forging a consensus is a laborious process which, at least in principle, is always contentious, open to contestations, and thus prone to destabilization. As the concerns surfacing in relation to SvK's cable decision and the energy pilot initiative illustrate, forging a consensus did not appear to be straightforward at this moment in time. The examples provided

\footnotetext{
${ }^{1003}$ Länsstyrelsen Gotland 2017. Rapport Gotlands Energidialog 2017 - Omställning till ett smart och hållbart energisystem.

${ }^{1004}$ Ibid. p. 31. Such an expression also conveys a notion of experimentation as temporally bounded, even in the case of the energy pilot initiative with such a broad scope and wide-ranging ambitions.

1005 Ibid.

${ }^{1006}$ Bulkeley 2016. Accomplishing Climate Governance. Recall Foucault's insistence that governance is not about chasing one dogmatic goal, but rather about a whole series of specific finalities.
} 
illustrate how, from its very inception, the energy pilot initiative came to include a constant opening up and closing down of relations through practices of bricolage, including realignments and contestations. It is equally important to note that certain positions which would probably appear untenable in Swedish environmental politics in other contexts, e.g. in relation to control of the energy system and stronger political steering by the state, as emerged during the Energy Dialogue, ${ }^{1007}$ appeared rather marginalized and difficult to incorporate into the intervention as it was assembled. So even though power within the emergent disposition was dispersed in a sense, certain actors - and the positions afforded to them through the phrasing of the governmental initiative and their historical positions within the energy system - appear to have greater opportunities to have an impact, thus granting these actors problem formulation privilege, and thereby imprinting the process of assembling intervention with a specific problematization. Here, the broader political rationality underpinning smart energy experimentation has explanatory value. As we have seen throughout previous chapters, publicprivate partnership constellations, techno-economic expertise, and initiatives to make economic growth green tend to be facilitated as smart energy experimentation arranges environmental governance, crowding out alternative positions. Experimentation, as we have seen, tends to be conditioned by and set up in line with assumptions infused by the political rationality. Or, it seems that such experiments find it easier to attract funding and establish or consolidate infrastructures of circulation which allow access to policy networks.

\section{Ordering the field of intervention through coordination}

The Energy Agency occupied a central position as intervention was assembled, since it was given the role of principal coordinating actor by the government, with the mandate to appoint further actors and suggest regulatory changes if deemed necessary. Thus, the Energy Agency gained a central role in terms of enrolling actors into the initiative and, by virtue of its assignment, of formulating a specific problematization through the initiative. It is also a major funder of energy-related research in Sweden. This further reflects the broader political rationality; the Coordination Council and subsequently the Swedish Smart Grid Forum were afforded similar roles at the national level, highlighting how governmental actors are mainly positioned as facilitators and coordinators as smart energy experimentation arranges environmental governance. Considering how the Energy Agency is consequently a central actor for defining the field of intervention and how the environmental condition should be improved through the energy pilot initiative, it is relevant to take a closer look at how it interpreted and operationalized its assignment from the government. A civil servant at the Energy Agency involved in the initiative stated that:

${ }^{1007}$ Which are not necessarily peripheral positions in practice, see e.g. Wallsten 2017. Assembling the Smart Grid; Anshelm et al. 2018. Svensk gruvpolitik i omvandling. 
You know about the background, if that SvK decision hadn't been taken, this assignment would not have existed. I'm pretty sure of that. They are interconnected and that is quite natural. ${ }^{1008}$

This quotation illustrates how the inception of the energy pilot initiative was intimately linked to SvK's decision, although it should be noted that a representative from SvK claimed no knowledge of such a link. ${ }^{1009}$ The interviewee at the Energy Agency further explained:

Get as many on board as possible. [...] There are many who have to be involved, and it's a cooperation project. If we suggest something that nobody wants, which might push the imagination beautifully but if nobody wants it, it is rather uninteresting. And that makes this as much into a cooperation and collaboration project as anything else. So you need to get all these key actors on board. ${ }^{1010}$

Based on the phrasing of the initiative in the governmental decision, the Energy Agency's role consisted of coordination, but in practice it is central to how the energy pilot initiative arranges governance since it was also afforded the possibility to specifically pick which actors to involve in the initiative. Assembling intervention thus came to revolve largely around attempting to align different actors' agendas in 2017, which can be illustrated with the following quotation:

In terms of actors, there are no boundaries really. It's the whole energy system so, but key actors so to speak, it's a lot about achieving acceptance for the assignment on the island. So it's the Region, the County Administrative Board, super important, but it's equally important to get parts of the business community on board. Speaking about one of these macro trends, so to speak, the best we can accomplish is if the actors whom we involve in the assignment in different ways, if they start to see business opportunities between themselves, and solutions to their challenges. Your problem could perhaps be my business opportunity, and the other way around. ${ }^{1011}$

This quotation illustrates how the Energy Agency attempted to provide a diagnosis of possibilities to make intervention desirable for different actors. It is also a clear reflection of the broader political rationality, emphasizing the need for cooperation and turning environmental issues into business opportunities and economic profit through smart energy experimentation. The interviewee claimed that:

I think that a lot of the pieces of the puzzle are there, but to fit it all together, all the pieces, on a Sweden in miniature, that's of a different magnitude, but I'm pretty convinced that the pieces of the puzzle are there. ${ }^{1012}$

Here, it becomes clear how practices of bricolage instantly became central to accomplishing governance through the energy pilot initiative. The idea conveyed, that of Gotland as a miniature Sweden where a puzzle had to be put together using existing pieces, is quite telling in this regard. However, it was also clear that the Energy Agency was acutely aware of the

\footnotetext{
${ }^{1008}$ Interview EXEA4.

${ }^{1009}$ Interview EXSvK, EXSvK 1.

${ }^{1010}$ Interview EXEA4.

${ }^{1011}$ Ibid.

${ }^{1012}$ Ibid.
} 
aforementioned regional political aspects as well, connected to the delicate nature of the energy pilot initiative through its interconnection to SvK's cable decision. The Energy Agency employee said:

And to dare a little bit, too. To dare quite a lot, but at the same time, as it were, what I go on about all the time, it can't be an experimental workshop, it has to be for real. ${ }^{1013}$

This tallies with how experimentation simultaneously appears to signify something risky and detached from reality, and not only an opportunity, in relation to the energy pilot initiative in 2017.

In practice, when completing its task of producing a pre-study on how Gotland could become a pilot for Swedish energy transformation, the Energy Agency spent time on the island meeting with different actors. ${ }^{1014}$ According to the interviewee, the Energy Agency had been assigned a task that was in a sense impossible, because of the very short timeframe before the pre-study was due to be published, but stated that meeting different actors on Gotland:

It's about shifting mindset a little bit, which happens quickly. I think you get proof of that often, so if you can get these key individuals within different organizations to understand that what we propose, maybe it isn't so very utopian as it sounds [...]. ${ }^{1015}$

This quotation underscores the fragility inherent in processes of realigning agendas. It highlights how the Energy Agency attempted to forge a consensus, thus indicating that authorization was practiced through the modality of consensus. We have already seen how this was far from straightforward, however, because of the circumstances surrounding the energy pilot initiative, indicating that forging a consensus would by no means be a smooth process. It also illustrates how the Energy Agency occupied a central role in terms of orchestrating power, because of its ability to decide on whom to involve, and its central role in molding the initiative in specific ways, implicitly shutting out other possible directions. Of course, as the emphasis on alignment and bricolage shows, the Energy Agency was far from being an omnipotent wielder of power that could completely determine the course of action; power is relationally constituted across spaces rather than a property of any one actor. This is also enshrined in the civil servant's statement that there are "no boundaries" in terms of actors wishing to become involved. However, through the phrasing of the assignment, the government had afforded the Energy Agency a central role, and it appears quite clear that the final word on determining the direction lay with the agency. The emphasis on pragmatism and aligning agendas also illustrates how experimentation arranges governance in ways that are far from straightforward, and does not necessarily involve open-ended testing, as the previous cases of experiments have shown.

\footnotetext{
${ }^{1013}$ Ibid.

${ }^{1014}$ Ibid; Interview EE Gotland County Administrative Board; Interview GM GEAB; Interview EnvE Region Gotland.

${ }^{1015}$ Interview EXEA4.
} 
Internally, the Energy Agency organized itself into different groups such as digitalization, smart grids, transportation, farming, and so on, consisting of experts within the agency working with such issues. The task for these groups was to identify and suggest specific possible measures which could be included in the pre-study, based on a template that the project management team decided on. So the idea was to draw up a list of possible measures, and then "put together the puzzle", in the words of the civil servant, i.e. to decide which measures to include in the final version of the pre-study. ${ }^{1016}$ The interviewee added that it was entirely possible for external actors to contact the Energy Agency and suggest measures to be included in the pre-study as well. ${ }^{1017}$ Describing the process, the interviewee explained that:

For now, working with the measures, probably for a few more weeks. Then we will have a list and then we can see, there will probably be duplicates. Of course we would like to promote measures that encompass all sectors. And if you have a measure that can include more than [one sector], that's better of course. Then we will see pretty quickly which suggestions for measures will work, and which won't. [...] I would like to emphasize list, choose, prioritize pretty hard, and then analyze. Of course, we also have to consider the circumstances on the island. [...] Then it's about sorting out who will do what. Responsibilities and roles, and of course that will be a mix. [...] Funding will be a trickier part to suggest. There are many grants [...] there are lots of possibilities. It's not obvious for everyone all the time that these exist, so it could become a matter of packaging it and clarifying. ${ }^{1018}$

The quotation illustrates the central role of the Energy Agency in assembling intervention, highlighting knowledge politics in the energy pilot initiative. It was up to the Energy Agency to decide which measures can be considered realistic and which to exclude, based on internally agreed criteria, although the agency has to take into account the interests and aims of different actors on Gotland. It was thus given a central position in terms of deciding which knowledge is valuable and relevant for the energy pilot initiative, and which can be excluded. Although, as we have seen, it would be impossible for the agency to do so without recognizing the wishes of actors on Gotland. In terms of the politics of arranging environmental governance through experimentation, the crux of the matter is whose problem formulation and solution make it into different central elements as intervention is assembled, such as the pre-study. The civil servant at the agency continued:

Yes partly, of course, if the pre-study flies, if there will be attention, if the politicians want to take it further, then it's definitely a first systematic step toward a sustainable society. It is. It's supposed to

be a pilot, a source of inspiration. Tons of good things have been done around the country, but what's interesting about Gotland is that it becomes like a little mini-Sweden almost where we try to do everything all at once during a pretty short period of time $[\ldots] .{ }^{1019}$

This quotation echoes how other experts across governmental institutions and policy networks talked about Gotland and the energy pilot initiative, as well as some lines of reasoning that

\footnotetext{
${ }^{1016}$ Ibid.

${ }^{1017}$ Ibid.

${ }^{1018}$ Ibid.

${ }^{1019}$ Ibid.
} 
came up in relation to SGG. As the frictions connected specifically to experimentation as testing illustrate, however, it was by no means considered an opportunity by everyone. It is relevant to note that the Swedish Smart Grid Forum, also described as a central actor in the governmental assignment, had not become involved in the energy pilot initiative in any way at this stage. ${ }^{1020}$

The pre-study was published in mid-2018, during a public presentation on Gotland by the Energy Agency. Its contents largely reflect articulations from the interviewee. Considering how it provides direction and is thus a first step in supplying the governmental assignment with substance, the pre-study constitutes an important element of accomplishing environmental governance through the energy pilot initiative. The agency emphasizes how the energy pilot initiative is an opportunity for Gotland, thus assembling intervention through a diagnosis of possibilities. Early on in the text, it is established that it is entirely possible to create a renewable and robust energy system on Gotland, and specific socio-material elements are drawn upon to substantiate this claim. For example, it is stated that the physical preconditions are excellent on Gotland, including in terms of wind resources, hours of sunshine, and bio resources, and there is an emphasis on Gotland having a history of being a node for innovation, testing, and commercialization of new energy technology. Additionally, ambitious energy and climate policy goals from the Region and the County Administrative Board are invoked, as well as strong entrepreneurial and local engagement in energy issues on the island. ${ }^{1021}$ This further illustrates how the agency attempted to align different agendas through the initiative, trying to forge a consensus by emphasizing cooperation and collaboration, as well as win-win solutions. Uncertainty related to the future is also emphasized, such as by stating that both the requirements and the available technology might change over time, which is used to further amplify the assumed need for collaboration between actors. Authorization of the intervention clearly took on the modality of consensus, although - as we have seen - not without contestations. The Energy Agency establishes continuity as an integral element as intervention is assembled, underlining in the pre-study how it is integral to focus further upon how to proceed after the document's publication. ${ }^{1022}$

As these sections have illustrated, the entangled processes of authorization and assembling intervention entailed a constant opening up and closing down of relations between 2017 and 2018. These sections have highlighted how lines of conflict were initially laid bare, illuminating how there are essentially myriad different possible paths for experimentation to arrange environmental governance. This further highlights how experiments play a central role in the disposition taking shape through the energy pilot initiative, since experiments are ascribed the

\footnotetext{
${ }^{1020}$ Interview CM1 Swedish Smart Grid Forum.

${ }^{1021}$ Energimyndigheten 2018. Smart och förnybart energisystem på Gotland: Energimyndighetens förstudie om hur Gotland kan bli en pilot i omställningen till ett hållbart energisystem i Sverige. ER 2018:5. Bromma: Arkitektkopia.

${ }^{1022}$ Ibid. p. 7.
} 
ability to steer in specific directions and contribute to governance being accomplished in specific ways at the expense of other possibilities. In principle, the governmental assignment handed to the Energy Agency stipulated some overarching frames which the actors involved have to relate to, but in practice it seems to have been quite open at this point in time. This openness can be traced through the actions of the Energy Agency, one of the central actors in the initiative, which navigated the assignment and continuously tried to mold it. By the agency's own admission, the initiative had a unique character and was much more operative than the assignments the agency usually receives from the government. ${ }^{1023}$ As we saw in the previous part of this chapter, experiments such as Smart Grid Gotland - which came to be constituted as essentially different from the energy pilot initiative by virtue of its narrower focus, cast as a technology development and grid-owner project - are no less political. However, the lines of conflict and contestations, which were also present in the case of SGG, ${ }^{1024}$ became more accentuated through the energy pilot initiative, probably in part because of its wide-ranging scope which leaves a great deal open to interpretation and thus contestation.

The assignment handed to the Energy Agency reflects the broader political rationality underpinning smart energy experimentation in terms of basic structure, goals, and ambitions, as well as through the coordinating role afforded to the Energy Agency. It does, however, deviate in certain ways, refracting the political rationality. For instance, the role assigned to the Energy Agency is significantly different than that given to the Smart Grid Forum, which occupies a similar role at the national level, in terms of coordination, since the agency was granted quite a far-reaching mandate through the phrasing of the energy pilot initiative. Additionally, we can see the refraction of the political rationality through the awakening of alternative visions and hopes that the initiative aroused on the island, alongside a sense of precarity and peril. Thus, these sections have highlighted how the energy pilot initiative was a cause for both hope and concern in its initial stages, seemingly charged with the potential to accomplish environmental governance that is significantly different compared to SGG.

\section{Weaving existing problematics and programs into the energy pilot initiative: establishing an order of things through twists and turns}

This section will continue unpacking the processes of authorizing and assembling intervention from late 2018 to mid-2019. The Energy Agency received a renewed assignment from the government following the publication of the pre-study, to facilitate making Gotland an energy pilot region and a pioneer in the transformation to a renewable energy system. In late 2018, an Energy Dialogue was arranged by the County Administrative Board on the theme of "flexible energy systems". A few days later, the Energy Agency gave a brief presentation about the ongoing work involved in the energy pilot initiative, and Vattenfall presented a pre-study

\footnotetext{
${ }^{1023}$ Interview EXEA4.

${ }^{1024}$ Cf. Wallsten 2017. Assembling the Smart Grid.
} 
of how to connect new electricity production to the grid on Gotland without jeopardizing grid stability. ${ }^{1025}$ Observations and informal conversations during these events provided additional glimpses of the entangled processes of authorizing and assembling intervention. Assembling intervention by providing a diagnosis of possibilities surfaced on several occasions. For instance, it was reinforced in a presentation at the 2018 Energy Dialogue by a high-ranking politician on Gotland - who connected the energy pilot initiative to the national climate policy framework - stating that the energy pilot initiative provided opportunities to make things happen in a clear, coherent way. Similar articulations appeared in local daily media outlets on Gotland during that time period, including descriptions of the energy pilot initiative as a fantastic opportunity for innovation, development, and economic growth on Gotland.

Ambivalence toward the initiative among actors on Gotland also surfaced. During the presentation at the Energy Dialogue, the aforementioned politician also accentuated how the energy pilot initiative presented several challenges, and that a new power line connecting Gotland's regional grid to the transmission grid on the mainland was absolutely necessary. In an informal conversation, an expert working with environmental and energy issues at the County Administrative Board expressed frustration that the energy pilot initiative had yet to contribute to any meaningful environmental action on Gotland, or any action at all really that mattered to Gotlanders. The expert claimed that the Energy Agency had barely offered even piecemeal information about how it would proceed with the energy pilot initiative, even in meetings with representatives from the agency. This highlights the simultaneous feelings of precarity and eagerness which were seemingly present among actors on Gotland, as well as the central role of the Energy Agency in assembling the intervention, for example through its mandate to assign responsibilities to different actors.

However, the focus of most presentations during the Energy Dialogue in 2018 was mainly on the energy pilot initiative as an opportunity for Gotland. A representative from the Swedish Smart Grid Forum underlined how energy policy in general needs to be based on consensus, praising the 2017 Energy Agreement as a landmark in this regard. It was stated that Gotland has enormous possibilities to contribute to energy transformation through the innovation spirit inherent on the island, i.e. portraying Gotland as being at the forefront of technology development. Further, the representative from the Forum stated that the idea of Gotland as a local energy system disconnected from the large-scale grid might not be applicable but was still interesting, although the main question was how to develop such a configuration in a fair and equitable way in relation to the current energy infrastructure. The specific problematization painted by this presentation - one of Gotland as an innovative space where new solutions are tested for the benefit of the rest of Sweden, and that questions can be asked

\footnotetext{
${ }^{1025}$ See Lidström et al. 2018. Förstudie Gotland: Förbättrad leveranssäkerhet och ökad kapacitet för ytterligare fönybar elproduktion. Vattenfall AB, R\&D, Power Technology.
} 
in relation to the socio-technical configuration of the energy system - indicates how the Forum also occupied a central position for the energy pilot initiative.

At the time, the Forum was working on a separate initiative regarding roles and responsibilities in the future smart energy system. This separate assignment came to be articulated as a part of the energy pilot initiative on Gotland through the Energy Agency's roadmap for Gotland, highlighting how intervention was assembled via bricolage, i.e. interlinking different elements and programs. The Forum's representative also claimed that coordination was a key aspect for a successful energy transition, with reference to Germany as a cautionary tale since the energy transition there, or energiewende, was described as unfolding in a disorganized fashion. This move further reinforces the point made by the Forum's representative about the need for cooperation and consensus, clearly mirroring the broader political rationality underpinning smart energy experimentation. ${ }^{1026}$ The recurrence of such an emphasis might also indicate the negotiations necessary to forge a consensus and quell the contestations that constantly threaten to destabilize it.

Such contestations appeared during workshops at the Energy Dialogue, where a broad spectrum of actors engaged in energy converged. For instance, it was stated by someone involved in micro-production of electricity on the island that for the energy pilot initiative to succeed, it was vital that the Energy Agency would manage to create forms of participation for the local population, while embedding the initiative locally on the island. It was stated by several attendees that the initiative has to come to mean something to everyone on Gotland. Further, one attendee stated that it would not be sufficient to take a chance on individuals being creative in their respective workshops or that things will work out by themselves; there was simply no time for that if environmental goals were to be met and a crisis averted. Political decisions and courage were necessary, in the attendee's opinion. The same person also emphasized how testing and upscaling of such tests were crucial to a successful energy transition. These observations during the 2018 Energy Dialogue reinforce how the energy pilot initiative seemed to be a source of ambivalence among actors on Gotland. There was palpable frustration at the lack of action, and an ongoing campaign to make SvK reverse its decision on the transmission cable or to push the Energy Agency to take it into account in the energy pilot initiative, indicating a sense of precarity in the shadow of a distant and undecided state. On the other hand, there were also examples of a strong desire to find locally adapted solutions, to take the initiative and mold the energy pilot into an opportunity for Gotland, especially with reference to the initiative constituting a concrete form of mobilization for energy transformation. While the Energy Agency occupies a prominent position and a central role in the energy pilot initiative, there are clearly processes of opening up the initiative going on as actors on Gotland attempt to steer it in different directions. These actors did not behave as helpless victims, but actively attempted to tinker with the energy pilot initiative, albeit 
seemingly often out of frustration, as the tensions related to experimentation as testing illustrate.

Examples from presentations given by the Energy Agency and Vattenfall can further accentuate how intervention was authorized and assembled through bricolage, drawing upon problematics and invoking heterogeneous elements into the intervention, aligning existing agendas and programs. A representative from the Energy Agency described how Gotland was intended to become a source of inspiration for the rest of Sweden, and how actions with the potential for scalability would be prioritized. The Energy Agency had assigned Vattenfall the responsibility for conducting a pre-study related to grid connection and stability, as well as hiring the green liberal think tank Fores to map how different islands worked with so-called energy centers to visualize different projects and energy technologies. These two initiatives were explicitly described as pieces, or rather tiles, in the energy pilot initiative. This illustrates how the energy pilot initiative is less a matter of governance springing fully formed from an intention to address environmental issues, and more a matter of assemblage through aligning elements into a coherent ordering of the space of the intervention. ${ }^{1027}$ The reference to tiles conveys how a step-by-step approach was taking shape through the energy pilot initiative, and how relations were forged as elements were drawn into the intervention following the enrollment of different actors by the Energy Agency. Attempts at narrowing down and enclosing the space for action were constantly faced with the possibility of being opened up again, or becoming reconfigured through the realignment of existing elements or programs around the energy pilot initiative. Embedded in the rhetoric of testing, trialing, and scaling up through the energy pilot initiative, there thus seems to be a constant ongoing struggle, one that is more or less consciously waged, between different priorities, agendas, and goals. The ongoing negotiations and assembling of elements cast the field of intervention for environmental governance differently, as observed previously through Vattenfall and GEAB's insistence on the energy system being inherently large-scale contra the hopes voiced of a different, decentralized energy system on the island. Such delineations become even more accentuated with the removal of the cement producer Cementa from the field of intervention, as we saw before, despite Cementa being one of the highest-emitting industries in Sweden.

Vattenfall came to be cast by the Energy Agency as a central actor in the energy pilot initiative, since it owns the HVDC transmission cables and the connection point between the electricity grid on Gotland and the mainland grid, as well as owning the grid on Gotland through its 75\% ownership of GEAB. Thus, Vattenfall was made partially responsible for finding a solution to the conundrum posed by SvK's decision not to construct a new transmission cable. ${ }^{1028}$ As mentioned, the energy pilot initiative was construed by some actors on Gotland as an opportunity to move away from the current large-scale energy system dominated by a few

${ }^{1027}$ Cf. Bulkeley 2016. Accomplishing Climate Governance. p. 81.

${ }^{1028}$ Interview EE Gotland County Administrative Board; Interview EXEA4. 
large private companies, toward a different socio-technical configuration. The Energy Agency's appointment of Vattenfall as a central actor in the energy pilot initiative grants Vattenfall a mandate to influence how experimentation arranges governance. During its presentation of the pre-study, Vattenfall drew substantially on techno-economic modelling of the electricity system, focusing on calculated probabilities for different situations, based on data regarding electricity production on the island and export of excess electricity from Gotland to the mainland transmission grid.

The presenters also drew on their experiences in Smart Grid Gotland, stating that many households had participated and that most participants were very pleased. SGG was presented as an electricity market test which had been very successful. This indicates how Vattenfall attempted to legitimize the central position it had been assigned by the Energy Agency in the energy pilot initiative, at least in connection with the transmission cable and possibilities for developing energy storage, with reference to the knowledge Vattenfall had built up through Smart Grid Gotland. This underlines how Vatenfall was able to use its prominent position and organizational resources as leverage; conducting many experiments facilitates retaining a prominent position in a future smart energy system. Thus, knowledge politics of smart energy experimentation came into the spotlight; generating knowledge through experiments grants access to policy networks to influence green transformation. The opportunity to generate knowledge through experiments, in turn, depends on being able to climb a threshold only some have the capacity for. This, then, may well become a self-perpetuating order, illustrating how some find it easier to generate specific kinds of knowledge, allowing such knowledgeconfiguring activities to delineate energy transformation and filter out complexities, thus solidifying historical power relations in the energy sector. The pre-study concluded that it was possible to maintain grid stability and allow the connection of new electricity production on Gotland through a combined installation of battery storage and the development of a marketplace for flexibility services, at least in the medium term. ${ }^{1029}$ The presenters explicitly stated that a new connection to the mainland grid was necessary, at least around 2035.

Vattenfall and the Energy Agency explicitly drew another EU-funded research project which Vattenfall was undertaking at the time, CoordiNet, into the energy pilot initiative as a solution to Vattenfall's call to develop a local flexibility market on Gotland. This further illustrates how different elements, such as existing programs and initiatives, were drawn into the intervention, by creating relations between actors and technical configurations. Drawing CoordiNet into the energy pilot initiative demonstrates how Vattenfall was, in practice, given a mandate to influence how governance was arranged as intervention was assembled. Vattenfall was implicitly handed the possibility to influence the socio-technical configuration of the energy system, where certain configurations fall outside the scope of the intervention, thus constituting the field of intervention in a specific way at the expense of other possibilities. 
For instance, Vattenfall claimed in response to questions from the audience during a presentation that aggregators would be necessary for the local flexibility marketplace to be developed through CoordiNet, since it would be too expensive to install several hundreds of new smart meters in households on Gotland and too complex to oversee several hundreds of households buying and selling electricity across the grid. This resembles the fear of losing control of the energy system seen among grid operators. In response to a statement from an actor engaged in wind power on Gotland, claiming that a clear decision needs to be taken for things to happen on the island, representatives from Vattenfall argued that too many aspects were still shrouded and obscure, citing questions of financing and ownership of battery storage which still had to be sorted out by the government. This example illustrates how accomplishing environmental governance through experimentation is not aimless, and does not necessarily unfold through neutral testing. The example demonstrates how Vattenfall appears to act strategically, showing how accomplishing governance in the case of the energy pilot initiative is contingent but purposeful, shaped by different agendas, and risking the displacement of specific goals for the elevation of other goals, such as control of the energy system for incumbent utilities.

As these examples show, the process of forging a consensus on Gotland was far from settled in late 2018. Negotiations reaching across socio-material spectrums were lively, including the material infrastructure of the electricity system on Gotland and the contested connection to the mainland grid, embedding the energy pilot initiative on the island through authorization practices, enrolling and establishing relations between different actors as intervention was assembled. Such processes pose the question of where power resides as smart energy experimentation arranges environmental governance - for instance, who is actually enrolling whom as intervention is assembled? The examples above convey how the Energy Agency is certainly a central actor, but is essentially also muddling through in its task of facilitating making Gotland an energy pilot region. It is attempting to forge a consensus by aligning different agendas, making intervention desirable for different actors, but processes of ordering environmental governance by making the energy pilot initiative coherent and contained are constantly challenged as myriad different actors, concerns, and elements become articulated and drawn into the intervention. We have seen how there seems to have been a constant movement among actors on Gotland between casting the energy pilot initiative on the one hand as a peril - as clearly expressed in 2017 through descriptions such as not making the initiative an experimental workshop and strong claims about the need for a new transmission cable - and on the other hand as an opportunity, and active attempts to shape the initiative into an opportunity, as seen at the 2018 Energy Dialogue with references to the initiative as a mobilization and business opportunity.

Processes of accomplishing governance through experimentation thus followed the pattern established initially as the energy pilot initiative was launched. The political rationality underpinning smart energy experimentation clearly conditioned the initiative, visible in the emphasis on cooperation, win-win situations, and energy transformation as an opportunity for boosting economic growth through green energy technology export, instituting particular 
knowledge politics as outlined above. However, owing to the particular regional situation and the socio-technical infrastructure of the power grid, the phrasing of the initiative also struck a chord with those on the island who harbored hopes of a different energy system, and as the twists and turns accounted for highlight, different actors attempted to seize the opportunity by influencing the initiative in particular ways through assembling practices.

One such actor was the County Administrative Board, which attempted to interweave the energy pilot initiative with regional environmental and energy policy goals. This included presenting the energy pilot initiative as an opportunity, i.e. as a diagnosis of possibilities, in 2018. While recognizing that there were actors on Gotland who were frustrated at a perceived lack of action in the energy pilot initiative, an interviewee from the County Administrative Board stated that:

What the appointment has done, besides the Energy Agency working on it, I think, is that many people on Gotland are asking themselves, how can we contribute to the pilot? [...] It has started things up, or I think it's beginning to. There are lots of things going on in smaller projects [...]. ${ }^{1030}$

The quotation illuminates how the energy pilot initiative is argued to open up opportunities for Gotland connected to energy transformation. The interviewee continued:

Money from the Agency for Economic and Regional Growth [...] and Leader Gute have issued a call related to energy. These funds were already there, earmarked for energy [...] but I think specifically having been appointed [as an energy pilot region] makes Leader Gute organize extra mobilization and marketing, that there are these funds to start pre-studies within this area and so on. And I think that many people, perhaps specifically because of the energy pilot, they have entertained these thoughts, an idea has been formed, and then you apply for these funds. We have, I think there are 18-19 energy projects ongoing on Gotland right now on a smaller scale. And then industries like Cementa have their bigger plans, and so on. [...] Many are still raising their hands, you can see that there is an engagement, because we're all going to be part of this transition. ${ }^{1031}$

Here, the energy pilot initiative is cast as an opportunity, although not in a straightforward sense. The quotation further underlines the seemingly centrifugal character of the energy pilot initiative, as more and more existing programs - such as EU regional funds - were drawn into the initiative, while disparate ongoing energy experiments are articulated as taking place under the umbrella of the energy pilot initiative. The energy pilot initiative appears to have become a junction through which different agendas come to be realigned. Although, as we have seen, this is neither an aimless nor a seamless process. It serves to arrange governance in specific ways through experimentation, conditioned by the broader political rationality. Knowledge politics of accomplishing environmental governance through the energy pilot initiative could be glimpsed during the interview with the energy expert, for example through the following quotation:

\footnotetext{
${ }^{1030}$ Interview EE Gotland County Administrative Board.
}

${ }^{1031}$ Ibid. 
And then we try to, I guess, for some of those ideas there are already funds available, although it might be national funds or there are funds to apply for which are not only for Gotland, but which are also for Gotland. So then you can try to, it's possible to try and steer them in that way. [...] And have time to write an application. You know all about that, the time it consumes. And then maybe, if there are companies who want to start something, or non-profit organizations, to dedicate quite a lot of time without knowing that you will get these funds at the end. Because not everyone gets funding. And if you aren't resourceful to start with, the application won't turn out good, and then you won't receive funding either $[\ldots] .{ }^{1032}$

As smart energy experimentation becomes an important avenue for arranging environmental governance, being granted funding for projects consequently becomes a central issue through the political rationality's inherent tendency toward projectified public-private partnership constellations, often with the goal of commercialization. This order entails that resourceful actors with good knowledge of the complicated and intricate research funding ecosystem benefit greatly and gain an advantage over others. This was reflected in the section on SGG previously, when a project manager at Vattenfall explained how he came to be involved in the experiment because of his skills at writing funding applications and his knowledge of the funding system. As initiatives based on project funding - as different as Smart Energy City, the energy pilot initiative, or Hyllie - become a central avenue for arranging environmental governance, the preconditions for energy transformation are created accordingly, for instance through policy development. This illustrates how there is a self-perpetuating knowledge politics to smart energy experimentation, which seems to favor certain actors and pathways at the expense of others. Recall how a civil servant at the Energy Agency reflexively discussed the difficult balancing act of utilizing the resources of large, incumbent utilities without ending up in their lap in a previous chapter. Unintentionally, as a result of the broader political rationality, as well as the current socio-technical energy system infrastructure and the historically sedimented power relations inherited through it, smart energy experimentation arranges environmental governance so that experimentation is geared in favor of incumbent, large private companies.

As already mentioned, actors on Gotland did not come across as helpless victims, despite having to deal with a situation that was far from ideal. The energy expert at the County Administrative Board described how, in talks with the Energy Agency, it was not entirely clear within what capacity Gotland was to become a pilot region; however, it was clear that one dimension included achieving the national environmental policy goals before other Swedish regions, especially the energy and climate policy goals. By being appointed an energy pilot region, Gotland is thus supposed to reach national environmental policy goals first and show the rest of Sweden how it is possible to scale up such ambitions to the rest of the country, illustrating how experimentation in the form of testing through piloting and then scaling up is increasingly becoming a central avenue of governance in Swedish environmental politics. The

${ }^{1032}$ Ibid. 
energy expert stated that making Gotland a pilot region presents challenges, since Gotland's preconditions are far from ideal, with reference to a mapping of regionalization of national energy and climate policy goals which indicated that Gotland will reach these goals last of all Swedish regions, due to factors such as its the reliance on fossil fuels for transportation and Cementa's fossil fuel-based operations. ${ }^{1033}$ However, the energy expert continued by stating that:

We have good preconditions for renewable energy, and it's easier to look at an energy system of an island [...] so I think it's great that we will get this venture because we might not have managed these things so easily. [...] To be appointed as a pilot can involve other actors who wouldn't have been involved otherwise. You see that you have a role to play in helping Gotland becoming a pilot. So that's where I hope to get a little bit of help, too. ${ }^{1034}$

In this instance, the energy pilot initiative is realigned with Gotland's energy and climate policy ambitions, and turned into a resource for achieving goals which might otherwise have been very difficult. In relation to such ambitions, it appears that the County Administrative Board attempted to enroll the Energy Agency in a new climate and energy strategy being developed at the time. The interviewee stated that:

And when we have discussed the energy and climate strategy, so far we are working with five focus areas, where one is $[\ldots]$ sustainable energy systems [...] that focus area will to a large extent be the Energy Agency's roadmap. So they will become responsible for driving that forward.$^{1035}$

This quotation illustrates how the energy pilot initiative comes to be even more clearly aligned with energy and climate policy goals on Gotland, and thus entangled with the agendas of the County Administrative Board and Region Gotland. The Energy Agency's governmental assignment to make Gotland a pilot region is turned into a resource which can contribute to environmental ambitions on Gotland. Throughout the energy and climate strategy, the energy pilot initiative is woven into suggested measures across issue areas related to energy, and the Energy Agency is cast as a central actor for achieving environmental goals on Gotland. ${ }^{1036}$ Perhaps this is made possible by the unusual character of the governmental assignment handed to the Energy Agency; the energy expert at the County Administrative Board explained how it had not been entirely clear how the Energy Agency would embed the assignment locally on Gotland, and it was not entirely clear which roles the Energy Agency wanted the County Administrative Board and Region Gotland to assume. ${ }^{1037}$ This further illustrates how the energy pilot initiative entailed twists and turns as the intervention was authorized and assembled, elucidating how the initiative involves the possibility of opening up for challenging the broader political rationality underpinning smart energy experimentation.

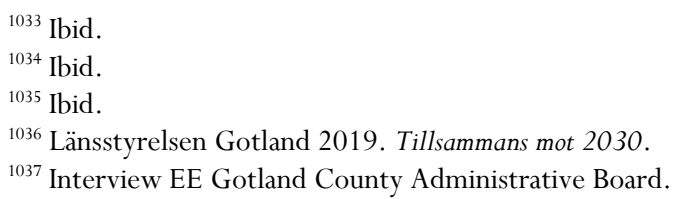


The interviewee also reflected on causality in chains of events, such as whether it is the Energy Agency's energy pilot assignment, frequent power outages on Gotland, SvK's decision, or other matters that have been the main driver on Gotland. This line of thought illustrates the contingencies of accomplishing environmental governance. As we have seen, all of the problematics mentioned by the energy expert and more have been drawn into the energy pilot initiative by different actors, providing a common junction through which agendas become realigned. Or, rather, a constant struggle to define the scope and field of intervention, as well as the boundaries of the intervention, is continuously unfolding. As these and other examples in this section show, the energy pilot initiative appears to have a centrifugal effect through which elements are drawn into the intervention, new relations are created and existing relations are reconfigured, resulting in both possibilities and vulnerabilities as intervention is assembled. We have seen how experimentation arranges environmental governance through twists and turns, and knowledge politics instituted through the political rationality underpinning smart energy experimentation becomes infused into the energy pilot initiative. Environmental governance becomes a matter of latching on to funding infrastructures through access to the Energy Agency for some actors, and for others to utilize the Energy Agency as a resource for energy and climate policy goals, highlighting how the political rationality is also refracted as ambitions are to be realized and intervention is assembled. For yet others, it is a matter of attempting to push the socio-technical configuration of the energy system in a different direction, although this course of action seems to have been difficult to weave into the energy pilot initiative thus far. There seems to be an ongoing opening up and closing down of relations, defining the field of intervention. The Energy Agency, however, occupies a central position through its ability to enroll specific actors into the assignment, distribute responsibilities, and provide access to funding, making the agency a central actor for assembling intervention.

\section{Folding future into present: collaboration for a green energy future on Gotland and beyond}

Related to the central role of the Energy Agency, a key element of assembling the intervention was the roadmap developed by the agency and published in mid-2019. We will now move to 2019, to analyze the roadmap and interviews with representatives from the Energy Agency and the Swedish Smart Grid Forum, i.e. the central national actors in the energy pilot initiative thus far. This section will constitute the final part of the snapshot of the entangled processes of authorizing and assembling intervention as they have unfolded through the energy pilot initiative up until the summer of 2019.

The Energy Agency's central role is reflected in the roadmap, which was unveiled at a public presentation in late April 2019. In the document, central actors are specified, including the County Administrative Board, Region Gotland, the Energy Markets Inspectorate, Svenska Kraftnät, and the Swedish Armed Forces. These are the actors the Energy Agency has enrolled as being central for the energy pilot initiative. The inclusion of the Swedish Armed Forces signals a shift away from the pre-study published in 2018, as an emphasis on security and 
robustness is amplified in the roadmap. There is also an emphasis on the importance of dialogue with many different actors on Gotland in the development of the roadmap. ${ }^{1038}$ Authorization worked through the modality of consensus throughout the initiative up until this point, which is reflected in the document. There is an emphasis on cooperation and collaboration, similarly to the new energy and climate strategy developed by the County Administrative Board titled “Together toward 2030". Importantly, it is also stated in the roadmap that the document is one of many steps toward creating a sustainable energy system on Gotland, reiterating the aforementioned ideas of transforming the energy system through a stepwise process. This further highlights how elements and existing programs are drawn into the intervention as it is assembled, such as an amplified focus on security in the roadmap and the inclusion of Gotland in the EU initiative Clean Energy for EU Islands during the process of developing the roadmap. ${ }^{1039}$ The Energy Agency also explicitly connects to the Paris climate agreement, the United Nation's global goals, and Sweden's energy and climate policy goals as the impetus for making Gotland an energy pilot region, stipulating how the three overarching energy policy goals of security of supply, competitiveness, and ecological sustainability constitute the guiding principles for the entire initiative. ${ }^{1040}$

In terms of the overarching framework of the roadmap, it is constructed around specific measures to be taken, including appointed actors who are responsible for these measures. It is stated that these measures are intended to concretize the pre-study published in the previous year. ${ }^{1041}$ The measures span the areas of local embedding of the energy pilot initiative, a flexible and robust electricity system, climate-smart industry, a fossil-free transport system, resource efficient buildings, and farming. ${ }^{1042}$ It is specifically stated that measures which are scalable for transforming the energy system across the entire country have been prioritized, and all measures have been assessed based on their economic consequences. ${ }^{1043}$ It is further stated that funding will mainly come from various existing financial sources, both private and public, but the Energy Agency also suggested that a new annual call specifically for projects on Gotland needs to be instituted in order for Gotland to become a pilot region and accelerate the energy transition. The Energy Agency also emphasizes cooperation and expresses a wish to develop collaboration in the future with the appointed central actors as well as other actors on Gotland, and articulates that it aims to structure the ongoing work of the energy pilot initiative as a program internally at the agency, and also to link a working group and reference group including representatives of the central actors to this program. ${ }^{1044}$ The desire to institute

${ }^{1038}$ Energimyndigheten 2019. Energipilot Gotland: Färdplan för att möjliggöra att Gotland blir pilot för ett hållbart energisystem. ER 2019:09. Bromma: Arkitektkopia.

${ }^{1039}$ Ibid. p. 7.

${ }^{1040}$ Ibid. p. 10.

${ }^{1041}$ Ibid. p. 10.

1042 Ibid.

${ }^{1043}$ Ibid. p. 7.

${ }^{1044}$ Ibid. p. 9. 
a program internally at the agency highlights continuity problems that appear in projectified governance contexts. The reason behind the wish to institute a program was to retain the structure of personnel, as by now many contact points had been established on the island while the individuals were well-known, underlining the importance of embodied knowledge for long-term endeavors. Proceeding in project form would undeniably bring fragmentation, since it might necessitate shifting personnel and breaking up the established internal organization at the agency.

There is also an emphasis on regular evaluation, and revising the roadmap as the energy pilot initiative proceeds, in collaboration with Uppsala University's Campus Gotland, Region Gotland, and the County Administrative Board. This overarching framework provides an additional illustration of how the Energy Agency approaches the task assigned by the government. It seems to be an extension of the ongoing attempts to forge a consensus, thus authorizing the intervention, as well as further examples of the centrifugal character of the initiative as additional elements are drawn into the intervention. It also illustrates how experimentation arranges governance in specific ways through the initiative. A disposition is emerging through the energy pilot initiative, as specific actor constellations are being formed, relations between actors are being forged, and agendas are being realigned. The socio-technical infrastructure of the grid is also emerging as a central element of accomplishing governance, as we saw in the previous section in which specific configurations were articulated as being possible and others as less likely, for instance with reference to the structure of the flexibility market developed by Vattenfall and the question of energy storage on Gotland, as well as the connection to the mainland transmission grid. Roles and responsibilities are assigned, while different existing programs such as funding infrastructures and EU initiatives are drawn into the intervention as it is assembled and authorization is practiced.

Specifically, the Energy Agency and other involved actors are keen to promote the tentative character of the energy pilot initiative. In the roadmap, it is stated that making Gotland an energy pilot region that achieves environmental goals before the rest of Sweden is a matter of testing, and then revising the roadmap along the way. The phrasing of Gotland specifically as a pilot thus seems to entail being a frontrunner, moving ahead for the rest of Sweden to follow, and testing, albeit within a range of different areas connected to energy in different ways, as the overarching groups of measures in the roadmap indicate. The scope of the energy pilot initiative is thus very far-ranging, although it has been narrowed down temporarily through interlinkage with other ongoing initiatives such as the CoordiNet project run by Vattenfall, as well as the County Administrative Board's mapping of different small-scale energy projects on Gotland. Connected to this, several elements already discussed in previous sections are also present in the roadmap. Gotland is articulated as an arena and a node for innovation, tests, and the commercialization of new energy technology. ${ }^{1045}$ 
Demonstration on Gotland of what works and what does not, first on a small scale and then scaling up, is articulated as the key feature of the energy pilot initiative, which will result in Gotland becoming a place where the possibility of transforming to a sustainable energy system will eventually be demonstrated, it is claimed. ${ }^{1046}$ This underscores a tension which runs through different experiments, and among experts across governmental institutions and policy networks: experiments are ascribed the ability to demonstrate what works and what does not through testing, although they are also described as being vital for demonstrating that specific pathways of energy transformation are desirable and possible, sometimes expressed as a need to spread positive examples and sometimes expressed as experiments being vital for marketing specific products or competencies. There appears to be a connection to the broader political rationality underpinning smart energy experimentation, and the ensuing ambitions of making Sweden into an environmental frontrunner by exporting smart energy technology. This seemingly posits boundaries around how experimentation is allowed to arrange governance, or at least shape the setup of experiments. In the roadmap, there is also an emphasis on embedding the initiative locally among actors on Gotland, making it meaningful for Gotlanders to engage in the energy pilot, and a strong emphasis on consensus and collaboration runs throughout the document. There is an emphasis on mobilizing actors on Gotland, as well as knowledge transfer from the energy pilot initiative and scaling up to the rest of Sweden. However, not much is explained about how this is imagined to happen in practice. Nonetheless, there is a clear idea expressed that the energy pilot initiative will spark further small-scale projects, or experiments, on Gotland, which will contribute to Gotland achieving environmental policy goals before the rest of Sweden. ${ }^{1047}$ The clearest articulation of scalability is that: "the more demonstration projects there are, the more robust results there will be to spread nationally". ${ }^{1048}$ Scaling up thus appears to be a concept which is generally taken for granted in the document, which as we have seen throughout this study is often the case among different actors, at least on the surface.

This is a logical consequence of the broader political rationality; if the main remedy of environmental harm is to develop new products and services, new experiments geared toward commercialization will always be needed. There are, however, also many examples of actors critically reflecting on what it means to scale something up, although - as we have seen - who is responsible for learning and doing the upscaling in practice is often unclear, as different actors tend to think that these issues are for someone else to deal with. This can also be productively understood through the lens of the broader political rationality underpinning smart energy experimentation, since governance arrangements such as public-private partnership constellations working in individual projects and networked governance with unclear responsibilities are favored. Thus, accomplishing environmental governance through 
smart energy experiments often appears to entail an almost organic idea of learning and upscaling, frequently defined as reaching out to as many different publics and forums as possible, and regularly crystallized into marketing efforts, place-branding, or internal knowledge circulation with the purpose of organizational change and the commercialization of new technologies. This illustrates the tension between testing and marketing, where marketing often gets the upper hand as the political rationality entails conditioning experiments toward commercial endeavors driven by established private companies, in the hope of greening economic growth through developing ever more new products and exporting such smart energy technology. It is important to emphasize that testing is never innocent, ${ }^{1049}$ although the marketing and frontrunner emphasis squeezes out ambitions of open testing into the marginal, making such ambitions secondary to export and credibility-making.

According to a civil servant at the Energy Agency, the agency was handed some additional directives by the government when developing the roadmap, and based on these the agency came to emphasize speeding up the transformation and scaling up in the final version of the text. ${ }^{1050}$ It was posited that:

[...] so I think that when you look at the roadmap, and at what the contribution is, so to speak, I don't think you should stare blindly at the individual measures, it's rather that you can get the entire system to move. ${ }^{1051}$

In this quotation, it appears that the Energy Agency's ambition with the energy pilot initiative is to change several large socio-technical systems, as also indicated by the broad span of measures in the roadmap. The interviewee further stated that:

What we want rather is for these actors themselves to see advantages in advancing their positions, to become more offensive. To want more, to see the value of it. ${ }^{1052}$

Clearly, the agency was still attempting to forge a consensus by offering a diagnosis of possibilities at the time of the interview. It attempted to make the intervention desirable for different actors by drawing on broad problematics, assembling these into the junction provided by the energy pilot initiative wherein agendas can be realigned. As we have seen previously, this endeavor is far from straightforward. There was a frequent emphasis on collaboration between actors from different parts of society throughout the interview, as well as in the roadmap, indicative of arranging governance through public-private partnerships to a large extent. It is also stated that endeavors connected to the initiative need to be profitable, which echoes a phrasing at the 2017 Energy Dialogue where an attendee explained how no energy transition will ever come to pass unless it is made profitable. This emphasis on profit, implicitly

${ }^{1049}$ Cf. Marres \& Stark 2020. Put to the test; Edwards \& Bulkeley 2017. Heterotopia and the urban politics of climate change experimentation.

${ }^{1050}$ Interview EXEA4.

${ }^{1051}$ Ibid.

${ }^{1052} \mathrm{Ibid}$. 
assigning a central role to private companies, is in line with the broader political rationality underpinning smart energy experimentation. The civil servant at the agency stated that:

Then I think that in the long run, let's say that we get this roadmap rolling, or the energy pilot rolling, and perhaps accelerate over time, then I hope, and that's more of a hope I guess, that it's something that you want to be a part of. And perhaps choose to go to the island and engage in different projects starting up. [...] you see that you can be part of a bigger context. [...] You latch on. ${ }^{1053}$

This quite clearly illustrates how environmental governance is accomplished through the initiative. The Energy Agency attempts to assume the role of coordinating and facilitating, assigning roles to different actors, and to create an arena through the energy pilot initiative which, in the long term, will make it profitable and desirable for different actors to engage in the energy pilot. The main form of engagement appears to be via different projects, i.e. it will be up to different actors to apply for funds through different channels to carry out experiments which are then articulated as part of the energy pilot. Testing in general is articulated by the interviewee, and in the roadmap, as a central characteristic of the energy pilot initiative. The following quotation demonstrates this:

You have new services that might need to enter [the energy system] given that you have more renewable electricity production, and in the light of that I think that it can be valuable to test different business models, test different technical solutions on a smaller scale, or, well, under delimited forms you might say perhaps. And during a delimited period of time, to see if the results turn out to be what you hope for or expect, or whether they are something else before you go for

$$
\text { it. }{ }^{1054}
$$

The interviewee showed an awareness that there are however clearly multiple, very different ideas on the island about what it means to be a frontrunner, i.e. there are different ideas about which pathways the energy pilot initiative should take, and the interviewee stated that there are very diverging interests both among actors on Gotland and among different national actors as well as within the Energy Agency, meaning constant negotiations. ${ }^{1055}$ The interviewee stated that "sometimes you have to be prepared to wheel and deal a little bit", and specifically stated that in relation to the group of measures in the roadmap connected to a robust and flexible electricity system there are many actors with strong interests, such as Vattenfall, GEAB, the Energy Markets Inspectorate, and so on. ${ }^{1056}$ This underlines both the contingencies as the energy pilot initiative unfolds through twists and turns, and the contested nature of energy transformation.

Connected to this line of reasoning, the interviewee also stated that the Energy Agency refrained from setting any timeline for the energy pilot initiative, since it was considered

\footnotetext{
${ }^{1053}$ Ibid.

${ }^{1054}$ Ibid.

${ }^{1055}$ Ibid.

${ }^{1056}$ Ibid.
} 
important that such measures came from Region Gotland. This was motivated since it creates legitimacy on the island and takes the Energy Agency out of the spotlight somewhat, according to the interviewee. ${ }^{1057}$ This further highlights important aspects of assembling and authorizing intervention. It seems clear that the agency is attempting to take on a coordinating role, while others, mainly actors on Gotland and a few government agencies, will be responsible for operationalizing the energy pilot initiative. This is mainly set up to unfold through collaborative experiments enabled by project funding, essentially mirroring how smart energy experimentation arranges environmental governance at the national level. However, the ability to appoint specific actors, as well as the problem formulation privilege that is placed with the Energy Agency, grants them an elevated position. They appear aware of this, and in order for the ordering of environmental governance which is undertaken to be perceived as legitimate, constituting a rightful orchestration of power, they emphasize enrolling certain actors on Gotland. As we have seen, this also means that these actors, such as the County Administrative Board, are also attempting to realign the energy pilot initiative with their own agendas, e.g. through drawing the Energy Agency into their own energy and climate strategy for Gotland, with responsibility for the focus area of sustainable energy systems.

Through the interview with the civil servant at the Energy Agency, it also became clearer how the agency relates to the characterization of the initiative specifically as a pilot, and whether it can be considered a next step after experiments such as Smart Grid Gotland. The interviewee explained:

Well it depends on how you view it. It is a new approach, definitely [the energy pilot initiative]. I mean normally when we talk about a pilot we talk about, well you apply a technology, well we can take the case of Cementa and Cemzero [a large project attempting to decarbonize Cementa's production through electrification and carbon capture and storage]. There you've looked at the preconditions in an initial project, the next step is a pilot, the next step is demonstration, the next step is, well, full-scale implementation really. So normally when we talk about a pilot at the agency we think about testing a technology at one facility. And here it's not just about that, but infinitely much more. [...] The forms of cooperation, making different actors want to do things, making individuals do things and engage. For one reason or another. ${ }^{1058}$

Through this instance, quite a clear difference between the energy pilot initiative and other pilots, presumably including SGG, is articulated. Spatial boundaries and the scope of the intervention are articulated as essentially different from other pilots. However, the notion of achieving transformation of the energy system through a stepwise process of different types of experiments is present, a notion which - as we have seen in previous chapters - appears to flow as an undercurrent across smart energy experimentation, clearly in line with the broader political rationality. The interviewee further draws upon the now familiar TRL scale, stating that the agency hopes that the energy pilot initiative will "be on the second half of that scale", 
further accentuating such notions of change. ${ }^{1059}$ The quotation also underscores how assembling and authorizing intervention hinges upon providing a diagnosis of possibilities, enticing others to engage by making the intervention desirable. This suggests that the political rationality underpinning smart energy experimentation conditions the energy pilot initiative, as significant effort is devoted by the Energy Agency to making experimentation profitable. Additionally, the quotation highlights contingencies of accomplishing governance, as interlinkages between different socio-material elements are created, reinforced, and potentially unmade. As we have seen throughout this chapter, such elements include specific technologies for monitoring the power grid, a regional energy and climate strategy, testing, notions of scale, and the material configuration of the electricity system.

The contingencies of accomplishing environmental governance through the energy pilot initiative are further accentuated through the involvement of the Swedish Smart Grid Forum. During the development of the pre-study in 2017, it was unclear what the Forum's role in the energy pilot initiative would be. ${ }^{1060}$ Its involvement, as detailed in the directive from the government to the Energy Agency for the pre-study, came to be delineated to a broader endeavor it was already undertaking, related to roles and responsibilities in the future smart energy system. ${ }^{1061} \mathrm{~A}$ cabinet member of the Forum explained how the question of roles and responsibilities is very delicate, since there are strong interests related to the socio-technical configuration of the energy system. ${ }^{1062}$ The interviewee also stated that making Gotland into a national project was a good move, since it constituted a way of turning a challenge into a possibility, referencing SvK's cable decision. ${ }^{1063}$ Gotland was further described as a testbed by the interviewee, which could hopefully become internationally profiled. ${ }^{1064}$ This echoes both the Energy Agency's attempts to make Gotland into an arena where many different tests are undertaken, which can then be scaled up, and the insistence among some actors that the energy pilot initiative was full of promises. Further, it mirrors the significant emphasis on marketing within smart energy experimentation, reflected in the Swedish frontrunner and export ambitions.

Related to the contingencies of accomplishing environmental governance, the cabinet member stated the energy pilot initiative appeared to be a "moving matter", in a constant state of flux. ${ }^{1065}$ The cabinet member further explained that the initial idea was that the Forum should work closely with Vattenfall as it developed its pre-study related to connecting new electricity

1059 Ibid.

${ }^{1060}$ Interview CM1 Swedish Smart Grid Forum.

${ }^{1061}$ Interview EXEA4; Energimyndigheten 2019. Energipilot Gotland; Interview CM2 Swedish Smart Grid Forum.

${ }^{1062}$ Interview CM2 Swedish Smart Grid Forum.

${ }^{1063}$ Ibid.

${ }^{1064}$ Ibid.

1065 Ibid. 
production and grid stability, where the Forum should specifically evaluate whether the solutions suggested by Vattenfall would be possible to scale up anywhere across Sweden. However, as the interviewee explained, this initial idea changed when Vattenfall became engaged in the CoordiNet project:

And that project has kind of become woven into this Gotland assignment, which perhaps was not from the beginning about, well, there was a strong interest related to looking at a flexibility market, not only technical solutions, and this answered to that I would say. This means that there are completely different time horizons for these projects, so our delivery to the Energy Agency has been to look at flexibility resources, we look at load management, load curtailment, aggregation, and then we look at the question of energy communities and their relation to contemporary regulations [...]. As a kind of knowledge basis. And they have received that. And, well, that's where we are now. ${ }^{1066}$

This provides yet another example of how existing agendas have come to be realigned through the locus of the energy pilot initiative, and how ongoing programs and endeavors are drawn into the initiative as intervention is assembled. Ordering environmental governance through the energy pilot initiative has thus been largely a matter of bricolage so far, and a constant opening up and closing down of relations through ongoing negotiations. Consequently, the energy pilot initiative appears to have a centrifugal effect where more and more elements are drawn into it as intervention is assembled, while at the same time ongoing endeavors become interlinked with the initiative.

Attending analytically to processes of authorizing and assembling intervention highlights how the energy pilot initiative arranges environmental governance differently compared to SGG and the urban experiments of the previous chapter. The initiative was immediately charged with the potential of opening up how environmental governance could become arranged through its unique character, compared to the other experiments, leading to twists and turns where relations were continuously opened up and closed down. Still, as we have seen it is also conditioned by the broader political rationality underpinning smart energy experimentation, instituting specific knowledge politics. The Energy Agency is, by virtue of the framework of the energy pilot initiative set out in the governmental directives handed to it, afforded a key position knowledge-wise, for example in terms of appointing central actors as well as owning the problem formulation privilege and through being a major funder of the types of initiatives which are increasingly becoming interlinked with the energy pilot initiative. Thus, the agency has a strong position through being able to enroll specific actors which might close certain doors and open others.

Through this prominent position in terms of adding flesh to the bones of the energy pilot initiative, the agency occupies a prime position for assembling intervention. A central characteristic is the tentative qualities connected to testing woven into the energy pilot 
initiative, not least by the Energy Agency. There is a passage in the roadmap which highlights a central tension of smart energy experimentation connected to testing. The Energy Agency states that while measures connected to the area of flexible and robust electricity system will not be able to solve "all future challenges", they are important steps along the way "for a Gotland with increased renewable electricity production and a robust electricity system". ${ }^{1067}$ Additionally, it is also stated that the energy pilot initiative will include constant revisions of the suggested measures, so changes are to be expected, which was also emphasized in interviews with key actors, but the measures suggested by the agency are still described as scalable and relevant for the rest of Sweden. This illustrates how a specific problem with a specific solution is construed, i.e. increasing renewable electricity production on the island and connecting it to the large-scale grid, but also a larger tension cutting across smart energy experimentation. There is a substantial emphasis on prioritizing scalable solutions, which are relevant not only for Gotland but also for the rest of Sweden on the one hand, while on the other hand uncertainties and tentativeness of testing are emphasized. There is at least a friction between such an emphasis; is it possible to test under uncertain conditions and learn through such tests, if there is an imperative that what is being tested has to be possible to scale up and be relevant across all of Sweden and hopefully exported abroad? It is again worth noting that what scaling up means in practice is not clearly expressed in the roadmap. The incessant emphasis on scaling up in the energy pilot initiative also begs the question: Where is Smart Grid Gotland?

Consequently, in the following sections we will closely examine different types of circulations connected to the energy pilot initiative, as well as specific ideas about circulations. This is especially relevant considering that scaling up is a substantial, if not the most central, focus of the entire energy pilot initiative, while such a focus can also disentangle the interrelation between SGG and the energy pilot initiative.

\section{Circulations: scaling up through infrastructure of nodes and channels?}

As stated, circulations connected to the energy pilot initiative entail different temporalities when compared for instance to Smart Energy City or Smart Grid Gotland. No material construction has commenced for the energy pilot, and it does not consist of an individual, spatially confined experiment; it is rather an ecology of interventions. Studying circulations in the case of the energy pilot initiative thus means unpacking notions connected to circulations, such as upscaling, and how different actors attempt to institute infrastructures of circulation in a different temporality than SGG, for example - in other words, studying circulations in the case of the energy pilot means focusing on a different phase of the intervention than e.g. Smart Energy City, as well as a more encompassing scale. As argued, this constitutes a relevant

${ }^{1067}$ Energimyndigheten 2019. Energipilot Gotland. p. 29. 
empirical avenue to investigate an attempt at instigating transformative change through "moving beyond" experiments as it unfolds, which can reveal what meaning is attributed to scaling up, both as a notion and in practice.

A central focus of this section will be the interrelation between Smart Grid Gotland and the energy pilot initiative, specifically asking whether and how knowledge or other aspects of SGG are circulated into the energy pilot. Consequently, the following section on the interrelation between SGG and the energy pilot will to a large extent revolve around the question of whether and how scaling up happens in practice on Gotland, unpacking what upscaling comes to entail in practice in circumstances described by some as ideal for scaling up. Then, we will move to examine forms of circulation associated specifically with the energy pilot initiative, especially related to a measure in the Energy Agency's roadmap about establishing a so-called energy center on Gotland. Through this analytical focus, it is possible to gain a deeper understanding of how environmental governance is accomplished through smart energy experimentation, for example in terms of creating interlinkages and attempting to gain traction for specific problematizations formed and upheld through experiments. As in the previous chapter, the question of whether the energy pilot initiative facilitates the creation of infrastructures that enable movement, the channels of movement, and the actors facilitating movement is of particular interest, since such a focus can help with unpacking how elements of a governmental apparatus are stitched together. It can further highlight how the political rationality underpinning smart energy experimentation facilitates the creation of certain infrastructures of circulation, as well as elucidating twists and turns as dynamic processes of accomplishing governance unfold.

\section{Circulating elements of SGG into the energy pilot initiative: scaling up as a modality of circulation?}

As we saw in a previous chapter, experts across governmental institutions and policy networks described the energy pilot initiative as a golden opportunity for scaling up, referring to the recent conclusion of Smart Grid Gotland. ${ }^{1068}$ Similar aspirations were expressed in the Energy Agency's initial assignment of producing a pre-study. In the text describing the assignment, it was specifically stated that experiences from previous smart energy projects were to be taken into account in the pre-study. ${ }^{1069}$ As shown, several actors on Gotland also expressed hopes that the energy pilot initiative would constitute a next step after SGG. An energy expert at the County Administrative Board, for instance, stated that:

[...] the Energy Agency has an assignment that involves looking at the entirety. It should utilize experiences from Smart Grid Gotland. ${ }^{1070}$

\footnotetext{
${ }^{1068}$ E.g. Interview EXE2.

${ }^{1069}$ Regeringskansliet 2017. Smart och förnybart energisystem på Gotland. p. 2.

${ }^{1070}$ Interview EE Gotland County Administrative Board.
} 
In this instance, it appears quite clear that the Energy Agency has been assigned the role of learning from SGG and making sure that this knowledge is utilized in the energy pilot initiative. The interviewee further stated that the energy pilot initiative could hopefully be a continuation of SGG, and a way of moving beyond experiments, through learning from SGG. ${ }^{1071}$ As we have seen, there are several factors complicating hopes of straightforward upscaling. In general, actors tend to attribute responsibility for learning from and moving beyond experiments to someone else. Recall, for example, how civil servants at the Energy Agency articulated that learning from experiments was mainly for the private companies involved, whilst other experts at the national level stated that this responsibility lies with the Energy Markets Inspectorate, and an interviewee at the Energy Markets Inspectorate claimed that it was rather up to the Energy Agency to learn from experiments.

According to a civil servant at the Energy Agency, the energy pilot initiative could be understood as a next step beyond experiments such as SGG. It was further stated that:

Then specifically how we will relate to Smart Grid Gotland, I assume that there are good opportunities to take the outcomes of that project into account. Ideally one of my groups is looking at it. But I wouldn't say that this is, that our assignment is a Smart Grid Gotland 2.0. [...] No, it's not quite as simple as that. [...] There are other actors here as well, it's much, much broader. ${ }^{1072}$

As we saw in the previous section, the energy pilot initiative tends to be articulated as essentially different from SGG, often with reference to the spatial and temporal boundaries and the scope of the two endeavors. The interviewee specifically noted that no specific timeline has been set for the duration of the energy pilot initiative. ${ }^{1073}$ Obviously, this is in glaring contrast to Smart Grid Gotland. In practice, however, experiences from SGG were circulated in a sense into the energy pilot initiative during the development of the pre-study, albeit in an indirect way. As highlighted in the previous section, the agency organized its work with the pre-study according to specific thematic groups where experts within the agency contributed to a large list of measures which could potentially be included in the pre-study. According to the civil servant:

[...] our way of working with measures is, it's people who work with this. Who work with the demonstrations, for example. [...] and when I mention these focus areas there are those who are responsible for each area and those are all internal. ${ }^{1074}$

The interviewee further explained how it might be relevant to also consider input provided to the Energy Agency by external actors, where the participants in Smart Grid Gotland constituted one such example, and in general the interviewee stated there were many different ways of ensuring experiences from previous experiments could be utilized in the energy pilot

\footnotetext{
${ }^{1071}$ Ibid.

${ }^{1072}$ Interview EXEA4.

${ }^{1073}$ Ibid.

${ }^{1074}$ Ibid.
} 
initiative. ${ }^{1075}$ However, the main method for transferring knowledge from previous experiments such as SGG, as specified by the interviewee, was to involve different experts within the agency in the thematic group on smart grids. In these groups, different ideas of measures for the pre-study were compiled and then it was up to the core group involved in the energy pilot initiative to decide which to include in the actual pre-study. In other words, it is a form of knowledge circulation internally within the Energy Agency, where the involvement of knowledgeable personnel for developing suggested measures to make Gotland an environmental frontrunner is intended to ensure that knowledge is transferred. Thus, an infrastructure of circulation was established within the confines of the Energy Agency. This further elucidates how smart energy experimentation arranges environmental governance in line with a project structure, as elucidated by the temporary pooling of expertise within the agency in order to launch new experiments within the energy pilot initiative. Recall how experts at the agency explained how knowledge tended to remain with individuals involved with experiments funded by the agency.

It is difficult to analyze this process in practice, since it was conducted internally at the agency. Smart Grid Gotland is, however, not mentioned in detail in the published version of the prestudy. It is stated that SGG provided many good results related to demand flexibility, and it was further stated that creating price signals and incentives for local flexibility was difficult in the experiment. However, this was articulated as a key question for the entire Swedish electricity system. ${ }^{1076}$ Connected to this point, SGG was mainly mobilized in the pre-study related to Vattenfall's assignment to develop an additional pre-study about how to enable connection of new electricity production on the island without risking grid stability. It was stated specifically that Vattenfall's pre-study could be considered a continuation of SGG, which had illustrated the continued need to create incentives for actors to be flexible and find solutions for unlocking flexibility in the electricity market. ${ }^{1077}$ As we saw in the previous section, Vattenfall appears to be using its involvement in SGG during presentations to consolidate the central position it has been afforded in the energy pilot initiative, and this can be considered a form of circulation in terms of circulating a specific story, using SGG to showcase Vattenfall's competence. In a sense, then, participating in SGG allowed Vattenfall to consolidate its prominent position in the energy system as experimentation arranges environmental governance. Nonetheless, the interrelation between SGG and the energy pilot initiative appears to complicate notions of straightforward upscaling.

Despite such complications, smart energy experimentation is generally motivated through experiments' assumed contribution to transformative change of infrastructures, whereas the energy pilot initiative was regularly referred to as a golden opportunity for scaling up SGG. As we have seen, this tends to be referred to as scaling up no matter which space of governance

\footnotetext{
1075 Ibid.

${ }^{1076}$ Energimyndigheten 2017. Smart och förnybart energisystem på Gotland. p. 24.

1077 Ibid. p. 27.
} 
one taps into - it is as common among experts across governmental institutions as it is in the corridors of grid operators or the halls of local public administrations. As we saw in the section on SGG, notions of scaling up are further complicated since much of the technical configuration trialed was essentially dismantled after the experiment had been concluded. Project managers at Vattenfall claimed no knowledge of what would follow on from SGG, and implied that this was rather a matter for GEAB, while interviewees at GEAB stated that SGG had been concluded and dismantled. As stated in the section on SGG, GEAB did not want to keep much of the technical equipment installed, so much of this was simply taken down or sold. An interviewed civil servant at the Energy Agency reiterated how the approach of developing the pre-study meant an inventory was created, including SGG, where relevant pieces could be singled out and applied on Gotland. ${ }^{1078}$ It was stated that it was essentially up to individual experts within the agency to take stock of different areas, so it was difficult to say exactly whether or which aspects from SGG had influenced the energy pilot initiative. The interviewee stated that:

I mean, I don't know the details of Smart Grid Gotland anymore, some things are forgotten quicker than you would like sometimes. But there I suspect that the debriefing is done through the final report, slap-bang. Then Smart Grid Gotland is debriefed and finished, while this [the energy pilot initiative] will be continuously ongoing in different ways. I mean today there aren't many people who remember Smart Grid Gotland. It is debriefed. A traditional research project really. But with Gotland we can't work with a debriefing sometime in x number of years, here it's rather about spreading the message continuously as things happen. ${ }^{1079}$

Again, differences in spatial and temporal boundaries are underscored as essentially different between the two endeavors. Crucially, it is stated that since SGG has been concluded, no one remembers it anymore. ${ }^{1080}$ As in the case of the urban smart energy experiments of the previous chapter, circulations occur in the case of SGG as well. As we saw in the section on SGG, the grid operator GEAB commercialized certain parts of SGG, such as offering the smart summer house and smart church services, as well as some parts of the technical setup enabling monitoring of the low-voltage grid. Vattenfall decided to implement the ICT solution for monitoring the low-voltage grid in other parts of Sweden as well, indicating a circulation of knowledge internally in the organization as well as the circulation of a specific technical configuration.

As we have seen throughout this study, there are problems connected to upscaling, which is often interlinked with a notion of sequential change of socio-technical infrastructures through experiments. Other goals often seem to displace such goals, or at least take precedence. The broader political rationality underpinning smart energy experimentation hinges upon ever

\footnotetext{
${ }^{1078}$ Interview EXEA4.

1079 Ibid.

${ }^{1080}$ This is reminiscent of how a project manager at ABB expressed how SGG was now "shut down", and there would be no continuation.
} 
more products being developed, thus conditioning experimentation to arrange governance through a self-perpetuating stream of new experiments carried out in the form of spatiotemporally bounded public-private partnership projects, favoring private companies with know-how about funding infrastructure, strong brands, and wide-ranging social networks. Consequently, hopes of scaling up SGG to achieve transformative change through the energy pilot initiative seem to be misplaced, since the infrastructures of circulation highlighted thus far rather reflects the need implied by the political rationality for ever more projects. The analytical point here is to highlight the prevalence of the idea of upscaling, firmly woven into Swedish smart energy policy and imprinted in EU research funding and global environmental politics, for example through Agenda 2030 and the nationally determined contributions connected to the Paris climate agreement. Despite the prominence of the seductive and treacherously straightforward idea of upscaling, in practice there seems to be less clarity among actors related to how something should be scaled up and whose responsibility it is to scale up in practice, for instance. As underscored above, actors engaged in smart energy generally tend to ascribe the responsibility for learning and scaling up experiments to actors other than themselves.

Circulations of knowledge generated in SGG into the energy pilot initiative, for example, thus appear to have been rather sparse, despite hopes pinned on scaling up SGG through the energy pilot initiative. SGG complicates ideas of upscaling in and of itself. However, this does not appear to affect the ambition of making the energy pilot initiative scalable to the rest of Sweden. Again, the point is not to assign blame, but rather to unpack upscaling. Notions of upscaling imply notions of scalability, thus making it relevant to ask questions such as how different actors think about and attempt to scale up experiments in practice. And the most pertinent question in the context of this study: What does the notion of upscaling do in relation to how smart energy experimentation arranges environmental governance? Throughout interviews with experts across governmental institutions and policy networks, in the examination of policy documents and other relevant texts, and across different cases of smart energy experimentation, a common feature associated with upscaling is the commercialization of technologies, and of implementing such new technical solutions in the existing grid infrastructure. This could be argued to pour more fuel on the gigantic bonfire of unsustainable political-economic relations that energy infrastructures are woven into, rather than contributing to green energy futures, as scholars of energy transition and environmental politics have shown. ${ }^{1081}$ This is intimately connected to how governance is accomplished through experiments, i.e. the specific socio-technical infrastructures reconfigured or reinforced through such accomplishments. The case of the energy pilot initiative and that of Västerås clearly show that other options exist, and that experimentation can arrange environmental governance in completely different ways. Conditioned by the broader political

${ }^{1081}$ See e.g. Boyer 2019. Energopolitics; Howe 2019. Ecologics; Dunlap 2019. Renewing Destruction; Dawson 2020. People's Power: Reclaiming the Energy Commons. New York: OR Books. 
rationality, experimentation arranges environmental governance which clearly runs the risk of goals connected to economic growth displacing goals connected to ecological sustainability, which can be seen across smart energy experiments, visible through unpacking the prevalent notion of upscaling. The constant opening up and closing down of relations connected to the energy pilot initiative demonstrates that there are possibilities of tinkering, and possibly subversion, refracting the broader political rationality underpinning smart energy experimentation. Processes of accomplishing environmental governance through smart energy experimentation are open in principle, but smart energy experimentation appears to arrange governance in a manner that is weighted and geared toward certain interests and goals in practice, indicating how the broader political rationality conditions and is co-constituted through experiments.

\section{Making the energy pilot initiative reverberate: orchestrating circulations through a central node}

Besides articulations of the energy pilot initiative as an opportunity for scaling up SGG, there is a substantial emphasis on upscaling within the energy pilot initiative itself. In the renewed assignment handed to the Energy Agency by the government in 2018, it is stated that there are considerable benefits to creating a regionally coherent arena where technology, business models, and regulations can be tested and interactions between different parts of the energy system take place, since this will be valuable for the transition of the energy system. ${ }^{1082}$ To achieve this, it is stated that measures which are scalable for the rest of Sweden shall be prioritized, and that lessons from the energy transition on Gotland shall be collected. ${ }^{1083}$ This emphasis on learning and scaling up is underscored further in the roadmap document published by the Energy Agency, as well as in interviews with employees at the agency. It is therefore relevant to unpack how such notions of scaling up feature across central documents and among experts dealing with such questions in practice, despite the energy pilot initiative remaining at a largely conceptual stage.

Throughout the documents published connected to the energy pilot initiative, there is an emphasis on embedding the initiative locally on Gotland. In the pre-study published in 2017, it is articulated that this local embedding will mainly revolve around establishing a so-called energy center on Gotland. This would come to be intimately connected to notions of upscaling further down the line. In principle, an energy center can be many different things, i.e. very different setups and functions can be assigned to an energy center. According to interviewees at the Energy Agency, there was a long-standing interest in establishing such a center among actors on the island, and as soon as it became clear that the Energy Agency would advocate the establishment of such a center, a plethora of actors announced their interest in tying the energy

\footnotetext{
${ }^{1082}$ Regeringskansliet 2018. Uppdrag till Statens energimyndighet att möjliggöra att Gotland blir en pilot för ett hållbart energisystem. p. 2.

${ }^{1083}$ Ibid. p. 3.
} 
center to their own activities, such as micro-producers of electricity wanting to become the energy center. ${ }^{1084}$ The Energy Agency tasked the liberal green think tank Fores with mapping how other islands, such as the Orkney Islands and Samsø, have worked with establishing energy centers. Utilizing the establishment of an energy center as the central measure for embedding the energy pilot initiative locally on Gotland was consolidated in the roadmap document published in 2018. According to an interviewee at the Energy Agency:

[...] my feeling here is that the center's role has grown in importance in a way. [...] I think it's an interesting idea that you had this measure called local embedding and the method was to establish a center. ${ }^{1085}$

The energy center is further described as:

[...] a competence center which will function as, well working broadly with possessing knowledge and competence related to energy questions, and working with counselling and support in different ways, to create a larger impact. [...] I see this as another regional energy agency, but we elevate it and create some kind of pilot character both in the counselling and in this regional energy agency office role. To be able to collect experiences, in the rest of the country. ${ }^{1086}$

Another interviewee at the agency described the center as "a kind of regional energy office 2.0". ${ }^{1087}$ During interviews with employees at the Energy Agency, it soon became clear that this energy center is imagined to play a central role for circulations of the energy pilot initiative. When discussing how being assigned earmarked funds from the government constitutes a key aspect of increasing the chances of the energy pilot initiative coming to pass the way the Energy Agency wished for, a civil servant at the agency stated that:

We have requested 50 million kronor per year, and there we see a few different calls focused on different areas. There we hope that actors on Gotland, either by themselves or in collaboration with other actors, will suggest different types of projects, demonstrations, tests, whatever it might be. ${ }^{1088}$

Besides illustrating further how intervention is assembled in the case of the energy pilot initiative, through attempting to create a funding mechanism specifically connected to the initiative by interconnecting it with existing funding infrastructures of the Energy Agency, this illustrates a specific modality of circulation which seems crucial to how upscaling is attempted in the energy pilot initiative. The interviewee explained further:

And then we also want to create the preconditions to illustrate it and demonstrate it through this energy center, for example then. [...] We're also thinking that it should be able to expand, that it

\footnotetext{
${ }^{1084}$ Interview EXEA4; Interview EXEA5.

${ }^{1085}$ Interview EXEA5.

${ }^{1086}$ Ibid.

${ }^{1087}$ Interview EXEA4. Regional energy offices employ energy and climate advisors, tasked with aiding the public with energy efficiency matters as well as increasing the share of renewable energy in the energy system. For a more exhaustive overview, see Kjeang 2019. Good advice need not be expensive: On personalised energy advising in an increasingly digitised society. Research report 2019:12. Karlstad: Karlstad University. ${ }^{1088}$ Interview EXEA4.
} 
will become a hub for people with an interest in energy. You will be able to come to the energy center, and then you can see there which projects are going on around the island, you can visit them, touch and feel the technologies, or whatever it might be. [...] Like a showroom. ${ }^{1089}$

In this quotation, a specific attempt at organizing circulations of the energy pilot initiative becomes visible, through creating a specific infrastructure of circulations tied to experiments. The Energy Agency wishes to create specific funding calls for the energy pilot initiative, and then the projects, or experiments, awarded funding can be publicly demonstrated at the energy center, with visitors being directed to the sites of actual experiments via the center. The idea of the center is thus to become a node through which channels to different energy experiments ongoing on Gotland can be established, and, crucially, demonstrated. The interviewee stated:

So, partly energy and climate counselling, efforts to raise competence [...]. And then this showroom part, and then a project factory where you will also be able to work out different types of project proposals that you might get funding for. There are no guarantees. ${ }^{1090}$

Demonstrating ongoing experiments, making them visible, is thus considered central to the energy pilot initiative. Another civil servant at the Energy Agency referred to the energy center as a knowledge node, with the possibility to reach out. ${ }^{1091}$ The knowledge politics of experiments connected to funding infrastructures, as discussed previously, is also highlighted through the quotation, as there are essentially no guarantees. The interviewee stated that more target groups can be reached through the energy center, since:

Well it could be for instance that you create new purposes connected to energy and climate counselling. And then it's also specifically to show. You are going to be able to come to Gotland, other interested parties, you can look at Samsø, they have almost created a tourist venture around their operations on the island. The idea I suppose isn't for this to be a tourist magnet, but it's that, well people with an interest in energy from the rest of Sweden, the rest of Europe, the world might be pretentious, but to be able to come there and get interested in what happens on Gotland and be able to visit and look around. But that's not in a year or two, that's [...] Down the line. You don't start there, first you have to build the infrastructure in some way. ${ }^{1092}$

The illustrations provided in the quotations above underscore how the Energy Agency appears to work with particular notions of how the energy pilot initiative can have an impact, as captured by the concept of circulations. It aims to create an infrastructure on the island, an infrastructure of circulations, with the energy center as a central node, through which much of what will happen in the energy pilot can be visualized and demonstrated, and thus stir people into action. ${ }^{1093}$ Testing and learning are emphasized by the interviewee, and the modality of

\footnotetext{
${ }^{1089}$ Ibid.

${ }^{1090}$ Ibid.

${ }^{1091}$ Interview EXEA5.

${ }^{1092}$ Interview EXEA4.

${ }^{1093}$ Interview EXEA5.
} 
circulation enshrined through these examples is intimately connected to the emphasis on upscaling in the energy pilot initiative:

It's difficult to say that specifically that will be scaled up, I think it's about how you handle the whole system, and then we'll see which projects will be carried out, if Vattenfall builds its energy storage, which lessons can be learned from that and applied in different places around the country. [...] And then visualize them [individual experiments connected to the energy pilot initiative], so that you can actually come and find out about them.

I: Through this energy center?

EXEA4: Yes. Hands on. You can go there, see okay this is here on Gotland, what am I interested in, can I visit it? ${ }^{1094}$

In relation to the role of the energy center as a node in an infrastructure of circulations through which the energy pilot is intended to become circulated across and beyond Gotland, the interviewee further stated:

I think that will be our responsibility to a large degree [upscaling], to talk about what is happening and how things have gone, what we need to add. But I mean, if you look at CoordiNet for example, they have their own channels for spreading the message of how things are going. [...] The energy center will have a very outward operation. It will market itself. Some of these projects that will be done, they will want to market themselves too. ${ }^{1095}$

In this instance, there is a widespread notion of reaching as many publics as possible to visualize ongoing experiments in the form of marketing surfaces. The notions of circulation connected to the energy center resemble the visitor operations run by E.ON in Hyllie in a sense, even if the idea at this stage is for the energy pilot to become more encompassing. Specifying further what actually makes an experiment scalable was however difficult, and the interviewee stated that:

I don't think you should stare blindly at, in some cases you can, like a single measure will be innovative or powerful enough in its effects to raise interest and be scalable. But in other cases I think it's the entirety that's interesting. And then it's up to us to communicate the entirety, and how the pilot is progressing. And then it's up to each and every one to think about, I mean it doesn't look the same anywhere in the region, the circumstances are different, so there it's up to them to look at what you're interested in and think that you can learn from. ${ }^{1096}$

As has been the case throughout this study, upscaling seems to be shrouded in a certain takenfor-grantedness, i.e. in documents and among interviewees there is a commonsense view that a technology, which seems to be the principal focus, becomes scaled up if it works, generally through commercialization. In this quotation, it becomes clear that the Energy Agency considers itself responsible for spreading awareness and reaching as many publics as possible with information, but that the processes of scaling up a technological component, or a socio-

\footnotetext{
${ }^{1094}$ Interview EXEA4.

1095 Ibid.

${ }^{1096}$ Ibid.
} 
technical configuration, seem to be for others. The phrasing that a measure needs to raise interest for it to be scalable appears relevant, in connection with the emphasis on marketing through different channels. This was further reflected upon by another civil servant at the Energy Agency, who stated that:

[...] we must affect the whole of society now that we are to transition and the demands become so much higher. And we need to deal with all people really. Households, private companies, and affect the individual $[\ldots]$. And then this is an important part, to partly work with counselling, to partly show what happens if we go for this, we need to be able to describe and demonstrate what happens, not least for Gotlanders. To involve them in that way, things are happening here, you are frontrunners. And I mean this is an important function for our entire transition. ${ }^{1097}$

Importantly, the Energy Agency is not assuming a central role for actually circulating the energy pilot initiative, but rather as an orchestrator of circulations:

$$
[\ldots] \text { we're creating an arena and a knowledge node [... }{ }^{1098}
$$

The interviewee further articulated that the Energy Agency will be part of the board for the energy center, and thus contribute to providing directions and orchestration, which together with collaboration is described as crucial for the success of the energy pilot initiative. ${ }^{1099}$ The quotation elucidates how the Energy Agency attempts to make the energy pilot initiative reverberate across and beyond Gotland, by creating an infrastructure of circulations on the island which interlinks different ongoing energy-related experiments to the energy pilot initiative, as well as hopefully attracting actors from the mainland and getting new experiments started through the "project factory" at the energy center. ${ }^{1100}$ This clearly illustrates how experimentation arranges environmental governance through the energy pilot initiative, as the agency attempts to order the field of intervention. It appears to be conditioned by the broader political rationality underpinning experimentation, which is especially visible in the specific notions of change flowing as an undercurrent through statements and texts and the emphasis on experiments as spatio-temporally bounded collaborative projects aiming for commercialization. However, the agency clearly intends for the initiative to take on a centrifugal character, including ever more initiatives, making the energy pilot into an ecology of interventions through establishing an infrastructure of circulations.

A civil servant at the agency stated that in order to make others feel involved in energy transformation, you need to show what is going on, again highlighting a perceived need to demonstrate technical artefacts trialed through experiments. ${ }^{1101}$ The energy center is explicitly described as a hub, which can provide a connection point to other so-called knowledge nodes

\footnotetext{
${ }^{1097}$ Interview EXEA5.

${ }^{1098}$ Ibid.

${ }^{1099}$ Ibid.

${ }^{1100}$ Ibid; Interview EXEA4.

${ }^{1101}$ Interview EXEA5.
} 
on the island, defined as spaces where experiments are ongoing. ${ }^{1102}$ Related to upscaling, the interviewee stated specifically that energy and climate counsellors could potentially assume an integral role through the energy center, via interconnections created between the so-called regional energy office 2.0 to be created on Gotland and other regional energy offices around Sweden, thus creating linkages between different experiments across the country. ${ }^{1103}$ The climate and energy counsellors are thereby afforded a central position as orchestrators, intimately connected to notions of scaling up the energy pilot initiative.

However, there is a principal emphasis on visualizing, demonstrating, and making visible connected to the energy center. A civil servant at the Energy Agency stated that:

That things are tested on Gotland is the principle. But then it has to be primarily us, but of course there might be municipalities who take the idea home with them and think that it's really good and go for it. But otherwise we have to assume the responsibility for spreading, talking about what's happening on Gotland, we need to help market what will happen in different ways. ${ }^{1104}$

Reflecting further on upscaling, the interviewee stated:

The difference is of course that Gotland is a pretty small region, and it's only one municipality. So that gives specific preconditions. [...] But at the same time, it's Gotland's character as an island and the limited size that also make it possible to conduct tests on a slightly smaller scale. ${ }^{1105}$

In this quotation, the interviewee touches upon the difficulty of upscaling that arises since socio-technical configurations have to be embedded into local circumstances, or woven into existing socio-material webs, which complicates claims of generalizability or a widespread rolling out of a new technology, for example. However, Gotland is again emphasized as a particularly suitable space for experimentation, including with specific reference to the material configuration of the power grid on the island. ${ }^{1106}$ The interviewee returned to the importance of demonstration through experiments to motivate society, enabled by the energy center, as a central feature of upscaling. Additionally, hopes were expressed that the specific type of regional energy office that could be developed through the energy center would be scaled up across Sweden, specified as other regional energy offices adopting similar working methods to those that will be used on Gotland. ${ }^{1107}$ The interviewee stated, in accordance with other actors, that:

$[\ldots]$ we need to highlight the good examples that we've got. ${ }^{1108}$

\footnotetext{
${ }^{1102}$ Ibid.

${ }^{1103}$ Ibid.

${ }^{1104}$ Ibid.

${ }^{1105}$ Ibid.

${ }^{1106}$ Ibid.

${ }^{1107}$ Ibid.

${ }^{1108}$ Ibid.
} 
As we have seen throughout this section of the chapter, the attempts to institute an infrastructure of circulations contribute to accomplishing environmental governance through stitching together the governmental apparatus where experimentation is becoming increasingly important. The dominant modality of circulation is infused with particular notions of upscaling, constituting a central attempt at instigating transformative change beyond individual experiments. The ideas and organizational infrastructure being shaped through the energy center, mainly by the Energy Agency, convey how experimentation arranges environmental governance. This centers on making smart energy experiments reverberate across and beyond the island, to strike a chord with virtually anyone who can possibly be reached, with the intention to mobilize them into action. Specifically, a story about technological development told through the demonstration of positive examples of experiments is intended to circulate, stirring listeners into action.

The energy center is intended to become a node, or a conductor, to enable such circulations through different channels, or a "project factory" as described by the interviewees at the Energy Agency. Hopes are pinned on demonstrating positive examples of experimentation, among these smart energy experiments, through establishing an infrastructure of circulations where channels are created and branch out between different actors on the island and beyond, with the intention of creating momentum and accelerating the pace of energy transformation, thus enabling Gotland to become an environmental frontrunner for the rest of Sweden to follow. What we see crystallized in the energy center, albeit not yet materialized as my fieldwork drew to a close, is thus a specific way of arranging governance, including hopes of mobilization for environmental action that are enabled through specific forms of circulation. The County Administrative Board has created a digital map where different ongoing energy experiments on Gotland are made visible, and perhaps sometimes made invisible, displaying a similar mode of circulation as is intended through the energy center. It was explicitly stated during interviews that this map will hopefully become integrated into the energy center once it has a physical location. This displays a similar notion of how the circulation of positive examples of energy experiments will contribute to mobilization.

However, it appears rather unclear what it is that is supposed to be scaled up, and how, in practice. The idea of reaching as many publics as possible by demonstrating smart energy experiments which can be connected to the larger umbrella of the energy pilot initiative, mainly through the node which the energy center is intended to constitute, appears to be the prevalent form of upscaling intended to achieve transformative change through smart energy experiments. At least, it constitutes a dominant modality of circulation within the energy pilot initiative, reflecting more broadly the dominance of the political rationality underpinning smart energy experimentation, as we have seen throughout the study.

\section{Summarizing reflections}

The energy pilot initiative, formally a governmental assignment handed to the Energy Agency, elucidates how accomplishing environmental governance unfolds through contingent processes. As has been explicated throughout the previous sections, the energy pilot initiative 
has created both precarity and opportunities among actors on Gotland and beyond. It elucidates knowledge politics of smart energy experimentation, since - as has been shown performing experiments relies largely upon managing to interlink the experiment with several specific infrastructures, which are not readily available to anyone. For instance, knowledge of funding infrastructures is necessary, as well as the time and resources to write applications, and the calls are set up through specific strategies, highlighting how projectification conditions the horizon of possibilities for smart energy experiments. Attempts at aligning interventions with the broader political rationality underpinning smart energy experimentation, especially drawing upon the ambition of making Sweden into an environmental frontrunner by exporting smart energy technology, are also something which unites almost all smart energy experiments explored in this study, including the energy pilot initiative.

The Energy Agency has clearly attempted to forge a consensus, constituting the primary modality of authorization of the energy pilot initiative. The constant negotiations related to the agency's attempt to forge a consensus have resulted in opening up and closing down relations, for example in relation to the boundaries, the form, and the focus of the intervention, leading to the inclusion and exclusion of actors and forms of political participation. The energy pilot initiative has also taken on a centrifugal character as it unfolds, seemingly drawing ever more elements and problematics into the process of assembling intervention. However, as we have seen, certain elements and agendas find it substantially more difficult to become enrolled than others. Related specifically to learning from the energy pilot, the organization of learning in practice appears somewhat diffuse, since actors tend to place the responsibility for learning on actors other than themselves. Further, notions of upscaling are complicated through the interrelation between Smart Grid Gotland and the energy pilot initiative.

The case of the energy pilot clearly illuminates how the broader political rationality becomes refracted by local dynamics and unfolding micro-politics as intervention is assembled. While the Energy Agency has certainly been handed a difficult task and is essentially muddling through to the best of its abilities, the politics of the energy pilot initiative are inescapable. Essentially, a substantial infrastructure project that had long been planned by the Swedish authorities was scrapped and replaced with an amorphous initiative that was yet to receive any state funding, leaving the Energy Agency with virtually no other choice than to align the initiative with its existing funding calls and research programs, thus making the ecology of interventions largely a matter of amassing experiments on Gotland under a joint umbrella. It is difficult to avoid the idea that this mode of experimentation amounts to serving up a façade of being active among the actors positioned as central through such an arrangement, the incumbent energy companies, without anyone really being willing to invest and stake out a direction, leaving Gotland in a strange, precarious limbo. Still, as we have seen, a potent dynamic influencing how the energy pilot arranges environmental governance is the political energies on the island; the many local actors wishing to experiment with doing things differently. Further, the County Administrative Board resourcefully attempted to realign the energy pilot initiative with its own plans and agendas, drawing the Energy Agency into its new regional climate and energy strategy and making it responsible for a portion of this strategy. 
These dynamics, in turn, are facilitated by the Energy Agency's attempt to set up the energy pilot as an encompassing ecology of interventions rather than a single pilot project. Such dynamics elucidate how smart energy experiments become an arena of politics; in the energy pilot case, they activated local actors as much as being strategically used by powerful incumbents such as Vattenfall.

Circulations, or rather a specific modality of circulation, have become a central part of accomplishing environmental governance through the initiative. There are specific ideas at the Energy Agency, and the process of turning these ideas into practice has begun, which relate to making the energy pilot initiative circulate across and beyond Gotland. It could be argued that it is a particular problematization of energy transformation - based upon particular notions of change, and made visible through focusing on the proposed energy center - that is intended to circulate, through which traction can be gained for this particular problematization. This constitutes an ordering of environmental governance since it includes specific ideas about how to achieve transformative change through experiments, assigning specific roles to different actors. We have seen how accomplishing governance in the case of the energy pilot has been full of twists and turns, although these are not entirely random; the processes of accomplishing environmental governance are thoroughly permeated by politics. These processes constitute a field of intervention, defining the environmental condition to be improved and the sociomaterial elements that need to be enrolled, entailing a specific problematization as outlined throughout the chapter.

\section{Analytical discussion}

This chapter has highlighted how the broader political rationality underpinning smart energy experimentation institutes conditions of possibility for experiments while being refracted through processes of accomplishing environmental governance on the ground. Despite hopes of the energy pilot initiative constituting an upscaling of SGG, the interrelation between SGG and the energy pilot appears complicated rather than straightforward. The energy pilot has been cast as a much broader intervention, rather encompassing an ecology of interventions, and it was less than clear which experiences from SGG were actually articulated as being relevant for the energy pilot initiative. Interviewees at GEAB, for instance, were keen to emphasize how the two interventions were of different characters.

Politics of accomplishing governance through experimentation surfaced in the analysis, illustrating how such politics are no less present in experiments articulated as matters for techno-economic experts, in the case of SGG, which as we have seen is also a political move of suppression in itself. Even though contestations emerged in connection with SGG, these contestations were amplified and clearly accentuated in the case of the energy pilot initiative. Ordering the field of intervention in the case of the energy pilot initiative encompassed attempts at narrowing down the space for action, but this constantly faced the possibility of being opened up again. This puts the spotlight on the question of the construction of boundaries of experiments. Both SGG and the energy pilot initiative are in a sense 
geographically bound to the island of Gotland, although as we have seen there are hopes expressed in relation to the energy pilot initiative that it can become interlinked with initiatives beyond Gotland. The inclusion of CoordiNet into the energy pilot is a further example of a constantly ongoing negotiation of the initiative's boundaries. SGG seems to have been more successful in upholding boundaries; perhaps too successful, as one of the involved project managers stated that they had not managed to maintain an interest in the experiment until it was finished, and that the consortium had not managed to engage with any publics to any significant extent. The boundaries of experiments are always porous, but the case of the energy pilot initiative - which has taken on a rather centrifugal character and seems to be constantly expanding - illustrates how boundaries can be more or less open in practice. It is also relevant to note that the energy pilot initiative has no clear timeframe, as of yet, which is in striking contrast to all the other experiments in this study, and is tentatively contradictory to the core intention of accelerating energy transformation. Recall how it was articulated in the case of SGG that the experiment had probably gone on for too long.

This draws our attention to a tension which has cut across all experiments explored in this study: the tension between uncertain testing and learning through experimentation and the actual possibilities for learning stipulated through the omnipresent market emphasis imbued by the broader political rationality underpinning smart energy experimentation. The very notion of experimentation caused more severe tension in the case of Gotland compared to the urban experiments; recall for instance how Gotland was viewed favorably as an experimental site because of its character as a "miniature Sweden", whilst it was simultaneously articulated that the energy pilot initiative must be for real and not an experimental workshop. In relation to such articulations, testing and learning were recurrently expressed as central, not least to learn from mistakes or what did not work in an experiment. This has been frequently expressed across the entire empirical material, not just in connection with Gotland. However, it has also been expressed just as often that experiments are vital to create momentum through their function as positive examples, i.e. a central objective of experiments is to persuade actors to walk united along specific paths toward the future sustainable energy system, and such paths tend to be aligned with the broader political rationality by favoring paths of consensus-building to facilitate developing new products for commercialization. This has frequently been interconnected with the goal of marketing often ascribed to experiments, i.e. that experiments are necessary to substantiate claims of Sweden's status as environmental frontrunner, and that to be able to realize export ambitions associated with smart energy, experiments have to be packaged and presented as highly successful. As we saw, such considerations surfaced multiple times in relation to both SGG and the energy pilot initiative.

The crux of the matter in the context of this study is how experimentation arranges environmental governance through processes such as those just mentioned. Judging by the publicized nature and the constant reference to the three so-called flagship projects as well as the energy pilot initiative, despite some of these being criticized by interviewees, it seems that experiments which are in line with the broader political rationality underpinning smart energy experimentation find it easier to get noticed and gain traction. As discussed throughout the 
study, there is a knowledge politics at play here; carrying out experiments requires the ability to latch on to specific infrastructures which are not readily available to anyone, such as funding infrastructures and policy networks, whilst experiments generating knowledge to support Swedish export ambitions and environmental frontrunner claims become noticed to a greater extent. Such aspects are highlighted through the concept of circulations.

Properly accounting for this necessitates looking more closely into unfolding processes within experiments, not least - as we have seen - through the energy pilot initiative. It is probably no coincidence that it was in a discussion about the energy pilot that a civil servant brought up justice-related aspects of energy transformation, posing the rhetorical question of whether a Gotlander should be afforded fewer possibilities to construct solar panels than someone living on mainland Sweden. The question of whether or not expanding and increasing energy use is an intrinsic feature of a successful energy transformation - as is widely assumed in smart energy experimentation - could, however, just as easily be asked in the light of energy justice and rebound effect concerns. However, more profound critique and questioning of technoeconomic reasoning and the broader political rationality is significantly marginalized across the entire empirical material. ${ }^{1109}$

${ }^{1109}$ Cf. e.g. Mulvaney 2019. Solar Power; Boyer 2019. Energopolitics; Pellizzoni 2015. Ontological Politics in a Disposable World; Dauvergne 2016. Environmentalism of the Rich. 


\section{Concluding discussion: opening up and closing down fields of intervention through smart energy experimentation}

This concluding chapter consists of three parts. First, I will summarize the broader political rationality that underpins smart energy experimentation and how it becomes crystallized into particular arrangements at the national level. I will also discuss how this can be interpreted as smart energy experimentation increasingly becoming incorporated into a broader governmental apparatus. This part summarizes the arguments of the first two empirical chapters. Second, I will draw together the findings of the third and fourth empirical chapters to contrast how environmental governance is accomplished across the different cases of smart energy experiments. This includes reflecting upon dynamics that shaped how experimentation arranged governance in different local settings as interventions were assembled, creating tensions with and partly diverging from the political rationality. Finally, I will relate the insights gained through the study to previous literature, to reflect upon what has been learnt and where this leaves us in terms of the main questions animating the study.

\section{Incorporating smart energy experimentation into green governmental apparatus?}

This thesis has investigated how smart energy experimentation arranges environmental governance across several spaces of governance. The first two empirical chapters focused on governmental institutions and policy networks, mainly at a national level but also including international organizations. ${ }^{1110}$ Analytically, the research question of how experimentation arranges environmental governance in these spaces of governance was approached through the

\footnotetext{
${ }^{1110}$ As discussed in the two chapters outlining the theoretical approach of this thesis, rigid notions of scales such as international - national - local are easily disturbed when governance is approached processually. In practice, such scales overlap, merge, and blend continuously as socio-spatial relations are reconfigured - for instance through processes of accomplishing governance. Therefore, I must repeat that I conceptualize such scales as relationally constituted in this study; as will be discussed in this closing chapter, we have seen throughout the thesis how the broader political rationality is continuously coconstituted across spaces of governance - from local contexts via national governmental institutions to international organizations - but, through dynamics of accomplishing governance, tensions surface between assembling practices and broader political rationality across such spaces of governance. Cf. Asdal 2011. Politikkens Natur - Naturens Politikk; Brenner 2019. New Urban Spaces: Urban theory and the scale question. New York: Oxford University Press.
} 
concept of political rationality. An important aim of these chapters was to situate smart energy experimentation, and literature that helps to historicize this phenomenon thus constituted a central point of departure. Empirically, the two chapters moved across governmental institutions and policy networks, entailing analysis from an aggregated analytical perspective as well as investigating more closely how experts across such spaces of governance deliberated upon experimentation and attempted to deal with it in practice. Thus, the chapters spanned the plans, maps, and techniques of governing as well as the "mentalite", such as assumptions, demarcations, and knowledge claims underpinning and emanating from the broader political rationality.

The first two empirical chapters showed how a broader political rationality underpinned smart energy experimentation, which appears to become increasingly woven into a broader governmental apparatus. Central characteristics of this political rationality as it crystallized in the field of smart energy experimentation included emphasizing green growth and the development and export of new energy technology as prime goals of experimentation, projectification, public-private partnership constellations, techno-economic language, cooperation, and consensus-seeking. ${ }^{111}$ The emphasis on green growth and export ambitions, argued to simultaneously solve a range of other issues, reflect the historically firmly rooted position of ecological modernization in Swedish politics. This supports the interpretation of a broader political rationality which becomes crystallized in a slightly different shape over time across different areas of environmental politics. ${ }^{1112}$ The analysis in the first two empirical chapters showed how smart energy experimentation arranged environmental governance in line with such ecomodern policy programs. It is primarily large, established energy and technology companies that apply for funding from government agencies to cooperate with municipalities and regions in individual projects to develop new green products and services, which can then be disseminated across the energy system as well as exported, thereby leading to green transformation. This partly answers to the question of how experimentation arranges environmental governance, particularly at the national level, as well as who are positioned as central for generating knowledge in experiments.

Here, experiments were generally ascribed the role of reducing uncertainty, to find technoeconomically optimal routes forward toward a seemingly inevitable energy transition. Despite clearly diverging positions surfacing, there was a substantial emphasis on cooperation and consensus across the empirical material. Consensus and cooperation are mobilized as virtues, in line with how the political culture of Swedish energy politics has evolved historically, i.e. as elements in a problem-solving, non-confrontational setting where politics are perceived as best organized through cooperation, often around techno-economic projects, rather than

${ }^{1111}$ Clearly, such aspects chime with an encompassing neoliberal political rationality, extending far beyond Sweden, as dissected by other scholars. Cf. Brown 2015. Undoing the Demos; Pellizzoni \& Ylönen (eds.) 2012. Neoliberalism and Technoscience.

${ }^{1112}$ Cf. Brown 2015. Undoing the Demos. p. 117. 
playing out antagonistically. ${ }^{1113}$ Consensus and cooperation are also mobilized to unite actors around the common goal of increased economic growth in green technology sectors - in the case of this thesis it is smart energy that has been scrutinized as such an endeavor - which is also in line with the historically dominant position of ecomodernism as a policy program within Swedish governmental institutions. ${ }^{114}$ Positions did diverge, for example in relation to retaining or decommissioning nuclear power and related questions of balance and capacity in the large-scale power grid. Further examples include a civil servant at the Energy Agency who raised questions about the societal implications of the TSO Svenska Kraftnät's decision to withdraw its plans for a new link between the regional grid on Gotland and the Swedish mainland transmission grid, leading to questions of how to realize a just energy transformation in terms of political participation. Such questions were rather marginalized in the empirical material, highlighting how marginalization occur as experimentation arranges environmental governance. A cabinet member of the Swedish Smart Grid Forum additionally underscored that questions of roles and responsibilities in the future smart energy system entailed strong vested interests, while a cabinet member of the previous Energy Commission remarked that potential power shifts in the energy sector would not come about easily, since currently dominant actors would not be keen to let go of their prominent positions.

Despite such instances highlighting conflict dynamics, the emphasis on cooperation and consensus remained very strong across the empirical material. A significant effort was devoted to framing smart energy experimentation as a neutral search for techno-economic optimums, visible for instance in articulations on the risk of sub-optimization and frequent statements about how the Energy Commission had managed to unite the energy sector and everyone was currently pulling in the same direction. Such an emphasis on consensus and cooperation reoccurred across documents and interviews. A prominent example was the frequent calls for evidence-basing policymaking, underscoring the central position of Science (capital S) for smart energy experimentation. Invoking the need for Science as an authoritative source of knowledge tended to be mobilized alongside techno-economic knowledge claims. Here, we can discern part of the answer to the research questions of which knowledge claims are viewed as legitimate and robust. Recall, for instance, how a civil servant at the Energy Agency stated that Swedish energy policy tends to rely on techno-economic analysis, including in cases where socio-economic analysis would be more appropriate, such as in the example of Svenska Kraftnät's cable decision. Invoking Science and leaning into techno-economic knowledge claims can be viewed in the light of striving for consensus; several interviewees remarked that it was necessary for Sweden to back up its green frontrunner and export ambitions with actual pilot projects, which is easier if a united front is shown outwardly. This elucidates the tension that could be observed, which several interviewees raised as a concern themselves, between

${ }^{1113}$ Cf. Kall 2011. Förnyelse med förhinder.

${ }^{1114}$ Anshelm 2002. Det gröna folkhemmet - Striden om den ekologiska moderniseringen av Sverige. 
ambitions of uncertain testing and marketing to back up green export ambitions through experiments.

Experimentation tended to be depicted as more or less open to anyone, and there was a strong common-sense accentuation on how experimentation works. Such notions were often accompanied by particular ideas about socio-technical change. Several interviewees across governmental institutions and policy networks explained how, through experiments, an issue could be actualized, leading to mobilization of relevant actors. In the long run, as scaling up experiments creates ripple effects, such processes lead to changes of energy infrastructure as well as creating green growth through exports, thus ensuring a green transformation. Often it was private or state-owned companies who were the designated doers in this arrangement; recall for instance how several interviewees explained that the three large flagship projects had "set things in motion", whereas government officials stated that no pilot projects come to pass before the industry is ready. This partly answers the research question of how actors imagine broader transformative change to occur beyond individual experiments. The emphasis on cooperation and consensus is further reflected in such notions of change, and is inscribed into actual governance arrangements. A clear example is the instituting of coordinating state bodies, such as the Coordination Council and the Smart Grid Forum, aiming to connect public and private actors in different experiments, networks, and cooperative endeavors to incite a green energy transformation that delivers on the promises of green growth and exports. Instituting such coordinating bodies on the national level, to establish interlinkages and maintain consensus, further elucidates the research question of how experimentation arranges environmental governance.

The political rationality underpinning smart energy experimentation in Sweden institutes goals of green growth, the development of new products and services, and export ambitions, creating openings for the involvement of large, incumbent private companies as principal actors of experimentation, which tends to be stressed as necessary in the assumptions about socio-technical change nested across governmental institutions and policy networks. As the need for cooperation is emphasized, notions of scientific neutrality are mobilized, and a techno-economic language is utilized to a significant extent, smart energy experimentation risks arranging governance as a largely depoliticized endeavor and casting it as a matter of neutral testing. Interlinkages between concerns of political participation and experimentation, for example, which are prevalent in academic literature, were shrouded in national policy. Clearly, this order of things gives impetus to and dovetails with neoliberalization processes. This is evident, for example, in the prevalence of public-private partnership constellations in networked governance settings, where profit has become a guiding governance principle and expanding capital's reach constitutes a central goal; smart energy technology tends to be 
sourced by large, established private companies, as we have seen. ${ }^{115}$ This further answers the research question of which actors are described as central for doing smart energy experiments and why, which we see in the connection to goals of green economic growth and export as well as the organizational capacity possessed by these actors as well as their historically sedimented positions of power. Additionally, the tendency to favor goals of marketing and commercialization appears to complicate learning from experiments, since it becomes difficult to voice mistakes or lessons learned through failures in a socio-political context dominated by goals of marketing, commercialization, and export among different actors and on different levels of policymaking. The overall setup of experimentation, often embodying implicit notions of change through creating momentum, appears to benefit already dominant actors to a large extent, and to allow them to retain their prominent positions in the energy system. This setup underlines how the broader political rationality infuses consensus around central questions of arranging environmental governance through smart energy experimentation; there is broad agreement on how knowledge generation through experiments should be organized, including the need to involve large, incumbent private companies, and on how export ambitions for the purposes of green growth are necessary to drive experimentation, which necessitates a consensus to unite actors around such common goals. Consequently, characteristics that are often ascribed to experimentation - such as adaptive testing and learning - seem to increasingly become co-opted and provide impetus to neoliberalization processes.

The emphasis on consensus, cooperation, and evidence-basing policymaking through experimentation, often intertwined with drawing on Science as an authoritative source of knowledge, further underlines how smart energy experimentation interplays with neoliberalization processes through the broader political rationality - a marked characteristic of such processes is the downplaying of politics, rather favoring technicized policymaking such as benchmarking practices and cost-benefit assessments. ${ }^{1116}$ However, because of the conflict potential of environmental issues - since they are inherently political, raising for example questions of values, imagination, and societal organization - there is always a formidable potential of repoliticization which is visible also in the case of smart energy experimentation. ${ }^{1117}$ Consequently, attempts to depoliticize such questions always require work and are never successful by default. ${ }^{1118}$ Despite the meagre impact on smart energy policy, we could observe clearly diverging positions among policymakers and technical experts

${ }^{1115}$ Cf. Pellizzoni \& Ylönen 2012. Introduction. p. 3; McLaren \& Agyeman 2019. Smart for a reason; Crouch 2011. The strange non-death of neoliberalism.

${ }^{1116}$ See e.g. Hay 2007. Why we hate politics. Cambridge: Polity; Fawcett et al. (eds.) 2017. Anti-Politics, Depoliticization, and Governance; Mouffe 2005. On the Political; Brown 2015. Undoing the Demos.

1117 Cf. Haikola \& Anshelm 2018. Depoliticization, Repoliticization, and Environmental Concerns; Perreault et al. (eds.) 2015. Routledge handbook of political ecology.

${ }^{1118} \mathrm{Or}$, to paraphrase Bulkeley, such aspects highlight how governance is always an accomplishment in the making. 
across governmental institutions and policy networks, indicating conflict dynamics. The successful suppression of such contestations can be productively interpreted through the historical political culture of Swedish energy politics. The energy system has been constructed in line with industrial modern ideals as a large-scale, complex socio-technical system with prominently centralized ownership structures, despite the prevalence of conflict and controversy, particularly in Swedish energy politics - partly through an increasingly tight interweaving of techno-economic expertise and knowledge claims with energy policy. The historically dominant position of ecological modernization, firmly nested within Swedish governmental institutions at least since the mid-1990s, reinforces the interpretation of a broader political rationality enveloping Swedish environmental politics - even though it might crystallize slightly differently and morph across different areas of environmental policy. ${ }^{119}$

The broader political rationality is rendered visible through tensions and different positions related to experimentation that can be isolated in the empirical material, as interviewees themselves reflexively problematize aspects of it. Examples include the energy field expert who exclaimed how, worryingly, knowledge generated through experiments tends to stay within the bounds of participating large, incumbent private companies who are granted too much leeway to decide for themselves which kinds of technological components they are interested in testing and developing. Similarly, several interviewees expressed concerns about how marketing tends to crowd out other goals in experimentation. Recall how a civil servant reflected upon how experiments with well thought-out marketing strategies run by large companies with significant reach and strong brands gained more traction than the ones that actually generated interesting results. Clearly, such logics are imbued by the broader political rationality underpinning smart energy experimentation, and as stated they provide impetus to neoliberalization processes. Considering the many traces of this political rationality across the empirical material, it might not be a bold claim to interpret this as smart energy experimentation becoming increasingly incorporated into a green governmental apparatus spanning Swedish environmental politics. To speak with Foucault, Braun, Pellizzoni, and others, smart energy experimentation comes to incorporate elements of such an already existing broader political rationality, becoming increasingly enmeshed with a green governmental apparatus as heterogeneous elements are interlinked.

\section{The micro-politics of experimentation: refracting political rationality through dynamics of accomplishing governance}

Under the previous heading, we could indeed conclude that smart energy experimentation is increasingly intertwined with a green governmental apparatus extending across Swedish environmental politics, underpinned by a broader political rationality. Returning to the 
argument of the third and fourth empirical chapters, this picture becomes more nuanced. As discussed at length at the beginning of this thesis, governance is continuously arranged across different spaces, not only in the halls of governmental institutions or formalized policy networks such as the Smart Grid Forum or ISGAN. Academic literature honing in on how experimentation arranges governance on a smaller scale, often by way of micro-empiricist approaches, shows how governance not only unfolds through policy implementation or political decisions, but is also arranged in more distributed, complex ways. Essentially, such literature underlines the risks of all-too-encompassing social theorizing; imposing predefined concepts deductively may well smother empirical material rather than helping to unpack it, while smoothing out complexities which can in fact be quite revealing. ${ }^{1120}$ This strain of literature reminds us that governance is continuously arranged from below, showing how experiments can contribute to reconfiguring society in a more wide-ranging way than is often imagined by transforming socio-technical infrastructures and socio-material relations. Recall, for instance, the claim of Marres and Stark about how testing is intimately linked to material and organizational modification of society, potentially redefining relations between test sites and their "environments", or Bulkeley and Castán Broto's claim that singular experiments may become incorporated into broader governmental programs through infrastructures of circulation. ${ }^{1121}$

The third and fourth empirical chapters of this thesis take such insights as their cue and look across cases of smart energy experiments to investigate how environmental governance is accomplished in local settings and beyond. By contrasting cases of experiments and diving deep into the larger experimental initiative on Gotland, it was possible to unpack how environmental governance was accomplished in different ways across the experiments, aided by the lens of accomplishing governance and circulations. As convincingly shown by Murray Li, whose insights inform the theoretical approach of accomplishing governance, the plans, maps, and techniques of governing tend to become reconfigured through processes of accomplishing governance, as unexpected things happen. We could clearly see how the broader political rationality instituted certain conditions of possibility for smart energy experiments, preforming the setup of experiments for instance through underlying assumptions about socio-technical change informing political techniques such as research funding strategies. We could just as clearly observe how the political rationality was refracted across the different cases, owing to particular dynamics that influenced how processes of

${ }^{1120}$ Cf. Gibson-Graham 2006. The end of capitalism (as we knew it): a feminist critique of political economy. Minneapolis: University of Minnesota Press. Gibson-Graham firmly argues that describing complex, heterogeneous phenomena by way of encompassing concepts, such as capital, risks exaggerating the omnipresence of capital and invokes a sense of unavoidability which does not tally with what we know about social change. Hence, being able to move between historicizing and complexities in concrete settings is essential in analytical endeavors. See also Boyer 2019. Energopolitics; Pellizzoni \& Ylönen 2012. Conclusion. p. 232.

${ }^{1121}$ Marres \& Stark 2020. Put to the test; Castán Broto \& Bulkeley 2018. Realigning Circulations. 
accomplishing governance unfolded. The different smart energy experiments encompass different discursive constitutions of the problem to be governed, different actor constellations, different knowledge generation practices and ownership of knowledge, and different types of circulations - indicating how governance is an accomplishment in the making.

In contrasting the different experiments, several key differences emerged in relation to the specific research questions I set out to investigate in this study. This includes questions of how environmental governance was accomplished, elucidating differences in terms of which relations were forged through smart energy experimentation, how fields of intervention were shaped, which actors were positioned as central and which were excluded, and which knowledge claims were foregrounded. In Hyllie, we observed a gradual realignment of actor positions, forming an attempt to change the energy system through a coordinated, tight publicprivate partnership mode of infrastructure development. Smart Energy City was also authorized through the modality of consensus, whereas the governance arrangements in Norra Djurgårdsstaden and Stockholm were rather reminiscent of loosely arranged, networked governance, despite an insistence on close cooperation. This was based on reconciling the interests of different actors who gathered around the common vision of making NDS into another green innovation district in the lineage of several such districts, positioning private companies as central for knowledge generation while infrastructures of circulation to a large extent leaned into different involved actors' established networks. In Hyllie, the use of partner contracts within and beyond Malmö illuminated different, coordinated infrastructures of circulation. The Västerås experiment exemplified grassroots mobilization and ambitions of openly sharing knowledge, while explicitly politicizing energy transformation.

While both NDS and Hyllie invoked elements of the broader political rationality, refracting it in the process, Västerås can be interpreted as a critique of and challenge to this political rationality. Power relations within the socio-technical configuration of the energy system were explicitly problematized, constituting an attempt to subvert the current order of things, and thus implying arranging governance in significantly different ways. As discussed in the third empirical chapter, perhaps it is even possible to argue that the Västerås experiment constitutes a heterotopia embodying a different political rationality. More differences in terms of how governance was accomplished through experimentation surfaced in the fourth chapter, focusing on the case of Gotland as an energy pilot region. As the energy pilot initiative unfolded, the field of intervention was continuously opened up and closed down as relations were assembled, with opportunities for reconfiguring governance seemingly wide open at certain points in time. Controversies and contestations surfaced more clearly in the case of the energy pilot compared to NDS and Hyllie, partly explained by dynamics revealed through the inclusion of a brief section on the preceding Smart Grid Gotland experiment. All cases also instituted different infrastructures of circulation whereby knowledge claims and competencies were moved; whereas the cases of SGG and Smart Energy City resembled each other in certain ways, particularly through internal knowledge circulation within participating private actors' organizations, the envisioned circulations of infrastructure in the energy pilot initiative more closely resembled those of Hyllie. Even though the energy pilot initiative entails an ecology of 
interventions rather than a confined experiment such as in Hyllie, both experimental endeavors configured coordinated attempts at circulation, constituting expansive infrastructures of circulation, although for different reasons; the modalities of circulation in Hyllie were predicated upon the close cooperation between the City of Malmö and E.ON, whereas the envisioned infrastructure of circulations in the energy pilot initiative hinged upon the prominent position of the Energy Agency.

This indicates how local dynamics and unfolding, contingent practices of assembling intervention contributed to smart energy experimentation accomplishing environmental governance differently across the cases. ${ }^{1122}$ Consequently, despite the apparent dominance of the broader political rationality, we can see divergent accomplishments across different sites of experiments. It is therefore no exaggeration to claim that smart energy experimentation can also create opportunities for different modes of environmental governance. In the case of Västerås, goals of democratizing the energy system and politicizing energy transformations are clearly articulated and configured into the experimental setup. The case of Hyllie illustrates a mode of infrastructure development through experimentation in close public-private partnerships, where politics surface in relation to negotiations over environmental goals, for instance. Additionally, E.ON clearly circulates aspects of the Hyllie experiment to reconfigure and extend its operations into becoming an IT infrastructure actor and thus expanding its business portfolio - the access gained to properties' building management systems allow for further usage beyond "smart district heating" in a future, increasingly digitalized smart energy system, potentially reconfiguring roles and responsibilities within urban infrastructure provision.

This elasticity of experimentation is not highlighted in national policymaking to any significant extent, and there is no public debate connected to experimentation. It does, however, underscore how broader relations are certainly an integral part of how experimentation arranges environmental governance - as we have seen, elements of ecomodern policy programs, projectification, a preference for public-private partnership constellations, striving

${ }^{1122}$ To reiterate, broader governance arrangements pre-existing smart energy experimentation are also accomplishments. Such arrangements might become reconfigured, challenged, or consolidated through processes of accomplishing governance through experimentation. A political rationality is continuously upheld across many different sites - or spaces of governance, which is the preferred term in this study. A political rationality might "grease the wheels" of certain accomplishments, whereas certain accomplishments might co-constitute, consolidate, or challenge political rationality no matter through which avenue one empirically approaches such processes. In this study the spaces receiving most of the analytical attention in terms of accomplishing governance are the different cases of experiments, which is primarily where I have attended empirically to such processes. However, the reflections offered by different interviewees across governmental agencies and policy networks, as they struggle with various aspects of experimentation, underline how the processes within such settings are also accomplishments; think, for example, of all the negotiations that must have occurred throughout the myriad activities and forums arranged by the Smart Grid Forum. Accomplishing governance, then, is never "only" a local question (local in the scale sense), but processes that unfold across many different spaces of governance. 
toward green growth, and export ambitions are all aspects of how smart energy experimentation arranges governance, giving impetus to neoliberalization processes. As we saw across the cases, however, governance can be accomplished in different ways through specific actions and unfolding, contingent processes. Processes of accomplishing governance across spaces of governance - governmental institutions, policy networks, local smart energy experiments, local public administration - can contribute to consolidating and reinforcing particular broader governance arrangements, as well as destabilizing and changing them. Together, both the broader arrangements and the concrete accomplishments elucidate how smart energy experimentation arranges environmental governance.

Additionally, the strength of the broader political rationality could be observed on several occasions in the empirical material, such as goals of green growth and export crowding out possibilities of uncertain testing and learning. The case of Västerås further underlines the strength of the political rationality. This strength was demonstrated when the Energy Markets Inspectorate clarified that it would be illegal to transfer self-produced electricity between different properties, and thus the plans for a DC nanogrid ground to a halt before it could be tested. The relative marginalization of the Västerås experiment, compared to the other experiments, as well as the relative lack of incorporating elements related to desiring a different energy future into the energy pilot initiative on Gotland, elucidate how the broader political rationality entails arranging governance through experimentation so that some practices become reasonable and progressive, while others remain marginal. This ties into the knowledge politics of smart energy experiments. As we saw in the third empirical chapter, the cases of Smart Energy City and Hyllie contributed to foregrounding knowledge claims that reinforce central assumptions of ecomodern policy programs while contestable political questions were filtered out. Concrete examples include questions about the sustainability of waste incineration in the case of Hyllie, visible in subtle contestations around the set policy goals related to renewable or recycled energy. ${ }^{1123}$ In Smart Energy City, emissions and energy use related to consumption and transportation practices of the upper middle class were kept off limits as intervention was assembled. In other words, the desirability of different energy futures was filtered out through the experiments, consolidating assumptions that are central for the broader political rationality - such as the possibility of combining deep decarbonization with increased economic growth. Such questions have long haunted environmental politics and are still far from resolved - particularly in light of the urgent need for drastic action to

\footnotetext{
${ }^{1123}$ Political aspects of waste incineration could, for example, include instrumental aspects such as to what extent current incineration practices, mainly burning municipal solid waste for electricity and heat (CHP) in Sweden, contributes to emissions (which is a currently ongoing discussion). It could also include more fundamental questioning of the sustainability of such practices, as have scholars calling contemporary political-economic practices into question on the basis of thermodynamic principles. See e.g. GeorgescuRoegen 1971. The entropy law and the economic process. Cambridge, Mass.: Harvard University Press; Hornborg 2016. Global Magic: technologies of appropriation from ancient Rome to Wall Street. New York, NY: Palgrave Macmillan.
} 
reduce climate impact, such hopes have been questioned. ${ }^{1124}$ Despite these concerns, several of the studied smart energy experiments are based upon and tend to consolidate knowledge claims to the contrary, relegating such concerns to the background.

This interplays with the setup of smart energy experimentation in Sweden, which also reflects knowledge politics. Large, incumbent energy utilities with in-house R\&D departments, indepth knowledge of the research funding infrastructure, technical expertise, established social networks, and access to policymakers find it easier to experiment and gain traction for their experiments than others, thus enabling these actors to imprint how experimentation arranges environmental governance through their knowledge-configuring activities. We could see how learning from experiments was regularly expressed as a central goal of experimentation, whereas learning in practice came across as rather fragmented; recall how actors across the entire smart energy landscape tended to place this task with actors other than themselves. Often, knowledge generated through experimentation tended to become circulated mainly within the bounds of the private companies involved. This order of things appears to reinforce how "moving beyond" experiments is synonymous with carrying out more experiments - an arrangement which perpetuates and gives further impetus to similar modes of experimentation, and is obviously entangled with underlying notions of socio-technical change as discussed above. Further, it has been convincingly argued that a green transformation must be based on a total reduction of energy use - especially in high-income countries with a historical debt in terms of massive environmental footprints. ${ }^{1125}$ In Swedish smart energy experiments, the goal has rather revolved around shifting energy use in time, mainly electricity and district heating; recall how in the case of Gotland there were active attempts to increase electricity use during periods of high electricity production from wind power. ${ }^{1126}$ Another example was the Swedish Environmental Protection Agency's written remittance to the policy document (SOU) produced by the Coordination Council, which made it clear that the contribution of smart grids to sustainability would depend on a number of factors - and consequently such assumptions could not be taken for granted. Such concerns were marginalized, as prominent smart energy experiments rather consolidate assumptions of how the digitalization of the energy system contributes to sustainability per se.

The experiment in Västerås, and certain articulations in the case of the energy pilot initiative on Gotland, provide counterpoints to such knowledge claims, indicating deviating knowledge

\footnotetext{
${ }^{1124}$ For a recent scholarly contribution on such concerns in relation to energy transformation, see Foxon 2018. Energy and Economic Growth: Why we need a new pathway to prosperity. London: Routledge; for literature on the relation between economic growth and environmental issues, see e.g. Hickel \& Kallis 2020. Is Green Growth Possible?; Haberl et al. 2020. A systematic review of the evidence on decoupling of GDP, resource use and GHG emissions, part II: synthesizing the insights. Environmental Research Letters 15(6); Warde et al. 2018. The Environment. p. 140-141; Andersson \& Westholm 2019. Slaget om framtiden.

${ }^{1125}$ Cf. Petrocultures Research Group 2016. After Oil; Pirani 2018. Burning Up; Hornborg 2019. Nature, society, and justice in the Anthropocene.

${ }^{1126}$ Cf. Bakke 2017. The Grid. p. xvi-xvii.
} 
politics. In the case of Västerås, visualizing the materiality of energy flows is emphasized in contrast to the ambition of "making it easy for customers" echoing across the other two urban experiments. Here, environmental impacts of material and energy use for construction are problematized, while the experiment presents an explicit attempt at reconfiguring ownership structures and agency within the socio-technical energy infrastructure. This indicates how very different knowledge claims are foregrounded through the Västerås experiment. In the case of Gotland, there were more contestations over knowledge claims, indicating how the character of the energy pilot initiative contributes to opening up and closing down relations continuously as intervention was assembled.

Tying together the analysis of how governance is accomplished through experimentation across the cases, certain dynamics can be singled out as influencing governance arrangements. First, the local context mattered for how governance was accomplished; experiments are entangled within local already existing socio-material webs of relations and processes of placemaking. Even experiments that are seemingly very similar on the surface, such as Smart Energy City and smart energy experimentation in Hyllie, display key differences owing to such dynamics. While casting smart energy experimentation as mainly a matter of creating green economic growth, substantiating export ambitions, and building credibility for Sweden's green frontrunner ambitions are obviously aligned with the broader political rationality, as is the insistence on experimenting in project form and public-private partnership constellations, actor relations crystallized significantly differently in Malmö compared to Stockholm. In particular, the relations between private companies and public administration appeared to differ significantly in practice, despite such similarities on the surface. This can be understood productively through dynamics imbued by the local context; in Malmö there is a longstanding strong relationship between the City and E.ON (formerly Sydkraft), in contrast to Stockholm.

Second, the socio-technical configuration of the large-scale power grid infrastructure and the historically sedimented power relations in the electricity sector that have co-evolved alongside it, particularly the centralized ownership structures, also influenced how governance was accomplished. A few private companies are the major grid owners in Sweden, which became evident as a public servant in Malmö stated that they had to work together with E.ON since "they own the solution", which they interlaced with their own district heating grid, further reflecting the need for a close partnership constellation in the region of Skåne. The grid infrastructure presented very different challenges on Gotland, necessitating different programs of action which invited contestations to a greater extent than in Malmö or Stockholm. The centralized ownership structures further influenced how governance was accomplished, especially in terms of who managed to surpass the threshold to actually generate knowledge in smart energy experiments. For instance, knowledge of and skills to navigate funding infrastructures are necessary, as are the time and resources to write applications. This illuminates how a few established actors with organizational resources and capital reappeared as central actors across experiments - a tendency further reinforced through their historically sedimented positions of power within the Swedish energy system. Additionally, the calls are set up through specific strategies, and as we saw, goals of green growth and the widespread 
projectification condition the horizon of possibilities for smart energy experiments, indicating how the broader political rationality conditions how experimentation arranges environmental governance.

The cases of smart energy experiments elucidate micro-politics of smart energy experimentation through dynamics emerging as intervention is assembled across different local socio-material webs of relations, realigning interests as well as reinforcing historically sedimented power relations. Such micro-politics underscore how green transformation is essentially a political struggle, visible through the opening up and closing down of relations as different elements are assembled and certain actors attempt to imprint transformation processes through smart energy experimentation.

\section{Smart energy experimentation as depoliticizing and repoliticizing environmental governance}

To conclude this thesis, I will now look to connect the analysis conducted with the literature it builds upon, to draw out implications about what has been learnt and where this leaves us.

First, this thesis has illustrated how smart energy experimentation is largely an arena for politics, whether it plays out loudly, as in the cases of Västerås and Gotland, or through more subtle registers, such as in Hyllie or Stockholm. As we have seen, smart energy experimentation positions historically dominant actors in the Swedish energy system, primarily large private energy companies, as central agents of environmental governance, and how the projectified research funding infrastructure tends to favor such actors. The broader political rationality preformats experimentation, leading to governance arrangements that are set up to the advantage of these actors. This became further visible via instances where upscaling was discussed in the empirical material; the constant shifting of responsibility elucidated how instigating broader transformative change seemed to be synonymous with conducting more experiments, which in turn was further facilitated by projectification and the emphasis on collaborative networked governance, as well as the need to develop ever more new products and services in the name of greening economic growth and achieving Swedish export ambitions.

The case of the energy pilot initiative provided rich illustrations of how the broader political rationality underpinning smart energy experimentation was refracted by dynamics on the ground through unfolding processes of accomplishing environmental governance, highlighting micro-politics of experimentation. The mode of experimentation facilitated by the political rationality allowed incumbents such as Vattenfall to utilize their experiences from previous experiments, notably Smart Grid Gotland, to increasingly turn themselves into an obligatory 
passage point in the socio-technical configuration being shaped on Gotland. ${ }^{1127}$ They skillfully navigated the jungle of entangled research funding infrastructures and, via the CoordiNet EU project, they attempted to influence the buildup of new configurations, including curtailing the possibility of user participation by establishing flexibility market setups for electricity that require large-scale aggregation, thus subtly cutting off alternative pathways. This highlights the power relations forged as governance is accomplished; Vattenfall was building upon the credibility established through having experiments such as Smart Grid Gotland in its backlog, to make sure a large-scale energy infrastructure is retained in which it remains a dominant player. Still, as we saw throughout the fourth empirical chapter, a potent dynamic on the island was the political energies harbored by many local actors who wished to experiment differently. We could also observe how the County Administrative Board became increasingly active in processes of assembling intervention, as it resourcefully drew upon the energy pilot initiative to realign it with its own priorities. Notably, it invoked the Energy Agency in its new energy and climate strategy, making the agency responsible for a portion of the strategy. These dynamics elucidate how smart energy experimentation becomes an arena of politics where ambitions of green transformation are turned into practice through unfolding processes of accomplishing governance. In the case of the energy pilot, experimentation allowed powerful incumbents such as Vattenfall to strategically maneuver the unfolding attempts at transformation to retain their dominant position, as well as channeling the political energies of local actors with hopes of significantly different energy futures.

The political rationality seems, however, to contribute primarily to smothering rather than highlighting different possible energy futures and productive conflict dynamics; through techniques instituted for governing such as the TRL scale, politics of green transformation are shrouded by smart energy experimentation. Or, as shown, politics are displaced from open arenas where they can be contested into more obscure realms, which are only accessible for some. Crucially, politics are displaced into realms where some have the leverage to affect which pathways will be walked. Such leverage owes to historically sedimented power relations that allow for strategic use of experimentation, to assert dominance and try to mold energy transformation onto particular preferred pathways, as highlighted above. To an extent, this also hinges upon the consensus-seeking and cooperation-inclined modes of experimentation engendered through broader governance arrangements, to achieve the goal of making Sweden a green smart energy frontrunner and export nation. This highlights how a faith in good liberal discussion and rationality obscures contestations emerging across cases of experiments, concealing the politics of experimentation and the politics in experiments, and benefiting actors who are already dominant. This works in tandem with the abundant techno-economic knowledge claims we have seen foregrounded through experimentation, as well as an emphasis

${ }^{1127}$ See Callon 1984. Some Elements of a Sociology of Translation: Domestication of the Scallops and the Fishermen of St Brieuc Bay. The Sociological Review, 32(1); cf. Laclau \& Mouffe 1985. Hegemony and Socialist Strategy. 
on consensus and collaboration to showcase a united front and thereby achieve ambitions of green growth and smart energy technology exports. ${ }^{1128}$ As we have seen, these aspects further dovetail with and provide impetus for neoliberalization processes. Such an effort to make politics invisible is politics par excellence. Consequently there are evident risks that experimentation becomes system-preserving rather than a catalyst for change. ${ }^{1129}$

Flowing as an undercurrent through such governance arrangements was a particular notion of socio-technical change, as we have seen throughout the thesis, including specific ideas about how experiments contribute to knowledge generation and learning. Such assumptions inform the setup of experimentation - as we saw in the prevalence of the TRL scale, and the sequential order of innovation that it signifies. First, we carry out experiments to generate knowledge; then, this knowledge is disseminated across society; and, finally, experiments can be scaled up. In the empirical chapters, we have seen how it is not that simple. Rather, particular infrastructures of circulation are established through experiments, or in some cases existing such channels are tapped into; nevertheless, the circulation of knowledge is much more limited than tends to be imagined. Often, it seems to remain within the bounds of a few private companies. As highlighted, such processes of circulation illuminate the knowledge politics of smart energy experimentation. Further, circulations appear more complex and less temporally bound than is often imagined in the literature; as we saw for example in the case of Smart Energy City, circulation appeared before and during the experiment, but less afterwards. Additionally, the case of the E.ON employee who circulated across country borders provides an example of embodied knowledge. If upscaling was straightforward, E.ON would simply have copied the decidedly successful template of the Hyllie experiment and implemented elsewhere. It was necessary to physically move a knowledgeable person, embodying knowledge generated and relations forged through the experiences gained in Hyllie, highlighting how knowledge dissemination and upscaling is a much more complex matter. Through this study processes of circulation could be discerned, such as in the case of the E.ON employee, but to gain a deeper understanding of the role of circulations in accomplishing governance, additional studies need to be undertaken. It would, for example, have been fruitful to follow the E.ON employee with an ethnographic approach, perhaps drawing on policy mobilities literature, to gain a deeper understanding of such processes of circulation and the role of embodied knowledge. Such studies could provide important input for our understanding of how experimentation arranges environmental governance, as well as better calibrating our understanding of contemporary processes of infrastructural change. In any case, this study has highlighted how a differentiated conceptualization of circulations can help deepen our understanding of how experimentation arranges environmental governance.

${ }^{1128}$ Cf. Mouffe 2005. On the Political; Swyngedouw 2013. The Non-political Politics of Climate Change.

${ }^{1129}$ Cf. Geels 2014. The stickiness of socio-technical regimes; Luque-Ayala et al. 2018. Rethinking Urban Transitions: An analytical framework. p. 20. 
Consequently, we have seen how experiments constitute arenas for politics, where processes of accomplishing governance institute micro-politics that contributes to reconfiguring governance arrangements. ${ }^{1130}$ This was especially visible in the case of the energy pilot initiative on Gotland. What we have seen in this thesis, however, is an obvious tendency of smart energy experimentation to obscure contestations over energy futures; recall the relative marginalization of the Västerås experiment and the impossibility of constructing a nanogrid, as well as the difficulties of incorporating the alternative visions of the future energy system prevalent on Gotland into the energy pilot initiative so far. The displacement of politics into arenas that are only accessible to some does not mean an erasure of the political, as if that would ever be possible. ${ }^{1131}$ What it does mean, however, is potentially suppressing or at least delaying serious consideration of other, more radical ways to set up experimentation. What Västerås tells us is how difficult it currently is to experiment with different energy community setups, for example. The governance arrangements shaped and sustained as experimentation accomplishes environmental governance to a significant extent result in sustaining an ecomodern environmental politics while giving impetus to neoliberalization processes. As we have seen, this is not necessarily inherent in experimentation; if it is considered a particular dispositif, it is rather the result of particular dynamics of accomplishing governance, historically sedimented power relations, and the socio-technical power grid infrastructure. Västerås and Gotland illustrate how it is possible to subvert and challenge dominant political rationality through experimenting differently.

So, despite the evidently dominant position of the broader political rationality and the increasing incorporation of smart energy experimentation into a green governmental apparatus, the accomplishments we can trace across cases of experiments, especially Gotland and Västerås, show how smart energy experimentation can be done differently and make politics of green transformation discernible. These experiments elucidate how experiments can successfully become woven into local socio-material webs of relations while at the same time bringing out different possible energy futures. To facilitate a just energy transformation that reinvigorates democracy, such politics of green energy transformation must be brought out, enabling the desirability of and pathways toward different energy futures to be debated agonistically. ${ }^{1132}$ To circle back to the literature this thesis builds upon, let us examine an argument made by Bruce Braun that touches upon such aspects. In line with fellow political ecologists such as Paul Robbins and Sarah Moore, Braun draws attention to how there seems to be an underlying trust in "good liberal and communicative discussion" within much of the

${ }^{1130}$ Cf. Marres \& Stark 2020. Put to the test; Engels et al. 2019. Testing future societies?; Laurent 2011. Technologies of Democracy; Nadaï \& Labussière 2018. Technological Demonstration at the Core of the Energy Transition; Bulkeley et al. 2015. An urban politics of climate change.

${ }^{1131}$ Cf. Mouffe 2005. On the Political; Mouffe 2013. Agonistics.

${ }^{1132}$ Cf. Mouffe 2013. Agonistics; Andersson \& Westholm 2019. Slaget om Framtiden. 
prevalent academic thinking about experimentation. ${ }^{1133}$ He states that it is difficult to escape a sense of implicit normativity permeating the accounts of experimentation and inventiveness, i.e. the ideal of the structured, rational conversation often embedded in ideals of liberal democracy. ${ }^{1134}$ Braun also notes how approaches that put great emphasis on procedural democratic issues, such as accounts of experimentation arguing for the inclusivity and inherent possibilities of experimenting, often seem to fall back on a view of politics completely devoid of politics. ${ }^{1135}$ The nurturing of disagreement and openness to difference and surprise are central to the so-called "experimental turn", which includes segments of the micro-inclined literature providing analytical insights for this thesis, but these approaches lack attention toward barriers to participation or the histories and relations which shaped the current situation, Braun argues. ${ }^{1136}$ This latter aspect in particular is surprising for Braun, as he states that with the spatially bounded nature of much of the thinking about experimental approaches, one risks completely overlooking the political-economic arrangements which inevitably form an integral part of issues connected to climate change, for instance, with which the "experimental turn" is concerned.

Braun's discussion of the literature might as well have been explicitly concerned with processes of how smart energy experimentation arranges environmental governance. Much of the mentalité of experimentation is highly compatible with depoliticizing, neoliberal consensusseeking, based on "good liberal communication and discussion", suppressing the political and displacing politics to less visible arenas. In the light of glaciers melting before our very eyes and monuments being raised in memoriam, while California is ravaged by wildfires and Bangladesh is moving closer to uninhabitability due to sea-level rise, such modes of experimentation, tapping into hopes for silver bullets in the guise of green growth and technomanagerial salvation, are opened to serious questioning. While experimentation can certainly aid in opening up debates on energy futures, and the pathways there, currently smart energy experimentation appears rather inclined to uphold the broader political rationality - lending further credibility to projectification, consensus-seeking, and collaborative public-private partnership constellations where the historically dominant private companies in the electricity sector seek to fulfill ambitions of green growth and smart energy technology exports. As has been stated, the intention of this thesis is not to criticize individuals, or even necessarily organizations. ${ }^{1137}$ In a Foucauldian vein, the intention is rather to highlight the power relations shaped and sustained, or the power effects, of how experimentation arranges environmental

${ }^{1133}$ Braun 2015. From Critique to Experiment? Rethinking political ecology for the Anthropocene. p. 109. In Perreault, Bridge, and McCarthy (eds.). Routledge handbook of political ecology. Abingdon, Oxon: Routledge. pp. 102-114.

${ }^{1134}$ Braun 2015. From Critique to Experiment? p. 109; Cf. Mouffe 2013. Agonistics.

${ }^{1135}$ Braun 2015. From Critique to Experiment? p. 110.

${ }^{1136}$ Ibid. p. 110.

1137 See Pellizzoni \& Ylönen 2012. Hegemonic contingencies: Neoliberalized technoscience and neorationality. p. 56. In Pellizzoni \& Ylönen (eds.) 2012. Neoliberalism and Technoscience. pp. 47-74. 
governance. For Foucault, critique in itself was an experimental practice, in the sense that critique is about investigating the order in which any articulation, for instance experimentation, becomes possible and legitimate. ${ }^{1138}$ As Foucault pointed out, power is not by necessity a matter of intentions, but of effects. The political rationality upheld by and conditioning smart energy experimentation has certain power effects, as have the accomplishments we see across cases of experiments, despite the intentions of different actors.

Finally, let us circle back to the main question animating this study, how smart energy experimentation arranges environmental governance, and the politics of such processes. I claimed in the introductory chapter that the approach of this study makes it possible to study how governance is arranged beyond isolated experiments. Taking claims from different strands of literature concerned with governance seriously - mainly the need to historicize and take already existing power relations into account on the one hand while recognizing how governance is always arranged in distributed ways across micro-settings on the other - and invoking concepts to that end has provided a way of doing so. Attending to different spaces of governance, we have seen how broader governance arrangements, pre-existing smart energy experimentation, are co-constituted through such experimentation through drawing upon the concept of political rationality. Through a processual approach to governance, the lens of accomplishing governance, we have further seen that smart energy experimentation continuously opens up and closes down fields of intervention for environmental governance as relations are forged through assembling practices. Thus, accomplishing governance draws upon and invokes, as well as challenges and reconfigures, elements of the broader political rationality. This occurred across different spaces of governance; governance is an accomplishment in the making as much in governmental institutions as on the ground in Norra Djurgårdsstaden or on Gotland. Further, aided by the concept of circulations we have observed how knowledge claims from experiments might become incorporated into broader governmental programs and governance arrangements through infrastructures of circulation, visible especially in the cases of Hyllie and Gotland.

Thus, building upon claims in the literature ranging from Bulkeley and Castán Broto's reflections on the role of circulations for climate governance, via Pellizzoni's insistence on the necessity of historicizing within social science, to scholars within STS such as Marres and Stark or Engels who have shown how society is continuously reconfigured across manifold microsettings, has provided a platform to answer calls for analyzing how experiments influence governance echoed across the literatures on environmental politics and energy transitions. By drawing upon these literatures, invoking political rationality, accomplishing governance, and circulations, a broad understanding of governance has been outlined, which helps us understand how experimentation arranges governance beyond singular experiments. The study contributes to ongoing discussions with a particular way of conceptualizing how

${ }^{1138}$ Braun 2015. From Critique to Experiment? p. 112; Pellizzoni 2015. Ontological Politics in a Disposable World. 
processes of accomplishing governance changes or sustains already existing governance arrangements, conditioned by and co-constituting as well as challenging broader political rationality, as well as how singular experiments may become incorporated into broader programs of governance. Hopefully, I have provided a possible answer to the question of how smart energy experimentation arranges environmental governance through this endeavor, focused on the politics of such processes.

To avoid blinding ourselves to what green energy transformation smart energy experimentation shapes in practice, it is necessary to conceptualize experimentation as arranging governance across spaces in a wide-ranging fashion. It is necessary to historicize in order to gauge the conditions of possibility for smart energy experimentation, taking power relations into account, to sensitize analysis toward the power effects of such experimentation. On the other hand, this must not lead to sweeping generalizations; it is just as necessary to attend granularly to micro-political processes that are central to how experimentation arranges environmental governance, as we have seen. It is not enough to attend to critical analysis from an overarching perspective, nor can micro-empiricist approaches tell us enough about how smart energy experimentation arranges environmental governance. Opening up smart energy experimentation is essential, both for public debate and within elite policymaking circles - this can allow for the fostering of generative modes of experimentation. Perhaps it will enrich and facilitate possibilities of experimenting for change, change that we know is necessary, turning experiments into important catalysts toward different modes of existence. 


\section{References}

\section{Books and articles}

Adam, B. 1998. Timescapes of modernity: the environment and invisible hazards. London: Routledge.

Agrawal, A. 2005. Environmentality: Technologies of government and the making of subjects. Durham: Duke University Press.

Ahlborg, H. 2017. Towards a conceptualization of power in energy transitions. Environmental Innovation and Societal Transitions, 25. pp. 122-141.

Allen, J. 2003. The Whereabouts of Power: Politics, Government and Space. Geografiska Annaler B, 86(1). pp. 19-32.

Alm, M. 2006. Nationell kraft och lokal motkraft: En diskursanalys av konflikten kring SwePol Link. Dissertation. Linköping: Linköping University.

Alvesson, M. \& Sköldberg, K. 2017. Tolkning och reflektion: vetenskapsfilosofi och kvalitativ metod. 3rd ed. Lund: Studentlitteratur.

Andersson, D. 2020. Artificial Earth: On the Genealogy of Planetary Technicity. Dissertation. Linköping: Linköping University.

Andersson, Å. 1985. Kreativitet - StorStadens framtid: en bok om Stockholm. Stockholm: Prisma.

Andersson, H. \& Klevard Setterwall, Å. 1995. Energiboken: kunskapsläge och forskningsfront. Stockholm: Statens råd för byggnadsforskning.

Andersson, J. \& Westholm E. 2019. Slaget om framtiden: forskningens roll i konflikten mellan tillväxt och miljö. Stockholm: Santérus förlag.

Ansell, C. \& Bartenberger, M. 2016. Varieties of experimentalism. Ecological Economics, 130. pp. 64-73. 
Anshelm, J. 2012. Kampen om klimatet: Miljöpolitiska strider i Sverige 2006-2009. Storå: Pärspektiv.

Anshelm, J. 2006. Bergsäkert eller våghalsigt? Frågan om kärnavfallets hantering i det offentliga samtalet i Sverige 1950-2002. Lund: Arkiv.

Anshelm, J. 2002. Det gröna folkhemmet - Striden om den ekologiska moderniseringen av Sverige. In Hedrén (ed.). Naturen som brytpunkt: om miljöfrågans mystifieringar, konflikter och motsägelser. Eslöv: B. Östlings bokförl. Symposion. pp. 34-61.

Anshelm, J. 2000. Mellan frälsning och domedag: om kärnkraftens politiska idéhistoria i Sverige 1945-1999. Eslöv: B. Östlings bokförl. Symposion.

Anshelm, J. 1995. Socialdemokraterna och miljöfrågan: en studie av framstegstankens paradoxer. Stockholm: B. Östlings bokförl. Symposion.

Anshelm, J. \& Hultman, M. 2014. Discourses of global climate change: Apocalyptic framing and political antagonisms. Abingdon,

Anshelm, J., Haikola, H., and Wallsten, B. (eds.) 2018. Svensk gruvpolitik i omvandling: Aktörer, kontroverser, möjliga världar. Gidlunds förlag.

Asdal, K. 2011. Politikkens Natur - Naturens Politikk. Oslo: Univ. forl.

Atkinson, P. \& Silverman, D. 1997. Kundera's immortality: The interview society and the invention of the self. Qualitative Inquiry, 3(3). pp. 304-325.

Avelino, F., Grin, J., Pel, B., and Jhagroe, S. 2016. The politics of sustainability transitions. Journal of Environmental Policy \& Planning, 18(5). pp. 557-567.

Bakke, G. 2017. The Grid: the fraying wires between Americans and our energy future. New York, NY: Bloomsbury Publishing Plc.

Barry, A. 2001. Political machines: Governing a technological society. London \& New York: Athlone Press. 
Bauman, Z. 2007. Consuming life. Cambridge: Polity.

Beck, U. 2009. World at risk. Cambridge: Polity Press.

Beck, U. 1997. Subpolitics: Ecology and the Disintegration of Institutional Power. Organization \& Environment, 10(1). pp. 52-65.

Bergquist, A-K. \& Söderholm, K. 2014. Industry Strategies for Energy Transition in the Wake of the Oil Crisis. Business and Economic History On-Line, 12. pp. 1-18.

Bernstein \& Hoffman 2018. The politics of decarbonization and the catalytic impact of subnational climate experiments. Policy Sciences, 51. pp. 189-211.

Binkley, S. \& Capetillo Ponce, J. (eds.) 2009. A Foucault for the 21st Century: Governmentality, Biopolitics and Discipline in the New Millennium. Newcastle: Cambridge Scholars Publishing.

Birch, K. 2017. Techno-economic Assumptions. Science as Culture, 26(4). pp. 433-444.

Bladh, M. 2007. El nära och långt borta: hur kan hushållen agera på elmarknaden? Linköping: Tema T, Linköping University.

Blühdorn, I. \& Deflorian, M. 2019. The Collaborative Management of Sustained Unsustainability: On the performance of Participatory Forms of Environmental Governance. Sustainability, 11(4). pp. 1-17.

Blühdorn, I. \& Welsh, I. (eds.) 2014. The politics of unsustainability: Eco-politics in the postecologist era. London: Routledge.

Bohlin, I. \& Sager, M. (eds.) 2011. Evidensens många ansikten: Evidensbaserad praktik i praktiken. Lund: Arkiv.

Bonnedahl, K. 2012. Från ekonomiskt till hållbart, från exploatering till samexistens: en bok om att tänka om. Lund: Studentlitteratur.

Boyer, D. 2019. Energopolitics: Wind and power in the Anthropocene. Duke University Press. 
Braun, B. 2015. From Critique to Experiment? Rethinking political ecology for the Anthropocene. In Perreault, Bridge, and McCarthy (eds.). Routledge handbook of political ecology. Abingdon, Oxon: Routledge. pp. 102-114.

Braun, B. 2014. A New Urban Dispositif? Governing life in an age of climate change. Environment and Planning D: Society and Space, 32(1). pp. 49-64.

Brenner, N. 2019. New Urban Spaces: Urban theory and the scale question. New York: Oxford University Press.

Brown, W. 2015. Undoing the Demos: Neoliberalism's stealth revolution. New York: Zone Books.

Bulkeley, H. 2016. Accomplishing Climate Governance. Cambridge: Cambridge University Press.

Bulkeley, H., McGuirk, P., and Dowling, R. 2016. Making a smart city for the smart grid? The urban material politics of actualizing smart electricity networks. Environment and Planning A, 48(9). pp. 1709-1726.

Bulkeley, H. \& Newell, P. 2015. Governing Climate Change. Second edition. Abingdon, Oxon: Routledge.

Bulkeley, H. \& Castán Broto, V. 2013. Government by experiment? Global cities and the governing of climate change. Transactions of the Institute of British Geographers, 38(3). pp. 361 375.

Bulkeley, H. \& Betsill, M. 2003. Cities and Climate Change: Urban sustainability and global environmental governance. London: Routledge.

Bulkeley, H., Paterson, M., and Stripple, J. 2016. Toward a cultural politics of climate change: devices, desires, and dissent. Cambridge: Cambridge University Press.

Bulkeley, H., Castán Broto, V., and Edwards, G. 2015. An urban politics of climate change: Experimentation and the governing of socio-technical transitions. London: Routledge. 
Burke, M. \& Stephens, J. 2016. Political power and renewable energy futures: A critical review. Energy Research \& Social Science, 35. pp. 78-93.

Büttner, S. 2019. The European Dimension of Projectification: Implications of the Project Approach in EU Funding Policy. In Hodgson, Fred, Bailey, and Hall (eds.) 2019. The Projectification of the Public Sector. Routledge. pp. 149-168.

Buzdugan, S. \& Payne, A. 2016. The Long Battle for Global Governance. Abingdon, Oxon: Routledge.

Bylund, J. 2006. Planning, Projects, Practice: A Human Geography of the Stockholm Local Investment Programme in Hammarby Sjöstad. Dissertation. Stockholm: Stockholm University.

Callon, M. 1984. Some Elements of a Sociology of Translation: Domestication of the Scallops and the Fishermen of St Brieuc Bay. The Sociological Review, 32(1). pp. 196-233.

Callon, M. \& Law, J. 2004. Guest Editorial - Introduction: Absence-Presence, Circulation, and Encountering in Complex Space. Environment and Planning D: Society and Space, 22(1). pp. $3-11$.

Cardullo, P. \& Kitchin, R. 2019. Smart urbanism and smart citizenship: The neoliberal logic of 'citizen-focused' smart cities in Europe. Environment and Planning C: Politics and Space, 37(5). pp. 813-830.

Cashmore, M., Stissing Jensen, J., and Späth, P. 2019. Introduction: The knowledge politics of urban sustainability transitions. Introduction. In Stissing Jensen, J., Cashmore, M., and Späth, P. (eds.). The Politics of Urban Sustainability Transitions: Knowledge, Power and Governance. pp. 1-16. Abingdon, Oxon: Routledge.

Castán Broto, V. \& Bulkeley, H. 2018. Realigning Circulations: How Urban Climate Change Experiments Gain Traction. In Turnheim et al. (eds). Innovating Climate Governance. pp. 6984.

Cavanagh, C. \& Benjaminsen, T. 2017. Political ecology, variegated green economies, and the foreclosure of alternative sustainabilities. Journal of Political Ecology, 24(1). pp. 200-216. 
Chalmers, A. 2013. What is this thing called science? 4. ed. Maidenhead: Open University Press/McGraw-Hill Education.

Charmaz, K. 2014. Constructing Grounded Theory. 2nd edition. Thousand Oaks, CA: Sage Publications

Coletta, C., Evans, L., Heaphy, L., and Kitchin, R. 2019. Creating Smart Cities. Abingdon, Oxon: Routledge.

Corn, J. (ed.) 1986. Imagining Tomorrow: History, Technology, and the American Future. Cambridge, MA: MIT Press.

Crouch, C. 2011. The strange non-death of neoliberalism. Cambridge: Polity.

Crutzen, P. \& Stoermer, E. 2000. The "Anthropocene". IGBP Newsletter 41(17-18).

Cugurullo, F. 2018. Exposing smart cities and eco-cities: Frankenstein urbanism and the sustainability challenges of the experimental city. Environment and Planning A: Economy and Space, 50(1). pp. 73-92.

Cunsolo, A. \& Ellis, N. 2018. Ecological grief as a mental health response to climate changerelated loss. Nature Climate Change, 8. pp. 275-281.

Dannestam, T. 2009. Stadspolitik i Malmö: Politikens meningsskapande och materialitet. Dissertation. Lund: Lund University.

Darier, É. (ed.) 1999. Discourses of the environment. Malden, Mass.: Blackwell.

Darier, É. 1996. Environmental Governmentality: The Case of Canada's Green Plan. Environmental Politics, 5(4). pp. 585-606.

Dauvergne, P. 2016. Environmentalism of the Rich. Cambridge, MA: The MIT Press.

Dauvergne, P. 2008. The shadows of consumption: consequences for the global environment. Cambridge, Mass.: MIT Press. 
Davidson, M. 2017. Governance. In Jayne, M. \& Ward, K. (eds). Urban Theory: New Critical Perspectives. London: Routledge. pp. 146-157.

Dawson, A. 2020. People's Power: Reclaiming the Energy Commons. New York: OR Books.

Dean, M. 2010. Governmentality: power and rule in modern society. 2. ed. Thousand Oaks, CA: SAGE Publications.

Death, C. 2013. The Limits of Climate Governmentality. In Stripple, J. \& Bulkeley, H. (eds.). Governing the climate: new approaches to rationality, power and politics. pp. 77-92.

Dryzek, J. 2013. The Politics of the Earth: Environmental discourses. 3. ed. Oxford: Oxford University Press.

Dunlap, A. 2019. Renewing Destruction: wind energy development, conflict and resistance in a Latin American context. Lanham: Rowman \& Littlefield International.

Easterling, K. 2016. Extrastatecraft: The power of infrastructure space. London: Verso.

Eder, K. 1996. The social construction of nature: A sociology of ecological enlightenment. London: Sage.

Edwards, G. \& Bulkeley, H. 2017. Heterotopia and the urban politics of climate change experimentation. Environment and Planning D: Society and Space, 36(2). pp. 350-369.

Engels, F., Wentland, A., and Pfotenhauer, S. 2019. Testing future societies? Developing a framework for test beds and living labs as instruments of innovation governance. Research Policy, 48(9). pp. 1-11.

Eriksson, O. \& Finnveden, G. 2009. Plastic waste as a fuel - $\mathrm{CO}_{2}$-neutral or not? Energy \& Environmental Science, 2(9). pp. 907-914.

Ernstson, H. \& Swyngedouw, E. (eds.) 2019. Urban Political Ecology in the Anthropo-Obscene: Interruptions and Possibilities. Abingdon, Oxon: Routledge. 
Ervine, K. 2018. Carbon. Polity Press.

Evans, J., Karvonen, A., and Raven, R. (eds.) 2016. The experimental city. Abingdon, Oxon: Routledge.

Fassin, D. 2017. The endurance of critique. Anthropological Theory, 17(1). pp. 4-29.

Fawcett, P., Flinders, M., Hay, C., and Wood, M. (eds.) 2017. Anti-Politics, Depoliticization, and Governance. First edition. Oxford: Oxford University Press.

Flick, U., von Kardorff, E., and Steinke, I. (eds.) 2004. A companion to qualitative research. Sage.

Flyvbjerg, B. 2001. Making Social Science Matter. Cambridge: Cambridge University Press.

Foss Ballo, I. 2015. Imagining energy futures: Sociotechnical imaginaries of the future Smart Grid in Norway. Energy Research \& Social Science, 9. pp. 9-20.

Foucault, M. 2011. Vetandets Arkeologi. 2nd ed. Lund: Arkiv.

Foucault, M. 2007. Security, territory, population: lectures at the Collège de France, 1977-1978. Edited by Senellart, M. \& Davidson, A. Houndmills, Basingstoke, Hampshire: Palgrave Macmillan.

Foucault, M. 1986. Of Other Spaces. Diacritics, 16(1). pp. 22-27.

Foucault, M. 1972. The archaeology of knowledge. New York: Pantheon Books.

Franzén, M., Hertting, N., and Thörn, H. 2016. Stad till salu: Entreprenörsurbanismen och det offentliga rummets värde. Göteborg: Daidalos.

Frishammar, J., Söderholm, P., Bäckström, K., Hellsmark, H., and Ylinenpää , H. 2014. The role of pilot and demonstration plants in technological development: synthesis and directions for future research. Technology Analysis \& Strategic Management, 27(1). pp. 1-18. 
Fuenfschilling, L., Frantzeskaki, N., and Coenen, L. 2018. Urban experimentation and sustainability transitions. European Planning Studies, 27(2). pp. 219-228.

Gabrys, J. 2014. Programming Environments: Environmentality and Citizen Sensing in the Smart City. Environment and Planning D: Society and Space, 32(1). pp. 30-48.

Geels, F. 2014. Regime Resistance against Low-Carbon Transitions: Introducing Politics and Power into the Multi-Level Perspective. Theory, Culture \& Society, 31(5). pp. 21-40.

Geels, F. 2002. Technological transitions as evolutionary reconfiguration processes: a multilevel perspective and a case-study. Research Policy, 31(8-9). pp. 1257-1274.

Geels, F., Schwanen, T., Sorrell, S., Jenkins, K., and Sovacool, B. 2018. Reducing energy demand through low carbon innovation: A sociotechnical transitions perspective and thirteen research debates. Energy Research \& Social Science, 40. pp. 23-35.

Georgescu-Roegen, N. 1971. The entropy law and the economic process. Cambridge, Mass.: Harvard University Press.

George, A. \& Bennet, A. 2005. Case studies and theory development in the social sciences. Cambridge, Mass.: MIT Press.

Gibson-Graham, J.K. 2006. The end of capitalism (as we knew it): a feminist critique of political economy. Minneapolis: University of Minnesota Press.

Glynos, J. \& Howarth, D. 2007. Logics of Critical Explanation in Social and Political Theory. London: Routledge.

Godin, B. \& Vinck, D. (eds.) 2017. Critical studies of innovation: alternative approaches to the pro-innovation bias. Cheltenham, UK: Edward Elgar Publishing.

Graham, S. \& Marvin, S. 2001. Splintering urbanism: networked infrastructures, technological mobilites and the urban condition. London: Routledge. 
Granath, M. 2016. The smart city - how smart can "IT" be?: discourses on digitalisation in policy and planning of urban development. Dissertation. Linköping : Linköping University.

Granberg, M. 2003. Kommunikativ process eller beslutsentreprenad? Politiker, planerare och medborgare i samhällsplaneringen. Örebro University, Centrum för stadsmiljöforsknings skriftserie, report no. 57.

Green, J. 2014. Rethinking Private Authority: Agents and Entrepreneurs in Global Environmental Governance. Princeton University Press.

Green, A. 2006. Hållbar energianvändning i svensk stadsplanering. Dissertation. Linköping: Linköping University.

Gross, M. 2016. Give Me an Experiment and I Will Raise a Laboratory. Science, Technology, \& Human Values, 41(4). pp. 613-634.

Gross, M. \& Heinrichs, H. (eds.) 2010. Environmental Sociology: European Perspectives and Interdisciplinary Challenges. Dordrecht: Springer Netherlands.

Gullberg, A. \& Lilja, S. (eds.). Makten i stadshuset. Stockholms lokalpolitik under 1900-talet. Stockholm: Stockholmia förlag.

Haarstad, H. 2016. Where are urban energy transitions governed? Conceptualizing the complex governance arrangements for low-carbon mobility in Europe. Cities, 54. pp. 4-10.

Haberl, H., Wiedenhofer, D., Virág, D., et al. 2020. A systematic review of the evidence on decoupling of GDP, resource use and GHG emissions, part II: synthesizing the insights. Environmental Research Letters, 15(6). pp. 1-42.

Haikola, S. \& Anshelm, J. 2018. Depoliticization, Repoliticization, and Environmental Concerns - Swedish mining Politics as an Instance of Environmental Politicization. ACME: An International Journal for Critical Geographies, 17(2). pp. 561-596.

Hajer, M. 2016. Foreword. In Evans, Karvonen, and Raven (eds.) 2016. The experimental city. Abingdon, Oxon: Routledge. pp. xvi-xix. 
Hajer, M. \& Wagenaar, H. (eds.) 2003. Deliberative Policy Analysis: Understanding governance in the network society. Cambridge: Cambridge University Press.

Hajer, M. 1995. The Politics of Environmental Discourse: Ecological Modernization and the Policy Process. Oxford: Oxford University Press.

Hale, T. 2020. Transnational Actors and Transnational Governance in Global Environmental Politics. Annual Review of Political Science, 23:1. pp. 203-220.

Hale, T. 2016. "All Hands on Deck": The Paris Agreement and Nonstate Climate Action. Global Environmental Politics, 16(3). pp. 12-22.

Hall, P. 2019. Why is innovation policy projectified? Political causes in the case of Sweden. In Hodgson et al. (eds.). The Projectification of the Public Sector. pp. 35-55.

Haraway, D. 2016. Staying with the trouble: making kin in the Chthulucene. Durham: Duke University Press.

Hargreaves, T., Nye, M., and Burgess, J. 2013. Keeping energy visible? Exploring how householders interact with feedback from smart energy monitors in the longer term. Energy Policy, 52. pp. 126-134.

Harvey, D. 1989. From Managerialism to Entrepreneurialism: The Transformation in Urban Governance in Late Capitalism. Geografiska Annaler. Series B, Human Geography, 71(1). pp. 317.

Hay, C. 2007. Why we hate politics. Cambridge: Polity.

Hay, C. 2002. Political Analysis: a critical introduction. Basingstoke: Palgrave.

Hedrén, J. (ed.) 2002. Naturen som brytpunkt: Om miljöfrågans mystifieringar, konflikter och motsägelser. Stockholm/Stehag: Brutus Östlings Bokförlag Symposion.

Hedrén, J. 1994. Miljöpolitikens natur. Dissertation. Linköping: Linköping University. 
Hellsmark, H., Frishammar, J., Söderholm, P., and Ylinenpää, H. 2016. The role of pilot and demonstration plants in technology development and innovation policy. Research Policy, 45(9). pp. 1743-1761.

Hickel, J. \& Kallis, G. 2020. Is Green Growth Possible? New Political Economy, 25(4). pp. 469-486.

Hix, S. \& Høyland, B. 2011. The Political System of the European Union. 3. ed. Basingstoke: Palgrave Macmillan.

Hojckova, K., Sandén, B., and Ahlborg, H. 2018. Three electricity futures: Monitoring the emergence of alternative system architectures. Futures, 98. pp. 72-89.

Holgersen, S. \& Malm, A. 2016. "Green fix" as crisis management. Or: In which world is Malmö the world's greenest city? Geografiska Annaler B, 97(4). pp. 275-290.

Hommels, A. 2005. Unbuilding Cities: Obduracy in Urban Sociotechnical Change. Cambridge, Mass.: MIT.

Hood, C. 1995. The "New Public Management" in the 1980s: Variations on a Theme. Accounting, Organizations and Society, 20 (2-3). pp. 93-109.

Hoogma, R., Kemp, R., Schot, J., and Truffer, B. 2002. Experimenting for Sustainable Transport: The Approach of Strategic Niche Management. London: Spon.

Hodgson, D., Fred, M., Bailey, S., and Hall, P. (eds.) 2019. The Projectification of the Public Sector. Abingdon, Oxon: Routledge.

Hoffman, M. 2011. Climate governance at the crossroads: experimenting with a global response after Kyoto. Oxford: Oxford University Press.

Hollands, R. 2015. Critical Interventions into the Corporate Smart City. Cambridge Journal of Regions, Economy and Society, 8. pp. 61-77.

Hollands, R. 2008. Will the Real Smart City Please Stand Up? City, 12(3). pp. 303-320. 
Hornborg, A. 2019. Nature, Society, and Power in the Anthropocene: Unravelling the MoneyEnergy-Technology Complex. Cambridge: Cambridge University Press.

Hornborg, A. 2017. Dithering while the planet burns: Anthropologists' approaches to the Anthropocene. Reviews in Anthropology, 46(2-3). pp. 61-77.

Hornborg, A. 2016. Global Magic: Technologies of appropriation from ancient Rome to Wall Street. New York, NY: Palgrave Macmillan.

Howarth, D. 2013. Poststructuralism and after: structure, subjectivity and power. New York: Palgrave Macmillan.

Howe, C. 2019. Ecologics: Wind and power in the Anthropocene. Durham: Duke University Press.

Hughes, T. 1983. Networks of power: Electrification in Western society, 1880-1930. Baltimore: Johns Hopkins Univ. Press.

Hult, A. 2017. Unpacking Swedish Sustainability: The promotion and circulation of sustainable urbanism. Dissertation. Stockholm: Royal Institute of Technology (KTH).

Hultman, M. 2015. Den Inställda Omställningen: svensk energi- och miljöpolitik i möjligheternas tid 1980-1991. Möklinta: Gidlund.

Hultman, M. 2010. Full Gas Mot en (O)hållbar Framtid. Dissertation. Linköping: Linköping University.

Hysing, E. 2014. A Green Star Fading? A Critical Assessment of Swedish Environmental Policy Change. Environmental Policy and Governance, 24(4). pp. 262-274.

Högselius, P. \& Kaijser, A. 2007. När folkhemselen blev internationell: Elavregleringen i ett historiskt perspektiv. Stockholm: SNS Förlag.

Ingelstam, L. \& Kaijser, A. 1982. Kommer vackra mål att dränkas i el och kol? PLAN, 1-2. 
Jayne, M. \& Ward, K. (eds) 2017. Urban Theory: New Critical Perspectives. London: Routledge.

Johannisson, K. 1988. Det mätbara samhället: statistik och samhällsdröm i 1700-talets Europa. Stockholm: Norstedt.

Jonas, A., McCann, E., and Thomas, M. 2015. Urban Geography: A Critical Introduction. Chichester, West Sussex: Wiley Blackwell.

Joss, S., Sengers, F., Schraven, D., Caprotti F., and Dayot, Y. 2019. The Smart City as Global Discourse: Storylines and Critical Junctures across 27 Cities. Journal of Urban Technology, 26. pp. 3-34.

Kall, A-S. 2011. Förnyelse med förhinder. Dissertation. Linköping: Linköping University.

Kallis, G. 2018. Degrowth. Newcastle upon Tyne: Agenda Publishing.

Karvonen, A., Cugurullo, F., and Caprotti, F. (eds.) 2019. Inside smart cities: place, politics and urban innovation. Abingdon, Oxon: Routledge.

Karvonen, A. \& Van Heur, B. 2014. Urban laboratories: Experiments in reworking cities. International Journal of Urban and Regional Research, 38(2). pp. 379-392.

Kjeang, A. 2019. Good advice need not be expensive: On personalised energy advising in an increasingly digitised society. Research report 2019:12. Karlstad: Karlstad University.

Knorr Cetina, K. 1999. Epistemic Cultures: how the sciences make knowledge. Cambridge, Mass.: Harvard University Press.

Kotler, P., Haider, D., and Rein, I. 2002. Marketing Places. New York: Free Press.

Krausman, F., Lauk, C., Haas, W., and Wiedenhofer, D. 2018. From resource extraction to outflows of wastes and emissions: The socioeconomic metabolism of the global economy, 1900-2015. Global Environmental Change, 52. pp. 131-140. 
Kristensson Uggla, B. 1994. Kommunikation på bristningsgränsen: en studie i Paul Ricoeurs projekt. Dissertation. Lund: Lund University.

Kronsell, A. \& Mukhtar-Landgren, D. 2018. Experimental governance: the role of municipalities in urban living labs. European Planning Studies, 26(5). pp. 988-1007.

Kvale, S. \& Brinkmann, S. 2014. Den kvalitativa forskningsintervjun. Lund: Studentlitteratur.

Kåring-Wågman, A. 2008. När staten flyttade från sta'n. In Gullberg \& Lilja (eds.). Makten i stadshuset. Stockholms lokalpolitik under 1900-talet. Stockholm: Stockholmia förlag. pp. 265 283.

Labussière, O. \& Nadaï, A. (eds.). Energy Transitions. A Socio-technical Inquiry. Cham: Palgrave Macmillan. pp. 191-237.

Laclau, E. \& Mouffe, C. 1985. Hegemony and Socialist Strategy. London: Verso.

Larkin, B. 2013. The Politics and Poetics of Infrastructure. Annual Review of Anthropology, 42. pp. 327-343.

Latour, B. 2004. Why has critique run out of steam? Critical Inquiry, 30(2). pp. 225-248.

Latour, B. 2004. Politics of Nature: How to bring the sciences into democracy. Cambridge, Mass.: Harvard University Press.

Latour, B. 1999. Pandora's Hope: Essays on the Reality of Science Studies. Cambridge: Harvard University Press.

Latour, B. 1988. The Pasteurization of France. Cambridge, MA: Harvard University Press.

Latour, B. \& Woolgar, S. 1986. Laboratory life: the construction of scientific facts. [New ed.] Princeton, N.J.: Princeton Univ. Press.

Laurent, B. 2016. Political experiments that matter: Ordering democracy from experimental sites. Social Studies of Science, 46(5). pp. 773-794. 
Laurent, B. 2011. Technologies of Democracy: Experiments and Demonstrations. Science and Engineering Ethics, 17(4). pp. 649-666.

Lee, J-H., Hancock, M., and Hu, M-C. 2014. Towards an Effective Framework for Building Smart Cities: Lessons from Seoul and San Francisco. Technological Forecasting and Social Change, 89. pp. 80-99.

Lemke, T. 2011. 'The birth of bio-politics': Michel Foucault's lecture at the Collége de France on neo-liberal governmentality. Economy and Society, 30(2). pp. 190-207.

Lemke, T. 2007. An Indigestible Meal?: Foucault, Governmentality and State Theory. Distinktion: Scandinavian Journal of Social Theory, 8(2). pp. 43-64.

Levenda, A. 2019. Thinking critically about smart city experimentation: entrepreneurialism and responsibilization in urban living labs. Local Environment, 24(7). pp. 565-579.

Levenda, A. 2018. Urban Living Labs for the Smart Grid: Experimentation, governmentality and urban energy transitions. In Marvin et al. (eds). Urban Living Labs. pp. 52-73.

Levenda, A. 2018. Mobilizing smart grid experiments: Policy mobilities and urban energy governance. Environment and Planning C: Politics and Space, 37(4). pp. 634-651.

Levenda, A., Mahmoudi, D., and Sussman, G. 2015. The Neoliberal Politics of "Smart": Electricity Consumption, Household Monitoring, and the Enterprise Form. Canadian Journal of Communication, 40(4). pp. 615-636.

Lewin, L. 1998. Majoritarian and Consensus Democracy: the Swedish Experience. Scandinavian Political Studies, 21(3). pp. 195-206.

Lidskog, R. \& Elander, I. 2012. Ecological Modernization in Practice? The Case of Sustainable Development in Sweden. Journal of Environmental Policy \& Planning, 14(4). pp. 411-427.

Lovell, H. 2018. The promise of smart grids. Local Environment, 24(7). pp. 580-594. 
Lundqvist, L. 2004. Sweden and ecological governance: straddling the fence. Manchester: Manchester University Press.

Luque-Ayala, A., Bulkeley, H., and Marvin, S. 2018. Rethinking Urban Transitions: An analytical framework. In Luque-Ayala, A., Bulkeley, H., and Marvin, S. (eds.). Rethinking Urban Transitions. pp. 13-36.

Luque-Ayala, A., Bulkeley, H., and Marvin, S. (eds.) 2018. Rethinking Urban Transitions: Politics in the low carbon city. Abingdon, Oxon: Routledge.

Lösch, A. \& Schneider, C. 2017. Transforming power/knowledge apparatuses: the smart grid in the German energy transition. Innovation: The European Journal of Social Science Research, 29(3). pp. 262-284.

Lövbrand, E. \& Stripple, J. 2011. Making climate change governable: accounting for carbon as sinks, credits and personal budgets. Critical Policy Studies, 5:2.

Lövbrand, E., Beck, S., Chilvers, J., et al. 2015. Who speaks for the future of Earth? How critical social science can extend the conversation on the Anthropocene. Global Environmental Change, 32. pp. 211-218.

Machen, R. 2019. Critical research impact: On making space for alternatives. Area, 52(2). pp. 329-341.

MacKenzie, D. 2006. An engine not a camera. Cambridge, Mass.: MIT Press.

Madureira, AM. 2013. Physical Planning in Entrepreneurial Urban Governance Experiences from the Bo01 and Brunnshög Projects, Sweden. European Planning Studies, 22(11). pp. 2369-2388.

Magnusson, D. 2013. District heating in a liberalized energy market: A new order? Dissertation. Linköping: Linköping University.

Magone, JM. 2011. Contemporary European Politics. London: Routledge. 
Malette, S. 2009. Foucault for the next century: eco-governmentality. In Binkley, S. \& Capetillo Ponce, J. (eds.). A Foucault for the 21st Century: Governmentality, Biopolitics and Discipline in the New Millennium. Newcastle: Cambridge Scholars Publishing. pp. 221-239.

Malm, A. 2016. Fossil Capital: The rise of steam-power and the roots of global warming. London: Verso.

Malm, A. \& Hornborg, A. 2014. The geology of mankind? A critique of the Anthropocene narrative. Anthropocene Review, 1(1). pp. 62-69.

Markard, J. 2018. The next phase of the energy transition and its implications for research and policy. Nature Energy, 3(8). pp. 628-633.

Marres, N. \& Stark, D. 2020. Put to the test: For a new sociology of testing. The British Journal of Sociology, 71(3). pp. 423-443.

Marvin, S. \& Luque-Ayala, A. 2020. Urban Operating Systems: Producing the Computational City. MIT Press.

Marvin, S. \& Luque-Ayala, A. 2016. Urban Operating Systems: Diagramming the City. International Journal of Urban and Regional Research, 41(4). pp. 84-103.

Marvin, S., Luque-Ayala, A., and McFarlane, C. (eds.) 2016. Smart Urbanism - Utopian vision or false dawn? Abingdon, Oxon: Routledge.

Marvin, S., Bulkeley, C., Mai, L., McCormick, K., and Voytenko Palgan, Y. (eds.) 2018. Urban living labs: Experimenting with city futures. London: Routledge Taylor \& Francis.

Mayring, P. 2004. Qualitative content analysis. In Flick et al. (eds.). A companion to qualitative research. pp. 266-269.

McCann, E. 2011. Urban Policy Mobilities and Global Circuits of Knowledge: Toward a Research Agenda. Annals of the Association of American Geographers, 101(1). pp. 107-130. 
McCann, E. \& Ward, K. (eds.) 2011. Mobile Urbanism: cities and policymaking in the global age. Minneapolis: University of Minnesota Press.

McCann, E. \& Ward, K. 2011. Introduction. Urban Assemblages: Territories, Relations, Practices, and Power. In McCann \& Ward (eds.). Mobile Urbanism. pp. xiii-xxxv.

McLaren, D. \& Agyeman, J. 2019. Smart for a reason: Sustainability and social inclusion in the sharing city. In Coletta, C., Evans, L., Heaphy, L., and Kitchin, R. 2019. Creating Smart Cities. pp. 169-181.

Mitchell, T. 2013. Carbon Democracy: Political power in the age of oil. London: Verso.

Moore, J. 2015. Capitalism in the web of life: ecology and the accumulation of capital. New York: Verso.

Morrison, TH., Adger, WN., Brown, K. et al. 2019. The black box of power in polycentric environmental governance. Global Environmental Change, 57.

Mouffe, C. 2013. Agonistics: thinking the world politically. London: Verso.

Mouffe, C. 2005. On the Political. London: Routledge.

Mouffe, C. 2000. The Democratic Paradox. London: Verso.

Mulvaney, D. 2019. Solar Power: innovation, sustainability, and environmental justice. Oakland, California: University of California Press.

Murray Li, T. 2019. Problematising the Project System: Rural Development in Indonesia. In Hodgson et al. (eds). The Projectification of the Public Sector. pp. 56-74.

Murray Li, T. 2017. The Practice of Critique: A Comment on Fassin. Anthropological Theory, 17(2). pp. 262-264.

Murray Li, T. 2007. The Will to Improve: Governmentality, development, and the practice of politics. Durham, N.C.: Duke University Press. 
Mutter, A. 2019. Mobilizing sociotechnical imaginaries of fossil-free futures - Electricity and biogas in public transport in Linköping, Sweden. Energy Research \& Social Science, 49. pp. 1-9.

Möllers, N. 2016. Shifting in and out of context: Technoscientific drama as technology of the self. Social Studies of Science, 46(3). pp. 351-373.

Naber, R., Raven., R., Kouw., M., and Dassen, T. 2017. Scaling up sustainable energy innovations. Research Policy, 110. pp. 342-354.

Nadai, A. \& Labussière, O. 2018. Technological Demonstration at the Core of the Energy Transition. In Labussière, O. \& Nadaï, A. (eds.). Energy Transitions. pp. 191-237.

Nasiritousi, N. 2016. Shapers, brokers and doers: the dynamic roles of non-state actors in global climate change governance. Dissertation. Linköping: Linköping University.

Nikoleris, A. 2018. On the role of envisioned futures in sustainability transitions. Diss. Lund: Lund University.

Nixon, R. 2011. Slow violence and the environmentalism of the poor. Cambridge, Mass.: Harvard University Press.

Norgaard, KM. 2011. Living in denial: climate change, emotions, and everyday life. Cambridge, Mass.: MIT Press.

Noy, C. 2008. Sampling Knowledge: The Hermeneutics of Snowball Sampling in Qualitative Research. International Journal of Social Research Methodology, 11(4). pp. 327-344.

Oels, A. 2005. Rendering climate change governable: from biopower to advanced liberal government. Journal of environmental policy and planning, 7(3). pp. 185-207.

Overdevest, C., Bleicher, A., and Gross, M. 2010. The Experimental Turn in Environmental Sociology: Pragmatism and New Forms of Governance. In Gross, M. \& Heinrichs, H. (eds.) 2010. Environmental Sociology. pp. 279-294. 
Parks, D. 2018. The Sustainable City Becomes Climate-smart: how smart city ideas reshape urban environmental governance. Dissertation. Linköping: Linköping University.

Pallesen, T. \& Jacobsen, P. 2018. Solving infrastructural concerns through a market reorganization: A case study of a Danish smart grid demonstration. Energy Research \& Social Science, 41. pp. 80-88.

Pellizzoni, L. 2015. Ontological Politics in a Disposable World: The New Mastery of Nature. Farnham: Ashgate.

Pellizzoni, L. \& Ylönen, M. (eds.) 2012. Neoliberalism and Technoscience: Critical Assessments. Farnham: Ashgate.

Pellizoni, L. \& Ylönen, M. 2012. Introduction. In Pellizoni \& Ylönen (eds.) 2012. Neoliberalism and Technoscience. pp. 1-24.

Pellizzoni, L. \& Ylönen, M. 2012. Hegemonic contingencies: Neoliberalized technoscience and neorationality. In Pellizzoni, L. \& Ylönen, M. (eds.) 2012. Neoliberalism and Technoscience. pp. 47-74.

Pellizoni, L. \& Ylönen, M. 2012. Conclusion. In Pellizoni \& Ylönen (eds.) 2012.

Neoliberalism and Technoscience. pp. 231-238.

Perreault, T., Bridge, G., and McCarthy, J. (eds.) 2015. Routledge handbook of political ecology. Abingdon, Oxon: Routledge.

Peters, G. 2012. Institutional theory in political science: the new institutionalism. 3rd ed. London: Continuum.

Petrocultures Research Group 2016. After Oil. Edmonton: University of Alberta.

Pfotenhauer, S., Juhl, J., and Aarden, E. 2019. Challenging the "deficit model" of innovation: Framing policy issues under the innovation imperative. Research Policy, 48(4). pp. 895-904. 
Pirani, S. 2019. Burning Up: A Global History of Fossil Fuel Consumption. London: Pluto Press.

Ranciére, J. 2006. Hatred of Democracy. London: Verso.

Rhodes, R. 1997. Understanding Governance: Policy Networks, Governance, Reflexivity and Accountability. London: Open University Press.

Ringel, F. 2018. Back to the Postindustrial Future - An Ethnography of Germany's Fastest-Shrinking City. Berghahn Books.

Robinson, J. 2011. The Spaces of Circulating Knowledge: City Strategies and Global Urban Governmentality. In McCann, E. \& Ward, K. (eds.). Mobile Urbanism: Cities and Policymaking in the Global Age. Minneapolis: University of Minnesota Press. pp. 15-40.

Robbins, P. 2012. Political ecology: A critical introduction. Chichester: Wiley.

Rockström, J., Steffen, W., Noone, K. et al. 2009. A safe operating space for humanity. Nature, 461. pp. 472-475.

Rose, N. \& Miller, P. 2008. Governing the present: administering economic, social and personal life. Cambridge: Polity.

Rosenau, J. 1997. Along the domestic-foreign frontier: exploring governance in a turbulent world. Cambridge: Cambridge Univ. Press.

Rosenau, J. \& Czempiel, E-O. 1992. Governance without Government: Order and change in World Politics. Cambridge: Cambridge Univ. Press.

Rosental, C. 2013. Toward a Sociology of Public Demonstrations. Sociological Theory, 31(4). pp. 343-365.

Rostow, W. 1960. The stages of economic growth: a non-communist manifesto. Cambridge: Cambridge at the University Press. 
Roth, P. 1987. Meaning and method in the social sciences: a case for methodological pluralism. Ithaca, N.Y.: Cornell Univ. Press.

Rutherford, S. 2007. Green governmentality: insights and opportunities in the study of nature's rule. Progress in Human Geography, 31(3). pp. 291-307.

Sadowski, J. 2020. Too smart: how digital capitalism is extracting data, controlling our lives, and taking over the world. Cambridge, Massachusetts: The MIT Press.

Sadowski, J. \& Levenda, A. 2020. The anti-politics of smart energy regimes. Political Geography, 81. pp. 1-8.

Saldaña, J. 2015. The coding manual for qualitative researchers. 3. edition Thousand Oaks, CA: Sage Publications.

Schick, L. \& Winterheik, B.R. 2013. Innovating Relations - or Why Smart Grid is not too Complex for the Public. Science \& Technology Studies, 26(3). pp. 82-102.

Schindler, S. \& Marvin, S. 2018. Constructing a universal logic of urban control? International standards for city data, management, and interoperability. City, 22(2). pp. 298 307.

Schlosberg, D. \& Coles, R. 2016. The new environmentalism of everyday life:

Sustainability, material flows and movements. Contemporary Political Theory, 15. pp. 160-181.

Schot, J. \& Geels, F. 2008. Strategic niche management and sustainable innovation journeys: theory, findings, research agenda, and policy. Technology Analysis \& Strategic Management, 20(5). pp. 537-554.

Scoones, I., Leach, M., and Newell, P. (eds.) 2015. The politics of green transformations. Abingdon: Routledge.

Scoones, I., Newell, P., and Leach, M. 2015. The politics of green transformations. In Scoones, I., Leach, M., and Newell, P. (eds.) The politics of green transformations. pp. 1-24. 
Segal, H. 1986. The Technological Utopians. In Corn, J. (ed.). Imagining Tomorrow: History, Technology, and the American Future. Cambridge, MA: MIT Press.

Sengers, F., Wieczorek, A., and Raven, R. 2019. Experimenting for sustainability transitions: A systematic literature review. Technological Forecasting and Social Change, 145. pp. 153-164.

Sengers, F., Berkhout, F., Wieczorek, A., and Raven, R. 2016. Experimenting in the city: unpacking notions of experimentation for sustainability. In Evans et al. (eds.) The Experimental City. pp. 15-31.

Shapin, S. \& Schaffer, S. 1985. Leviathan and the Air-Pump: Hobbes, Boyle, and the experimental life. Princeton, N.J.: Princeton Univ. Press.

Sinclair, T. 2012. Global Governance. Cambridge: Polity.

Smith, A. \& Raven, R. 2012. What is protective space? Reconsidering niches in transitions to sustainability. Research Policy, 41(6). pp. 1025-1036.

Späth, P. \& Rohracher, H. 2012. Local Demonstrations for Global Transitions - Dynamics across Governance Levels Fostering Socio-Technical Regime Change Towards Sustainability. European Planning Studies, 20(3). pp. 461-479.

Späth, P. \& Rohracher, H. 2010. 'Energy regions': The transformative power of regional discourses on socio-technical futures. Research Policy, 39(4). pp. 449-458.

Stephens, J. Wilson, E., and Peterson, T.R. 2015. Smart grid (R)evolution: electric power struggles. New York, NY, USA: Cambridge University Press.

Stissing Jensen, J., Cashmore, M., and Späth, P. (eds.) 2019. The Politics of Urban Sustainability Transitions: Knowledge, Power and Governance. Abingdon, Oxon: Routledge.

Strengers, Y. 2013. Smart energy technologies in everyday life: Smart utopia?. New York: Palgrave Macmillan. 
Stripple, J. (undated), unpublished manuscript. Mobilising climate-smart Malmö:

Encountering three forms of circulation.

Stripple, J. \& Bulkeley, H. 2019. Towards a material politics of socio-technical transitions: Navigating decarbonisation pathways in Malmö. Political Geography, 72.

Stripple, J. \& Bulkeley, H. 2013. Governing the climate: new approaches to rationality, power and politics. New York: Cambridge University Press.

Summerton, J. 2004. Do Electrons Have Politics? Constructing User Identities in Swedish Electricity. Science, Technology, \&Human Values, 29(4). pp. 486-511.

Swyngedouw, E. 2013. The Non-political Politics of Climate Change. ACME: An International Journal for Critical Geographies, 12(1). pp. 1-8.

Swyngedouw, E. 2010. Apocalypse Forever? Post-Political Populism and the Spectre of Climate Change. Theory Culture \& Society, 27. pp. 213-232.

Szeman, I. 2019. On Petrocultures: Globalization, culture, and energy. Morgantown: West Virginia University Press.

Szulecki, K. 2018. Conceptualizing energy democracy. Environmental Politics, 27(1). pp. 21 41 .

Söderström, O., Paasche, T., and Klauser, F. 2014. Smart cities as corporate storytelling. City, 18(3). pp. 307-320.

Tarasova, E. 2017. Anti-nuclear movements in discursive and political contexts: between expert voices and local protests. Dissertation. Huddinge: Södertörns högskola.

Teleman, H. (ed.). Hållbarhetens villkor. Arena: Malmö, Sweden.

Temenos, C. \& McCann, E. 2013. Geographies of Policy Mobilities. Geography Compass, 7(5). pp. 344-357. 
Torregrosa-Hetland, S., Pelkonen, A., Oksanen, J., and Kander, A. 2019. The prevalence of publicly stimulated innovations - A comparison of Finland and Sweden, 1970-2013. Research Policy, 48(6). pp. 1373-1384.

Tozer, L. \& Klenk, N. 2018. Discourses of carbon neutrality and imaginaries of urban futures. Energy Research \& Social Science, 35. pp. 174-181.

Trindade, E., Hinnig, M., Moreira da Costa, E. et al. 2017. Sustainable Development of Smart Cities: A Systematic Review of the Literature. Journal of Open Innovation: Technology, Market, and Complexity, 3 (11). pp. 1-14.

Turnheim, B., Kivimaa, P., and Berkhout, F. (eds.) 2018. Innovating Climate Governance: Moving Beyond Experiments. Cambridge: Cambridge University Press.

Uggla, Y. \& Soneryd, L. 2017. Green Governmentality, Responsibilization and Resistance: International ENGOs' issue framings of future energy supply and climate change mitigation. Socijalna Ekologija, Zagreb, 26(3). pp. 87-104.

Vanolo, A. 2014. Smartmentality: The Smart City as Disciplinary Strategy. Urban Studies, 51(5). pp. 883-898.

van Asselt, H., Huitema, D., and Jordan, A. 2018. Global Climate Governance after Paris: Setting the Stage for Experimentation? In Turnheim et al. (eds.). Innovating Climate Governance. pp. 27-46.

van der Heijden, J. 2019. Studying urban climate governance: Where to begin, what to look for, and how to make a meaningful contribution to scholarship and practice. Earth System Governance, 1. pp. 1-10.

Verbong, G. \& Geels, F. 2010. Exploring sustainability transitions in the electricity sector with socio-technical pathways. Technological Forecasting and Social Change, 77(8). pp. 1214 1221.

Vesnic-Alujevic, L., Breitegger, M., and Guimarães Pereira, Â. 2016. What smart grids tell about innovation narratives in the European Union: Hopes, imaginaries and policy. Energy Research \& Social Science, 12. pp. 16-26. 
Vogler, J. 2003. Taking Institutions Seriously: How Regimes Can Be Relevant to Multilevel Environmental Governance. Global Environmental Politics, 3(2). pp. 25-39.

von Bergmann-Winberg, M-L. \& Wihlborg, E. (eds.) 2011. Politikens entreprenörskap - kreativ problemlösning och förändring. Malmö: Liber.

Wallsten, A. 2017. Assembling the Smart Grid: On the Mobilization of Imaginaries, Users and Materialities in a Swedish Demonstration Project. Dissertation. Linköping: Linköping University.

Wallsten, A. \& Parks, D. 2020. The Struggles of Smart Energy Places: Regulatory Lock-In and the Swedish Electricity Market. Annals of the American Association of Geographers, 110(2).

Wangel, J. 2015. Developing Sweden's transmission grid: What are the drivers and barriers? Stockholm: Stockholm Environment Institute.

Wangel, J. 2013. Hur hållbara är Hammarby sjöstad och Norra Djurgårdstaden? In Teleman (ed.). Hållbarhetens villkor.

Warde, P., Robin, L., and Sörlin, S. 2018. The Environment: a history of the idea. Baltimore, Maryland: Johns Hopkins University Press.

Wiig, A. 2015. IBM's smart city as techno-utopian policy mobility. City, 19(2-3). pp. 258273.

Winner, L. 1980. Do artefacts have politics? Daedalus, 109(1). pp. 121-136.

Winther Jørgensen, M. \& Phillips, L. 2000. Diskursanalys som teori och metod. Lund: Studentlitteratur.

Wittrock, B. \& Lindström, S. 1984. De stora programmens tid - forskning och energi i svensk politik. Stockholm: Akademilitteratur.

Wynne, B. 1992. Misunderstood misunderstanding: Social identities and public uptake of science. Public Understanding of Science, 1(3). pp. 281-304. 
Ylijoki, O-H. 2016. Projectification and conflicting temporalities in academic knowledge production. Theory of Science, 38(1). pp. 7-26.

\section{Online resources}

Ahlbom 2015. Smarta fiaskot för prestigebygget i Norra Djurgårdsstaden. NyTeknik 2015-0214. https://www.nyteknik.se/nyheter/smarta-fiaskot-for-prestigebygget-i-norradjurgardsstaden-6336033 [2019-06-18]

Alestig 2017. "Gotland en förebild för Sverige - och världen". Svenska Dagbladet - SvD Näringsliv. 2017-09-20. https://www.svd.se/gotland-kan-bli-en-forebild-for-sverige-ochvarlden [2019-08-26].

Boverket 2018. Planning Process. https://www.boverket.se/en/start/building-insweden/swedish-market/laws-and-regulations/planning-process/ [2019-06-17].

Clean Energy Ministerial (undated). ABOUT THE CLEAN ENERGY MINISTERIAL. http://www.cleanenergyministerial.org/about-clean-energy-ministerial [2019-05-23].

https://www.eon.se/privat/for-hemmet/100koll/om-100koll.html [2019-10-22]

European Commission 2017. Clean energy for all Europeans package.

https://ec.europa.eu/energy/topics/energy-strategy/clean-energy-all-europeans en [2019-05-24].

ETC 2022 [sic]. Presentation av ETC Hyreshus. Published 2022-01-01 [sic]. https://www.etc.se/etc-hyreshus/presentation-av-etc-hyreshus [2019-07-03].

Forum för smarta elnät n.d. Varför smarta elnät. http://swedishsmartgrid.se/varfor-smartaelnat/ [2018-02-28].

Forum för smarta elnät n.d. Bakgrund - Samordningsrådet för smarta elnät. http://swedishsmartgrid.se/om-oss/bakgrund--samordningsradet-for-smarta-elnat/ [201910-22]. 
IEA 2019. Tracking Clean Energy Progress. https://www.iea.org/tcep/ [2019-09-17].

IPCC 2018. Global Warming of $1.5^{\circ} \mathrm{C}$, an IPCC special report on the impacts of global warming of $1.5^{\circ} \mathrm{C}$ above pre-industrial levels and related global greenhouse gas emission pathways, in the context of strengthening the global response to the threat of climate change, sustainable development, and efforts to eradicate poverty. IPCC Special Report. https://www.ipcc.ch/sr15/ [2019-10-22].

ISGAN (undated). About Us. https://www.iea-isgan.org/about-us/ [2019-05-23].

Javelius \& Backman Hannerz 2015. Yttrande över slutbetänkande från Samordningsrådet för smarta elnät- Planera för effekt! (SOU 2014:84). Naturvårdsverket. Stockholm.

Mälarstrandens utveckling AB (undated). Projektet Öster Mälarstrand.

https://www.ostermalarstrand.se/projektet/ [2019-07-03].

Neuman 2018. Gilla läget och satsa på alternativ till tredje elkabeln. Sveriges Radio P4 Gotland. 2018-11-06.

https://sverigesradio.se/sida/artikel.aspx?programid=94\&artikel=7079704 [2019-08-26].

Näringsdepartementet 2016. Mikael Damberg inviger "Smart Energy City" på Norra Djurgårdsstaden i Stockholm. Press release.

https://www.regeringen.se/pressmeddelanden/2016/11/mikael-damberg-inviger-smartenergy-city-pa-norra-djurgardsstaden-i-stockholm/ [2019-06-18].

Sunér Fleming 2017. Remissvar Kraftsamling för framtidens energi SOU 2017:02. Svenskt Näringsliv. Stockholm.

Stiernstedt 2019. Stockholm en förebild - med brister. Dagens Industri 2019-06-10. Available online: https://www.di.se/hallbart-naringsliv/stockholm-en-forebild-medbrister/?fbclid=IwAR1 yMBBUR06olFcomLpcaOT65r8Uk1R4HPZBORboO89hgNDqsN2t yFNx52U [2019-06-17]

Stockholms stad 2019. Hållbar stadsutveckling drar många besökare till Stockholm . https: / / vaxer.stockholm/nyheter/2019/03/hallbar-stadsutveckling-drar-manga-besokaretill-stockholm/ [2019-06-17]. 
Stockholms stad 2017. Program för hållbar stadsutveckling: Norra Djurgårdsstaden visar vägen mot en hållbar framtid; Stockholms stad 2019. Norra Djurgårdsstaden.

https://vaxer.stockholm/omraden/norra-djurgardsstaden/?page-21-1243=0\#page-21$\underline{1243}$ [2019-06-17].

Sveriges Radio 2016. Energiuppgörelse klar mellan fem partier. 2016-06-10.

https: / / sverigesradio.se/sida/artikel.aspx?programid=83\&artikel=6450597 [2018-05-02].

SVT Nyheter 2016. Kritik från V och SD. 2016-06-10.

https://www.svt.se/nyheter/inrikes/kritik-fran-v-och-sd [2018-05-02].

The Energy Markets Inspectorate 2020. Tillstånd behövs för ledningar som överför solenergi mellan flerbostadshus. Published 2020-06-26.

https://www.ei.se/sv/nyhetsrum/nyheter/nyheter-2020/tillstand-behovs-for-ledningarsom-overfor-solenergi-mellan-flerbostadshus/ [2020-10-13].

UNFCCC 2019. About. https://climateaction.unfccc.int/views/about.html [2019-09-20].

https://vaxer.stockholm/ [2019-06-17]

https://vaxer.stockholm/omraden/norra-djurgardsstaden/?page-21-1243=0\#page-21$\underline{1243}$ [2019-06-17].

https://vaxer.stockholm/tema/hallbara-och-smarta-losningar/ [2019-06-17]

https://www.vinnova.se/p//Aktiva-huset-i-den-hallbara-staden/[2019-06-18]

Widegren 2019. Gotland ger inte upp kampen för en ny elkabel till fastlandet. SVT Nyheter 2019-07-03. https://www.svt.se/nyheter/lokalt/ost/gotland-ger-inte-upp-kampen-foren-ny-elkabel [2019-08-26].

Widegren 2017. Politikerna tar strid för elkabel. SVT Nyheter 2017-06-17.

https://www.svt.se/nyheter/lokalt/ost/politikerna-tar-strid-for-elkabel [2019-08-29].

Widegren \& Lindskog 2017. Stopp för ny elproduktion på Gotland. SVT Nyheter. 2017-09- 
05. https://www.svt.se/nyheter/lokalt/ost/stopp-for-ny-elproduktion-pa-gotland [201908-26].

\section{Reports, policy documents, briefings etc.}

Ander 2019. Smarta elnät i stadsmiljö i Norra Djurgårdsstaden - slutrapport. Eskilstuna: Energimyndigheten.

Axberg et al. 2020. Kapacitetsutmaningen i elnäten. Ei R2020:06. Eskilstuna: Energimarknadsinspektionen.

Bonde et al. 2019. Klimatpolitiska rådets rapport 2019. Stockholm.

Byman 2016. Fem vägval för Sverige - Syntesrapport: IVA-projektet Vägval el. IVA. Stockholm.

Energimarknadsinspektionen 2010. Anpassning av elnäten till ett uthålligt energisystem. EIR R2010:18. Eskilstuna: Energimarknadsinspektionen.

Energimyndigheten 2020. Energiläget 2020. ET 2020:1. Bromma: Arkitektkopia.

Energimyndigheten 2019. Energipilot Gotland: Färdplan för att möjliggöra att Gotland blir pilot för ett hållbart energisystem. ER 2019:09. Bromma: Arkitektkopia.

Energimyndigheten 2018. Smart och förnybart energisystem på Gotland: Energimyndighetens förstudie om hur Gotland kan bli en pilot i omställningen till ett hållbart energisystem i Sverige. ER 2018:5. Bromma: Arkitektkopia.

E.ON, VA SYD, and the City of Malmö 2011. Klimatkontrakt för Hyllie.

European Commission 2012. Communication from the Commission: Smart Cities and Communities - European Innovation Partnership. Brussels, 10.7.2012 C (2012) 4701 final.

European Commission 2009. Communication from the Commission: Investing in the Development of Low Carbon Technologies (SET-Plan). Brussels, COM (2009) 519/4. 
European Commission 2006. European Technology Platform Smart Grids: Vision and Strategy for Europe's Electricity Networks of the Future. Directorate-General for Research, Sustainable Energy Systems. EUR 22040.

Fortum et al. (undated). Norra Djurgårdsstaden - smart elnät i stadsmiljö: Förstudie.

Forum för smarta elnät 2017. Strategi för en ökad flexibilitet i elsystemet genom smarta elnät. Stockholm: Regeringskansliet.

Forum för smarta elnät 2017. Strategin från forskning till internationalisering: rekommendationer. Stockholm: Regeringskansliet.

Gustavsson \& Wedberg 2017. Smart Grid Gotland - slutrapport. Eskilstuna: Energimyndigheten.

IEA 2016. Nordic Energy Technology Perspectives 2016: Cities, flexibility and pathways to carbonneutrality. Paris.

IRP 2018. The weight of cities: resource requirements of future urbanization. Swilling et al. A Report by the International Resource Panel. United Nations Environment Programme. Nairobi: Kenya.

Johansson \& Berne 2016. Smarta nät för ett hållbart energisystem i Hyllie - slutrapport. Eskilstuna: Energimyndigheten.

Kaijser \& Kander 2013. Framtida energiomställningar i historiskt perspektiv. Rapport 6550. Naturvårdsverket. Stockholm.

Lidström et al. 2018. Förstudie Gotland: Förbättrad leveranssäkerhet och ökad kapacitet för ytterligare förnybar elproduktion. Vattenfall AB, R\&D, Power Technology.

Länsstyrelsen Gotland 2019. Tillsammans mot 2030: En energi- och klimatstrategi för Gotland. Gotland: Visby. Dnr: 485-2019.

Länsstyrelsen Gotland 2017. Rapport Gotlands Energidialog 2017 - Omställning till ett smart och hållbart energisystem. 
Länsstyrelsen Gotland 2012. Klimat- och energimål för Gotland 2012-2020. Gotland: Visby.

Malmö stad 2015. Miljöprogram Hyllie: Mål och åtgärder för förverkligandet av Öresundsregionens klimatsmartaste stadsdel. Malmö.

Miljö- och energidepartementet 2015. Kommittédirektiv: Översyn av energipolitiken. Dir. 2015:2. Stockholm.

Miljö- och energidepartementet 2015. Inrättande av forum för smarta elnät. Protokoll II:6 vid regeringssammanträde. Stockholm.

Miljö- och energidepartementet 2016. Ramöverenskommelse mellan Socialdemokraterna, Moderaterna, Miljöpartiet de gröna, Centerpartiet och Kristdemokraterna. Stockholm.

Näringsdepartementet 2017. Regeringens strategiska samverkansprogram. Fact sheet. N2017.40. Stockholm.

Näringsdepartementet 2012. Kommittédirektiv: Samordningsråd med kunskapsplattform för smarta elnät. Dir. 2012:48. Stockholm.

Regeringskansliet 2018. Uppdrag till Statens energimyndighet att möjliggöra att Gotland blir en pilot för ett hållbart energisystem. Regeringsbeslut. Miljö- och energidepartementet: Stockholm.

Regeringskansliet 2017. Smart och förnybart energisystem på Gotland. Regeringsbeslut. Miljöoch energidepartementet: Stockholm.

Regeringens proposition 2016/17:66. Forskning och innovation på energiområdet för ekologisk hållbarhet, konkurrenskraft och försörjningstrygghet. Stockholm: Miljö- och energidepartementet.

Regeringens proposition 2010/11:153. Stärkt konsumentroll för utvecklad elmarknad och uthålligt energisystem. Stockholm.

Regeringens proposition 1996/97:84. En uthållig energiförsörjning. Stockholm. 
Regeringens proposition 1975:30. Regeringens proposition om enerighushållningen m.m. Stockholm.

Region Gotland 2015. Miljöprogram. Gotland: Visby.

Region Gotland 2014. Energi 2020: energiplan för Gotland. Gotland: Visby.

Region Gotland 2008. Vision Gotland 2025: Regionalt utvecklingsprogram för Gotland - RUP. Gotland: Visby.

SOU 2018:76. Mindre aktörer i energilandskapet - förslag med effekt. Stockholm: Miljö- och energidepartementet.

SOU 2017:2. Kraftsamling för framtidens energi. Stockholm: Miljö- och energidepartementet.

SOU 2014:84. Planera för effekt! Stockholm: Näringsdepartementet.

SOU 2003:80 EFUD - en del i omställningen av energisystemet. Stockholm.

SOU 1995:39. Omställning av energisystemet. Stockholm: Näringsdepartementet.

Stockholms stad 2018. Översiktsplan för Stockholm. Stockholm.

Stockholms stad 2017. Program för hållbar stadsutveckling: Norra Djurgårdsstaden visar vägen mot en hållbar framtid. Stockholm.

Stockholms stad 2016. Stockholms stads miljöprogram 2016-2019. Stockholm.

Stockholms stad 2010. Övergripande program för hållbar stadsutveckling. Stockholm.

The Commission on Global Governance 1995. Our global neighbourhood: the report of the Commission on Global Governance. Oxford: Oxford University Press. 
Tillväxtanalys 2015. Innovationspolitik för framtidens energisystem: Analys av internationella policyexperiment. Rapport 2015:05. Östersund.

Vinnova 2019. Uppdrag att bistå i arbetet med regeringens samverkansprogram för innovation . Stockholm.

Wolf 2012. Dags att välja framtidens energisystem. Naturskyddsföreningen, Stockholm.

Wolf \& Andersson 2018. Elnätets roll i framtidens energisystem: Möjligheter, hinder och drivkrafter för smarta elnätslösningar. Power Circle. Stockholm. 


\section{Appendix - Interview guide, example of question clusters}

- How did you first come into contact with the concept of smart grids? What is a smart grid from your perspective? To which problems are they solutions?

- Can you tell me about the most pressing questions in the energy transformation and smart grids, and the evolution of these discussions from your previous role up until now?

- How do you view the ongoing smart energy pilot projects in light of this? Have they raised new such questions, and if so which? How were these new questions noticed in the forums where you are active? How do you proceed with this new knowledge, does it affect organization $\mathrm{X}$ where you are active in any way?

- Questions pertaining to timeline of how the pilot projects were perceived and related to, e.g. how they came into play in different policy networks where the interviewee has been/is active and in which forms.

- Questions on specific pilot projects, e.g. its boundaries (smart grid/smart city), knowledge generated, where such knowledge ends up, whether it is possible to transfer lessons learned to other places and if so how, the relation to other pilot projects undertaken by the interviewee's affiliated organization, if actor networks were established through the pilot project and if so how, what the next step for the interviewee's affiliated organization will be after the pilot project, who expressed interest in the experiment and how and whether this changed over time, and whether knowledge is transferred in any institutionalized form.

- Questions pertaining to the role of pilot projects for energy transformation, such as whether they matter and how, the role of pilot projects relative to other policy instruments, and the role of interlinked funding infrastructures such as EU-funding and national funding for smart energy experimentation.

- Questions related to the character of different specific pilot projects or broader policy initiatives, e.g. whether, why, and how they constitute experiments, pilots, demonstrations, etc.

- Questions pertaining to scaling up and transformative change, both general questions about "next steps" after pilot projects and specific questions about e.g. the Gotland as 
an energy pilot initiative.

- Questions about how specific pilot projects have affected politics and infrastructural development, and vice versa, e.g. related to national rules and regulations as well as locally.

- Questions pertaining to the interviewee's visions of the future energy system and pilot projects.

- Summarizing, asking whether the interviewee wishes to add something, snowballing. 


\section{FACULTY OF ARTS AND SCIENCES}

Linköping Studies in Arts and Sciences no. 800, 2021

Department of Thematic Studies - Technology and social change

Linköping University

SE-581 83 Linköping, Sweden

www.liu.se

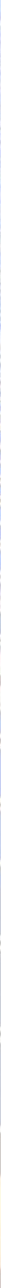

